\title{
COMBINED BIOLOGICAL AND ADVANCED OXIDATION PROCESSES FOR THE TREATMENT OF AN ACTUAL SLAUGHTERHOUSE WASTEWATER
}

\author{
by
}

\section{CIRO FERNANDO BUSTILLO LECOMPTE}

\author{
Bachelor of Engineering in Civil Engineering \\ University of Cartagena, Cartagena, Bolívar, Colombia, 2008
}
Master of Applied Science in Environmental Applied Science and Management Ryerson University, Toronto, Ontario, Canada, 2012

\author{
A dissertation \\ presented to Ryerson University \\ in partial fulfilment of the \\ requirements for the degree of \\ Doctor of Philosophy \\ in the Program of \\ Environmental Applied Science and Management
}

Toronto, Ontario, Canada, 2016

(C) Ciro Fernando Bustillo Lecompte 2016 


\section{AUTHOR'S DECLARATION FOR ELECTRONIC SUBMISSION OF A DISSERTATION}

I hereby declare that I am the sole author of this dissertation. This is a true copy of the dissertation, including any required final revisions, as accepted by my examiners.

I authorize Ryerson University to lend this dissertation to other institutions or individuals for the purpose of scholarly research.

I further authorize Ryerson University to reproduce this dissertation by photocopying or by other means, in total or in part, at the request of other institutions or individuals for the purpose of scholarly research.

I understand that my dissertation may be made electronically available to the public. 


\title{
ABSTRACT \\ Combined Biological and Advanced Oxidation Processes for the Treatment of an Actual Slaughterhouse Wastewater
}

\author{
Ciro Fernando Bustillo Lecompte \\ Doctor of Philosophy, 2016 \\ Environmental Applied Science and Management \\ Ryerson University
}

Environmental protection initiatives and increasing market demand for green practices are driving the meat processing industry to consider sustainable methods for wastewater treatment of slaughterhouse wastewater. Onsite treatment is the preferred option to treat the slaughterhouse effluents for water reuse and potential energy recovery due to the conversion of organics into biogas. A thorough review of advancements in slaughterhouse wastewater characteristics, treatment, and management in the meat processing industry, environmental impacts, health effects, and regulatory frameworks relevant to the slaughterhouse wastewater management is presented in this study. Significant progress in high-rate anaerobic treatment, nutrient removal, advanced oxidation processes, and combined processes for an actual slaughterhouse wastewater treatment are highlighted. The optimization of individual and combined processes was performed in this study using quadratic modeling, degradation mechanisms, and response surface methodology to maximize $\mathrm{CH}_{4}$ yield and the removal of TOC and TN while minimizing TSS and $\mathrm{H}_{2} \mathrm{O}_{2}$ residuals. The effects of the flow rate, $\mathrm{pH}$, influent TOC concentration, $\mathrm{H}_{2} \mathrm{O}_{2}$ dosage, and their interaction on the overall treatment efficiency and $\mathrm{CH}_{4}$ yield were studied. In the final part of this study, an optimized combined anaerobic-aerobic and $\mathrm{UV} / \mathrm{H}_{2} \mathrm{O}_{2}$ system with recycle was evaluated using a costeffectiveness analysis by minimizing treatment time, electrical energy consumption, and the overall incurred treatment costs. The agreement between model predictions and experimental values indicated that the proposed models could describe the performance of individual and combined systems for actual SWW treatment. The maximum TOC and TN removals of 91.29 and $86.05 \%, \mathrm{CH}_{4}$ yield of $55.72 \%$, and minimum $\mathrm{H}_{2} \mathrm{O}_{2}$ residual of $1.45 \%$ were found at optimum conditions of influent TOC concentration of $626 \mathrm{mg} / \mathrm{L}$, feed flow rate of $45 \mathrm{~mL} / \mathrm{min}, \mathrm{H}_{2} \mathrm{O}_{2}$ dosage of $350 \mathrm{mg} / \mathrm{L}$, and $\mathrm{pH}$ of 6.59. The minimum total retention time was determined to be $10 \mathrm{~h}$ with individual residence times of $6.82 \mathrm{~h}, 2.40 \mathrm{~h}$, and $47 \mathrm{~min}$ in the $\mathrm{ABR}$, AS bioreactor, and $\mathrm{UV} / \mathrm{H}_{2} \mathrm{O}_{2}$ photoreactor, respectively. A minimum electrical power consumption of $0.0194 \mathrm{kWh}$ for an overall treatment cost of $0.12 \$ / \mathrm{m}^{3}$ were obtained based on the cost-effectiveness analysis. Results show that the application of combined biological and advanced oxidation processes is useful for on-site slaughterhouse wastewater treatment.

Keywords: Slaughterhouse wastewater, anaerobic digestion, activated sludge, advanced oxidation processes, process optimization, cost-effectiveness analysis. 


\section{ACKNOWLEDGMENTS}

I would like to express my sincere gratitude to my supervisor, Dr. Mehrab Mehrvar, of the Department of Chemical Engineering at Ryerson University, for his guidance, assistance, and financial support throughout the successful completion of this research. Research funding from the Natural Sciences and Engineering Research Council of Canada (NSERC), Ontario Trillium Scholarship (OTS) Program, Colciencias (a federal grant agency of Colombia), and Ryerson University especially the Faculty of Engineering and Architectural Science, the Yeates School of Graduate Studies, and the Graduate Programs in Environmental Applied Science and Management is also greatly appreciated.

My sincere gratitude is also extended to Dr. Amarjeet Bassi from Western University, London, Ontario, Canada, for serving as the external member of my Ph.D. dissertation committee, Dr. Michael Arts, Molecular Science Graduate Program Director at Ryerson University (Chair of the defence), Dr. Kimberley Gilbride and Dr. Vadim Bostan from the Department of Chemistry and Biology part of the Environmental Applied Science and Management Graduate Programs at Ryerson University, Dr. Ramdhane Dhib from the Department of Chemical Engineering as the external program member at Ryerson University, for serving as committee members of my Ph.D. dissertation defence.

In addition, I want to acknowledge the Engineering Technologists of the Department of Chemical Engineering for their technical support and assistance on my experimental setup. Dr. Mehrvar's research team with whom I shared many times of enlightenment and entertainment, and provided me with great support, as well as their help in troubleshooting, support and advice, especially during the regular group research meetings. Dr. Edgar Quiñones and Dr. Samira Ghafoori for their unconditional help, guidance, advice and encouragement, which have helped me in my personal and professional development. As well as Ashbridges Bay Wastewater Treatment Plant for providing the anaerobic and aerobic activated sludge essential for the processes used in this research and the Meat Processing Plants that participated in this research study by providing responses to the questionnaires and actual slaughterhouse wastewater samples.

I would also like to show appreciation to my friends Juan Felipe and Maria Clara; my cousins Gustavo, Lucila, and Lucy; my aunts and uncles; my beloved mother, Candelaria, my brother, Carlos, and my lovely wife, Liseth, for their love, guidance, patience, understanding, sacrifice and invaluable support throughout my $\mathrm{PhD}$ studies. I also offer regards and greetings to all those who supported me in any way during the completion of this research and whose names were not mentioned.

Finally, I am grateful that I chose Ryerson University to purse both my MASc and PhD programs, where I gained a lot of knowledge in research and tremendous experience in teaching both in capacity of fully responsible instructor of two undergraduate courses for the School of Occupational and Public Health, OHS 523 Safety Evaluation Techniques (Fall 2015) and OHS 323 Accident Theory and Analysis (Winter 2016) and Teaching Assistantships for the CHE 315 Unit Operations Laboratory and CHE 424 Food Process Engineering undergraduate courses in the department of Chemical Engineering. 
This doctoral dissertation is dedicated to the love of my life Liseth Sierra Vitola whose unconditional love, patience, and sacrifice has encouraged me to improve every day 


\section{TABLE OF CONTENTS}

AUTHOR'S DECLARATION FOR ELECTRONIC SUBMISSION OF A DISSERTATION ........ ii

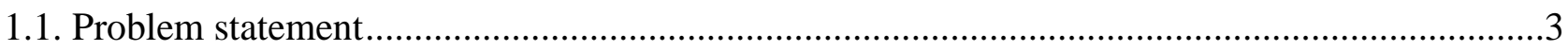

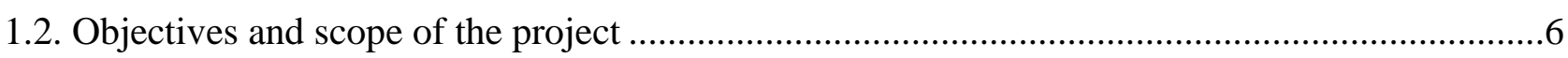

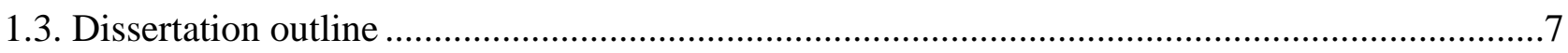

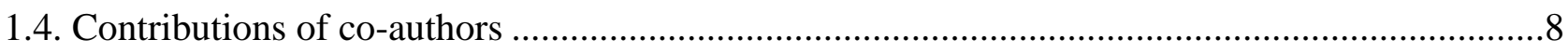

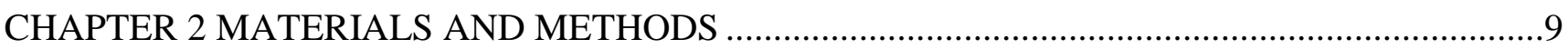

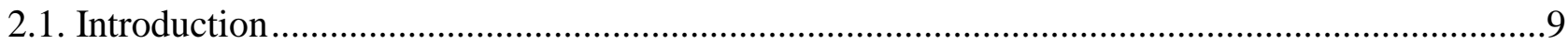

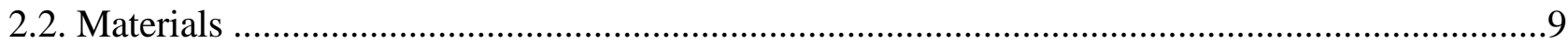

2.2.1. Actual slaughterhouse wastewater samples ........................................................

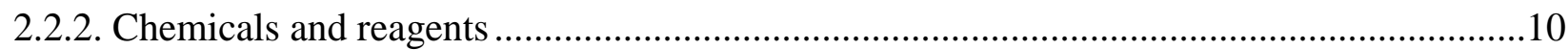

2.2.3. Anaerobic and aerobic inoculum....................................................................... 10

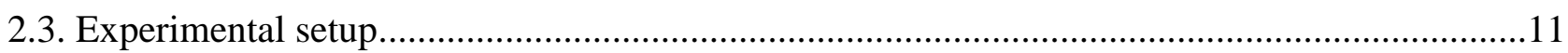

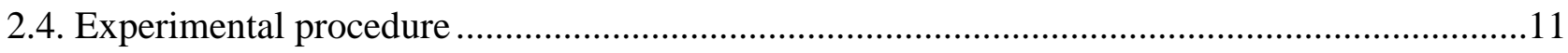

2.4.1. Acclimatization of the inoculum ............................................................................. 11

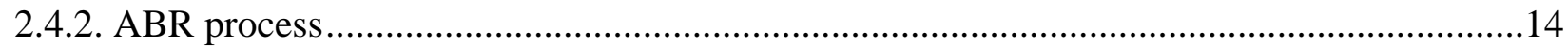

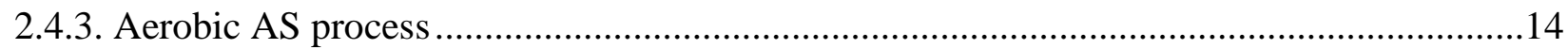

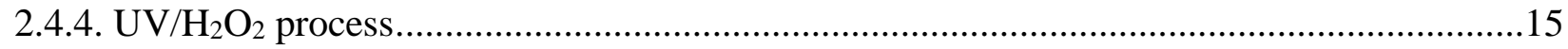

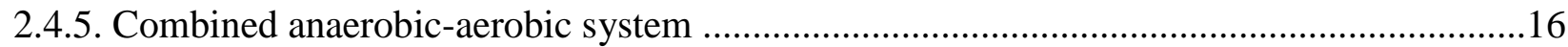


2.4.6. Combined anaerobic-aerobic and $\mathrm{UV} / \mathrm{H}_{2} \mathrm{O}_{2}$ system

2.5. Research methods ................................................................................................. 17

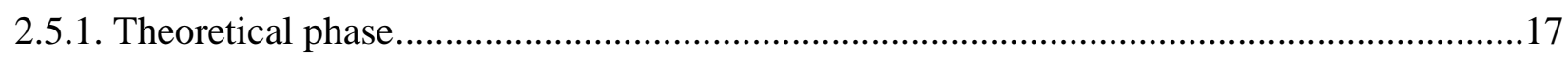

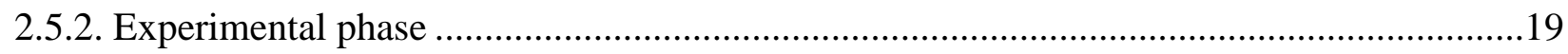

2.6. Experimental design, modeling, and optimization ......................................................19

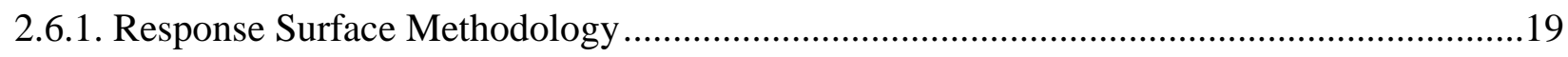

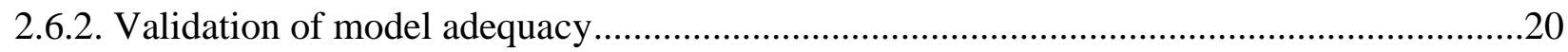

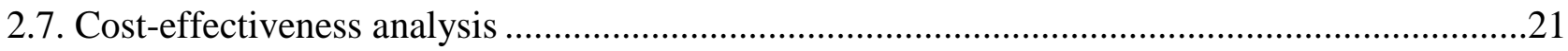

2.8. Analytical techniques and equipment for sample analysis .........................................21

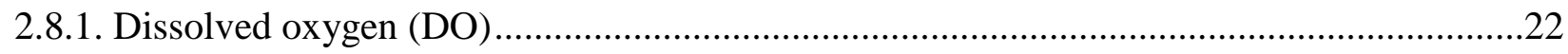

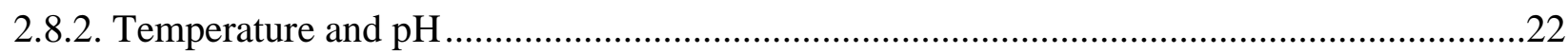

2.8.3. Total suspended solids (TSS) and volatile suspended solids (VSS) ..............................22

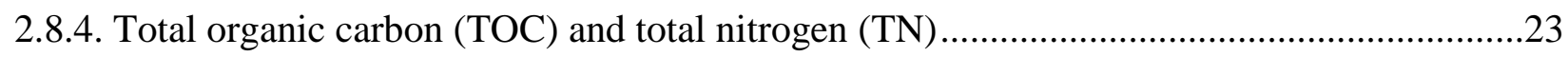

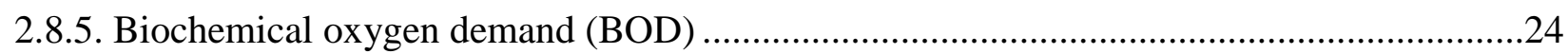

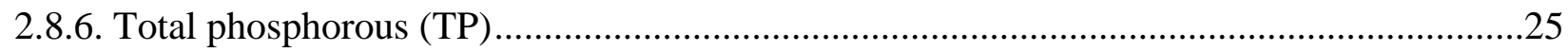

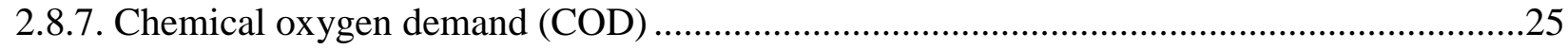

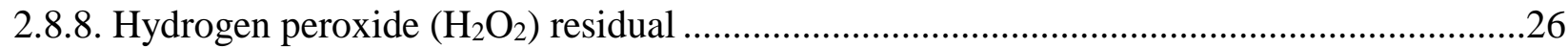

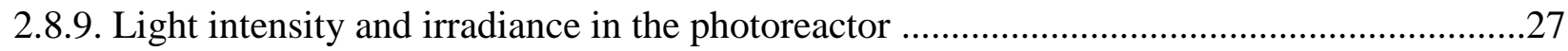

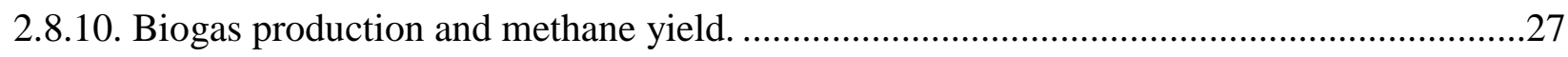

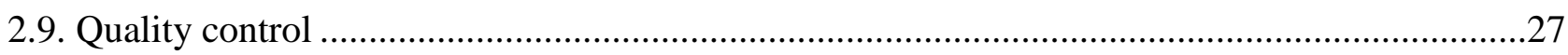

CHAPTER 3 SLAUghterhouse WASTEWATER CHARACTERISTICS, TREATMENT, AND MANAGEMENT IN THE Meat Processing Industry: A REVIEW on Trends And AdVAnCES ...................................22

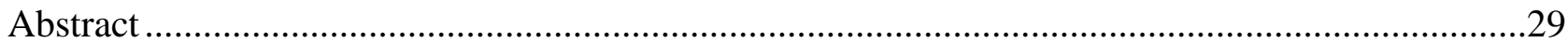

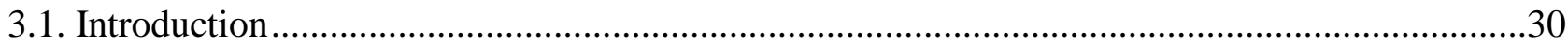

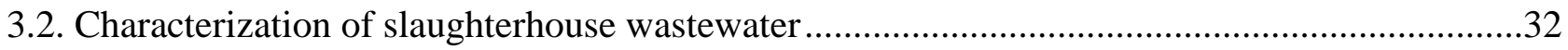

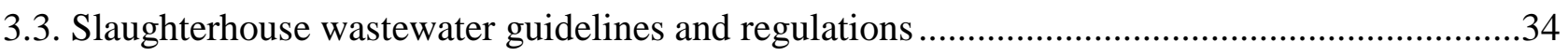

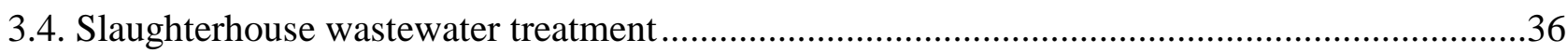




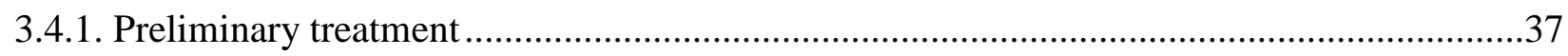

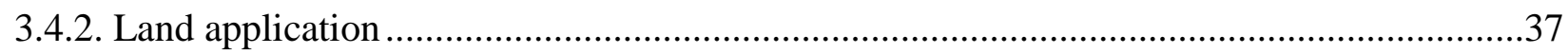

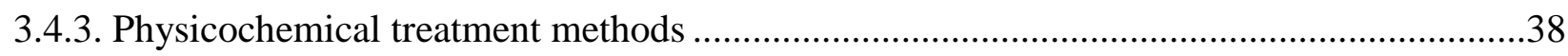

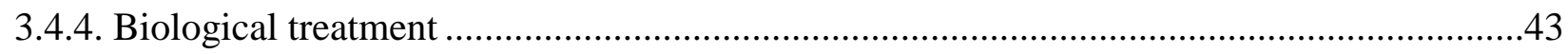

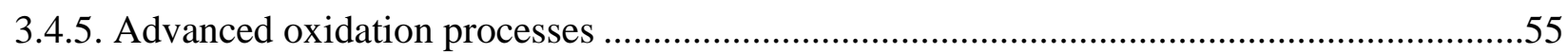

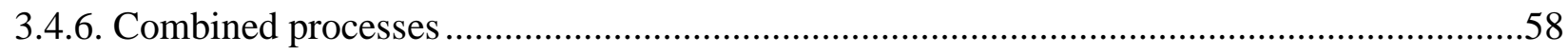

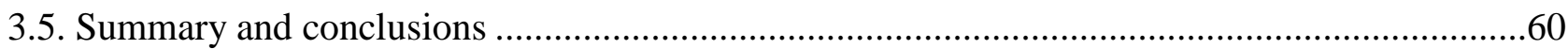

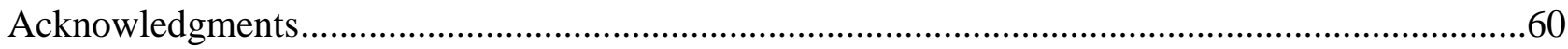

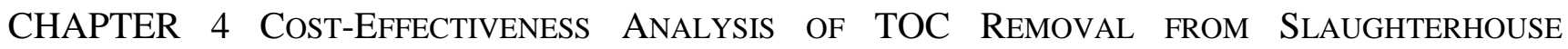
Wastewater USing Combined ANaerobic-AerobiC ANd UV/ $\mathrm{H}_{2} \mathrm{O}_{2}$ Processes ...............................63

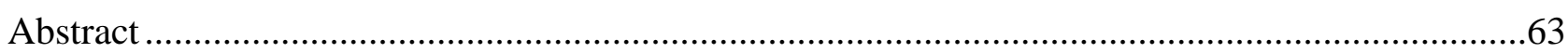

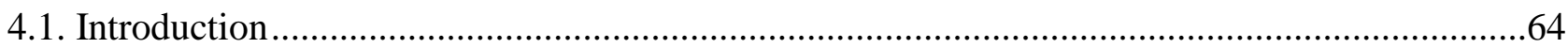

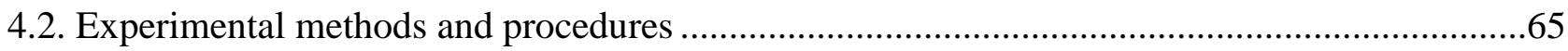

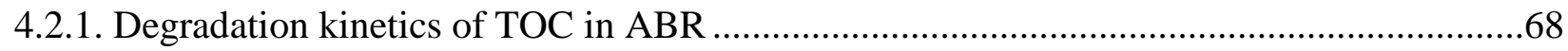

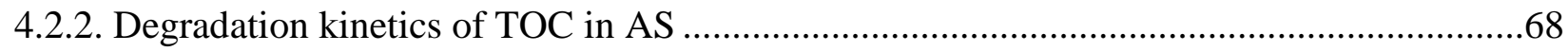

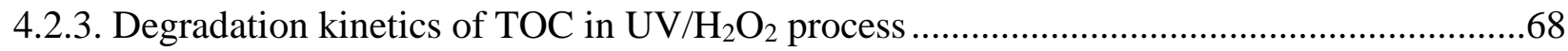

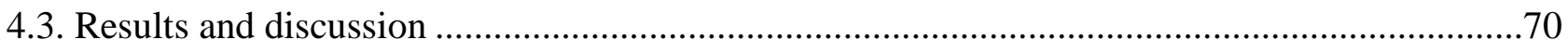

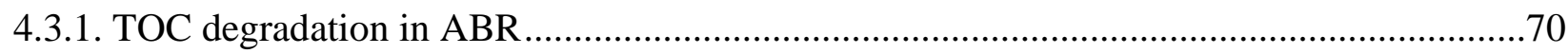

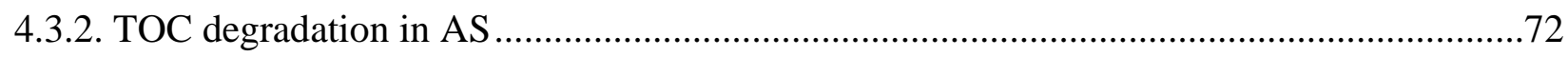

4.3.3. TOC Degradation in combined anaerobic-aerobic processes ……………………………....74

4.3.4. TOC Degradation in $\mathrm{UV} / \mathrm{H}_{2} \mathrm{O}_{2}$ process .........................................................................

4.3.5. TOC degradation in combined anaerobic-aerobic and $\mathrm{UV} / \mathrm{H}_{2} \mathrm{O}_{2}$ processes ........................75

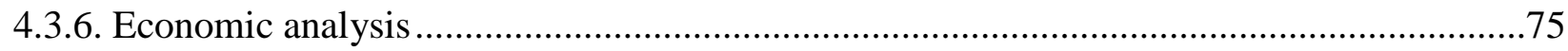

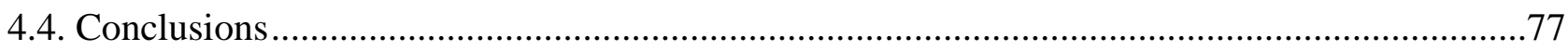

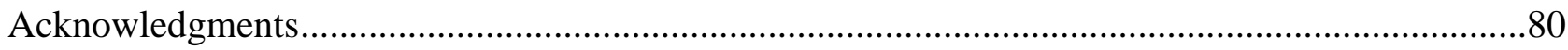


CHAPTER 5 Treatment of ACtual Slaughterhouse Wastewater By COMBINED ANAerobiCAerobic Processes for Biogas Generation and Removal of Organics and Nutrients: An Optimization Study Towards a Cleaner Production in the MeAt Processing Industry ........81

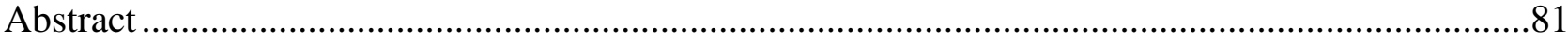

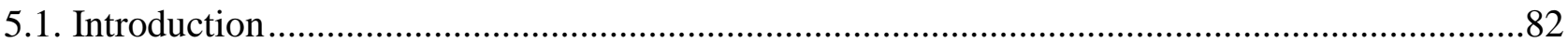

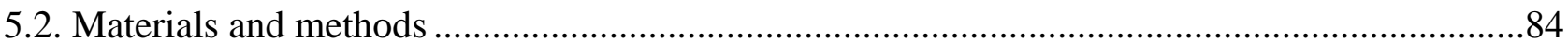

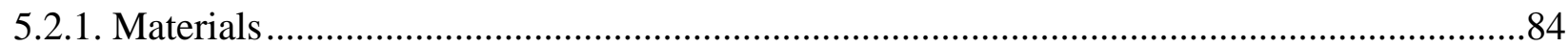

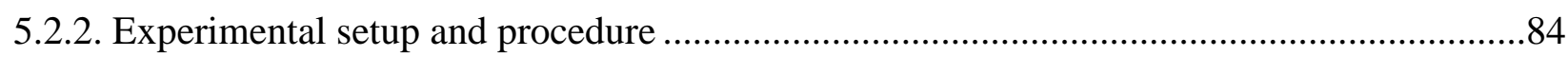

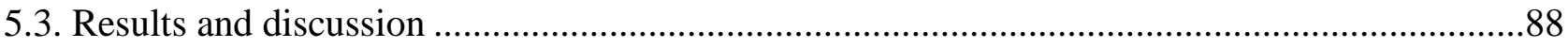

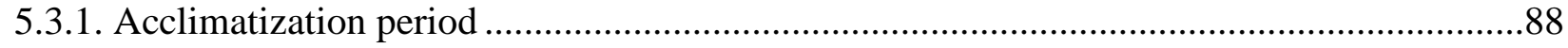

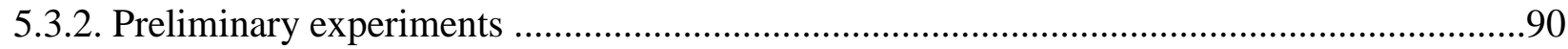

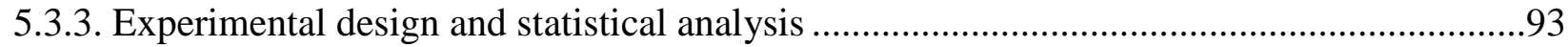

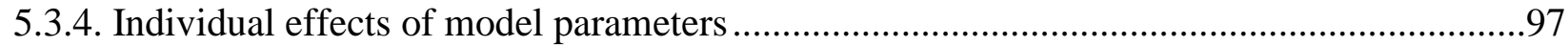

5.3.5. Interaction of model parameters, 2D contour plots, and 3D response surface...................98

5.3.6. Optimization of operating conditions and process parameters .....................................100

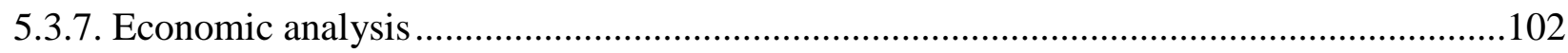

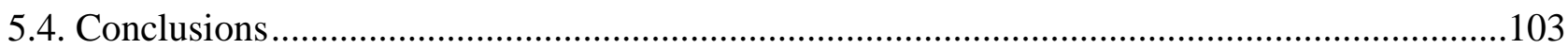

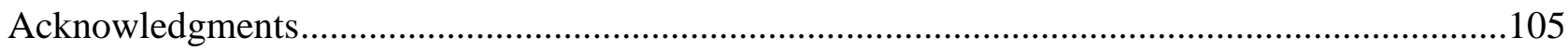

CHAPTER 6 Photochemical Degradation of AN Actual Slaughterhouse Wastewater By CONTINUOUS UV/H $\mathrm{H}_{2} \mathrm{O}_{2}$ PHOTOREACTOR WITH RECYCLE........................................................106

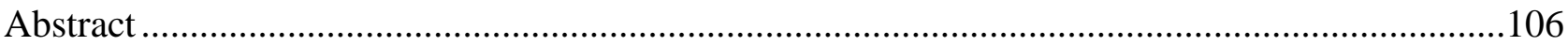

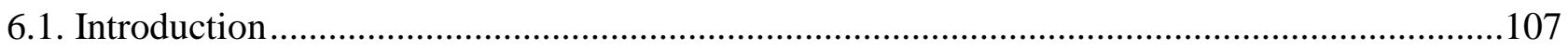

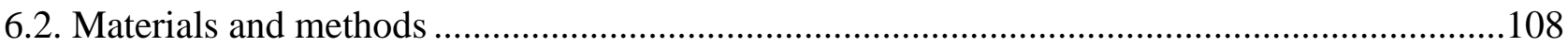

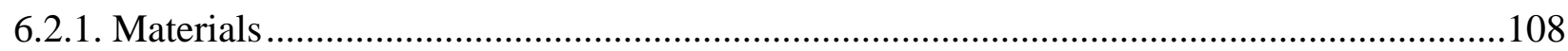

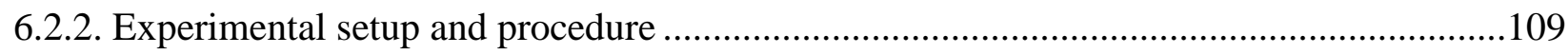

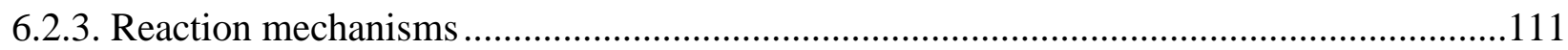

6.2.4. Photon irradiation balance ................................................................................... 113 
6.2.5. Experimental design and optimization studies

6.3. Results and discussion

6.3.1. Preliminary experiments

6.3.2. Experimental design and statistical analysis

6.3.3. Individual effect of model parameters

6.3.4. Interaction of model parameters, $2 \mathrm{D}$ contour plots, and 3D response surface

6.3.5. Optimization of operating conditions and process parameters

6.4. Conclusions

Acknowledgments.

CHAPTER 7 SLAUGHTERHOUSE WASTEWATER CHARACTERIZATION AND TREATMENT: AN ECONOMIC AND Public HEALTH NECESSITY OF THE MEAT PROCESSING INDUSTRY IN ONTARIO, CANADA............134

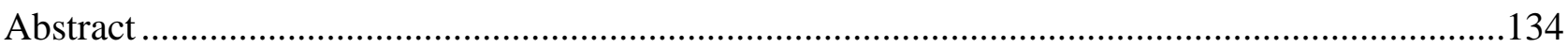

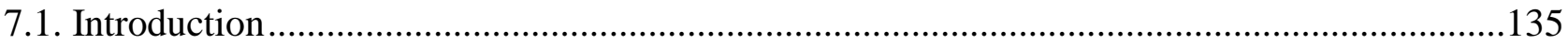

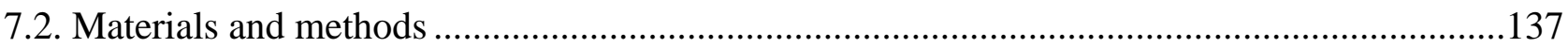

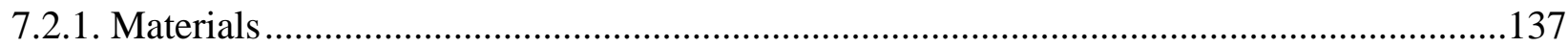

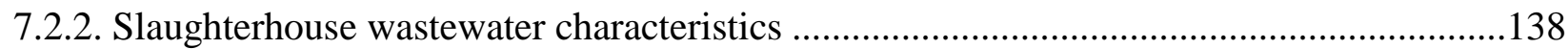

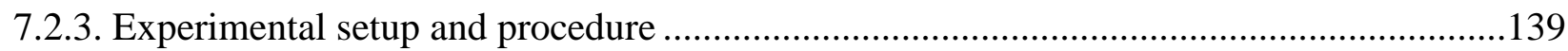

7.2.4. Experimental design and optimization .................................................................. 141

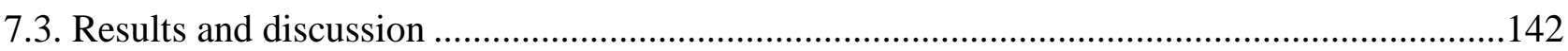

7.3.1. Experimental design and statistical analysis .............................................................142

7.3.2. Individual and cross-factor interaction effects of model parameters .............................146

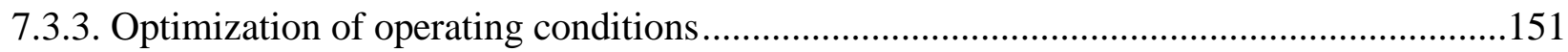

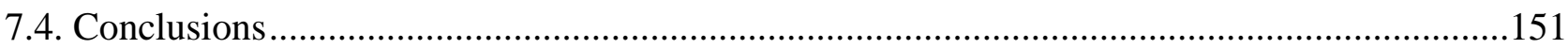

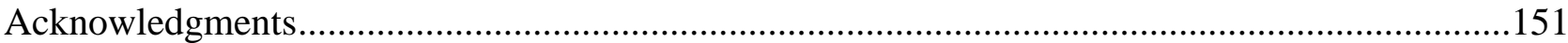

CHAPTER 8 TREATMENT OF AN ACTUAL SLAUGHTERHOUSE WASTEWATER BY INTEGRATION OF BIOLOGICAL AND ADVANCED OXIDATION PROCESSES: MODELING, OPTIMIZATION, AND COST-

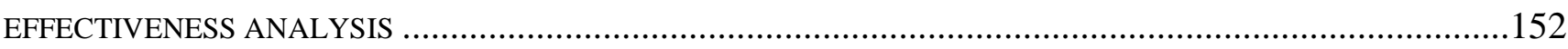


Abstract

8.1. Introduction

8.2. Materials and methods

8.2.1. Materials 155

8.2.2. Experimental setup. 156

8.2.3. Experimental procedure 156

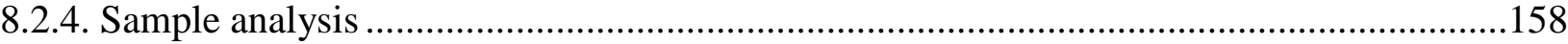

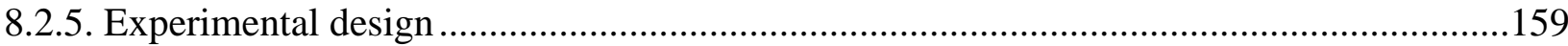

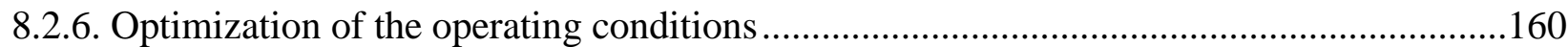

8.2.7. Slaughterhouse wastewater degradation models ....................................................... 160

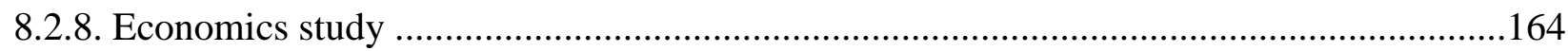

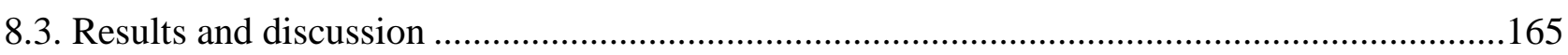

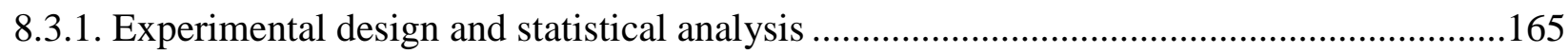

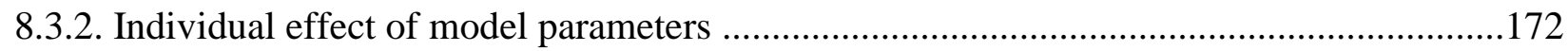

8.3.3. Interaction of model parameters, 2D contour plots, and 3D response surface.................174

8.3.4. Optimization of operating conditions and process parameters ...................................176

8.3.5. Analysis of reactors for the combined $\mathrm{ABR}-\mathrm{AS}-\mathrm{UV} / \mathrm{H}_{2} \mathrm{O}_{2}$ processes for the actual

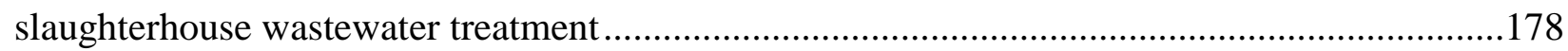

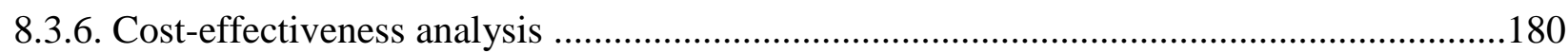

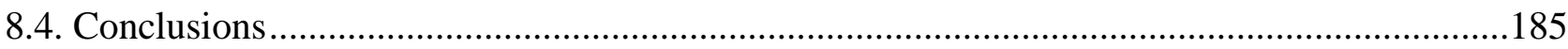

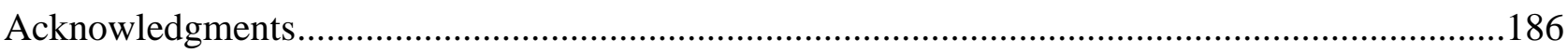

CHAPTER 9 CONCLUSIONS AND RECOMMENDATIONS ..................................................187

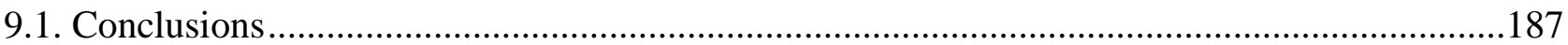

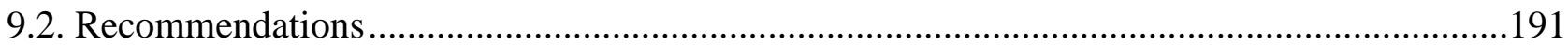

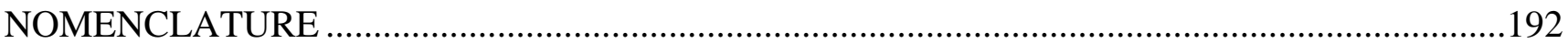

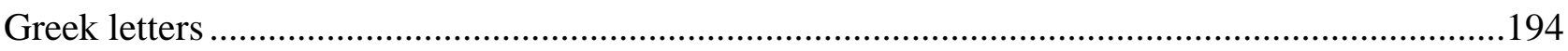

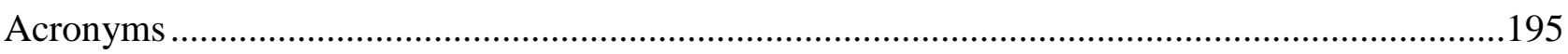


Appendix A. Abstract reprint from Journal of Environmental Management 161 (2015) 287-302, with permission from Elsevier. License Number 3830960007849.

Appendix B. Abstract reprint from Journal of Environmental Management 134 (2014) 145-152, with permission from Elsevier. License Number 3830951278377. 198

Appendix C. Abstract reprint from Journal of Environmental Chemical Engineering 4 (2016) 719-732, with permission from Elsevier. License Number 3830960158225.

Appendix D. Abstract reprint from Journal of Geoscience and Environment Protection 4 (2016) 175186. Open Access. .200

Appendix E. Abstract reprint from J. Environ. Manage. (2016), In Press.....................................201

Appendix F. Provincially licensed meat plants in Ontario..........................................................202

Appendix G. Research ethics board approval and renewal. ..................................................210

Appendix H. Questionnaire and consent agreement. ........................................................212

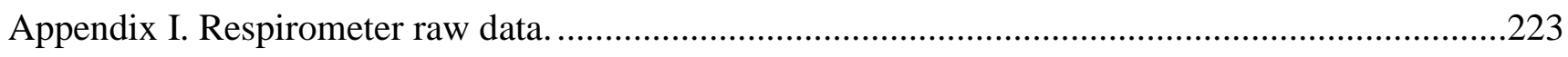

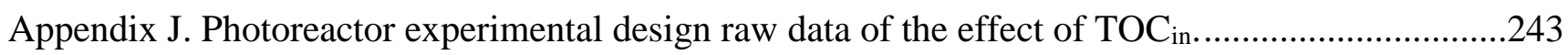

Appendix K. Photoreactor experimental design raw data of the effect of $\mathrm{H}_{2} \mathrm{O}_{2}$ in. ......................244

Appendix L. Photoreactor experimental design raw data of the effect of flow rate.........................245

Appendix M. Photoreactor experimental design raw data of the effect of recycle ratio...................246

Appendix N. Analysis of residuals in the photoreactor models. ..............................................247

Appendix O. Analysis of residuals in the biological processes models. .....................................251

Appendix P. Combined anaerobic-aerobic $\mathrm{UV} / \mathrm{H}_{2} \mathrm{O}_{2}$ processes reactor-modeling example. ............255

Appendix Q. Combined anaerobic-aerobic $\mathrm{UV} / \mathrm{H}_{2} \mathrm{O}_{2}$ processes energy estimation. .......................256

Appendix R. Combined anaerobic-aerobic $\mathrm{UV} / \mathrm{H}_{2} \mathrm{O}_{2}$ processes overall treatment costs estimation. .257

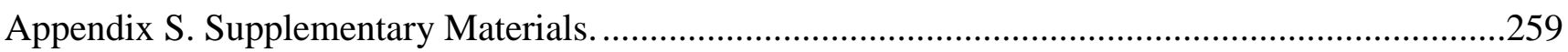

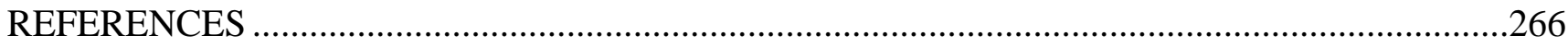




\section{LIST OF TABLES}

Page

Table 2.1. Characteristics of the actual slaughterhouse wastewater from selected provincially licensed meat processing plants along with study range values and detection limits............................10

Table 3.1. Freshwater consumption in beverage and food industries............................................30

Table 3.2. General characteristics of slaughterhouse wastewater. ................................................32

Table 3.3. Characteristics of slaughterhouse wastewater from selected provincially inspected meat

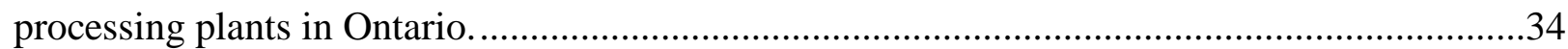

Table 3.4. Comparison of standard limits of different jurisdictions worldwide for slaughterhouse

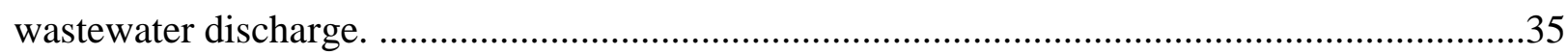

Table 3.5. Comparison of different membrane dimensions and pore size exclusion used in SWW

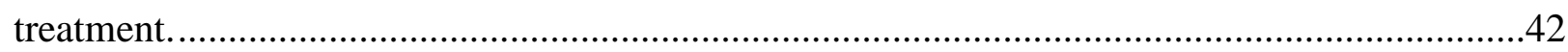

Table 3.6. Comparison of different technologies and their combination for slaughterhouse wastewater treatment. .61

Table 4.1. Common characteristics of slaughterhouse wastewater. ............................................64

Table 4.2. Technical conditions for the biological systems and AOPs. ..........................................66

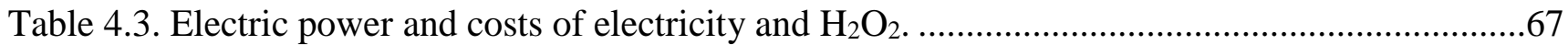

Table 5.1. Characteristics of the actual slaughterhouse wastewater from selected provincially licensed

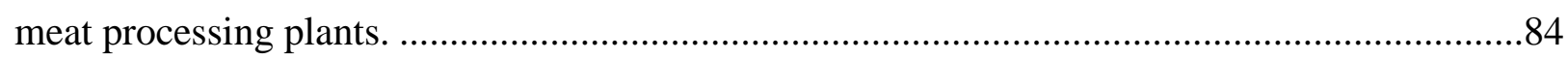

Table 5.2. Independent variables with coded levels based on a three-factor, three-level BBD...........87

Table 5.3. Three-factor, three-level BBD for RSM, along with the observed and predicted percent TOC removal, TN removal, Biogas yield, and TSS residual.....................................................94

Table 5.4. ANOVA of the prediction results for the percent TOC and TN removal, Biogas yield, and TSS residual by quadratic modeling. ......................................................................... 96

Table 6.1. Characteristics of the actual slaughterhouse wastewater from selected provincially licensed meat processing plants along with study range values and detection limits...........................109

Table 6.2. Reaction mechanisms for complete mineralization of SWW by $\mathrm{UV} / \mathrm{H}_{2} \mathrm{O}_{2}$ process. .........112

Table 6.3. Independent variables with coded levels based on a four-factor, five level CCD.............113

Table 6.4. Four-factor, five-level CCD for RSM, along with the observed and predicted percent TOC removal and $\mathrm{H}_{2} \mathrm{O}_{2}$ residual. 
Table 6.5. ANOVA results for prediction of percent TOC removal by quadratic modeling. 119

Table 6.6. ANOVA results for prediction of percent $\mathrm{H}_{2} \mathrm{O}_{2}$ residual by quadratic modeling.

Table 7.1. Common characteristics of slaughterhouse wastewater in the study. 138

Table 7.2. Independent variables with coded levels based on a four-factor, five level CCD

Table 7.3. Four-factor, five-level CCD with observed and predicted percent TOC removal and $\mathrm{H}_{2} \mathrm{O}_{2}$ residual. 143

Table 7.4. ANOVA of the prediction results for the percent TOC and $\mathrm{H}_{2} \mathrm{O}_{2}$ residual by quadratic modeling.

Table 8.1. Characteristics of the actual slaughterhouse wastewater from selected provincially licensed meat processing plants with study range values for the combined $\mathrm{ABR}-\mathrm{AS}-\mathrm{UV} / \mathrm{H}_{2} \mathrm{O}_{2}$ system.

Table 8.2. Independent variables with coded levels based on a four-factor, five level CCD for the combined $\mathrm{ABR}-\mathrm{AS}-\mathrm{UV} / \mathrm{H}_{2} \mathrm{O}_{2}$ system for SWW treatment.

Table 8.3. Four-factor, five-level CCD with observed and predicted percentual TOC removal, TN removal, $\mathrm{H}_{2} \mathrm{O}_{2}$ residual, and $\mathrm{CH}_{4}$ production values. 166

Table 8.4. Coefficients table for the percentual TOC removal, TN removal, $\mathrm{H}_{2} \mathrm{O}_{2}$ residual, and $\mathrm{CH}_{4}$ production quadratic models.

Table 8.5. ANOVA of the prediction results for the percentual TOC removal, TN removal, $\mathrm{H}_{2} \mathrm{O}_{2}$ residual, and $\mathrm{CH}_{4}$ production by quadratic modeling. 168

Table S.1. Comparison of different technologies maximum efficiencies for slaughterhouse wastewater treatment from 2014 to 2016. 265 


\section{LIST OF FIGURES}

Page

Figure 2.1. Schematic diagram of (a) the combined anaerobic-aerobic processes for the treatment of SWW and the individual processes (b) anaerobic baffled reactor, (c) aerobic activated sludge bioreactor, and (d) $\mathrm{UV} / \mathrm{H}_{2} \mathrm{O}_{2}$ photoreactor with recycle. .12

Figure 2.2. Laboratory scale combined $\mathrm{ABR}-\mathrm{AS}-\mathrm{UV} / \mathrm{H}_{2} \mathrm{O}_{2}$ system with recycle..........................13

Figure 2.3. Diagram representation of the research methods used in this study..............................18

Figure 3.1. Schematic diagram of a typical electrocoagulation unit. ..............................................40

Figure 3.2. Schematic diagram of a typical anaerobic filter system...............................................46

Figure 3.3. Schematic diagram of a typical activated sludge system. ..........................................50

Figure 3.4. Schematic diagram of a single lamp $\mathrm{UV} / \mathrm{H}_{2} \mathrm{O}_{2}$ photoreactor.....................................57

Figure 4.1. Mineralization of SWW in continuous mode without recycling for different processes. $\mathrm{TOC}_{\text {in }}=1000 \mathrm{mg} / \mathrm{L} \cdot \mathrm{Q}=5.90 \mathrm{~mL} / \mathrm{min}$.

Figure 4.2. Comparison of the $\mathrm{TOC} \mathrm{TOC}_{\text {in }}$ predicted values using Equation (4.8) and the experimental data of the SWW treatment in continuous mode without recycling for different processes: (a) ABR, (b) AS, (c) ABR-AS, (d) AS-ABR, (e) UV/ $\mathrm{H}_{2} \mathrm{O}_{2}$, and (f) ABR-AS-UV/ $/ \mathrm{H}_{2} \mathrm{O}_{2}$. The markers are the corresponding experimental data. The lines are the corresponding model predictions. $\mathrm{TOC}_{\text {in }}=1000 \mathrm{mg} / \mathrm{L} \cdot \mathrm{Q}=5.90 \mathrm{~mL} / \mathrm{min}$. .73

Figure 4.3. Operation costs per kilogram of TOC removed for each process: (a) ABR process alone, AS process alone, combined ABR-AS processes, combined AS-ABR processes, and ABR-AS$\mathrm{UV} / \mathrm{H}_{2} \mathrm{O}_{2}$ processes; (b) $\mathrm{UV} / \mathrm{H}_{2} \mathrm{O}_{2}$ process alone, as a function of TOC removal in continuous mode without recycling. $\mathrm{TOC}_{\text {in }}=1000 \mathrm{mg} / \mathrm{L} . \mathrm{Q}=5.90 \mathrm{~mL} / \mathrm{min}$. 76

Figure 4.4. Absolute operation costs compared with percentage of TOC removal for different processes in continuous mode without recycling. $\mathrm{TOC}_{\text {in }}=1000 \mathrm{mg} / \mathrm{L} . \mathrm{Q}=5.90 \mathrm{~mL} / \mathrm{min}$. .78

Figure 4.5. Operational costs per $\mathrm{m}^{3}$ of treated water compared with mineralization degree: comparison between the (a) ABR process alone, AS process alone, combined ABR-AS processes, combined AS-ABR processes, combined ABR-AS-UV/ $\mathrm{H}_{2} \mathrm{O}_{2}$ processes, and (b) $\mathrm{UV} / \mathrm{H}_{2} \mathrm{O}_{2}$ process alone in continuous mode without recycling. $T O C_{o}=1000 \mathrm{mg} / \mathrm{L} . Q=5.90 \mathrm{~mL} / \mathrm{min}$.

Figure 5.1. Schematic diagram of the combined anaerobic-aerobic processes for the treatment of SWW. 
Figure 5.2. Biomass concentration in the anaerobic baffled reactor during acclimatization and the aerobic activated sludge bioreactor. Error bars represent the standard deviation of the experimental data.

Figure 5.3. Maximum remaining values of (a) TOC, (b) TN, (c) COD, (d) TP, (e) Turbidity, and (f) TSS from SWW using combined anaerobic-aerobic processes in continuous mode with inlet concentrations of TOC, TN, COD, TP, and TSS of up to $941,214,1950,0.38$, and $750 \mathrm{mg} / \mathrm{L}$, respectively, as well as an influent turbidity of 1000 formazin turbidity units (FTU). Error bars represent the standard deviation of the experimental data.

Figure 5.4. Respirometry testing results for different samples of raw SWW, treated SWW by aerobic AS bioreactor alone, treated SWW by ABR alone, and treated SWW by combined ABR-AS processes. The initial TOC concentration is $75.00 \mathrm{mg} / \mathrm{L}$ and mean standard deviation is 6.43 $\mathrm{mg} / \mathrm{L} . \mathrm{BOD}_{5}$ is obtained as the oxygen uptake at the $120 \mathrm{~h}$ mark. .92

Figure 5.5. Individual effect of the (a) influent concentration of TOC, (b) flow rate, and (c) $\mathrm{pH}$ on percent TOC removal, percent TN removal, biogas yield, and TSS residual. The dashed lines represent model predicted values, whereas the marker points represent the experimental values. Error bars represent the standard deviation of the experimental data.... .99

Figure 5.6. 3D plots of the cross-factor interaction effect between the influent TOC concentration and the feed flow rate $\left(X_{1} X_{2}\right)$ on: (a) percent TOC removal (b) percent TN removal, and (c) TSS residual; interaction effect between the influent TOC concentration and $\mathrm{pH}\left(X_{1} X_{3}\right)$ on: (d) TOC removal, (e) TN removal, and (f) biogas yield; interaction effect between the feed flow rate and $\mathrm{pH}\left(X_{2} X_{3}\right)$ on: (g) biogas yield and (h) TSS residual; and (i) the desirability parameter interaction. 101

Figure 5.7. Operational costs per cubic meter of treated actual slaughterhouse wastewater against TOC removal efficiency: comparison of individual ABR and AS processes with the combined ABRAS system in continuous mode. .104

Figure 6.1. Schematic diagram of the laboratory-scale single lamp continuous $\mathrm{UV} / \mathrm{H}_{2} \mathrm{O}_{2}$ photoreactor with effluent recycle. $Q$ and $r$ are the flow rate and recycle ratio, respectively. $C_{S W W i n}, C_{S W W o u t}$, and $C_{S W W M}$ are the slaughterhouse wastewater concentration in the influent, in the effluent, and entering the photoreactor, respectively. $C_{H 2 O 2 i n}, C_{H 2 O 2 o u t}$, and $C_{H 2 O 2 M}$ are the hydrogen peroxide concentration in the influent, in the effluent, and entering the photoreactor, respectively. 110

Figure 6.2. Profiles of TOC removal and $\mathrm{H}_{2} \mathrm{O}_{2}$ residual in a laboratory-scale single lamp continuous $\mathrm{UV} / \mathrm{H}_{2} \mathrm{O}_{2}$ photoreactor with effluent recycle for SWW treatment under different conditions of (a) 
influent concentration of TOC, (b) influent $\mathrm{H}_{2} \mathrm{O}_{2}$ concentration, (c) flow rate, and (d) recycle ratio.

Figure 6.3. Validation of the percent TOC removal model using different plots: (a) internally studentized residuals versus predicted values, (b) normal probability, and (c) observed experimental data versus predicted values.

Figure 6.4. Validation of the percent $\mathrm{H}_{2} \mathrm{O}_{2}$ residual model using different plots: (a) internally studentized residuals versus predicted values, (b) normal probability, and (c) observed experimental data versus predicted values.

Figure 6.5. The individual effect of model parameters on the percent TOC removal: (a) influent concentration of TOC, (b) influent $\mathrm{H}_{2} \mathrm{O}_{2}$ concentration, (c) flow rate, and (d) recycle ratio. The continuous lines represent model predicted values, whereas the dashed lines represent the $95 \%$ confidence interval bands. .125

Figure 6.6. The individual effect of model parameters on the $\mathrm{H}_{2} \mathrm{O}_{2}$ residual: (a) influent concentration of TOC, (b) influent $\mathrm{H}_{2} \mathrm{O}_{2}$ concentration, (c) flow rate, and (d) recycle ratio. The continuous lines represent model predicted values, whereas the dashed lines represent the $95 \%$ confidence interval bands. .126

Figure 6.7. Interaction effects of different parameters on the percent TOC removal using 3D response surface and 2D contours: (a) influent concentration of TOC and $\mathrm{H}_{2} \mathrm{O}_{2}\left(X_{1} X_{2}\right)$, (b) influent concentration of TOC and flow rate $\left(X_{1} X_{3}\right)$, (c) influent concentration of TOC and recycle ratio $\left(X_{1} X_{4}\right)$, (d) influent $\mathrm{H}_{2} \mathrm{O}_{2}$ concentration and flow rate $\left(X_{2} X_{3}\right)$, (e) influent $\mathrm{H}_{2} \mathrm{O}_{2}$ concentration and recycle ratio $\left(X_{2} X_{4}\right)$, and (f) flow rate and recycle ratio $\left(X_{3} X_{4}\right)$. 128

Figure 6.8. Interaction effects of different parameters on the $\mathrm{H}_{2} \mathrm{O}_{2}$ residual using 3D response surface and 2D contours: (a) influent concentration of TOC and $\mathrm{H}_{2} \mathrm{O}_{2}\left(X_{1} X_{2}\right)$, (b) influent concentration of TOC and flow rate $\left(X_{1} X_{3}\right)$, (c) influent concentration of TOC and recycle ratio $\left(X_{1} X_{4}\right)$, (d) influent $\mathrm{H}_{2} \mathrm{O}_{2}$ concentration and flow rate $\left(X_{2} X_{3}\right)$, (e) influent $\mathrm{H}_{2} \mathrm{O}_{2}$ concentration and recycle ratio $\left(X_{2} X_{4}\right)$, and (f) flow rate and recycle ratio $\left(X_{3} X_{4}\right)$.

Figure 6.9. Desirability response surface, maximizing the percent removal of TOC and minimizing the $\mathrm{H}_{2} \mathrm{O}_{2}$ residual at optimum factor settings: (a) influent concentration of TOC and $\mathrm{H}_{2} \mathrm{O}_{2}\left(X_{1} X_{2}\right)$ interaction with optimum flow rate $(15 \mathrm{~mL} / \mathrm{min})$ and recycle ratio $(0.18)$; (b) flow rate and recycle ratio $\left(X_{3} X_{4}\right)$ interaction with optimum influent TOC concentration $(24 \mathrm{mg} / \mathrm{L})$ and $\mathrm{H}_{2} \mathrm{O}_{2}(860$

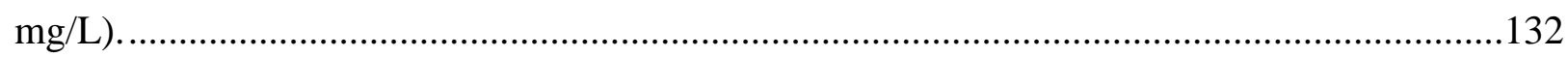

Figure 7.1. On-site slaughterhouse wastewater treatment in Ontario..........................................136 
Figure 7.2. Schematic diagram of the combined anaerobic, aerobic, and $U V / \mathrm{H}_{2} \mathrm{O}_{2}$ processes for the treatment of SWW.

Figure 7.3. Internally studentized residuals versus predicted values for (a) percent TOC removal and (b) $\mathrm{H}_{2} \mathrm{O}_{2}$ residual. 147

Figure 7.4. Internally studentized residuals versus normal probability for (a) percent TOC removal and (b) $\mathrm{H}_{2} \mathrm{O}_{2}$ residual. 148

Figure 7.5. Observed experimental data versus predicted values for (a) percent TOC removal and (b) $\mathrm{H}_{2} \mathrm{O}_{2}$ residual.

Figure 7.6. 3D surfaces and 2D plots of the interaction effects of: (a) influent TOC concentration and $\mathrm{H}_{2} \mathrm{O}_{2}$ dosage $\left(X_{1} X_{3}\right)$, flow rate and $\mathrm{H}_{2} \mathrm{O}_{2}$ dosage $\left(X_{2} X_{3}\right)$, and $\mathrm{H}_{2} \mathrm{O}_{2}$ dosage and $\mathrm{pH}\left(X_{3} X_{4}\right)$ on the TOC removal; and (d) influent TOC concentration and $\mathrm{H}_{2} \mathrm{O}_{2}$ dosage $\left(X_{1} X_{3}\right)$, (e) flow rate and pH $\left(X_{2} X_{4}\right)$, and (f) $\mathrm{H}_{2} \mathrm{O}_{2}$ dosage and $\mathrm{pH}\left(X_{3} X_{4}\right)$ on $\mathrm{H}_{2} \mathrm{O}_{2}$ residual. .150

Figure 8.1. Schematic diagram of (a) the combined anaerobic-aerobic processes for the treatment of SWW and the individual processes (b) anaerobic baffled reactor, (c) aerobic activated sludge bioreactor, and (d) $\mathrm{UV} / \mathrm{H}_{2} \mathrm{O}_{2}$ photoreactor with recycle. .157

Figure 8.2. Individual effect of the (a) influent concentration of TOC; (b) flow rate; (c) inlet $\mathrm{H}_{2} \mathrm{O}_{2}$ concentration; and (d) $\mathrm{pH}$ on the percentual TOC removal, TN removal, $\mathrm{H}_{2} \mathrm{O}_{2}$ residual, and $\mathrm{CH}_{4}$ yield. The dashed lines represent model predicted values, whereas the marker points represent the experimental values. Error bars represent the standard deviation of the experimental data......173

Figure 8.3. 3D surfaces and 2D plots of the interaction effects of (a) the influent TOC concentration with inlet $\mathrm{H}_{2} \mathrm{O}_{2}$ concentration $\left(X_{1} X_{3}\right)$ and (b) the inlet $\mathrm{H}_{2} \mathrm{O}_{2}$ concentration with $\mathrm{pH}\left(X_{3} X_{4}\right)$ on the percentual TOC removal; (c) the influent TOC concentration with $\mathrm{pH}\left(X_{1} X_{4}\right)$ and (d) the flow rate with $\mathrm{pH}\left(\mathrm{X}_{2} \mathrm{X}_{4}\right)$ on the percentual TN removal; (e) the influent TOC concentration with inlet $\mathrm{H}_{2} \mathrm{O}_{2}$ concentration $\left(X_{1} X_{3}\right)$ and (f) the flow rate with $\mathrm{pH}\left(X_{2} X_{4}\right)$ on the percentual $\mathrm{H}_{2} \mathrm{O}_{2}$ residual; and $(\mathrm{g})$ the influent TOC concentration with flow rate $\left(X_{1} X_{2}\right)$ and $(\mathrm{h})$ the influent TOC concentration with $\mathrm{pH}\left(X_{1} X_{4}\right)$ on the $\mathrm{CH}_{4}$ production in the combined $\mathrm{ABR}-\mathrm{AS}-\mathrm{UV} / \mathrm{H}_{2} \mathrm{O}_{2}$ processes. .175

Figure 8.4. Desirability 2D plots maximizing the percentual TOC removal, TN removal, and $\mathrm{CH}_{4}$ production while minimizing the $\mathrm{H}_{2} \mathrm{O}_{2}$ residual at optimum factor settings of influent TOC concentration of $626 \mathrm{mg} / \mathrm{L}$, feed flow rate of $45 \mathrm{~mL} / \mathrm{min}$, inlet $\mathrm{H}_{2} \mathrm{O}_{2}$ concentration of $350 \mathrm{mg} / \mathrm{L}$, and $\mathrm{pH}$ of 6.59 in the combined $\mathrm{ABR}-\mathrm{AS}-\mathrm{UV} / \mathrm{H}_{2} \mathrm{O}_{2}$ processes.

Figure 8.5. Comparison of model predictions and experimental data of TOC/TOCin as a function of retention time for different (a) influent concentrations of TOC; (b) inlet $\mathrm{H}_{2} \mathrm{O}_{2}$ concentration; (c) and $\mathrm{pH}$ in the combined $\mathrm{ABR}-\mathrm{AS}-\mathrm{UV} / \mathrm{H}_{2} \mathrm{O}_{2}$ processes; and (d) effect of retention time to reduce 
the TOC concentration in the actual slaughterhouse wastewater. The lines are the corresponding model predictions. Initial conditions: $\mathrm{T}=22^{\circ} \mathrm{C}$, recycle rate $=0.18$, and optimum operating conditions of $[\mathrm{TOC}]_{\mathrm{in}}=626 \mathrm{mg} / \mathrm{L}$, inlet $\mathrm{H}_{2} \mathrm{O}_{2}$ concentration $=350 \mathrm{mg} / \mathrm{L}$, and $\mathrm{pH}=6.59$, excepting when analyzing each effect accordingly.

Figure 8.6. Comparison of individual $\mathrm{ABR}, \mathrm{AS}$, and $\mathrm{UV} / \mathrm{H}_{2} \mathrm{O}_{2}$ processes with the combined $\mathrm{ABR}-\mathrm{AS}-$ $\mathrm{UV} / \mathrm{H}_{2} \mathrm{O}_{2}$ system in continuous mode with recycle: (a) Electrical energy consumption based on the residence time in the photoreactor; and (b) Operational costs per cubic meter of treated actual slaughterhouse wastewater.

Figure S.1. Internally studentized residuals versus predicted values for the percentual TOC removal, TN removal, $\mathrm{H}_{2} \mathrm{O}_{2}$ residual, and $\mathrm{CH}_{4}$ production (a, b, c, and d, respectively); and model validation using experimental data for the percentual TOC removal, percentual TN removal, $\mathrm{H}_{2} \mathrm{O}_{2}$ residual, and $\mathrm{CH}_{4}$ production (e, $\mathrm{f}, \mathrm{g}$, and h, respectively) in the combined $\mathrm{ABR}-\mathrm{AS}-\mathrm{UV} / \mathrm{H}_{2} \mathrm{O}_{2}$ processes.

Figure S.2. The individual effect of model parameters on the percentual TOC removal: (a) influent concentration of TOC; (b) flow rate; (c) inlet $\mathrm{H}_{2} \mathrm{O}_{2}$ concentration; and (d) $\mathrm{pH}$ in the combined $\mathrm{ABR}-\mathrm{AS}-\mathrm{UV} / \mathrm{H}_{2} \mathrm{O}_{2}$ processes. The continuous lines represent model predicted values; whereas the dashed lines represent the $95 \%$ confidence interval bands. .260

Figure S.3. The individual effect of model parameters on the percentual TN removal: (a) influent concentration of TOC; (b) flow rate; and (c) $\mathrm{pH}$ in the combined $\mathrm{ABR}-\mathrm{AS}-\mathrm{UV} / \mathrm{H}_{2} \mathrm{O}_{2}$ processes. The continuous lines represent model predicted values; whereas the dashed lines represent the $95 \%$ confidence interval bands.

Figure S.4. The individual effect of model parameters on the percentual $\mathrm{H}_{2} \mathrm{O}_{2}$ residual: (a) influent concentration of TOC; (b) flow rate; (c) inlet $\mathrm{H}_{2} \mathrm{O}_{2}$ concentration; and (d) $\mathrm{pH}$ in the combined $\mathrm{ABR}-\mathrm{AS}-\mathrm{UV} / \mathrm{H}_{2} \mathrm{O}_{2}$ processes. The continuous lines represent model predicted values; whereas the dashed lines represent the $95 \%$ confidence interval bands. 262

Figure S.5. The individual effect of model parameters on the $\mathrm{CH}_{4}$ yield: (a) influent concentration of TOC; (b) flow rate; and (c) $\mathrm{pH}$ in the combined $\mathrm{ABR}-\mathrm{AS}-\mathrm{UV} / \mathrm{H}_{2} \mathrm{O}_{2}$ processes. The continuous lines represent model predicted values; whereas the dashed lines represent the $95 \%$ confidence interval bands. 263

Figure S.6. Maximum remaining values of (a) COD, (b) BOD, (c) TOC, (d) TN, (e) TP, and (f) TSS from an actual slaughterhouse wastewater SWW using combined ABR-AS-UV/ $\mathrm{H}_{2} \mathrm{O}_{2}$. Error bars represent the standard deviation of the experimental data. .264 


\section{CHAPTER 1 \\ INTRODUCTION}

Water and wastewater treatment has become crucial for the continuing development of current society. The progressively stricter standards for effluent discharge worldwide have made the development of advanced wastewater treatment technologies necessary (Environment Canada, 2000; US EPA, 2004; World Bank Group, 2007). Moreover, the decreasing availability of freshwater resources along with the growing population has rearranged the objectives in the wastewater treatment field from disposal to reuse and recycling. As a result, a high level of treatment efficiency has to be achieved. Given the differences in location, economic resources, and living standards of different countries and characteristics of water and its pollutants, many nations have adopted diverse techniques for water and wastewater treatment (Daigger, 2009).

The meat-processing sector produces large amounts of slaughterhouse wastewater (SWW) due to the slaughtering of animals and birds and cleaning of the slaughterhouse facilities and meat processing plants (MPPs). The meat processing industry uses $24 \%$ of the total freshwater consumed by the food and beverage industry and up to $29 \%$ of that consumed by the agricultural sector worldwide (Mekonnen and Hoekstra, 2012; Gerbens-Leenes et al., 2013). Moreover, the global production of beef, pork, and poultry meat has been doubled in the past decade and is projected to grow steadily until 2050. Furthermore, the number of slaughterhouse facilities are increasing, which results in an expected higher volume of slaughterhouse wastewater (SWW) to be treated.

Slaughterhouses are part of a large industry, which is common to numerous countries worldwide where meat is an important part of their diet. Therefore, SWWs require significant treatment for a safe and sustainable release to the environment (Johns, 1995). Therefore, the treatment and disposal of wastewater from slaughterhouses and MPPs are an economic and public health necessity (Debik and Coskun, 2009). SWWs have been considered as an industrial waste in the category of agricultural and food industries and classified as one of the most harmful wastewaters to the environment by the United States Environmental Protection Agency (US EPA) since SWW discharge may cause deoxygenation of rivers and contamination of groundwater (US EPA, 2004). 
Slaughterhouse wastewater (SWW) effluents are becoming one of the major agribusiness concerns because of the elevated amounts of water used during slaughtering, processing, and cleaning of the abattoir facilities. Although physical, chemical, and biological treatment can be used for SWW degradation, each treatment process has different benefits and drawbacks depending on the SWW characteristics, best available technology, jurisdiction, and regulations (Tabrizi and Mehrvar, 2004; Barrera et al., 2012; Franke-Whittle and Insam, 2013; Bustillo-Lecompte and Mehrvar, 2015; Valta et al., 2015; Bustillo-Lecompte et al., 2015, 2016a).

The organic matter concentration in SWW is usually high and the residues are moderately solubilized, leading to a highly polluting effect (Ruiz et al., 1997). They usually contain high levels of organics, pathogenic and non-pathogenic viruses and bacteria, and detergents and disinfectants used for cleaning activities (Debik and Coskun, 2009). The SWW is typically assessed in terms of bulk parameters because of the diverse pollutant loads in the SWW derived from the type and number of animals slaughtered that fluctuate amid the meat industry (Bustillo-Lecompte and Mehrvar, 2015). SWW usually contain high levels of organics and nutrients, expressed as bulk components such as biochemical oxygen demand (BOD), chemical oxygen demand (COD), and total organic carbon (TOC). Thus, SWW is considered detrimental worldwide and on-site treatment would be the best option to treat and disinfect the effluents to be discharged safely into receiving waters (Debik and Coskun, 2009; Wu and Mittal, 2011; Bustillo-Lecompte et al., 2013, 2014; Bustillo-Lecompte and Mehrvar, 2015).

According to Mittal (2006), slaughterhouses in Ontario, Canada, typically discharge the SWW into the municipal sewer system after preliminary treatment. Thus, slaughterhouses commonly pay surcharges, penalties, or fines to dispose their effluents into receiving municipal wastewater treatment plants. Moreover, as of June 2016 there are currently 134 licensed MPPs in Ontario that can process 100-200 animals per month. Approximately 53\% of Ontario's slaughterhouses do not treat their wastewater on-site before disposal. Dissolved air flotation (DAF) or aeration is the typical method of preliminary treatment with $16 \%$ of Ontario's slaughterhouses using it at their facilities. The rest of slaughterhouses (31\%) use passive methods such as lagoons or storage tanks to settle solids (Figure 7.1) (Bustillo-Lecompte and Mehrvar, 2015).

Direct discharge of untreated slaughterhouse effluents to a water body is not practical due to the high organic load of the SWW. Therefore, appropriated disposal and treatment is required. It may also 
be stated that in terms of operation and economics, it is beneficial to implement combined processes for the management of slaughterhouse effluents since it couples the benefit of different technologies to improve high strength industrial wastewater treatment (Bustillo-Lecompte et al., 2014).

Although physical, chemical, and biological treatment can be used for SWW degradation, each treatment process has different benefits and drawbacks depending on the SWW characteristics, best available technology, jurisdictions, and regulations. Furthermore, the recovery of valuable by-products from the slaughterhouse effluents is currently focused on the high-quality treatment, the biogas generation, the nutrients, and the fertilizers (Kist et al., 2009; Rajakumar et al., 2011; Barrera et al., 2012; Franke-Whittle and Insam, 2013; Bustillo-Lecompte and Mehrvar, 2015; Bustillo-Lecompte et al., 2013, 2014, 2016a). Hence, the interaction of cross-factor and single-factor effects on the overall

process efficiency and biogas yield has not been widely evaluated, rather the microorganism characterization, disinfection, and denitrification have been the focus of studies in recent years (FrankeWhittle and Insam, 2013; Bustillo-Lecompte and Mehrvar, 2015).

On the other hand, research on wastewater treatment commonly includes the study of different contaminants, the effects of operating variables, and the efficiency of the processes. Nevertheless, there are limited studies on the economic information and analysis, reaction mechanisms, and kinetic modeling that may help to estimate the costs of different technologies for scale-up and industrial applications (Durán et al., 2012; Benedetti et al., 2013; Ghafoori et al., 2012, 2013, 2014a).

\subsection{Problem statement}

Typically, SWWs are treated in anaerobic reactors because of the high organic concentrations (Cao and Mehrvar, 2011). Anaerobic treatment is the preferred biological treatment because of its effectiveness in treating high-strength wastewater such as SWW with less complex equipment requirements. Anaerobically treated effluents require post-treatment to comply with required discharge limits. Although anaerobic treatment is efficient, the complete stabilization of the organic matter is not possible by anaerobic treatment alone; its effluent contains solubilised organic matters, which are more suited for treatment using aerobic processes (Cao and Mehrvar, 2011; Bustillo-Lecompte et al., 2013, 2014). Therefore, aerobic treatment systems are more frequently used in wastewater treatment since they operate at higher rates than conventional anaerobic treatment methods. Taking into account that oxygen requirements and treatment time are directly proportional to an increase in wastewater strength, 
aerobic treatment are commonly used for further treatment and nutrient removal following physicochemical and anaerobic treatment methods (Bustillo-Lecompte and Mehrvar, 2015).

Nevertheless, neither anaerobic nor aerobic processes should be employed alone for efficient treatment, since aerobic or anaerobic treatment alone do not produce effluents that comply with effluent discharge limits when treating high organic strength wastewaters. The benefits of the combined anaerobic-aerobic processes include potential resource recovery from the conversion of organic pollutants into biogas with high overall treatment efficiency (Chan et al., 2009).

However, SWWs may contain toxic and non-biodegradable organic substances, which make biological treatment alone insufficient (Oller et al., 2011). Thus, advanced oxidation processes (AOPs) are used to improve the biodegradability of SWW, which may contain non-biodegradable organics and inactivate both pathogenic and non-pathogenic microorganisms without adding additional chemicals to the SWW, avoiding the formation of hazardous by-products. Consequently. AOPs are an attractive alternative to conventional treatment systems and a complementary treatment method to biological processes for the treatment of slaughterhouse effluents (Oller et al., 2011; Cao and Mehrvar, 2011; Barrera et al., 2012; Bustillo-Lecompte and Mehrvar, 2015; Bustillo-Lecompte et al., 2013, 2014, 2016a, 2016b).

Several AOPs have been investigated for SWW treatment, such as ozonation, gamma radiation, and $\mathrm{UV} / \mathrm{H}_{2} \mathrm{O}_{2}$ (Wu and Doan, 2005; Melo et al., 2008; De Sena et al., 2009; Luiz et al., 2009; Cao and Mehrvar, 2011; Barrera et al., 2012; Bustillo-Lecompte et al., 2014; Bustillo-Lecompte et al., 2015). However, the $\mathrm{UV} / \mathrm{H}_{2} \mathrm{O}_{2}$ process has been found to be more efficient for $\mathrm{SWW}$ treatment. The $\mathrm{UV} / \mathrm{H}_{2} \mathrm{O}_{2}$ process is five times faster in inactivation and inhibition of microorganisms as well as in degrading aromatic compounds than other AOP technologies. Removal efficiencies of up to 97, 95, and 75\% could be achieved by the $\mathrm{UV} / \mathrm{H}_{2} \mathrm{O}_{2}$ process for COD, BOD, and TOC, respectively (De Sena et al., 2009; Luiz et al., 2009; Cao and Mehrvar, 2011; Wu and Mittal, 2011; Barrera et al., 2012; Bustillo-Lecompte et al., 2013, 2014). Thus, AOPs could be considered to enhance the SWW quality for water reuse purposes.

The combined processes for wastewater treatment can be considered to be multifactor systems due to the interaction of different parameters on the overall process efficiency including organics concentration, reaction time, $\mathrm{pH}$, light source intensity, oxidant concentration, output power, among 
others, which have not been widely investigated. Therefore, the optimization of such systems requires considering both single-factor and cross-factor effects through a design of experiments (DOE) to identify the factors that influence the multivariable system while overcoming the limitations of traditional experimental methods in terms of the number of experimental trials, time, and materials (Ghafoori et al., 2012, 2014a, 2015; Bustillo-Lecompte et al., 2016a, 2016b). On the other hand, the available information on the reaction mechanisms and detailed kinetic modeling of combined biological and AOP systems involving all free radicals and molecular species for the degradation of SWW is limited (Ghafoori et al., 2012; Bustillo-Lecompte and Mehrvar, 2015).

The optimization of parameters by conventional methods needs time, materials, and a large number of experiments. On the other hand, parameters such as $\mathrm{H}_{2} \mathrm{O}_{2}$ residuals, known to be toxic to microorganisms in biological post-treatment, and recycle ratio, known as the ratio of recycle flow rate to the main feed flow rate, are not widely investigated. Moreover, conventional methods fail to consider the combined effects of all the factors involved. Therefore, a DOE is used to overcome the limitations of conventional methods and consequently optimize the factors involved. Conversely, response surface methodology (RSM) has been recognized to be statistically reliable to analyze multifactor systems in chemical treatment processes. RSM considers cross-factor interactions to attain optimal responses using the minimum number of experiments (Ghafoori et al., 2012, 2014a, 2015; Bustillo-Lecompte et al., 2016a; Šereš et al., 2016).

As a result, adopting combined processes for SWW treatment is considered operationally and economically advantageous because it incorporates and optimizes the advantages of different technologies to achieve high-quality effluents from industrial and high-strength wastewaters (Mehrvar and Tabrizi, 2006; De Nardi et al., 2011; Bustillo-Lecompte et al., 2013, 2014; Mowla et al., 2014; Bustillo-Lecompte and Mehrvar, 2015). Furthermore, considering the eventual reduction in operation and maintenance costs, high removal efficiency requirements, potential energy recovery from biogas production, and enhanced quality for water reuse purposes, combined biological processes and AOP systems are recommended for SWW treatment provided that the system be optimized at an appropriate residence time in each reactor (Tabrizi and Mehrvar, 2004; Oller et al., 2011; Bustillo-Lecompte and Mehrvar, 2015). 


\subsection{Objectives and scope of the project}

The purpose of this study is to evaluate the current wastewater treatment technologies used in the meat processing sector in Ontario; thus, to assess possible alternatives in order to minimize the impact of the discharge of these wastewaters to the environment. In this study, the information on current meat processing plants (MPPs) in Ontario, including characteristics of the actual wastewater and type of treatment/storage/disposal used is examined. This study required sampling of an actual slaughterhouse wastewater (SWW), experimental work to assess the overall removal of organics and nutrients, optimization of reactors and systems for SWW treatment, potential energy recovery from biological processes, modeling, and cost-efficiency analysis for industry applications. This study is highly beneficial as a contribution to the advancement of knowledge due to the lack of information and enforcement on adequate treatment of SWWs. In summary, the objectives of the present study are:

1. To perform an exhaustive review on SWW characteristics, treatment, and management in the meat processing industry;

2. To evaluate the performance of combined biological and advanced oxidation processes for the treatment of an actual slaughterhouse wastewater.

3. To evaluate the effects of different variables on the overall treatment of an actual slaughterhouse wastewater, including influent concentration of organics, oxidant dosage, feed flow rate, $\mathrm{pH}$, and their interaction on the overall treatment efficiency, effluent pollutant residuals, and potential energy recovery;

4. To describe common degradation mechanisms and predict the percentual TOC removal as the output variable with time in the optimized combined processes for the actual SWW treatment;

5. To evaluate the effect of a recycle stream in the $\mathrm{UV} / \mathrm{H}_{2} \mathrm{O}_{2}$ process on the TOC removal and $\mathrm{H}_{2} \mathrm{O}_{2}$ residual in the effluent.

6. To optimize operating conditions of the reactors for SWW treatment, overall treatment time, and energy consumption

7. To evaluate the operating costs of treating SWW for individual processes and the proposed ABRAS-UV/ $\mathrm{H}_{2} \mathrm{O}_{2}$ system for TOC removal using a cost-effectiveness analysis (CEA) by minimizing the incurred treatment costs, the electrical energy consumption, and the retention time required for the efficient treatment of actual slaughterhouse effluents and potential energy recovery. 


\subsection{Dissertation outline}

This dissertation is written in a manuscript-based format such that the chapters can be read independently. The materials and methods used in the present dissertation are presented in Chapter 2. The reader might find a few repetitions in the subsequent chapters due to the format of this dissertation. Nevertheless, all chapters were integrated into a logical progression from chapter to chapter to create a unified and consistent dissertation. The following publications resulted from this $\mathrm{PhD}$ work and are listed in the order of presentation in this dissertation:

1. C. Bustillo Lecompte; and M. Mehrvar; (2015) Slaughterhouse wastewater characteristics, treatment, and management in the meat processing industry: a review on trends and advances. Journal of Environmental Management 161, pp. 287-302. (Chapter 3).

2. C. Bustillo Lecompte; M. Mehrvar and E. Quiñones Bolaños (2014) Cost-Effectiveness Analysis of TOC Removal from Slaughterhouse Wastewater using Combined Anaerobic-Aerobic and $U V / H_{2} \mathrm{O}_{2}$ Processes. Journal of Environmental Management 134, pp. 145-152. (Chapter 4).

3. C. Bustillo Lecompte; and M. Mehrvar; (2016) Treatment of actual slaughterhouse wastewater by combined anaerobic-aerobic processes for biogas generation and removal of organics and nutrients: an optimization study towards a cleaner production in the meat processing industry. Journal of Cleaner Production. (Submitted). (Chapter 5).

4. C. Bustillo Lecompte; S. Ghafoori; and M. Mehrvar (2016) Photochemical degradation of an actual slaughterhouse wastewater by continuous $\mathrm{UV} / \mathrm{H}_{2} \mathrm{O}_{2}$ photoreactor with recycle. Journal of Environmental Chemical Engineering 4 (1), pp. 719-732. (Chapter 6).

5. C. Bustillo Lecompte; M. Mehrvar and E. Quiñones Bolaños (2016) Slaughterhouse wastewater characterization and treatment: an economic and public health necessity of the meat processing industry in Ontario, Canada. Journal of Geoscience and Environment Protection 4, pp. 175-186. (Chapter 7).

6. C. Bustillo Lecompte; and M. Mehrvar; (2016) Treatment of actual slaughterhouse wastewater by integrating biological and advanced oxidation processes: modeling, optimization, and cost-effectiveness analysis. Journal of Environmental Management. (In Press). (Chapter 8).

Finally, Chapter 9 outlines the main findings and conclusions of this study as the original contribution of the dissertation to the advancement of knowledge in the research area of industrial wastewater treatment, as well as the recommendations for future work. Finally, some supplementary materials are provided in Appendix $\mathrm{S}$ to complement chapters presented in this dissertation. 


\subsection{Contributions of co-authors}

The principal author, Ciro Fernando Bustillo-Lecompte, wrote all Chapters presented in this dissertation. The principal author was also in charge of and responsible for the design and identification of the research undertaken, performed analysis on all samples, interpreted and analysed data and questionnaires, and prepared manuscripts for submission to refereed journals.

Chapters 3, 4, 5, 6, 7 and 8 have been submitted to refereed journals and were co-authored by Dr. Mehrab Mehrvar, the sole dissertation supervisor, who guided the development and the progress of the project, helped in data interpretation and manuscript revisions and evaluation by providing editorial and technical advice, and acted as corresponding author. Dr. Edgar Quiñones-Bolaños, Professor of Environmental Engineering of the University of Cartagena, Cartagena de Indias, Colombia, provided assistance in data analysis to portions of the work performed in Chapters 4 and 7, and is listed as a coauthor accordingly. Finally, Dr. Samira Ghafoori, faculty member of the Australian College of Kuwait, Mishrif, Kuwait City, Kuwait, provided assistance in data analysis to portions of the work performed in Chapter 6, and is listed as a co-author accordingly. 


\section{CHAPTER 2 \\ MATERIALS AND METHODS}

\subsection{Introduction}

This study aims to identify the most recent trends and advances in meat processing effluent management and common practices in slaughterhouse wastewater (SWW) treatment and characteristics. This study is also focused on determining the performance and the treatment ability of the $\mathrm{ABR}$, the aerobic $\mathrm{AS}$, and the $\mathrm{UV} / \mathrm{H}_{2} \mathrm{O}_{2}$ processes, as well as their combination for the treatment of actual SWW. Therefore, this chapter presents the main materials and methods used to carry out this project.

\subsection{Materials}

\subsubsection{Actual slaughterhouse wastewater samples}

Actual SWW sources may contain feces, urine, blood, lint, fat, carcasses, and non-digested food from slaughtered animals, production leftovers, and cleaning of the facilities (Bustillo-Lecompte et al., 2013; Bustillo-Lecompte and Mehrvar, 2015). Therefore, all solids and large particles were separated from the wastewater using a mesh with a $4.00 \mathrm{~mm}$ sieve size. Actual SWW samples were taken from selected provincially licensed meat processing plants directly from their source in Ontario, Canada, at different times of the study (OMAFRA, 2014, 2015a, 2015b). Although SWW composition varies according to the industrial process and water demand, they usually contain high levels of organics and nutrients, typically measured as biochemical oxygen demand (BOD), chemical oxygen demand (COD), total organic carbon (TOC), total suspended solids (TSS), total nitrogen (TN), and phosphorus (TP). Thus, homogenized actual SWW samples had an average TOC concentration of $862 \mathrm{mg} / \mathrm{L}$. Table 2.1 shows the overall SWW characteristics from the selected provincially licensed meat processing plants (Bustillo-Lecompte and Mehrvar, 2015, 2016a, 2016b). The SWW features and common ranges are listed as BOD, COD, TOC, TSS, TN, and $\mathrm{pH}$. Ten sample sites were used depending on the TOC range of each stage of the study. Distilled water (DW) was used to dilute SWW samples in order to adjust the influent TOC concentrations to different DOE levels accordingly. 
Table 2.1. Characteristics of the actual slaughterhouse wastewater from selected provincially licensed meat processing plants along with study range values and detection limits.

\begin{tabular}{llll}
\hline Parameter & Range & Mean & Detection limits \\
\hline BOD (mg/L) & $37.95-8,231$ & 2,649 & $0.000-10,000$ \\
COD (mg/L) & $76.43-14,256$ & 5,577 & $0.000-15,000$ \\
Color (mg/L Pt scale) & $178.0-391.0$ & 289.0 & $0.000-500.00$ \\
TN (mg/L) & $6.120-841.0$ & 427.0 & $0.100-25,000$ \\
TOC (mg/L) & $10.51-1,718$ & 862.1 & $0.100-25,000$ \\
TP (mg/L) & $0.143-200.0$ & 42.81 & $0.020-125.00$ \\
TSS (mg/L) & $0.287-9,938$ & 3,092 & $0.000-750.00$ \\
Turbidity (FAU $)$ & $271.0-279.0$ & 275.0 & $0.000-1,000.0$ \\
pH & $4.90-8.10$ & 6.95 & $4.0-10$ \\
\hline
\end{tabular}

${ }^{\mathrm{a}} \mathrm{FAU}$, formazin attenuation units.

\subsubsection{Chemicals and reagents}

A $30 \% \mathrm{w} / \mathrm{w}$ hydrogen peroxide solution was used as the AOP oxidant and purchased from SigmaAldrich (Oakville, $\mathrm{ON})$, whereas $\mathrm{NaOH}(50 \% \mathrm{w} / \mathrm{w})$ and $\mathrm{H}_{2} \mathrm{SO}_{4}(98 \% \mathrm{w} / \mathrm{w})$ were obtained from EMD Millipore (Etobicoke, ON) for $\mathrm{pH}$ adjustment. The $\mathrm{H}_{2} \mathrm{O}_{2}$ residual was measured using the copperneocuproine method (Baga et al., 1988; Kosaka et al., 1998; Brandhuber and Korshin, 2009; Hamad et al., 2014; Bustillo-Lecompte et al., 2016a). The reagents and materials required by this method were neocuproine (2,9-dimethyl-1,10-phenanthroline) purchased from Sigma-Aldrich (Oakville, ON), ethanol was purchased from BDH (Mississauga, ON), copper (II) sulfate pentahydrate, $\mathrm{K}_{2} \mathrm{HPO}_{4}$, and $\mathrm{NaH}_{2} \mathrm{PO}_{4}$ were purchased from Sigma-Aldrich (Oackville, ON). All chemicals and reagents were used as received.

\subsubsection{Anaerobic and aerobic inoculum}

The anaerobic and aerobic sludge seeds were obtained from the Ashbridges Bay Wastewater Treatment Plant, a municipal wastewater treatment plant in Toronto, Ontario. The sludge samples were transported in 20-L closed containers and used as received. The inoculum was acclimatized in eight weeks by feeding the actual slaughterhouse wastewater (SWW) continuously into the bioreactors using a peristaltic pump at a constant flow rate of $75 \mathrm{~mL} / \mathrm{min}$ while gradually increasing its concentration on biweekly basis from 25,50 , and $75 \%$ to $100 \%$ of the actual SWW. 


\subsection{Experimental setup}

An anaerobic baffled reactor (ABR), an aerobic activated sludge (AS) reactor, and a $\mathrm{UV} / \mathrm{H}_{2} \mathrm{O}_{2}$ photoreactor, were operated in continuous mode and used individually and as a combined system at the laboratory scale for SWW treatment. The schematic diagram of the experimental setup for the combined $\mathrm{ABR}-\mathrm{AS}-\mathrm{UV} / \mathrm{H}_{2} \mathrm{O}_{2}$ processes is illustrated in Figure 2.1 while Figure 2.2 shows the laboratory scale experimental setup.

The combined biological and advanced oxidation system consisted of three reactors (Figure 2.1). First, a 36-L ABR with five chambers, individual headspaces, and biogas collection piping was used for anaerobic treatment (Figure 2.1b). In the ABR, a $45^{\circ}$ slanted-edge baffle within each ABR chamber permitted the down- and up-flow course of the actual SWW, providing effective mixing and contact time between the SWW and the biomass. Second, a 12.65-L AS bioreactor was used for aerobic treatment (Figure 2.1c). The air flow rate in the AS bioreactor was supplied using an air diffuser and was set to $1.2-2.0 \mathrm{~L} / \mathrm{min}$ by a control valve with air flow meter to guarantee nitrifying bacteria growth and dissolved oxygen (DO) concentrations over $2.0 \mathrm{mg} / \mathrm{L}$. Finally, a 1.35-L photoreactor with recycle and uniform light distribution was used as the AOP (Figure 2.1d). The stainless steel cylindrical photoreactor (Barrier SL-1S - Siemens Inc., Markham, ON) had an external diameter of $8 \mathrm{~cm}$ and a length of $34 \mathrm{~cm}$ and a $2.5 \mathrm{~cm}$ diameter UV-C lamp was inserted into the center of the photoreactor with an output power of $6 \mathrm{~W}$ and a $254 \mathrm{~nm}$ wavelength. A quartz sleeve was used to protect the lamp from fouling and maintain a uniform UV-C radiation emission.

\subsection{Experimental procedure}

\subsubsection{Acclimatization of the inoculum}

Anaerobic and aerobic sludge seeds were loaded into the anaerobic and aerobic bioreactors, respectively. Twelve liters of an anaerobic sludge seed $(38000 \mathrm{mg} / \mathrm{L})$, using $2.4 \mathrm{~L}$ of the inoculum for each of the five chambers of the ABR (1/3 of the total working volume), and $5 \mathrm{~L}$ of an aerobic sludge seed $(3000 \mathrm{mg} / \mathrm{L})$ were loaded into the anaerobic and aerobic bioreactors, respectively. The inoculum was acclimatized in eight weeks by feeding the actual SWW continuously into the bioreactors using a peristaltic pump at a constant flow rate of $75 \mathrm{~mL} / \mathrm{min}$. 


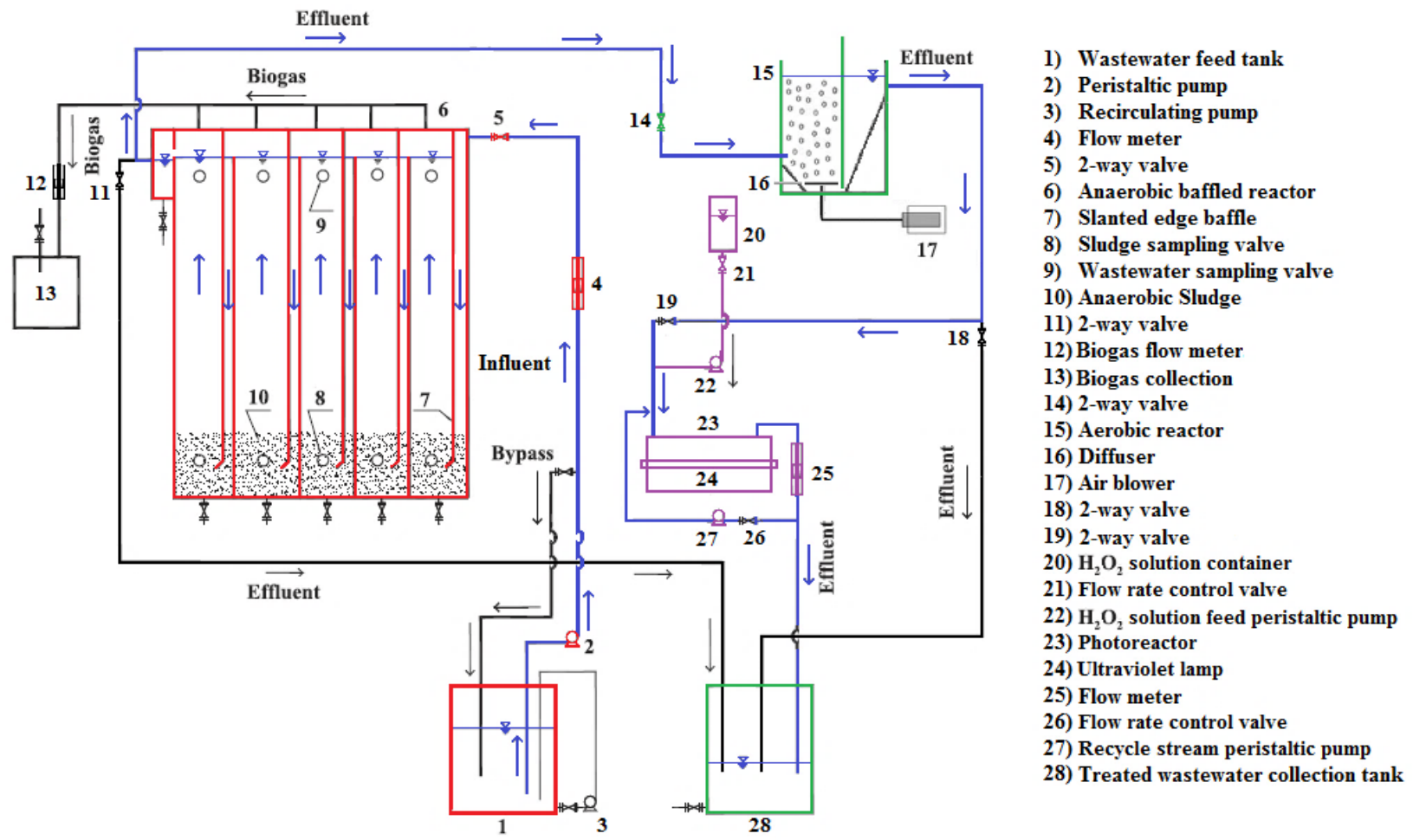

(a) Combined anaerobic-aerobic processes for the treatment of SWW
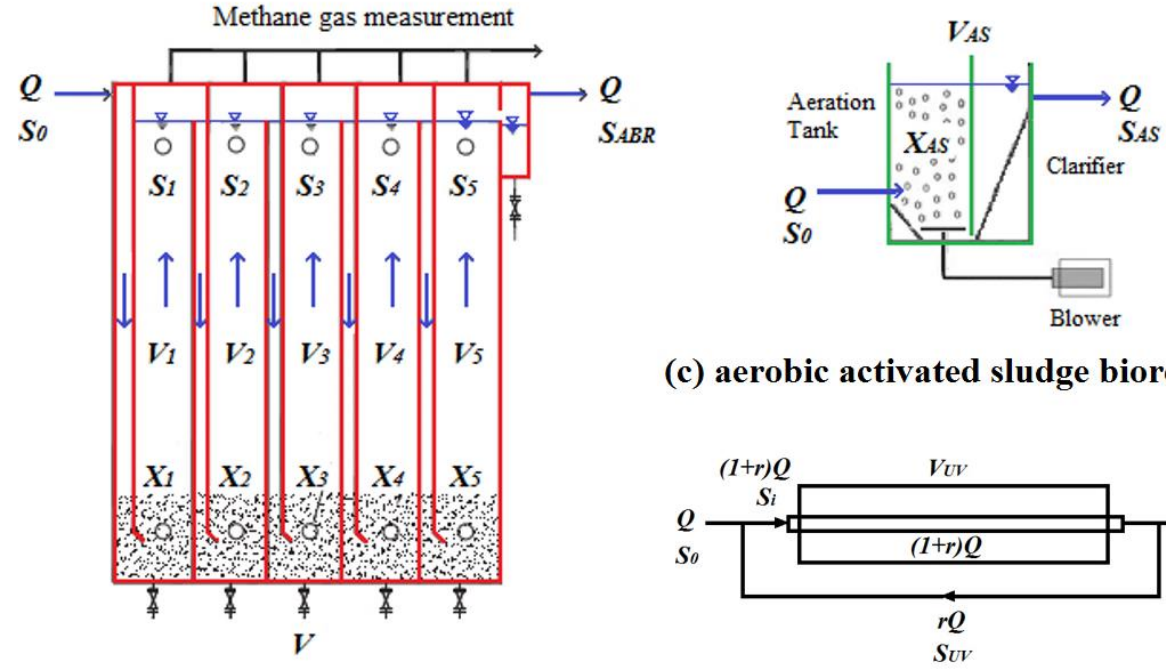

(c) aerobic activated sludge bioreator

(b) anaerobic baffled reactor

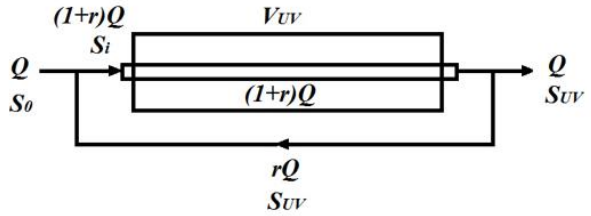

(d) $\mathrm{UV} / \mathrm{H}_{2} \mathrm{O}_{2}$ photoreactor with recycle

Figure 2.1. Schematic diagram of (a) the combined anaerobic-aerobic processes for the treatment of SWW and the individual processes (b) anaerobic baffled reactor, (c) aerobic activated sludge bioreactor, and (d) $\mathrm{UV} / \mathrm{H}_{2} \mathrm{O}_{2}$ photoreactor with recycle. 


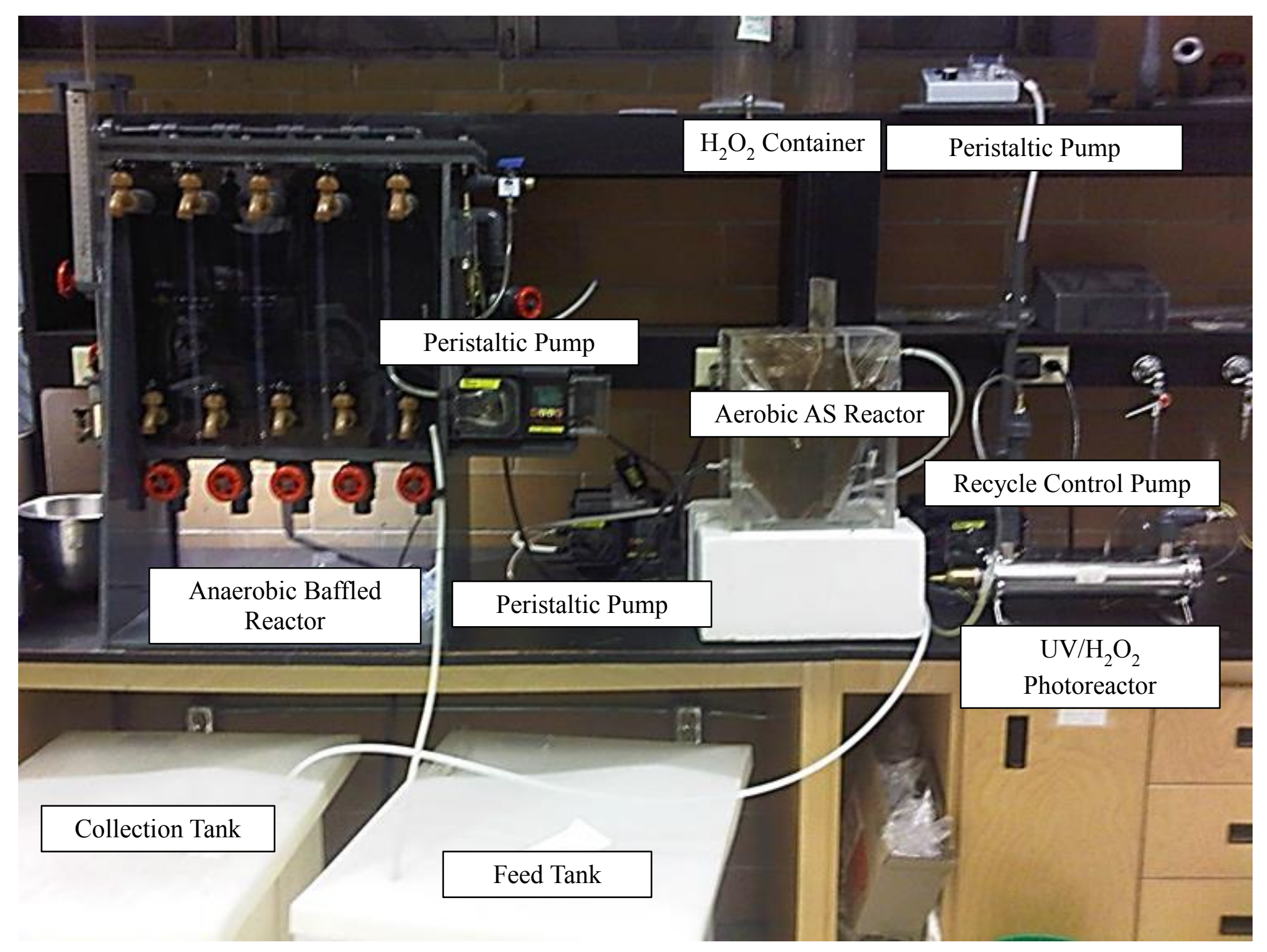

Figure 2.2. Laboratory scale combined $\mathrm{ABR}-\mathrm{AS}-\mathrm{UV} / \mathrm{H}_{2} \mathrm{O}_{2}$ system with recycle. 
During the 60-days acclimatization period, the influent substrate concentration was gradually increased biweekly from 25,50 , and $75 \%$ to $100 \%$ of the actual SWW. Biomass growth was monitored by collecting samples from each compartment of both ABR and AS bioreactors during the acclimatization period by measuring the concentrations of both total suspended solids (TSS) and volatile suspended solids (VSS).

\subsubsection{ABR process}

After the 60-day acclimatization period, the ABR was run alone using different influent concentrations of the actual SWW and various flow rates. Operating conditions were in the range of 50$1650 \mathrm{mgTOC} / \mathrm{L}, 15-135 \mathrm{~mL} / \mathrm{min}, \mathrm{pH}$ from 3 to 11 , and HRT from 4.5 to $40 \mathrm{~h}$. The $\mathrm{SWW}$ was homogenized and fed continuously from a feed tank using a peristaltic pump (Blue-White Industries Ltd. Flexflo A-100NV). The actual SWW was passed through an acrylic flow meter (Omega FL-2018) in order to measure the flow rate. The flow was then directed to the ABR using the 3-way valve and flowed downwards and upwards within the five compartments of the ABR. Those compartments contained an anaerobic sludge layer where the biological degradation occurs. Each compartment had a sludge sampling port, located $10 \mathrm{~cm}$ from the base of the $A B R$ and $4 \mathrm{~cm}$ from the side of the $45^{\circ}$ slanted edge baffle, to measure TSS and VSS. The actual SWW sampling ports were located $40 \mathrm{~cm}$ from the base of the $\mathrm{ABR}$ and $4 \mathrm{~cm}$ from the side of the $45^{\circ}$ slanted edge baffle.

Samples during treatment were taken by gravity from every compartment. When collecting samples, the first $5 \mathrm{~mL}$ were eliminated to avoid the effect of the sampling ports; then, volumes of 10 $\mathrm{mL}$ were collected from each sampling port. Finally, the treated effluent was either discharged into the collection tank or flowed into the aerobic AS bioreactor for post-treatment. All experiments were repeated in triplicates, and the average values were reported.

\subsubsection{Aerobic AS process}

The aerobic AS process was run as an individual process after the acclimatization period using different influent concentrations and various flow rates. The operating conditions for the AS bioreactor were similar to those in the ABR and HRTs varied from 1.6 to $14 \mathrm{~h}$.

The actual SWW was homogenized and fed continuously from a feed tank using a peristaltic pump. The actual SWW was passed through an acrylic flow meter. The flow was then directed to the AS 
reactor using the 3-way valve and flowed into the aeration tank, where oxygen was introduced by a diffuser at a constant air flow rate of $2 \mathrm{~L} / \mathrm{min}$ followed by a clarifier. Samples of $10 \mathrm{~mL}$ were taken from the aeration tank and the clarifier. The treated effluent was either discharged into the collection tank or flowed into the $\mathrm{UV} / \mathrm{H}_{2} \mathrm{O}_{2}$ photoreactor for post-treatment. All experiments were repeated in triplicates, and the average values were reported.

\subsection{4. $\mathrm{UV} / \mathrm{H}_{2} \mathrm{O}_{2}$ process}

The aerobic $\mathrm{UV} / \mathrm{H}_{2} \mathrm{O}_{2}$ process was run alone using different influent concentrations of the actual SWW and various flow rates. Operating conditions were in the range of 10-626 mgTOC/L, 100-1500 $\mathrm{mgH}_{2} \mathrm{O}_{2} / \mathrm{L}, 15-135 \mathrm{~mL} / \mathrm{min}, \mathrm{pH}$ from 3 to 11 , and HRT from 0.2 to $1.5 \mathrm{~h}$. The following procedure was implemented to carry out each experiment for quality control:

1) The UV lamp was switched on for 30 min prior to the start of each experiment to guarantee light intensity stabilization within the photoreactor and to remove any possible background materials.

2) SWW samples were filtered to separate the liquid portion of the wastewater from the solids.

3) Filtered SWW samples were then diluted to reach the desired TOC concentration and guarantee the accuracy of the feed concentration value in a 6-L solution (i.e. an actual slaughterhouse wastewater sample with a concentration of $26.42 \mathrm{mg} / \mathrm{L}$ was diluted to $25.00 \mathrm{mg} / \mathrm{L}$ ).

4) The SWW solution with the desired TOC concentration was fed to the photoreactor by a variable speed peristaltic pump to control and adjust the flow rate.

5) An adequate $\mathrm{H}_{2} \mathrm{O}_{2}$ concentration was calculated based on the material balance for each experiment.

6) The $\mathrm{H}_{2} \mathrm{O}_{2}$ solution was also fed to the system by a secondary variable speed peristaltic pump at the time the SWW solution started to be fed to the photoreactor.

7) A recycle stream was controlled using the third variable speed peristaltic pump to adjust the flow rate to the desired recycle ratio.

8) Effluent samples were taken at 15-min intervals until the system reached steady state conditions.

An experiment without UV irradiation, called the dark experiment, was also conducted to evaluate the possible adsorption of organic compounds on the UV photoreactor walls. All experiments were repeated in triplicates, and the average values were reported. 


\subsubsection{Combined anaerobic-aerobic system}

After the acclimatization period, the combined ABR-AS system was run using different influent concentrations of the actual SWW and various flow rates. Operating conditions were in the range of 50$1650 \mathrm{mgTOC} / \mathrm{L}, 15-135 \mathrm{~mL} / \mathrm{min}, \mathrm{pH}$ from 3 to 11, and HRT from 6 to $54 \mathrm{~h}$. The following procedure was used in performing each experiment in the combined ABR-AS processes for quality control:

1) For every experiment, six SWW samples of 20-L were collected from MPPs and filtered onsite to separate the liquid from the solid portion of the SWW.

2) Filtered SWW samples were then diluted to reach the desired TOC concentration of the feed in a $120-\mathrm{L}$ solution.

3) A $1 \mathrm{~N}$ solution of sulfuric acid $\left(\mathrm{H}_{2} \mathrm{SO}_{4}\right)$ and a $50 \%$ solution of sodium hydroxide $(\mathrm{NaOH})$ were used to adjust the $\mathrm{pH}$.

4) The SWW solution with the desired TOC concentration and $\mathrm{pH}$ was fed into the combined $\mathrm{ABR}-\mathrm{AS}$ processes by a variable speed peristaltic pump to control and adjust the flow rate.

5) Effluent samples were taken at $3 \mathrm{~h}$ intervals until the system reached steady state conditions.

6) All experiments were repeated in triplicates, and the average values were reported.

\subsubsection{Combined anaerobic-aerobic and $\mathrm{UV} / \mathrm{H}_{2} \mathrm{O}_{2}$ system}

After the acclimatization period, experiments for combined processes of the ABR, the aerobic AS, and $\mathrm{UV} / \mathrm{H}_{2} \mathrm{O}_{2}$ were conducted using different influent concentrations of the actual $\mathrm{SWW}$ and various flow rates. Operating conditions were in the range of 50-1650 mgTOC/L, 15-135 mL/min, $\mathrm{pH}$ from 3 to 11 , and HRT from 6.2 to $55.6 \mathrm{~h}$. The following procedure was used during the performance of each experiment in the combined $\mathrm{ABR}-\mathrm{AS}-\mathrm{UV} / \mathrm{H}_{2} \mathrm{O}_{2}$ system for quality control:

1) For every experiment, six SWW samples of 20-L were collected from MPPs and filtered on-site to separate the liquid from the solid portion of the SWW.

2) Filtered SWW samples were diluted to reach the desired TOC concentration of the feed in a 120-L solution.

3) Sulfuric acid $\left(\mathrm{H}_{2} \mathrm{SO}_{4}\right)$ solution at $98 \%$ and sodium hydroxide $(\mathrm{NaOH})$ solution at $50 \%$ w/w were used to adjust the $\mathrm{pH}$.

4) The SWW solution with the desired TOC concentration and $\mathrm{pH}$ was fed to the combined ABR$\mathrm{AS}-\mathrm{UV} / \mathrm{H}_{2} \mathrm{O}_{2}$ system by a variable speed peristaltic pump to control and adjust the flow rate. 
5) The required $\mathrm{H}_{2} \mathrm{O}_{2}$ concentration was calculated based on the material balance for each experiment, by which the $\mathrm{H}_{2} \mathrm{O}_{2}$ solution flow rate to the photoreactor was adjusted and fed by a secondary variable speed peristaltic pump.

6) In the photoreactor, there was a recycle stream, for which a third variable speed peristaltic pump was used to adjust the flow rate to the desired recycle ratio.

7) Effluent samples were taken at 3-h intervals until the system reached steady state conditions.

8) All experiments were repeated in triplicates, and the average values were reported.

\subsection{Research methods}

A mixed methods approach was used in this dissertation. Figure 2.3 shows the diagram representation of the research methods used in this study to determine the types of wastewater treatment technologies currently used in the meat-processing sector in Ontario, to assess possible alternatives in order to minimize the impact of the discharge of the slaughterhouse effluents to the environment and the overall treatment costs. Therefore, the study was divided into two phases, theoretical and experimental as shown in Figure 2.3.

\subsubsection{Theoretical phase}

The objectives, background research, scope and boundaries are depicted in a preliminary stage. The sampling of sludge and the actual SWW categories were introduced in the theoretical stage because their determination was based on the analysis of the information collected from the facilities through questionnaires and a literature review (Bustillo-Lecompte and Mehrvar, 2015). Furthermore, the information about the meat processing industry in Ontario was collected using questionnaires sent to current meat processing plants (MPPs) in Ontario (Appendix F), as well as conducting literature review on SWW characteristics. An approval from the research ethics board and a renewal (Appendix G) were obtained to conduct the questionnaires distributed along with a consent form (Appendix $\mathrm{H}$ ). The questionnaire addressed the characteristics of the actual SWW, type of animals being processed, the number of animals slaughtered per year, and the type of treatment/storage/disposal used in those MPPs and served as basis for the literature review shown in Chapter 3 of this dissertation (Bustillo-Lecompte and Mehrvar, 2015). 


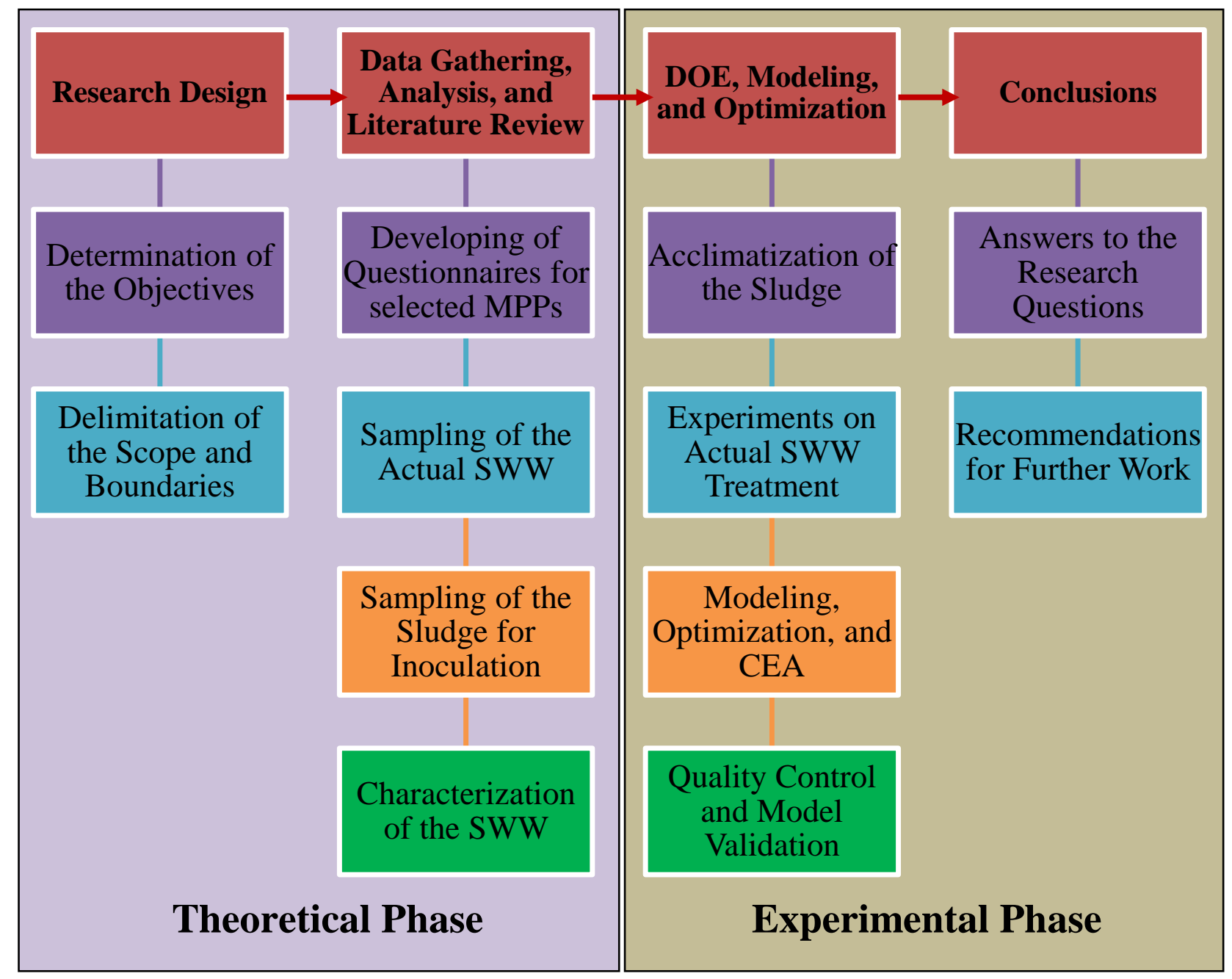

Figure 2.3. Diagram representation of the research methods used in this study. 


\subsubsection{Experimental phase}

The experimental phase was essential to accomplishing the objectives of this study. This experimental phase was focused on the sampling of actual SWW and further experiments for the removal of organics and nutrients, $\mathrm{CH}_{4}$ production, and overall treatment time and costs minimization. Thus, current technologies costs and efficiencies were examined via cost-effectiveness analysis (CEA), followed by the optimization of reactors and systems for SWW treatment, modeling, and a final CEA at optimum conditions. Chapters 4 to 8 provide an appraisal of the experimental phase results (BustilloLecompte et al. 2014, 2016a, 2016b; Bustillo-Lecompte and Mehrvar, 2016a, 2016b).

\subsection{Experimental design, modeling, and optimization}

DOE is used to overcome the limitations of conventional experimental methods, in terms of time, materials, and the number of experimental trials, to optimize the factors involved in the treatment process. The DOE permits the optimization of all parameters and consider the combined effects of all the factors involved. Besides, the response surface methodology (RSM) has been recognized to be statistically reliable to analyze multifactor systems in biological and chemical treatment processes. RSM considers cross-factor interactions to attain optimal responses using the minimum number of experiments (Ghafoori et al., 2012, 2014a, 2015; Bustillo-Lecompte et al., 2016a; Šereš et al., 2016).

\subsubsection{Response Surface Methodology}

Response surface methodology (RSM) is a combination of mathematical and statistical techniques that is an effective tool for developing, improving, and optimizing different processes. In addition to the significant applications in the design, development, and formulation of new products, it could be used in the improvement of existing product designs. The most important application of RSM is in industrial processes, especially where different input variables or factors influence some performance measure or

quality characteristic of the process. This performance measure or quality characteristic of the process is called response. In many real applications of RSM, there is more than one response. The input variable or the factors are called independent variables and the typical designs are either a Box-Behnken Design (BBD) or a Central Composite Design (CCD), depending on the number of factors and their levels. In optimization, the responses could be coupled to selected variables by linear or quadratic models. A quadratic model equation for predicting the response functions (organic degradation and TOC removal efficiencies) could be developed using a second order polynomial expression as follows (Ghafoori et al., 
2012, 2014a, 2015; Bustillo-Lecompte et al., 2016a, 2016b; Bustillo-Lecompte and Mehrvar, 2016a, 2016b):

$Y_{i}=\beta_{o}+\sum_{i=1}^{k} \beta_{i} X_{i}+\sum_{i=1}^{k} \beta_{i i} X_{i}^{2}+\sum_{i=1}^{k-1} \sum_{j=2}^{k} \beta_{i j} X_{i} X_{j}+c$

where $\beta_{o}, \beta_{i}, \beta_{i i}$, and $\beta_{i j}$ are the constant, linear, quadratic, and cross-factor interaction coefficients, respectively; $X_{i}$ and $X_{j}$ represent the independent variables; $Y_{i}$ is the predicted response; and $k$ and $c$ are the number of factors and the residual term, respectively.

On the other hand, to obtain a simultaneous objective function that represents the geometric mean of all transformed responses, the desirability multiple response method was used to combine the desirable ranges for each response as shown in Equation (2.2) (Myers et al., 2004; Bustillo-Lecompte et al., 2016a, 2016b; Bustillo-Lecompte and Mehrvar, 2016a, 2016b):

$D=\left(d_{1} \times d_{2} \times d_{3} \times d_{4} \ldots \times d_{n}\right)^{1 / n}=\left(\prod_{i=1}^{n} d_{i}\right)^{1 / n}$

where $D, d_{i}$, and $n$ are the desirability objective function, each individual response range, and the number of responses, respectively. For a simultaneous optimization, each response requires low and high values for the optimization. Otherwise, if any response is found outside of its desirability range, the overall desirability becomes equal to zero.

\subsubsection{Validation of model adequacy}

Generally, in RSM, it is always essential to: (i) validate the fitted model to ensure that it provides an adequate approximation to the true system, and (ii) verify that none of the least square regression assumptions is violated. Proceeding with exploration and optimization of a fitted response surface likely gives misleading results unless the model provides a satisfactory fit. The residual from the least square fit, which refers to the difference between the model prediction and the observation, is a good indicator for the model adequacy. A validation of the normality assumption is made by constructing a normal probability plot of the residuals. If the residual plot lies on the straight line, then the normality assumption is satisfied. Another plot to validate the model adequacy is the plot of residuals over the predicted 
response. If the residuals scatter randomly on the display in form of a "gunshot pattern", the model is adequate (Mehrvar et al., 2000). However, the scaled residuals are often more preferable as they convey more information than the ordinary least square residuals. One of the scaled residuals more widely used is the studentized residual. The studentized residuals are found by dividing the residuals by their standard deviations. If the points scatter randomly between the outlier detection limit of -3 and +3 , the model adequacy is satisfied.

\subsection{Cost-effectiveness analysis}

A CEA is an economic analysis that compares the relative costs and effects of two or more courses of action. Thus, in order to gain the maximum benefit from the combined system, the residence time in each reactor and the treatment efficiency should be optimized. Therefore, three objective functions were defined as constrains, including the individual retention time minimization, the total power consumption minimization, and the overall treatment cost minimization. In combined processes, there is a relationship between the HRT and the volume of each reactor. Considering the flow rate of the $\mathrm{H}_{2} \mathrm{O}_{2}$ negligible, this relationship can be represented by Equation (2.9).

$$
\frac{V_{A B R}}{t_{A B R}}=\frac{V_{A S}}{t_{A S}}=\frac{V_{U V}}{t_{U V}}
$$

where,

$$
\begin{aligned}
& V_{A B R}=\text { volume of the } \mathrm{ABR}(\mathrm{L}) ; \\
& V_{A S}=\text { volume of the aerobic AS reactor }(\mathrm{L}) ; \\
& V_{U V}=\text { volume of the } \mathrm{UV} \text { photoreactor }(\mathrm{L}) ; \\
& t_{A B R}=\text { hydraulic retention time of the ABR process }(\mathrm{h}) ; \\
& t_{A S}=\text { hydraulic retention time of the aerobic AS process }(\mathrm{h}) ; \text { and } \\
& t_{U V}=\text { hydraulic retention time of the } \mathrm{UV} / \mathrm{H}_{2} \mathrm{O}_{2} \text { process }(\mathrm{h}) .
\end{aligned}
$$

\subsection{Analytical techniques and equipment for sample analysis}

Different variables of the SWW were measured, including DO, temperature, and $\mathrm{pH}$, measured daily by a DO meter (YSI 58 Dissolved Oxygen Meter, Yellow Springs, OH) and a pH meter (Thermo Scientific Orion 230A+, Ottawa, ON), respectively. TOC and TN measured automatically by a TOC/TN analyzer (Teledyne Tekmar Apollo 9000 Combustion, Mason, OH). COD and TP were measured by 
colorimetry method (Orbeco-Hellige MC500 Multi-Parameter Colorimeter, Sarasota, FL). BOD was measured by respirometry assays (Bioscience BI-2000 Electrolytic, Allentown, PA). The concentrations of TSS and VSS were measured according to the Standard Methods of the American Public Health Association (APHA, 1998, 2012). The $\mathrm{H}_{2} \mathrm{O}_{2}$ residuals were measured with a UV-Visible Spectrophotometer (Ultrospec 1100 pro - Amersham Biosciences, Amersham, UK) at $454 \mathrm{~nm}$ using neocuproine and copper (Bustillo-Lecompte et al., 2016a). Three replicates were made for each analytical measurement and the average values were reported along with the standard deviation. The details of each analytical technique are explained in the following sections.

\subsubsection{Dissolved oxygen (DO)}

The DO of influent and effluent samples of the SWW was measured by a dissolved oxygen meter (YSI 58 Dissolved Oxygen Meter, Yellow Springs, OH) equipped with a BOD bottle probe (YSI 5905 BOD Probe). The DO meter was calibrated using air-saturated water, obtained by aerating water for at least $15 \mathrm{~min}$ at a constant temperature, using the calibration by temperature measurement function of the DO meter.

\subsubsection{Temperature and $\mathrm{pH}$}

Temperature and $\mathrm{pH}$ of influent and effluent samples of the SWW were measured by a portable pH meter (Thermo Scientific Orion 230A+, Ottawa, ON). This instrument has a pH resolution of 0.01, a $\mathrm{pH}$ accuracy of \pm 0.02 , a temperature range of -5.0 to $105.0^{\circ} \mathrm{C}$, a temperature resolution of $0.1^{\circ} \mathrm{C}$, and a temperature accuracy of $\pm 1.0^{\circ} \mathrm{C}$. The $\mathrm{pH}$ meter was calibrated using either a $\mathrm{pH} 4.01$ and 7.00 buffer solution or a 7.00 and 10.01 buffer solution, depending on the expected sample range, at room temperature.

\subsubsection{Total suspended solids (TSS) and volatile suspended solids (VSS)}

TSS and VSS of the SWW effluent of each reactor, and the anaerobic and aerobic sludge were measured according to sections 2540D and 2540E of Standard Methods (APHA, 1998, 2012) to observe the growth of microorganisms in the reactors or to assess whether the effluent solids concentrations reached an adequate disposal level. For the TSS values, filter papers and aluminum weighing dishes were dried in an oven (Binder Oven FED 53) at $105^{\circ} \mathrm{C}$ for $1 \mathrm{~h}$. Well-mixed sludge samples of 5 to $10 \mathrm{~mL}$ were separately filtered by weighed filter papers using a Buchner funnel connected to a vacuum system. Then, each of the filter papers were transferred to one weighed and dried aluminum-weighing dish. 
Combinations of dishes, sludge samples, and filter papers were heated in the oven at $105^{\circ} \mathrm{C}$ for $1 \mathrm{~h}$. After cooling in a desiccator, they were weighed again. Thus, the TSS values were determined by Equation (2.10).

$T S S=\frac{\left(W_{1}-W_{2}-W_{3}\right)}{V}$

where,

$$
\begin{aligned}
& W_{1}=\text { sum of the weights of the dried filter paper, dish and solids of the sample (mg); } \\
& W_{2}=\text { weight of the dried filter paper (mg); } \\
& W_{3}=\text { weight of the dried dish }(\mathrm{mg}) ; \text { and } \\
& V=\text { volume of the sample (L). }
\end{aligned}
$$

To determine the VSS concentrations, the combinations of dishes, sludge samples, and filter papers after drying in the oven were burned in a furnace (Thermo Scientific Lindberg® Blue M® Muffle Furnace) at $550^{\circ} \mathrm{C}$ for $15 \mathrm{~min}$. After cooling in a desiccator, they were also weighed. Thus, the VSS values were determined by Equation (2.11), where $W_{4}$ is the sum of the weights of the solids of the sample and the dish after burning.

$V S S=\frac{\left(W_{1}-W_{2}-W_{3}\right)-\left(W_{4}-W_{3}\right)}{V}=T S S-\frac{\left(W_{4}-W_{3}\right)}{V}$

\subsubsection{Total organic carbon (TOC) and total nitrogen (TN)}

A Teledyne Tekmar Apollo 9000 Combustion TOC/TN Analyzer equipped with an automated sampler measured TOC and TN concentrations. Before sample analyses, the TOC/TN analyzer was calibrated and samples were centrifuged at 5,000 rpm for $10 \mathrm{~min}$ (Thermo Scientific Heraeus Multifuge $\mathrm{X} 1)$. Standards were prepared by adding a carbon source or a nitrogen source to distilled water to achieve determined levels of carbon or nitrogen. The reagent solutions were prepared as follows:

1) Potassium hydrogen phthalate (KHP) was used as an organic carbon source for TOC calibration. The KHP was dried in an oven at $105^{\circ} \mathrm{C}$ for $2 \mathrm{~h}$ prior to the preparation of stock standard solution and stored in a desiccator. For preparation of a 1,000 mg/L of KHP stock standard solution, an accurate $2,125 \mathrm{mg}$ of KHP was dissolved in distilled water and diluted to $1 \mathrm{~L}$. A series of standard solutions, covering the expected range of sample concentrations, such as $1-400 \mathrm{mg} / \mathrm{L}$, 
was prepared by accurately diluting the $1,000 \mathrm{mg} / \mathrm{L}$ of stock standard solution with distilled water. Through running TOC standard calibration analysis, a TOC calibration curve for the range $1-400 \mathrm{mg} / \mathrm{L}$ was obtained for analyzing TOC concentrations.

2) Potassium nitrate $\left(\mathrm{KNO}_{3}\right)$ was used as a nitrogen source for $\mathrm{TN}$ calibration. The $\mathrm{KNO}_{3}$ was dried in the oven at $80^{\circ} \mathrm{C}$ and cooled in the desiccator; then, $7.22 \mathrm{~g}$ of it was dissolved in distilled water and diluted to $1 \mathrm{~L}$ in order to prepare $1,000 \mathrm{mg} / \mathrm{L}$ of stock standard solution. A series of working standard solutions covering the expected range of sample concentrations, such as 1-20 $\mathrm{mg} / \mathrm{L}$, were prepared by accurately diluting the $1,000 \mathrm{mg} / \mathrm{L}$ of stock standard solution with distilled water. Through running TN standard calibration analysis, a TN calibration curve for the range $1-20 \mathrm{mg} / \mathrm{L}$ was obtained for analyzing TN concentrations.

Thus, TOC and TN removal efficiencies were determined by Equations (2.12) and (2.13), respectively. Using the influent (in) and effluent (eff) values for each parameter.

$$
\begin{aligned}
& T O C=\frac{\left(T O C_{i n}-T O C_{e f f}\right)}{T O C_{i n}} \times 100 \% \\
& T N=\frac{\left(T N_{i n}-T N_{e f f}\right)}{T N_{i n}} \times 100 \%
\end{aligned}
$$

\subsubsection{Biochemical oxygen demand (BOD)}

Respirometry assays were used to measure the oxygen uptake of the microorganisms in the SWW media. Respirometry experiments were performed using a BI-2000 electrolytic respirometer (Bioscience BI-2000 Electrolytic, Allentown, PA) in order to observe the biodegradability of the untreated and treated wastewater samples while measuring their $\mathrm{BOD}_{5}$. The respirometer has eight $1 \mathrm{~L}$ bioreactor vessels, which were prepared according to the standard methods (APHA, 1998, 2012). Each respirometer bioreactor was loaded with $10 \mathrm{~mL}$ of acclimatized activated sludge, $10 \mathrm{~mL}$ of the wastewater sample, and filled up to $1 \mathrm{~L}$ with distilled water. The bioreactors required continuous aeration to obtain air saturation conditions and continuous agitation, which were provided automatically by the equipment. Respirometer tests were carried out for $120 \mathrm{~h}$ (5-days) or more if ultimate BOD (BODU) was needed. The temperature in each reactor vessel was constant at $25^{\circ} \mathrm{C}$ with an oxygen generation rate of $75 \mathrm{mg} / \mathrm{L}$. Cumulative oxygen uptake data was recorded every $0.05 \mathrm{~h}$. The data was accessed on computer screen through the instrument software. Two control samples, untreated solution and sludge, were used as control. 


\subsubsection{Total phosphorous (TP)}

The analysis of the TP was carried out according to Section 4500P of Standard Methods (APHA, 1999). Since phosphorus exists in several distinct forms in wastewater samples and the approved test method measures only the orthophosphate form, a pre-treatment method was used to convert the various forms of phosphate-phosphorus to the orthophosphate form.

The samples were digested to convert both the polyphosphate and the organic phosphate to the orthophosphate form at the same time. After digestion, the vanadomolybdophosphoric acid colorimetric method (Orbeco-Hellige MC500 Multi-Parameter Colorimeter, Sarasota, FL) was used for routine analysis in the range of 1 to $20 \mathrm{mgTP} / \mathrm{L}$.

\subsubsection{Chemical oxygen demand (COD)}

COD analysis was performed using pre-packaged mercury-free and premixed COD vials based on Section 5220 of Standard Methods (APHA, 1998, 2012). Three types of COD vials with the ranges 5150, 20-900 and 100-4,500 $\mathrm{mgCOD} / \mathrm{L}$ were used accordingly. A COD reactor was preheated to $150^{\circ} \mathrm{C}$ before testing.

During every test, a $2.5 \mathrm{~mL}$ sample was carefully added into one COD vial of ranges 5-150 or 20$900 \mathrm{mgCOD} / \mathrm{L}$, and $0.5 \mathrm{~mL}$ sample were carefully added into one COD vial of range 100-4,500 $\mathrm{mgCOD} / \mathrm{L}$. Then, the vial was thoroughly shaken by hand. COD standards and a DW blank were processed exactly the same as the samples. COD vials containing sample, COD standard, and blank, were heated in the $\mathrm{COD}$ reactor for $2 \mathrm{~h}$ at $150 \pm 2^{\circ} \mathrm{C}$, and then they were removed from the reactor and placed in a rack until they cooled and any suspended precipitate in the vials settled down.

After the outsides of vials were wiped to remove dust, the vials were placed into the Orbeco-Hellige MC500 Multi-Parameter Colorimeter one by one, to measure their COD concentrations under a standard curve covering the expected range of sample concentrations. The wavelength of 440, 600, and $600 \mathrm{~nm}$ were set for the ranges 5-150, 20-900 and 100-4,500 $\mathrm{mgCOD} / \mathrm{L}$, respectively. According to the requirements of the test method for using the COD vials, blanks of the ranges 20-900 and 100-4,500 $\mathrm{mgCOD} / \mathrm{L}$ were used to set the zero in the colorimeter before sample testing. 


\subsubsection{Hydrogen peroxide $\left(\mathrm{H}_{2} \mathrm{O}_{2}\right)$ residual}

The $\mathrm{H}_{2} \mathrm{O}_{2}$ residual was measured with a UV-Visible Spectrophotometer (Ultrospec 1100 pro Amersham Biosciences, Amersham, UK) at $454 \mathrm{~nm}$ using the copper (II) ion and 2,9-dimethyl-1,10phenanthroline (neocuproine) method, also known as the copper-DMP method (Baga et al., 1988; Kosaka et al., 1998; Brandhuber and Korshin, 2009; Hamad et al., 2014; Bustillo-Lecompte et al., 2016a).

This method facilitates the determination of hydrogen peroxide in aqueous solutions based on reduction of copper (II) ions by $\mathrm{H}_{2} \mathrm{O}_{2}$ in the presence of excess of DMP to form a yellow copper (I)DMP cationic complex, which is determined directly by spectrophotometric measurement at $454 \mathrm{~nm}$. The stoichiometry follows the reduction of copper (II) with $\mathrm{H}_{2} \mathrm{O}_{2}$ as follows:

$$
2 \mathrm{Cu}^{2+}+4 \mathrm{DMP}+\mathrm{H}_{2} \mathrm{O}_{2} \rightarrow 2 \mathrm{Cu}(\mathrm{DMP})_{2}^{+}+\mathrm{O}_{2}+2 \mathrm{H}^{+}
$$

The $\mathrm{Cu}(\mathrm{DMP})_{2}{ }^{+}$product color is stable and not sensitive to light (Baga et al., 1988; Kosaka et al., 1998; Brandhuber and Korshin, 2009). The reagents and materials required by this method are readily available, including DMP (purchased and used as received from Sigma-Aldrich, Oakville, ON), Ethanol (purchased and used as received from BDH, Mississauga, ON), copper (II) sulfate pentahydrate (purchased from Sigma-Aldrich, Oakville, ON and dissolved in distilled water to make a $0.01 \mathrm{M}$ copper (II) sulfate solution), a $\mathrm{H}_{2} \mathrm{O}_{2}$ solution ( $\left.30 \% \mathrm{w} / \mathrm{w}\right)$ purchased and used as received from Sigma-Aldrich, Oakville, ON, and a phosphate buffer solution $(0.1 \mathrm{M})$ prepared from $\mathrm{K}_{2} \mathrm{HPO}_{4}$ and $\mathrm{NaH}_{2} \mathrm{PO}_{4}\left(\mathrm{Sigma}^{-}\right.$ Aldrich Oakville, $\mathrm{ON}$ ) with $\mathrm{pH}$ adjusted to 7.0 by $\mathrm{H}_{2} \mathrm{SO}_{4}(1 \mathrm{~N})$ and $\mathrm{NaOH}(50 \%$ w/w), accordingly.

All experiments involving the measurement of $\mathrm{H}_{2} \mathrm{O}_{2}$ were conducted in 10-mL volumetric flasks. $1 \mathrm{~mL}$ of each reagent, DMP, ethanol, and the $0.01 \mathrm{M}$ copper (II) sulfate solution was added to the flask and mixed. A measured volume of $\mathrm{H}_{2} \mathrm{O}_{2}$ was added to the volumetric flask for a known concentration, and then the flask was filled up with distilled water to the 10 -mL mark. The blank solution was prepared in the same manner but without $\mathrm{H}_{2} \mathrm{O}_{2}$.

After mixing, the absorbance of the sample was measured using UV-Visible Spectrophotometry at $454 \mathrm{~nm}$. Using the difference in absorbance between the sample and blank solutions, a calibration curve was generated and the $\mathrm{H}_{2} \mathrm{O}_{2}$ concentrations were calculated, accordingly (Kosaka et al., 1998; Hamad et al., 2014; Bustillo-Lecompte et al., 2016a). 


\subsubsection{Light intensity and irradiance in the photoreactor}

The light intensity is the output energy of the UV source and the irradiance is the amount of UV light arriving at the surface to be treated. Thus, the irradiance of the UV-C lamp of the photoreactor was determined by direct measurement using a digital radiometer (Spectroline DRC-100X, Spectronics Corp., Westbury, NY).

The radiometer consists of a sensitive electronic ammeter with a UV-C sensor probe (Spectroline DIX-254A, Spectronics Corp., Westbury, NY) that produces a current proportional to the incident irradiance. The radiometer takes direct measurements in the range of $0-19,990 \mu \mathrm{W} / \mathrm{cm}^{2}$, precalibrated by Spectronics Corp. using fully characterized primary standard detectors. For each experimental trial in the $\mathrm{UV} / \mathrm{H}_{2} \mathrm{O}_{2}$ photoreactor, the UV lamp was switched on for 30 min prior to the start of each experiment to guarantee light intensity stabilization within the photoreactor and to remove any possible background materials.

\subsubsection{Biogas production and methane yield.}

Biogas analysis was performed using a portable gas analyzer (Landtec Biogas 5000, Colton, CA) for $\mathrm{CH}_{4}, \mathrm{CO}_{2}, \mathrm{O}_{2}$, and $\mathrm{N}_{2}$-balance in a volume percentage measurement. The online portable biogas analyser was used for continuous accurate gas monitoring. This instrument also measured flow rate and temperature in the ABR. All experiments were repeated in triplicates; thus, average values were reported.

\subsection{Quality control}

In wastewater research, due to the importance of laboratory analyses, quality assurance programs to insure the reliability of the wastewater data are essential. Quality assurance programs have two primary functions in the laboratory. First, the programs should continually monitor the reliability, accuracy and precision of the results. The second function is the control of quality, to meet the program requirements for reliability. The steps in quality control (QC) vary with the type of analysis. In any instrumental method, calibration and revision of instrumental response are QC functions. 
All of the experimental variables that affect the results should be considered, evaluated, and controlled. Thus, physical and chemical measurement methods on wastewater were performed by the following criteria:

1) The selected methods measured desire constituents of water samples in the presence of normal interferences with sufficient precision and accuracy to meet the water data needs.

2) The selected procedures used equipment and skills ordinarily available in the average laboratory for water pollution control or any water supply laboratory.

3) The selected methods were sufficiently tested to have established their validity.

4) The selected methods were sufficiently rapid to permit repetitive routine use in the examination of large numbers of water samples.

5) Statistical analysis and experimental design guaranteed reliability of the experimental data and further analysis of the information. 


\title{
CHAPTER 3
}

\section{Slaughterhouse Wastewater Characteristics, Treatment, AND Management in The Meat Processing IndUSTRY: A REVIEW ON TRENDS AND ADVANCES*}

\begin{abstract}
A thorough review of advancement in slaughterhouse wastewater (SWW) characteristics, treatment, and management in the meat processing industry is presented. This study also provides a general review of the environmental impacts, health effects, and regulatory frameworks relevant to the SWW management. A significant progress in high-rate anaerobic treatment, nutrient removal, advanced oxidation processes (AOPs), and the combination of biological treatment and AOPs for SWW treatment is highlighted. The treatment processes are described and few examples of their applications are given. Conversely, few advances are accounted in terms of waste minimization and water use reduction, reuse, and recycle in slaughterhouses, which may offer new alternatives for cost-effective waste management. An overview of the most frequently applied technologies and combined processes for organic and nutrient removal during the last decade is also summarized. Several types of individual and combined processes have been used for the SWW treatment. Nevertheless, the selection of a particular technology depends on the characteristics of the wastewater, the available technology, and the compliance with regulations. This review facilitates a better understanding of current difficulties that can be found during production and management of the SWW, including treatment and characteristics of the final effluent.
\end{abstract}

Keywords: Slaughterhouse wastewater (SWW), wastewater treatment, combined processes, biological treatment, advanced oxidation processes (AOPs).

\footnotetext{
* Reprinted, with minor editorial changes to fulfill formatting requirements, from:

C. Bustillo-Lecompte and M. Mehrvar (2015) Slaughterhouse wastewater characteristics, treatment, and management in the meat processing industry: a review on trends and advances. Journal of Environmental Management 161, pp. $287-302$. With permission from Elsevier. License Number 3830960007849. DOI: 10.1016/j.jenvman.2015.07.008.
} 


\subsection{Introduction}

The increasing growth of world population has augmented the pollution of freshwater due to the inadequate discharge of wastewater, especially in developing countries (US EPA, 2004; Leitão et al., 2006; Gopala Krishna et al., 2009; Feng et al., 2009). For this reason, water and wastewater treatment has become crucial for the continuing development of the society. Moreover, the progressively stricter standards for effluent discharge worldwide have made the developing of advanced wastewater treatment technologies necessary (Environment Canada, 2000, 2012; US EPA, 2004; World Bank Group, 2007). Besides, the continuing decreasing availability of freshwater resources has rearranged the objectives in the wastewater treatment field from disposal to reuse and recycling. As a result, a high level of treatment efficiency has to be achieved. Given the differences in location, economic resources, living standards of different countries, and characteristics of water and its pollutants, many nations adopt diverse techniques for water and wastewater treatment (Daigger, 2009).

The meat-processing sector produces large volumes of slaughterhouse wastewater (SWW) due to the slaughtering of animals and cleaning of the slaughterhouse facilities and meat processing plants (MPPs). The meat processing industry uses $24 \%$ of the total freshwater consumed by the food and beverage industry (Table 3.1 ) and up to $29 \%$ of that consumed by the agricultural sector worldwide (Mekonnen and Hoekstra, 2012; Gerbens-Leenes et al., 2013).

\section{Table 3.1. Freshwater consumption in beverage and food industries.}

Reprinted from J. Environ. Manage. 161 (2015) 287-302, with permission from Elsevier.

\begin{tabular}{lc}
\hline Food Industry & Water consumption (\%) \\
\hline Meat Processing & 24 \\
Beverages & 13 \\
Dairy & 12 \\
Other Food & 11 \\
Fruits and Vegetables & 10 \\
Bakery and Tortilla Products & 9 \\
Grain and Oilseeds & 9 \\
Sugar and Confectionary & 5 \\
Animal Food & 5 \\
Seafood & 2 \\
\hline
\end{tabular}


SWW composition varies significantly depending on the diverse industrial processes and specific water demand (Matsumura and Mierzwa, 2008; Debik and Coskun, 2009; Bustillo-Lecompte et al., 2013, 2014). Slaughterhouses are part of a large industry, which is common to numerous countries worldwide where meat is an important part of their diet. Therefore, SWWs require significant treatment for a safe and sustainable release to the environment (Johns, 1995).

Nevertheless, review articles on SWW and the meat processing industry are not widely available (Bull et al., 1982; Tritt and Schuchardt, 1992; Johns, 1995; Salminen and Rintala, 2002; Mittal, 2006; Arvanitoyannis and Ladas, 2008), rather characterization of microorganisms present in SWW and disinfection are the focus in recent years (Franke-Whittle and Insam, 2013).

According to Mittal (2006), slaughterhouses and MPPs in Ontario, Canada, commonly discharge the SWW into the municipal sewer system after preliminary onsite treatment (Mittal, 2006). Thus, MMPs usually pay fines to dispose of their wastewater at municipal wastewater treatment plants (Massé and Masse, 2000a). According to Wu and Mittal (2011), there are approximately 142 MPPs in Ontario that can process 100-200 animals per month. About 53\% of Ontario's slaughterhouses do not treat their wastewater prior to disposal. Only $16 \%$ of Ontario's slaughterhouses use dissolved air flotation (DAF) or aeration. The remaining $31 \%$ of slaughterhouses utilize passive systems such as storage tank or lagoon to settle solids.

This review aims to identify the most recent trends and advances in meat processing effluent management and SWW treatment technologies, common practices on storage, management, treatment, and disposal, along with SWW characteristics, guidelines, and regulations. Furthermore, this study presents current technologies based on the technical advances in efficiency, design, performance, and optimization of the SWW treatment processes for organics and nutrient removal, including biological treatment, combined processes, advanced oxidation processes (AOPs), and water reuse. Thus, the assessment of possible alternatives to minimize operational and maintenance (O\&M) costs is also discussed. 


\subsection{Characterization of slaughterhouse wastewater}

The global meat production was doubled in the last three decades (Mekonnen and Hoekstra, 2012; FAO, 2013). Bouwman et al. (2013) have projected a steady doubling growth of meat production until 2050. Furthermore, the production of beef has been increasing continuously in recent years, mostly in India and China due to income increases and the shift toward a western-like diet rich in proteins (Pingali, 2007). From 2002 to 2007 , the annual global production of beef was increased to $14.7 \times 10^{6}$ metric tons, representing an increase of $29 \%$ over eight years (FAO, 2013). As a result, it can be inferred that the number of slaughterhouse facilities will increase, resulting in a greater volume of high-strength wastewater to be treated.

According to Table 3.1, the meat processing industry is one of the major consumers of freshwater in the food and beverage processing facilities, which makes slaughterhouses a significant producer of wastewater effluents (De Sena et al., 2009). The World Bank Group (2007) classifies a slaughterhouse plant as a meat processing facility that may consume between 2.5 and $40 \mathrm{~m}^{3}$ of water per metric tons of meat produced. Common SWW characteristics have been described in previous studies and summarized in Table 3.2.

Table 3.2. General characteristics of slaughterhouse wastewater.

Reprinted from J. Environ. Manage. 161 (2015) 287-302, with permission from Elsevier.

\begin{tabular}{|c|c|c|}
\hline Parameter & Range & Mean \\
\hline TOC (mg/L) & $70-1,200$ & 546 \\
\hline $\mathrm{BOD}_{5}(\mathrm{mg} / \mathrm{L})$ & $150-4,635$ & 1,209 \\
\hline $\mathrm{COD}(\mathrm{mg} / \mathrm{L})$ & $500-15,900$ & 4,221 \\
\hline $\mathrm{TN}(\mathrm{mg} / \mathrm{L})$ & $50-841$ & 427 \\
\hline $\mathrm{TSS}(\mathrm{mg} / \mathrm{L})$ & $270-6,400$ & 1,164 \\
\hline $\mathrm{pH}$ & $4.90-8.10$ & 6.95 \\
\hline $\mathrm{TP}(\mathrm{mg} / \mathrm{L})$ & $25-200$ & 50 \\
\hline Orto-PO $4(\mathrm{mg} / \mathrm{L})$ & $20-100$ & 25 \\
\hline Orto- $\mathrm{P}_{2} \mathrm{O}_{5}(\mathrm{mg} / \mathrm{L})$ & $10-80$ & 20 \\
\hline $\mathrm{K}(\mathrm{mg} / \mathrm{L})$ & $0.01-100$ & 90 \\
\hline Color (mg/L Pt scale) & $175-400$ & 290 \\
\hline Turbidity $\left(\mathrm{FAU}^{\mathrm{a}}\right)$ & $200-300$ & 275 \\
\hline
\end{tabular}

${ }^{\mathrm{a}} \mathrm{FAU}$, formazin attenuation units. 
SWW is usually evaluated in terms of bulk parameters due to the specific amounts of SWW and pollutant loads related to the animals slaughtered and processed that vary among the meat processing industry, usually containing considerable amounts of total phosphorus (TP), total nitrogen (TN), total organic carbon (TOC), chemical oxygen demand (COD), total suspended solids (TSS), and biochemical oxygen demand (BOD) (Tritt and Schuchardt, 1992; Johns, 1995; Mittal, 2006; Cao and Mehrvar, 2011; Wu and Mittal, 2011; Barrera et al., 2012; Bustillo-Lecompte et al., 2013, 2014).

SWW is considered detrimental worldwide due to its complex composition of fats, proteins, and fibers from the slaughtering process (Johns, 1995; Ruiz et al., 1997; Wu and Mittal, 2011; BustilloLecompte et al., 2014). The major part of the contamination is caused by blood and by stomach and intestinal mucus (Tritt and Schuchardt, 1992). Furthermore, SWW contains high levels of organics, pathogenic and non-pathogenic microorganisms, and detergents and disinfectants used for cleaning activities (Massé and Masse, 2000a; Debik and Coskun, 2009). SWW samples also include nutrients, heavy metals, color, and turbidity, among others. It is also important to note that disinfectant, cleaning agents, and pharmaceuticals for veterinary purposes can be present in the SWW (Tritt and Schuchardt, 1992).

In the present study, a questionnaire was distributed to 128 slaughterhouses licensed by the Ontario Ministry of Agriculture and Rural Affairs (OMAFRA, 2014) in order to gather information on the current characteristics of the actual SWW, type of animals processed, and the type of treatment, storage, or disposal methods used in Ontario, Canada. Thirty-nine questionnaires were returned for an overall response rate of $30.47 \%$. It was found that $51 \%$ of the MPPs do not treat their wastewater onsite; $17 \%$ use aerobic treatment, i.e. DAF; 32\% utilize passive systems such as storage tanks to settle solids; and only $2 \%$ utilize grease trap for fat separation and blood collection.

Moreover, a typical MPP in Ontario has been established more than 20 years ago, it operates 30 weeks per year, slaughters approximately 600 animals per day, with a maximum capacity of over 2500 animals/day, and mean water usage per day of $2000 \mathrm{~m}^{3}$. Besides, there were $10 \mathrm{SWW}$ samples taken from selected provincially licensed MPPs at the time of study. Table 3.3 shows overall SWW characteristics gathered from the returned questionnaires and the $10 \mathrm{SWW}$ samples. 
Table 3.3. Characteristics of slaughterhouse wastewater from selected provincially inspected meat processing plants in Ontario.

Reprinted from J. Environ. Manage. 161 (2015) 287-302, with permission from Elsevier.

\begin{tabular}{lll}
\hline Parameter & Range & Mean \\
\hline TSS (mg/L) & $0.39-9,938$ & 3,092 \\
$\mathrm{COD}(\mathrm{mg} / \mathrm{L})$ & $527-14,256$ & 5,577 \\
$\mathrm{BOD}(\mathrm{mg} / \mathrm{L})$ & $200-8,231$ & 2,649 \\
$\mathrm{TOC}(\mathrm{mg} / \mathrm{L})$ & $72.5-1,718$ & 862 \\
$\mathrm{TN}(\mathrm{mg} / \mathrm{L})$ & $60-339$ & 156 \\
$\mathrm{TP}(\mathrm{mg} / \mathrm{L})$ & $25.7-75.9$ & 42.8 \\
Orto-PO & $(\mathrm{mg} / \mathrm{L})$ & 52.1 \\
Orto-P2O5 $(\mathrm{mg} / \mathrm{L})$ & $30.1-77.3$ & 48.3 \\
$\mathrm{~K}(\mathrm{mg} / \mathrm{L})$ & $27.2-76.2$ & 0.04 \\
Pb (mg/L) & $0.01-0.06$ & 34.3 \\
Color $(\mathrm{mg} / \mathrm{L} \mathrm{Pt} \mathrm{scale)}$ & $\mathrm{n} / \mathrm{a}$ & 289 \\
Turbidity (FAU $\left.{ }^{\mathrm{a}}\right)$ & $178-391$ & 275 \\
$\mathrm{pH}$ & $271-279$ & 6.5 \\
\hline
\end{tabular}

${ }^{\mathrm{a}} \mathrm{FAU}$, formazin attenuation units.

\subsection{Slaughterhouse wastewater guidelines and regulations}

Regulations and guidelines are essential components in dealing with the environmental impact of slaughterhouses in the meat processing industry. The treatment systems used in the meat processing industry are commonly viewed as a regulatory requirement. Therefore, it increases capital and O\&M costs, which yields negative financial impacts (Sneeringer, 2009). Nevertheless, compliance with current environmental legislation may provide an extra source of revenue by including energy recovery from the treatment, such as biogas production from anaerobic treatment. The standards and regulations governing the meat processing industry vary significantly worldwide. In several countries, slaughterhouses are regulated by tradition and practice (Casani et al., 2005).

SWWs have been considered as an industrial waste in the category of agricultural and food industries and classified as one of the most harmful wastewaters to the environment by the United States Environmental Protection Agency (US EPA). SWW discharge may cause deoxygenation of rivers and 
contamination of groundwater (US EPA, 2004). Typically, anaerobic treatment is used because of the high organic concentrations present in SWWs (Cao and Mehrvar, 2011; Akbaripoor et al., 2014). Nevertheless, a complete degradation of organic matter present in SWW is not conceivable using anaerobic treatment alone. MPP effluents contain solubilized organic material that is adequate for posttreatment using aerobic systems. For that reason, either anaerobic or aerobic processes should not be used as the sole treatment alternative because of the characteristics of their final effluents that are required to comply with current effluent discharge limits and standards (Chan et al., 2009; Bustillo-Lecompte et al., 2013).

Table 3.4 describes the standard levels and concentration limits of organic constituents to be discharged into water bodies as recommended by different worldwide agencies, including the Australian and New Zealand Environment and Conservation Council (ANZECC, 2000), Environment Canada (2000, 2012), the Council of the European Communities (CEC, 1991), US EPA (2004), among others.

Table 3.4. Comparison of standard limits of different jurisdictions worldwide for slaughterhouse wastewater discharge.

Reprinted from J. Environ. Manage. 161 (2015) 287-302, with permission from Elsevier.

\begin{tabular}{lccccc}
\hline Parameter & $\begin{array}{c}\text { World Bank } \\
\text { Standards }\end{array}$ & $\begin{array}{c}\text { EU } \\
\text { Standards }\end{array}$ & $\begin{array}{c}\text { US } \\
\text { Standards }\end{array}$ & $\begin{array}{c}\text { Canadian } \\
\text { Standards }^{\mathbf{a}}\end{array}$ & $\begin{array}{c}\text { Australian } \\
\text { Standards }\end{array}$ \\
\hline BOD (mg/L) & 30 & 25 & 26 & $5-30$ & $6-10$ \\
COD (mg/L) & 125 & 125 & $\mathrm{n} / \mathrm{a}$ & $\mathrm{n} / \mathrm{a}$ & $3 \times$ BOD \\
TSS (mg/L) & 50 & 35 & 30 & $5-30$ & $10-15$ \\
TN (mg/L) & 10 & 10 & 8 & 1 & $0.1-15$ \\
\hline
\end{tabular}

${ }^{\mathrm{a}}$ In the case of the Canadian standards the range is specific to freshwater lakes and slow-flowing streams: $5 \mathrm{mg} / \mathrm{L}$; rivers, streams, and estuaries: $20 \mathrm{mg} / \mathrm{L}$; and shoreline: $30 \mathrm{mg} / \mathrm{L}$.

However, the selection of a particular treatment technology is subject to the SWW characteristics, available technology, and compliance with current regulations. For instance, some MPPs are allowed to discharge their effluent into the municipal sewer system after demonstrating an adequate reduction of BOD loads by preliminary treatment (Mittal, 2006). The main factors determining whether a plant can discharge into a municipal sewer or not are related to the plant size as well as the volume and organic concentration of the wastewater produced (US EPA, 2004). Benefits of the combined anaerobic-aerobic processes include potential resource recovery from the conversion of organic pollutants into biogas with 
high overall treatment efficiency (Chan et al., 2009). However, SWWs may contain toxic and nonbiodegradable organic substances that make biological treatment alone insufficient (Oller et al., 2011). Thus, advanced oxidation processes (AOPs) can be employed as an alternative to improve the SWW biodegradability containing recalcitrant, non-biodegradable, refractory, and toxic compounds.

\subsection{Slaughterhouse wastewater treatment}

Direct discharge of raw SWW effluents to a water body is impractical due to their high organic strength. Therefore, appropriated disposal, preliminary treatment, and/or further treatment of SWW are performed. The first step in SWW management is the minimization of the process inputs (Johns, 1995). It is usually preferable to identify and minimize wastewater generation at its source. Although typical water consumption varies considerably in the meat processing business, a regular slaughterhouse generates vast amounts of wastewater and is commonly not an efficient user of fresh water. Recovery of valuable by-products from SWW is currently focused on high-quality effluents, biogas, fertilizers, and nutrients (Amorim et al., 2007; Kist et al., 2009).

SWW treatment methods are similar to current technologies used in municipal wastewater and may include preliminary, primary, secondary, and even tertiary treatment. Thus, SWW management methods after preliminary treatment are various, but they can be divided into five major subgroups: land application, physicochemical treatment, biological treatment, AOPs, and combined processes (Valta et al., 2015). Each system has its own advantages and disadvantages, which are discussed below.

Land application usually involves direct irrigation of the SWW onto agricultural land (Bull et al., 1982; Mittal, 2006). Physicochemical treatment involves the separation of the SWW into various components, typically the separation of solids from the liquor by sedimentation or coagulation/flocculation, and removal of pollutants using electrocoagulation (EC) and membrane technologies (Bull et al., 1982; Johns, 1995; San José, 2004; Mittal, 2006; Eryuruk et al., 2014; Almandoz et al., 2015). Biological treatment is divided into anaerobic and aerobic systems as well as constructed wetlands (CWs). Aerobic systems are more common since they commonly operate at a higher rate than anaerobic systems; whereas, anaerobic systems require less complex equipment since no aeration system is required; nevertheless, both anaerobic and aerobic systems may be further sub-divided into other processes, which have their own advantages and disadvantages (Bull et al., 1982; Tritt and Schuchardt, 1992; Johns, 1995; San José, 2004; Mittal, 2006; Bugallo et al., 2014; Vymazal, 2014). AOPs are diverse 
and include $\mathrm{UV} / \mathrm{H}_{2} \mathrm{O}_{2}$ and $\mathrm{UV} / \mathrm{O}_{3}$ for the oxidation and degradation of organic and inorganic materials present in SWW through reactions with hydroxyl radicals ( ${ }^{\circ} \mathrm{OH}$ ) (Mittal, 2006; Melo et al., 2008; Luiz et al., 2009, 2011; Cao and Mehrvar, 2011; Barrera et al., 2012; Bustillo-Lecompte et al., 2013, 2014). Finally, combined processes are cost-effective with high removal efficiencies that can lead to a reduction in O\&M costs compared to individual processes (Tritt and Schuchardt, 1992; Chan et al., 2009; Luiz et al., 2011; Cao and Mehrvar, 2011; Bustillo-Lecompte et al., 2013, 2014).

\subsubsection{Preliminary treatment}

In preliminary treatment, all solids and large particles generated during the slaughtering process are separated from wastewater. Typical unit operations for the preliminary removal of TSS in wastewater include regular screeners, strainers, or sieves. Large solids in wastewater with a diameter of 10-30 mm

are retained on the mesh of the screener. Rotary screeners are used to retain solids with a diameter of more than $0.5 \mathrm{~mm}$ in order to avoid fouling, clogging, or jamming of the equipment. Screw screen compactors are used to transport, dewater, and compact all the remaining solids from the previous screeners, minimizing the moisture content and volume in order to be treated as solid waste (San José, 2004; Mittal, 2006). Other pre-treatments include catch basins, homogenization/equalization, flotation, and settlers. Furthermore, screening can separate up to $60 \%$ of the solids from the SWW and remove more than $30 \%$ of the BOD (Mittal, 2006).

\subsubsection{Land application}

In land application, biodegradable materials can be used to provide nutrients to the soil by directly placing them into the land. One drawback of the land application is related to the temperature and the geography (San José, 2004). For instance, the land application in temperate countries is not feasible throughout the year due to the winter season. Therefore, the SWW requires being stored during that period; thus, energy usage related to the treatment and transportation increases. Other disadvantages include aesthetics, odor, soil contamination, possible surface and groundwater pollution, and pathogens presence and persistence (Avery et al., 2005). On the other hand, advantages of land application include the recovery of useful by-products from the SWW, alternative source of fertilizer, and improvement of soil structure (Mittal, 2004, 2006). 


\subsubsection{Physicochemical treatment methods}

Following preliminary treatment, it is recommended to send the effluent to a subsequent primary or secondary treatment, depending on the strength of the SWW. One of the typical methods of the primary treatment is the DAF process, especially for reducing fat, TSS, and BOD in SWW (Al-Mutairi et al., 2008; De Nardi et al., 2011). Physicochemical treatment methods usually involve the separation of solids from the liquid. Different physicochemical treatment technologies are discussed in the following subsections.

\subsubsection{Dissolved air flotation}

DAF systems refer to the water-solid separation method by introducing air into a SWW influent, where the air is introduced from the bottom of the vessel. Hence, light solids, fat, and grease are transported to the surface forming a sludge blanket, where a scraping assembly constantly removes scum.

The efficiency of the DAF system can be enhanced by adding polymers and other flocculants for $\mathrm{pH}$ adjustment and flocculation of particulate matter. Blood coagulants such as ferric chloride and aluminum sulfate can be also added to the SWW to promote protein aggregation and precipitation in addition to fat and grease flotation. The DAF process efficiencies for COD and BOD removal are usually from 30 to $90 \%$ and from 70 to $80 \%$, respectively. DAF systems are also capable of achieving moderate to high nutrient removal (Johns, 1995; Mittal, 2006; Al-Mutairi et al., 2008; De Nardi et al., 2011). Conversely, DAF drawbacks are related to regular malfunctioning and poor TSS separation (Kiepper, 2001).

\subsubsection{Coagulation and flocculation}

Coagulants and flocculants are added into a reactor vessel where the floc is conditioned. The ideal size for separation during flotation is searched, and it is necessary to balance the $\mathrm{pH}$ after addition of the coagulant in order to achieve an appropriate flocculation (San José, 2004). Aluminum sulfate, ferric chloride, ferric sulfate, and aluminum chlorohydrate have been used as coagulants to treat SWW. Results show TP, TN, and COD removals of up to $99.9,88.8$, and $75.0 \%$, respectively, using polyaluminum chloride as the reagent. Moreover, if inorganic coagulant aids are used, the sludge volume can be reduced by 41.6\% (Núñez et al., 1999; Aguilar et al., 2002; Mittal, 2006; De Sena et al., 2008). 
Satyanarayan et al. (2005) studied the physicochemical treatment of SWW effluent using anionic polyelectrolyte, ferrous sulfate, lime, and alum as coagulants. Among these coagulants, lime alone achieves removal rates of up to $38.9,36.1$, and $41.9 \%$ for BOD, COD, and TSS, respectively. The combination of ferrous sulfate and lime improves the COD removal rate to $56.8 \%$. Likewise, the combination of lime and alum also results in an increased COD removal of up to 42.6\%. On the other hand, using combined ferrous sulfate and anionic polyelectrolyte, although not cost-effective, results in good removal rates of up to 54.2, 49.6, and 43.8\% for TSS, BOD, and COD, respectively. Whereas, if alum is used in combination with lime, the generation of sludge is increased.

Amuda and Alade (2006) used the coagulation-flocculation technology at the laboratory-scale for the removal of TP, TSS, and COD from SWW. Several coagulants including ferric chloride, ferric sulfate, and alum were used. Results show that although alum was effective for the removal of TP and TSS from SWW, ferric sulfate was more efficient in reducing COD. Results show maximum COD, TP, and TSS removal efficiencies of up to 65, 34, and 98\%, respectively. Tariq et al. (2012) used lime and alum individually and in combination as coagulants for the treatment of SWW. Results show that as the alum dose increases, COD removal increases to a maximum of $92 \%$ along with the sludge volume, which makes the process not feasible. Conversely, an increase in lime dosage increased the COD reduction to a maximum of $74 \%$, whereas the sludge settling was high, and the sludge volume decreased as compared to that of alum. At the end, the combined dosages of lime and alum give a maximum removal of $85 \%$ in COD with low sludge volume.

\subsubsection{Electrocoagulation}

The EC process has been recently used for SWW treatment as a cost-effective advanced wastewater treatment technology. EC has been confirmed to be an effective technology for the removal of organics, nutrients, heavy metals, and even pathogens from SWW by introducing an electric current without adding chemicals (Kobya et al., 2006; Emamjomeh and Sivakumar, 2009; Bayar et al., 2011; Qin et al., 2013). Figure 3.1 illustrates a typical EC reactor. $\mathrm{Al}, \mathrm{Fe}, \mathrm{Pt}, \mathrm{SnO}_{2}, \mathrm{TiO}_{2}$, among others, can be utilized as electrodes for the EC process, being Fe and Al the most widely used. Thus, the EC process involves onsite generation of $\mathrm{M}^{3+}$ ions using sacrificial anodes. Additionally, these sacrificial electrodes might be interacting with $\mathrm{H}^{+}$ions in an acidic medium, or with $\mathrm{OH}^{-}$ions in an alkaline medium (Bayramoglu et al., 2006; Kobya et al., 2006; Bayar et al., 2011, 2014; Ozyonar and Karagozoglu, 2014). 


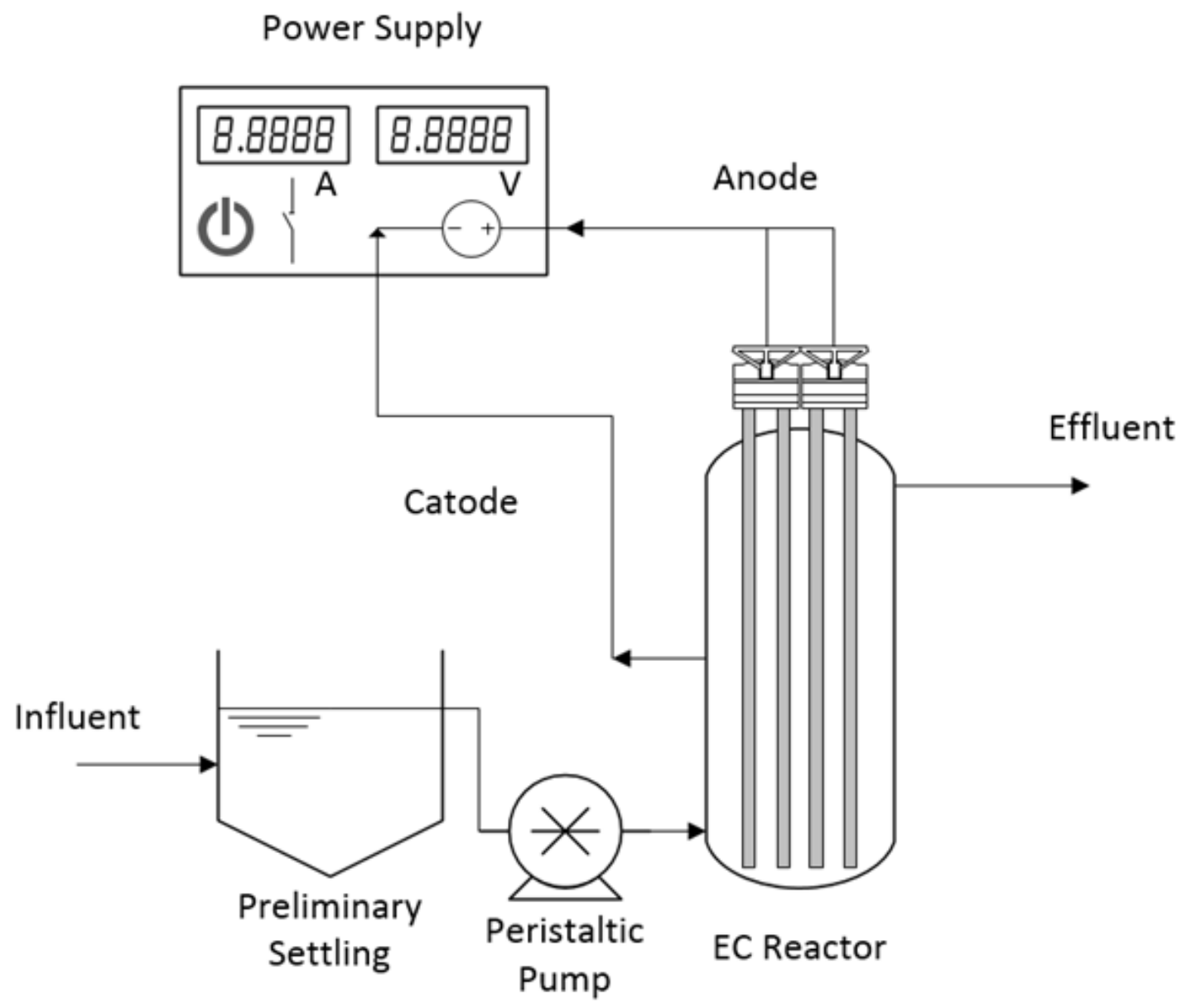

Figure 3.1. Schematic diagram of a typical electrocoagulation unit.

Reprinted from J. Environ. Manage. 161 (2015) 287-302, with permission from Elsevier. 
Kobya et al. (2006) studied the influence of $\mathrm{pH}$, operating time, electrode material, and current density of the EC process for SWW treatment on oil-grease and COD removal, sacrificial electrode and electrical energy consumption. Up to $93 \%$ of $\mathrm{COD}$ was removed using $\mathrm{Al}$ as the electrode material, whereas maximum oil-grease efficiency was obtained using Fe as the electrode material, reaching $98 \%$ removal. Nevertheless, it was found that further work is required at the pilot-scale to assess the costeffectiveness of the EC process.

Bayramoglu et al. (2006) conducted a cost-effectiveness analysis (CEA) for the treatment of SWW using EC with a particular focus on COD removal. Total operating cost included O\&M, electricity, sacrificial electrodes ( $\mathrm{Fe}$ and $\mathrm{Al}$ ) depreciation, and sludge handling costs. Other performance parameters included $\mathrm{pH}$, current density, and operating time. Results show that Fe sacrificial electrodes are more cost-effective than Al electrodes, with total operating costs between 0.30 and $0.40 \$ / \mathrm{m}^{3}$, nearly $50 \%$ of the total costs of using Al. Similar results were obtained by Ozyonar and Karagozoglu (2014), when calculating total costs for $\mathrm{Al}$ and $\mathrm{Fe}$ sacrificial electrodes at optimum conditions. Al electrodes were found less cost-effective than Fe electrodes with total costs of 2.76 and $0.87 \$ / \mathrm{m}^{3}$, respectively.

Likewise, Asselin et al. (2008) evaluated the EC process in economic terms for the removal of organic compounds from SWW. Experiments were conducted at laboratory pilot-scale by using mild steel and Al sacrificial electrodes. Results show that using mild steel bipolar electrodes achieves COD, BOD, TSS, turbidity, and oil-grease removals of up to $84,87,93,94$, and 99\%, respectively. Thus, involving a total cost, including energy, electrode consumptions, chemicals, and sludge disposal, of 0.71 $\$ / \mathrm{m}^{3}$ of treated SWW effluent, which is comparable to that found by Bayramoglu et al. (2006).

Awang et al. (2011) used the EC process for the post-treatment of SWW. The effects of current density, reaction time, and influent $\mathrm{COD}$ on color, $\mathrm{COD}$, and $\mathrm{BOD}$ removal efficiencies were investigated using a 3-level factorial design and response surface methodology (RSM). The optimum conditions were obtained at COD influent concentrations of $220 \mathrm{mg} / \mathrm{L}, 55 \mathrm{~min}$ reaction time, and current density near $30 \mathrm{~mA} / \mathrm{cm}^{2}$. Thus, a removal response of 96.80, 81.30, and 85.00\% was achieved for color, BOD, and COD, respectively.

On the other hand, Bayar et al. $(2011,2014)$ studied the influence of current density and $\mathrm{pH}$ on the treatment of SWW by means of EC with $\mathrm{Al}$ electrodes. High removal efficiencies at low $\mathrm{pH}$ and current density values were obtained. Thus, COD removal efficiencies of up to $85 \%$ were obtained with the 
current density of $0.5 \mathrm{~mA} / \mathrm{cm}^{2}$ at $\mathrm{pH}$ of 3.0. Likewise, Ahmadian et al. (2012) examined the performance of EC for SWW treatment in a batch system using Fe electrodes. Augmenting current density, operating time and electrode number improved organic matter and nutrient removal rates. Results show removal efficiencies of up to $97,93,84$, and $81 \%$ for BOD, COD, TN, and TSS, respectively.

\subsubsection{Membrane technology}

Membrane technology is becoming an alternative for SWW treatment. Reverse osmosis (RO), nanofiltration (NF), ultrafiltration (UF), and microfiltration (MF) processes are able to remove particles, colloids, and macromolecules depending on the pore size (Table 3.5). Membrane processes are also increasingly used for removal of bacteria, microorganisms, particulates, and organic matter in SWW treatment (Almandoz et al., 2015).

\section{Table 3.5. Comparison of different membrane dimensions and pore size exclusion used in SWW treatment.}

Reprinted from J. Environ. Manage. 161 (2015) 287-302, with permission from Elsevier.

\begin{tabular}{|c|c|c|c|c|c|c|}
\hline $\begin{array}{l}\text { Membrane } \\
\text { type }\end{array}$ & $\begin{array}{c}\text { Pore } \\
\text { size }(\mu \mathrm{m})\end{array}$ & $\begin{array}{c}\text { TOC } \\
\text { removal }(\%)\end{array}$ & $\begin{array}{c}\text { COD } \\
\text { removal }(\%)\end{array}$ & $\begin{array}{c}\text { BOD } \\
\text { removal }(\%)\end{array}$ & $\begin{array}{c}\text { TN } \\
\text { removal }(\%)\end{array}$ & Reference \\
\hline $\begin{array}{l}\text { Microfiltration } \\
\text { (MF) }\end{array}$ & $0.08-0.55$ & 44.81 & 90.63 & - & 45.22 & $\begin{array}{l}\text { Almandoz et al. } \\
(2015)\end{array}$ \\
\hline $\begin{array}{l}\text { Ultrafiltration } \\
\text { (UF) }\end{array}$ & 0.03 & $75-96$ & $83-97$ & - & $27-44$ & $\begin{array}{l}\text { Gürel and } \\
\text { Büyükgüngör (2011) }\end{array}$ \\
\hline $\begin{array}{l}\text { Ultrafiltration } \\
\text { (UF) }\end{array}$ & $0.01-0.10$ & - & $94.52-94.74$ & $97.80-97.89$ & - & Yordanov (2010) \\
\hline $\begin{array}{l}\text { Reverse } \\
\text { Osmosis (RO) }\end{array}$ & $0.001-0.005$ & - & 85.8 & 50 & 90 & $\begin{array}{l}\text { Bohdziewicz and } \\
\text { Sroka }(2005)\end{array}$ \\
\hline
\end{tabular}

Bohdziewicz and Sroka (2005) studied the performance of the RO process for SWW treatment as secondary effluent. The raw SWW was first pretreated using activated sludge (AS). Thus, the characteristics of the influent SWW for RO treatment were 76.0, 10.0, 3.6, and $13.0 \mathrm{mg} / \mathrm{L}$ for COD, BOD, TP, and TN, respectively. Results showed a removal efficiency of 85.8, 50.0, 97.5, and 90.0\%, after RO treatment, for COD, BOD, TP, and TN, respectively. Therefore, it can be concluded that RO is a feasible technology for SWW post-treatment. 
Yordanov (2010) investigated the feasibility of using UF for SWW treatment. Results showed that the UF could be an efficient purification method by achieving 98 and 99\% removal of TSS and fats, respectively. The efficiencies of BOD and COD removals were 97.80-97.89 and 94.52-94.74\%, respectively.

Gürel and Büyükgüngör (2011) investigated the performance of membrane bioreactors (MBRs) for nutrients and organics removal from SWW. The initial COD, TP, and TN concentrations were 571, 16, and $102 \mathrm{mg} / \mathrm{L}$, respectively. An UF membrane was utilized in the MBR. Up to 44, 65, 96, and 97\% removals were obtained for TN, TP, TOC, and COD, respectively. Although organic matter was successfully removed, a high nitrate concentration in the treated effluent remained. Thus, denitrification is required to further treat this effluent.

Almandoz et al. (2015) evaluated the effectiveness of a MF ceramic composite membrane (CM). The results show a total insoluble residue rejection of $100 \%$, high bacterial removal (87-99\%), as well as TOC, TN, and COD removal rates of 44.81, 45.22, and 90.63\%, respectively. Thus, making the ceramic CM suitable for MF treatment of SWW.

Although membrane processes can achieve high organic removal, nutrients' removals require this process to be coupled with another conventional process (Gürel and Büyükgüngör, 2011). Furthermore, membrane processes can face major problems of fouling while processing highly concentrated feed streams such as SWW, which is difficult to remove and can greatly restrict the permeation rate through the membranes due to the formation of thick biofouling layers onto the membrane surfaces (He et al., 2005; Selmane et al., 2008).

\subsubsection{Biological treatment}

Reducing BOD concentration in SWW is the focus of the secondary treatment by removing soluble organic compounds that remain after primary treatment (Pierson and Pavlostathis, 2000). Biological treatment is usually applied as a secondary treatment process in MPPs, where aerobic and anaerobic digestion are used as individual or combined processes depending on the characteristics of the SWW being treated (Martínez et al., 1995). 
Biological treatment is used to remove organics and eventually pathogens from SWW effluents using microorganisms. Furthermore, the biological treatment is able to remove up to $90 \%$ BOD from MPP effluents by aerobic or anaerobic processes (Mittal, 2006). Biological treatment may include different combinations of various processes including anaerobic, aerobic, and facultative lagoons, AS, and trickling filters among others (Massé and Masse, 2000a).

\subsubsection{Anaerobic treatment}

Anaerobic digestion is the preferred biological treatment that is applied in SWW treatment due to its effectiveness in treating high-strength wastewater (Cao and Mehrvar, 2011). During anaerobic treatment, different bacteria degrade organic compounds into $\mathrm{CO}_{2}$ and $\mathrm{CH}_{4}$ in the absence of oxygen. Besides, anaerobic systems have several advantages such as high COD removal, low sludge production (5-20\%) compared to those of aerobic systems, and less energy requirements with potential nutrient and biogas recovery (Massé and Masse, 2000a; Mittal, 2006; Chan et al., 2009; Bustillo-Lecompte et al., 2014).

Although anaerobic treatment possesses great advantages, it hardly produces effluents that comply with current discharge limits and standards (Table 3.4). Although anaerobic treatment is an efficient process, the SWW organic strength makes it difficult to achieve complete stabilization of the organic compounds (Chan et al., 2009). Hence, anaerobically treated effluents usually need additional posttreatment, in which the removal of organic matter and other constituents such as TN, TP, and pathogenic organisms, is completed (Chernicharo, 2006; Oliveira and Von Sperling, 2009; Gomec, 2010). Moreover, the associated higher space-time yield contributes considerably to the economic viability of anaerobic treatment plants (Tritt and Schuchardt, 1992). Thus, the combination of anaerobic-aerobic systems is a potential alternative to conventional methods in order to satisfy current effluent discharge standards (Chan et al., 2009; Bustillo-Lecompte et al., 2013). Typical configurations for SWW anaerobic treatment include anaerobic baffled reactor (ABR), anaerobic filter (AF), anaerobic lagoon (AL), up-flow anaerobic sludge blanket (UASB), and anaerobic sequencing batch reactor (SBR).

\subsection{Anaerobic baffled reactor}

ABRs are considered an optimized version of a common septic tank. ABRs have a series of compartments and baffles under which the SWW flows under and over from the inlet to the outlet. Since there is an increased contact time with the active biomass, a higher biodegradation occurs. The up-flow 
compartments provide an improved removal of organics with BOD and COD removals of up to $90 \%$ (Barber and Stuckey, 1999; Kuşçu and Sponza, 2005).

Cao and Mehrvar (2011) evaluated the performance of the combined $\mathrm{ABR}$ and $\mathrm{UV} / \mathrm{H}_{2} \mathrm{O}_{2}$ processes at a laboratory-scale to treat SWW. Results show that combined processes had higher removal efficiencies for SWW treatment rather than using individual processes. Maximum TOC removals of up to $95 \%$ were obtained for influent concentrations of $973 \mathrm{mgTOC} / \mathrm{L}$ after 3.8 days of treatment.

Bustillo-Lecompte et al. (2013) studied individual biological treatment using an ABR at a laboratory-scale to treat SWW with an influent concentration of $183.35 \mathrm{mgTOC} / \mathrm{L}$ and $63.38 \mathrm{mgTN} / \mathrm{L}$. Maximum removals of up to 88.88 and $51.52 \%$ were achieved for TOC and TN, respectively.

Bustillo-Lecompte et al. (2014) also evaluated the effectiveness and performance of the ABR process for the treatment of SWW using a CEA by assessing the total electricity cost, hydraulic retention time (HRT), and removal percentage of TOC. Results show that costs increase with the amount of TOC removed, especially if high TOC removal rates are required.

As a result, if low or intermediate amounts of TOC are to be removed, the ABR as an individual process can be comparable to combined processes in economic terms since electricity costs gradually increase. Therefore, biogas production is an important asset to be used due to its potential energy recovery that will be translated into cost savings for MPPs because of the characteristics of SWWs (BustilloLecompte et al., 2014).

\subsection{Anaerobic filter}

Anaerobic filters (AFs) are fixed-bed biological reactors with filtration chambers. AFs are commonly found working in series. When the SWW runs through the filtration chambers, particles are confined inside; then, the organic material is removed by the active biomass attached to the filter surface. AFs are used as secondary treatment due to its high solid removal and biogas recovery rates. An AF is designed as an anaerobic digestion column packed with different types of media (Mittal, 2006). A typical anaerobic filter is presented in Figure 3.2. 


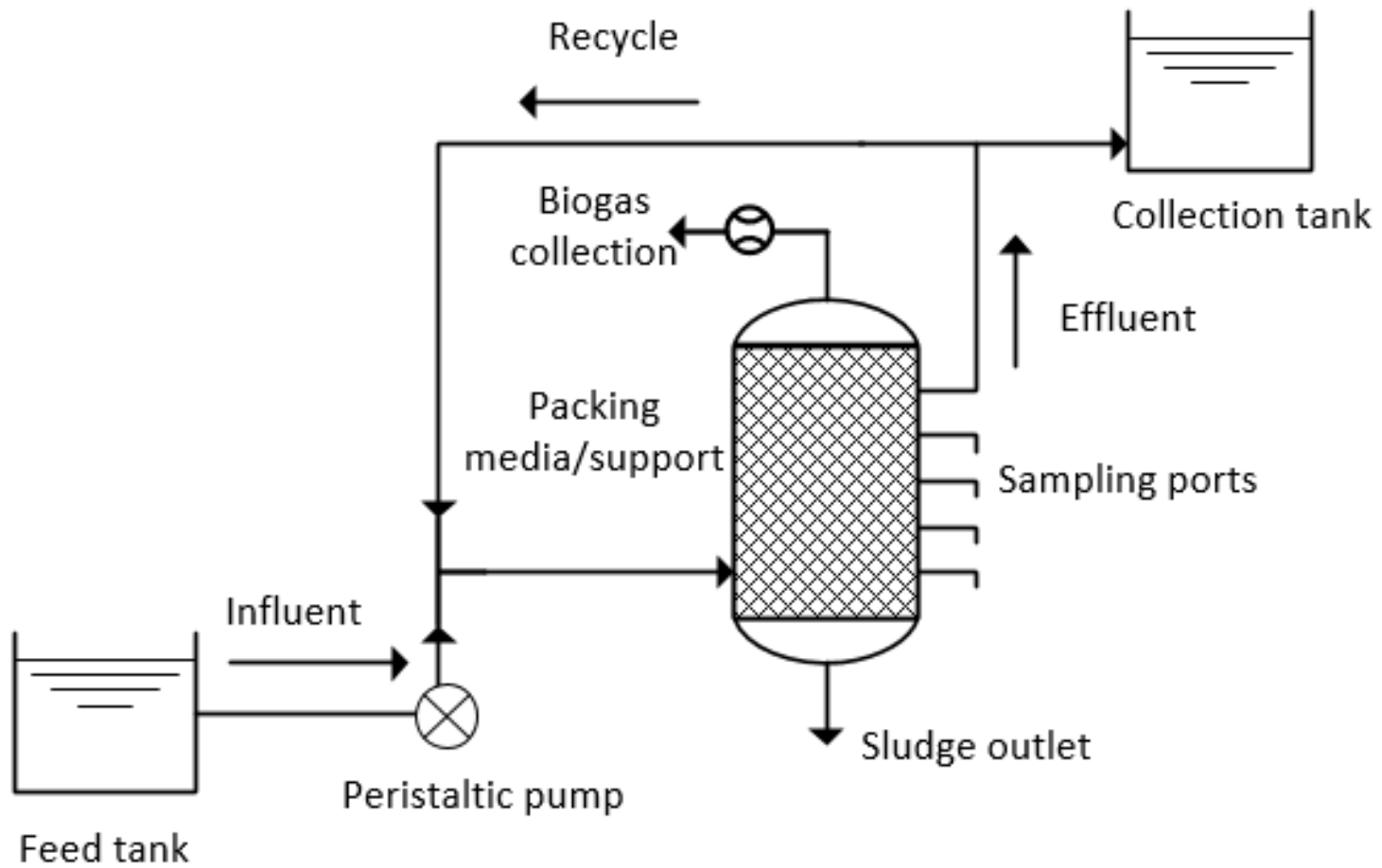

Figure 3.2. Schematic diagram of a typical anaerobic filter system.

Reprinted from J. Environ. Manage. 161 (2015) 287-302, with permission from Elsevier. 
The performance of up-flow anaerobic filters (UAFs) has been examined under thermophilic and mesophilic conditions for SWW treatment (Gannoun et al., 2009, 2013). The results showed that COD removal efficiencies of up to $90 \%$ could be achieved for organic loading rates (OLRs) of $9000 \mathrm{mg} / \mathrm{L}$ day under mesophilic conditions and $72 \%$ under thermophilic conditions.

Rajakumar et al. (2011) evaluated the performance of an UAF reactor for SWW treatment under low up-flow velocity, at mesophilic conditions of up to $35^{\circ} \mathrm{C}$. COD removals of $79 \%$ were achieved at OLRs of $10.05 \mathrm{~kg} / \mathrm{m}^{3}$ day and HRT of $12 \mathrm{~h}$. The average produced methane varied between 46 and $56 \%$. The lower velocity used in the study conducted by Rajakumar et al. (2011) allowed an active microbial formation with stable $\mathrm{pH}$ demonstrating that $\mathrm{SWW}$ can be treated using AFs under low up-flow velocity.

Stets et al. (2014) assessed the performance of AF bioreactors for SWW treatment by evaluating the influence of the characteristics of the support medium, substrate, and microorganisms present in the sludge. Three AF configurations were studied using different support media resulting in maximum COD removals of up to $80 \%$ and TN removals of up to $90 \%$ at HRT of 1 day.

Martinez et al. (2014) compared the effectiveness of two up-flow anaerobic packed-bed filters (UAPFs) for SWW treatment at a laboratory-scale, under mesophilic conditions, and using different packing material. The production of $\mathrm{CH}_{4}$ was assessed at various OLRs and feeding conditions. The COD removal reached $60 \%$ for an influent concentration of up to $15800 \mathrm{mg} / \mathrm{L}$. The UAPF was proven self-sufficient in terms of energy requirements, providing sufficient heating power for the SWW treatment plant.

\subsection{Anaerobic lagoon}

ALs are popular in countries where weather and land availability permit the construction of lagoons for the treatment of SWW (Johns, 1995; Mittal, 2006). The wastewater influent usually flows from the bottom of the lagoon, and although some gas mixing may be present, ALs are not mechanically mixed. Thus, a scum layer is typical to appear on the surface of the ALs, ensuring anaerobic conditions and low heat loss. Typical ALs are constructed with a depth of 3-5 $\mathrm{m}$ for HRTs of 5-10 days. Efficiencies of ALs to remove BOD, COD, and TSS have been reported to be 97, 96, and 95\%, respectively (US EPA, 2004; Mittal, 2006; McCabe et al., 2014). 
The main drawbacks of ALs are related to odor regeneration and weather conditions. Therefore, synthetic floating covers are used to trap odor and collect biogas; these covers must be durable to resist inclement weather, temperature change, wind, ice and snow accumulation (Mittal, 2006). On the other hand, ALs are the preferred option because of their simplicity and low O\&M costs (McCabe et al., 2014).

\subsection{Up-flow anaerobic sludge blanket reactor and anaerobic sequencing batch reactor}

An anaerobic SBR requires low capital and O\&M costs. The feeding, reactions, settling, and decanting stages take place in the same basin and anaerobic SBRs also eliminate the requirements of complete mixing. Nevertheless, intermittent mixing may occur in the course of the reacting cycles (Massé and Masse, 2000a; Mittal, 2006). Moreover, in order to optimize the performance of anaerobic SBRs, an intermittent feeding strategy of the SWW influent eliminates the need for a recycling stream or an equalizing tank (Masse and Massé, 2005).

UASB reactors are similar to anaerobic SBRs. The UASB process uses granules to capture bacteria; the SWW enters from the bottom of the reactor, flows upward through the sludge blanket, the biomass film, and exits at the top of the vessel. Essentially, UASB reactors consist of three stages: liquid as SWW, solid as biomass, and gas as $\mathrm{CO}_{2}$ and $\mathrm{CH}_{4}$ produced during digestion (Mittal, 2006; Del Nery et al., 2007, 2008).

Caldera et al. (2005) evaluated the performance of a UASB reactor of $4 \mathrm{~L}$ at mesophilic conditions for the treatment of SWW. Influent COD concentrations were varied from 1820 to $12790 \mathrm{mg} / \mathrm{L}$. Experiments were conducted for 90 days at HRT of $24 \mathrm{~h}$. The results demonstrated an adequate efficiency of the UASB reactor to treat SWW of up to $94.31 \%$ for the removal of COD.

Chávez et al. (2005) evaluated the removal of BOD from SWW using 3 L UASB reactors and a 3levels factorial design and RSM. A maximum 95\% removal of BOD was obtained with OLRs up to $31000 \mathrm{mg} / \mathrm{L}$ under optimum conditions, with temperature values ranging between 25 and $39^{\circ} \mathrm{C}$ at $\mathrm{HRTs}$ between 3.5 and $4.5 \mathrm{~h}$.

Miranda et al. (2005) assessed the performance of an 800- $\mathrm{m}^{3}$ UASB for SWW treatment. Influent concentrations of COD and oil and grease (O\&G) were in the range of 1400-3600 and 413-645 mg/L, 
respectively. Results show that the UASB performance was enhanced when influent COD/O\&G ratios remained at $10 \%$. Thus, O\&G and COD removal efficiencies reached $27-58$ and $70-92 \%$, respectively.

Rajakumar and Meenambal (2008) evaluated the performance of the UASB process for SWW treatment. Influent COD concentrations varied from 3000 to $4800 \mathrm{mg} / \mathrm{L}$. The UASB reactor showed an

optimum COD removal efficiency of up to $90 \%$ at a HRT of $10 \mathrm{~h}$. Moreover, results show that by reducing HRT to less than $10 \mathrm{~h}$ in the UASB, sludge wash out appears and lower COD removal efficiencies of less than $70 \%$ are obtained (Rajakumar et al., 2012).

Mijalova Nacheva et al. (2011) analyzed the performance of a UASB reactor under ambient conditions for SWW treatment after solid separation. COD removal efficiencies increased proportionally to OLRs. Thus, COD removal efficiencies of up to $90 \%$ were obtained with the influent COD concentrations of $3437 \mathrm{mg} / \mathrm{L}$. Although UASB reactors are found to be efficient for SWW treatment, a posttreatment is required to comply with current water quality standards for water body discharge.

\subsubsection{Aerobic treatment}

In aerobic systems, aerobic bacteria are accountable for the removal of organic materials in the presence of oxygen. The treatment time and the amount of required oxygen increase suddenly with the strength of SWW. Aerobic treatment is commonly used for final decontamination and removal of nutrients after using physicochemical or anaerobic techniques (Chernicharo, 2006). Aerobic reactors may have several configurations. However, the biological process is very similar, and being necessary to define if nitrogen removal is required (San José, 2004). Typical configurations for SWW aerobic treatment include activated sludge (AS), rotating biological contactors (RBCs), and aerobic SBR.

\subsection{Activated sludge process}

$\mathrm{AS}$ is an aerobic treatment method that brings the effluent into contact with air and free-floating flocs of microorganisms including bacteria and protozoa. The AS process has been widely applied in different industries as a commonly known cost-effective method for the treatment of SWW. The purpose of the AS process is to remove soluble and insoluble organics from the wastewater and to change this material into a flocculent microbial suspension that is then settled in a clarifier. Two distinct mechanisms are applied in AS, adsorption and oxidation of the organic matter (Bull et al., 1982; Al-Mutairi, 2008). A typical AS system is depicted in Figure 3.3. 


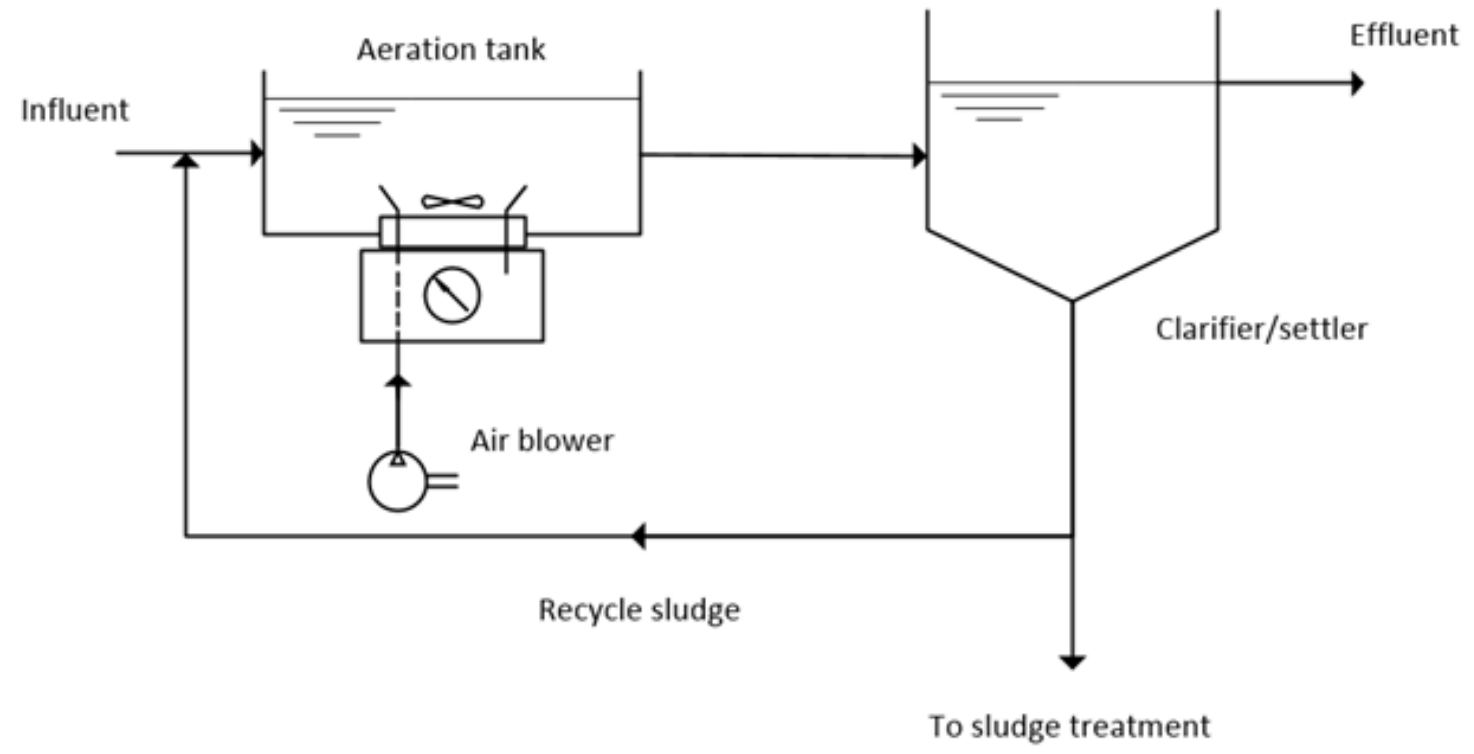

Figure 3.3. Schematic diagram of a typical activated sludge system.

Reprinted from J. Environ. Manage. 161 (2015) 287-302, with permission from Elsevier. 
AS systems, treating SWW, produce poor settling flocs because of fats present in SWW influents and low dissolved oxygen (DO) levels. Design criteria of the AS process for SWW treatment require extended aeration to minimize the sludge production. The HRT are longer than that of typical municipal wastewater treatment plants to guarantee a sludge age in the range of 5-20 days, recommended for SWW treatment (Johns, 1995).

Pabón and Gélvez (2009) evaluated the performance of a $144 \mathrm{~m}^{3}$ full-scale AS reactor for SWW treatment. The average treated flow was $1.38 \mathrm{~L} / \mathrm{s}$ with a 2-day HRT. Oxygen was injected using a highefficiency air equipment. Bulk SWW parameters, including BOD, COD, and TSS with an influent concentration of 5242, 9040, and $2973 \mathrm{mg} / \mathrm{L}$, respectively, were evaluated. Maximum removal efficiencies of $94.09,89.73$, and $89.03 \%$ were achieved for TSS, BOD, and COD, respectively.

Fongsatitkul et al. (2011) examined the performance of the AS system to treat SWW. Two $10 \mathrm{~L}$ continuous-flow reactors running in parallel with internal recycle (IR) were used. The COD removal efficiency reached up to $97.60 \%$, the total Kjeldahl nitrogen (TKN) removal rate ranged from 81.50 to 95.60\%, and the TP removal reached its maximum around $85-89 \%$.

Hsiao et al. (2012) evaluated different kinetic parameters for an AS reactor treating SWW using the Monod equation and compared to the data obtained from the experiment. The AS system at the temperature of $26^{\circ} \mathrm{C}$ removed up to $97.20 \%$ of COD from SWW. Predicted values were validated by the experimental values. The sensitivity analysis indicated that the COD residual concentration was highly sensitive to the variation of the maximum specific substrate utilization rate, producing a noticeable COD intensification.

Carvalho et al. (2013) aimed to evaluate the role of AS process in the removal of veterinary drugs including enrofloxacin, tetracycline, and ceftiofur from SWW in batch reactors. Sludge bioreactors with initial pharmaceutical concentrations of $100 \mathrm{~g} / \mathrm{L}$ presented removal rates of $68 \%$ for enrofloxacin and $77 \%$ for tetracycline from the aqueous phase. Results showed that sorption to wastewater organic content and biomass was accountable for a significant fraction of the pharmaceuticals removal. Nevertheless, these removal rates are still low for effluent discharge. Therefore, it is required to consider alternative methods for treating this effluent such as AOPs. 
Bustillo-Lecompte et al. $(2013,2014)$ evaluated the effectiveness, performance, and costs of an AS reactor for the treatment of SWW using a CEA. The aerobic AS reactor obtained the best performance under TOC and TN influent concentrations of 1009 and $254 \mathrm{mg} / \mathrm{L}$ with up to $95.03 \%$ TOC and $73.46 \%$ TN removals, respectively. At higher influent TOC and TN concentrations, the TOC and TN removal are higher. For an influent concentration of $639 \mathrm{mgTOC} / \mathrm{L}$ and $144 \mathrm{mgTN} / \mathrm{L}$, TOC removals reached $89.66 \%$ and TN removals reached $43.19 \%$ at HRT of 5 days, whereas at 8 days, TOC removals reached $94.26 \%$, and TN removals reached $75.15 \%$. On the other hand, by means of the CEA, it was found that the AS process is an efficient process with optimum TOC removal of up to $88 \%$ at a cost of $4 \$ / \mathrm{kg}$ of TOC removed. Thus, if low or intermediate amounts of TOC are to be removed, the AS process is comparable to combined processes in economic terms.

\subsection{Rotating biological contactor}

The RBC process allows the wastewater to be exposed to a biological medium in order to absorb and metabolize the organic content as well as to remove other pollutants before discharge to the environment (Mittal, 2006). However, the performance of an RBC to treat SWW has been reported as inadequate in literature (Bull et al., 1982; Johns, 1995) compared to conventional aerobic treatment systems such as the AS process.

Torkian et al. (2003) investigated the performance of a 6-stage RBC pilot plant for post-treatment of SWW. The overall removal efficiencies for BOD and COD decreased by increasing the OLR. Results indicated successful post-treatment of SWW to meet regulatory requirements with a BOD removal efficiency of up to $88 \%$. On the other hand, Al-Ahmady (2005) studied the COD removal in RBC systems as a function of the OLR. A wide range of COD removal of 40-85\% can be obtained when treating SWW by RBCs because of the specific OLR applied, especially during the first stages of the system.

\subsection{Aerobic sequencing batch reactor}

In an aerobic SBR, there are five stages including filling, reaction, settling, decanting/drawing, and idle. In the first stage, the feed enters the reactor while mixing is provided by mechanical means in the absence of air (anoxic phase). Then, the aeration of the mixed liquor is executed for the reactions to occur (aerobic phase). During the third stage, the TSS start to settle since there is no aeration or mixing. During the fourth stage, the clean supernatant liquor exits the tank as the effluent. 
Filali-Meknassi et al. (2005a; 2005b) studied the performance of an aerobic SBR for SWW treatment with influent concentrations of $5000 \mathrm{mgCOD} / \mathrm{L}$ and $360 \mathrm{mgTN} / \mathrm{L}$. Overall efficiencies were achieved for COD and $\mathrm{TN}$ in the range 95-96\% and 95-97\%, respectively. Likewise, Lemaire et al. (2008, 2009) evaluated the performance of SBRs under six-hour cycles for SWW treatment. High efficiencies for COD, TP, and TN removal of 95, 98, and 97\% were achieved, respectively.

Conversely, Li et al. (2008) assessed the influence of the aeration rate on organics and nutrients removal from SWW using two laboratory-scale SBRs operated at ambient temperature for $8 \mathrm{~h}$. The influent concentrations of TN and COD were 350 and $4000 \mathrm{mg} / \mathrm{L}$, respectively. Results show that at higher aeration rates, the TN removal efficiency increases considerably. For instance, at an aeration rate of $0.4 \mathrm{~L} / \mathrm{min}$, TN and COD removal efficiencies reached 34 and 90\%, respectively. Conversely, aeration rates above $0.8 \mathrm{~L} / \mathrm{min}$ permitted removal efficiencies of up to 97 and $95 \%$ for COD and TN, respectively.

Zhan et al. (2009) examined the TN removal from SWW in a SBR at laboratory-scale using two aeration strategies, intermittent and continuous, at low DO range. Under the intermittent aeration strategy, the maximum DO was fixed at $10 \%$ saturation. On the other hand, under the continuous aeration strategy, the DO was maintained at $10 \%$ saturation during the first hour of the reaction phase, and then at $2 \%$ for the remaining reaction phase. TN removals of 91 and $95 \%$ were accomplished by continuous and intermittent aeration, respectively. Therefore, an on-site measurement of DO levels can be used to regulate the SBR operation in order to improve TN removal.

Mees et al. $(2011,2014)$ used a 5-L aerobic SBR with suspended biomass for the removal of organics and nutrients from SWW. Optimal conditions were obtained by a central composite design (CCD) at 16-h cycles. 20 cycles were completed to investigate the kinetics for the degradation of COD and TN. Up to $85.91 \%$ and $62.13 \%$ removal efficiencies were achieved for TN and COD, respectively.

Kundu et al. $(2013,2014)$ evaluated the performance of a SBR for the removal of TN and COD from SWW at laboratory-scale. Influent concentrations of TN and COD were 90e180 and 950-1050 $\mathrm{mg} / \mathrm{L}$, respectively. Results showed a COD removal of up to $95 \%$ at $8 \mathrm{~h}$. A reasonable degree of nitrification between 74.75 and $90.12 \%$ was achieved for TN influent concentrations of 176.85 and 96.58 $\mathrm{mg} / \mathrm{L}$, respectively. Kinetic coefficients were also determined. 
Pan et al. (2014) evaluated the removal of TN from SWW at low temperatures of up to 11C through partial nitrification-denitrification, by means of an 8-L SBR. The influent concentration of the SWW contained COD, TN, TP, and TSS concentrations of 6068, 571, 51, $1800 \mathrm{mg} / \mathrm{L}$, respectively. OLRs of up to $610 \mathrm{mgCOD} / \mathrm{L}$ day were used at cycles of $12 \mathrm{~h}$. The optimum aeration rate was found to be 0.6 $\mathrm{L} / \mathrm{min}$ at maximum TP, COD, and TN removal efficiencies of 96, 98, and 98\%, respectively.

\subsubsection{Constructed wetlands}

CWs are an attractive alternative to conventional wastewater treatment, especially in rural areas since the biological treatment is a cost-effective method (Chan et al., 2009; Oller et al., 2011; BustilloLecompte et al., 2014). This is due to low O\&M costs, simplicity in design, and relatively few impacts on the environment. CWs simulate the mechanisms of natural wetlands for water purification, combining biological, physical, and chemical processes that occur when microorganisms, soil, atmosphere, plants, and water interact. This interaction results in the appearance of sedimentation, filtration, adsorption, biodegradation, photosynthesis, photo-oxidation, and subsequent organics and nutrients uptake by the system.

Gutiérrez-Sarabia et al. (2004) studied a full-scale constructed subsurface-flow wetland system. The CW accounted for $30 \%$ of the organic matter removal in the system. Although the treatment system achieved satisfactory pollutant removals of 91,89 , and $85 \%$ for $\mathrm{BOD}_{5}, \mathrm{COD}$, and TSS, respectively, the final effluent could not meet local standards. Moreover, the TP removal was null.

Soroko (2007) evaluated the performance of CW systems for the treatment of SWW. Two vertical flow constructed wetlands (VFCWs) and one horizontal flow constructed wetland (HFCW) were used. The SWW influent had average concentrations of 3188, 2500, and $500 \mathrm{mg} / \mathrm{L}$ for COD, BOD, and TN, respectively. Results showed that sand and gravel beds of CWs could be effective in removal of organic substances, up to $97.40,99.90$, and $78.20 \%$ of COD, BOD, and TN from the SWW influent, respectively.

Carreau et al. (2012) constructed a CW with Typha latifolia for the treatment of SWW with HRT of 111 days and $89 \%$ active volume. Up to $95,72,88$, and $87 \%$ removal efficiencies were achieved for BOD, TSS, TP, and TN, respectively. Likewise, Odong et al. (2013) investigated different CWs for the treatment of SWW with influent concentrations of COD, BOD, and TN in the ranges of 293-314, 79-87, 
and 56-64 mg/L, respectively. Results showed a broad range of removal for different vegetation. COD, $\mathrm{BOD}$, and TN removal rates ranged from 28.28 to $75.03,9.27$ to 71.40 , and 5.20 to $25.40 \%$, respectively.

\subsubsection{Advanced oxidation processes}

AOPs are becoming an interesting alternative to conventional treatment and a complimentary treatment option, as either pre-treatment or post-treatment, to current biological processes. Furthermore, AOPs may inactivate microorganisms without adding additional chemicals to the SWW in comparison to other techniques such as chlorination that are commonly used in water disinfection, thus, avoiding the possible formation of hazardous by-products (De Sena et al., 2009; Bustillo-Lecompte et al., 2015). Therefore, AOPs have come handy to be recognized as advanced degradation, water reuse, and pollution control processes showing excellent overall results as complimentary treatment (Tabrizi and Mehrvar, 2004; Mehrvar and Venhuis, 2005; Venhuis and Mehrvar, 2005; Mehrvar and Tabrizi, 2006; Edalatmanesh et al., 2008; De Sena et al., 2009; Cao and Mehrvar, 2011; Barrera et al., 2012; Mohajerani et al., 2012; Bustillo-Lecompte et al., 2013, 2014; Hamad et al., 2014; Mowla et al., 2014; Ghafoori et al., 2015).

Millamena (1992) used Ozonation technology for the treatment of SWW. Results showed that the utilization of a low concentration ozone stream of $110 \mathrm{mg} / \mathrm{h}$ for the removal of the majority of organics in slaughterhouse wastewater was not feasible. With pre-treatment, the overall efficiency of ozonation in terms of BOD removals was in the order of $42 \%$, TOC reached $34 \%$ removal, and better removal was attained with COD at $58 \%$.

Wu and Doan (2005) also used Ozonation for the treatment of SWW. Results show that ozone was effective in disinfecting SWW after 8 min using an ozone dosage of up to $23.09 \mathrm{mg} / \mathrm{min}$ per L. Up to $99 \%$ of microorganisms were inactivated. Nevertheless, the COD and BOD removal were only 10.70 and $23.60 \%$, respectively.

Melo et al. (2008) evaluated gamma radiation (GR) for the treatment of SWW. Low COD, BOD, and TSS efficiency removals were obtained at a dose rate of $0.9 \mathrm{kGy} / \mathrm{h}$. Nevertheless, a decrease of BOD in the range of 38.65-85.75\% was observed at high-absorbed irradiation dosages ( $25 \mathrm{kGy} / \mathrm{h})$. Although the results obtained at high doses, the costs associated with this technology are its main drawback. 
The $\mathrm{UV} / \mathrm{H}_{2} \mathrm{O}_{2}$ process is one of the most widely used AOPs. The $\mathrm{UV} / \mathrm{H}_{2} \mathrm{O}_{2}$ process has been found to be effective for SWW treatment. Oxidation and degradation of pollutants by $\mathrm{UV} / \mathrm{H}_{2} \mathrm{O}_{2}$ rely on hydroxyl radicals ( ${ }^{\circ} \mathrm{OH}$ ), a highly reactive species produced from the reaction of the $\mathrm{H}_{2} \mathrm{O}_{2}$ with the UV light (Tabrizi and Mehrvar, 2004; Mehrvar and Tabrizi, 2006; Edalatmanesh et al., 2008; De Sena et al., 2009; Luiz et al., 2009; Cao and Mehrvar, 2011; Barrera et al., 2012; Mohajerani et al., 2012; Hamad et al., 2014; Mowla et al., 2014; Bustillo-Lecompte et al., 2015; Ghafoori et al., 2015). A schematic diagram of a single lamp $\mathrm{UV} / \mathrm{H}_{2} \mathrm{O}_{2}$ photoreactor system is presented in Figure 3.4.

Luiz et al. (2009) evaluated the $\mathrm{UV} / \mathrm{H}_{2} \mathrm{O}_{2}$ process for the treatment of a secondary SWW effluent. Results show that the $\mathrm{UV} / \mathrm{H}_{2} \mathrm{O}_{2}$ treatment was more effective than conventional $\mathrm{UV}$ alone in removing organic matter. The $\mathrm{UV} / \mathrm{H}_{2} \mathrm{O}_{2}$ process was five times more rapidly in degrading aromatics than UV only. Up to $95 \%$ in COD removal efficiency was reached after $5 \mathrm{~h}$ of treatment.

De Sena et al. (2009) studied the effectiveness of AOPs for the treatment of SWW using $\mathrm{UV} / \mathrm{H}_{2} \mathrm{O}_{2}$ and photo-Fenton in a laboratory scale. Results showed that the AOPs increased the removal of organics from pre-treated SWW samples with overall COD and BOD removal rates of up to 97.60 and $95.70 \%$, respectively. Thus, AOPs might be considered to enhance SWW effluents quality for water reuse purposes.

Cao and Mehrvar (2011) evaluated a $\mathrm{UV} / \mathrm{H}_{2} \mathrm{O}_{2}$ photoreactor as the post-treatment of a synthetic SWW at a laboratory scale. A TOC influent concentration of $157.6 \mathrm{mg} / \mathrm{L}$ was used. Up to 84, 64, and $83 \%$ of BOD, TOC, and COD removals, respectively, were obtained at HRTs of $2.5 \mathrm{~h}$ with a $\mathrm{H}_{2} \mathrm{O}_{2}$ dosage of $529 \mathrm{mg} / \mathrm{L}$. The $\mathrm{H}_{2} \mathrm{O}_{2}$ dosage of $3.5 \mathrm{mgH} 2 \mathrm{O} 2 / \mathrm{h}$ per $\mathrm{mg}$ TOC in the influent was found to be the optimum for the $\mathrm{UV} / \mathrm{H}_{2} \mathrm{O}_{2}$ process.

The degradation of TOC and microorganism disinfection from synthetic SWW secondary effluents were investigated by Barrera et al. (2012) using UV-C and vacuum-ultraviolet (VUV). TOC removals ranged from 5.5 to $12.2 \%$ for $\mathrm{UV}-\mathrm{C} / \mathrm{H}_{2} \mathrm{O}_{2}$ and $\mathrm{VUV} / \mathrm{H}_{2} \mathrm{O}_{2}$, respectively. Optimum $\mathrm{H}_{2} \mathrm{O}_{2} / \mathrm{TOC}$ molar ratios of 1.5 and 2.5 were found for VUV and UV-C, respectively. Furthermore, it was discovered that the photochemical processes were capable of rapid bacteria inactivation in less than 30 seconds. 


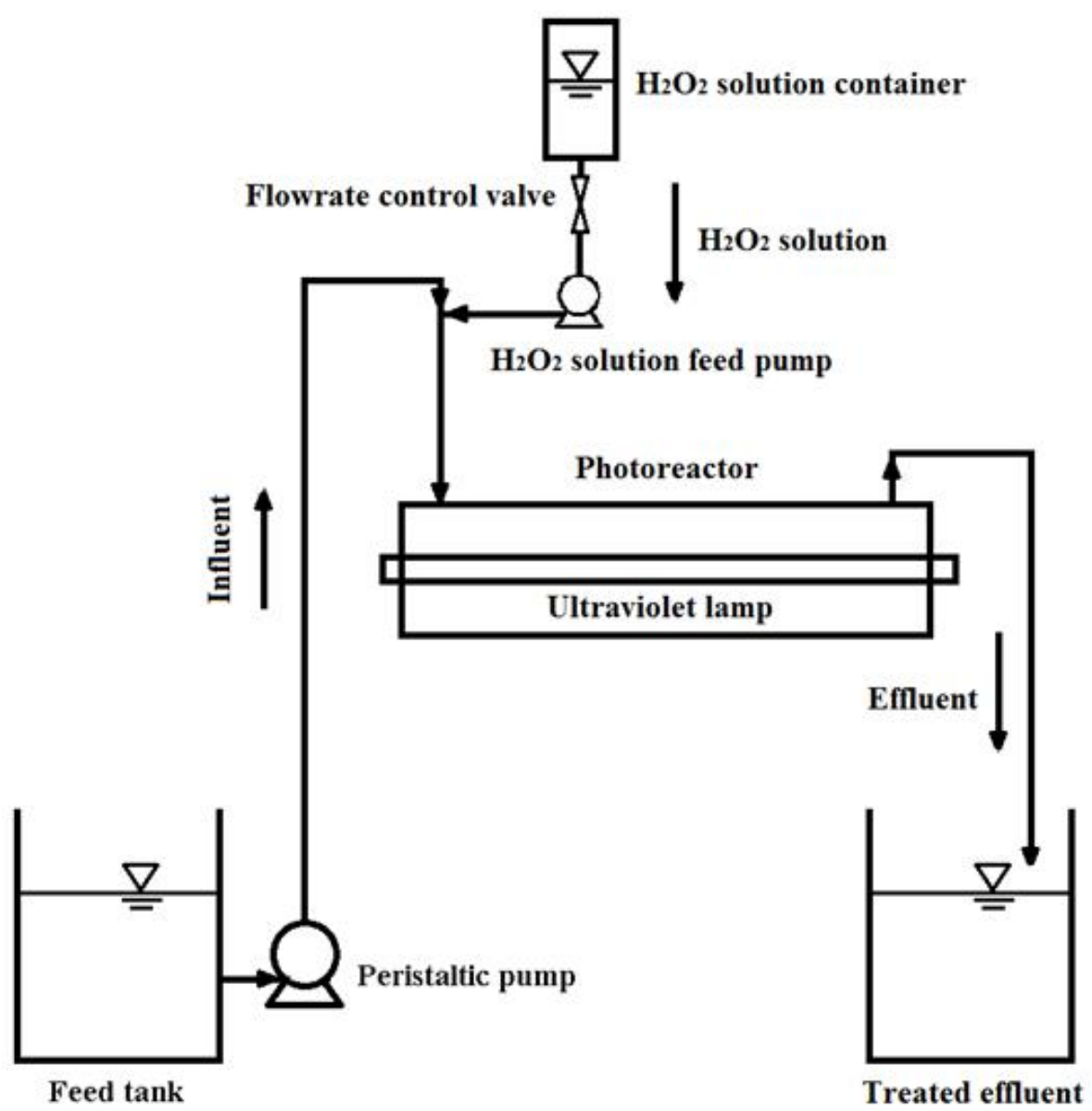

Figure 3.4. Schematic diagram of a single lamp $\mathrm{UV} / \mathrm{H}_{2} \mathrm{O}_{2}$ photoreactor.

Reprinted from J. Environ. Manage. 161 (2015) 287-302, with permission from Elsevier. 
Bustillo-Lecompte et al. (2013) evaluated the performance of the $\mathrm{UV} / \mathrm{H}_{2} \mathrm{O}_{2}$ process for the SWW treatment. TOC loadings of up to $350 \mathrm{mg} / \mathrm{L}$ were used in the SWW influent. An optimum TOC removal of $75 \%$ was obtained for influent concentrations of up to $65 \mathrm{mgTOC} / \mathrm{L}$ and HRTs of 180 min with $\mathrm{H}_{2} \mathrm{O}_{2}$ dosages of $900 \mathrm{mg} / \mathrm{L}$. An optimum molar ratio dosage of $14.03 \mathrm{mgH}_{2} \mathrm{O}_{2} / \mathrm{mgTOC}_{\text {in }}$ was also found for the $\mathrm{UV} / \mathrm{H}_{2} \mathrm{O}_{2}$ process.

Bustillo-Lecompte et al. (2014) compared the $\mathrm{UV} / \mathrm{H}_{2} \mathrm{O}_{2}$ alone to other treatment technologies to treat SWW as an individual method. The $\mathrm{UV} / \mathrm{H}_{2} \mathrm{O}_{2}$ alone was found to be the least efficient process with optimum removals of up to $50 \%$ at a cost of $67 \$ / \mathrm{kg}$ of TOC removed. Moreover, the TOC removal was not significantly increased by augmenting the HRT. Therefore, although the $\mathrm{UV} / \mathrm{H}_{2} \mathrm{O}_{2}$ process is effective to treat the SWW, the $\mathrm{UV} / \mathrm{H}_{2} \mathrm{O}_{2}$ is expensive if applied alone. Consequently, SWW treatment by the combination of AOPs and biological processes is recommended while they are optimized at an appropriate residence time in each reactor.

\subsubsection{Combined processes}

SWW effluents are part of the food and beverage industry wastewaters (Oller et al., 2011; Vymazal, 2014; Valta et al., 2015). SWWs are one of the major concerns of the agro-industrial sector because of the high amounts of water used in the process of slaughtering and further cleaning of the facilities (De Sena et al., 2009; Oller et al., 2011; Valta et al., 2015).

It may be stated that it is beneficial, in terms of operation and economics, to implement combined processes for the treatment of SWW since it couples the benefit of different technologies to improve high strength industrial wastewater management (Kuşçu and Sponza, 2006; Ahn et al., 2007; Chan et al., 2009; Bazrafshan et al., 2012; Cao and Mehrvar, 2011; Barrera et al., 2012; Bazrafshan et al., 2012; Bustillo-Lecompte et al., 2013, 2014).

Del Pozo and Diez (2005) evaluated a combined anaerobic-aerobic fixed-film reactor for SWW treatment under sub-mesophilic conditions $\left(25^{\circ} \mathrm{C}\right)$. Overall COD removals of up to $93 \%$ were obtained for OLRs of $0.77 \mathrm{~kg} / \mathrm{m}^{3}$ day, along with TN removals of up to $67 \%$ for a TN influent load of $0.084 \mathrm{~kg}$ $\mathrm{N} / \mathrm{m}^{3}$ day. Denitrification only implied $12-34 \%$ of the TN removal being limited by DO levels above 0.5 $\mathrm{mg} / \mathrm{L}$ in the anaerobic section. 
Bohdziewicz and Sroka (2005) considered combined AS-RO system for the treatment of SWW. The raw SWW was first pretreated using activated sludge (AS). Results showed a high removal of contaminants from the SWW by the combined processes, including COD (99.80\%), BOD (99.83\%), TP (99.76\%), and TN (99.77\%).

Mahtab et al. (2009) evaluated a combined coagulation/adsorption process for SWW effluents using various coagulants, such as alum, ferrous sulfate, ferric chloride, and lime. Results show that optimum COD removal efficiencies of up to $92 \%$ are obtained by using alum as the coagulant. Nevertheless, it was concluded that the combined coagulation/adsorption process made not significant improvement in COD removal from SWW.

A laboratory scale anaerobic-aerobic system, consisting of an AF attached to an aerobic SBR, was used for SWW treatment (López- López et al., 2010). The AF operated with OLR in the range of 3.7$16.5 \mathrm{~kg} / \mathrm{m}^{3}$ day and at HRTs of up to $72 \mathrm{~h}$. Up to $81 \%$ COD removals were obtained and was found to be inversely correlated to OLRs. When coupling the AF to the SBR, over 95\% COD was removed in 9 h. Moreover, optimum conditions were detected at OLRs below $11 \mathrm{~kg} / \mathrm{m}^{3}$ day with HRT of $24 \mathrm{~h}$.

On the other hand, Cao and Mehrvar (2011) evaluated the combined ABR and $\mathrm{UV} / \mathrm{H}_{2} \mathrm{O}_{2}$ processes at laboratory scale for synthetic SWW treatment. Results showed that combined processes are more efficient than individual processes for SWW treatment. Up to 95\% TOC, 98\% COD, and 97\% BOD removals were obtained for influent concentrations of $973 \mathrm{mg} / \mathrm{L}$ at HRTs in the ABR of up to 3.8 days and $3.6 \mathrm{~h}$ within the $\mathrm{UV} / \mathrm{H}_{2} \mathrm{O}_{2}$ reactor.

Bazrafshan et al. (2012) assessed the performance of combined chemical coagulation (CC) and EC for the SWW treatment. BOD and COD removal rates were directly proportional to the applied voltage and coagulant dosage with up to $99 \%$ removal efficiencies for both parameters. As a result, the combined CC-EC processes were found to be more efficient than EC alone for SWW treatment.

Bustillo-Lecompte et al. $(2013,2014)$ evaluated the performance and operating costs of treating SWW using combined biological and AOPs. A comparison was made in terms of the treatment capability and overall costs for different technologies including $\mathrm{ABR}, \mathrm{AS}$, and $\mathrm{UV} / \mathrm{H}_{2} \mathrm{O}_{2}$. Overall efficiencies reached 75.22, 89.47, 94.53, 96.10, 96.36, and 99.98\% by the $\mathrm{UV} / \mathrm{H}_{2} \mathrm{O}_{2}, \mathrm{ABR}, \mathrm{AS}$, combined AS-ABR, combined ABR-AS, and combined ABR-AS-UV/ $/ \mathrm{H}_{2} \mathrm{O}_{2}$ processes, respectively. A CEA was performed 
at optimal conditions for the SWW treatment by optimizing the total electricity cost, $\mathrm{H}_{2} \mathrm{O}_{2}$ consumption, and HRT. The combined ABR-AS-UV/ $/ \mathrm{H}_{2} \mathrm{O}_{2}$ processes reached a maximum TOC removal of $99 \%$ in $76.5 \mathrm{~h}$ with an estimated cost of $6.79 \$ / \mathrm{m}^{3}$ day.

The combined ABR-AS-UV/ $\mathrm{H}_{2} \mathrm{O}_{2}$ system was proven the most cost-effective solution compared to other processes for the TOC removal under these conditions. Nevertheless, the selection of a particular treatment method for SWW treatment requires an analysis of the characteristics of the SWW being treated and the best available technology (BAT) in order to comply with current regulations and different jurisdictions worldwide.

\subsection{Summary and conclusions}

A summary of the most commonly applied technologies and combined processes during the last decade is portrayed in Table 3.6, with particular attention to treatment efficiencies in terms of organic and nutrient removal, highlighting commonly used parameters, such as COD, TOC, BOD, and TN. The treatment efficiency of SWW varies extensively, it depends on several factors including, but not limited to, the characteristics of the SWW, the HRT, and the pollutant concentration in the influent. Table 3.6 also reveals that several types of individual and combined processes have been used for the SWW treatment.

SWWs are commonly pre-treated by screening, settling, blood collection, and fat separation, followed by physicochemical treatment, including DAF, coagulation/flocculation, and/or secondary biological treatment. Although the organic matter and nutrient removal can achieve high efficiencies, the treated SWW effluent usually need further treatment by membrane technologies, AOPs, or other appropriate treatment methods as combined processes. AOPs may also provide high-quality treated water

allowing water recycle in the meat processing industry. Therefore, combined processes have evolved into a reliable technology that is nowadays successfully used for many types of SWW effluents. However, the selection of a specific treatment mainly depends on the characteristics of the SWW being treated, the BAT, and the compliance with current regulations under different political jurisdictions.

\section{Acknowledgments}

The financial support of Natural Sciences and Engineering Research Council of Canada (NSERC), Ontario Trillium Scholarship (OTS) Program, and Ryerson University is greatly appreciated. 
Table 3.6. Comparison of different technologies and their combination for slaughterhouse wastewater treatment.

Reprinted from J. Environ. Manage. 161 (2015) 287-302, with permission from Elsevier.

\begin{tabular}{|c|c|c|c|c|c|c|c|c|c|c|}
\hline Processes $^{1}$ & $\begin{array}{l}\text { HRT }^{2} \\
\text { (h) }\end{array}$ & $\begin{array}{l}\mathrm{TOC}_{\mathrm{in}}{ }^{3} \\
(\mathrm{mg} / \mathrm{L})\end{array}$ & $\begin{array}{l}\mathrm{COD}_{\text {in }}{ }^{3} \\
(\mathrm{mg} / \mathrm{L})\end{array}$ & $\begin{array}{l}\mathrm{BOD}_{\text {in }}{ }^{3} \\
(\mathrm{mg} / \mathrm{L})\end{array}$ & $\begin{array}{l}\mathrm{TN}_{\mathrm{in}}{ }^{3} \\
(\mathrm{mg} / \mathrm{L})\end{array}$ & $\begin{array}{l}\text { TOC } \\
\text { removal (\%) }\end{array}$ & $\begin{array}{l}\text { COD } \\
\text { removal (\%) }\end{array}$ & $\begin{array}{l}\text { BOD } \\
\text { removal (\%) }\end{array}$ & $\begin{array}{l}\text { TN } \\
\text { removal (\%) }\end{array}$ & Reference \\
\hline AeP-RO & $8-36$ & - & 5,300 & 2,900 & 557 & - & 99.80 & 99.83 & 99.77 & Bohdziewicz and Sroka (2005) \\
\hline AnaP & $24-2,160$ & 3,500 & $1,820-12,790$ & - & 1,176 & - & $71.51-94.31$ & - & - & Caldera et al. (2005) \\
\hline AnaP & 360 & - & $5,800-11,600$ & $4,524-8,700$ & $11-11,150$ & - & - & $20.20-95.60$ & - & Chávez et al. (2005) \\
\hline AnaP-AeP & $23-91$ & - & $1,190-2,800$ & $610-1,150$ & $150-260$ & - & 93.00 & 97.00 & 69.00 & Del Pozo and Diez (2005) \\
\hline $\mathrm{AeP}$ & 49 & - & $5,000-5,098$ & - & $349-370$ & - & $95.00-96.00$ & - & $86.00-88.00$ & Filali-Meknassi et al. (2005a) \\
\hline AeP & 48 & - & $5,155-5,675$ & - & $369-431$ & - & 96.00 & - & $97.00-99.00$ & Filali-Meknassi et al. (2005b) \\
\hline AnaP-AeP & 249 & - & 3,000 & - & - & - & $90-92$ & - & - & Kuşçu and Sponza (2005) \\
\hline AnaP & $24-48$ & - & 7,083 & - & 547 & - & 93.9 & - & - & Masse and Massé (2005) \\
\hline AnaP & $18-27$ & - & $1,400-3,600$ & - & $13-179$ & - & $70.60-92.60$ & - & - & Miranda et al. (2005) \\
\hline $\mathrm{CC}$ & - & - & $10,226-15,038$ & $5,042-8,320$ & - & - & $32.20-63.60$ & $34.70-67.80$ & - & Satyanarayan et al. (2005) \\
\hline $\mathrm{AOP}$ & 0.13 & - & - & - & - & - & 10.70 & 23.60 & - & Wu and Doan (2005) \\
\hline EC & 0.42 & - & $2,600-2,900$ & $10,000-12,000$ & - & - & $60.00-93.00$ & - & - & Bayramoglu et al. (2006) \\
\hline $\mathrm{EC}$ & 0.42 & - & $2,600-2,900$ & $12,000-10,000$ & - & - & $60.00-93.00$ & - & - & Kobya et al. (2006) \\
\hline AnaP-AeP & 249 & - & 3,000 & - & $70-147$ & - & $80.00-99.00$ & - & 77.40 & Kuşçu and Sponza (2006) \\
\hline AnaP-AeP & 24 & - & $6,000-14,500$ & - & $300-1,000$ & - & 99.00 & - & 46.00 & Ahn et al. (2007) \\
\hline AnaP & - & - & 3,102 & - & 186 & - & - & - & - & Amorim et al. (2007) \\
\hline AnaP & 69 & - & $2,360-4,690$ & $1,190-2,624$ & $147-233$ & - & $57.00-67.00$ & $48.50-63.00$ & $36.00-40.00$ & Del Nery et al. (2007) \\
\hline AnaP & $30-80$ & - & $7,148-20,400$ & $3,501-8,030$ & - & - & $62.00-96.40$ & 93.96 & - & Saddoud and Sayadi (2007) \\
\hline $\mathrm{CW}$ & - & - & 3,188 & $2,452-2,500$ & 494-500 & - & 97.40 & 99.90 & 78.20 & Soroko (2007) \\
\hline $\mathrm{AeP}$ & $3.0-8.0$ & - & 431 & 1,320 & 5.6 & - & 72.00 & 99.00 & - & Al-Mutairi et al. (2008) \\
\hline EC & $1.0-1.5$ & - & $1,290-1,670$ & $2,700-3,100$ & - & - & 82.00 & 86.00 & - & Asselin et al. (2008) \\
\hline AnaP & - & - & $1,913-5,157$ & $1,559-2,683$ & - & - & $21.00-58.00$ & $14.00-64.00$ & - & De Nardi et al. (2008) \\
\hline GR & - & - & - & 3,860 & - & - & - & $38.65-85.75$ & - & Melo et al. (2008) \\
\hline $\mathrm{AeP}$ & 42 & - & $6,400-8,320$ & - & $260-306$ & - & 95.00 & - & 97.00 & Lemaire et al. (2008) \\
\hline AeP & 8.0 & - & $2,850-4,700$ & $1,000-2,900$ & $250-350$ & - & 97.00 & - & 94.00 & Li et al. (2008) \\
\hline AnaP & $10-3,600$ & $1,030-3,000$ & $3,000-4,800$ & $750-1,890$ & $109-325$ & $15.00-86.00$ & $18.00-80.00$ & & & Rajakumar and Meenambal (2008) \\
\hline AnaP & 60 & - & $4,200-9,100$ & - & $565-785$ & - & $72.20-98.60$ & - & $45.90-63.70$ & Debik and Coskun (2009) \\
\hline AeP-AOP & 0.50 & - & $2,800-3,000$ & $1,400-1,600$ & - & - & $80.30-97.60$ & $70.30-95.70$ & - & De Sena et al. (2009) \\
\hline AnaP & 48 & - & $5,800-6,100$ & - & $530-810$ & - & $80.00-92.00$ & - & - & Gannoun et al. (2009) \\
\hline AnaP & $48-240$ & - & $2,100-2,425$ & - & $250-260$ & - & $88.00-99.00$ & - & $76.00-78.00$ & Kabdaşl et al. (2009) \\
\hline AnaP & 10 & - & $2,373-2,610$ & $900-2,000$ & $78-457$ & - & $96.00-97.00$ & $95.58-97.88$ & $52.00-93.00$ & Kist et al. (2009) \\
\hline AnaP & 42 & - & $7,460-9,300$ & - & $271-317$ & - & 95.00 & - & 97.00 & Lemaire et al. (2009) \\
\hline $\mathrm{AOP}$ & 5 & - & - & - & - & - & $18.00-95.00$ & - & - & Luiz et al. (2009) \\
\hline CC-AdP & 2 & - & 6,605 & 5,703 & - & - & $91.10-96.80$ & $93.50-96.80$ & - & Mahtab et al. (2009) \\
\hline $\mathrm{AeP}$ & 29 & - & 9,040 & 5,242 & - & - & 89.03 & 89.73 & - & Pabón and Gélvez (2009) \\
\hline CC-AeP & 0.33 & - & $2,000-3,000$ & - & $100-200$ & - & 80.00 & - & 90.00 & Wang et al. (2009) \\
\hline $\mathrm{AeP}$ & 104 & - & $2,800-3,500$ & - & $220-350$ & - & $98.00-99.00$ & - & $91.00-95.00$ & Zhan et al. (2009) \\
\hline AeP & - & - & 24,000 & 1,198 & 139 & - & 90.00 & - & - & Al-Mutairi (2010) \\
\hline AnaP-AeP-CC & $16-72-$ & - & $6,363-11,000$ & $5,143-8,360$ & $46.6-138$ & - & $50.10-97.42$ & $97.76-98.92$ & $73.48-92.72$ & López-López et al. (2010) \\
\hline AnaP & $30-97$ & - & $8,450-41,900$ & 21,000 & - & - & $18.60-56.90$ & - & - & Marcos et al. (2010) \\
\hline UF & - & - & $3,610-4,180$ & $1,900-2,200$ & - & - & $94.52-94.74$ & 97.80-97.89 & - & Yordanov (2010) \\
\hline EC & 1.2 & - & 2,171 & 1,123 & - & - & $75.00-90.00$ & - & - & Bayar et al. (2011) \\
\hline AnaP-AOP & $76-91$ & $80-950$ & $2,110-2,305$ & $1,020-1,143$ & $80-334$ & $89.90-95.00$ & 97.70 & 96.60 & $1.00-6.00$ & Cao and Mehrvar (2011) \\
\hline AnaP-AeP-UV & 12 & - & $23-70$ & $0.0-5.0$ & $2.0-21$ & 85.00 & - & - & 79.00 & De Nardi et al. (2011) \\
\hline AnaP-AeP & 16 & - & $876-1,987$ & 12,000 & $84-409$ & - & $90.60-97.60$ & - & $81.50-95.60$ & Fongsatitkul et al. (2011) \\
\hline
\end{tabular}




\begin{tabular}{|c|c|c|c|c|c|c|c|c|c|c|}
\hline Processes $^{1}$ & $\begin{array}{l}\text { HRT }^{2} \\
\text { (h) }\end{array}$ & $\begin{array}{l}\mathrm{TOC}_{\text {in }}{ }^{3} \\
(\mathrm{mg} / \mathrm{L})\end{array}$ & $\begin{array}{l}\mathrm{COD}_{\text {in }}{ }^{3} \\
(\mathrm{mg} / \mathrm{L})\end{array}$ & $\begin{array}{l}\mathbf{B O D}^{3}{ }^{3} \\
(\mathrm{mg} / \mathrm{L})\end{array}$ & $\begin{array}{l}\mathbf{T N}_{\mathrm{in}}{ }^{3} \\
(\mathrm{mg} / \mathrm{L})\end{array}$ & $\begin{array}{l}\text { TOC } \\
\text { removal (\%) }\end{array}$ & $\begin{array}{l}\text { COD } \\
\text { removal (\%) }\end{array}$ & $\begin{array}{l}\text { BOD } \\
\text { removal (\%) }\end{array}$ & $\begin{array}{l}\mathrm{TN} \\
\text { removal (\%) }\end{array}$ & Reference \\
\hline UF & $720-1,344$ & $50-328$ & $114-1,033$ & - & $82-127$ & $75.00-96.00$ & $83.00-97.00$ & - & $27.00-44.00$ & Gürel and Büyükgüngör (2011) \\
\hline AeP & - & - & $298-1,115$ & - & - & - & 53.65 & 84.32 & - & Mees et al. (2011) \\
\hline AnaP & $12-48$ & - & 6,500 & 2,900 & - & - & $75.00-83.00$ & - & - & Méndez-Romero et al. (2011) \\
\hline AnaP & - & - & 3,437 & 2,646 & 218 & - & $76-90$ & - & $8.20-10.10$ & Mijalova Nacheva et al. (2011) \\
\hline AnaP & 12 & - & $3,000-4,800$ & $750-1,890$ & $109-325$ & - & $70.00-78.00$ & - & - & Rajakumar et al. (2011) \\
\hline $\mathrm{EC}$ & 0.83 & - & - & - & - & & $62.00-93.00$ & $66.00-97.00$ & $56.00-84.00$ & Ahmadian et al. (2012) \\
\hline AOP & 2.5 & 1,000 & - & - & - & 57.60 & - & - & - & Barrera et al. (2012) \\
\hline $\mathrm{EC}-\mathrm{CC}$ & 25 & - & $4159-5817$ & $2204-2543$ & $92-137$ & - & $80-98$ & $75-93$ & $75-80$ & Bazrafshan et al. (2012) \\
\hline $\mathrm{AeP}$ & $12-20$ & - & 5,220 & - & 4,500 & - & - & - & - & Dallago et al. (2012) \\
\hline AeP-UF & 48 & - & $1,764-2,244$ & $1,529-1,705$ & $435-665$ & 91.00 & 98.00 & - & - & Keskes et al. (2012) \\
\hline AnaP & $20-96$ & - & $5,659-9,238$ & $5,571-6,288$ & - & - & $92.10-96.60$ & $98.00-98.78$ & - & Park et al. (2012) \\
\hline $\mathrm{CC}$ & 3.0 & - & 6,970 & 5,820 & - & - & $85.46-92.00$ & 85.40 & - & Tarig et al. (2012) \\
\hline AnaP & $8.0-24$ & - & $3,000-4,800$ & $750-1,890$ & - & - & $70.00-86.00$ & - & - & Rajakumar et al. (2012) \\
\hline AnaP & $794-3,948$ & - & 70,673 & - & - & - & $54.00-98.00$ & - & - & Affes et al. (2013) \\
\hline AnaP-AeP & 24 & - & 418 & 117 & 169 & - & 95.00 & - & 76.00 & Barana et al. (2013) \\
\hline AnaP-AeP-AOP & $75-168$ & $941-1,009$ & - & $630-650$ & $254-428$ & $89.50-99.90$ & - & 99.70 & $76.40-81.60$ & Bustillo-Lecompte et al. (2013) \\
\hline $\mathrm{AeP}$ & 240 & 0.10 & 150 & - & - & - & $68.00-77.00$ & - & - & Carvalho et al. (2013) \\
\hline $\mathrm{AeP}$ & 1.0 & - & 18,200 & 10,500 & - & - & $81.31-93.08$ & - & - & Hossaini et al. (2013) \\
\hline AeP & 48 & $1,152-1,312$ & $2,052-2,296$ & $1,529-1,705$ & $435-665$ & - & 89 & - & - & Keskes et al. (2013) \\
\hline $\mathrm{AeP}$ & 23 & - & $5,590-11,750$ & $3,450-4,365$ & $214-256$ & - & $74-94$ & - & - & Louvet et al. (2013) \\
\hline AnaP & $39-72$ & - & $1,040-24,200$ & - & $296-690$ & - & 30 & - & - & McCabe et al. (2013) \\
\hline AnaP & 172 & - & $1,790-4,760$ & $834-3,186$ & $90-196$ & - & $79.00-89.00$ & $84.00-94.00$ & - & Nery et al. (2013) \\
\hline $\mathrm{CW}$ & - & - & $293-3,141$ & $79-87$ & $52-64$ & - & $28.28-75.03$ & $9.27-71.40$ & $5.20-25.40$ & Odong et al. (2013) \\
\hline AnaP & $24-36$ & - & $2,273-20,073$ & - & $570-1,603$ & - & $51.00-72.00$ & - & $3.50-21.60$ & Siqueira et al. (2013) \\
\hline EC & 1.0 & - & 2,171 & 1,123 & 148 & - & $69.00-83.00$ & - & $-\quad 00000$ & Bayar et al. (2014) \\
\hline AnaP-AeP-AOP & $41-76$ & $100-1,200$ & - & $610-4,635$ & $50-841$ & $75.22-99.98$ & - & - & - & Bustillo-Lecompte et al. (2014) \\
\hline $\mathrm{EC}$ & 1.5 & - & 840 & - & - & - & 90.00 & - & - & Eryuruk et al. (2014) \\
\hline EC & - & - & - & - & - & - & $55.00-60.00$ & - & - & Hernández-Ramírez et al. (2014) \\
\hline AeP & $3.0-96$ & - & $6,185-6,840$ & - & $1,950-3,400$ & - & $9.42-80.11$ & - & $8.81-93.22$ & Kundu et al. (2014) \\
\hline AeP-AnaP & 888 & - & $1,400-2,500$ & - & $200-250$ & - & $30.20-98.68$ & - & $22.40-96.16$ & Li et al. (2014) \\
\hline AnaP & 24 & - & $49-137$ & $30-76$ & $6.1-27$ & - & 13.90 & 11.30 & $42.30-77.20$ & Manh et al. (2014) \\
\hline AnaP & $46-72$ & - & $12,000-15,800$ & - & - & - & 60.00 & - & - & Martinez et al. (2014) \\
\hline AnaP & $48-72$ & - & $1,014-12,100$ & $1,410-7,020$ & - & - & 83.62 & 94.23 & - & McCabe et al. (2014) \\
\hline AOP & $0.04-1.0$ & - & $3,337-4,150$ & $1,950-2,640$ & - & - & $76.70-90.70$ & - & - & Ozyonar and Karagozoglu (2014) \\
\hline $\mathrm{AeP}$ & $12-3,360$ & 1,435 & $6,057-6,193$ & $4,214-4,240$ & $547-576$ & - & $97.80-98.20$ & - & 97.70 & Pan et al. (2014) \\
\hline $\mathrm{AeP}$ & $12-16$ & - & $356-384$ & - & $143-175$ & - & - & - & $80.76-91.09$ & Mees et al. (2014) \\
\hline AnaP & $24-480$ & - & 88 & - & - & - & $67.00-80.00$ & - & 90.00 & Stets et al. (2014) \\
\hline AnaP & 2,640 & - & 18,600 & - & 5,200 & - & - & - & $28.00-65.80$ & Yoon et al. (2014) \\
\hline MF & - & 183 & 480 & - & 115 & 44.81 & 90.63 & - & 45.22 & Almandoz et al. (2015) \\
\hline
\end{tabular}

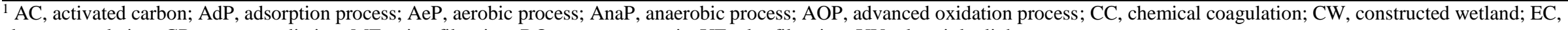
electrocoagulation; GR, gamma radiation; MF, microfiltration; RO, reverse osmosis; UF, ultrafiltration; UV, ultraviolet light.

${ }^{2}$ HRT, Hydraulic retention time.

${ }^{3} \mathrm{TOC}_{\text {in }} ; \mathrm{COD}_{\text {in }}$; BOD in; $\mathrm{TN}_{\text {in }}$, influent concentration of total organic carbon, chemical oxygen demand, biochemical oxygen demand, and total nitrogen, respectively. 


\title{
CHAPTER 4
}

\section{COST-EFFECTIVENESS ANALYSIS OF TOC REMOVAL}

FROM SLAUGHTERHOUSE WASTEWATER

\section{using Combined Anaerobic-Aerobic and UV/H2 $\mathbf{H}_{2}$ Processes*}

\begin{abstract}
The objective of this study is to evaluate the operating costs of treating slaughterhouse wastewater (SWW) using combined biological and advanced oxidation processes (AOPs). This study compares the performance and the treatment capability of an anaerobic baffled reactor (ABR), an aerated completely mixed activated sludge reactor (AS), and a $\mathrm{UV} / \mathrm{H}_{2} \mathrm{O}_{2}$ process, as well as their combination for the removal of the total organic carbon (TOC). Overall efficiencies are found to be up to $75.22,89.47$, 94.53, 96.10, 96.36, and 99.98\% for the $\mathrm{UV} / \mathrm{H}_{2} \mathrm{O}_{2}, \mathrm{ABR}$, AS, combined AS-ABR, combined ABR-AS, and combined $\mathrm{ABR}-\mathrm{AS}-\mathrm{UV} / \mathrm{H}_{2} \mathrm{O}_{2}$ processes, respectively. Due to the consumption of electrical energy and reagents, operating costs are calculated at optimal conditions of each process. A cost-effectiveness analysis (CEA) is performed at optimal conditions for the SWW treatment by optimizing the total electricity cost, $\mathrm{H}_{2} \mathrm{O}_{2}$ consumption, and hydraulic retention time (HRT). The combined ABR-AS$\mathrm{UV} / \mathrm{H}_{2} \mathrm{O}_{2}$ processes have an optimal TOC removal of $92.46 \%$ at an HRT of $41 \mathrm{~h}$, a cost of $\$ 1.25 / \mathrm{kg}$ of TOC removed, and $\$ 11.60 / \mathrm{m}^{3}$ of treated SWW. This process reaches a maximum TOC removal of $99 \%$ in $76.5 \mathrm{~h}$ with an estimated cost of $\$ 2.19 / \mathrm{kg}$ TOC removal and $\$ 21.65 / \mathrm{m}^{3}$ treated $\mathrm{SWW}$, equivalent to $\$ 6.79 / \mathrm{m}^{3}$ day.
\end{abstract}

Keywords: Cost-effectiveness analysis (CEA), slaughterhouse wastewater (SWW), activated sludge (AS), advanced oxidation processes (AOPs), $\mathrm{UV} / \mathrm{H}_{2} \mathrm{O}_{2}$, TOC.

\footnotetext{
* Reprinted, with minor editorial changes to fulfill formatting requirements, from:

C. Bustillo-Lecompte, M. Mehrvar, and E. Quiñones-Bolaños (2014) Cost-Effectiveness Analysis of TOC Removal from Slaughterhouse Wastewater using Combined Anaerobic-Aerobic and $\mathrm{UV} / \mathrm{H}_{2} \mathrm{O}_{2}$ Processes. Journal of Environmental Management 134, pp. 145-152. With permission from Elsevier.
}

License Number 3830951278377. DOI: 10.1016/j.jenvman.2013.12.035. 


\subsection{Introduction}

Slaughterhouse wastewater (SWW) is considered detrimental worldwide due to its composition, characterized mostly by a complex mixture of fats, proteins, and fibers (Johns, 1995; Muñoz, 2005). Wastewaters from slaughterhouses and meat processing plants (MPPs) have been considered as an industrial wastewater in the category of agricultural and food industries (Seif and Moursy, 2001). It has been classified as one of the most harmful wastewaters to the environment by the United States Environmental Protection Agency (US EPA, 2004). The effluent discharge from slaughterhouses causes deoxygenation of rivers (Quinn and McFarlane, 1989) and contamination of groundwater (Massé and Masse, 2000a).

The organic matter concentration in SWW is usually high and the residues are moderately solubilized, leading to a highly polluting effect (Ruiz et al., 1997). They usually contain high levels of organics, pathogenic and non-pathogenic viruses and bacteria, and detergents and disinfectants used for cleaning activities (Debik and Coskun, 2009). High concentrations of biochemical oxygen demand (BOD), chemical oxygen demand (COD), total organic carbon (TOC), total nitrogen (TN), and total suspended solids (TSS) in SWW containing flesh and blood have been reported to be 4635, 15900, 1200, 841, and $2800 \mathrm{mg} / \mathrm{L}$ or more, respectively (Tritt and Schuchardt, 1992; Massé and Masse, 2000b). Several studies have described the common characteristics of SWW (Gariepy et al., 1989; Seif and Moursy, 2001; Cao and Mehrvar, 2011; Wu and Mittal, 2011; Barrera et al., 2012; Bustillo-Lecompte et al., 2013). These characteristics are summarized in Table 4.1, in which their common ranges and averages of COD, TOC, BOD, TSS, TN, and pH for SWW are presented.

Table 4.1. Common characteristics of slaughterhouse wastewater.

Reprinted from J. Environ. Manage. 134 (2014) 145-152, with permission from Elsevier.

\begin{tabular}{lll}
\hline Parameter & Range & Average \\
\hline TOC (mg/L) & $100-1,200$ & 546 \\
BOD (mg/L) & $610-4,635$ & 1,209 \\
COD (mg/L) & $1250-15,900$ & 4,221 \\
TN (mg/L) & $50-841$ & 427 \\
TSS (mg/L) & $300-2,800$ & 1,164 \\
pH & $4.90-8.10$ & 6.95 \\
\hline
\end{tabular}


Commonly, research on wastewater treatment includes the study of different contaminants, the effects of operating variables, and the efficiency of the processes. Nevertheless, there are limited studies on the economic information and analysis, reaction mechanisms, and kinetic modeling that may help to estimate the costs of different technologies for scale-up and industrial applications (Durán et al., 2012; Benedetti et al., 2013; Ghafoori et al., 2012, 2013, 2014a). The operational costs considered in the cost-effectiveness analysis (CEA) are those related to the electrical energy consumption, the chemical consumption, and the replacement of UV lamps.

The objectives of this study are to evaluate the effectiveness and performance of the ABR, AS, and $\mathrm{UV} / \mathrm{H}_{2} \mathrm{O}_{2}$ processes, as well as their combination for the treatment of SWW using a CEA in order to determine the best and optimal alternative method of treatment by evaluating the total electricity cost, the effects of the HRT, the cost of $\mathrm{H}_{2} \mathrm{O}_{2}$ consumption, and the removal percentage of TOC. The results obtained from this study help to extend the information on combined biological and advanced oxidation processes, their performance, and effectiveness on removing organic contaminants from SWW.

\subsection{Experimental methods and procedures}

Six different systems for the treatment of SWW were evaluated in this study, including $\mathrm{UV} / \mathrm{H}_{2} \mathrm{O}_{2}$, AS, ABR, combined ABR-AS, combined AS-ABR, and combined ABR-AS-UV/ $\mathrm{H}_{2} \mathrm{O}_{2}$ processes. The performance of these systems was analyzed in the previous study through the measurements of the removal efficiencies of TOC (Bustillo-Lecompte et al., 2013).

A summary of different processes compared in this study is shown in Table 4.2. This table also includes a short description of installations and optimal operating conditions. A CEA was used to determine the best alternative for SWW treatment from six different systems evaluated in this economic study including $\mathrm{UV} / \mathrm{H}_{2} \mathrm{O}_{2}$, AS, ABR, combined ABR-AS, combined AS-ABR, and combined ABRAS-UV/ $\mathrm{H}_{2} \mathrm{O}_{2}$ processes. The economic analysis was carried out by analyzing the removal of TOC in

the SWW since the degradation rate with respect to TOC is directly proportional to the rate of electricity used (Bolton et al., 2001). According to APHA (1998), the TOC analysis may be more suitable for determining organic matter content since it takes into account all of its different oxidation states. Moreover, TOC analysis provides a more accurate appraisal of the total organic compounds present in a water/wastewater sample in comparison to BOD or COD, without producing any toxic analytical 
waste (Dubber and Gray, 2010). The TOC can be quantified by measuring the $\mathrm{CO}_{2}$ generated when the organic compounds are oxidized. Thus, TOC analysis excludes the inorganic carbon compounds in order to obtain more accurate results of the organic contamination in source water.

Table 4.2. Technical conditions for the biological systems and AOPs.

Reprinted from J. Environ. Manage. 134 (2014) 145-152, with permission from Elsevier.

\begin{tabular}{lccccc}
\hline Process & $\begin{array}{c}\text { Volume } \\
(\mathbf{L})\end{array}$ & $\begin{array}{c}\text { No. of } \\
\text { Pumps }\end{array}$ & $\begin{array}{c}\text { HRT } \\
(\mathbf{h})\end{array}$ & $\begin{array}{c}\mathbf{H}_{2} \mathbf{O}_{2} \text { consumed } \\
(\mathbf{L})\end{array}$ & $\begin{array}{c}\text { TOC removal } \\
(\boldsymbol{\%})\end{array}$ \\
\hline $\mathrm{UV} / \mathrm{H}_{2} \mathrm{O}_{2}$ & 1.35 & 1 & 3 & 0.094 & $75.22 \%$ \\
$\mathrm{ABR}$ & 33.7 & 1 & 168 & $\mathrm{n} / \mathrm{a}$ & $89.47 \%$ \\
$\mathrm{AS}$ & 12 & 1 & 168 & $\mathrm{n} / \mathrm{a}$ & $94.53 \%$ \\
$\mathrm{AS}-\mathrm{ABR}$ & 45.7 & 2 & 150 & $\mathrm{n} / \mathrm{a}$ & $96.10 \%$ \\
$\mathrm{ABR}-\mathrm{AS}$ & 45.7 & 2 & 150 & $\mathrm{n} / \mathrm{a}$ & $96.36 \%$ \\
$\mathrm{ABR}-\mathrm{AS}-\mathrm{UV} / \mathrm{H}_{2} \mathrm{O}_{2}$ & 47.05 & 3 & 96 & 0.2814 & $99.98 \%$ \\
\hline
\end{tabular}

The total cost of each wastewater system was calculated by adding the operating and maintenance $(\mathrm{O} \& \mathrm{M})$ costs as well as the power consumption for each process. The O\&M consisted of the part replacement, chemical, and electrical costs. Consistent with Bolton et al. (2001), costs related to installation and commissioning were not considered in this analysis because the industry and potential users will be able to have a standardized procedural basis for comparison. For UV systems, the operation and maintenance costs include changing lamps every $3000 \mathrm{~h}$ of service and chemical costs of $2.50 \$ / \mathrm{L}$ for consumables such as $\mathrm{H}_{2} \mathrm{O}_{2}$. The rates of $\mathrm{H}_{2} \mathrm{O}_{2}$ and electrical consumptions for different devices used for calculating the costs are shown in Table 4.3 with a common TOC concentration in the SWW influent of $1000 \mathrm{mg} / \mathrm{L}$. According to the Ontario Energy Board (OEB, 2013), the market price of electricity based on tiered prices in August 2013 was $0.091 \$ / \mathrm{kWh}$. The power consumption was calculated for each process based upon the power consumed in a year multiplied by the electricity rate as follows (Bolton et al., 2001):

$$
J=E_{r}\left(\frac{1000 P t}{V\left(S_{i b}-S_{f}\right)}\right)
$$


where,

$$
\begin{aligned}
& E_{r}=\text { energy rate }(\$ / \mathrm{kWh}) \\
& J=\text { electricity cost }(\$ / \mathrm{kg}) \\
& P=\text { power rating of system }(\mathrm{kW}) \\
& S_{\text {in }}=\text { concentration of limiting substrate in influent }(\mathrm{mg} / \mathrm{L}) \\
& S_{f}=\text { concentration of limiting substrate in effluent }(\mathrm{mg} / \mathrm{L}) \\
& t=\text { hydraulic retention time }(\mathrm{h}) \\
& V=\text { total reactor volume }(\mathrm{L})
\end{aligned}
$$

\begin{tabular}{|c|c|}
\hline Item & Electric Power $(\mathbf{k W})$ \\
\hline \multicolumn{2}{|l|}{$\mathrm{UV} / \mathrm{H}_{2} \mathrm{O}_{2}$} \\
\hline Lamp & 0.125 \\
\hline Pump & 0.08 \\
\hline Mini-pump for $\mathrm{H}_{2} \mathrm{O}_{2}$ dosage & 0.007 \\
\hline Power Rating & 0.212 \\
\hline \multicolumn{2}{|l|}{$A B R$} \\
\hline Pump & 0.08 \\
\hline Power Rating & 0.08 \\
\hline \multicolumn{2}{|l|}{$A S$} \\
\hline Pump & 0.08 \\
\hline Diffuser & 0.12 \\
\hline Power Rating & 0.2 \\
\hline \multicolumn{2}{|l|}{ Combined ABR-AS } \\
\hline Pumps & 0.16 \\
\hline Diffuser & 0.12 \\
\hline Power Rating & 0.28 \\
\hline \multicolumn{2}{|l|}{ Combined $A S-A B R$} \\
\hline Pumps & 0.16 \\
\hline Diffuser & 0.12 \\
\hline Power Rating & 0.28 \\
\hline \multicolumn{2}{|l|}{ Combined ABR-AS-UV/H $\mathrm{H}_{2} \mathrm{O}_{2}$} \\
\hline Lamp & 0.125 \\
\hline Pumps & 0.24 \\
\hline Diffuser & 0.12 \\
\hline mini-pump for $\mathrm{H}_{2} \mathrm{O}_{2}$ dosage & 0.005 \\
\hline Power Rating & 0.49 \\
\hline
\end{tabular}

Table 4.3. Electric power and costs of electricity and $\mathrm{H}_{2} \mathrm{O}_{2}$.

Reprinted from J. Environ. Manage. 134 (2014) 145-152, with permission from Elsevier.

Note: Energy Cost (Ontario Energy Board 2013: $0.091 \$ / \mathrm{kWh}$ ); $\mathrm{H}_{2} \mathrm{O}_{2}$ Cost $=2.50 \$ / \mathrm{L}$ 


\subsubsection{Degradation kinetics of TOC in ABR}

The kinetic model Equation (4.2) developed by Kennedy and Barriault (2007) describes the limiting substrate concentration driving force within different compartments of an ABR without recycling. Thus, the first order rate constant could be calculated from operational treatment data knowing the limiting substrate concentrations and biomass in each compartment.

$$
S_{i}=\frac{S_{i-1}}{\left(1+k_{i} \mathrm{X}_{i} V_{i} t / V\right)} \quad(\text { for } i \geq 1)
$$

where,

$k_{i}=$ first order rate coefficient of limiting substrate in compartment $i$ of the ABR

$S_{i}=$ concentration of limiting substrate in compartment $i$ of the ABR $(\mathrm{mg} / \mathrm{L})$

$S_{i-1}=$ limiting substrate concentration in compartment $i-1$ of the $\mathrm{ABR},\left(S_{i-1}=S_{\text {in }}\right.$ for $\left.i-1=0\right)$

$V_{i}=$ volume of compartment $i$ in ABR (L)

$\mathrm{X}_{i}=$ biomass concentration of limiting substrate in compartment $i$ of the ABR (mg/L)

\subsubsection{Degradation kinetics of TOC in $A S$}

The kinetic model Equation (4.3) developed by Reynolds and Yang (1966) for the completely mixed activated sludge process is based on growth relationships and material balances on the limiting substrate and biological cell mass. This equation was used to predict the effluent concentrations of TOC in the AS reactor.

$S_{f}=\frac{S_{i n}}{(1+K X t)}$

where,

$K=$ first order rate coefficient of limiting substrate

$X \overline{\mathrm{X}} \overline{\mathrm{X}}=$ biomass concentration of limiting substrate (mg/L)

\subsubsection{Degradation kinetics of $\mathrm{TOC}$ in $\mathrm{UV} / \mathrm{H}_{2} \mathrm{O}_{2}$ process}

According to Bolton et al. (2001), the overall kinetics in terms of the rate of removal of a specific component, including TOC, can often be described by simple rate expressions that are either zero-order 
or first-order. In general, most processes involved in AOPs, such as $\mathrm{UV} / \mathrm{H}_{2} \mathrm{O}_{2}$, can be modeled by the following simple mechanisms:

$$
\begin{array}{ll}
\mathrm{H}_{2} \mathrm{O}_{2} \rightarrow 2^{\bullet} \mathrm{OH} & R_{1}=\xi p / V_{T} \\
\cdot \mathrm{OH}+\text { TOC } \rightarrow \text { products } & R_{2}=k_{T O C}[\cdot \mathrm{OH}][\mathrm{TOC}] \\
\cdot \mathrm{OH}+U_{i} \rightarrow \text { products } & R_{3}=k_{U_{i}}[\cdot \mathrm{OH}]\left[U_{i}\right]
\end{array}
$$

where,

$$
\begin{aligned}
& \xi=\text { constant that depends on the type of AOP }(\mathrm{mg} / \mathrm{h} . \mathrm{W}) \\
& k_{T O C} \text { and } k_{U i}=\text { second-order rate constants }(\mathrm{L} / \mathrm{mg} . \mathrm{h}) \\
& p=\text { power rating for system }(\mathrm{W}) \\
& R_{l}=\text { reaction rate of }{ }^{\circ} \mathrm{OH}(\mathrm{mg} / \mathrm{L} . \mathrm{h}) \\
& R_{2}=\text { reaction rate of }{ }^{\circ} \mathrm{OH} \text { with TOC }(\mathrm{mg} / \mathrm{L} . \mathrm{h}) \\
& R_{3}=\text { reaction rate of }{ }^{\circ} \mathrm{OH} \text { with a scavenger }\left(U_{i}\right)(\mathrm{mg} / \mathrm{L} \cdot \mathrm{h}) \\
& U_{i}=\text { a scavenger for }{ }^{\circ} \mathrm{OH}, \text { where } i=a, b, \ldots, n(\mathrm{mg} / \mathrm{L}) \\
& V_{T}=\text { treated } \mathrm{SWW} \text { volume }(\mathrm{L})
\end{aligned}
$$

A steady-state analysis of this general mechanism yields the overall reaction rate for the $\mathrm{UV} / \mathrm{H}_{2} \mathrm{O}_{2}$ process as shown in Equation (4.7). This simple mechanism is either zero or first-order in TOC. If the concentration of TOC is high $\left(k_{T O C}[T O C]>>\Sigma_{i} k_{U i}\left[U_{i}\right]\right)$, the reaction rate is zero-order in TOC as shown in Equation (4.8). On the other hand, if the concentration of TOC is low ( $k_{T O C}$ [TOC] $\left.<<\Sigma_{i} k_{U i}\left[U_{i}\right]\right)$, the reaction rate is first-order in TOC with observed rate constant $k_{T O C}$ ' as shown in Equation (4.9). According to Bolton et al. (2001), the difference between "high" and "low" concentrations varies considerably with the system but is often approximately $100 \mathrm{mg} / \mathrm{L}$.

$$
\begin{aligned}
& -\frac{d[\text { TOC }]}{d t}=\frac{\xi p k_{T O C}[\text { TOC }] / V_{T}}{k_{T O C}[T O C]+\sum_{i} k_{U_{i}}\left[U_{i}\right]} \\
& -\frac{d[T O C]}{d t}=\frac{\xi p}{V_{T}} \\
& k_{T O C}^{\prime}=\frac{\xi p k_{T O C}}{V_{T} \sum_{i} k_{U_{i}}\left[U_{i}\right]}
\end{aligned}
$$


Therefore, Equation (4.8) was used to predict the effluent TOC concentrations from the $\mathrm{UV} / \mathrm{H}_{2} \mathrm{O}_{2}$ process alone because of the high concentration in the influent (>1000 mg TOC/L). Likewise, due to expected TOC concentrations of less than $100 \mathrm{mg} / \mathrm{L}$, Equation (4.9) was used to predict the effluent concentrations of TOC for the $\mathrm{UV} / \mathrm{H}_{2} \mathrm{O}_{2}$ process as a post-treatment in combined processes.

\subsection{Results and discussion}

Figure 4.1 shows the comparison of six treatment methods in terms of mineralization capacity, measured in grams of TOC removed as a function of operating time. Initial conditions of the experiments included a TOC concentration in the influent of $1000 \mathrm{mg} / \mathrm{L}$ and a flow rate of $5.90 \mathrm{~mL} / \mathrm{min}$. It can be observed that combined $\mathrm{ABR}-\mathrm{AS}-\mathrm{UV} / \mathrm{H}_{2} \mathrm{O}_{2}$ processes were more technically efficient than the other processes because they could remove $15 \%$ more TOC during the same operating time. Still, this apparent advantage must be confirmed in economic terms.

\subsubsection{TOC degradation in $A B R$}

The first order rate constant in each compartment in the ABR was calculated by Equation (4.2). Thus, the mass balances for all five compartments of the ABR are shown in the following equations:

$$
\begin{aligned}
& S_{1}=\frac{S_{i n}}{\left(1+k_{1} \mathrm{X}_{1} V_{1} t / V\right)}=\frac{S_{\text {in }}}{(1+0.1062 t)} \\
& S_{2}=\frac{S_{1}}{\left(1+k_{2} \mathrm{X}_{2} V_{2} t / V\right)}=\frac{S_{1}}{(1+0.0537 t)} \\
& S_{3}=\frac{S_{2}}{\left(1+k_{3} \mathrm{X}_{3} V_{3} t / V\right)}=\frac{S_{2}}{(1+0.0376 t)} \\
& S_{4}=\frac{S_{3}}{\left(1+k_{4} \mathrm{X}_{4} V_{4} t / V\right)}=\frac{S_{3}}{(1+0.0329 t)} \\
& S_{5}=\frac{S_{4}}{\left(1+k_{5} \mathrm{X}_{5} V_{5} t / V\right)}=\frac{S_{4}}{(1+0.2209 t)}
\end{aligned}
$$




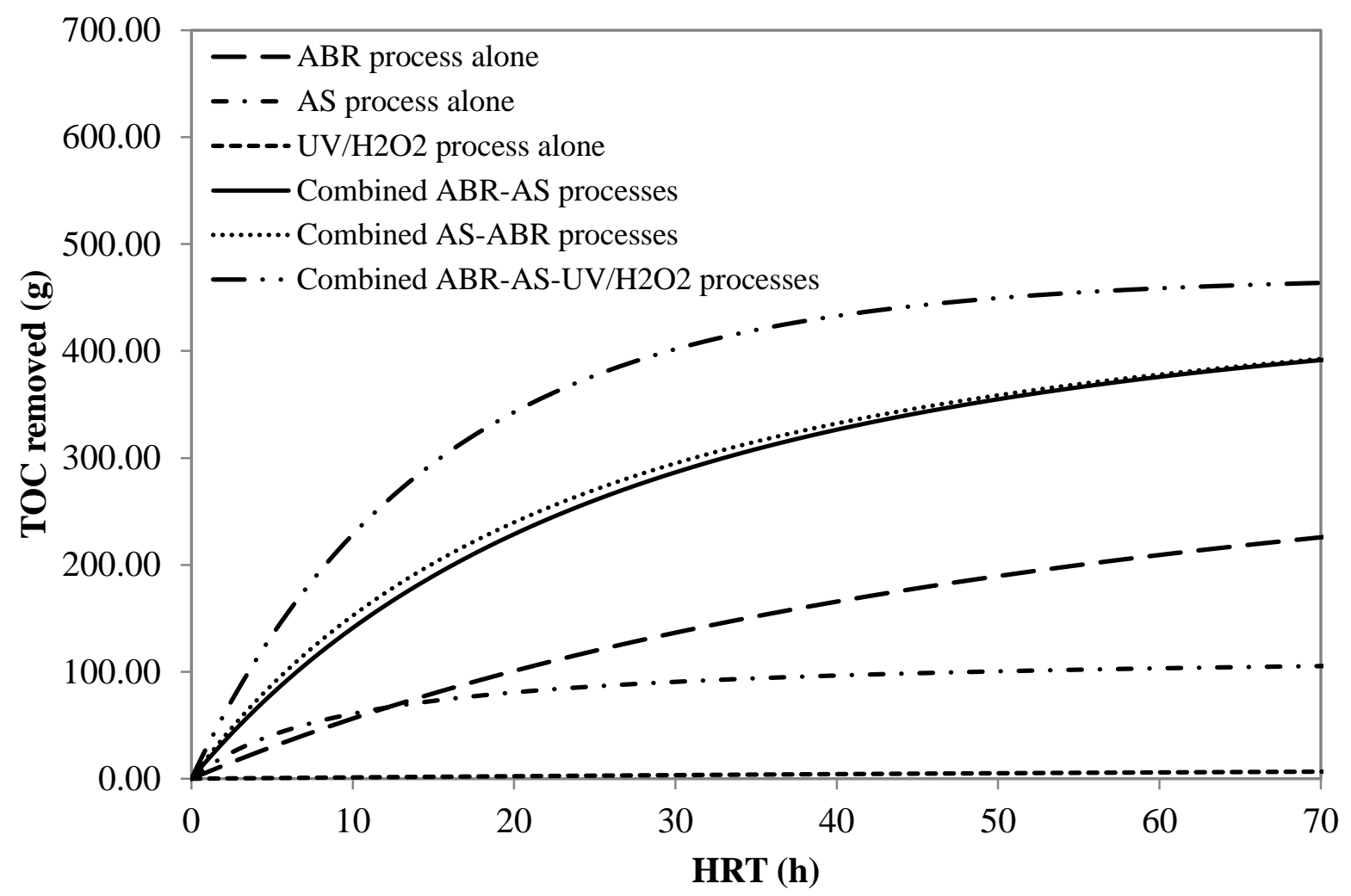

Figure 4.1. Mineralization of SWW in continuous mode without recycling for different processes. $\mathrm{TOC}_{\text {in }}=1000 \mathrm{mg} / \mathrm{L} \cdot \mathrm{Q}=5.90 \mathrm{~mL} / \mathrm{min}$.

Reprinted from J. Environ. Manage. 134 (2014) 145-152, with permission from Elsevier. 
The coefficient in Equation (4.14) is increased compared to the ones in Equations (4.11) to (4.13). This might be due to the high value of $k_{5}$ in compartment 5. Since there is no recycling, $S_{5}=S_{f}$, Equations (4.10) to (4.14) are reduced to Equations (4.15) and (4.16), which were used to predict the effluent TOC concentrations in the ABR, as part of combined processes and as an individual process, respectively.

$$
\begin{aligned}
& S_{f}=\frac{S_{i n}}{\left(1+9 \times 10^{4} k_{1} t / V\right)\left(1+8 \times 10^{4} k_{2} t / V\right)\left(1+1 \times 10^{5} k_{3} t / V\right)\left(1+7 \times 10^{4} k_{4} t / V\right)\left(1+8 \times 10^{4} k_{5} t / V\right)} \\
& S_{f}=\frac{S_{i n}}{(1+0.1062 t)(1+0.0537 t)(1+0.0376 t)(1+0.0329 t)(1+0.2209 t)}
\end{aligned}
$$

The non-linear least square function was used to determine the best-fit criterion, which means two sets of data are the closest to each other. The comparison between predicted values and the experimental data is presented in Figure 4.2a, which shows an agreement between the predicted model values and the experimental data. Therefore, Equation (4.16) could be used to predict the effluent TOC concentration at a specific HRT in the ABR process alone.

\subsubsection{TOC degradation in $A S$}

Equation (4.3) was used to calculate the first order rate constant in the AS reactor. Since there is no recycling, Equation (4.3) is reduced to Equations (4.17) and (4.18), which were used to predict the effluent TOC concentrations in the AS reactor, as part of combined processes and as an individual process, respectively.

$$
\begin{aligned}
& S_{f}=\frac{S_{i n}}{(1+2,399 K t)} \\
& S_{f}=\frac{S_{i n}}{(1+2.4669 t)}
\end{aligned}
$$

The comparison between predicted values and the experimental data is presented in Figure 4.2b, which shows an agreement between the predicted model values and the experimental data. Therefore, Equation (18) could be used to predict the effluent TOC concentration at a specific HRT in the AS process alone. 

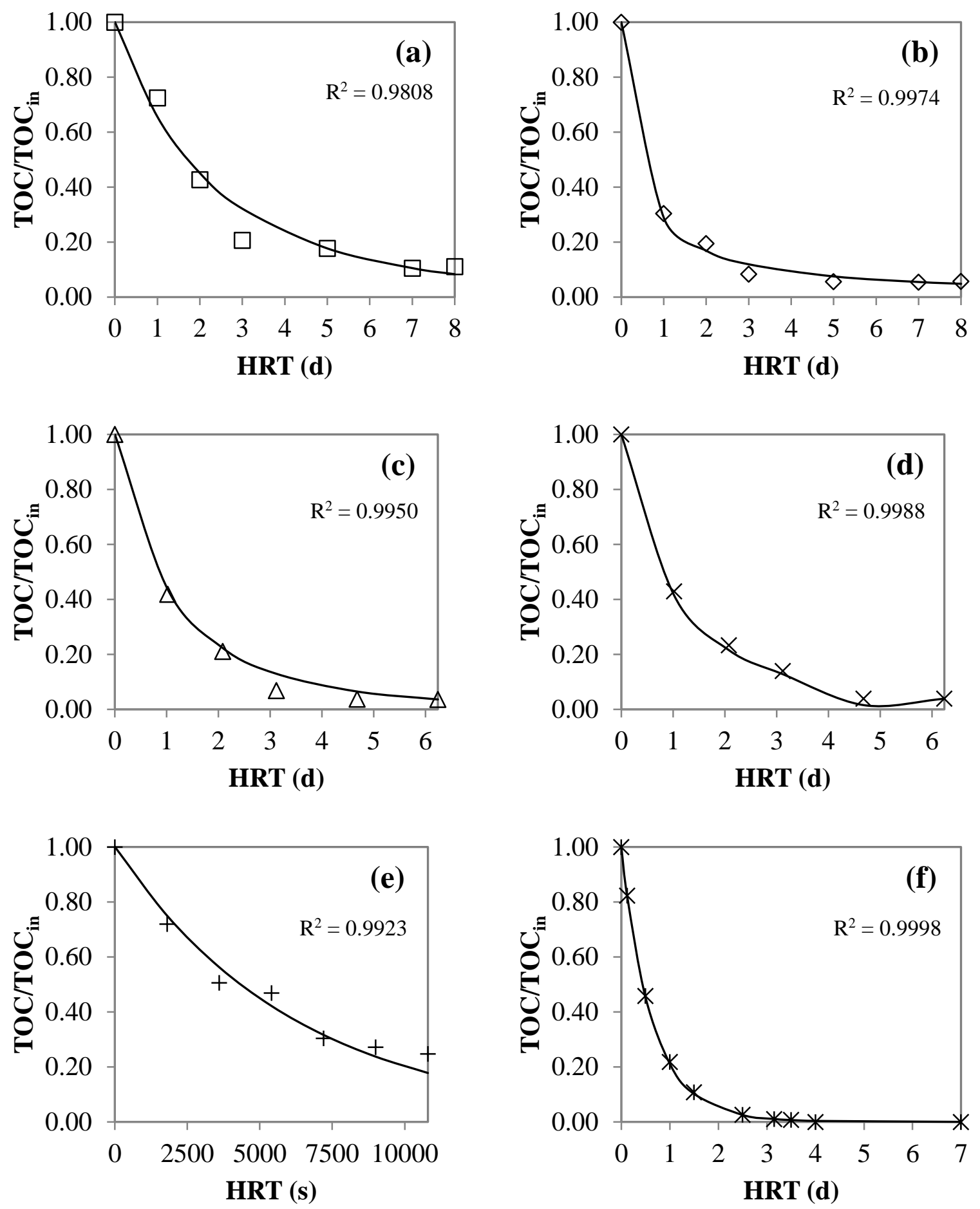

Figure 4.2. Comparison of the TOC/TOC $i n$ predicted values using Equation (4.8) and the experimental data of the SWW treatment in continuous mode without recycling for different processes: (a) ABR, (b) AS, (c) ABR-AS, (d) AS-ABR, (e) UV/H2 $\mathrm{H}_{2}$, and (f) ABR-AS-UV/ $\mathrm{H}_{2} \mathrm{O}_{2}$. The markers are the corresponding experimental data. The lines are the corresponding model predictions. TOC $_{\text {in }}=1000 \mathrm{mg} / \mathrm{L} . \mathrm{Q}=\mathbf{5 . 9 0} \mathrm{mL} / \mathrm{min}$.

Reprinted from J. Environ. Manage. 134 (2014) 145-152, with permission from Elsevier. 


\subsubsection{TOC Degradation in combined anaerobic-aerobic processes}

For the combined biological processes, two equations were developed by combining Equations (4.15) and (4.17) as shown in Equations (4.19) and (4.20). To obtain Equation (4.19) for combined ABR-AS processes, Equation (4.15) is substituted in Equation (4.17) because the effluent of the ABR process is the influent of the AS process. Conversely, to obtain Equation (4.20) for combined AS-ABR processes, Equation (4.17) is substituted into Equation (4.15), because the effluent of the AS process is the influent of the ABR process. Therefore, Equations (4.19) and (4.20) were used to predict the effluent TOC concentrations in the combined ABR-AS processes and the combined AS-ABR processes, respectively.

$$
\begin{aligned}
& S_{f}=\frac{S_{\text {in }}}{(1+0.1895 t)(1+0.0269 t)(1+0.0278 t)(1+0.0168 t)(1+0.1412 t)(1+0.5505 t)} \\
& S_{f}=\frac{S_{\text {in }}}{(1+0.0 .7974 t)(1+0.0185 t)(1+0.0021 t)(1+0.0784 t)(1+0.1053 t)(1+0.0866 t)}
\end{aligned}
$$

The comparison between predicted values and the experimental data for combined ABR-AS and AS-ABR processes are presented in Figure 4.2c and d, respectively. These figures show an agreement between the predicted model values and the experimental data. Therefore, Equations (4.19) and (4.20)

could be used to predict the effluent TOC concentrations at a specific HRT for combined ABR-AS and AS-ABR processes, respectively.

\subsubsection{TOC Degradation in $\mathrm{UV} / \mathrm{H}_{2} \mathrm{O}_{2}$ process}

Equation (4.8) was used to predict the TOC degradation in the $\mathrm{UV} / \mathrm{H}_{2} \mathrm{O}_{2}$ process alone due to a high concentration in the influent of up to $1000 \mathrm{mg}$ TOC/L. Likewise, due to expected TOC concentrations of less than $100 \mathrm{mg} / \mathrm{L}$ after combined anaerobic-aerobic processes, Equation (4.9) was used to predict the TOC degradation in the $\mathrm{UV} / \mathrm{H}_{2} \mathrm{O}_{2}$ process as post-treatment in combined processes. Thus, Equations (4.21) and (4.22) are obtained for individual and combined processes, respectively.

$$
\begin{aligned}
& S_{f}=S_{\text {in }} \times \exp \left(-7.10 \times 10^{-8} t\right) \\
& S_{f}=S_{\text {in }} \times \exp \left(\frac{-8.00 \times 10^{-6} t}{\left[\mathrm{H}_{2} \mathrm{O}_{2}\right]}\right)
\end{aligned}
$$


The comparison between predicted values and the experimental data for the $\mathrm{UV} / \mathrm{H}_{2} \mathrm{O}_{2}$ process alone is presented in Figure 4.2e. This figure shows an agreement between the predicted model values and the experimental data. Therefore, Equation (4.21) could be used to predict the effluent TOC concentration at a specific HRT for the treatment of $\mathrm{SWW}$ by $\mathrm{UV} / \mathrm{H}_{2} \mathrm{O}_{2}$ process alone.

\subsubsection{TOC degradation in combined anaerobic-aerobic and $\mathrm{UV} / \mathrm{H}_{2} \mathrm{O}_{2}$ processes}

For the combined ABR-AS-UV/ $\mathrm{H}_{2} \mathrm{O}_{2}$ processes, Equations (4.15), (4.17) and (4.22) were combined. As a result, Equation (4.23) was used to predict the effluent concentrations of TOC for the combined $\mathrm{ABR}-\mathrm{AS}$ and $\mathrm{UV} / \mathrm{H}_{2} \mathrm{O}_{2}$ processes.

$$
S_{f}=\frac{S_{\text {in }} \exp \left(-0.0393 t /\left[\mathrm{H}_{2} \mathrm{O}_{2}\right]\right)}{(1+0.3027 t)(1+0.1341 t)(1+0.0949 t)(1+0.0465 t)(1+0.0442 t)(1+0.2201 t)}
$$

The comparison between predicted values and the experimental data for the combined ABR-AS$\mathrm{UV} / \mathrm{H}_{2} \mathrm{O}_{2}$ processes is presented in Figure 4.2f. This figure shows an agreement between the predicted model values and the experimental data. Therefore, Equation (4.23) could be used to predict the effluent TOC concentration at a specific HRT for the treatment of SWW using combined ABR-AS-UV/ $\mathrm{H}_{2} \mathrm{O}_{2}$ processes.

\subsubsection{Economic analysis}

The cost of electricity per mass of TOC removed was estimated by Equation (4.1), which was defined for high TOC influent concentration, for each process by using the estimated values of the TOC concentrations in the influent $\left(S_{i n}\right)$ and effluent $\left(S_{f}\right)$ obtained by Equations (4.16), (4.18) to (4.21), and (4.23) for the ABR, AS, combined ABR-AS, combined AS-ABR, UV/ $\mathrm{H}_{2} \mathrm{O}_{2}$, and combined ABR-AS$\mathrm{UV} / \mathrm{H}_{2} \mathrm{O}_{2}$ processes, respectively.

Figure 4.3 shows the operational costs per kilogram of TOC removed, including optimization of HRT and $\mathrm{H}_{2} \mathrm{O}_{2}$ consumption for six processes as a function of the percentage of TOC removed. The $\mathrm{UV} / \mathrm{H}_{2} \mathrm{O}_{2}$ alone is the least efficient technology with an optimum removal of $49.88 \%$ at a high cost of $67.06 \$ / \mathrm{kg}$ of TOC removed. 

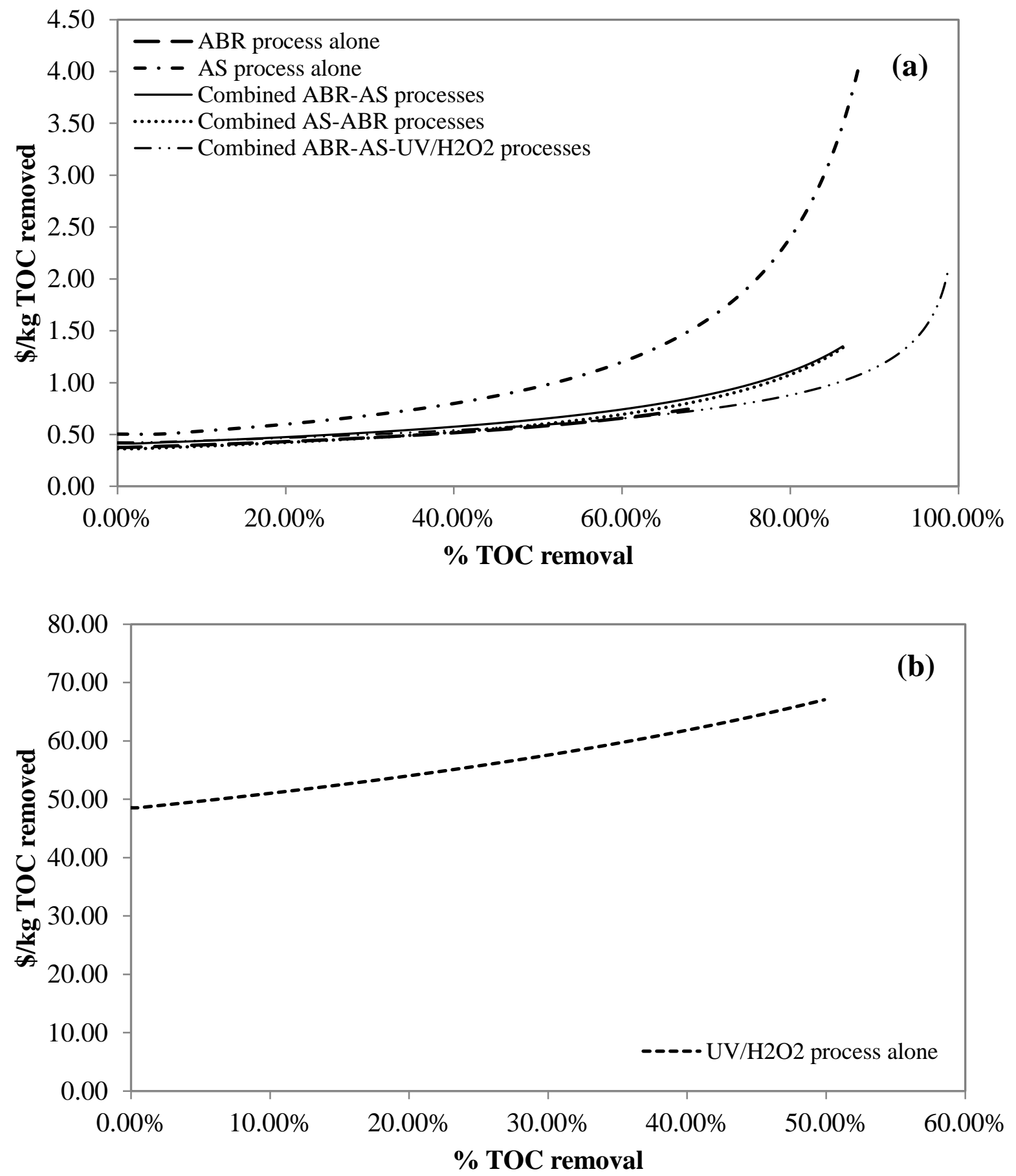

Figure 4.3. Operation costs per kilogram of TOC removed for each process: (a) ABR process alone, AS process alone, combined ABR-AS processes, combined AS-ABR processes, and ABRAS-UV/ $/ \mathrm{H}_{2} \mathrm{O}_{2}$ processes; (b) $\mathrm{UV} / \mathrm{H}_{2} \mathrm{O}_{2}$ process alone, as a function of $\mathrm{TOC}$ removal in continuous mode without recycling. TOC $_{\text {in }}=1000 \mathrm{mg} / \mathrm{L} . Q=5.90 \mathrm{~mL} / \mathrm{min}$.

Reprinted from J. Environ. Manage. 134 (2014) 145-152, with permission from Elsevier. 
The TOC removal does not significantly increase by augmenting the HRT (Figure 4.3b). In contrast, it was observed that the AS is an efficient process with an optimum TOC removal of $88.10 \%$ at a cost of $4.03 \$ / \mathrm{kg}$ of TOC removed (Figure $4.3 \mathrm{a}$ ).

The absolute operational costs (\$) compared to the percentage of TOC removed is shown in Figure 4.4. Two important facts should be noted, the costs increase with the amount of TOC removed for all six processes, especially when high TOC removal rates are achieved; and also, if low or intermediate amounts of TOC are to be removed, combined processes and individual processes are comparable in economic terms.

Finally, Figure 4.5 summarizes the operational costs for six processes in terms of $\$ / \mathrm{m}^{3}$ of treated wastewater, which is a useful measurement from an industrial viewpoint. It is confirmed that costs $\left(\$ / \mathrm{m}^{3}\right)$ increase dramatically with the TOC removal because of the electricity consumption in the $\mathrm{UV} / \mathrm{H}_{2} \mathrm{O}_{2}$ process alone, reaching values ten times higher than those of the processes that use biological treatment. Thus, in the combined processes, the main costs are initially for pumps, reagents, and air injection. However, when the removal rate of TOC is greater than $60 \%$, the electricity costs gradually increase. Therefore, the technology to produce biogas can be added to traditional anaerobic wastewater treatment systems, which can be used as an on-site renewable source of energy (Siqueira et al., 2013). Thus, cost savings could be expected for MPPs because energy costs may be offset by the production of on-site power from anaerobic wastewater treatment (González-González et al., 2013).

\subsection{Conclusions}

A CEA was used to determine the best alternative for SWW treatment from six different systems evaluated in this economic study, including $\mathrm{UV} / \mathrm{H}_{2} \mathrm{O}_{2}, \mathrm{AS}, \mathrm{ABR}, \mathrm{ABR}-\mathrm{AS}, \mathrm{AS}-\mathrm{ABR}$, and ABR-AS$\mathrm{UV} / \mathrm{H}_{2} \mathrm{O}_{2}$ processes. Thus, HRT was optimized since HRT affects the final removal efficiency of organic pollutants in wastewater and the operating costs of the system. The combined ABR-AS$\mathrm{UV} / \mathrm{H}_{2} \mathrm{O}_{2}$ processes were more technically efficient than other processes, removing $15 \%$ more TOC during the same amount of operating time. The $\mathrm{UV} / \mathrm{H}_{2} \mathrm{O}_{2}$ process alone is the least efficient technology with an optimum removal of $49.88 \%$ at a high cost of $67.06 \$ / \mathrm{kg}$ of TOC removed. If low or intermediate amounts of TOC are to be removed, combined and individual processes are comparable in economic terms. 


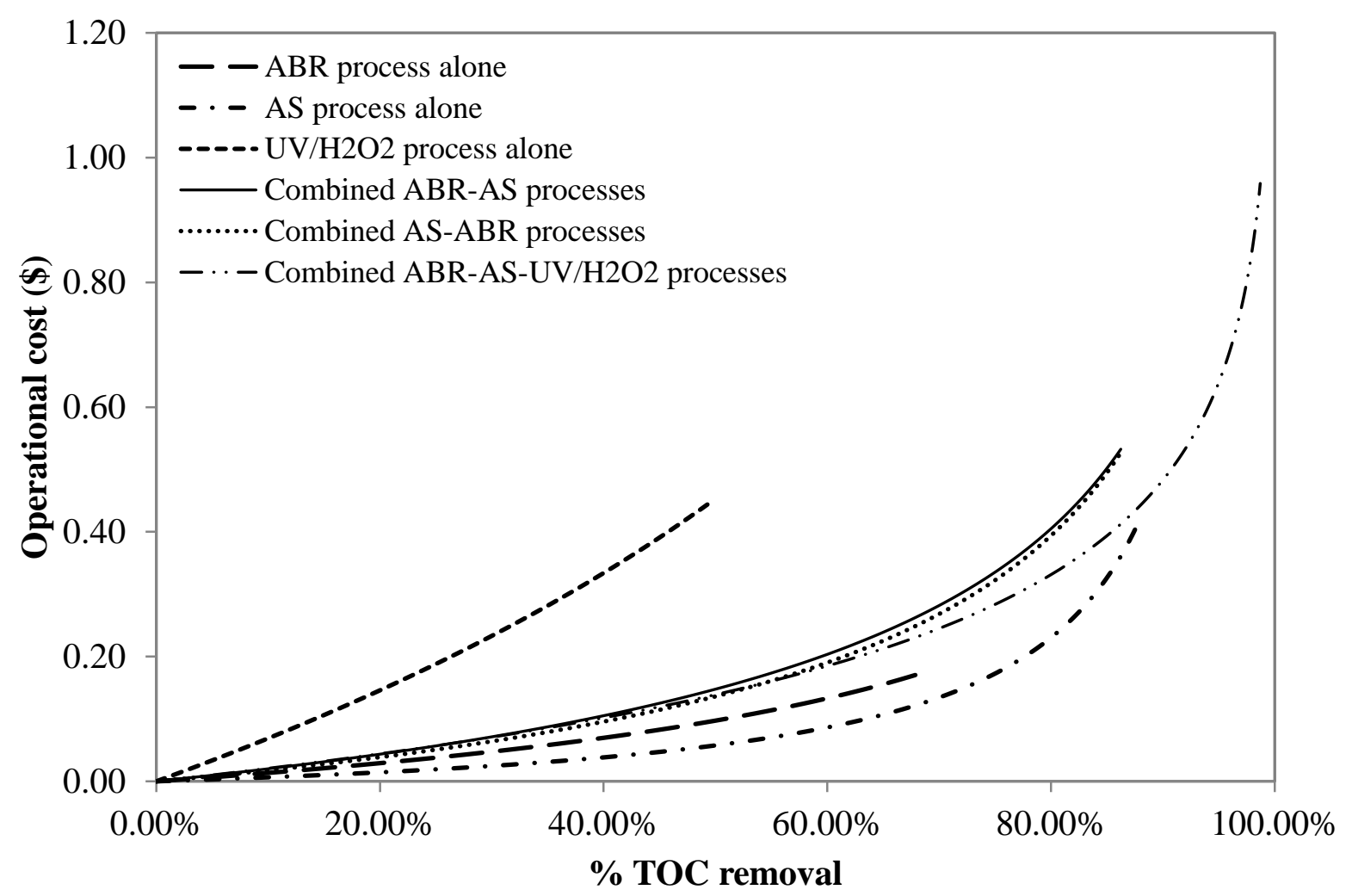

Figure 4.4. Absolute operation costs compared with percentage of TOC removal for different processes in continuous mode without recycling. $\mathrm{TOC}_{\text {in }}=1000 \mathrm{mg} / \mathrm{L} . \mathrm{Q}=5.90 \mathrm{~mL} / \mathrm{min}$.

Reprinted from J. Environ. Manage. 134 (2014) 145-152, with permission from Elsevier. 

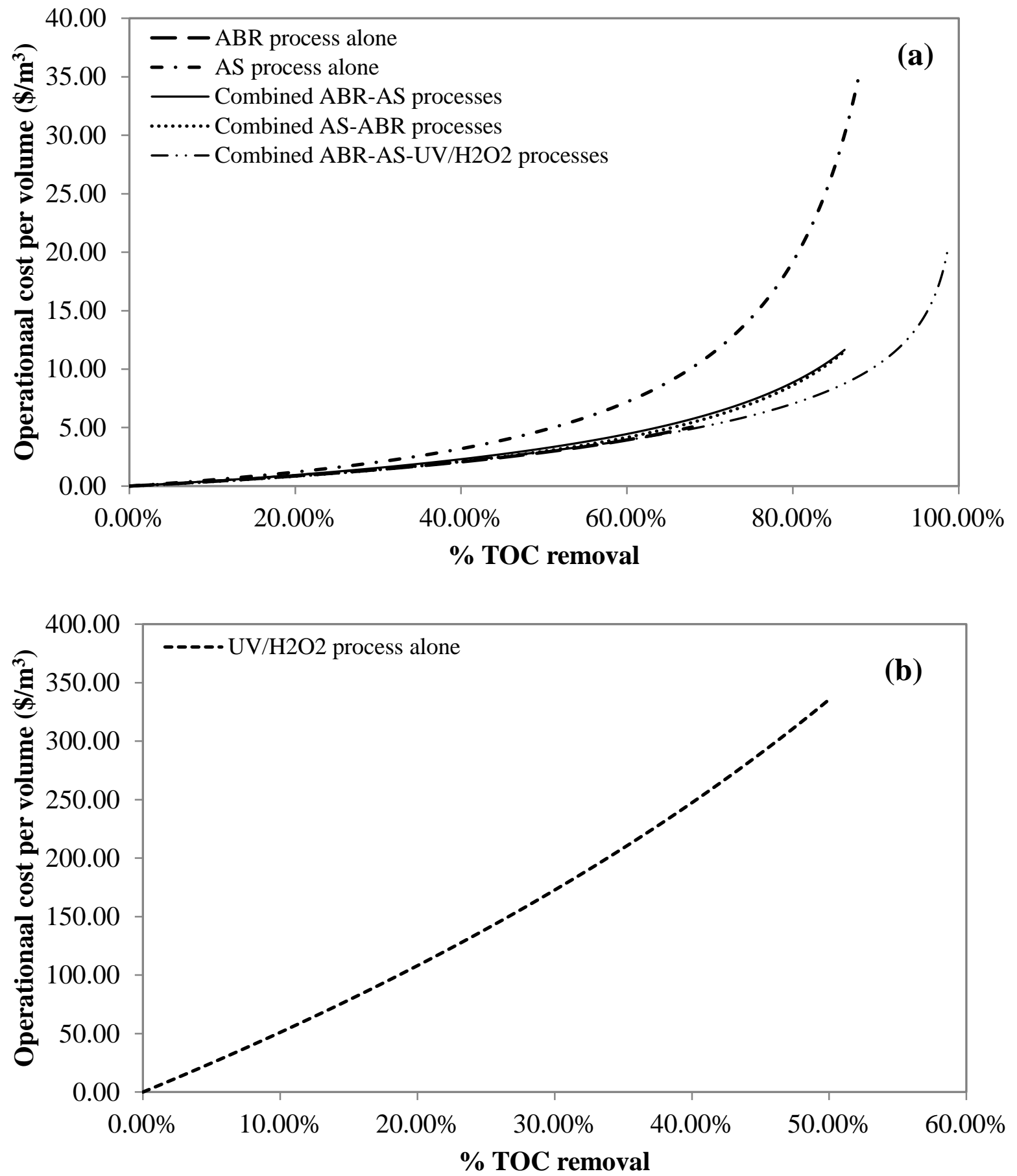

Figure 4.5. Operational costs per $\mathrm{m}^{3}$ of treated water compared with mineralization degree: comparison between the (a) ABR process alone, AS process alone, combined ABR-AS processes, combined AS-ABR processes, combined ABR-AS-UV/H2 $\mathrm{H}_{2} \mathrm{O}_{2}$ processes, and (b) $\mathrm{UV} / \mathrm{H}_{2} \mathrm{O}_{2}$ process alone in continuous mode without recycling. $T O C_{o}=1000 \mathrm{mg} / \mathrm{L} . Q=5.90 \mathrm{~mL} / \mathrm{min}$.

Reprinted from J. Environ. Manage. 134 (2014) 145-152, with permission from Elsevier. 
In combined processes, the main costs are initially for pumps, reagents, and air injection. Only when the TOC removal is higher than $60 \%$, the electricity costs increase. Finally, it was determined that the optimum system for the TOC removal was ABR-AS-UV/ $\mathrm{H}_{2} \mathrm{O}_{2}$, with an optimal TOC removal of $92.46 \%$ at an HRT of $41 \mathrm{~h}$, at a cost of $1.25 \$ / \mathrm{kg}$ of TOC removed and $\$ 11.60 / \mathrm{m}^{3}$ of treated SWW. It should be noted that this process reaches a TOC removal of $99 \%$ at a HRT of $76.5 \mathrm{~h}$ (3.19 days) with an estimated operational cost of $2.19 \$ / \mathrm{kg}$ of TOC removed and $21.65 \$ / \mathrm{m}^{3}$ of treated SWW, equivalent to $6.79 \$ /\left(\mathrm{m}^{3}\right.$ day) that could be reduced by subtracting the electrical costs by considering potential energy recovery from anaerobic pre-treatment. The combined ABR-AS-UV/ $/ \mathrm{H}_{2} \mathrm{O}_{2}$ system has been proven to be the most cost-effective solution among other processes for TOC removal. However, it may be necessary to assess its cost-effectiveness to all major constituents of SWW (i.e., BOD, COD, TN, etc.) in order to adopt such system for treating SWW.

\section{Acknowledgments}

The financial support of Natural Sciences and Engineering Research Council of Canada (NSERC), Ontario Trillium Scholarship (OTS) Program, and Ryerson University is greatly appreciated. 


\title{
CHAPTER 5
}

\section{Treatment of Actual Slaughterhouse Wastewater by Combined} Anaerobic-Aerobic Processes for Biogas Generation AND

\author{
REMOVAl OF ORganiCS AND NUTRIENTS: AN OPTIMIZATION STUDY \\ Towards a Cleaner Production in the Meat Processing Industry*
}

\begin{abstract}
Environmental protection initiatives and the increasing market demands for green practices are driving the meat processing industry to consider sustainable methods for wastewater treatment since slaughterhouse wastewater (SWW) is seen as detrimental worldwide. Thus, on-site treatment is the preferred option to treat the slaughterhouse effluents for water reuse and potential energy recovery due to the conversion of organics into biogas. The treatment of an actual SWW is studied in a combined biological system. An anaerobic baffled reactor (ABR) followed by an aerobic activated sludge (AS) reactor are used in continuous mode at laboratory scale. Response surface methodology (RSM) is used for process optimization to maximize biogas yield and to remove the total organic carbon (TOC) and total nitrogen (TN) while minimizing the total suspended solids (TSS) residuals. The effects of the flow rate, $\mathrm{pH}$, influent TOC concentration, and their interactions on the overall treatment efficiency and the biogas yield are studied. Maximum TOC and TN removals of 85.03 and $72.10 \%$, minimum TSS residual of $19.54 \mathrm{mg} / \mathrm{L}$, and maximum biogas yield of $116.56 \mathrm{~mL} / \mathrm{min}$ are found at the optimum operating conditions of influent TOC concentration of $343 \mathrm{mg} / \mathrm{L}$, feed flow rate of $63 \mathrm{~mL} / \mathrm{min}$, and $\mathrm{pH}$ of 6.84 . The agreement between model predictions and experimental values indicates that the proposed model could describe the performance of combined anaerobic-aerobic systems for SWW treatment and the reduction of operating costs via biogas production while providing high-quality treated effluent for water reuse.
\end{abstract}

Keywords: Slaughterhouse wastewater, anaerobic digestion, activated sludge, combined processes, response surface methodology, biogas yield.

\footnotetext{
* Reprinted, with minor editorial changes to fulfill formatting requirements, from:

C. Bustillo-Lecompte and M. Mehrvar (2016) Treatment of actual slaughterhouse wastewater by combined anaerobicaerobic processes for biogas generation and removal of organics and nutrients: an optimization study towards a cleaner production in the meat processing industry. Journal of Cleaner Production. (Submitted).
} 


\subsection{Introduction}

Generally, it is desirable to categorize and minimize wastewater generation at its source. Although typical water consumption varies considerably in the meat processing business, a regular slaughterhouse generates vast amounts of wastewater and is commonly a not efficient user of fresh water. Slaughterhouse wastewater (SWW) effluents are becoming one of the major agribusiness concerns worldwide because of the elevated amounts of water used during slaughtering, processing, and cleaning of the abattoir facilities.

Although physical, chemical, and biological treatment can be used for SWW degradation, each treatment process has different benefits and drawbacks depending on the SWW characteristics, best available technology, jurisdictions, and regulations. Furthermore, the recovery of valuable by-products from the slaughterhouse effluents is currently focused on high-quality treatment, biogas generation, nutrients, and fertilizers (Kist et al., 2009; Rajakumar et al., 2011; Barrera et al., 2012; Franke-Whittle and Insam, 2013; Bustillo-Lecompte et al., 2013, 2014, 2016a, 2016b; Bustillo-Lecompte and Mehrvar, 2015, 2016b).

The global production of meat, including beef, pork, and poultry, is projected to progressively grow until 2050. The number of slaughterhouses are augmenting, which represents an expected increase in the amount of SWW requiring treatment (Bustillo-Lecompte and Mehrvar, 2016b). SWWs are classified as one of the most detrimental industrial wastewaters by different agencies worldwide (Bustillo-Lecompte and Mehrvar, 2015) since the inadequate management of SWW is one of the reasons for rivers deoxygenation and groundwater pollution. Thus, the treatment and adequate disposal of SWW are a global economic and public health necessity and these effluents require significant treatment for a safe and sustainable release to the environment and (Bustillo-Lecompte et al., 2016b).

Anaerobic processes appear to be economically more attractive than aerobic processes for the treatment of SWW by achieving low sludge production and low energy requirement. However, anaerobically treated effluents should be further treated by other treatment methods to fulfill the discharge requirements (Chan et al., 2009; Bustillo-Lecompte et al., 2013). Therefore, combined anaerobic-aerobic processes could lead to a reduction in operation and maintenance costs, which make them more attractive than conventional methods (Tabrizi and Mehrvar, 2004; Mehrvar and Tabrizi, 2006; Bustillo-Lecompte et al., 2014). Other advantages include high removal efficiencies, smaller 
amounts of aerobic sludge production, and potential energy recovery due to the conversion of organics into biogas (Chan et al., 2009; Bustillo-Lecompte and Mehrvar, 2015).

The SWW treatment is usually evaluated in terms of bulk parameters due to the variation of the SWW characteristics related to the type of animals slaughtered. Typical parametrical analyses include $\mathrm{pH}$, chemical oxygen demand (COD), biochemical oxygen demand (BOD), total nitrogen (TN), total organic carbon (TOC), and total suspended solids (TSS) (Cao and Mehrvar, 2011; Barrera et al., 2012; Bustillo-Lecompte et al., 2013, 2014, Bustillo-Lecompte and Mehrvar, 2015). Hence, the interaction of cross-factor and single-factor effects on the overall process efficiency and biogas yield has not been widely evaluated, rather the microorganism characterization, disinfection, and denitrification are the main focus in recent years (Franke-Whittle and Insam, 2013; Bustillo-Lecompte and Mehrvar, 2015).

Consequently, the design of experiments (DOE) is used to surpass the limitations of traditional experimental methods in terms of time, materials, and the number of experimental trials. Likewise, the DOE permits the optimization of all parameters and consider the combined effects of all the factors involved. Besides, the response surface methodology (RSM) is used for cross-factor interaction analysis to achieve optimal responses using the minimum number of experiments (Ghafoori et al., 2012, 2014, 2015; Bustillo-Lecompte et al., 2016; Šereš et al., 2016).

In this study, the effects of the flow rate, $\mathrm{pH}$, the influent concentration of TOC, and their interactions on the overall efficiency of the combined anaerobic-aerobic processes and the biogas yield for the SWW treatment were investigated. The DOE was used to optimize the SWW treatment using combined anaerobic baffled reactor $(\mathrm{ABR})$ and aerobic activated sludge (AS) reactor in continuous mode at the laboratory scale by maximizing the biogas yield and the removal of TOC and TN while minimizing the TSS concentration in the effluent.

The optimal parametric values for the DOE were obtained using a Box-Behnken design (BBD) with three factors at three levels combined with RSM. Statistical models were also developed to predict the percent TOC and TN removal, the effluent concentration of TSS, and biogas yield as response variables by the combined anaerobic-aerobic processes. The statistical models were validated by an additional set of experiments at the optimum conditions in line with the DOE results. The use of combined biological processes as an alternative to conventional methods is a cost-effective approach for the treatment of meat processing effluents and adherence to pertinent regulations worldwide. As a 
result, the proposed models on SWW treatment by the combined ABR-AS system could be used as a base for future studies for the reduction of operating costs while providing high-quality treated effluents for water reuse.

\subsection{Materials and methods}

\subsubsection{Materials}

Actual SWW samples, with an average TOC concentration of $862 \mathrm{mg} / \mathrm{L}$, were taken from selected provincially licensed meat processing plants directly from their source in Ontario, Canada (OMAFRA, 2015b). The overall SWW characteristics from the selected meat processing plants are shown in Table 5.1 .

Table 5.1. Characteristics of the actual slaughterhouse wastewater from selected provincially licensed meat processing plants.

Submitted to J. Clean. Prod. (2016).

\begin{tabular}{ll}
\hline Parameter & Range \\
\hline BOD $(\mathrm{mg} / \mathrm{L})$ & $37.95-1,339$ \\
COD $(\mathrm{mg} / \mathrm{L})$ & $87.23-2,080$ \\
TN $(\mathrm{mg} / \mathrm{L})$ & $161.2-254.7$ \\
TOC $(\mathrm{mg} / \mathrm{L})$ & $90.41-1,694$ \\
TP $(\mathrm{mg} / \mathrm{L})$ & $0.257-22.98$ \\
TSS $(\mathrm{mg} / \mathrm{L})$ & $0.390-103.5$ \\
pH & $6.8-7.0$ \\
\hline
\end{tabular}

\subsubsection{Experimental setup and procedure}

A combined ABR-AS continuous system at the laboratory scale was used for the treatment of actual SWW. Figure 1 illustrates the schematic diagram of the experimental setup for the combined $\mathrm{ABR}-\mathrm{AS}$ processes. The $50 \mathrm{~L}$ combined ABR-AS system consisted of a 36-L ABR with five equalvolume chambers integrated with individual headspaces, biogas collection piping, and a 14-L aerobic AS reactor with a monitored air flow rate. A $45^{\circ}$ slanted-edge baffle within each ABR chamber permits the downflow and upflow course of the SWW, providing effective mixing and contact time between the SWW and the biomass. The AS air flow rate was set at $2 \mathrm{~L} / \mathrm{min}$ to guarantee nitrifying bacteria growth and dissolved oxygen (DO) concentrations over $2.0 \mathrm{mg} / \mathrm{L}$. 


\subsubsection{Acclimatization of the inoculum}

Twelve liters of an anaerobic sludge seed (38,000 mg/L), using 2.4 L of the inoculum for each of the five chambers of the ABR (1/3 of the total working volume), and $5 \mathrm{~L}$ of an aerobic sludge seed $(3,000 \mathrm{mg} / \mathrm{L})$ were loaded into the anaerobic and aerobic bioreactors, respectively. The inoculum was acclimatized in eight weeks by feeding the actual SWW continuously into the bioreactors using a peristaltic pump at a constant flow rate of $75 \mathrm{~mL} / \mathrm{min}$.

During the 60-days acclimatization period, the influent substrate concentration was gradually increased biweekly from 25,50 , and $75 \%$ to $100 \%$ of the actual SWW. Biomass growth within the combined ABR-AS processes was monitored by collecting samples from each compartment of both $\mathrm{ABR}$ and $\mathrm{AS}$ bioreactors during the acclimatization period by measuring the concentrations of both total suspended solids (TSS) and volatile suspended solids (VSS).

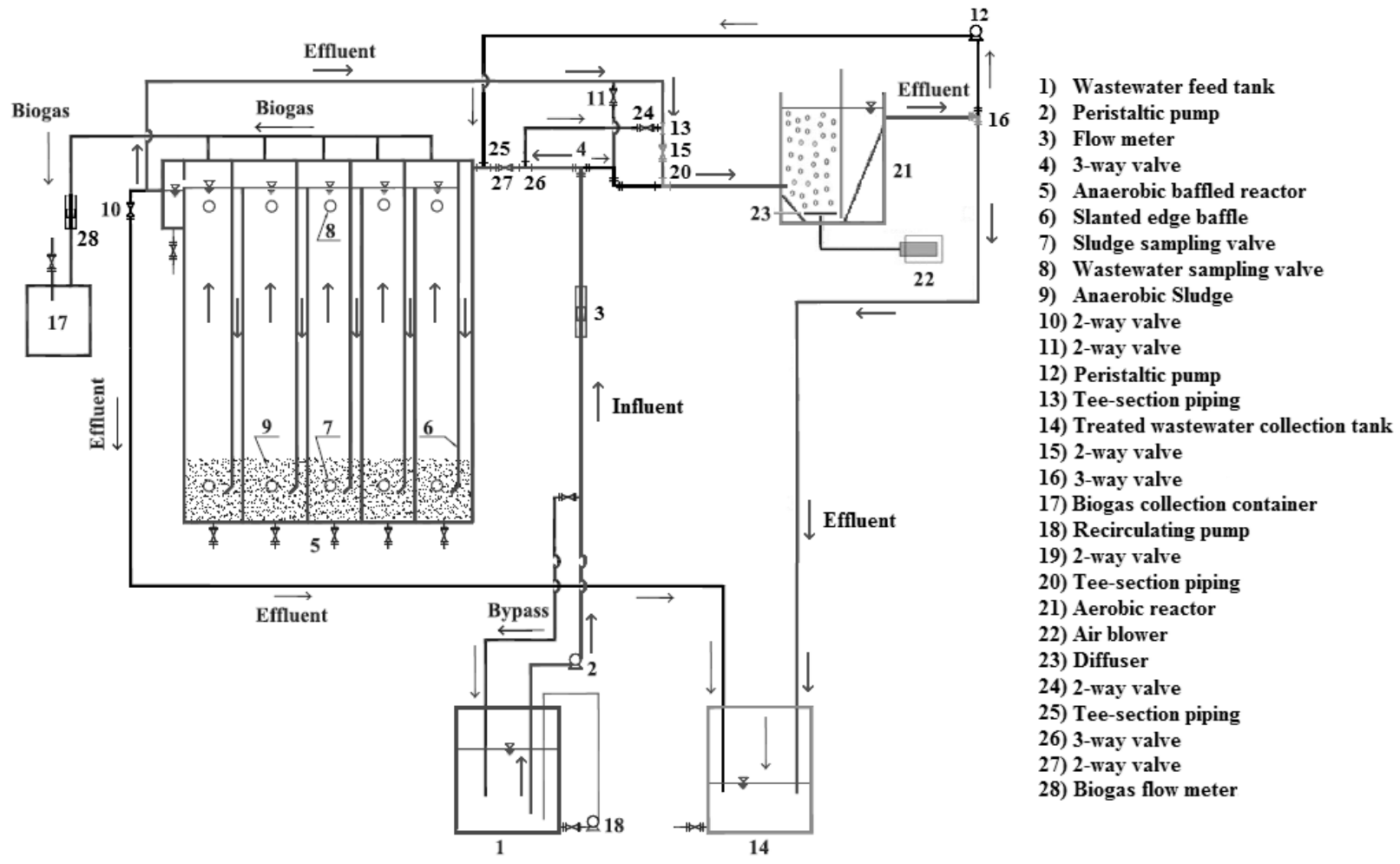

Figure 5.1. Schematic diagram of the combined anaerobic-aerobic processes for the treatment of SWW.

Submitted to J. Clean. Prod. (2016). 


\subsubsection{Slaughterhouse wastewater treatment and sample analysis}

After the 8-week acclimatization period, the following procedure was used in performing each experiment in the combined $\mathrm{ABR}-\mathrm{AS}$ processes for quality control:

1) SWW samples were filtered to separate the liquid portion of the wastewater from the solids.

2) Filtered SWW samples were then diluted to reach the desired TOC concentration of the feed in a $120-\mathrm{L}$ solution.

3) A $1 \mathrm{~N}$ solution of sulfuric acid $\left(\mathrm{H}_{2} \mathrm{SO}_{4}\right)$ and a $50 \%$ solution of sodium hydroxide $(\mathrm{NaOH})$ were used to adjust the $\mathrm{pH}$.

4) The SWW solution with the desired TOC concentration and $\mathrm{pH}$ was fed into the combined ABR-AS processes by a variable speed peristaltic pump to control and adjust the flow rate.

5) Effluent samples were taken at $3 \mathrm{~h}$ intervals until the system reached steady state conditions.

TOC and TN concentrations were analyzed for each sample using an automated TOC/TN analyzer (Teledyne Tekmar Apollo 9000, Mason, $\mathrm{OH}$ ). DO, pH, and temperature were measured daily using a dissolved oxygen meter (YSI 58 Dissolved Oxygen Meter, Yellow Springs, OH) and a pH meter (Thermo Scientific Orion 230A+, Ottawa, ON), respectively. The concentrations of TSS and VSS were measured according to the American Public Health Association (APHA, 2012) standards methods. The colorimetric method (Orbeco-Hellige MC500 Multi-Parameter Colorimeter, Sarasota, FL) was used for routine analysis of COD, TP, and Turbidity (APHA, 2012).

Moreover, the biodegradability of the SWW and the 5-days biochemical oxygen demand (BOD 5 ) were examined via respirometry assays. Four 1-L respirometry bioreactors (Bioscience BI-2000 Electrolytic, Allentown, PA) were inoculated using AS with an initial biomass concentration of 1,000 $\mathrm{mgVSS} / \mathrm{L}$.

The respirometry bioreactors were then filled with samples of SWW, treated SWW by ABR alone, treated SWW by aerobic AS bioreactor alone, and treated SWW by combined ABR-AS processes. Biogas analysis was performed using a portable gas analyzer (Landtec Biogas 5000, Colton, CA) for $\mathrm{CH}_{4}, \mathrm{CO}_{2}$, and $\mathrm{O}_{2}$ volume percentage measurement. All experiments were repeated in triplicates; thus, average values were reported. 


\subsubsection{Experimental design and optimization}

A three-factor along with three-level BBD in conjunction with RSM was used to maximize the biogas yield and the removal of TOC and TN while minimizing the TSS residuals. The influent concentration of TOC $\left(X_{1}\right)$, flow rate $\left(X_{2}\right)$, and $\mathrm{pH}\left(X_{3}\right)$ were used as independent factors in the DOE. The percent TOC and TN removals, the TSS residual, and the biogas yield were considered as the process responses. Thus, each factor was coded at three levels $(-1,0,+1)$ as shown in Table 5.2. Preliminary experiments were used to determine and select the particular ranges of the factors.

Table 5.2. Independent variables with coded levels based on a three-factor, three-level BBD. Submitted to J. Clean. Prod. (2016).

\begin{tabular}{lcccc}
\hline & & \multicolumn{3}{c}{ Coded levels } \\
Independent variable & Symbol & $\mathbf{- 1}$ & $\mathbf{0}$ & $\mathbf{1}$ \\
\hline $\mathrm{TOC}_{\text {in }}(\mathrm{mg} / \mathrm{L})$ & $X_{1}$ & 100 & 850 & 1,600 \\
Flow rate $(\mathrm{mL} / \mathrm{min})$ & $X_{2}$ & 45 & 75 & 105 \\
$\mathrm{pH}$ & $X_{3}$ & 5 & 7 & 9 \\
\hline
\end{tabular}

A quadratic model was used to estimate the parametric coefficients by correlating dependent and independent variables using the least-squares regression as shown in Equation (1) (Ghafoori et al., 2012, 2014, 2015; Bustillo-Lecompte et al., 2016a, 2016b; Bustillo-Lecompte and Mehrvar, 2016b):

$Y_{i}=\beta_{o}+\sum_{i=1}^{k} \beta_{i} X_{i}+\sum_{i=1}^{k} \beta_{i i} X_{i}^{2}+\sum_{i=1}^{k-1} \sum_{j=2}^{k} \beta_{i j} X_{i} X_{j}+c$

where $\beta_{o}, \beta_{i}, \beta_{i i}$, and $\beta_{i j}$ are the constant, linear, quadratic, and cross-factor interaction coefficients, respectively; $X_{i}$ and $X_{j}$ represent the independent variables; $Y_{i}$ is the predicted response; and $k$ and $c$ are the number of factors and the residual term, respectively.

The statistical software Design-Expert 9.0.4.1 was employed for the DOE and the estimation of the coefficients for each response function. The significance of each model equation, individual parameters, and factor interactions were evaluated by analysis of variance (ANOVA) at the confidence intervals of $95 \%(\alpha=0.05)$. 
Two-dimensional (2D) contour plots and three-dimensional (3D) surface responses were obtained in the quadratic models. Additional experimental runs were carried out to validate the quadratic models for maximum biogas yield, percent removals of TOC and TN, and minimum TSS in the effluent at the optimal operating conditions, calculated by the software numerical optimization method.

On the other hand, to obtain a simultaneous objective function that represents the geometric mean of all transformed responses, the desirability multiple response method was used to combine the desirable ranges for each response as shown in Equation (5.2) (Myers et al., 2009):

$$
D=\left(d_{1} \times d_{2} \times d_{3} \times d_{4} \ldots \times d_{n}\right)^{1 / n}=\left(\prod_{i=1}^{n} d_{i}\right)^{1 / n}
$$

where $D, d_{i}$, and $n$ are the desirability objective function, each individual response range, and the number of responses, respectively. For a simultaneous optimization, each response requires low and high values for the optimization. Otherwise, if any response is found outside of its desirability range, the overall desirability becomes equal to zero. In this case, the percent removal of TOC $\left(d_{1}\right)$, TN $\left(d_{2}\right)$, and biogas yield $\left(d_{3}\right)$ are maximized while the TSS residual $\left(d_{4}\right)$ is minimized.

\subsection{Results and discussion}

\subsubsection{Acclimatization period}

TSS and VSS concentrations were measured in both AS bioreactor and ABR, respectively, to observe the growth of the microorganisms while they were adapting to the bioreactor and SWW conditions. The SWW concentration was gradually increased to the highest TOC value $(1,718 \mathrm{mg} / \mathrm{L})$ of the SWW samples.

Figure 5.2 depicts a gradual growth in the biomass for the ABR and the AS bioreactor until the TSS and VSS were stabilized. After the 60-day acclimatization period, the anaerobic and aerobic biomass concentrations (VSS) increased to 24,000 and 2,800 mg/L, respectively. The temperature of the processes remained under sub-mesophilic conditions with an average temperature of $24.75^{\circ} \mathrm{C}$ in the combined ABR-AS system. 


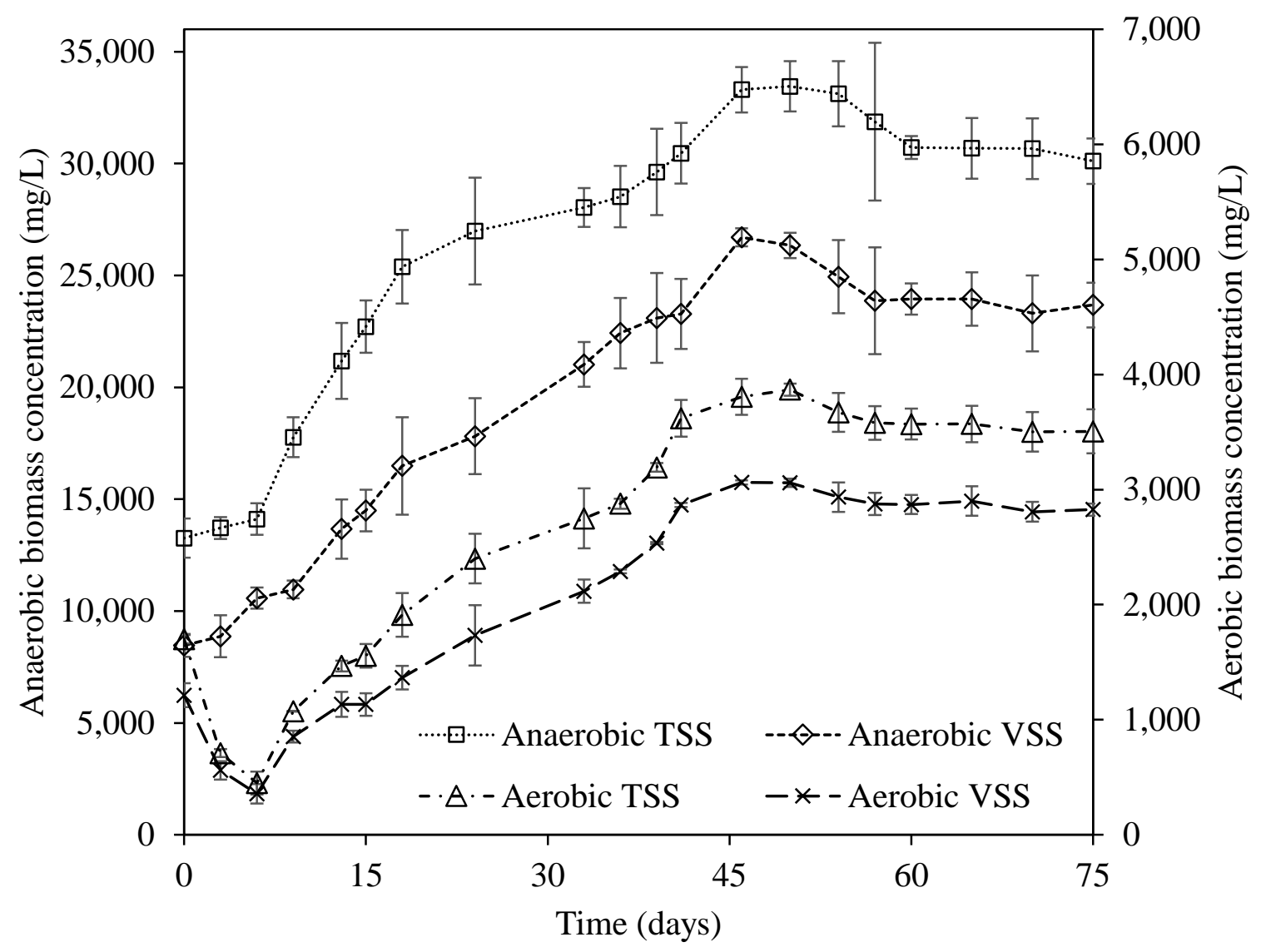

Figure 5.2. Biomass concentration in the anaerobic baffled reactor during acclimatization and the aerobic activated sludge bioreactor. Error bars represent the standard deviation of the experimental data.

Submitted to J. Clean. Prod. (2016). 


\subsubsection{Preliminary experiments}

Preliminary experiments were conducted for the treatment of SWW using the combined ABRAS system. Bulk parameters including TOC, TN, COD, TSS, total phosphorus (TP), and turbidity were analyzed. Figure 5.3 shows the obtained maximum removal values for TOC (Figure 5.3a), TN (Figure 5.3b), COD (Figure 5.3c), TP (Figure 5.3d), turbidity (Figure 5.3e), and TSS (Figure 5.3f) from the SWW by the combined anaerobic-aerobic processes in continuous mode.

Furthermore, removal rates of up to $90,81,98,84,97$, and 95\% were obtained for TOC, TN, COD, TP, turbidity, and TSS, respectively. Influent concentrations of TOC, TN, COD, TP, and TSS of up to $941,214,1950,0.38$, and $750 \mathrm{mg} / \mathrm{L}$, respectively, as well as an influent turbidity of 1,000 formazin turbidity units (FTU) were continuously fed to the combined ABR-AS system at a flow rate of 75 $\mathrm{mL} / \mathrm{min}$.

Respirometry assays were performed to evaluate the biodegradability of the SWW and the BOD removal efficiency of the individual and combined biological processes. Samples of raw SWW, treated SWW by ABR alone, treated SWW by aerobic AS reactor alone, and treated SWW by combined ABRAS processes were evaluated as shown in Figure 5.4. The initial TOC concentration was set at 75.00 $\mathrm{mg} / \mathrm{L}$ due to the small volume of the respirometry bioreactors $(1 \mathrm{~L})$. The theoretical oxygen demand was calculated to be $200.25 \mathrm{mg} / \mathrm{L}$, similar to the measured ultimate oxygen uptake of $202.29 \mathrm{mg} / \mathrm{L}$ and the measured COD of $205.64 \pm 6.43 \mathrm{mg} / \mathrm{L}$.

Besides, the $\mathrm{BOD}_{5}$ was obtained as the oxygen uptake at the $120 \mathrm{~h}$ mark for each sample. Therefore, the $\mathrm{BOD}_{5}$ concentration of the raw SWW was found to be $147.96 \mathrm{mg} / \mathrm{L}$, the $\mathrm{BOD}_{5} / \mathrm{COD}$ ratio was 0.72 , and the initial food to microorganism ratio $(F / M)$ was calculated to be 0.46 $\mathrm{mgO}_{2} / \mathrm{mgVSS}$.day, which indicates a desirable $F / M$. As a result, the majority of the organics in the actual SWW are considered biodegradable (Bustillo-Lecompte et al., 2015). Figure 5.4 also illustrates the $\mathrm{BOD}_{5}$ concentrations in the treated effluents by ABR alone, aerobic AS reactor alone, and combined $\mathrm{ABR}-\mathrm{AS}$ processes to be $61.66,47.75$, and $23.72 \mathrm{mg} / \mathrm{L}$, respectively. Thus, the $\mathrm{BOD}_{5} / \mathrm{COD}$ ratios of $0.30,0.23$, and 0.11 for the treated effluents by ABR alone, aerobic AS reactor alone, and combined $\mathrm{ABR}-\mathrm{AS}$ processes, respectively. It can be observed that as the $\mathrm{SWW}$ is oxidized, the $\mathrm{BOD}_{5} / \mathrm{COD}$ ratio decreases. The SWW treated effluent becomes less biodegradable since it has already been largely degraded. 

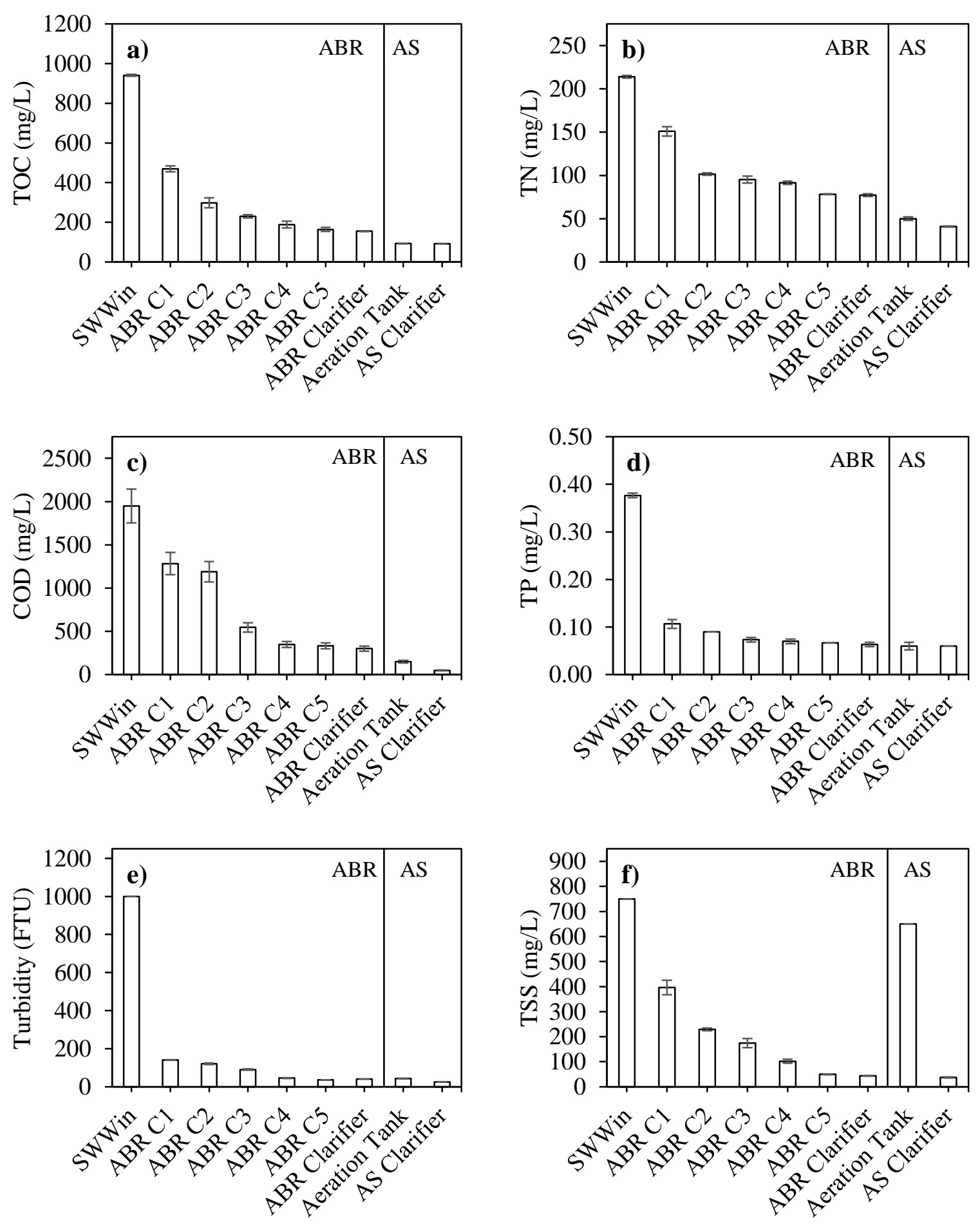

Figure 5.3. Maximum remaining values of (a) TOC, (b) TN, (c) COD, (d) TP, (e) Turbidity, and (f) TSS from SWW using combined anaerobic-aerobic processes in continuous mode with inlet concentrations of TOC, TN, COD, TP, and TSS of up to 941, 214, 1950, 0.38, and $750 \mathrm{mg} / \mathrm{L}$, respectively, as well as an influent turbidity of 1000 formazin turbidity units (FTU). Error bars represent the standard deviation of the experimental data.

Submitted to J. Clean. Prod. (2016). 


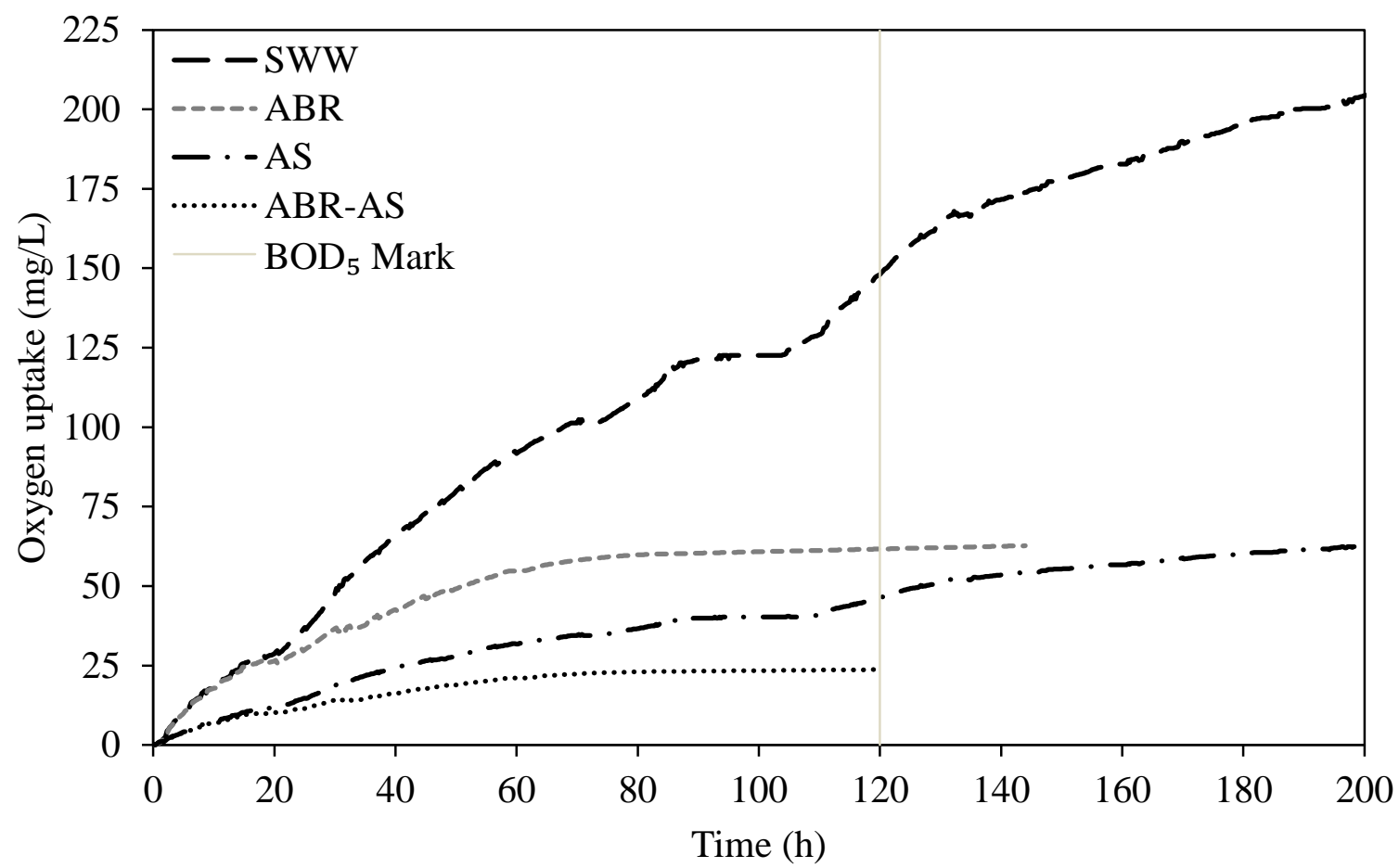

Figure 5.4. Respirometry testing results for different samples of raw $S W W$, treated $S W W$ by aerobic AS bioreactor alone, treated SWW by ABR alone, and treated SWW by combined ABRAS processes. The initial TOC concentration is $75.00 \mathrm{mg} / \mathrm{L}$ and mean standard deviation is 6.43 $\mathrm{mg} / \mathrm{L}$. BOD 5 is obtained as the oxygen uptake at the $120 \mathrm{~h}$ mark.

Submitted to J. Clean. Prod. (2016). 


\subsubsection{Experimental design and statistical analysis}

The influent TOC concentration was selected as one of the factors to be evaluated by DOE since the TOC analysis provides a more accurate appraisal of the total organic compounds present in a wastewater sample in comparison to BOD or COD, without producing any toxic analytical waste (Dubber and Gray, 2010; Bustillo-Lecompte et al., 2014, 2015). For nutrients evaluation, TN was selected due to the high concentration of TN in the influent SWW compared to that of TP. Furthermore, TN analysis was performed using an automated TOC/TN analyzer, which allowed rapid and accurate results while avoiding the generation of noxious analytical by-products compared to the vanadomolybdophosphoric acid colorimetric method used in TP analysis. The flow rate and the $\mathrm{pH}$ were also selected due to their direct relationship to microorganism activity and growth (Chan et al., 2009; Cao and Mehrvar, 2011; Bustillo-Lecompte et al., 2013).

Table 5.3 shows the three-factor, three-level BBD with observed and predicted values for the TOC and TN removal, the biogas yield, and the TSS residual of the combined ABR-AS continuous system. The RSM was used for parameter estimation, specifying the correlation between the input factors and the output responses, as previously shown in Equation (5.1). Consequently, in order to estimate the response functions for the percent TOC removal $\left(Y_{1}\right)$, the percent TN removal $\left(Y_{2}\right)$, the biogas yield $\left(Y_{3}\right)$, and the TSS residual $\left(Y_{4}\right)$, the second-order polynomial Equations (5.3) to (5.6) were developed in terms of the coded factors, including influent concentration of the TOC $\left(X_{1}\right)$, the flow rate $\left(X_{2}\right)$, and the $\mathrm{pH}\left(X_{3}\right)$ :

$$
\begin{aligned}
& Y_{1}=80.42-5.65 X_{1}-2.49 X_{2}+0.59 X_{3}+3.13 X_{1} X_{2}-1.29 X_{1} X_{3}+2.69 X_{2} X_{3}-1.55 X_{1}^{2} \\
& -1.94 X_{2}^{2}-3.00 X_{3}^{2} \\
& Y_{2}=62.85-8.59 X_{1}-9.29 X_{2}-1.18 X_{3}+7.43 X_{1} X_{2}+6.48 X_{1} X_{3}+0.35 X_{2} X_{3}-4.86 X_{1}^{2} \\
& -3.03 X_{2}^{2}-18.84 X_{3}^{2} \\
& Y_{3}=127.19+8.28 X_{1}-1.40 X_{2}-5.60 X_{3}-8.51 X_{1} X_{2}-6.77 X_{1} X_{3}+2.57 X_{2} X_{3}-0.35 X_{1}^{2} \\
& -19.18 X_{2}^{2}-12.84 X_{3}^{2} \\
& Y_{4}=22.52+3.30 X_{1}+5.03 X_{2}+2.35 X_{3}+2.60 X_{1} X_{2}+1.52 X_{1} X_{3}+0.64 X_{2} X_{3}+1.58 X_{1}^{2} \\
& -0.61 X_{2}^{2}+6.37 X_{3}^{2}
\end{aligned}
$$


Table 5.3. Three-factor, three-level BBD for RSM, along with the observed and predicted percent TOC removal, TN removal, Biogas yield, and TSS residual.

Submitted to J. Clean. Prod. (2016).

\begin{tabular}{|c|c|c|c|c|c|c|c|c|c|c|c|}
\hline \multirow[b]{2}{*}{ Run } & \multicolumn{3}{|c|}{ Independent coded variables } & \multicolumn{2}{|c|}{ TOC removal $(\%)$} & \multicolumn{2}{|c|}{ TN removal $(\%)$} & \multicolumn{2}{|c|}{ Biogas yield (mL/min) } & \multicolumn{2}{|c|}{ TSS residual $(\mathrm{mg} / \mathrm{L})$} \\
\hline & $\mathbf{X}_{1}$ & $\mathbf{X}_{2}$ & $\mathbf{X}_{3}$ & Observed & Predicted & Observed & Predicted & Observed & Predicted & Observed & Predicted \\
\hline 1 & -1 & -1 & 0 & 88.87 & 88.19 & 79.53 & 80.28 & 94.02 & 92.26 & 18.62 & 17.74 \\
\hline 2 & 1 & -1 & 0 & 70.80 & 70.64 & 48.89 & 48.23 & 125.62 & 125.84 & 25.95 & 26.16 \\
\hline 3 & -1 & 1 & 0 & 76.81 & 76.97 & 46.17 & 46.83 & 106.70 & 106.48 & 29.83 & 29.62 \\
\hline 4 & 1 & 1 & 0 & 71.25 & 71.93 & 45.25 & 44.50 & 104.28 & 106.04 & 33.43 & 34.31 \\
\hline 5 & -1 & 0 & -1 & 79.03 & 79.65 & 56.92 & 55.41 & 103.24 & 104.55 & 33.14 & 33.36 \\
\hline 6 & 1 & 0 & -1 & 70.84 & 70.93 & 25.36 & 25.25 & 135.32 & 134.65 & 37.76 & 36.88 \\
\hline 7 & -1 & 0 & 1 & 83.49 & 83.40 & 39.98 & 40.09 & 106.22 & 106.89 & 34.15 & 35.03 \\
\hline 8 & 1 & 0 & 1 & 70.15 & 69.53 & 34.35 & 35.86 & 111.22 & 109.91 & 44.83 & 44.61 \\
\hline 9 & 0 & -1 & -1 & 80.01 & 80.07 & 51.04 & 51.81 & 104.28 & 104.73 & 27.90 & 28.57 \\
\hline 10 & 0 & 1 & -1 & 70.49 & 69.72 & 31.67 & 32.52 & 97.89 & 96.80 & 37.31 & 37.30 \\
\hline 11 & 0 & -1 & 1 & 75.09 & 75.86 & 49.60 & 48.75 & 87.30 & 88.39 & 31.98 & 31.99 \\
\hline 12 & 0 & 1 & 1 & 76.34 & 76.28 & 31.64 & 30.87 & 91.18 & 90.73 & 43.95 & 43.28 \\
\hline 13 & 0 & 0 & 0 & 80.83 & 80.42 & 61.67 & 62.85 & 127.25 & 127.19 & 29.52 & 29.52 \\
\hline 14 & 0 & 0 & 0 & 79.94 & 80.42 & 62.27 & 62.85 & 125.13 & 127.19 & 28.71 & 29.52 \\
\hline 15 & 0 & 0 & 0 & 80.45 & 80.42 & 62.81 & 62.85 & 126.13 & 127.19 & 29.10 & 29.52 \\
\hline 16 & 0 & 0 & 0 & 81.05 & 80.42 & 63.45 & 62.85 & 129.01 & 127.19 & 29.92 & 29.52 \\
\hline 17 & 0 & 0 & 0 & 79.83 & 80.42 & 64.05 & 62.85 & 128.41 & 127.19 & 30.35 & 29.52 \\
\hline
\end{tabular}


Unfavorable effects are indicated by negative coefficients of the model components. In the case of TOC removal $\left(Y_{1}\right)$, the unfavorable effects come from the model components $X_{1}, X_{2}, X_{1} X_{3}, X_{1}^{2}, X_{2}^{2}$, and $X_{3}{ }^{2}$. Similarly, $X_{1}, X_{2}, X_{3}, X_{1}^{2}, X_{2}^{2}$, and $X_{3}^{2}$ have unfavorable effects on the TN removal $\left(Y_{2}\right)$. Correspondingly, $X_{2}, X_{3}, X_{1} X_{2}, X_{1} X_{3}, X_{1}^{2}, X_{2}^{2}$, and $X_{3}^{2}$ have unfavorable effects on the biogas yield $\left(Y_{3}\right)$. In contrast, only $X_{2}{ }^{2}$ was found to have an unfavorable effect on the TSS residual $\left(Y_{4}\right)$. On the other hand, positive coefficients indicate favorable effects on the model responses. For the percent TOC removal $\left(Y_{1}\right)$, the favorable effects come from the model components $X_{3}, X_{1} X_{2}$, and $X_{2} X_{3}$. In the same way, the model components $X_{1} X_{2}, X_{1} X_{3}$, and $X_{2} X_{3}$ have favorable effects on the TN removal $\left(Y_{2}\right)$. Likewise, $X_{1}$ and $X_{2} X_{3}$ have favorable effects on the biogas yield ( $Y_{3}$ ). Finally, $X_{1}, X_{2}, X_{3}, X_{1} X_{2}, X_{1} X_{3}$, $X_{2} X_{3}, X_{1}^{2}$, and $X_{3}^{2}$ are favorable to the TSS residual $\left(Y_{4}\right)$.

ANOVA was employed with a $95 \%$ confidence interval to estimate the statistical significance of the four quadratic models for percent TOC removal $\left(Y_{1}\right)$, TN removal $\left(Y_{2}\right)$, biogas yield $\left(Y_{3}\right)$, and TSS residual $\left(Y_{4}\right)$. Consequently, each factor coefficient was evaluated in terms of statistical significance using the Fisher's $(F)$ exact test by comparing probability $(p)$ values greater than $F$. Thus, small probability values $(p<0.05)$ indicate the significance of the model parameters, whereas $p$-values $>0.10$ indicate the non-significance of the model factors. The non-significance of the quadratic effect indicate the optimal levels are located at the limits of the experimental region (Botha et al., 2012; BustilloLecompte et al., 2016a). As shown in Table 5.4, the developed quadratic models for each response were found to be significant. $F$-values of $85.84,207.34,122.09$, and 77.16 were obtained for the percent TOC removal $\left(Y_{1}\right)$, the percent $\mathrm{TN}$ removal $\left(Y_{2}\right)$, the biogas yield $\left(Y_{3}\right)$, and the TSS residual $\left(Y_{4}\right)$, respectively.

Furthermore, the accuracy of the developed models to predict the response functions was confirmed by small probability values $(p<0.05)$. However, some model terms were found not to be significant $(p>0.10)$, including $X_{2} X_{3}$ for the percent TN removal; $X_{1}^{2}$ for the biogas yield; and $X_{2} X_{3}$ and $X_{l}^{2}$ for TSS residual. Besides, the adequate precision of the percent TOC removal $\left(Y_{1}\right)$, the percent TN removal $\left(Y_{2}\right)$, the biogas yield $\left(Y_{3}\right)$, and TSS the residual $\left(Y_{4}\right)$ were $31.79 \%, 53.15 \%, 32.90 \mathrm{~mL} / \mathrm{min}$, and $28.90 \mathrm{mg} / \mathrm{L}$, respectively. Thus, because all adequate precision values were greater than 4.00 , the developed models can be used to navigate the BBD space (Ghafoori et al., 2015). Moreover, the models lack of fit $p$-values were calculated to be $0.1318,0.1296,0.2950$, and 0.1501 for the percent TOC removal $\left(Y_{1}\right)$, TN removal $\left(Y_{2}\right)$, biogas yield $\left(Y_{3}\right)$, and TSS residual $\left(Y_{4}\right)$, respectively. Consequently, a not significant lack of fit $(p>0.10)$ is desirable, indicating the model fits the data well. 
Table 5.4. ANOVA of the prediction results for the percent TOC and TN removal, Biogas yield, and TSS residual by quadratic modeling.

Submitted to J. Clean. Prod. (2016).

\begin{tabular}{|c|c|c|c|c|c|c|}
\hline Source & Sum of squares & $d f^{a}$ & Mean square & $F$ value $^{\text {b }}$ & $p$-value $(\text { Prob. }>F)^{\mathrm{c}}$ & Remark \\
\hline TOC $_{\text {removal }}$ model & 452.28 & 9 & 50.254 & 85.835 & $<0.0001$ & Significant \\
\hline$X_{1}$ & 254.93 & 1 & 254.93 & 435.42 & $<0.0001$ & Significant \\
\hline$X_{2}$ & 49.402 & 1 & 49.402 & 84.380 & $<0.0001$ & Significant \\
\hline$X_{3}$ & 2.7613 & 1 & 2.7613 & 4.7163 & 0.0664 & \\
\hline$X_{1} X_{2}$ & 39.125 & 1 & 39.125 & 66.827 & 0.0001 & Significant \\
\hline$X_{1} X_{3}$ & 6.6306 & 1 & 6.6306 & 11.325 & 0.0120 & Significant \\
\hline$X_{2} X_{3}$ & 28.998 & 1 & 28.998 & 49.530 & 0.0002 & Significant \\
\hline$X_{1}^{2}$ & 10.067 & 1 & 10.067 & 17.195 & 0.0043 & Significant \\
\hline$X_{2}{ }^{2}$ & 15.867 & 1 & 15.867 & 27.102 & 0.0012 & Significant \\
\hline$X_{3}^{2}$ & 37.800 & 1 & 37.800 & 64.563 & 0.0001 & Significant \\
\hline Residual & 4.0983 & 7 & 0.5855 & & & \\
\hline Lack of Fit & 2.9539 & 3 & 0.9846 & 3.442 & 0.1318 & Not significant \\
\hline Pure error & 1.1444 & 4 & 0.2861 & & & \\
\hline Corrected total SS & 456.38 & 16 & & & & \\
\hline$R^{2}$ & 0.9910 & & & & & \\
\hline Adjusted $R^{2}$ & 0.9795 & & & & & \\
\hline Adequate Precision & 31.793 & & & & & \\
\hline $\mathrm{TN}_{\text {removal }}$ model & 3400.3 & 9 & 377.81 & 207.34 & $<0.0001$ & Significant \\
\hline$X_{1}$ & 590.82 & 1 & 590.82 & 324.25 & $<0.0001$ & Significant \\
\hline$X_{2}$ & 690.62 & 1 & 690.62 & 379.02 & $<0.0001$ & Significant \\
\hline$X_{3}$ & 11.092 & 1 & 11.092 & 6.0874 & 0.0430 & Significant \\
\hline$X_{1} X_{2}$ & 220.82 & 1 & 220.82 & 121.19 & $<0.0001$ & Significant \\
\hline$X_{1} X_{3}$ & 168.09 & 1 & 168.09 & 92.250 & $<0.0001$ & Significant \\
\hline$X_{2} X_{3}$ & 0.4970 & 1 & 0.4970 & 0.2728 & 0.6176 & Not significant \\
\hline$X_{1}^{2}$ & 99.553 & 1 & 99.553 & 54.636 & 0.0002 & Significant \\
\hline$X_{2}^{2}$ & 38.593 & 1 & 38.593 & 21.180 & 0.0025 & Significant \\
\hline$X_{3}^{2}$ & 1493.7 & 1 & 1493.7 & 819.76 & $<0.0001$ & Significant \\
\hline Residual & 12.755 & 7 & 1.8221 & & & \\
\hline Lack of Fit & 9.2245 & 3 & 3.0748 & 3.4838 & 0.1296 & Not significant \\
\hline Pure error & 3.5304 & 4 & 0.8826 & & & \\
\hline Corrected total $\mathrm{SS}^{\mathrm{d}}$ & 3413.0 & 16 & & & & \\
\hline$R^{2}$ & 0.9963 & & & & & \\
\hline Adjusted $R^{2}$ & 0.9915 & & & & & \\
\hline Adequate Precision & 53.145 & & & & & \\
\hline Biogas yield model & 3693.0 & 9 & 410.33 & 122.09 & $<0.0001$ & Significant \\
\hline$X_{1}$ & 548.80 & 1 & 548.80 & 163.29 & $<0.0001$ & Significant \\
\hline$X_{2}$ & 15.596 & 1 & 15.596 & 4.6405 & 0.0682 & \\
\hline$X_{3}$ & 250.99 & 1 & 250.99 & 74.680 & 0.0001 & Significant \\
\hline$X_{1} X_{2}$ & 289.34 & 1 & 289.34 & 86.090 & $<0.0001$ & Significant \\
\hline$X_{1} X_{3}$ & 183.33 & 1 & 183.33 & 54.549 & 0.0002 & Significant \\
\hline$X_{2} X_{3}$ & 26.368 & 1 & 26.368 & 7.8456 & 0.0265 & Significant \\
\hline$X_{1}^{2}$ & 0.5063 & 1 & 0.5063 & 0.1506 & 0.7095 & Not significant \\
\hline$X_{2}^{2}$ & 1549.6 & 1 & 1549.6 & 461.08 & $<0.0001$ & Significant \\
\hline$X_{3}^{2}$ & 694.09 & 1 & 694.09 & 206.52 & $<0.0001$ & Significant \\
\hline Residual & 23.526 & 7 & 3.3609 & & & \\
\hline Lack of Fit & 13.355 & 3 & 4.4516 & 1.7506 & 0.2950 & Not significant \\
\hline Pure error & 10.172 & 4 & 2.5429 & & & \\
\hline Corrected total $\mathrm{SS}^{\mathrm{d}}$ & 3716.5 & 16 & & & & \\
\hline$R^{2}$ & 0.9937 & & & & & \\
\hline Adjusted $R^{2}$ & 0.9855 & & & & & \\
\hline Adequate Precision & 32.903 & & & & & \\
\hline
\end{tabular}




\begin{tabular}{|c|c|c|c|c|c|c|}
\hline Source & Sum of squares & $d f^{a}$ & Mean square & $F$ value $^{b}$ & $p$-value $(\text { Prob. }>F)^{\mathrm{c}}$ & Remark \\
\hline TSS $_{\text {residual }}$ model & 557.45 & 9 & 61.940 & 77.160 & $<0.0001$ & Significant \\
\hline$X_{1}$ & 86.860 & 1 & 86.860 & 108.20 & $<0.0001$ & Significant \\
\hline$X_{2}$ & 202.01 & 1 & 202.01 & 251.65 & $<0.0001$ & Significant \\
\hline$X_{3}$ & 44.180 & 1 & 44.180 & 55.040 & 0.0001 & Significant \\
\hline$X_{1} X_{2}$ & 27.040 & 1 & 27.040 & 33.690 & 0.0007 & Significant \\
\hline$X_{1} X_{3}$ & 9.1800 & 1 & 9.1800 & 11.440 & 0.0117 & Significant \\
\hline$X_{2} X_{3}$ & 1.6400 & 1 & 1.6400 & 2.0400 & 0.1962 & Not significant \\
\hline$X_{I}^{2}$ & 10.480 & 1 & 10.480 & 13.050 & 0.0086 & Significant \\
\hline$X_{2}^{2}$ & 1.5500 & 1 & 1.5500 & 1.9400 & 0.2067 & Not significant \\
\hline$X_{3}^{2}$ & 170.98 & 1 & 170.98 & 213.01 & $<0.0001$ & Significant \\
\hline Residual & 5.6200 & 7 & 0.8000 & & & \\
\hline Lack of Fit & 3.9400 & 3 & 1.3100 & 3.1200 & 0.1501 & Not significant \\
\hline Pure error & 1.6800 & 4 & 0.4200 & & & \\
\hline Corrected total $\mathrm{SS}^{\mathrm{d}}$ & 563.07 & 16 & & & & \\
\hline$R^{2}$ & 0.9900 & & & & & \\
\hline Adjusted $R^{2}$ & 0.9772 & & & & & \\
\hline Adequate Precision & 28.902 & & & & & \\
\hline
\end{tabular}

Additionally, the model goodness of fit was validated by the determination coefficient $\left(R^{2}\right)$ and the adjusted $R^{2}$, which ensures the adequate variation of the quadratic model in terms of the experimental values. $R^{2}$ and adjusted $R^{2}$ values for the percent TOC removal $\left(Y_{1}\right)$, the percent TN removal $\left(Y_{2}\right)$, biogas yield $\left(Y_{3}\right)$, and TSS residual $\left(Y_{4}\right)$ were 0.9910 and 0.9795, 0.9963 and 0.9915, 0.9937 and 0.9855 , and 0.9900 and 0.9772 , respectively. Thus, the obtained $R^{2}$ and adjusted $R^{2}$ values for each model represent a high model significance.

\subsubsection{Individual effects of model parameters}

The significance of each model parameter was also evaluated using the $F$-exact test and $p$-values for each factor including linear, quadratic, and cross-factor interaction. As shown in Table 5.4, $p$-values lower than 0.05 identify model coefficients as significant. Therefore, the influent TOC concentration $\left(X_{l}\right)$ showed a significant effect on all responses.

The flow rate $\left(X_{2}\right)$ demonstrated a significant effect on the percent TOC removal $\left(Y_{1}\right)$, the percent TN removal $\left(Y_{2}\right)$, and TSS residual $\left(Y_{4}\right)$. Whereas, the $\mathrm{pH}\left(X_{3}\right)$ was found to be significant on the percent TN removal $\left(Y_{2}\right)$, biogas yield $\left(Y_{3}\right)$, and TSS residual $\left(Y_{4}\right)$ based on their $p$-value (Table 5.4).

Figure 5.5a illustrates the effect of the influent TOC concentration on the percent TOC removal, the percent TN removal, the biogas yield, and the TSS residual. It could be observed that the influent 
TOC concentration is inversely proportional to both the percent TOC and TN removals while being directly proportional to the biogas yield and TSS residual. These results were validated by analyzing six influent TOC concentrations (50, 400, 750, 1100, 1450, and $1800 \mathrm{mg} / \mathrm{L})$, selected and tested based on previous studies for SWW treatment (Cao and Mehrvar, 2011; Bustillo-Lecompte et al., 2013, 2014; Bustillo-Lecompte and Mehrvar, 2015).

On the other hand, Figure 5.5b depicts the effect of the feed flow rate on the percent TOC removal, the percent TN removal, the biogas yield, and the TSS residual. The predicted model results indicate that both the percent TOC and TN removals are inversely proportional to the feed flow rate, whereas there is a direct relationship between the feed flow rate and TSS residual.

Besides, an optimum flow rate is required for a maximum biogas yield. Six flow rates were used to validate the model results in the range of $15-165 \mathrm{mg} / \mathrm{L}$ ), selected and tested based on previous studies (Rajakumar et al., 2011; Bustillo-Lecompte et al., 2013, 2014), as shown in Figure 5.5b.

Finally, Figure 5.5c portrays the influence of $\mathrm{pH}$ adjustment on both the percent TOC and TN removals as well as on the biogas production and TSS residual. The predicted models demonstrate that to achieve a maximum percent TOC removal, the percent TN removal, and the biogas yield with minimum TSS residual, an optimum $\mathrm{pH}$ value is required. These trends were confirmed by evaluating six pH levels, selected based on previous studies (Al-Mutairi et al., 2008; De Nardi et al., 2011; Rajakumar et al., 2011). Consequently, it could be stated that the influent TOC concentration, the flow rate, and the $\mathrm{pH}$ are found to be factors of interest to be assessed by RSM.

\subsubsection{Interaction of model parameters, $2 D$ contour plots, and $3 D$ response surface}

As shown in Table 5.4, there was only one interaction in model parameters, between the feed flow rate and the $\mathrm{pH}\left(\mathrm{X}_{2} X_{3}\right)$, which indicated no significant effect on the percent TN removal and TSS residual, despite the fact that it was significant on both the TOC removal and the biogas yield simultaneously. Thus, it could be stated that the individual parameters are mainly influencing the trend for the TN removal and TSS residual as linear effects. Conversely, the cross-factor interaction of the influent TOC concentration with $\mathrm{pH}\left(X_{1} X_{3}\right)$ was found to have a high significant effect on both the percent TN removal and the TSS residual. The cross-factor interactions between independent variables were plotted into the 2D contour plots and 3D surfaces shown in Figure 5.6. 


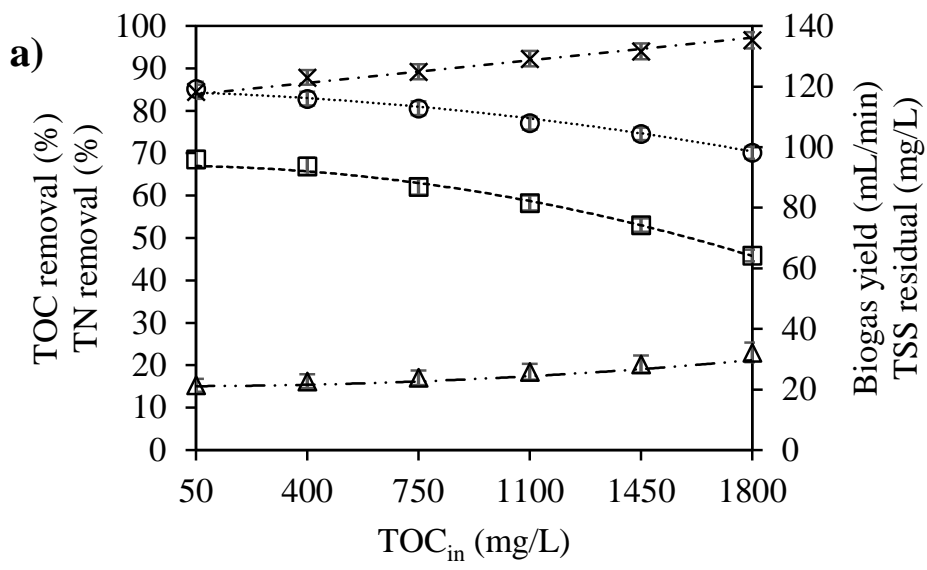

$$
\begin{aligned}
& \text { - TOCrem (\%) } \\
& \square \quad \text { TNrem }(\%) \\
& \times \text { Biogas ( } \mathrm{mL} / \mathrm{min}) \\
& \Delta \text { TSS (mg/L) } \\
& \text { Model TOCrem } \\
& \text { Model TNrem } \\
& \text {-. . . . Model Biogas } \\
& \text {-..- Model TSS }
\end{aligned}
$$
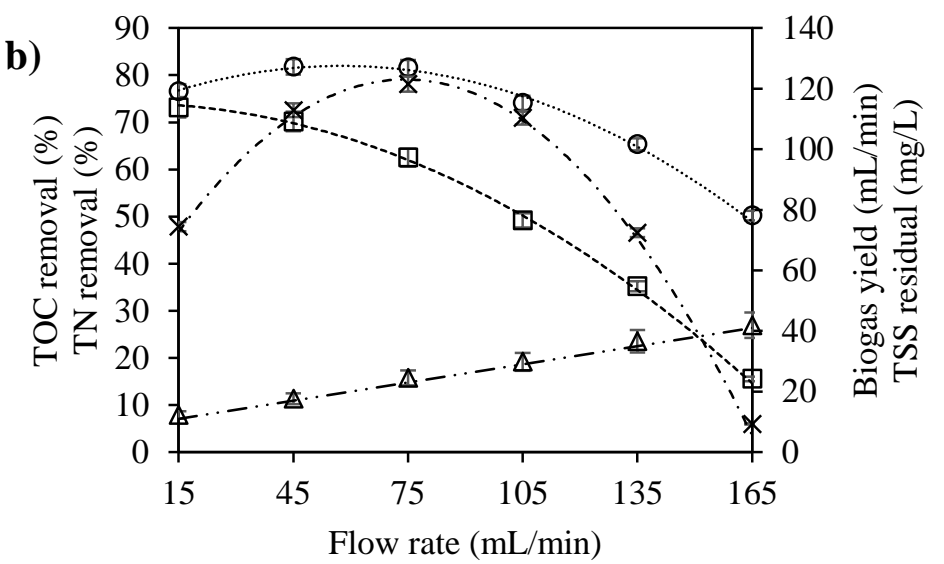

$$
\begin{aligned}
& \text { ○ TOCrem (\%) } \\
& \square \quad \text { TNrem }(\%) \\
& \times \text { Biogas }(\mathrm{mL} / \mathrm{min}) \\
& \Delta \text { TSS (mg/L) } \\
& \text { Model TOCrem } \\
& \text { Model TNrem } \\
& \text {-. - . Model Biogas } \\
& \text {-..- Model TSS }
\end{aligned}
$$

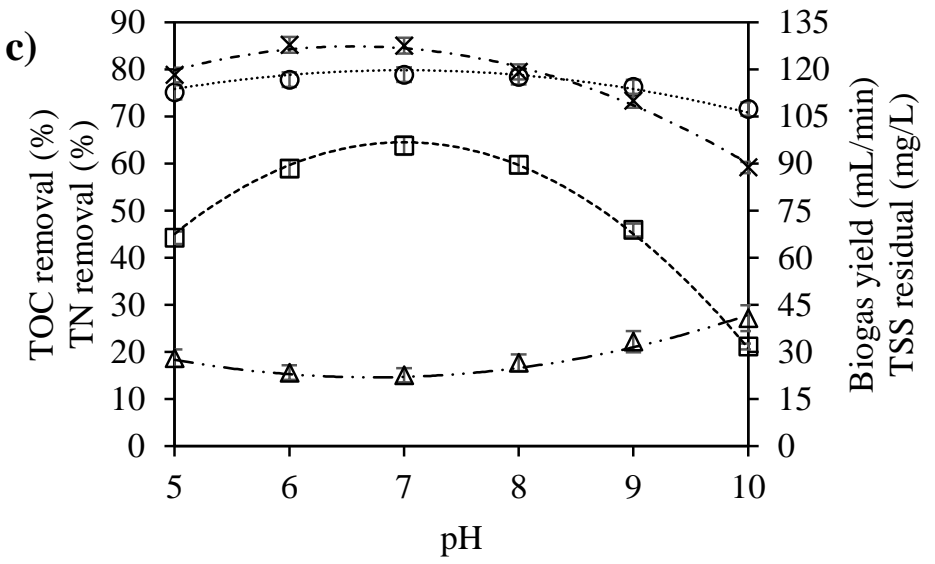

$$
\begin{aligned}
& \text { ○ TOCrem (\%) } \\
& \square \quad \text { TNrem }(\%) \\
& \times \quad \operatorname{Biogas}(\mathrm{mL} / \mathrm{min}) \\
& \Delta \quad \mathrm{TSS}(\mathrm{mg} / \mathrm{L}) \\
& \text { Model TOCrem } \\
& \text { Model TNrem } \\
& \text {-. - . Model Biogas } \\
& \text {-..- Model TSS }
\end{aligned}
$$

Figure 5.5. Individual effect of the (a) influent concentration of TOC, (b) flow rate, and (c) $\mathrm{pH}$ on percent TOC removal, percent TN removal, biogas yield, and TSS residual. The dashed lines represent model predicted values, whereas the marker points represent the experimental values. Error bars represent the standard deviation of the experimental data.

Submitted to J. Clean. Prod. (2016). 
As illustrated in Figures 5.6a, b, and c, the cross-factor interaction effects between the influent TOC concentration and the feed flow rate $\left(X_{1} X_{2}\right)$ on the percent TOC removal (Figure 5.6a), the percent TN removal (Figure 5.6b), and the TSS residual (Figure 5.6c) were examined. It could be inferred that a desirable interaction to reach maximum TOC and TN removal with minimum TSS residual is achieved when both the influent TOC concentration and the feed flow rate are minimum. In the case of the biogas yield, it is necessary to have a high influent TOC concentration at an optimum value for the feed flow rate, near the center point within the factor range, similar to the trend shown in Figure 5.6f.

On the other hand, Figure 5.6d, e, and f depict the cross-factor interaction effects between the influent TOC concentration and the $\mathrm{pH}\left(X_{1} X_{3}\right)$ on the percent TOC removal (Figure 5.6d), the percent TN removal (Figure 5.6e), and the biogas yield (Figure 5.6f). Results show that a desirable interaction to reach maximum TOC and TN removal is achieved when there is an optimum value for the $\mathrm{pH}$ near the center point within the factor range, and the influent TOC concentration is minimum. For biogas yield, it is necessary to have a high influent TOC concentration similar to the trend for the cross-factor interaction effects between the influent TOC concentration and the feed flow rate $\left(X_{1} X_{2}\right)$.

Finally, the cross-factor interaction effects between the feed flow rate and the $\mathrm{pH}\left(X_{2} X_{3}\right)$ on the biogas yield and TSS residual were illustrated in Figures 5.6g and h, respectively. It is revealed that a desirable interaction to reach maximum biogas yield is achieved when there is an optimum value for both the feed flow rate and the $\mathrm{pH}$ near the center points within the factor ranges (Figure 5.6g). Conversely, to reach the desired minimum TSS residual, there is an optimum value of $\mathrm{pH}$ near the center points within the factor ranges at low influent TOC concentrations (Figure 5.6h).

\subsubsection{Optimization of operating conditions and process parameters}

The RSM was used to determine the optimum experimental conditions of the three independent variables, including the influent concentration of TOC $\left(X_{1}\right)$, the flow rate $\left(X_{2}\right)$, and the $\mathrm{pH}\left(X_{3}\right)$ to obtain maximum percent TOC removal $\left(Y_{1}\right)$, maximum percent TN removal $\left(Y_{2}\right)$, and maximum biogas yield $\left(Y_{3}\right)$, with minimum TSS residual $\left(Y_{4}\right)$. The optimization was accomplished at defined optimization conditions using the built-in numerical optimization method of the statistical software Design-Expert 9.0.4.1. Equations (5.3) to (5.6) were defined as objective functions whereas the independent factors in their critical range were used as constraints. 

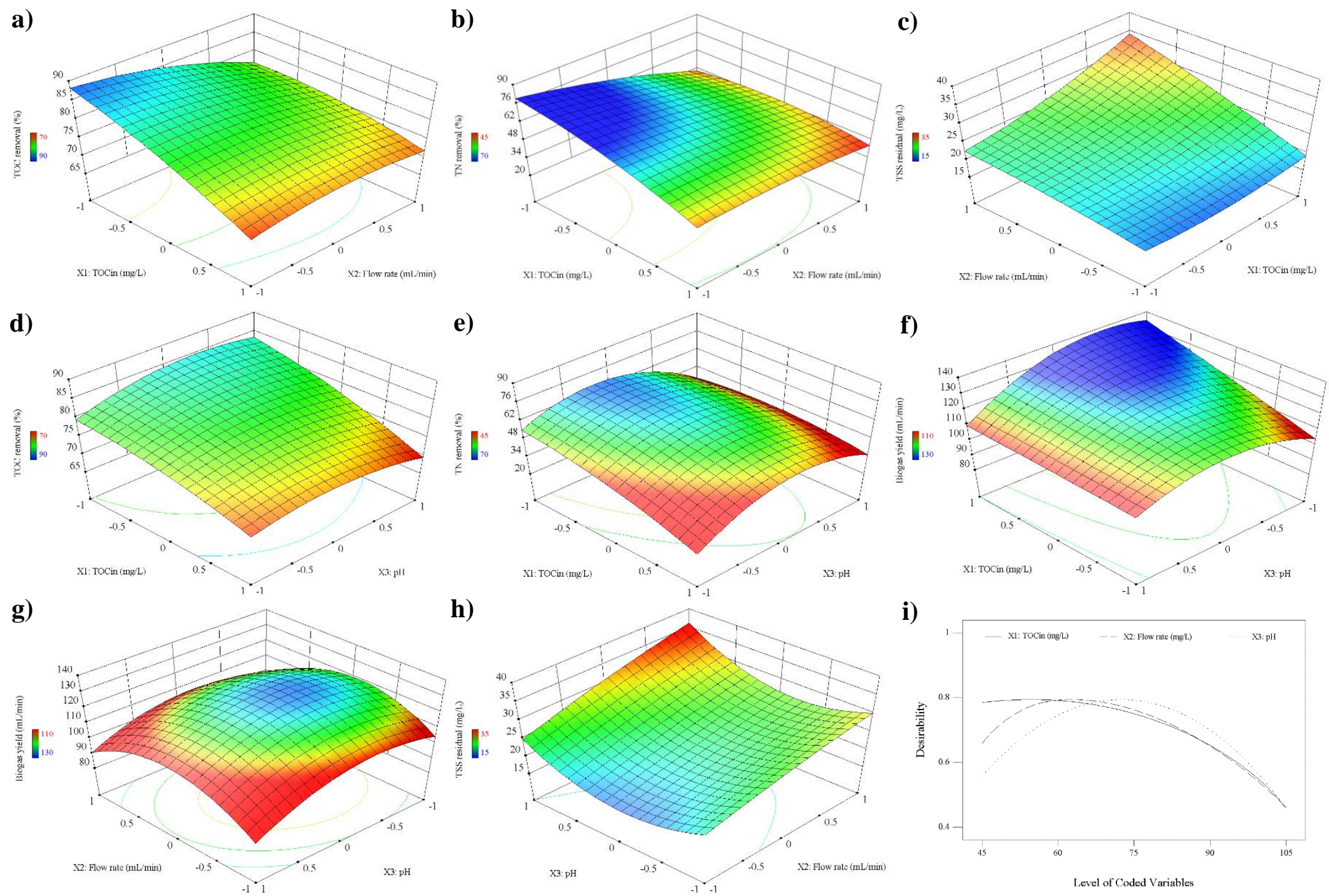

h)
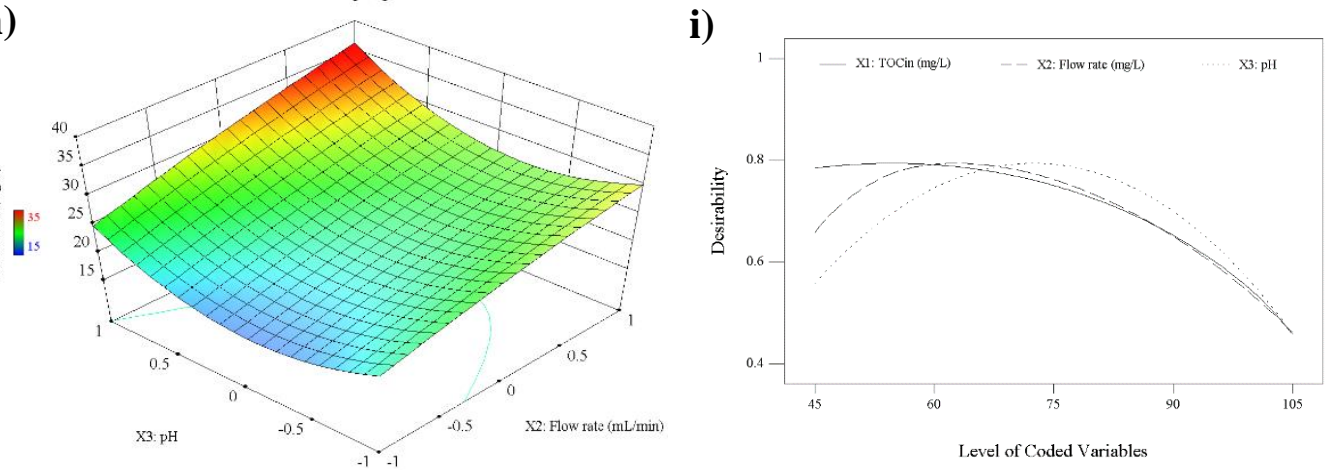

Figure 5.6. 3D plots of the cross-factor interaction effect between the influent TOC concentration and the feed flow rate $\left(X_{1} X_{2}\right)$ on: (a) percent TOC removal (b) percent TN removal, and (c) TSS residual; interaction effect between the influent TOC concentration and pH $\left(X_{1} X_{3}\right)$ on: (d) TOC removal, (e) TN removal, and (f) biogas yield; interaction effect between the feed flow rate and pH ( $\left.X_{2} X_{3}\right)$ on: (g) biogas yield and (h) TSS residual; and (i) the desirability parameter interaction. Submitted to J. Clean. Prod. (2016). 
The numerical optimization method explores the design space using the developed models to find the optimum factor conditions that meet the previously set goals of maximum percent TOC removal, maximum percent TN removal, and maximum biogas yield, with minimum TSS residual, simultaneously. The multiple response approach shown in Equation (5.2) was used to obtain the desirability parameter interaction plot (Figure 5.6i) at optimum factor settings by maximizing the percent TOC removal $\left(d_{1}\right)$, the percent TN removal $\left(d_{2}\right)$, and the biogas yield $\left(d_{3}\right)$, and minimizing the TSS residual $\left(d_{4}\right)$. Numerical optimization was used to maximize the biogas yield and the percent removals of TOC and TN while minimizing the TSS residual. Therefore, the desirability value of 0.79 was found to achieve the maximum removals of 85.03 and $72.10 \%$ for TOC and TN, respectively, minimum TSS residual of $19.54 \mathrm{mg} / \mathrm{L}$, and maximum biogas yield of $116.56 \mathrm{~mL} / \mathrm{min}$ at the optimum conditions of influent TOC concentration of $343 \mathrm{mg} / \mathrm{L}$, feed flow rate of $63 \mathrm{~mL} / \mathrm{min}$, and pH of 6.84 .

As a final point, the obtained optimal operating conditions were used in another experimental run to validate the predicted values. Consequently, the TOC removal of $84.92 \%$, the TN removal of $70.61 \%$,

the TSS residual of $19.76 \mathrm{mg} / \mathrm{L}$, and the biogas yield of $114.88 \mathrm{~mL} / \mathrm{min}$ were obtained experimentally. Thus, confirming the reliability of the model since all model parameters are within the $95 \%$ confidence intervals of $80.80-89.26 \%$ for TOC removal, $64.63-79.57 \%$ for TN removal, $14.58-24.50 \mathrm{mg} / \mathrm{L}$ for TSS residual, and 106.42-126.71 mL/min for biogas yield.

\subsubsection{Economic analysis}

In this study, $84.92 \%$ of the influent TOC concentration of $343 \mathrm{mg} / \mathrm{L}$ were removed at the optimal feed flow rate of $63 \mathrm{~mL} / \mathrm{min}$. Thus, the rate of the TOC removal per time was $18.35 \mathrm{mg} / \mathrm{min}$. On the other hand, the optimum biogas yield was $114.88 \mathrm{~mL} / \mathrm{min}$. These values were in line to those found in the literature for lab-scale biogas reactors (Liu et al., 2004; Kaparaju et al., 2009; Cadena Pereda et al., 2010). Hence, the total biogas production could be expressed in terms of TOC degraded:

$\frac{m L \text { biogas }}{m g \text { TOC removed }}=\frac{114.88 \mathrm{~mL} \text { biogas } / \mathrm{min}}{18.35 \mathrm{mg} \mathrm{TOC} / \mathrm{min}}=6.260 \mathrm{~mL}$ biogas $/ \mathrm{mg}$ TOC

Using the methane volume percentage of $35.43 \%$ obtained by biogas analysis (Landtec Biogas 5000, Colton, CA), the $\mathrm{CH}_{4}$ production was $2.21 \mathrm{~L} / \mathrm{kg}$ TOC removed. Consequently, by considering the lower heating value of methane of $35.9 \mathrm{MJ} / \mathrm{m}^{3}$, a daily energy generation of $0.58 \mathrm{kWh}$ is obtained. 
According to de Mes et al. (2003), biological processes for wastewater treatment have low energy requirements $\left(0.01-0.10 \mathrm{kWh} / \mathrm{m}^{3}\right)$. In this case, $0.01 \mathrm{kWh}$ is required for the combined ABR-AS system, representing only $2 \%$ of the generated power. Figure 5.7 compares the operational costs for the individual $\mathrm{ABR}$ and $\mathrm{AS}$ processes with those of the combined $\mathrm{ABR}-\mathrm{AS}$ system in terms of cost per cubic meter of the treated SWW versus the overall TOC removal. The costs related to installation and commissioning were not considered because the potential users in the meat processing industry must evaluate these particular costs separately in a case-by-case basis, depending on the number and type of animals being slaughtered per day, frequency in the cleaning of the facilities, and size of the meat processing plant. Therefore, the power consumption was used for each process multiplied by the electricity rate. A minimum overall treatment cost of $0.09 \$ / \mathrm{m}^{3}$ of actual SWW for a maximum TOC removal of $90 \%$ was achieved at the optimum operating conditions.

It is confirmed that the overall operational costs increase with the TOC removal because of the electricity consumption, especially in the AS process alone due to aeration, reaching values of up to five times higher than those of the combined ABR-AS system. Conversely, the costs have an inverse trend in the $\mathrm{ABR}$ process due to the potential energy recovery from $\mathrm{CH}_{4}$ production but the maximum removals were lower than $84 \%$. According to the Ontario Energy Board (OEB, 2016), the market price of electricity based on tiered prices for up to $750 \mathrm{kWh}$ in May 1, 2016 was $0.10 \$ / \mathrm{kWh}$. Thus, the laboratory scale combined ABR-AS system could generate $0.06 \$ /$ day. These values will be representative as a base for future studies on process optimization, modeling, and scale-up.

\subsection{Conclusions}

Results from the three-factor, three-level BBD to evaluate the treatment of SWW by the combined ABR-AS system demonstrated the influent TOC concentration showed significant effects on all responses including percent TOC removal, TN removal, TSS residual, and biogas yield. The feed flow rate was found to be significant on the percent TOC removal, TN removal, and TSS residual; and the $\mathrm{pH}$ was found to be significant on percent TN removal and biogas yield. There was only one crossfactor interaction, between the feed flow rate and the $\mathrm{pH}$, which showed no significant effect on two responses, percent TN removal and TSS residual, despite the fact that it was significant on TOC removal and biogas yield simultaneously. Accordingly, individual factors are influencing the trend for the TN removal and TSS residual as individual effects. 


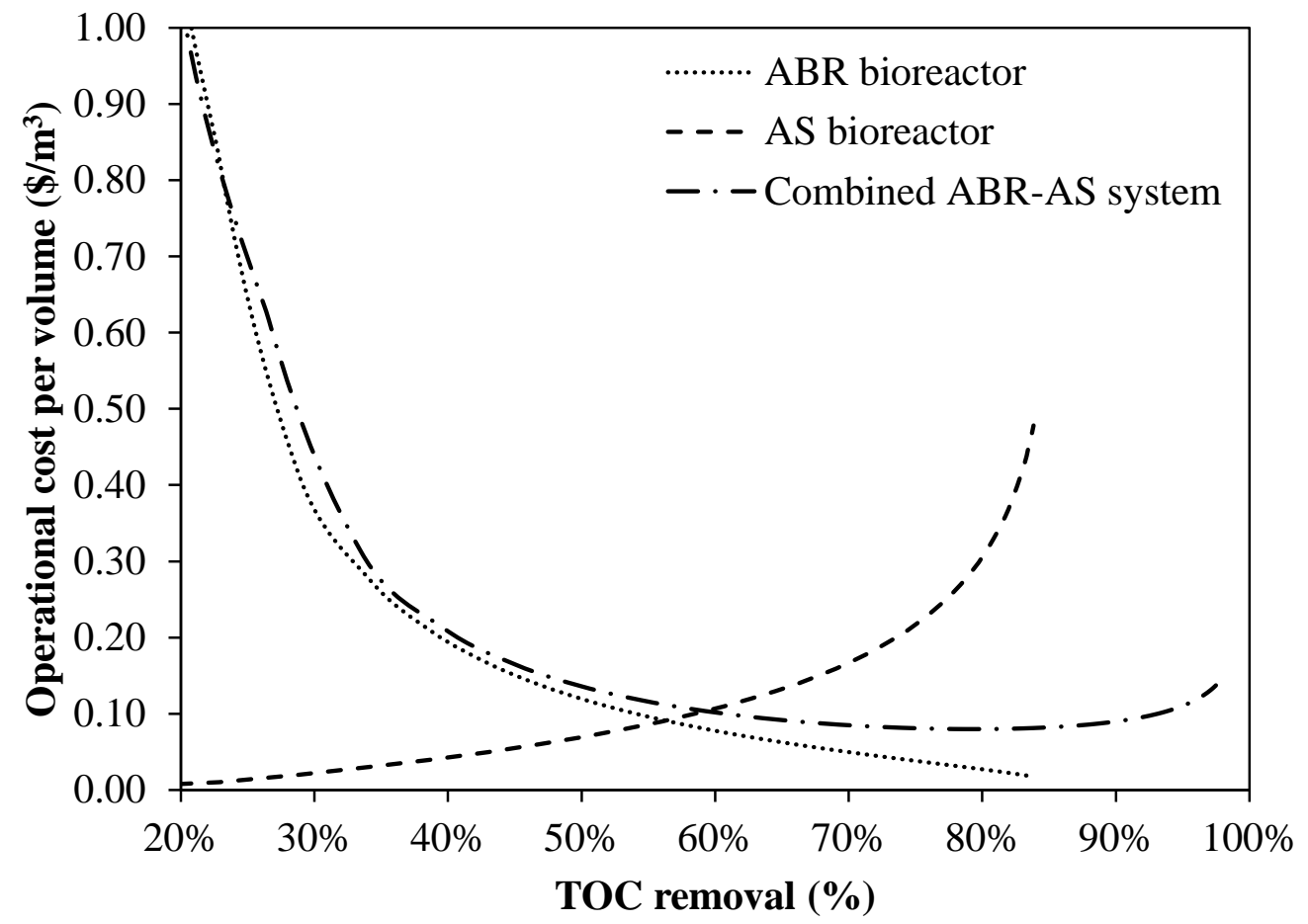

Figure 5.7. Operational costs per cubic meter of treated actual slaughterhouse wastewater against TOC removal efficiency: comparison of individual ABR and AS processes with the combined ABR-AS system in continuous mode.

Submitted to J. Clean. Prod. (2016). 
On the other hand, a desirable interaction to reach maximum TOC and TN removal with minimum TSS residual is achieved when both the influent TOC concentration and the feed flow rate are minimum, for biogas yield it is necessary a high influent TOC concentration at an optimum value for the feed flow rate. Furthermore, a maximum TOC and TN removal with minimum TSS residual is achieved when there is an optimum value for the $\mathrm{pH}$, and the influent TOC concentration is minimum. Likewise, a desirable interaction to reach maximum TOC and for biogas yield is achieved when there is an optimum value for both the feed flow rate and $\mathrm{pH}$.

Maximum removals of 85.03 and $72.10 \%$ for TOC and TN, respectively, minimum TSS residual of $19.54 \mathrm{mg} / \mathrm{L}$, and maximum biogas yield of $116.56 \mathrm{~mL} / \mathrm{min}$ were found at optimum conditions. The methane production was $2.21 \mathrm{~L} / \mathrm{kg}$ TOC removed, equivalent to a daily energy generation of $0.58 \mathrm{kWh}$. Thus, becoming a cost-effective alternative and simultaneously beneficial to the environment. The developed statistical models provided a detailed exploration of the simultaneous cross-factor interactive effects of the influent TOC concentration, the feed flow rate, and the $\mathrm{pH}$. Therefore, the proposed models explaining slaughterhouse wastewater treatment by combined anaerobic-aerobic processes for biogas production and organics removal could be used as a base for future studies for the reduction of

operating costs while providing high-quality treated wastewater for water reuse in the meat processing industry.

\section{Acknowledgments}

The financial support of Natural Sciences and Engineering Research Council of Canada (NSERC), Ontario Trillium Scholarship (OTS) Program, and Ryerson University is greatly appreciated. 


\title{
CHAPTER 6 \\ Photochemical Degradation \\ OF AN ACtual Slaughterhouse WasteWATER by Continuous UV/H2 $\mathrm{O}_{2}$ Photoreactor With Recycle*
}

\begin{abstract}
Slaughterhouse wastewater is treated using the $\mathrm{UV} / \mathrm{H}_{2} \mathrm{O}_{2}$ process in a continuous photoreactor with recycle, in which the effect of the recycle ratio (the ratio of recycle flow rate to the main feed flow rate) on the photoreactor efficiency is investigated. A four-factor, five-level central composite design along with response surface methodology is used to maximize the total organic carbon removal from an actual slaughterhouse wastewater and minimize the $\mathrm{H}_{2} \mathrm{O}_{2}$ residual in the effluent. The effects of the flow rate and the influent concentrations of total organic carbon and $\mathrm{H}_{2} \mathrm{O}_{2}$ on the photodegradation of the actual slaughterhouse wastewater are also investigated. Statistical models are developed to predict both the total organic carbon removal and the $\mathrm{H}_{2} \mathrm{O}_{2}$ residual as response variables. The recycle ratio is found to be significant in minimizing the $\mathrm{H}_{2} \mathrm{O}_{2}$ residual and the cross-factor interactions of recycle ratio with other variables demonstrate a significant effect on both total organic carbon removal and $\mathrm{H}_{2} \mathrm{O}_{2}$ residual. A maximum total organic carbon removal of $81 \%$ and a minimum $\mathrm{H}_{2} \mathrm{O}_{2}$ residual of less than $2 \%$ are found at optimum operating conditions of $24 \mathrm{mg} / \mathrm{L}$ influent total organic carbon, $860 \mathrm{mg} / \mathrm{L}$ influent $\mathrm{H}_{2} \mathrm{O}_{2}$ concentration, $15 \mathrm{~mL} / \mathrm{min}$ flow rate, and 0.18 recycle ratio. The model is validated under optimal operating conditions based on the experimental design results. The good agreement between model predictions and experimental values indicates that the proposed model could successfully describe the photochemical treatment of actual slaughterhouse wastewater by the continuous $\mathrm{UV} / \mathrm{H}_{2} \mathrm{O}_{2}$ process with recycle and its applicability as a post-treatment method.
\end{abstract}

Keywords: Slaughterhouse wastewater, advanced oxidation processes, recycle effect, $\mathrm{UV} / \mathrm{H}_{2} \mathrm{O}_{2}$, central composite design, experimental design.

\footnotetext{
* Reprinted, with minor editorial changes to fulfill formatting requirements, from:

C. Bustillo-Lecompte, S. Ghafoori, and M. Mehrvar (2016) Photochemical degradation of an actual slaughterhouse wastewater by continuous $\mathrm{UV} / \mathrm{H}_{2} \mathrm{O}_{2}$ photoreactor with recycle. Journal of Environmental Chemical Engineering 4 (1), pp. 719-732. With permission from Elsevier. License Number 3830960158225. DOI: 10.1016/j.jece.2015.12.009.
} 


\subsection{Introduction}

The global production of beef, pork, and poultry meat has been doubled in the past decade and is projected to grow until 2050. Furthermore, the number of slaughterhouse facilities are increasing, which results in an expected higher volume of slaughterhouse wastewater (SWW) to be treated. The SWW is typically assessed in terms of bulk parameters because of the diverse pollutant loads in the SWW derived from the type and number of animals slaughtered that fluctuate amid the meat industry (Bustillo-Lecompte and Mehrvar, 2015). SWW usually contain high levels of organics and nutrients, expressed as bulk components such as biochemical oxygen demand (BOD), chemical oxygen demand (COD), and total organic carbon (TOC). Thus, SWW is considered detrimental worldwide, and on-site treatment would be the best option to treat and disinfect the effluents to be discharged safely into receiving waters (Debik and Coskun, 2009; Wu and Mittal, 2011; Bustillo-Lecompte et al., 2013, 2014; Bustillo-Lecompte and Mehrvar, 2015).

Advanced oxidation processes (AOPs) are becoming an attractive alternative over conventional treatment and a complimentary treatment option, as either pre-treatment or post-treatment, to current biological processes for SWW treatment (De Sena et al., 2009; Luiz et al., 2009; Cao and Mehrvar, 2011; Wu and Mittal, 2011; Barrera et al., 2012; Bustillo-Lecompte et al., 2013, 2014). Furthermore, AOPs may inactivate microorganisms without adding additional chemicals to the SWW, avoiding the formation of hazardous by-products (De Sena et al., 2009; Luiz et al., 2009; Cao and Mehrvar, 2011; Barrera et al., 2012; Bustillo-Lecompte et al., 2015).

Several AOPs have been tested for SWW treatment including ozonation, gamma radiation, and UV/ $\mathrm{H}_{2} \mathrm{O}_{2}$ (Wu and Doan, 2005; Melo et al., 2008; De Sena et al., 2009; Luiz et al., 2009; Cao and Mehrvar, 2011; Barrera et al., 2012; Bustillo-Lecompte et al., 2014; Bustillo-Lecompte et al., 2015). However, the $\mathrm{UV} / \mathrm{H}_{2} \mathrm{O}_{2}$ process has been found to be more efficient for $\mathrm{SWW}$ treatment. The $\mathrm{UV} / \mathrm{H}_{2} \mathrm{O}_{2}$ process is five times faster in inactivation and inhibition of microorganisms as well as in degrading aromatic compounds than other technologies. Removal efficiencies of up to 97, 95, and $75 \%$ could be achieved by the $\mathrm{UV} / \mathrm{H}_{2} \mathrm{O}_{2}$ process for COD, BOD, and TOC, respectively (De Sena et al., 2009; Luiz et al., 2009; Cao and Mehrvar, 2011; Wu and Mittal, 2011; Barrera et al., 2012; Bustillo-Lecompte et al., 2013, 2014). Thus, AOPs might be considered to enhance the SWW quality for water reuse purposes. 
On the other hand, AOPs are considered multifactor systems due to the interaction of several parameters including organics concentration, light source intensity, oxidant concentration, reaction time, $\mathrm{pH}$, and output power. Therefore, the characterization of such systems requires the consideration of cross-factor and single-factor effects using the design of experiments (DOE) to identify those factors that influence the multivariable system (Ghafoori et al., 2015).

The optimization of parameters by conventional methods needs time, materials, and a large number of experiments. On the other hand, parameters such as $\mathrm{H}_{2} \mathrm{O}_{2}$ residuals, known to be toxic to microorganisms in biological post-treatment, and recycle ratio, known as the ratio of recycle flow rate to the main feed flow rate, are not widely investigated. Moreover, conventional methods fail to consider the combined effects of all the factors involved. Therefore, a DOE is used to overcome the limitations of conventional methods and consequently optimize the factors involved. Conversely, the response surface methodology (RSM) has been recognized to be statistically reliable to analyze multifactor systems in chemical treatment processes. RSM considers cross-factor interactions to attain optimal responses using the minimum number of experiments (Ghafoori et al., 2012, 2014a, 2015).

In this study, the effects of the recycle ratio, the flow rate, and the influent concentrations of TOC and $\mathrm{H}_{2} \mathrm{O}_{2}$, and their interactions on the photochemical treatment of $\mathrm{SWW}$ in a $\mathrm{UV} / \mathrm{H}_{2} \mathrm{O}_{2}$ photoreactor with recycle were investigated to evaluate its feasibility as a post-treatment method. The DOE was used to optimize the photochemical treatment of the SWW using $\mathrm{UV} / \mathrm{H}_{2} \mathrm{O}_{2}$ process in a continuous photoreactor with recycle by maximizing the TOC removal and minimizing the $\mathrm{H}_{2} \mathrm{O}_{2}$ residual in the effluent. The optimal parametric values for the DOE were obtained using a central composite design (CCD) using four factors at five levels combined with RSM. Statistical models were also developed to predict both percent TOC removal and $\mathrm{H}_{2} \mathrm{O}_{2}$ residual as response variables by the $\mathrm{UV} / \mathrm{H}_{2} \mathrm{O}_{2}$ process. As a final point, the statistical models were validated by an additional set of experiments carried out at optimum conditions according to the DOE results.

\subsection{Materials and methods}

\subsubsection{Materials}

Actual SWW samples were taken from selected provincially licensed meat processing plants directly from their source in Ontario, Canada, at the time of the study (OMAFRA, 2015a). SWW samples had an average TOC concentration of $862 \mathrm{mg} / \mathrm{L}$. Table 6.1 shows the overall SWW 
characteristics from the selected provincially licensed meat processing plants (Bustillo-Lecompte and Mehrvar, 2015). Three out of ten sample sites were used in this study due to the TOC low range of the slaughterhouse wastewater effluents obtained from the meat processing plants (11-94 mg/L). Distilled water (DW) was used to dilute SWW samples in order to adjust the influent TOC concentrations to different CCD levels accordingly. A hydrogen peroxide solution (30\% w/w) was purchased from Sigma-Aldrich and used as received.

Table 6.1. Characteristics of the actual slaughterhouse wastewater from selected provincially licensed meat processing plants along with study range values and detection limits.

Reprinted from J. Environ. Chem. Eng. 4 (2016) 719-732, with permission from Elsevier.

\begin{tabular}{lllll}
\hline Parameter & Range & Mean & Study range & Detection limits \\
\hline BOD (mg/L) & $37.95-8,231$ & 2,649 & $37.95-339.5$ & $0.000-10,000$ \\
COD (mg/L) & $87.23-14,256$ & 5,577 & $87.23-780.4$ & $0.000-15,000$ \\
TN (mg/L) & $6.120-339.2$ & 156.4 & $6.120-54.74$ & $0.100-25,000$ \\
TOC (mg/L) & $10.51-1,718$ & 86.21 & $10.51-94.01$ & $0.100-25,000$ \\
TP (mg/L) & $2.570-77.31$ & 4.281 & $2.570-22.98$ & $0.020-125.00$ \\
TSS (mg/L) & $0.390-738.0$ & 309.2 & $0.390-103.5$ & $0.000-750.00$ \\
pH & $6.0-7.1$ & 6.9 & $6.8-7.0$ & $4.0-10$ \\
\hline
\end{tabular}

\subsubsection{Experimental setup and procedure}

A laboratory-scale continuous photoreactor with recycle and uniform light distribution was used. Figure 6.1 shows the schematic diagram of the experimental setup for the $\mathrm{UV} / \mathrm{H}_{2} \mathrm{O}_{2}$ process with recycle. The stainless steel cylindrical photoreactor (Barrier SL-1S-Siemens Inc., Markham, ON) had a total operational volume of $1.35 \mathrm{~L}$ with an external diameter of $8 \mathrm{~cm}$ and a length of $34 \mathrm{~cm}$. A $2.5 \mathrm{~cm}$ in diameter UV-C lamp with output power of $6 \mathrm{~W}$ and $254 \mathrm{~nm}$ wavelength was inserted into the center of the photoreactor. A quartz sleeve covered the UV-C lamp to protect the lamp from fouling and maintain a uniform UV radiation emission. The following procedure was implemented to carry out each experiment for quality control:

1) The UV lamp was switched on for $30 \mathrm{~min}$ prior to the start of each experiment to guarantee light intensity stabilization within the photoreactor.

2) SWW samples were filtered to separate the liquid portion of the wastewater from the solids. 


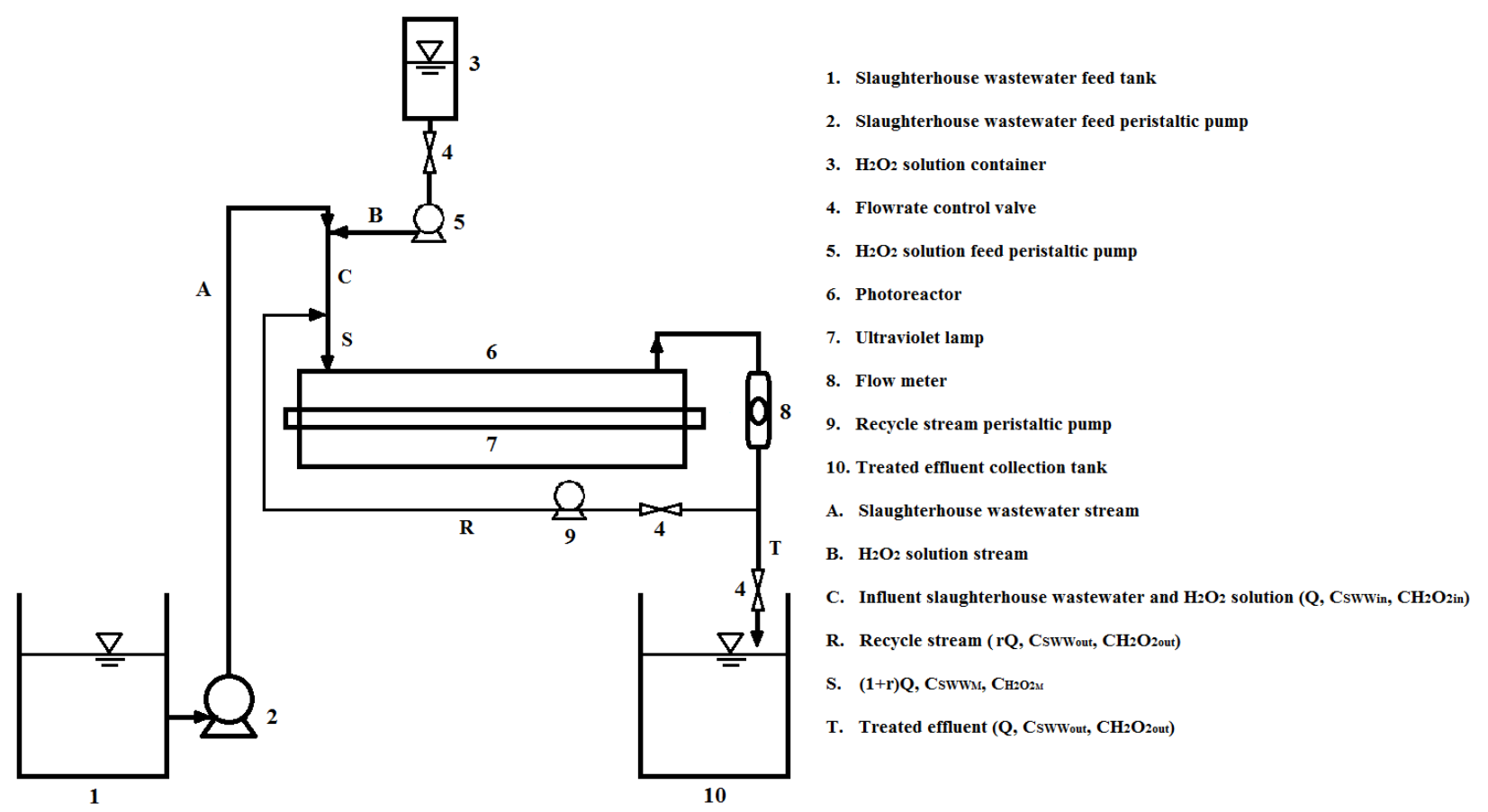

Figure 6.1. Schematic diagram of the laboratory-scale single lamp continuous $\mathrm{UV} / \mathrm{H}_{2} \mathrm{O}_{2}$ photoreactor with effluent recycle. $Q$ and $r$ are the flow rate and recycle ratio, respectively. $C_{S W W i n}, C_{S W W o u t}$, and $C_{S W W M}$ are the slaughterhouse wastewater concentration in the influent, in the effluent, and entering the photoreactor, respectively. $C_{H 2 O 2 i n}, C_{H 2 O 2 o u t}$, and $C_{H 2 O 2 M}$ are the hydrogen peroxide concentration in the influent, in the effluent, and entering the photoreactor, respectively.

Reprinted from J. Environ. Chem. Eng. 4 (2016) 719-732, with permission from Elsevier. 
3) Filtered SWW samples were then diluted to reach the desired TOC concentration and guarantee the accuracy of the feed concentration value in a 6-L solution (i.e. an actual slaughterhouse wastewater sample with a concentration of $26.42 \mathrm{mg} / \mathrm{L}$ was diluted to $25.00 \mathrm{mg} / \mathrm{L}$ ).

4) The SWW solution with the desired TOC concentration was fed to the photoreactor by a variable speed peristaltic pump to control and adjust the flow rate.

5) An adequate $\mathrm{H}_{2} \mathrm{O}_{2}$ concentration was calculated based on the material balance for each experiment.

6) The $\mathrm{H}_{2} \mathrm{O}_{2}$ solution was also fed to the system by a secondary variable speed peristaltic pump at the time the SWW solution started to be fed to the photoreactor.

7) A recycle stream was controlled using the third variable speed peristaltic pump to adjust the flow rate to the desired recycle ratio.

8) Effluent samples were taken at 15-min intervals until the system reached steady state conditions.

TOC concentration was analyzed for each sample using an automated TOC analyzer (Apollo 9000 Teledyne Tekmar, Mason, OH). The $\mathrm{H}_{2} \mathrm{O}_{2}$ residuals were measured with a UV-vis Spectrophotometer (Ultrospec 1100 pro-Amersham Biosciences, Amersham, UK) at $454 \mathrm{~nm}$ using neocuproine and copper (Hamad et al., 2014). All experiments were repeated in triplicates and the average values were reported. Furthermore, three replicates were made for each analytical measurement.

\subsubsection{Reaction mechanisms}

The $\mathrm{UV} / \mathrm{H}_{2} \mathrm{O}_{2}$ process uses ultraviolet radiation to cleave the $\mathrm{O}-\mathrm{O}$ bond in $\mathrm{H}_{2} \mathrm{O}_{2}$ and generate hydroxyl radicals ( $\left.{ }^{\circ} \mathrm{OH}\right)$. Subsequently, the ${ }^{\circ} \mathrm{OH}$ can be scavenged by any organic compound present in SWW to initiate a radical chain degradation of $\mathrm{H}_{2} \mathrm{O}_{2}$ in the critical chemical and photochemical reactions taking place in the $\mathrm{UV} / \mathrm{H}_{2} \mathrm{O}_{2}$ process (Table 6.2). All reaction mechanisms rate constants shown in Table 6.2 are based on widely accepted photochemical reactions, where the influent TOC and $\mathrm{H}_{2} \mathrm{O}_{2}$ dosage as well as other parameters are shown to have effect on the kinetics of the $\mathrm{UV} / \mathrm{H}_{2} \mathrm{O}_{2}$ process (Ghafoori et al., 2012). The complete mineralization of the actual SWW to $\mathrm{H}_{2} \mathrm{O}$ and $\mathrm{CO}_{2}$, disregarding other intermediates, is presented in Reactions R21. 
Table 6.2. Reaction mechanisms for complete mineralization of $\mathrm{SWW}$ by $\mathrm{UV} / \mathrm{H}_{2} \mathrm{O}_{2}$ process.

Reprinted from J. Environ. Chem. Eng. 4 (2016) 719-732, with permission from Elsevier.

\begin{tabular}{|c|c|c|c|}
\hline Number & Reaction & Rate constant & Reference \\
\hline $\mathrm{R} 1$ & $\mathrm{H}_{2} \mathrm{O}_{2} \stackrel{\phi_{\mathrm{H}_{2} \mathrm{O}_{2}}, h v}{\longrightarrow} 2 \cdot \mathrm{OH}$ & $0.50 \mathrm{~mol} / \mathrm{E}$ & Buxton et al. (1988) \\
\hline $\mathrm{R} 2$ & $\mathrm{H}_{2} \mathrm{O}_{2}+{ }^{\cdot} \mathrm{OH} \stackrel{k_{2}}{\rightarrow} \mathrm{HO}_{2}^{\bullet}+\mathrm{H}_{2} \mathrm{O}$ & $2.7 \times 10^{7} 1 / \mathrm{M} \mathrm{s}$ & Christensen et al. (1982) \\
\hline R3 & $\mathrm{HO}_{2}^{-}+{ }^{\bullet} \mathrm{OH} \stackrel{k_{3}}{\rightarrow} \mathrm{HO}_{2}^{\cdot}+\mathrm{OH}^{-}$ & $7.5 \times 10^{9} 1 / \mathrm{M} \mathrm{s}$ & Christensen et al. (1982) \\
\hline R4 & $\mathrm{O}_{2}^{\cdot-}+\mathrm{H}_{2} \mathrm{O}_{2} \stackrel{k_{4}}{\rightarrow} \mathrm{O}_{2}+{ }^{\bullet} \mathrm{OH}+\mathrm{OH}^{-}$ & $0.131 / \mathrm{M} \mathrm{s}$ & Weinstein and Bielski (1979) \\
\hline R5 & $\mathrm{O}_{2}^{\bullet-}+H^{+} \stackrel{k_{5}}{\rightarrow} \mathrm{HO}_{2}^{\bullet}$ & $1.0 \times 10^{10} 1 / \mathrm{M} \mathrm{s}$ & Bielski et al. (1985) \\
\hline R6 & $\mathrm{HO}_{2}^{\bullet}+H^{+} \stackrel{k_{6}}{\rightarrow} \mathrm{O}_{2}^{\bullet-}+H^{+}$ & $1.6 \times 10^{5} 1 / \mathrm{s}$ & Bielski et al. (1985) \\
\hline R7 & $2^{\bullet} \mathrm{OH} \stackrel{k_{7}}{\rightarrow} \mathrm{H}_{2} \mathrm{O}_{2}$ & $5.5 \times 10^{9} 1 / \mathrm{M} \mathrm{s}$ & Staehelin et al. (1984) \\
\hline $\mathrm{R} 8$ & $\mathrm{HO}_{2}^{\bullet}+\mathrm{O}_{2}^{\cdot-} \stackrel{k_{8}}{\rightarrow} \mathrm{HO}_{2}^{-}+\mathrm{O}_{2}$ & $9.7 \times 10^{7} 1 / \mathrm{M} \mathrm{s}$ & Bielski et al. (1985) \\
\hline R9 & $\mathrm{O}_{2}^{\cdot-}+\cdot \mathrm{OH}^{k_{9}} \rightarrow \mathrm{O}_{2}+\mathrm{OH}^{-}$ & $8.0 \times 10^{9} 1 / \mathrm{M} \mathrm{s}$ & Weinstein and Bielski (1979) \\
\hline R10 & $\mathrm{H}_{2} \mathrm{O}_{2} \stackrel{p K_{10}}{\longleftrightarrow} H^{+}+\mathrm{HO}_{2}^{-}$ & 11.6 & Weinstein and Bielski (1979) \\
\hline R11 & $\mathrm{HO}_{2}^{\cdot}+\mathrm{HO}_{2}^{\cdot} \stackrel{k_{11}}{\longrightarrow} \mathrm{H}_{2} \mathrm{O}_{2}+\mathrm{O}_{2}$ & $8.3 \times 10^{5} 1 / \mathrm{M} \mathrm{s}$ & Bielski et al. (1985) \\
\hline $\mathrm{R} 12$ & $2 \mathrm{HO}_{2}^{\cdot} \stackrel{k_{12}}{\longrightarrow} \mathrm{H}_{2} \mathrm{O}_{2}+\mathrm{O}_{2}$ & $1.5 \times 10^{6} 1 / \mathrm{M} \mathrm{s}$ & Buxton et al. (1988) \\
\hline R13 & $\mathrm{HO}_{2}^{\bullet}+\cdot \mathrm{OH}^{k_{14}} \rightarrow \mathrm{H}_{2} \mathrm{O}+\mathrm{O}_{2}$ & $6.6 \times 10^{9} 1 / \mathrm{M} \mathrm{s}$ & Buxton et al. (1988) \\
\hline R15 & $\mathrm{H}_{2} \mathrm{O}_{2}+\mathrm{HO}_{2}^{\cdot} \stackrel{k_{15}}{\longrightarrow} \mathrm{H}_{2} \mathrm{O}+\mathrm{O}_{2}+\cdot \mathrm{OH}$ & $3.001 / \mathrm{M} \mathrm{s}$ & Koppenol et al. (1978) \\
\hline R16 & $\mathrm{HO}_{2}^{\cdot}+{ }^{\bullet} \mathrm{OH} \stackrel{k_{16}}{\longrightarrow} \mathrm{H}_{2} \mathrm{O}+\mathrm{O}_{2}$ & $7.1 \times 10^{9} 1 / \mathrm{M} \mathrm{s}$ & Sehested et al. (1968) \\
\hline $\mathrm{R} 17$ & $\mathrm{HCO}_{3}^{-}+{ }^{\bullet} \mathrm{OH} \stackrel{k_{17}}{\rightarrow} \mathrm{CO}_{3}^{\cdot-}+\mathrm{H}_{2} \mathrm{O}$ & $8.5 \times 10^{6} 1 / \mathrm{M} \mathrm{s}$ & Buxton et al. (1988) \\
\hline $\mathrm{R} 18$ & $\mathrm{CO}_{3}^{2-}++^{\bullet} \mathrm{OH} \stackrel{k_{18}}{\longrightarrow} \mathrm{CO}_{3}^{\cdot-}+\mathrm{OH}^{-}$ & $3.9 \times 10^{8} 1 / \mathrm{M} \mathrm{s}$ & Buxton et al. (1988) \\
\hline R19 & $\mathrm{CO}_{3}^{\bullet-}+\mathrm{H}_{2} \mathrm{O}_{2} \stackrel{k_{19}}{\rightarrow} \mathrm{HCO}_{3}^{-}+\mathrm{HO}_{2}^{\bullet}$ & $4.3 \times 10^{5} 1 / \mathrm{M} \mathrm{s}$ & Crittenden et al. (1999) \\
\hline $\mathrm{R} 20$ & $\mathrm{TOC}+{ }^{\cdot} \mathrm{OH} \stackrel{k_{20}}{\longrightarrow}$ intermediates $\rightarrow \mathrm{CO}_{2}+\mathrm{H}_{2} \mathrm{O}$ & $7.0 \times 10^{5} 1 / \mathrm{M} \mathrm{s}$ & Barrera et al. (2012) \\
\hline $\mathrm{R} 21$ & $\mathrm{TOC}_{1}+{ }^{\cdot} \mathrm{OH} \stackrel{k_{21}}{\longrightarrow} \ldots \rightarrow \mathrm{CO}_{2}+\mathrm{H}_{2} \mathrm{O}$ & $1.1 \times 10^{5} 1 / \mathrm{M} \mathrm{s}$ & Bustillo-Lecompte et al. (2016) \\
\hline
\end{tabular}




\subsubsection{Photon irradiation balance}

Uniform light distribution was considered throughout the photoreactor because of the limited annular space inside the laboratory-scale photoreactor. Consequently, by employing the photon irradiation balance, the local volumetric rate of energy absorption (LVREA) could be written based on the Beer-Lambert law (Buxton et al., 1988; Ghafoori et al., 2014b), as shown below:

$$
L V R E A=I\left(\frac{\varepsilon_{\mathrm{H}_{2} \mathrm{O}_{2}}\left[\mathrm{H}_{2} \mathrm{O}_{2}\right]+\varepsilon_{\mathrm{HO}_{2}^{-}}\left[\mathrm{HO}_{2}^{-}\right]}{\varepsilon_{\mathrm{H}_{2} \mathrm{O}_{2}}\left[\mathrm{H}_{2} \mathrm{O}_{2}\right]+\varepsilon_{\mathrm{HO}_{2}^{-}}\left[\mathrm{HO}_{2}^{-}\right]+\varepsilon_{\mathrm{TOC} i}[\mathrm{TOCi}]}\right) \times\left(1-e^{-2.303 b\left\{\varepsilon_{\mathrm{H}_{2} \mathrm{O}_{2}}\left[\mathrm{H}_{2} \mathrm{O}_{2}\right]+\varepsilon_{\mathrm{HO}_{2}^{-}}\left[\mathrm{HO}_{2}^{-}\right]+\varepsilon_{\mathrm{TOC}}[\mathrm{TOC} i]\right\}}\right)
$$

where the intensity of the incident light $\left(I_{o}\right)$ was calculated to be $2 \times 10^{-5}$ Einstein/L.s by considering a $254 \mathrm{~nm}$ wavelength. The photon irradiance was estimated from the $14 \mathrm{~W}$ (input) low-pressure lamp per volume of the photoreactor and assuming $10 \%$ attenuation by the quartz sleeve, $33 \%$ efficiency for the low-pressure lamp, and considering the portion of the UV radiation absorption by $\mathrm{H}_{2} \mathrm{O}_{2}$. On the other hand, $\varepsilon_{\mathrm{H} 2 \mathrm{O} 2}, \varepsilon_{\mathrm{HO} 2^{-}}$, and $\varepsilon_{T O C i}$ are the molar extinction coefficients of $\mathrm{H}_{2} \mathrm{O}_{2}(18.71 / \mathrm{M} . \mathrm{cm}), \mathrm{HO}_{2}^{-}(210.0$ 1/M.cm), and $\operatorname{TOC}_{i}(132.7$ 1/M.cm) at $254 \mathrm{~nm}$, respectively. Lastly, $b$ is the effective path length, and, in this case, is the annular space in the photoreactor.

\subsubsection{Experimental design and optimization studies}

A four-factor along with five-level CCD in conjunction with RSM was used to maximize percent TOC removal and minimize percent $\mathrm{H}_{2} \mathrm{O}_{2}$ residuals in the effluent. The influent concentration of TOC $\left(X_{1}\right)$, influent $\mathrm{H}_{2} \mathrm{O}_{2}$ concentration $\left(X_{2}\right)$, flow rate $\left(X_{3}\right)$, and recycle ratio $\left(X_{4}\right)$ were used as independent factors in the DOE. The percent TOC removal and $\mathrm{H}_{2} \mathrm{O}_{2}$ residual were considered as dependent factors (i.e. process responses). Thus, each factor was coded at five levels (from -2 to +2 ), as shown in Table 6.3. Preliminary experiments were used to determine and select the critical ranges of the factors.

Table 6.3. Independent variables with coded levels based on a four-factor, five level CCD. Reprinted from J. Environ. Chem. Eng. 4 (2016) 719-732, with permission from Elsevier.

\begin{tabular}{lcccccc}
\hline & & \multicolumn{5}{c}{ Coded levels } \\
Independent variable & Symbol & $\mathbf{- 2}$ & $\mathbf{- 1}$ & $\mathbf{0}$ & $\mathbf{1}$ & $\mathbf{2}$ \\
\hline $\mathrm{TOC}_{\text {in }}(\mathrm{mg} / \mathrm{L})$ & $X_{1}$ & 10 & 25 & 40 & 55 & 70 \\
$\mathrm{H}_{2} \mathrm{O}_{2}$ in $(\mathrm{mg} / \mathrm{L})$ & $X_{2}$ & 300 & 600 & 900 & 1,200 & 1,500 \\
$\mathrm{Flow}$ rate $(\mathrm{mL} / \mathrm{min})$ & $X_{3}$ & 15 & 45 & 75 & 105 & 135 \\
Recycle ratio & $X_{4}$ & 0.0 & 0.2 & 0.4 & 0.6 & 0.8 \\
\hline
\end{tabular}


Equation (6.2) was used to predict the system responses as a quadratic model and estimate the parametrical coefficients by correlating dependent and independent variables using the least-squares regression (Ghafoori et al., 2012, 2014a, 2015):

$$
Y=\beta_{o}+\sum_{i=1}^{k} \beta_{i} X_{i}+\sum_{i=1}^{k} \beta_{i i} X_{i}^{2}+\sum_{i=1}^{k-1} \sum_{j=2}^{k} \beta_{i j} X_{i} X_{j}+c
$$

In this equation, $Y$ is the predicted response and $\beta_{o}, \beta_{i}, \beta_{i i}$, and $\beta_{i j}$ are the constant, linear, quadratic, and cross-factor interaction coefficients, respectively. $X_{i}$ and $X_{j}$ represent the independent variables; whereas, $k$ and $c$ are the number of factors and the residual term, respectively.

The statistical software Design-Expert 9.0.4.1 was employed for graphical and regression analysis to estimate the coefficients of the response functions. Moreover, the significance of the model equations, independent variables, and factor interactions were examined by analysis of variance (ANOVA) at 95\% confidence intervals (CI), i.e. $\alpha=0.05$. Three-dimensional (3D) surfaces and twodimensional (2D) contour plots were obtained while keeping another factor constant in the quadratic models. Experiments were carried out to validate the statistical models for maximum percent TOC removal and minimum $\mathrm{H}_{2} \mathrm{O}_{2}$ residual. Optimal operating conditions were estimated using the numerical optimization method built in the software. Lastly, an additional experimental run was carried out to validate the predicted optimal conditions for both response functions, the percent removal of TOC, and $\mathrm{H}_{2} \mathrm{O}_{2}$ residual.

The desirability multiple response method was used to combine the desirable ranges for each response in order to obtain a simultaneous objective function that represents the geometric mean of all transformed responses as shown in Equation (6.3) (Myers et al., 2004; Bustillo-Lecompte et al., 2016):

$$
D=\left(d_{1} \times d_{2} \times \ldots \times d_{n}\right)^{1 / n}=\left(\prod_{i=1}^{n} d_{i}\right)^{1 / n}
$$

In this equation, $D, d_{i}$, and $n$ are the desirability objective function, each response range, and the number of responses, respectively. If any of the analyzed responses is found to be outside of their desirability range, the overall desirability function becomes zero. Therefore, for a simultaneous optimization, each 
response is required to be assigned low and high values for optimization. In this case, the percent removal of TOC $\left(d_{1}\right)$ is maximized while the $\mathrm{H}_{2} \mathrm{O}_{2}$ residual $\left(d_{2}\right)$ is minimized.

\subsection{Results and discussion}

\subsubsection{Preliminary experiments}

Preliminary experiments were conducted to select the critical ranges of the influent TOC concentration, the influent $\mathrm{H}_{2} \mathrm{O}_{2}$ concentration, the flow rate, and the recycle ratio based on their effects on the percent TOC removal and the $\mathrm{H}_{2} \mathrm{O}_{2}$ residual. Figure 6.2 depicts the profiles for percent TOC removal and $\mathrm{H}_{2} \mathrm{O}_{2}$ residual in a laboratory-scale single lamp continuous $\mathrm{UV} / \mathrm{H}_{2} \mathrm{O}_{2}$ photoreactor with recycle. Different conditions of the influent TOC concentration (Figure 6.2a), the influent $\mathrm{H}_{2} \mathrm{O}_{2}$ concentration (Figure 6.2b), the flow rate (Figure 6.2c), and the recycle ratio (Figure 6.2d) were used.

As shown in Figure 6.2a, five influent TOC concentrations (10, 30, 50, 70, $90 \mathrm{mg} / \mathrm{L})$ were used. These influent concentrations were selected based on previous studies for the SWW treatment by UV/ $\mathrm{H}_{2} \mathrm{O}_{2}$ (De Sena et al., 2009; Luiz et al., 2009; Cao and Mehrvar, 2011; Wu and Mittal, 2011; Barrera et al., 2012; Bustillo-Lecompte et al., 2013, 2014). It can be observed that as the influent TOC concentration increases, the percent TOC removal decreases. Conversely, the $\mathrm{H}_{2} \mathrm{O}_{2}$ residual is minimum at an optimum influent TOC concentration value.

Figure $6.2 \mathrm{~b}$ depicts the influence of the influent $\mathrm{H}_{2} \mathrm{O}_{2}$ concentration on the TOC removal and the $\mathrm{H}_{2} \mathrm{O}_{2}$ residual. Five $\mathrm{H}_{2} \mathrm{O}_{2}$ concentrations $(300,600,900,1200$, and $1500 \mathrm{mg} / \mathrm{L})$ were selected and tested based on previous studies (Cao and Mehrvar, 2011; Wu and Mittal, 2011; Barrera et al., 2012; BustilloLecompte et al., 2013, 2014, 2015). Results show that by increasing the $\mathrm{H}_{2} \mathrm{O}_{2}$ concentration, the $\mathrm{H}_{2} \mathrm{O}_{2}$ residual also increases; whereas there is an optimum $\mathrm{H}_{2} \mathrm{O}_{2}$ concentration at which percent TOC removal is maximum.

Likewise, Figure 6.2c illustrates the effects of the flow rate on both the percent TOC removal and the $\mathrm{H}_{2} \mathrm{O}_{2}$ residual. Up to six flow rates were tested in the range of 15-165 mg/L. Results demonstrate that $\mathrm{H}_{2} \mathrm{O}_{2}$ residual is directly proportional to the flow rate while the TOC removal is inversely proportional to the flow rate as established by the profile trends. 

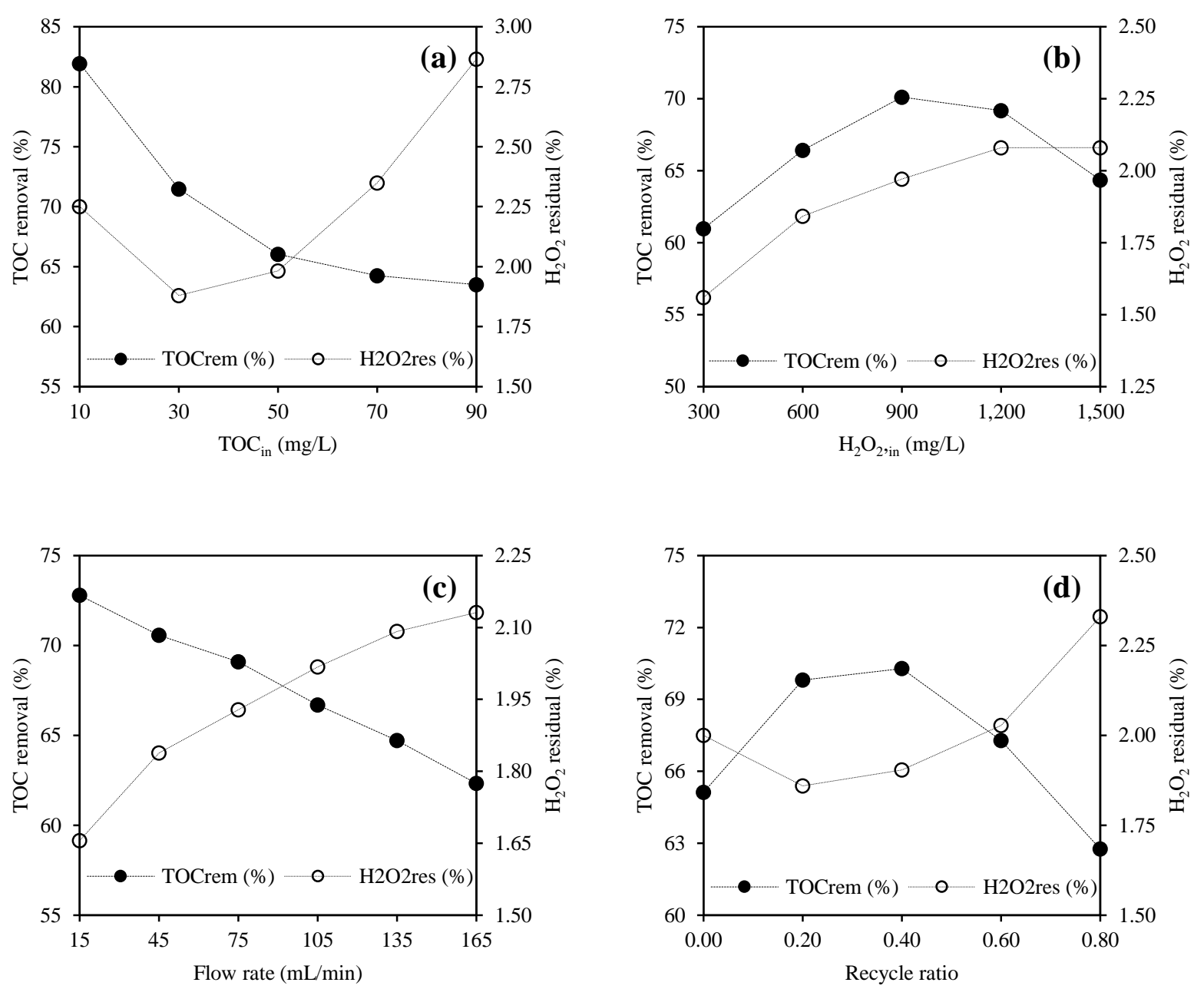

Figure 6.2. Profiles of TOC removal and $\mathrm{H}_{2} \mathrm{O}_{2}$ residual in a laboratory-scale single lamp continuous $\mathrm{UV} / \mathrm{H}_{2} \mathrm{O}_{2}$ photoreactor with effluent recycle for $\mathrm{SWW}$ treatment under different conditions of (a) influent concentration of TOC, (b) influent $\mathrm{H}_{2} \mathrm{O}_{2}$ concentration, (c) flow rate, and (d) recycle ratio.

Reprinted from J. Environ. Chem. Eng. 4 (2016) 719-732, with permission from Elsevier. 
As a final point, Figure 6.2d illustrates the profile trends of the TOC removal and the $\mathrm{H}_{2} \mathrm{O}_{2}$ residual in terms of recycle ratio. Results show that an optimum recycle ratio was required to achieve a maximum TOC removal with minimum $\mathrm{H}_{2} \mathrm{O}_{2}$ residual. Therefore, the recycle ratio was found to be a variable of interest to be evaluated using DOE and RSM.

\subsubsection{Experimental design and statistical analysis}

Table 6.4 portrays the four-factor, five-level CCD with observed and predicted values for both percent TOC removal and $\mathrm{H}_{2} \mathrm{O}_{2}$ residual by the developed quadratic models related to the $\mathrm{UV} / \mathrm{H}_{2} \mathrm{O}_{2}$ process in a continuous photoreactor with recycle for SWW treatment.

Table 6.4. Four-factor, five-level CCD for RSM, along with the observed and predicted percent TOC removal and $\mathrm{H}_{2} \mathrm{O}_{2}$ residual.

Reprinted from J. Environ. Chem. Eng. 4 (2016) 719-732, with permission from Elsevier.

\begin{tabular}{|c|c|c|c|c|c|c|c|c|}
\hline \multirow[b]{2}{*}{ Run } & \multicolumn{4}{|c|}{ Independent coded variables } & \multicolumn{2}{|c|}{ TOC removal (\%) } & \multicolumn{2}{|c|}{$\mathrm{H}_{2} \mathrm{O}_{2}$ residual $(\%)$} \\
\hline & $\mathbf{X}_{1}$ & $\mathbf{X}_{2}$ & $\mathbf{X}_{3}$ & $\mathbf{X}_{4}$ & Observed & Predicted & Observed & Predicted \\
\hline 1 & 1 & 1 & 1 & 1 & 66.12 & 64.88 & 2.03 & 2.06 \\
\hline 2 & -2 & 0 & 0 & 0 & 80.43 & 79.88 & 2.25 & 2.21 \\
\hline 3 & -1 & -1 & 1 & -1 & 69.21 & 69.03 & 1.63 & 1.66 \\
\hline 4 & 0 & 0 & 0 & 0 & 71.9 & 71.53 & 1.82 & 1.77 \\
\hline 5 & 1 & -1 & 1 & 1 & 60.55 & 61.08 & 1.96 & 2.01 \\
\hline 6 & -1 & 1 & -1 & -1 & 77.45 & 76.26 & 1.78 & 1.79 \\
\hline 7 & 0 & 0 & 0 & 0 & 71.96 & 71.53 & 1.75 & 1.77 \\
\hline 8 & -1 & 1 & 1 & 1 & 71.94 & 71.83 & 2.35 & 2.37 \\
\hline 9 & 0 & 0 & 0 & 0 & 72.08 & 71.53 & 1.75 & 1.77 \\
\hline 10 & 2 & 0 & 0 & 0 & 64.39 & 66.51 & 2.35 & 2.30 \\
\hline 11 & -1 & 1 & -1 & 1 & 76.17 & 76.38 & 1.87 & 1.88 \\
\hline 12 & 0 & -2 & 0 & 0 & 60.15 & 60.37 & 1.55 & 1.50 \\
\hline 13 & 1 & 1 & -1 & 1 & 66.83 & 66.35 & 1.79 & 1.82 \\
\hline 14 & -1 & -1 & 1 & 1 & 71.23 & 70.48 & 2.1 & 2.10 \\
\hline 15 & 0 & 0 & 2 & 0 & 64.7 & 65.99 & 2.17 & 2.12 \\
\hline 16 & 1 & -1 & 1 & -1 & 66.79 & 65.68 & 1.78 & 1.80 \\
\hline 17 & 1 & 1 & 1 & -1 & 64.31 & 62.72 & 2.42 & 2.43 \\
\hline 18 & -1 & -1 & -1 & 1 & 67.09 & 68.01 & 1.97 & 2.03 \\
\hline 19 & 0 & 0 & 0 & 2 & 63.41 & 63.69 & 2.3 & 2.25 \\
\hline 20 & 1 & -1 & -1 & -1 & 68.77 & 68.22 & 1.71 & 1.75 \\
\hline 21 & 0 & 0 & 0 & 0 & 72.31 & 71.53 & 1.77 & 1.77 \\
\hline 22 & 1 & -1 & -1 & 1 & 56.72 & 55.52 & 2.21 & 2.20 \\
\hline 23 & -1 & -1 & -1 & -1 & 74.31 & 74.65 & 1.36 & 1.36 \\
\hline 24 & -1 & 1 & 1 & -1 & 63.31 & 63.61 & 2.48 & 2.52 \\
\hline 25 & 1 & 1 & -1 & -1 & 72.44 & 72.29 & 1.94 & 1.96 \\
\hline 26 & 0 & 0 & 0 & 0 & 70.72 & 71.53 & 1.77 & 1.77 \\
\hline 27 & 0 & 0 & 0 & -2 & 66.89 & 68.18 & 1.99 & 1.95 \\
\hline 28 & 0 & 2 & 0 & 0 & 64.43 & 65.78 & 2.01 & 1.97 \\
\hline 29 & 0 & 0 & -2 & 0 & 72.81 & 73.08 & 1.61 & 1.58 \\
\hline 30 & 0 & 0 & 0 & 0 & 70.19 & 71.53 & 1.77 & 1.77 \\
\hline
\end{tabular}


RSM was employed for parameter estimation, indicating the relationship between the input factors and the responses, as shown in Equation (6.2). Thus, in order to predict the response functions for percent TOC removal $\left(Y_{1}\right)$ and $\mathrm{H}_{2} \mathrm{O}_{2}$ residual $\left(Y_{2}\right)$, the following second-order polynomial equations, Equations (6.4) and (6.5), respectively, were developed in terms of the coded factors:

$$
\begin{aligned}
& Y_{1}=71.53-3.34 X_{1}+1.35 X_{2}-1.77 X_{3}-1.12 X_{4}+0.62 X_{1} X_{2}+0.77 X_{1} X_{3}-1.52 X_{1} X_{4} \\
& -1.76 X_{2} X_{3}+1.69 X_{2} X_{4}+2.02 X_{3} X_{4}+0.42 X_{1}{ }^{2}-2.11 X_{2}{ }^{2}-0.50 X_{3}{ }^{2}-1.40 X_{4}{ }^{2} \\
& Y_{2}=1.77+0.02 X_{1}+0.12 X_{2}+0.13 X_{3}+0.08 X_{4}-0.05 X_{1} X_{2}-0.06 X_{1} X_{3}-0.06 X_{1} X_{4} \\
& +0.11 X_{2} X_{3}-0.15 X_{2} X_{4}-0.06 X_{3} X_{4}+0.12 X_{1}{ }^{2}-0.01 X_{2}{ }^{2}+0.01 X_{3}{ }^{2}+0.08 X_{4}{ }^{2}
\end{aligned}
$$

Negative coefficients for the model components, $X_{1}, X_{3}, X_{4}, X_{1} X_{4}, X_{2} X_{3}, X_{2}^{2}, X_{3}^{2}$ and $X_{4}^{2}$ in $Y_{1}$ and $X_{1} X_{2}, X_{1} X_{3}, X_{1} X_{4}, X_{2} X_{4}, X_{3} X_{4}$, and $X_{2}^{2}$ in $Y_{2}$, indicate unfavorable effects on the percent TOC removal and the $\mathrm{H}_{2} \mathrm{O}_{2}$ residual, respectively. While, positive coefficients for $X_{2}, X_{1} X_{2}, X_{1} X_{3}, X_{2} X_{4}, X_{3} X_{4}$, and $X_{1}^{2}$ in $Y_{1}$ and $X_{1}, X_{2}, X_{3}, X_{4}, X_{2} X_{3}, X_{1}^{2}, X_{3}^{2}$, and $X_{4}^{2}$ in $Y_{2}$ indicate favorable effects on the percent TOC removal and the $\mathrm{H}_{2} \mathrm{O}_{2}$ residual, respectively.

Coefficients with values close to zero represent lower relative intensity. Thus, $X_{1}^{2}$ and $X_{3}^{2}$ do not intensely affect the TOC removal while $X_{2}^{2}$ and $X_{3}^{2}$ do not intensely affect $\mathrm{H}_{2} \mathrm{O}_{2}$ residual. Although this evaluation provides a rapid analysis in terms of the parametrical effect on the response variables, ANOVA with 95\% CI was also applied to evaluate the statistical significance of the developed quadratic models for the percent TOC removal and the $\mathrm{H}_{2} \mathrm{O}_{2}$ residual as shown in Tables 6.5 and 6.6, respectively. The statistical significance of each factor coefficient, as shown in Equations (6.4) and (6.5), was determined by the Fisher's $(F)$ exact test, comparing probability $(p)$ values greater than $F$. As shown in Tables 6.5 and 6.6, the model $F$-values of 35.34 and 102.08 for TOC removal and $\mathrm{H}_{2} \mathrm{O}_{2}$ residual, respectively, imply the models are significant.

Besides, small probability values $(p<0.05)$ indicate significant model terms, which confirm the accuracy of the developed models to predict the response functions. On the other hand, $p$-values $>0.10$ indicate the model terms are not significant; in this case, $X_{l}^{2}$ is not significant for TOC removal while $X_{2}{ }^{2}$ and $X_{3}{ }^{2}$ are not significant for $\mathrm{H}_{2} \mathrm{O}_{2}$ residual. If the quadratic effect is not significant, then the optimal levels of the parameter are in the extremes of the experimental region (Beard et al., 2007; Botha et al., 2012). 
Table 6.5. ANOVA results for prediction of percent TOC removal by quadratic modeling.

Reprinted from J. Environ. Chem. Eng. 4 (2016) 719-732, with permission from Elsevier.

\begin{tabular}{|c|c|c|c|c|c|c|}
\hline Source & Sum of squares & $d f^{a}$ & Mean square & $F$ value $^{b}$ & $p$-value $(\text { Prob. }>F)^{\mathrm{c}}$ & Remark \\
\hline Model & 808.36 & 14 & 57.74 & 35.34 & $<0.0001$ & Significant \\
\hline$X_{1}$ & 268.40 & 1 & 268.40 & 164.30 & $<0.0001$ & Significant \\
\hline$X_{2}$ & 43.90 & 1 & 43.90 & 26.87 & 0.0001 & Significant \\
\hline$X_{3}$ & 75.40 & 1 & 75.40 & 46.16 & $<0.0001$ & Significant \\
\hline$X_{4}$ & 30.15 & 1 & 30.15 & 18.46 & 0.0006 & Significant \\
\hline$X_{1} X_{2}$ & 6.05 & 1 & 6.05 & 3.70 & 0.0735 & \\
\hline$X_{1} X_{3}$ & 9.52 & 1 & 9.52 & 5.83 & 0.0290 & Significant \\
\hline$X_{1} X_{4}$ & 36.72 & 1 & 36.72 & 22.48 & 0.0003 & Significant \\
\hline$X_{2} X_{3}$ & 49.35 & 1 & 49.35 & 30.21 & 0.0001 & Significant \\
\hline$X_{2} X_{4}$ & 45.70 & 1 & 45.70 & 27.97 & 0.0001 & Significant \\
\hline$X_{3} X_{4}$ & 65.53 & 1 & 65.53 & 40.11 & $<0.0001$ & Significant \\
\hline$X_{I}^{2}$ & 4.77 & 1 & 4.77 & 2.92 & 0.1082 & Not significant \\
\hline$X_{2}^{2}$ & 122.48 & 1 & 122.48 & 74.97 & $<0.0001$ & Significant \\
\hline$X_{3}^{2}$ & 6.77 & 1 & 6.77 & 4.15 & 0.0598 & \\
\hline$X_{4}^{2}$ & 53.62 & 1 & 53.62 & 32.82 & $<0.0001$ & Significant \\
\hline Residual & 24.50 & 15 & 1.63 & & & \\
\hline Lack of Fit & 20.82 & 10 & 2.08 & 2.83 & 0.1316 & Not significant \\
\hline Pure error & 3.68 & 5 & 0.74 & & & \\
\hline Corrected total $\mathrm{SS}^{\mathrm{d}}$ & 832.86 & 29 & & & & \\
\hline$R^{2}$ & 0.9706 & & & & & \\
\hline Adjusted $R^{2}$ & 0.9431 & & & & & \\
\hline Adequate Precision & 26.96 & & & & & \\
\hline \multicolumn{7}{|c|}{ Degrees of freedom $(d f)$} \\
\hline Fisher's $(F)$ exact te & value. & & & & & \\
\hline
\end{tabular}


Table 6.6. ANOVA results for prediction of percent $\mathrm{H}_{2} \mathrm{O}_{2}$ residual by quadratic modeling.

Reprinted from J. Environ. Chem. Eng. 4 (2016) 719-732, with permission from Elsevier.

\begin{tabular}{|c|c|c|c|c|c|c|}
\hline Source & Sum of squares & $d f^{a}$ & Mean square & $F$ value $^{b}$ & $p$-value $(\text { Prob. }>F)^{\mathrm{c}}$ & Remark \\
\hline Model & 2.21 & 14 & 0.16 & 102.08 & $<0.0001$ & Significant \\
\hline$X_{1}$ & 0.01 & 1 & 0.01 & 5.22 & 0.0374 & Significant \\
\hline$X_{2}$ & 0.33 & 1 & 0.33 & 211.21 & $<0.0001$ & Significant \\
\hline$X_{3}$ & 0.39 & 1 & 0.39 & 252.25 & $<0.0001$ & Significant \\
\hline$X_{4}$ & 0.14 & 1 & 0.14 & 93.20 & $<0.0001$ & Significant \\
\hline$X_{1} X_{2}$ & 0.04 & 1 & 0.04 & 28.51 & 0.0001 & Significant \\
\hline$X_{1} X_{3}$ & 0.06 & 1 & 0.06 & 38.81 & $<0.0001$ & Significant \\
\hline$X_{1} X_{4}$ & 0.06 & 1 & 0.06 & 37.24 & $<0.0001$ & Significant \\
\hline$X_{2} X_{3}$ & 0.19 & 1 & 0.19 & 122.34 & $<0.0001$ & Significant \\
\hline$X_{2} X_{4}$ & 0.36 & 1 & 0.36 & 232.76 & $<0.0001$ & Significant \\
\hline$X_{3} X_{4}$ & 0.06 & 1 & 0.06 & 38.81 & $<0.0001$ & Significant \\
\hline$X_{l}^{2}$ & 0.41 & 1 & 0.41 & 267.03 & $<0.0001$ & Significant \\
\hline$X_{2}^{2}$ & 0.00 & 1 & 0.00 & 0.94 & 0.3469 & Not significant \\
\hline$X_{3}^{2}$ & 0.00 & 1 & 0.00 & 2.86 & 0.1112 & Not significant \\
\hline$X_{4}^{2}$ & 0.19 & 1 & 0.19 & 125.01 & $<0.0001$ & Significant \\
\hline Residual & 0.02 & 15 & 0.00 & & & \\
\hline Lack of Fit & 0.02 & 10 & 0.00 & 3.03 & 0.1162 & Not significant \\
\hline Pure error & 0.00 & 5 & 0.00 & & & \\
\hline Corrected total $\mathrm{SS}^{\mathrm{d}}$ & 2.23 & 29 & & & & \\
\hline$R^{2}$ & 0.9896 & & & & & \\
\hline Adjusted $R^{2}$ & 0.9799 & & & & & \\
\hline Adequate Precision & 40.93 & & & & & \\
\hline
\end{tabular}

${ }^{a}$ Degrees of freedom $(d f)$

${ }^{\mathrm{b}}$ Fisher's $(F)$ exact test value.

${ }^{c}$ A probability value $(p)<0.05$ is considered significant, a $p$-value $>0.10$ is considered not significant.

d Total sum of squares corrected for the mean. 
The goodness of fit of the model was validated by the determination coefficient $\left(R^{2}\right)$ and the adjusted $R^{2}$ that ensures an adequate variation of the quadratic model to the experimental values. The values of $R^{2}$ and adjusted $R^{2}$ were found to be 0.9706 and 0.9431 for the percent TOC removal and 0.9896 and 0.9799 for the $\mathrm{H}_{2} \mathrm{O}_{2}$ residual, respectively. Thus, high $R^{2}$ and adjusted $R^{2}$ values represent a high model significance. The closer the values of $R^{2}$ and adjusted $R^{2}$ are to 1.0 , the better the model prediction is.

Furthermore, the adequate precision of the percent TOC removal and $\mathrm{H}_{2} \mathrm{O}_{2}$ residual were found to be 26.96 (Table 6.5) and 40.93 (Table 6.6), respectively. Since both adequate precision values were greater than 4.00, the model can be used to navigate the CCD design space (Ghafoori et al., 2012). Moreover, the lack of fit was calculated to measure how well the model fits the data. The lack of fit $p$ values of the percent TOC removal and the $\mathrm{H}_{2} \mathrm{O}_{2}$ residual were found to be 0.1316 (Table 6.5) and 0.1162 (Table 6.6), respectively. An insignificant lack of fit $(p>0.10)$ is a desirable property because it indicates that the model fits the data well.

On the other hand, the assumption of the constant variance was verified by plotting the internally studentized residual versus predicted values (Figures 6.3a and 6.4a). The studentized residuals are found by dividing the residuals by their standard deviations.

Figures 6.3a and 6.4a also show randomly scattered points within the outlier detection limits 3 and +3 . Therefore, model predictions, described in Equations (6.4) and (6.5), for both the percent TOC removal and the $\mathrm{H}_{2} \mathrm{O}_{2}$ residual, respectively, are satisfactory.

Moreover, the normal probability plot of residuals, shown in Figures $6.3 \mathrm{~b}$ and $6.4 \mathrm{~b}$ for the TOC removal and the $\mathrm{H}_{2} \mathrm{O}_{2}$ residual, respectively, showed a straight-line pattern followed by the points on the plot, not an S-shaped curve. Consequently, a transformation of the response is not required because of the normal distribution of the residuals (Ghafoori et al., 2014a).

The correlation between observed and predicted values is shown in Figures $6.3 \mathrm{c}$ and $6.4 \mathrm{c}$ for the TOC removal and the $\mathrm{H}_{2} \mathrm{O}_{2}$ residual, respectively. As a result, low discrepancies are represented by a straight-line trend, which indicates a good agreement between observed and predicted values. Hence, the quadratic model predictions for both percent TOC removal and $\mathrm{H}_{2} \mathrm{O}_{2}$ residual responses are satisfactory. 

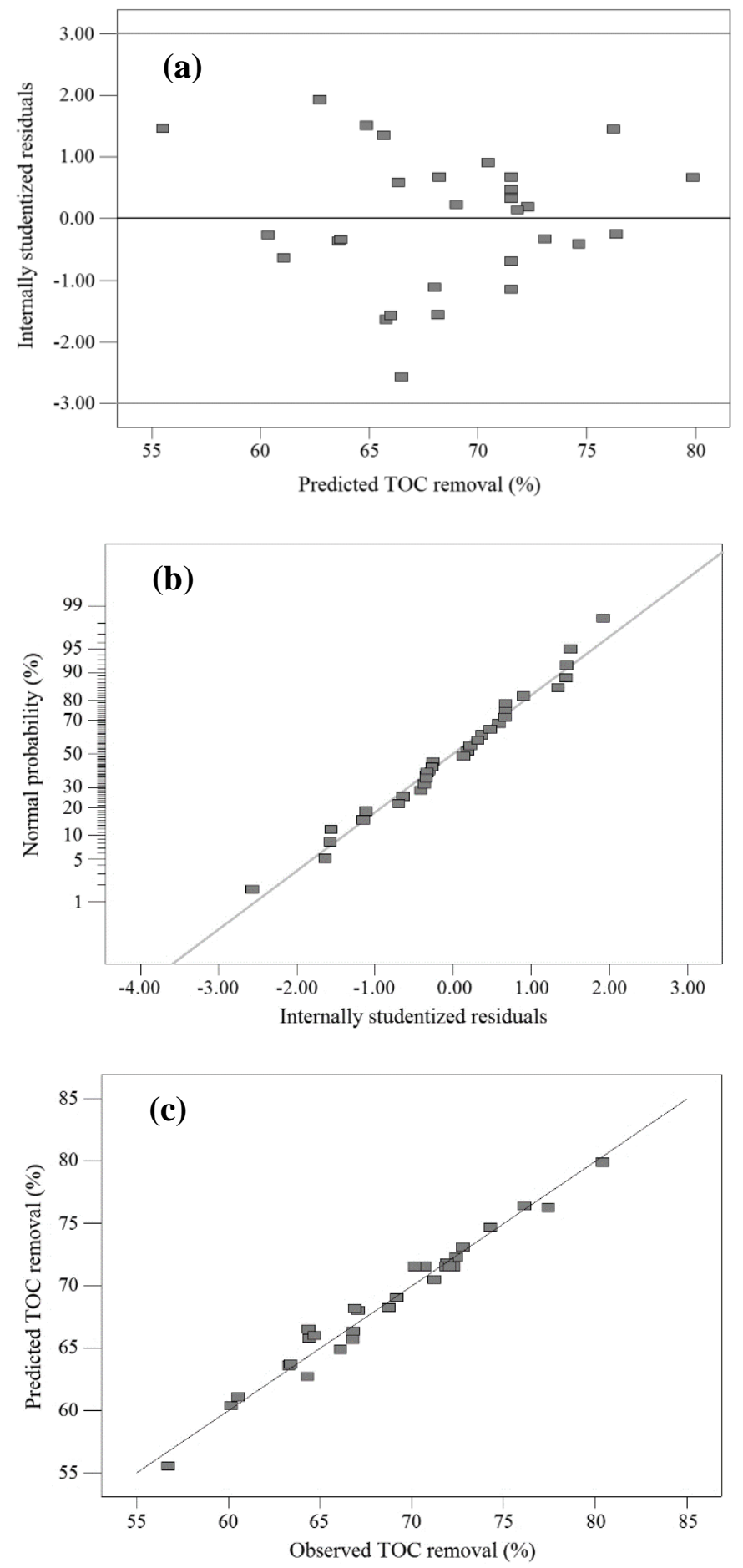

Figure 6.3. Validation of the percent TOC removal model using different plots: (a) internally studentized residuals versus predicted values, (b) normal probability, and (c) observed experimental data versus predicted values.

Reprinted from J. Environ. Chem. Eng. 4 (2016) 719-732, with permission from Elsevier. 

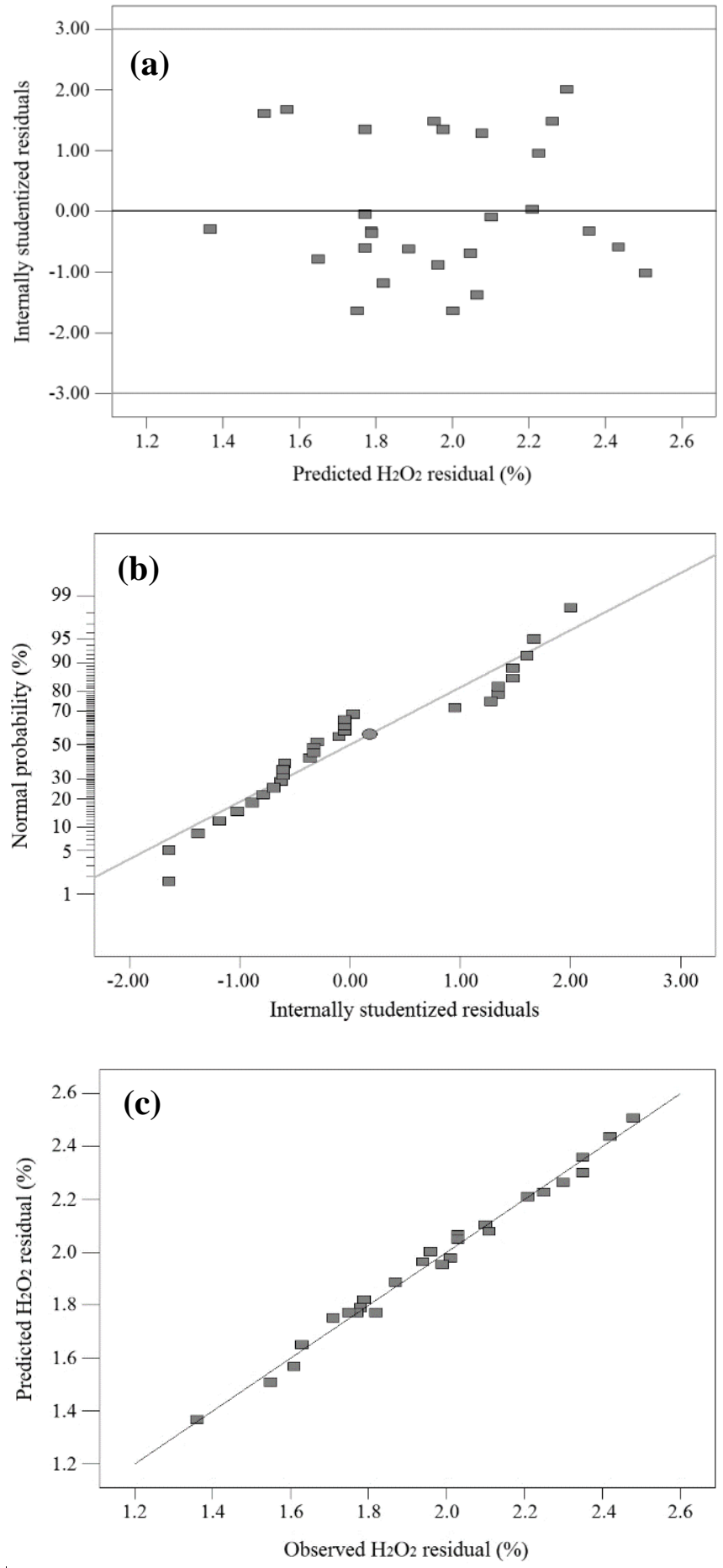

Figure 6.4. Validation of the percent $\mathrm{H}_{2} \mathrm{O}_{2}$ residual model using different plots: (a) internally studentized residuals versus predicted values, (b) normal probability, and (c) observed experimental data versus predicted values.

Reprinted from J. Environ. Chem. Eng. 4 (2016) 719-732, with permission from Elsevier. 


\subsubsection{Individual effect of model parameters}

Since the significance of the models (Tables 6.5 and 6.6) and the accuracy of the model predictions (Figures 6.3 and 6.4) were confirmed, it was required to examine the significance of each model factor. This evaluation was also performed using the $F$ exact test and $p$-values for each factor including linear, quadratic, and cross-factor interaction.

As presented in Tables 6.5 and 6.6, $p$-values lower than 0.05 indicate the significance of the model coefficients. Therefore, all four independent variables, influent TOC concentration $\left(X_{1}\right)$, influent $\mathrm{H}_{2} \mathrm{O}_{2}$ concentration $\left(X_{2}\right)$, flow rate $\left(X_{3}\right)$, and recycle ratio $\left(X_{4}\right)$, have significant effect on both responses, percent TOC removal, and $\mathrm{H}_{2} \mathrm{O}_{2}$ residual, based on their $p$-value.

Figures 6.5a and 6.6a depict the effect of the influent TOC concentration on the TOC removal and the $\mathrm{H}_{2} \mathrm{O}_{2}$ residual, respectively. It can be observed that the influent TOC concentration is inversely proportional to the percent TOC removal, whereas there is an optimum influent TOC concentration at which the $\mathrm{H}_{2} \mathrm{O}_{2}$ residual is minimum. Thus, this confirms the results obtained in the preliminary experiments as illustrated in Figure 6.2a.

On the other hand, Figures $6.5 \mathrm{~b}$ and $6.6 \mathrm{~b}$ illustrate the effect of the $\mathrm{H}_{2} \mathrm{O}_{2}$ concentration on the TOC removal and the $\mathrm{H}_{2} \mathrm{O}_{2}$ residual, respectively. The predicted models show that there is an optimum $\mathrm{H}_{2} \mathrm{O}_{2}$ concentration for a maximum percent TOC removal and a direct relationship between the influent $\mathrm{H}_{2} \mathrm{O}_{2}$ concentration and the $\mathrm{H}_{2} \mathrm{O}_{2}$ residual, confirming observed values from the preliminary studies as depicted in Figure 6.2b.

Similarly, Figures 6.5c and 6.6c show the effect of the flow rate on the percent TOC removal and the $\mathrm{H}_{2} \mathrm{O}_{2}$ residual, respectively. The predicted models confirm that the percent TOC removal is inversely proportional to the flow rate and that the $\mathrm{H}_{2} \mathrm{O}_{2}$ residual is directly proportional to the flow rate, as shown in Figure 6.2c.

Finally, Figures 6.5d and 6.6d depict the effects of the recycle ratio on the TOC removal and the $\mathrm{H}_{2} \mathrm{O}_{2}$ residual, respectively. The predicted models demonstrate that to achieve a maximum TOC removal with minimum $\mathrm{H}_{2} \mathrm{O}_{2}$ residual, an optimum recycle ratio is required. 

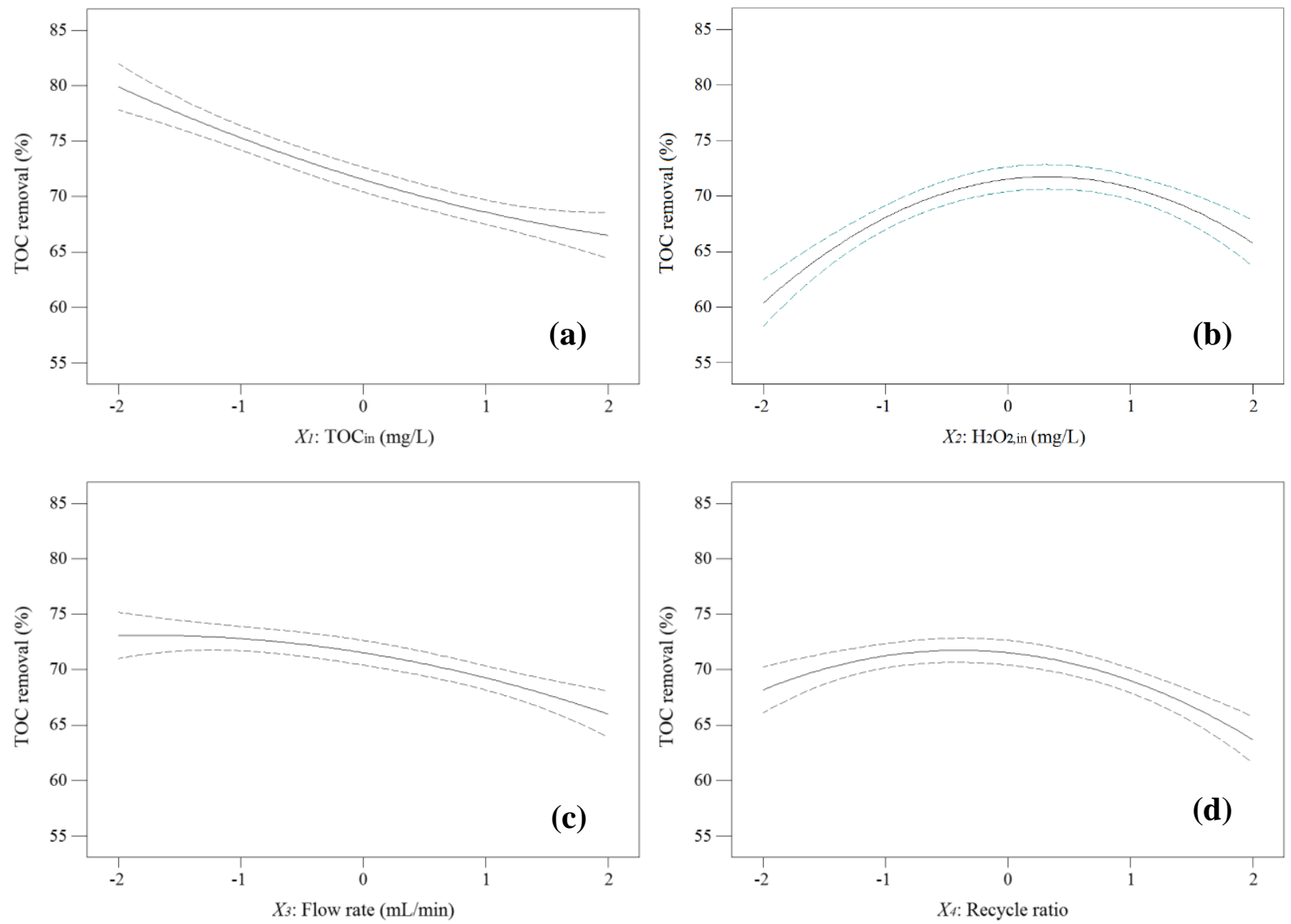

Figure 6.5. The individual effect of model parameters on the percent TOC removal: (a) influent concentration of TOC, (b) influent $\mathrm{H}_{2} \mathrm{O}_{2}$ concentration, (c) flow rate, and (d) recycle ratio. The continuous lines represent model predicted values, whereas the dashed lines represent the $\mathbf{9 5 \%}$ confidence interval bands.

Reprinted from J. Environ. Chem. Eng. 4 (2016) 719-732, with permission from Elsevier. 

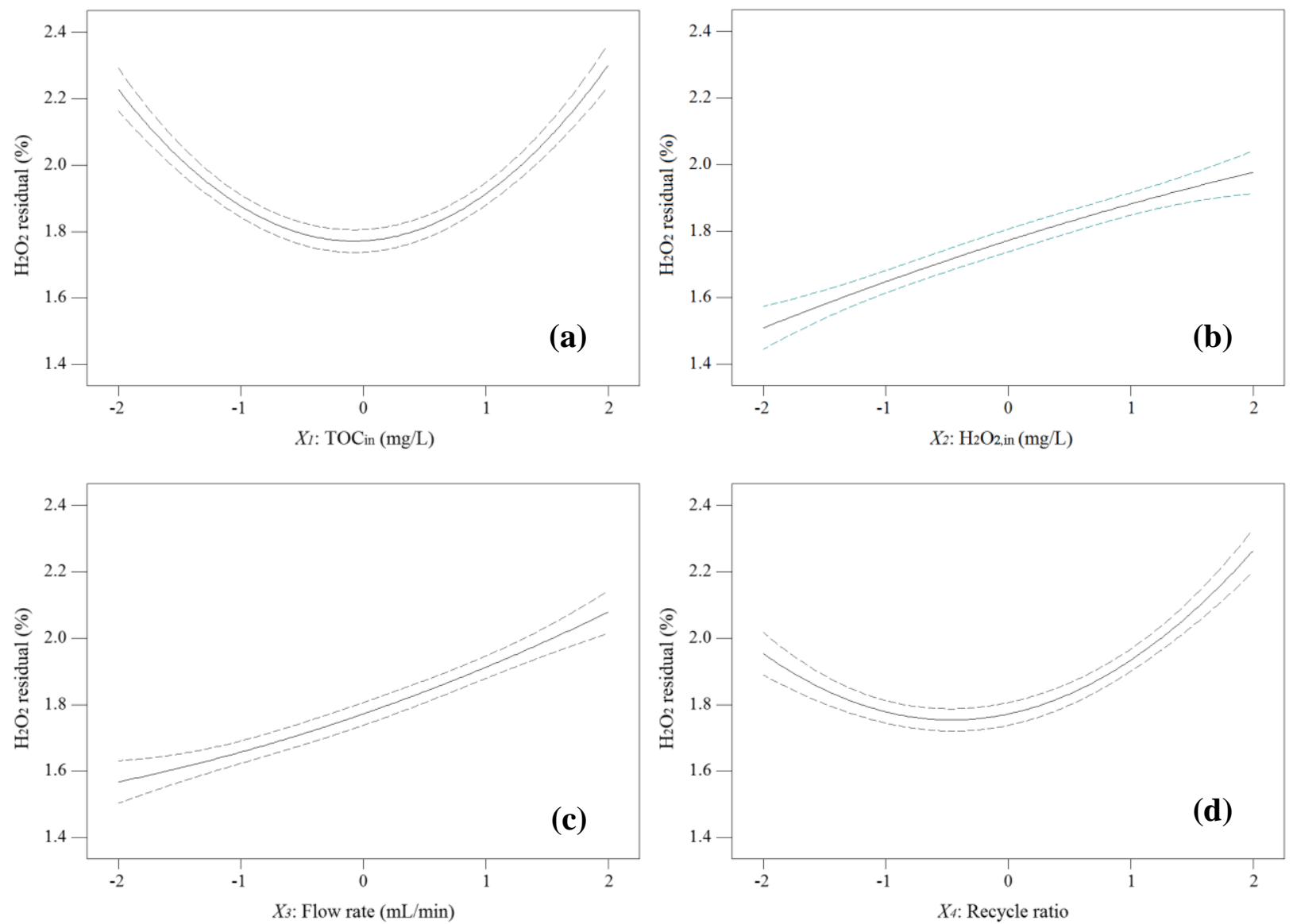

Figure 6.6. The individual effect of model parameters on the $\mathrm{H}_{2} \mathrm{O}_{2}$ residual: (a) influent concentration of TOC, (b) influent $\mathrm{H}_{2} \mathrm{O}_{2}$ concentration, (c) flow rate, and (d) recycle ratio. The continuous lines represent model predicted values, whereas the dashed lines represent the $95 \%$ confidence interval bands.

Reprinted from J. Environ. Chem. Eng. 4 (2016) 719-732, with permission from Elsevier. 
This confirms the trends observed in preliminary experiments (Figure 6.2d) and the significance of this variable. When the recycle ratio was augmented from 0.4 to 0.6 , the percent TOC removal decreased, probably due to an excess of $\mathrm{H}_{2} \mathrm{O}_{2}$ residual returning through the recycle stream, resulting in hydroxyl radical self-scavenging effect by recombination.

\subsubsection{Interaction of model parameters, $2 D$ contour plots, and $3 D$ response surface}

As shown in Tables 6.5 and 6.6, there was only one interaction among model parameters, between influent TOC and $\mathrm{H}_{2} \mathrm{O}_{2}$ concentrations $\left(X_{1} X_{2}\right)$, which did not indicate a significant effect on the percent TOC removal, despite the fact that it was significant on the $\mathrm{H}_{2} \mathrm{O}_{2}$ residual simultaneously. Thus, it can be stated that individual parameters clearly influence the trend for the TOC removal as linear effects.

On the contrary, the cross-factor interactions of the recycle ratio with other variables, including influent TOC concentration $\left(X_{1} X_{4}\right)$, influent $\mathrm{H}_{2} \mathrm{O}_{2}$ concentration $\left(X_{2} X_{4}\right)$, and flow rate $\left(X_{3} X_{4}\right)$, were found to have a high significant effect on both TOC removal and $\mathrm{H}_{2} \mathrm{O}_{2}$ residual.

The cross-factor interaction effects between independent variables were plotted into the 3D surfaces and 2D contour plots as shown in Figures 6.7 and 6.8 for the TOC removal and the $\mathrm{H}_{2} \mathrm{O}_{2}$ residual, respectively. These figures are the graphical representations of the regression analysis, where the response functions of two factors are presented while all others are at the fixed levels (Ghafoori et al., 2012, 2014a, 2015).

As shown in Figures 6.7 $(\mathrm{a}-\mathrm{c})$, the percent TOC removal decreases by increasing the influent TOC concentrations within the factor range. The effect of the influent TOC concentration on the percent TOC removal is essentially attributable to the absorption of UV radiation by organic compounds along with intermediates formed during the photochemical reactions.

Hence, the penetrability of the UV light is reduced at higher TOC concentrations; thus, the UV

light absorption by $\mathrm{H}_{2} \mathrm{O}_{2}$ becomes lower, causing a reduced amount of hydroxyl radicals, major contributor to the TOC reduction (Ghafoori et al., 2012, 2014a, 2015). 

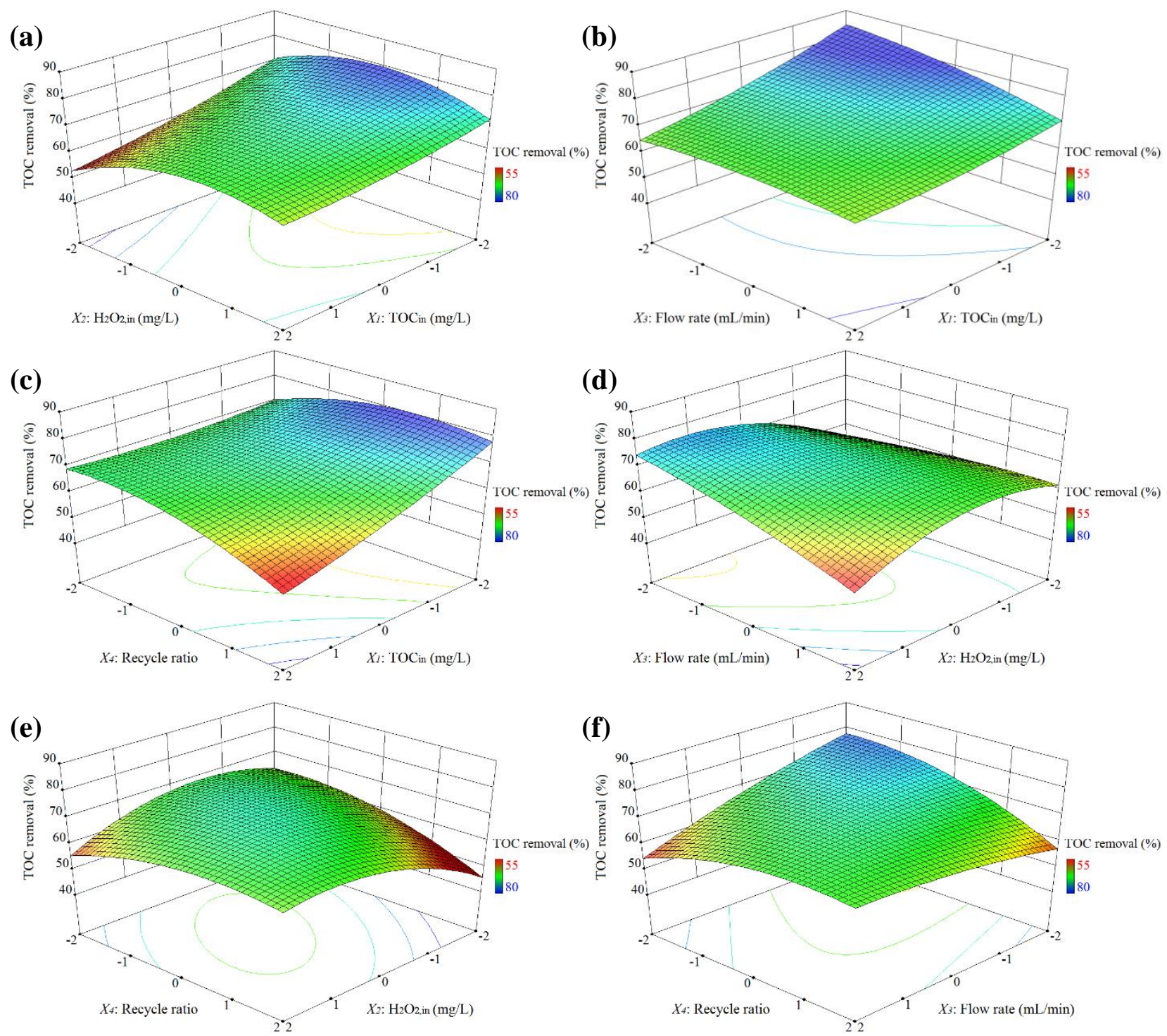

Figure 6.7. Interaction effects of different parameters on the percent TOC removal using 3D response surface and $2 \mathrm{D}$ contours: (a) influent concentration of TOC and $\mathrm{H}_{2} \mathrm{O}_{2}\left(X_{1} X_{2}\right)$, (b) influent concentration of TOC and flow rate $\left(X_{1} X_{3}\right)$, (c) influent concentration of TOC and recycle ratio $\left(X_{1} X_{4}\right)$, (d) influent $\mathrm{H}_{2} \mathrm{O}_{2}$ concentration and flow rate $\left(X_{2} X_{3}\right)$, (e) influent $\mathrm{H}_{2} \mathrm{O}_{2}$ concentration and recycle ratio $\left(X_{2} X_{4}\right)$, and (f) flow rate and recycle ratio $\left(X_{3} X_{4}\right)$.

Reprinted from J. Environ. Chem. Eng. 4 (2016) 719-732, with permission from Elsevier. 

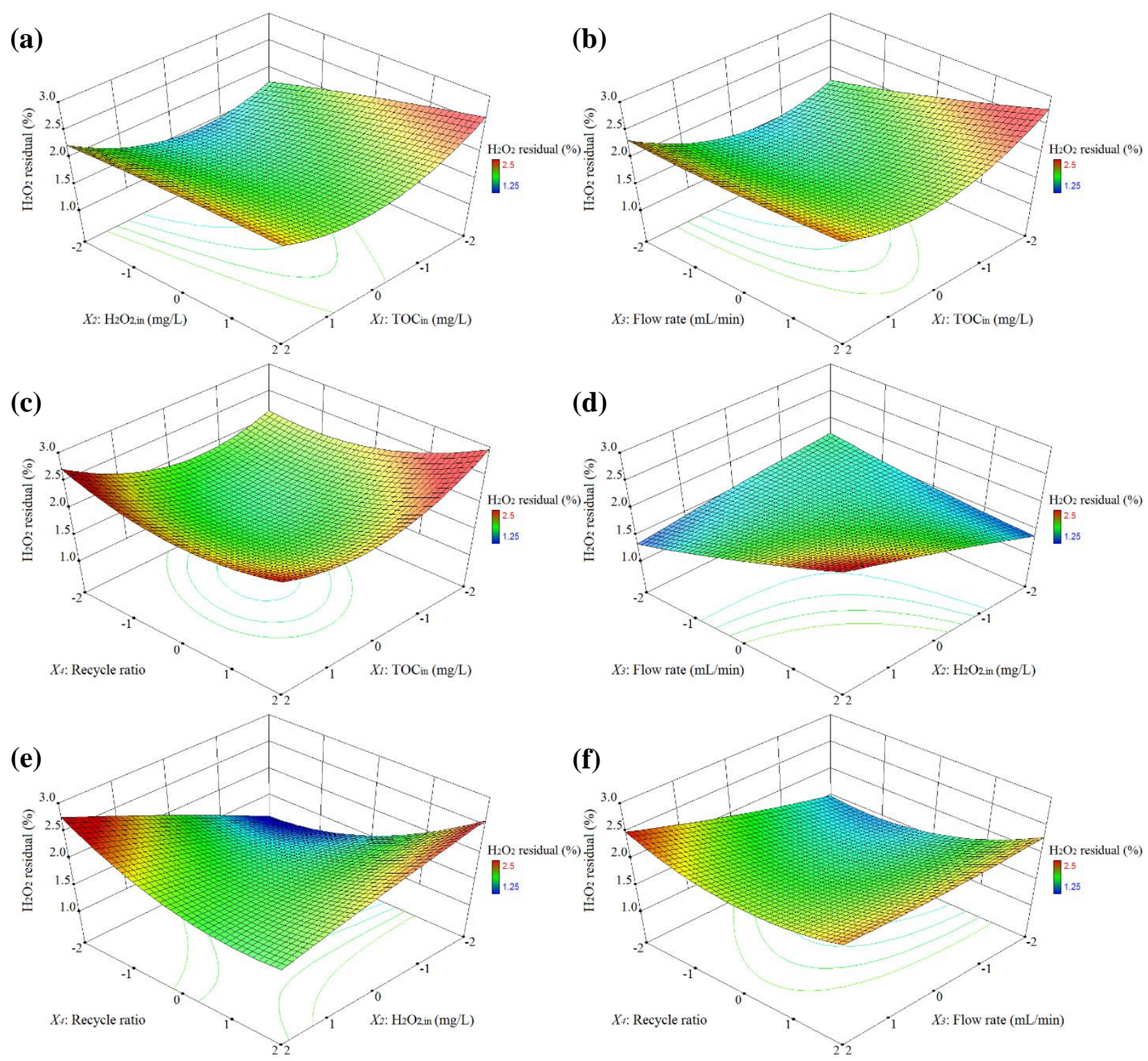

Figure 6.8. Interaction effects of different parameters on the $\mathrm{H}_{2} \mathrm{O}_{2}$ residual using 3D response surface and 2D contours: (a) influent concentration of TOC and $\mathrm{H}_{2} \mathrm{O}_{2}\left(X_{1} X_{2}\right)$, (b) influent concentration of TOC and flow rate $\left(X_{I} X_{3}\right)$, (c) influent concentration of TOC and recycle ratio $\left(X_{1} X_{4}\right)$, (d) influent $\mathrm{H}_{2} \mathrm{O}_{2}$ concentration and flow rate $\left(X_{2} X_{3}\right)$, (e) influent $\mathrm{H}_{2} \mathrm{O}_{2}$ concentration and recycle ratio $\left(X_{2} X_{4}\right)$, and (f) flow rate and recycle ratio $\left(X_{3} X_{4}\right)$.

Reprinted from J. Environ. Chem. Eng. 4 (2016) 719-732, with permission from Elsevier. 
On the other hand, Figures 6.7(a, d, e) depict the effects of the influent $\mathrm{H}_{2} \mathrm{O}_{2}$ concentration on the percent TOC removal. Results show that by augmenting the $\mathrm{H}_{2} \mathrm{O}_{2}$ concentration, the percent TOC removal also increases up to an optimum $\mathrm{H}_{2} \mathrm{O}_{2}$ concentration. After this point, the trend is reversed due to the excess of $\mathrm{H}_{2} \mathrm{O}_{2}$, resulting in hydroxyl radical scavenging effect (Mehrvar et al., 2001; Bali et al., 2004; Kralik et al., 2010).

Similar results are illustrated in Figures $6.8(\mathrm{a}-\mathrm{c})$, where the effect of the influent TOC concentration on the $\mathrm{H}_{2} \mathrm{O}_{2}$ residual is observed. In this case, by increasing the influent TOC concentration, the $\mathrm{H}_{2} \mathrm{O}_{2}$ residual is reduced up to an optimum concentration of TOC.

The interaction of the flow rate with other independent variables $\left(X_{1} X_{3}, X_{2} X_{3}\right.$, and $\left.X_{3} X_{4}\right)$ tend to be linear as confirmed in Figures 6.7 and $6.8(\mathrm{~b}, \mathrm{~d}, \mathrm{f})$. These interactions confirm that the percent TOC removal is inversely proportional to the flow rate, while the $\mathrm{H}_{2} \mathrm{O}_{2}$ residual is directly proportional to the flow rate.

Lastly, Figures 6.7 and 6.8 (c, e, f) depict the interaction effects of the recycle ratio with other variables, including the influent TOC concentration $\left(X_{1} X_{4}\right)$, the influent $\mathrm{H}_{2} \mathrm{O}_{2}$ concentration $\left(X_{2} X_{4}\right)$, and the flow rate $\left(X_{3} X_{4}\right)$ on the TOC removal and the $\mathrm{H}_{2} \mathrm{O}_{2}$ residual. The cross-factor interactions of the recycle ratio had a high significant effect on both TOC removal and $\mathrm{H}_{2} \mathrm{O}_{2}$ residual. Therefore, an optimum recycle ratio was required to achieve a maximum TOC removal with a minimum $\mathrm{H}_{2} \mathrm{O}_{2}$ residual in treating SWW effluents by $\mathrm{UV} / \mathrm{H}_{2} \mathrm{O}_{2}$ process.

\subsubsection{Optimization of operating conditions and process parameters}

The RSM was used to determine the optimum experimental conditions of the four independent variables, including the influent TOC concentration $\left(X_{1}\right)$, the influent $\mathrm{H}_{2} \mathrm{O}_{2}$ concentration $\left(X_{2}\right)$, the flow rate $\left(X_{3}\right)$, and the recycle ratio $\left(X_{4}\right)$, to obtain the maximum percent TOC removal and the minimum $\mathrm{H}_{2} \mathrm{O}_{2}$ residual.

The optimization was accomplished by maximizing the percent TOC removal while minimizing the $\mathrm{H}_{2} \mathrm{O}_{2}$ residual at defined optimization conditions using the numerical optimization method built into the statistical software Design-Expert 9.0.4.1. Equations (6.4) and (6.5) were defined as objective functions for the percent TOC removal and the $\mathrm{H}_{2} \mathrm{O}_{2}$ residual, respectively, and the independent factors 
in their critical range were used as constraints. The numerical optimization method explores the design space using the developed models to find the optimum factor conditions that meet the previously set goals of maximum TOC removal and minimum $\mathrm{H}_{2} \mathrm{O}_{2}$ residual simultaneously.

The multiple response approach (Equation 6.3) was used to obtain the desirability 3D response surface (Figure 6.9) by maximizing the percent removal of TOC $\left(d_{l}\right)$ and minimizing the $\mathrm{H}_{2} \mathrm{O}_{2}$ residual $\left(d_{2}\right)$ using the optimum factor settings. Thus, the optimum conditions to achieve the maximum TOC removal of $80.66 \%$ and minimum $\mathrm{H}_{2} \mathrm{O}_{2}$ residual of $1.35 \%$ after 120 min were found as follows: influent TOC concentration of $23.93 \mathrm{mg} / \mathrm{L}$, influent $\mathrm{H}_{2} \mathrm{O}_{2}$ concentration of $861.54 \mathrm{mg} / \mathrm{L}$, flow rate of 15.15 $\mathrm{mL} / \mathrm{min}$, and recycle ratio of 0.18 .

The obtained optimal operating conditions were used in another experimental run to validate the predicted values. Consequently, the TOC removal of $81.03 \%$ and $\mathrm{H}_{2} \mathrm{O}_{2}$ residual of $1.29 \%$ were obtained experimentally, confirming the reliability of the model since they are both between the $95 \%$ CI of 77.46-83.84\% for TOC removal and $1.26-1.59 \%$ for $\mathrm{H}_{2} \mathrm{O}_{2}$ residual.

\subsection{Conclusions}

Response surface methodology combined with a four-factor, five-level central composite design revealed reliable results for the treatment of slaughterhouse wastewater by $\mathrm{UV} / \mathrm{H}_{2} \mathrm{O}_{2}$ process in a continuous photoreactor with recycle. The accuracy of the developed quadratic models was evaluated using analysis of variance. Results demonstrated that the influent concentrations of total organic carbon and $\mathrm{H}_{2} \mathrm{O}_{2}$, the flow rate, and the recycle ratio presented considerable effect on the total organic carbon removal and the $\mathrm{H}_{2} \mathrm{O}_{2}$ residual.

The interaction between influent concentrations of total organic carbon and $\mathrm{H}_{2} \mathrm{O}_{2}\left(X_{1} X_{2}\right)$ did not indicate a significant impact on the total organic carbon removal while being significant on the $\mathrm{H}_{2} \mathrm{O}_{2}$ residual. In contrast, the cross-factor interactions of the recycle ratio with other variables, including the influent concentration of total organic carbon $\left(X_{1} X_{4}\right)$, the influent $\mathrm{H}_{2} \mathrm{O}_{2}$ concentration $\left(X_{2} X_{4}\right)$, and the flow rate $\left(X_{3} X_{4}\right)$, were found to have a high significant effect on both the total organic carbon removal and the $\mathrm{H}_{2} \mathrm{O}_{2}$ residual. Thus, an optimum recycle ratio was found to be highly significant to achieve a maximum total organic carbon removal with a minimum $\mathrm{H}_{2} \mathrm{O}_{2}$ residual for the treatment of slaughterhouse wastewater by $\mathrm{UV} / \mathrm{H}_{2} \mathrm{O}_{2}$ process. 

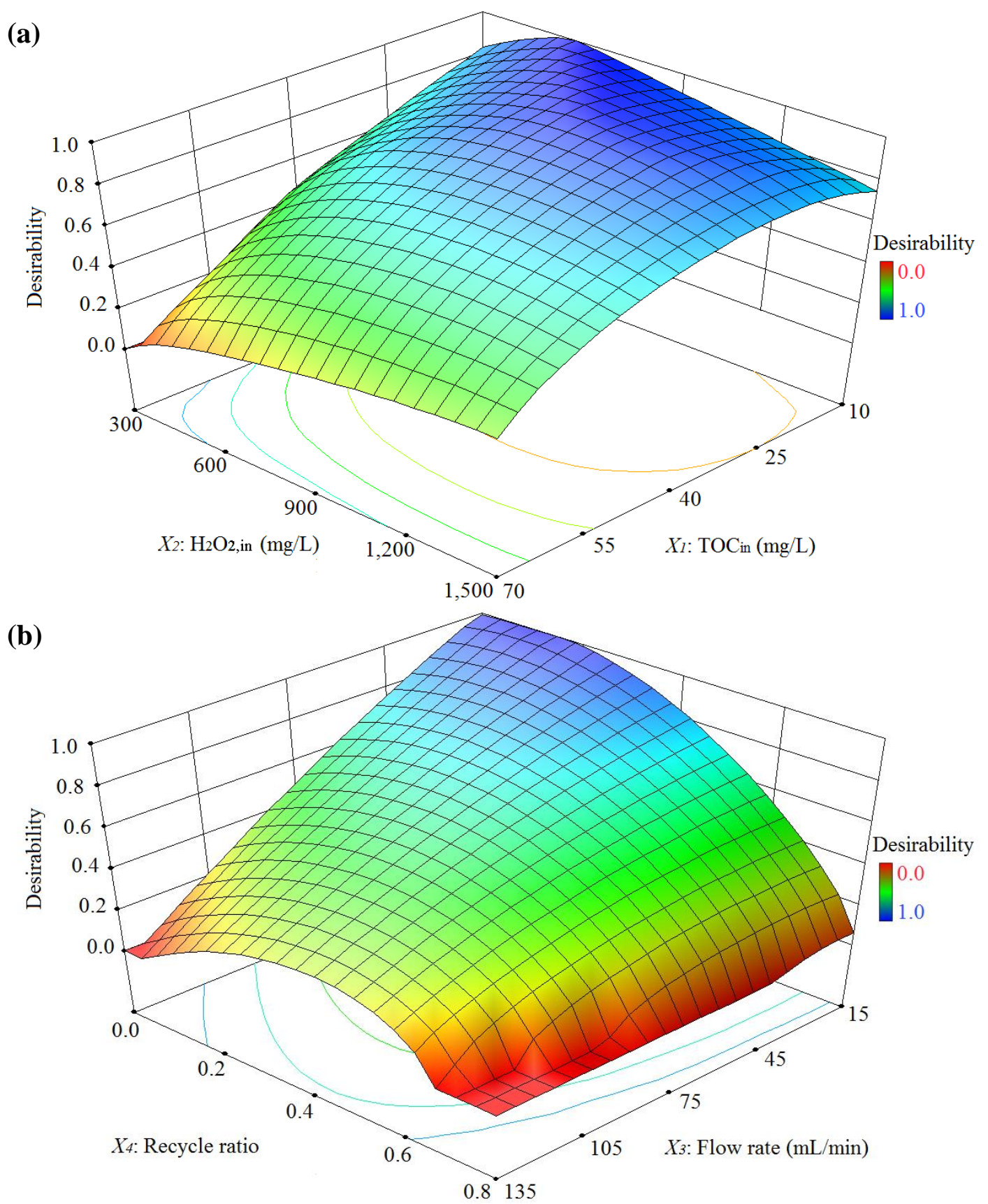

Figure 6.9. Desirability response surface, maximizing the percent removal of TOC and minimizing the $\mathrm{H}_{2} \mathrm{O}_{2}$ residual at optimum factor settings: (a) influent concentration of TOC and $\mathrm{H}_{2} \mathrm{O}_{2}\left(X_{1} X_{2}\right)$ interaction with optimum flow rate $(15 \mathrm{~mL} / \mathrm{min})$ and recycle ratio $(0.18)$; (b) flow rate and recycle ratio $\left(X_{3} X_{4}\right)$ interaction with optimum influent TOC concentration $(24 \mathrm{mg} / \mathrm{L})$ and $\mathrm{H}_{2} \mathrm{O}_{2}(860 \mathrm{mg} / \mathrm{L})$.

Reprinted from J. Environ. Chem. Eng. 4 (2016) 719-732, with permission from Elsevier. 
A maximum total organic carbon removal of $81 \%$ and minimum $\mathrm{H}_{2} \mathrm{O}_{2}$ residual of less than $2 \%$ were found at the optimum operating conditions of $24 \mathrm{mg} / \mathrm{L}$ influent concentration of total organic carbon, $860 \mathrm{mg} / \mathrm{L}$ influent $\mathrm{H}_{2} \mathrm{O}_{2}$ concentration, $15 \mathrm{~mL} / \mathrm{min}$ flow rate, and recycle ratio of 0.18 based on the developed quadratic models and the desirability multiple response method.

An additional experimental trial validated the model predictions for the maximum total organic carbon removal and minimum $\mathrm{H}_{2} \mathrm{O}_{2}$ residual at the obtained optimum operating conditions. The developed mathematical models provided a detailed exploration of the simultaneous cross-factor interactive effects of the independent variables on the responses. Therefore, the proposed models explaining the photochemical treatment of slaughterhouse wastewater by the continuous $U V / \mathrm{H}_{2} \mathrm{O}_{2}$ photoreactor with recycle could be used as a base for future studies on process optimization, photoreactor design, modeling, and scale-up. A continuous $\mathrm{UV} / \mathrm{H}_{2} \mathrm{O}_{2}$ photoreactor with recycle could significantly increase the removal of total organic carbon while reducing the percent $\mathrm{H}_{2} \mathrm{O}_{2}$ residual in the effluent as a post-treatment method. Thus, becoming a cost-effective alternative to conventional methods and beneficial to the environment.

\section{Acknowledgments}

The financial support of Natural Sciences and Engineering Research Council of Canada (NSERC), Ontario Trillium Scholarship (OTS) Program, and Ryerson University is greatly appreciated. 


\title{
CHAPTER 7
}

\section{Slaughterhouse WasteWATER CharaCterization}

\section{And Treatment: An Economic And Public Health NeCESSity OF THE MEAT PROCESSING INDUSTRY IN ONTARIO, CANADA*}

\begin{abstract}
The characteristics of the slaughterhouse effluents and current wastewater treatment practices in the province of Ontario, Canada are analyzed. Meat processing plants are found to produce large amounts of wastewater due to the slaughtering process and cleaning of their facilities. Furthermore, the composition of the wastewater varies according to the type and number of animals slaughtered and the water requirements of the process. However, the slaughterhouse wastewater usually contains high levels of organics and nutrients. Several slaughterhouses in Ontario discharge their wastewater into the municipal sewer system after primary pre-treatment at the meat processing plant. Therefore, due to the high-strength characteristics of the slaughterhouse effluents, an extensive treatment for a safe discharge into the environment is required. Thus, the combination of biological processes and advanced oxidation technologies for slaughterhouse wastewater treatment are evaluated in this study. Results show that the application of combined biological and advanced oxidation processes is recommended for on-site slaughterhouse wastewater treatment.
\end{abstract}

Keywords: Slaughterhouse wastewater, anaerobic digestion, activated sludge, advanced oxidation processes.

\footnotetext{
* Reprinted, with minor editorial changes to fulfill formatting requirements, from:

C. Bustillo-Lecompte, M. Mehrvar, and E. Quiñones-Bolaños (2016) Slaughterhouse wastewater characterization and treatment: an economic and public health necessity of the meat processing industry in Ontario, Canada. Journal of Geoscience and Environment Protection 4, pp. 175-186. Open Access. DOI: 10.4236/gep.2016.44021.
} 


\subsection{Introduction}

The treatment of water and wastewater has become crucial due to the continuous growth of world population and the pollution of freshwater because of not adequately treated wastewater discharged into environment, especially in developing countries (Bustillo-Lecompte and Mehrvar, 2015). Besides, the decreasing availability of freshwater has redirected the objectives in the area of wastewater treatment to recycling and reuse.

Nevertheless, diverse techniques are adopted for water and wastewater treatment depending on the differences in geographic location, financial resources, living standards, and life quality in different countries, as well as the characteristics of the wastewater effluents and pollutants (Daigger, 2009).

The meat processing industry produces large volumes of slaughterhouse wastewater (SWW) from the slaughtering of animals and cleaning of the slaughterhouse facilities. Up to $24 \%$ of the water used in the food and beverage industry is from the meat processing (Gerbens-Leenes et al., 2013). Slaughterhouses and meat processing plants (MPPs) are part of a large industry worldwide, where the composition of the wastewater depends on the diverse practices in the slaughtering process. Consequently, SWW requires significant treatment for a safe and sustainable release to the environment (Bustillo-Lecompte and Mehrvar, 2015).

According to Mittal (2006), slaughterhouses in Ontario, Canada, typically discharge the SWW into the municipal sewer system after a preliminary treatment. Thus, slaughterhouses commonly pay surcharges, penalties, or fines to dispose their effluents into receiving municipal wastewater treatment plants.

Moreover, there are currently 134 MPPs in Ontario that can process 100-200 animals per month. Approximately 53\% of Ontario's slaughterhouses do not treat their wastewater on-site before disposal. Dissolved air flotation (DAF) or aeration is the typical method of preliminary treatment with $16 \%$ of Ontario's slaughterhouses using it at their facilities. The rest of slaughterhouses (31\%) use passive methods such as lagoons or storage tanks to settle solids (Figure 7.1) (Bustillo-Lecompte and Mehrvar, 2015). 


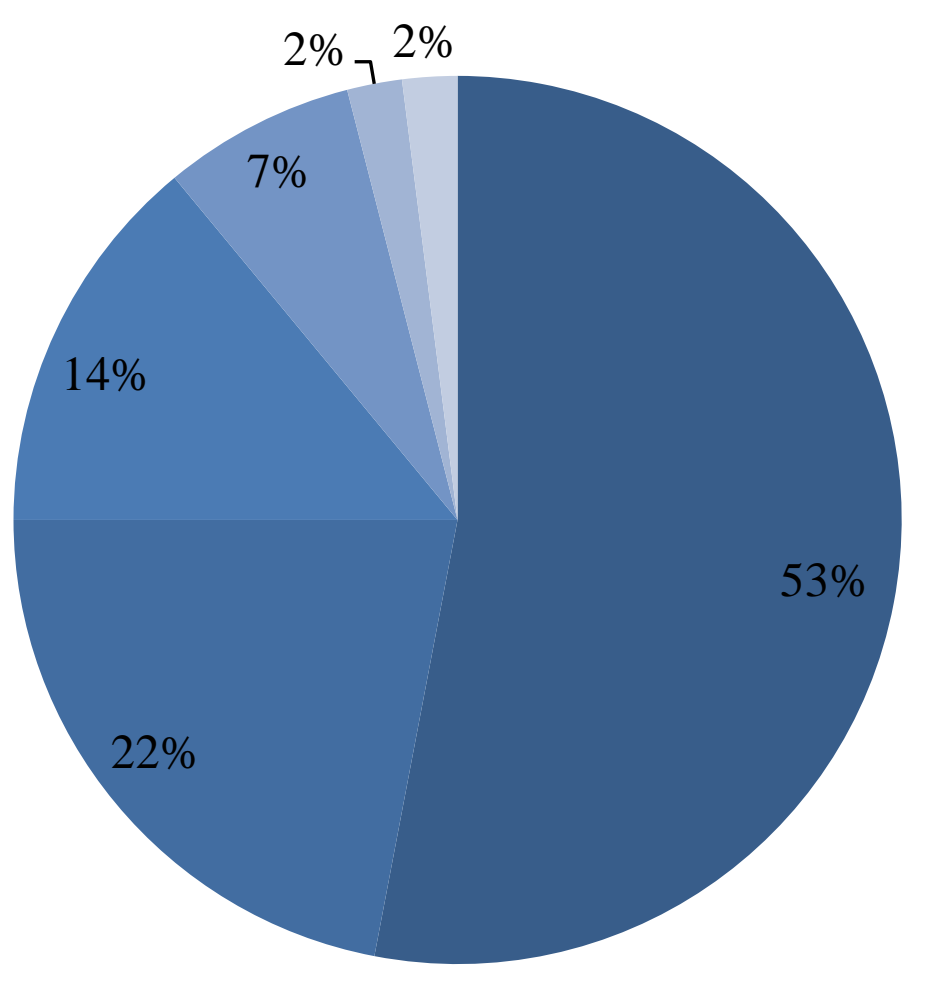

- No treatment

- Lagoon

- Dissolved Air Floatation (DAF)

- Storage

Aeration Treatment

Storage and lagoon

Figure 7.1. On-site slaughterhouse wastewater treatment in Ontario.

Reprinted from J. Geosci. Environ. Protection 4 (2016), pp. 175-186, Open Access. 
Direct discharge of untreated slaughterhouse effluents to a water body is not practical due to the high organic load of the SWW. Therefore, appropriated disposal and treatment is required. It may be also stated that in terms of operation and economics, it is beneficial to implement combined processes for the management of slaughterhouse effluents since it couples the benefit of different technologies to improve high strength industrial wastewater treatment (Bustillo-Lecompte et al., 2014).

Advantages of the combined processes include potential energy recovery from the conversion of organic pollutants into biogas with high overall treatment efficiency (Bustillo-Lecompte et al., 2014). However, SWWs may contain toxic and non-biodegradable organic substances, which make biological treatment alone insufficient (Bustillo-Lecompte and Mehrvar, 2015). Thus, advanced oxidation processes (AOPs) are used to improve the bio-treatability of wastewaters containing non-biodegradable organics, which are toxic to common microorganisms. AOPs are becoming an attractive alternative to conventional treatment methods and a complimentary treatment option to biological processes in SWW treatment. Furthermore, AOPs can inactivate microorganisms for disinfection while avoiding the formation of hazardous by-products (Barrera et al., 2012).

This study aims to identify the characteristics of the slaughterhouse wastewater in Ontario, Canada and discuss possible treatment alternatives to minimize the impact of the discharge of these wastewaters to the environment, and to optimize processes for organics and nutrient removal, including combined biological treatment and AOPs for water reuse. Consequently, the effects of the influent concentration of TOC, flow rate, $\mathrm{pH}, \mathrm{H}_{2} \mathrm{O}_{2}$ dosage, and their interactions on the overall treatment efficiency of the combined anaerobic-aerobic and $\mathrm{UV} / \mathrm{H}_{2} \mathrm{O}_{2}$ process and the effluent $\mathrm{H}_{2} \mathrm{O}_{2}$ residual concentration were investigated using the design of experiments (DOE) to optimize the combined processes in continuous mode at laboratory scale for SWW treatment. Statistical models were also developed to predict the percent TOC removal and the effluent concentration of $\mathrm{H}_{2} \mathrm{O}_{2}$ as response variables. The statistical models were validated by an additional set of experiments at the optimum conditions in line with the DOE results.

\subsection{Materials and methods}

\subsubsection{Materials}

Actual SWW samples were taken from selected provincially licensed meat processing plants directly from their source in Ontario, Canada (OMAFRA, 2015b). A 30\% w/w hydrogen peroxide 
solution was purchased from Sigma-Aldrich, whereas $\mathrm{NaOH}\left(50 \%\right.$ w/w) and $\mathrm{H}_{2} \mathrm{SO}_{4}(98 \%$ w/w) were obtained from EMD Millipore for $\mathrm{pH}$ adjustment.

\subsubsection{Slaughterhouse wastewater characteristics}

The main source of SWW are the feces, urine, blood, lint, fat, carcasses, and non-digested food in the intestines of the slaughtered animals, the production leftovers, and the cleaning of the facilities (Bustillo-Lecompte et al., 2013). The SWW composition varies according to the industrial process and water demand. Nevertheless, they usually contain high levels of organics and nutrients, typically measured as biochemical oxygen demand (BOD), chemical oxygen demand (COD), total organic carbon (TOC), total suspended solids (TSS), total nitrogen (TN), and phosphorus (TP).

Slaughterhouse effluents are considered detrimental worldwide due to its complex composition of fats, proteins, and fibers, as well as the presence of organics, nutrients, pathogenic and nonpathogenic microorganisms, detergents and disinfectants used for cleaning activities, and pharmaceuticals for veterinary purposes (Tritt and Schuchardt, 1992). Therefore, the treatment and disposal of wastewater from slaughterhouses and meat processing plants are an economic and public health necessity (Debik and Coskun, 2009). Table 7.1 attempts to summarize the typical characteristics of the slaughterhouse effluents in Ontario, Canada. The SWW features and common ranges are listed as BOD, COD, TOC, TSS, TN, and $\mathrm{pH}$.

Table 7.1. Common characteristics of slaughterhouse wastewater in the study.

Reprinted from J. Geosci. Environ. Protection 4 (2016), pp. 175-186, Open Access.

\begin{tabular}{ccc}
\hline Parameter & Range & Average \\
\hline $\mathrm{BOD}(\mathrm{mg} / \mathrm{L})$ & $610-4,635$ & 1,209 \\
$\mathrm{Ca}(\mathrm{mg} / \mathrm{L})$ & $32-316$ & 67 \\
$\mathrm{COD}(\mathrm{mg} / \mathrm{L})$ & $1250-15,900$ & 4,221 \\
$\mathrm{~K}(\mathrm{mg} / \mathrm{L})$ & $0.01-100$ & 90 \\
$\mathrm{Na}(\mathrm{mg} / \mathrm{L})$ & $62-833$ & 621 \\
$\mathrm{~Pb}(\mathrm{mg} / \mathrm{L})$ & $0.21-34$ & 4 \\
$\mathrm{TN}(\mathrm{mg} / \mathrm{L})$ & $50-841$ & 427 \\
$\mathrm{TOC}(\mathrm{mg} / \mathrm{L})$ & $100-1,200$ & 546 \\
$\mathrm{TP}(\mathrm{mg} / \mathrm{L})$ & $25-200$ & 50 \\
$\mathrm{TSS}(\mathrm{mg} / \mathrm{L})$ & $300-2,800$ & 1,164 \\
$\mathrm{pH}$ & $4.90-8.10$ & 6.95 \\
\hline
\end{tabular}




\subsubsection{Experimental setup and procedure}

An anaerobic baffled reactor (ABR), followed by an aerobic activated sludge (AS) reactor, and a $\mathrm{UV} / \mathrm{H}_{2} \mathrm{O}_{2}$ photoreactor, operated in continuous mode, were used in a combined system at the laboratory scale for SWW treatment. The schematic diagram of the experimental setup for the combined ABR$\mathrm{AS}-\mathrm{UV} / \mathrm{H}_{2} \mathrm{O}_{2}$ processes is illustrated in Figure 7.2.

The $50 \mathrm{~L}$ combined $\mathrm{ABR}-\mathrm{AS}-\mathrm{UV} / \mathrm{H}_{2} \mathrm{O}_{2}$ system consisted of a 36- $\mathrm{L}$ ABR with five equal-volume chambers integrated with individual headspaces, biogas collection piping, and a 13-L aerobic AS reactor with a monitored air flow rate, and a 1-L photoreactor with recycle and uniform light distribution. A $45^{\circ}$ slanted-edge baffle within each ABR chamber permits the down- and up-flow of the SWW, providing effective mixing and contact time between the SWW and the biomass. The AS airflow rate was set at $2 \mathrm{~L} / \mathrm{min}$ to guarantee nitrifying bacteria growth and dissolved oxygen (DO) concentrations over $2.0 \mathrm{mg} / \mathrm{L}$.

Anaerobic and aerobic sludge seeds were loaded into the anaerobic and aerobic bioreactors, respectively. The inoculum was acclimatized in two months by feeding the actual SWW continuously into the reactors at a constant flow rate $(75 \mathrm{~mL} / \mathrm{min})$ while gradually increasing its concentration.

The stainless steel cylindrical photoreactor (Barrier SL-1S - Siemens Inc., Markham, ON) had an external diameter of $8 \mathrm{~cm}$ and a length of $34 \mathrm{~cm}$ with a $2.5 \mathrm{~cm}$ diameter UV-C lamp and output power of $6 \mathrm{~W}$ with $254 \mathrm{~nm}$ wavelength was inserted into the center of the photoreactor. A quartz sleeve covered the UV-C lamp to protect the lamp from fouling and maintain a uniform UV radiation emission.

TOC concentrations were analyzed for each sample using an automated TOC analyzer (Teledyne Tekmar Apollo 9000, Mason, $\mathrm{OH})$. Temperature and $\mathrm{pH}$ were measured daily using a $\mathrm{pH}$ meter with a temperature probe (Thermo Scientific Orion 230A+, Ottawa, ON). The $\mathrm{H}_{2} \mathrm{O}_{2}$ residuals were measured with a UV-Visible Spectrophotometer (Ultrospec 1100 pro - Amersham Biosciences, Amersham, UK) at $454 \mathrm{~nm}$ using neocuproine and copper (Bustillo-Lecompte et al., 2016a). All experiments were repeated in triplicates, and the average values were reported. Furthermore, three replicates were made for each analytical measurement. 


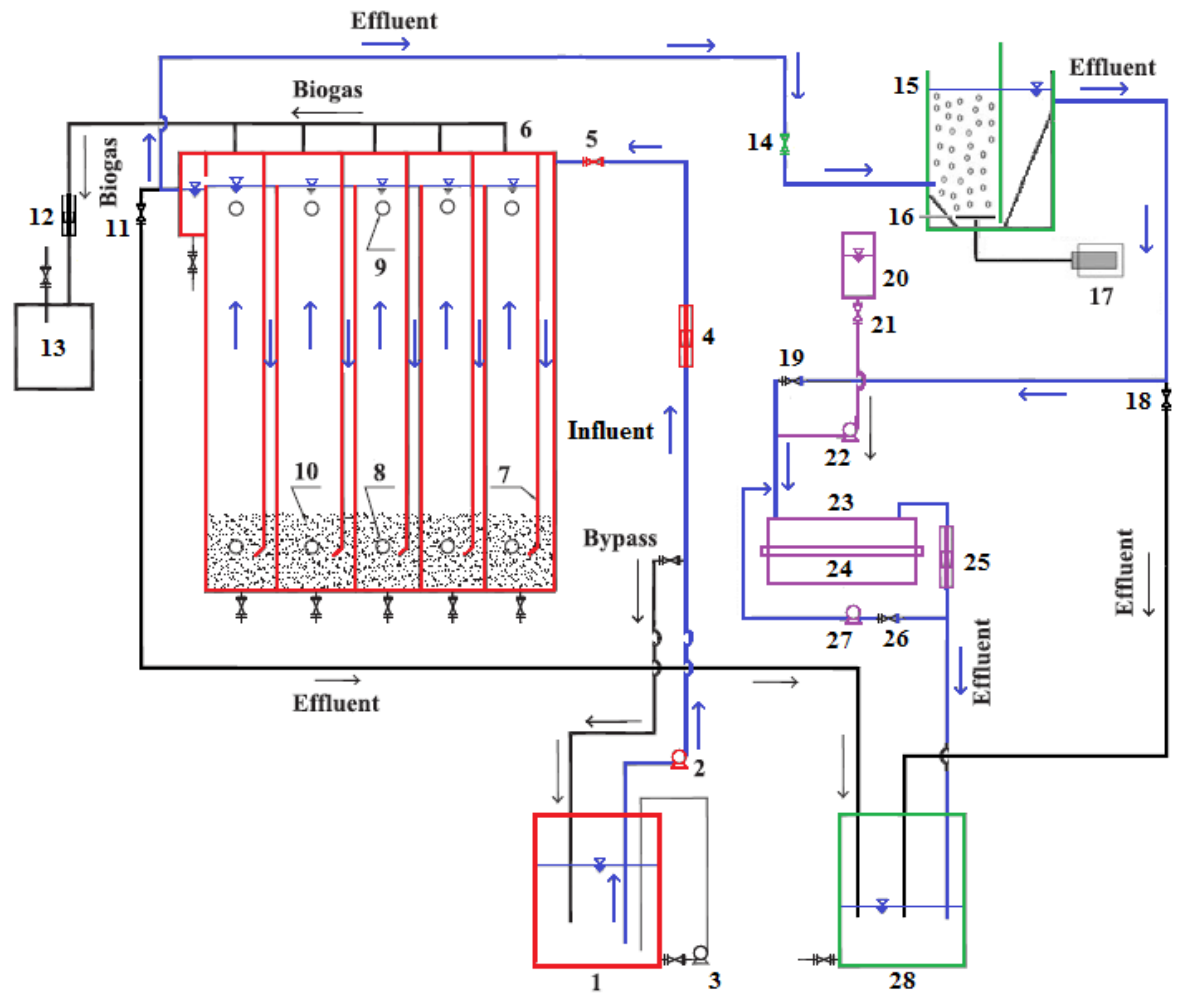

1) Wastewater feed tank

2) Peristaltic pump

3) Recirculating pump

4) Flow meter

5) 2-way valve

6) Anaerobic baffled reactor

7) Slanted edge baffle

8) Sludge sampling valve

9) Wastewater sampling valve

10) Anaerobic Sludge

11) 2-way valve

12) Biogas flow meter

13) Biogas collection

14) 2 -way valve

15) Aerobic reactor

16) Diffuser

17) Air blower

18) 2-way valve

19) 2-way valve

20) $\mathrm{H}_{2} \mathrm{O}_{2}$ solution container

21) Flow rate control valve

22) $\mathrm{H}_{2} \mathrm{O}_{2}$ solution feed peristaltic pump

23) Photoreactor

24) Ultraviolet lamp

25) Flow meter

26) Flow rate control valve

27) Recycle stream peristaltic pump

28) Treated wastewater collection tank

Figure 7.2. Schematic diagram of the combined anaerobic, aerobic, and $\mathrm{UV} / \mathrm{H}_{2} \mathrm{O}_{2}$ processes for the treatment of SWW.

Reprinted from J. Geosci. Environ. Protection 4 (2016), pp. 175-186, Open Access. 


\subsubsection{Experimental design and optimization}

A four-factor along with five-level CCD in conjunction with RSM was used to maximize percent TOC removal and minimize percent $\mathrm{H}_{2} \mathrm{O}_{2}$ residuals in the effluent. The influent concentration of TOC $\left(X_{1}\right)$, flow rate $\left(X_{2}\right), \mathrm{H}_{2} \mathrm{O}_{2}$ dosage $\left(X_{3}\right)$, and $\mathrm{pH}\left(X_{4}\right)$ were used as independent factors in the DOE; whereas, the percent TOC removal $\left(Y_{1}\right)$ and $\mathrm{H}_{2} \mathrm{O}_{2}$ residual $\left(Y_{2}\right)$ were considered process responses. Thus, each factor was coded at five levels, from -2 to +2 , as shown in Table 7.2. Previous studies (Bustillo-Lecompte and Mehrvar, 2015; OMAFRA, 2015b; Bustillo-Lecompte et al., 2015, 2016a) were used to determine and select the critical ranges of the factors.

Table 7.2. Independent variables with coded levels based on a four-factor, five level CCD. Reprinted from J. Geosci. Environ. Protection 4 (2016), pp. 175-186, Open Access.

\begin{tabular}{ccccccc}
\hline \multirow{2}{*}{ Independent variable } & Symbol & $\mathbf{- 2}$ & $\mathbf{- 1}$ & $\mathbf{0}$ & $\mathbf{1}$ & $\mathbf{2}$ \\
\hline $\mathrm{TOC}_{\text {in }}(\mathrm{mg} / \mathrm{L})$ & $X_{1}$ & 50 & 450 & 850 & 1,250 & 1,650 \\
Flow rate $(\mathrm{mL} / \mathrm{min})$ & $X_{2}$ & 15 & 45 & 75 & 105 & 135 \\
$\mathrm{H}_{2} \mathrm{O}_{2}$ in $(\mathrm{mg} / \mathrm{L})$ & $X_{3}$ & 100 & 300 & 500 & 700 & 900 \\
$\mathrm{pH}$ & $X_{4}$ & 3 & 5 & 7 & 9 & 11 \\
\hline
\end{tabular}

Equation (7.1) was used to predict the model responses as a quadratic model and estimate the parametrical coefficients by correlating dependent and independent variables using the least-squares regression (Bustillo-Lecompte et al., 2016a):

$$
Y=\beta_{o}+\sum_{i=1}^{k} \beta_{i} X_{i}+\sum_{i=1}^{k} \beta_{i i} X_{i}^{2}+\sum_{i=1}^{k-1} \sum_{j=2}^{k} \beta_{i j} X_{i} X_{j}+c
$$

where $\beta_{o}, \beta_{i}, \beta_{i i}$, and $\beta_{i j}$ are the constant, linear, quadratic, and cross-factor interaction coefficients, respectively; $X_{i}$ and $X_{j}$ represent the independent variables; $Y_{i}$ is the predicted response; and $c$ and $k$ are the residual term and the number of factors, respectively.

The Design-Expert 9.0.4.1 statistical software was employed for graphical and regression analysis to estimate the coefficients of the response functions. The significance of the independent variables, factor interactions, and model equations were examined by analysis of variance (ANOVA) at $95 \%$ confidence intervals (CI). Three-dimensional (3D) surfaces and two-dimensional (2D) contour plots were obtained while keeping another factor constant in the quadratic models. Experiments were carried 
out to validate the statistical models for maximum percent TOC removal and minimum $\mathrm{H}_{2} \mathrm{O}_{2}$ residual. Optimal operating conditions were estimated using the numerical optimization method built in the software. Lastly, an additional experimental run was carried out to validate the predicted optimal conditions for both response functions, the percent removal of TOC, and $\mathrm{H}_{2} \mathrm{O}_{2}$ residual. The desirability multiple response method was used to combine the desirable ranges for each response to obtaining a simultaneous objective function that represents the geometric mean of all transformed responses as shown in Equation (7.2) (Myers et al., 2004):

$D=\left(d_{1} \times d_{2} \times \ldots \times d_{n}\right)^{1 / n}=\left(\prod_{i=1}^{n} d_{i}\right)^{1 / n}$

where $D, d_{i}$, and $n$ are the desirability objective function, each response range, and the number of responses, respectively. If any of the analyzed responses is found to be outside of their desirability range, the overall desirability function becomes zero. Therefore, for a simultaneous optimization, each response is required to be assigned low and high values for optimization. In this case, the percent removal of TOC $\left(d_{1}\right)$ is maximized while the $\mathrm{H}_{2} \mathrm{O}_{2}$ residual $\left(d_{2}\right)$ is minimized.

\subsection{Results and discussion}

\subsubsection{Experimental design and statistical analysis}

Table 7.3 portrays the four-factor, five-level CCD with observed and predicted values for both percent TOC removal and $\mathrm{H}_{2} \mathrm{O}_{2}$ residual by the developed quadratic models related to the combined $\mathrm{ABR}-\mathrm{AS}-\mathrm{UV} / \mathrm{H}_{2} \mathrm{O}_{2}$ system in a continuous photoreactor for $\mathrm{SWW}$ treatment. RSM was employed for parameter estimation, indicating the relationship between the input factors and the responses, as shown in Equation (7.2). Thus, to predict the response functions for percent TOC removal and $\mathrm{H}_{2} \mathrm{O}_{2}$ residual, the second-order polynomial Equations (7.3) and (7.4) were developed, respectively:

$$
\begin{aligned}
& Y_{1}=86.67-4.96 X_{1}-0.59 X_{2}-0.91 X_{3}-1.82 X_{4}-0.47 X_{1} X_{2}-1.26 X_{1} X_{3}-0.31 X_{1} X_{4} \\
& +0.82 X_{2} X_{3}+0.33 X_{2} X_{4}-3.17 X_{3} X_{4}+0.93 X_{1}^{2}-0.02 X_{2}^{2}-1.06 X_{3}^{2}-1.88 X_{4}{ }^{2} \\
& Y_{2}=1.75-0.01 X_{1}+0.17 X_{2}+0.09 X_{3}+0.05 X_{4}-0.02 X_{1} X_{2}-0.03 X_{1} X_{3}-0.09 X_{1} X_{4} \\
& -0.02 X_{2} X_{3}+0.09 X_{2} X_{4}+0.04 X_{3} X_{4}+0.05 X_{1}{ }^{2}-0.01 X_{2}{ }^{2}+0.03 X_{3}{ }^{2}+0.04 X_{4}{ }^{2}
\end{aligned}
$$


Table 7.3. Four-factor, five-level CCD with observed and predicted percent TOC removal and $\mathrm{H}_{2} \mathrm{O}_{2}$ residual.

Reprinted from J. Geosci. Environ. Protection 4 (2016), pp. 175-186, Open Access.

\begin{tabular}{|c|c|c|c|c|c|c|c|c|}
\hline \multirow{2}{*}{ Run } & \multicolumn{4}{|c|}{ Independent coded variables } & \multicolumn{2}{|c|}{ TOC removal $(\%)$} & \multicolumn{2}{|c|}{$\mathrm{H}_{2} \mathrm{O}_{2}$ residual $(\%)$} \\
\hline & $X_{1}$ & $X_{2}$ & $X_{3}$ & $X_{4}$ & Observed & Predicted & Observed & Predicted \\
\hline 1 & 450 & 45 & 300 & 5 & 88.74 & 88.85 & 1.51 & 1.53 \\
\hline 2 & 1,250 & 45 & 300 & 5 & 83.11 & 83.01 & 1.78 & 1.78 \\
\hline 3 & 450 & 105 & 300 & 5 & 86.64 & 86.33 & 1.74 & 1.77 \\
\hline 4 & 1,250 & 105 & 300 & 5 & 78.42 & 78.60 & 1.92 & 1.94 \\
\hline 5 & 450 & 45 & 700 & 5 & 94.16 & 94.26 & 1.72 & 1.74 \\
\hline 6 & 1,250 & 45 & 700 & 5 & 83.29 & 83.37 & 1.84 & 1.87 \\
\hline 7 & 450 & 105 & 700 & 5 & 95.51 & 95.01 & 1.91 & 1.91 \\
\hline 8 & 1,250 & 105 & 700 & 5 & 82.58 & 82.24 & 1.93 & 1.95 \\
\hline 9 & 450 & 45 & 300 & 9 & 91.32 & 91.53 & 1.56 & 1.55 \\
\hline 10 & 1,250 & 45 & 300 & 9 & 84.25 & 84.46 & 1.42 & 1.46 \\
\hline 11 & 450 & 105 & 300 & 9 & 90.68 & 90.31 & 2.14 & 2.15 \\
\hline 12 & 1,250 & 105 & 300 & 9 & 81.58 & 81.35 & 1.98 & 1.97 \\
\hline 13 & 450 & 45 & 700 & 9 & 84.72 & 84.25 & 1.9 & 1.92 \\
\hline 14 & 1,250 & 45 & 700 & 9 & 71.97 & 72.14 & 1.71 & 1.69 \\
\hline 15 & 450 & 105 & 700 & 9 & 86.34 & 86.30 & 2.42 & 2.44 \\
\hline 16 & 1,250 & 105 & 700 & 9 & 72.71 & 72.31 & 2.11 & 2.13 \\
\hline 17 & 50 & 75 & 500 & 7 & 99.89 & 100.0 & 2.01 & 1.98 \\
\hline 18 & 1,650 & 75 & 500 & 7 & 80.48 & 80.48 & 1.95 & 1.93 \\
\hline 19 & 850 & 15 & 500 & 7 & 88.15 & 87.78 & 1.39 & 1.37 \\
\hline 20 & 850 & 135 & 500 & 7 & 84.63 & 85.42 & 2.08 & 2.05 \\
\hline 21 & 850 & 75 & 100 & 7 & 84.31 & 84.24 & 1.71 & 1.69 \\
\hline 22 & 850 & 75 & 900 & 7 & 80.11 & 80.60 & 2.09 & 2.06 \\
\hline 23 & 850 & 75 & 500 & 3 & 82.62 & 82.79 & 1.84 & 1.80 \\
\hline 24 & 850 & 75 & 500 & 11 & 75.28 & 75.53 & 2.01 & 2.00 \\
\hline 25 & 850 & 75 & 500 & 7 & 86.85 & 86.67 & 1.73 & 1.75 \\
\hline 26 & 850 & 75 & 500 & 7 & 85.95 & 86.67 & 1.73 & 1.75 \\
\hline 27 & 850 & 75 & 500 & 7 & 86.81 & 86.67 & 1.75 & 1.75 \\
\hline 28 & 850 & 75 & 500 & 7 & 86.30 & 86.67 & 1.76 & 1.75 \\
\hline 29 & 850 & 75 & 500 & 7 & 87.53 & 86.67 & 1.78 & 1.75 \\
\hline 30 & 850 & 75 & 500 & 7 & 86.60 & 86.67 & 1.75 & 1.75 \\
\hline
\end{tabular}


Negative coefficients for the model components $X_{1}, X_{2}, X_{3}, X_{4}, X_{1} X_{2}, X_{1} X_{3}, X_{1} X_{4}, X_{3} X_{4}, X_{2}^{2}, X_{3}^{2}$, and $X_{4}^{2}$ in $Y_{1}$ and $X_{1}, X_{1} X_{2}, X_{1} X_{3}, X_{1} X_{4}, X_{2} X_{3}$, and $X_{2}^{2}$ in $Y_{2}$, indicate unfavorable effects on the percent TOC removal and the $\mathrm{H}_{2} \mathrm{O}_{2}$ residual, respectively. Whereas, positive coefficients for $X_{2} X_{3}, X_{2} X_{4}$, and $X_{1}^{2}$ in $Y_{1}$ and $X_{2}, X_{3}, X_{4}, X_{2} X_{4}, X_{3} X_{4}, X_{1}^{2}, X_{3}^{2}$, and $X_{4}^{2}$ in $Y_{2}$ indicate favorable effects on the percent TOC removal and the $\mathrm{H}_{2} \mathrm{O}_{2}$ residual, respectively. Since the coefficients with values close to zero represent lower relative intensity, $X_{2}^{2}$ do not intensely affect the TOC removal while $X_{1}, X_{1} X_{2}, X_{2} X_{3}$, and $X_{2}^{2}$ do not intensely affect $\mathrm{H}_{2} \mathrm{O}_{2}$ residual.

Although this evaluation provides a rapid analysis of the parametrical effect on the response variables, ANOVA with 95\% CI was also applied to evaluate the statistical significance of the developed quadratic models for the percent TOC removal and the $\mathrm{H}_{2} \mathrm{O}_{2}$ residual. Thus, the statistical significance of each factor coefficient, as shown in Equations (7.3) and (7.4), was determined by the Fisher's $(F)$ exact test, comparing probability $(p)$ values greater than $F$. Consequently, the model Fvalues of 287.69 and 116.90 for TOC removal and $\mathrm{H}_{2} \mathrm{O}_{2}$ residual, respectively, imply the models are significant.

Besides, small probability values $(p<0.05)$ indicate significant model terms, which confirm the accuracy of the developed models to predict the response functions. Conversely, $p$-values $>0.10$ indicate the model terms are not significant; in this case, $X_{2}^{2}$ is not significant for both TOC removal and $\mathrm{H}_{2} \mathrm{O}_{2}$ residual. If the quadratic effect is not significant, then the optimal levels of the parameter are in the extremes of the experimental region (Botha et al., 2012).

The goodness of fit of the developed models was validated by the determination coefficient $\left(R^{2}\right)$ and the adjusted $R^{2}$ that ensures an adequate variation of the quadratic model to the experimental values. The values of $R^{2}$ and adjusted $R^{2}$ were found to be 0.9963 and 0.9928 for the percent TOC removal and 0.9909 and 0.9824 for the $\mathrm{H}_{2} \mathrm{O}_{2}$ residual, respectively, representing an adequate model significance. Moreover, the adequate precision for the percent TOC removal and $\mathrm{H}_{2} \mathrm{O}_{2}$ residual models were found to be 77.49 and 51.54 , respectively (Table 7.4). Since both values were greater than 4.00 , the model can be used to navigate the CCD design space (Ghafoori et al., 2012). The lack of fit was calculated to assess how well the model fits the data. The lack of fit $p$-values of the percent TOC removal and the $\mathrm{H}_{2} \mathrm{O}_{2}$ residual were found to be 0.6059 and 0.1145 , respectively. A not significant lack of fit $(p>0.10)$ indicates that the model fits the data well. 
Table 7.4. ANOVA of the prediction results for the percent $\mathrm{TOC}$ and $\mathrm{H}_{2} \mathrm{O}_{2}$ residual by quadratic modeling.

Reprinted from J. Geosci. Environ. Protection 4 (2016), pp. 175-186, Open Access.

\begin{tabular}{|c|c|c|c|c|c|c|}
\hline Source & Sum of squares & $d f^{a}$ & Mean square & F value $^{b}$ & p-value $($ Prob. $>$ F) & Remark \\
\hline $\mathrm{TOC}_{\text {removal }}$ model & 1064.8 & 14 & 76.057 & 287.69 & $<0.0001$ & Significant \\
\hline$X_{1}$ & 590.24 & 1 & 590.24 & 2232.6 & $<0.0001$ & Significant \\
\hline$X_{2}$ & 8.3308 & 1 & 8.3308 & 31.512 & $<0.0001$ & Significant \\
\hline$X_{3}$ & 19.911 & 1 & 19.911 & 75.313 & $<0.0001$ & Significant \\
\hline$X_{4}$ & 79.061 & 1 & 79.061 & 299.05 & $<0.0001$ & Significant \\
\hline$X_{1} X_{2}$ & 3.5721 & 1 & 3.5721 & 13.512 & 0.0022 & Significant \\
\hline$X_{1} X_{3}$ & 25.402 & 1 & 25.402 & 96.083 & $<0.0001$ & Significant \\
\hline$X_{I} X_{4}$ & 1.5006 & 1 & 1.5006 & 5.6762 & 0.0309 & Significant \\
\hline$X_{2} X_{3}$ & 10.726 & 1 & 10.726 & 40.57 & $<0.0001$ & Significant \\
\hline$X_{2} X_{4}$ & 1.69 & 1 & 1.69 & 6.3925 & 0.0232 & Significant \\
\hline$X_{3} X_{4}$ & 160.78 & 1 & 160.78 & 608.17 & $<0.0001$ & Significant \\
\hline$X_{I}^{2}$ & 23.766 & 1 & 23.766 & 89.894 & $<0.0001$ & Significant \\
\hline$X_{2}^{2}$ & 0.0088 & 1 & 0.0088 & 0.0333 & 0.8576 & Not significant \\
\hline$X_{3}^{2}$ & 30.989 & 1 & 30.989 & 117.22 & $<0.0001$ & Significant \\
\hline$X_{4}^{2}$ & 96.729 & 1 & 96.729 & 365.88 & $<0.0001$ & Significant \\
\hline Residual & 3.9656 & 15 & 0.2644 & & & \\
\hline Lack of Fit & 2.5139 & 10 & 0.2514 & 0.86581 & 0.6059 & Not significant \\
\hline Pure error & 1.4517 & 5 & 0.2903 & & & \\
\hline Corrected total $S S^{\mathrm{d}}$ & 1068.8 & 29 & & & & \\
\hline$R^{2}$ & 0.9963 & & & & & \\
\hline Adjusted $R^{2}$ & 0.9928 & & & & & \\
\hline Adequate Precision & 77.489 & & & & & \\
\hline $\mathrm{H}_{2} \mathrm{O}_{2}$ residual model & 1.3975 & 14 & 0.0998 & 116.9 & $<0.0001$ & Significant \\
\hline$X_{1}$ & 0.0045 & 1 & 0.0045 & 5.3139 & 0.0359 & Significant \\
\hline$X_{2}$ & 0.697 & 1 & 0.697 & 816.27 & $<0.0001$ & Significant \\
\hline$X_{3}$ & 0.2109 & 1 & 0.2109 & 247.03 & $<0.0001$ & Significant \\
\hline$X_{4}$ & 0.063 & 1 & 0.063 & 73.824 & $<0.0001$ & Significant \\
\hline$X_{1} X_{2}$ & 0.0068 & 1 & 0.0068 & 7.9709 & 0.0128 & Significant \\
\hline$X_{1} X_{3}$ & 0.0163 & 1 & 0.0163 & 19.038 & 0.0006 & Significant \\
\hline$X_{I} X_{4}$ & 0.1208 & 1 & 0.1208 & 141.42 & $<0.0001$ & Significant \\
\hline$X_{2} X_{3}$ & 0.006 & 1 & 0.006 & 7.034 & 0.0181 & Significant \\
\hline$X_{2} X_{4}$ & 0.1243 & 1 & 0.1243 & 145.52 & $<0.0001$ & Significant \\
\hline$X_{3} X_{4}$ & 0.0218 & 1 & 0.0218 & 25.479 & 0.0001 & Significant \\
\hline$X_{l}^{2}$ & 0.0729 & 1 & 0.0729 & 85.402 & $<0.0001$ & Significant \\
\hline$X_{2}^{2}$ & 0.0026 & 1 & 0.0026 & 3.0146 & 0.103 & Not significant \\
\hline$X_{3}^{2}$ & 0.0273 & 1 & 0.0273 & 32 & $<0.0001$ & Significant \\
\hline$X_{4}^{2}$ & 0.0392 & 1 & 0.0392 & 45.927 & $<0.0001$ & Significant \\
\hline Residual & 0.0128 & 15 & 0.0009 & & & \\
\hline Lack of Fit & 0.011 & 10 & 0.0011 & 3.0579 & 0.1145 & Not significant \\
\hline Pure error & 0.0018 & 5 & 0.0004 & & & \\
\hline Corrected total $S S^{\mathrm{d}}$ & 1.4103 & 29 & & & & \\
\hline$R^{2}$ & 0.9909 & & & & & \\
\hline Adjusted $R^{2}$ & 0.9824 & & & & & \\
\hline Adequate Precision & 51.542 & & & & & \\
\hline
\end{tabular}

a. Degrees of freedom $(d f)$

b. Fisher's $(F)$ exact test value.

c. A probability value $(p)<0.05$ is considered significant, a $p$-value $>0.10$ is considered not significant.

d. Total sum of squares corrected for the mean. 
On the other hand, the assumption of the constant variance was verified by plotting the internally studentized residual versus predicted values (Figures 7.3a and 7.3b). The studentized residuals were found dividing the residuals by their standard deviations showing a randomly scattered pattern within the outlier detection limits -3 and +3 . Therefore, model predictions, described in Equations (7.3) and (7.4), for both the percent TOC removal and the $\mathrm{H}_{2} \mathrm{O}_{2}$ residual, respectively, are satisfactory.

Moreover, the normal probability plot of residuals, shown in Figures 7.4a and 7.4b for the TOC removal and the $\mathrm{H}_{2} \mathrm{O}_{2}$ residual, respectively, showed a straight-line pattern followed by the points on the plot, not an S-shaped curve. Consequently, a transformation of the response is not required because of the normal distribution of the residuals (Bustillo-Lecompte et al., 2016a).

The correlation between the observed and predicted values is shown in Figures 7.5a and 7.5b for the TOC removal and the $\mathrm{H}_{2} \mathrm{O}_{2}$ residual, respectively. As a result, minor discrepancies are represented by a straight-line trend, which indicates a good agreement between observed and predicted values. Hence, the quadratic model predictions for both percent TOC removal and $\mathrm{H}_{2} \mathrm{O}_{2}$ residual responses are satisfactory.

\subsubsection{Individual and cross-factor interaction effects of model parameters}

The significance of each model factor was also evaluated using the $F$-exact test and $p$-values for each factor including linear, quadratic, and cross-factor interaction. All four independent variables including influent TOC $\left(X_{1}\right)$, flow rate $\left(X_{2}\right), \mathrm{H}_{2} \mathrm{O}_{2}$ dosage $\left(X_{3}\right)$, and $\mathrm{pH}\left(X_{4}\right)$ have a significant effect on both responses since their $p$-values are lower than 0.05 .

Besides, the cross-factor interactions of all model parameters, including the influent TOC concentration and flow rate $\left(X_{1} X_{2}\right)$, influent TOC concentration and $\mathrm{H}_{2} \mathrm{O}_{2}$ dosage $\left(X_{1} X_{3}\right)$, influent TOC concentration and $\mathrm{pH}\left(X_{1} X_{4}\right)$, flow rate and $\mathrm{H}_{2} \mathrm{O}_{2}$ dosage $\left(X_{2} X_{3}\right)$, flow rate and $\mathrm{pH}\left(X_{2} X_{4}\right)$, and $\mathrm{H}_{2} \mathrm{O}_{2}$ dosage and $\mathrm{pH}\left(X_{3} X_{4}\right)$ showed a significant effect on both TOC removal and $\mathrm{H}_{2} \mathrm{O}_{2}$ residual. The crossfactor interaction effects with the highest significance as per their $p$-values $<0.0001$ are illustrated in Figure 7.6. 

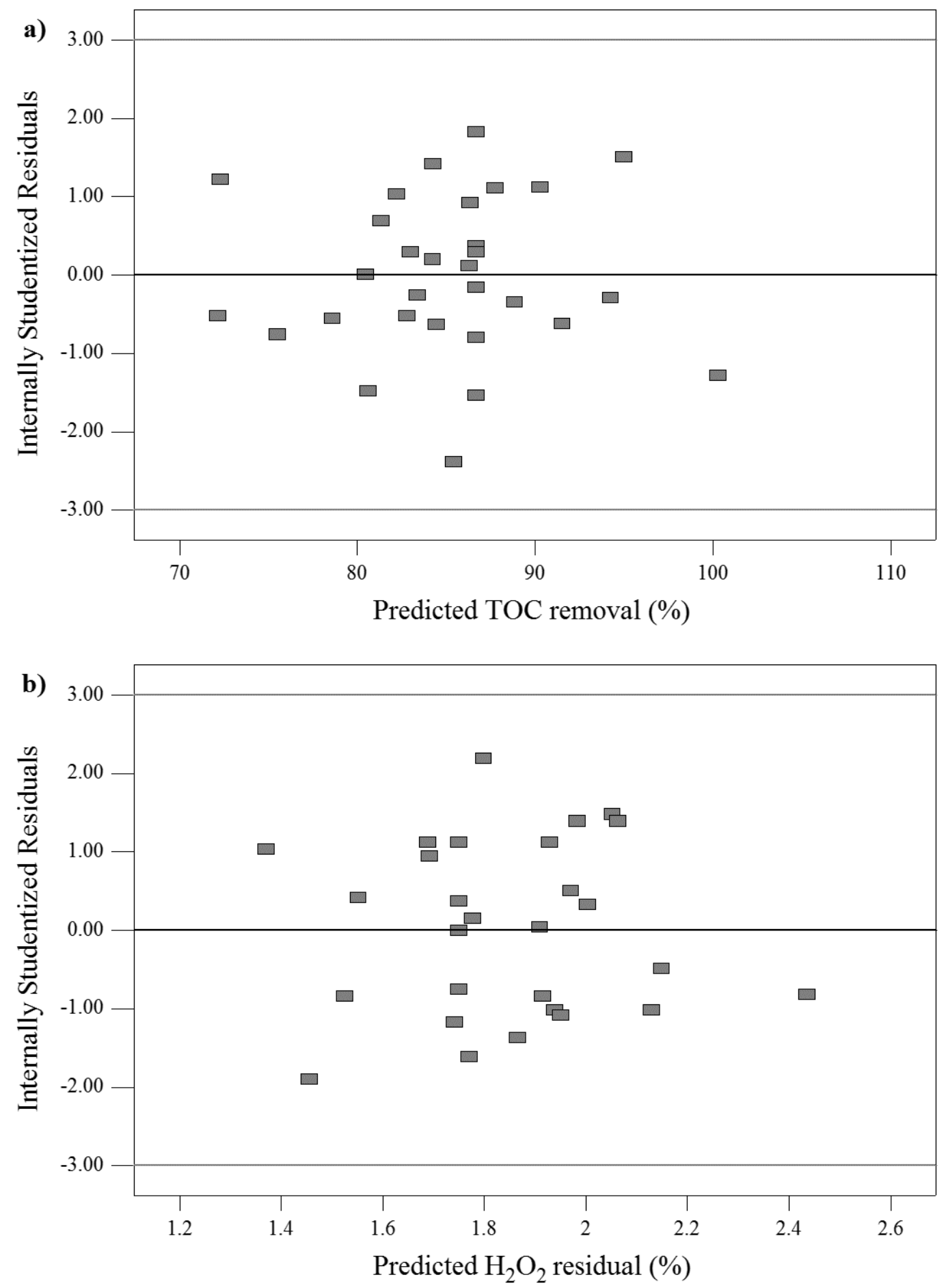

Figure 7.3. Internally studentized residuals versus predicted values for (a) percent TOC removal and (b) $\mathrm{H}_{2} \mathrm{O}_{2}$ residual.

Reprinted from J. Geosci. Environ. Protection 4 (2016), pp. 175-186, Open Access. 

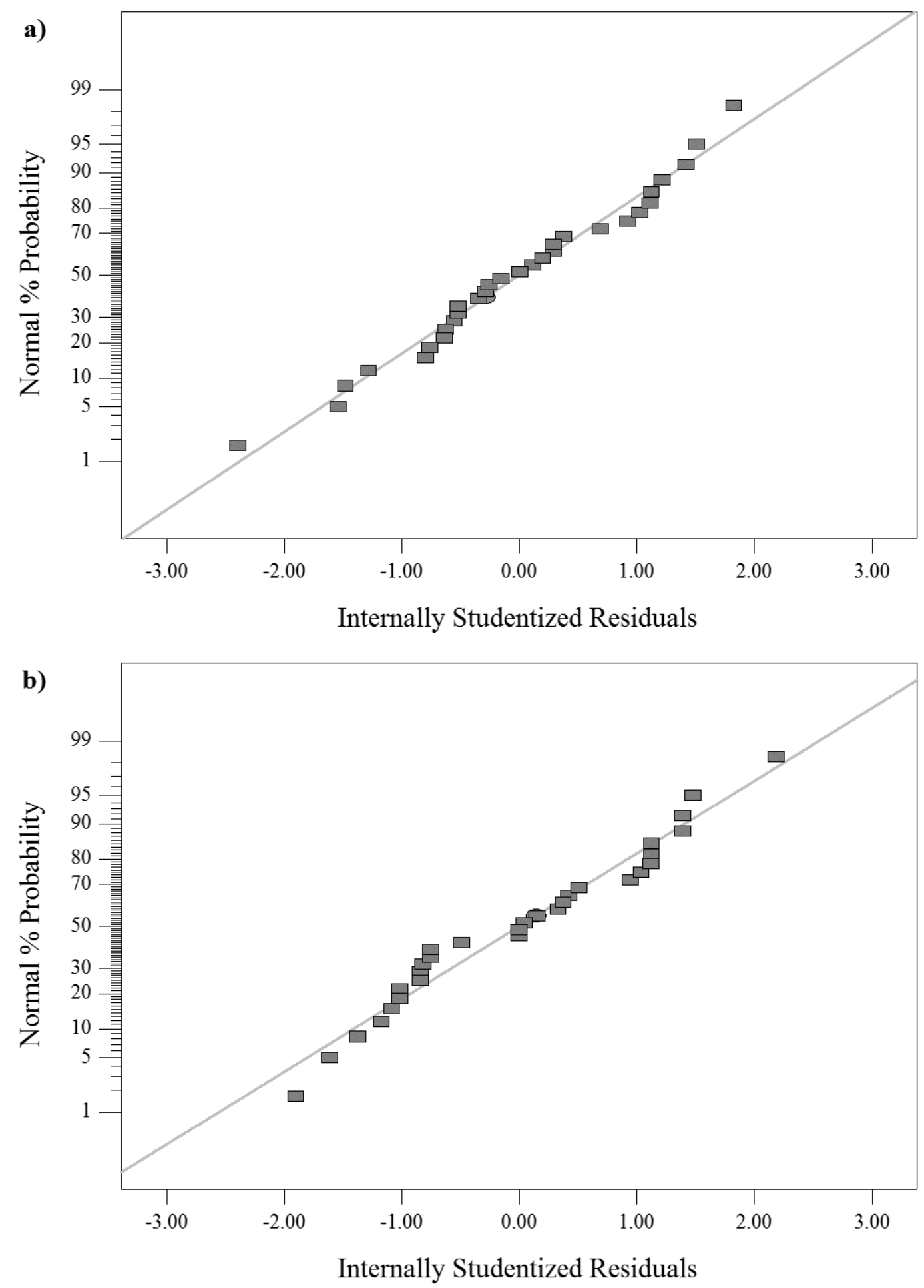

Figure 7.4. Internally studentized residuals versus normal probability for (a) percent TOC removal and (b) $\mathrm{H}_{2} \mathrm{O}_{2}$ residual.

Reprinted from J. Geosci. Environ. Protection 4 (2016), pp. 175-186, Open Access. 

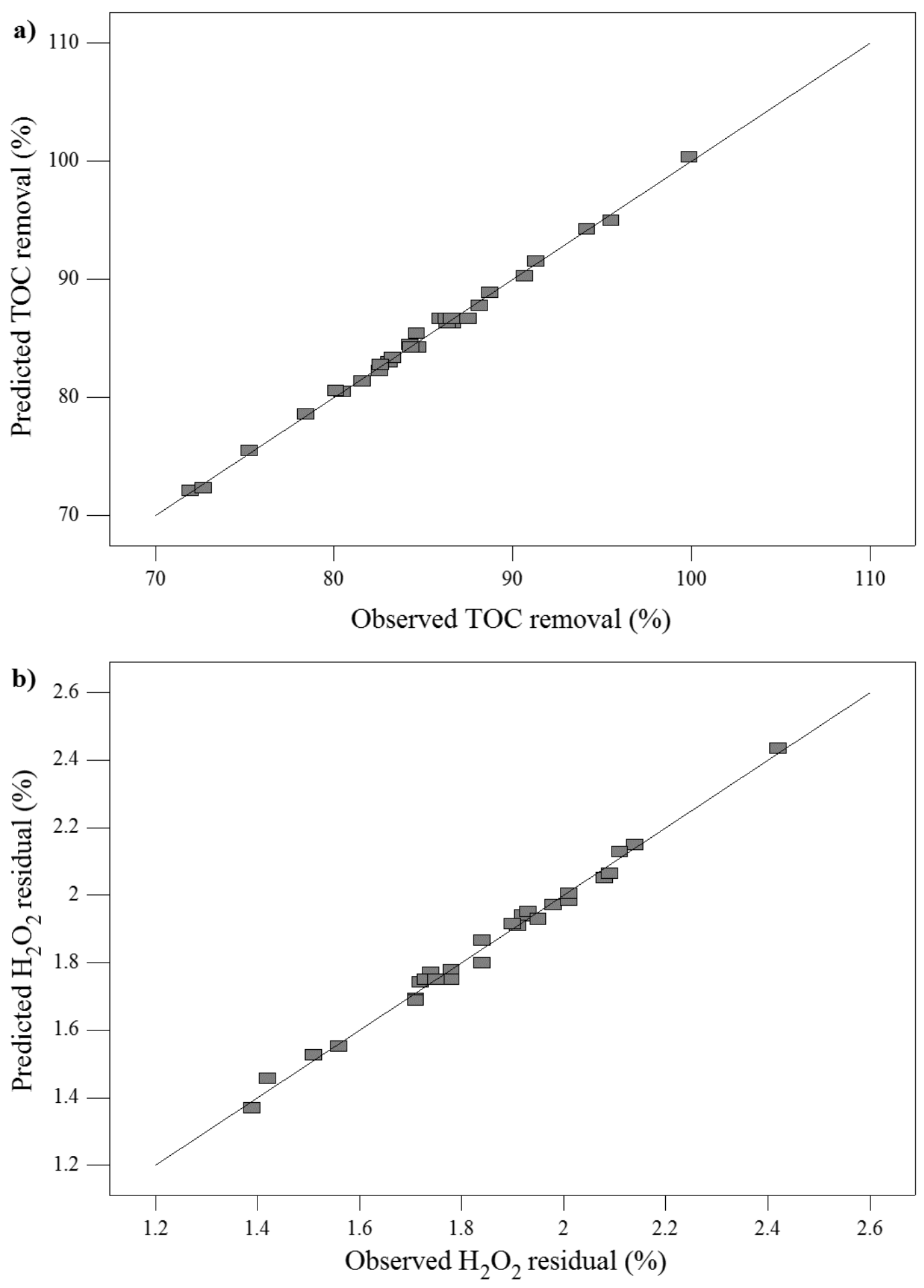

Figure 7.5. Observed experimental data versus predicted values for (a) percent TOC removal and (b) $\mathrm{H}_{2} \mathrm{O}_{2}$ residual.

Reprinted from J. Geosci. Environ. Protection 4 (2016), pp. 175-186, Open Access. 

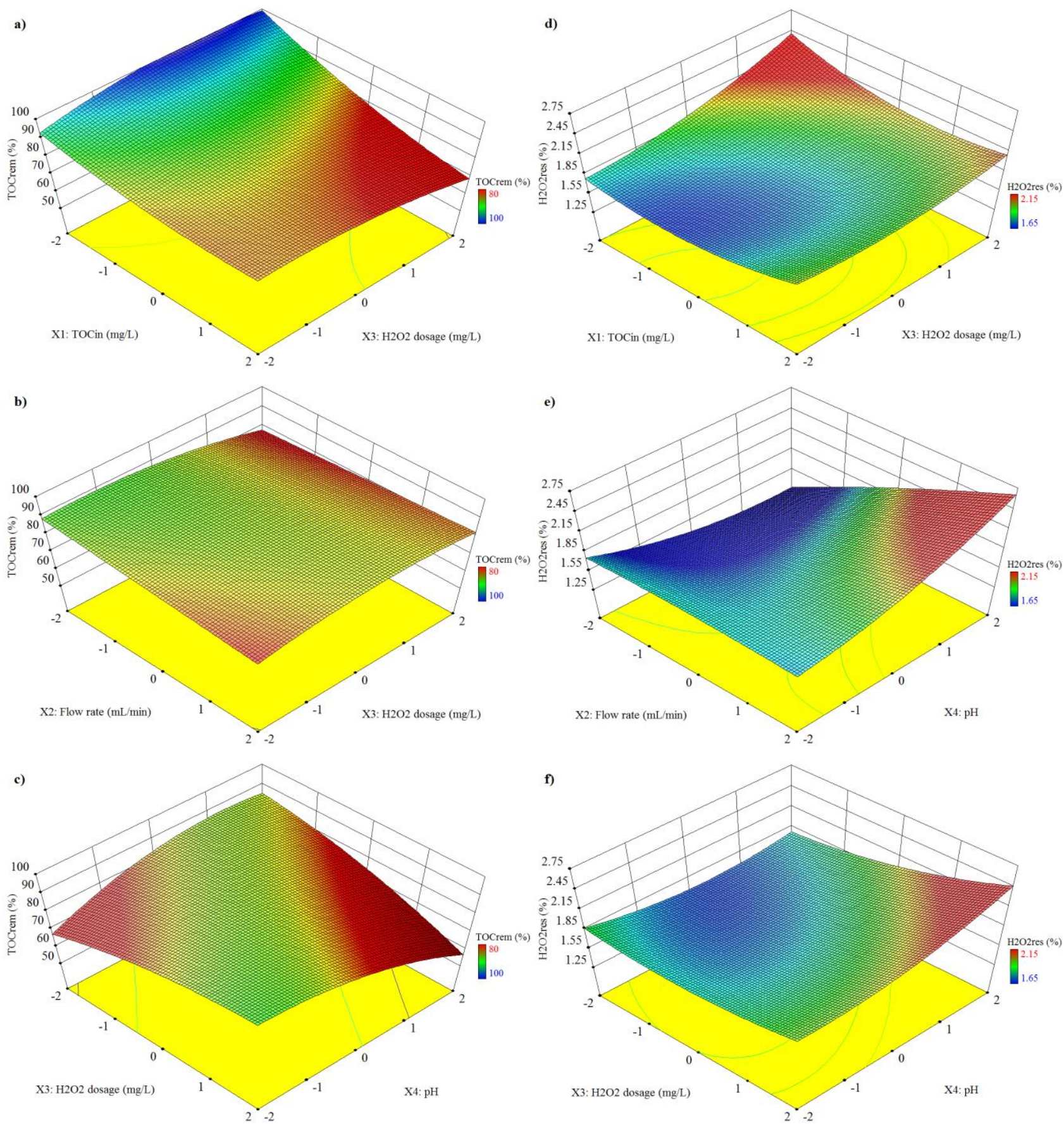

Figure 7.6. 3D surfaces and 2D plots of the interaction effects of: (a) influent TOC concentration and $\mathrm{H}_{2} \mathrm{O}_{2}$ dosage $\left(X_{1} X_{3}\right)$, flow rate and $\mathrm{H}_{2} \mathrm{O}_{2}$ dosage $\left(X_{2} X_{3}\right)$, and $\mathrm{H}_{2} \mathrm{O}_{2}$ dosage and pH $\left(X_{3} X_{4}\right)$ on the TOC removal; and (d) influent TOC concentration and $\mathrm{H}_{2} \mathrm{O}_{2}$ dosage $\left(X_{1} X_{3}\right)$, (e) flow rate and pH $\left(X_{2} X_{4}\right)$, and (f) $\mathrm{H}_{2} \mathrm{O}_{2}$ dosage and $\mathrm{pH}\left(X_{3} X_{4}\right)$ on $\mathrm{H}_{2} \mathrm{O}_{2}$ residual.

Reprinted from J. Geosci. Environ. Protection 4 (2016), pp. 175-186, Open Access. 


\subsubsection{Optimization of operating conditions}

The RSM was used to calculate the optimum conditions for the four independent variables to get maximum percent TOC removal and minimum $\mathrm{H}_{2} \mathrm{O}_{2}$ residual. Equations (3) and (4) were defined as objective functions for percent TOC removal and $\mathrm{H}_{2} \mathrm{O}_{2}$ residual, respectively, and the independent factors in their range were used as model constraints. Thus, the following optimum conditions to reach a maximum TOC removal of $98.9 \%$ and minimum $\mathrm{H}_{2} \mathrm{O}_{2}$ residual of $1.4 \%$ were found: influent TOC of $50 \mathrm{mg} / \mathrm{L}$, flow rate of $15 \mathrm{~mL} / \mathrm{min}, \mathrm{H}_{2} \mathrm{O}_{2}$ dosage of $344 \mathrm{mg} / \mathrm{L}$, and $\mathrm{pH}$ of 7.2. The obtained optimal operating conditions were used in an additional run to validate the predicted values. Obtaining a TOC removal of $97.8 \%$ and $\mathrm{H}_{2} \mathrm{O}_{2}$ residual of $1.3 \%$ were obtained experimentally, confirming the reliability of the model since the values are within the $95 \% \mathrm{CI}$.

\subsection{Conclusions}

The interaction effects of the influent TOC concentration, flow rate, $\mathrm{H}_{2} \mathrm{O}_{2}$ dosage, and $\mathrm{pH}$ had a significant effect on both TOC removal and $\mathrm{H}_{2} \mathrm{O}_{2}$ residual. Optimum conditions were found for each variable to achieve maximum TOC removal with minimum $\mathrm{H}_{2} \mathrm{O}_{2}$ residual. The developed mathematical models provided a comprehensive exploration of the cross-factor interactive effects of the independent variables on the responses. The proposed models explaining the treatment of SWW by the continuous $\mathrm{ABR}-\mathrm{AS}-\mathrm{UV} / \mathrm{H}_{2} \mathrm{O}_{2}$ system were found suitable for future studies on reactor design, modeling, and scale-up.

\section{Acknowledgments}

The financial support of Natural Sciences and Engineering Research Council of Canada (NSERC), Ontario Trillium Scholarship (OTS) program, Colciencias, University of Cartagena, and Ryerson University is greatly appreciated. 


\title{
CHAPTER 8
}

\section{TREATMENT OF AN ACTUAL SLAUGHTERHOUSE WASTEWATER BY INTEGRATION OF BIOLOGICAL AND ADVANCED OXIDATION PROCESSES: MODELING, OPTIMIZATION, AND COST-EFFECTIVENESS ANALYSIS*}

\begin{abstract}
Biological and advanced oxidation processes are combined to treat an actual slaughterhouse wastewater (SWW) by a sequence of an anaerobic baffled reactor, an aerobic activated sludge reactor, and a $\mathrm{UV} / \mathrm{H}_{2} \mathrm{O}_{2}$ photoreactor with recycle in continuous mode at laboratory scale. In the first part of this study, quadratic modeling along with response surface methodology are used for the statistical analysis and optimization of the combined process. The effects of the influent total organic carbon (TOC) concentration, the flow rate, the $\mathrm{pH}$, the inlet $\mathrm{H}_{2} \mathrm{O}_{2}$ concentration, and their interaction on the overall treatment efficiency, $\mathrm{CH}_{4}$ yield, and $\mathrm{H}_{2} \mathrm{O}_{2}$ residual in the effluent of the photoreactor are investigated. The models are validated at different operating conditions using experimental data. Maximum TOC and total nitrogen (TN) removals of 91.29 and $86.05 \%$, respectively, maximum $\mathrm{CH}_{4}$ yield of $55.72 \%$, and minimum $\mathrm{H}_{2} \mathrm{O}_{2}$ residual of $1.45 \%$ in the photoreactor effluent were found at optimal operating conditions. In the second part of this study, continuous distribution kinetics is applied to establish a mathematical model for the degradation of SWW as a function of time. The agreement between model predictions and experimental values indicates that the proposed model could describe the performance of the combined anaerobic-aerobic- $\mathrm{UV} / \mathrm{H}_{2} \mathrm{O}_{2}$ processes for the treatment of SWW. In the final part of the study, the optimized combined anaerobic-aerobic$\mathrm{UV} / \mathrm{H}_{2} \mathrm{O}_{2}$ processes with recycle were evaluated using a cost-effectiveness analysis to minimize the retention time, the electrical energy consumption, and the overall incurred treatment costs required for the efficient treatment of slaughterhouse wastewater effluents.
\end{abstract}

Keywords: Slaughterhouse wastewater, anaerobic digestion, activated sludge, advanced oxidation processes, process optimization.

\footnotetext{
* Reprinted, with minor editorial changes to fulfill formatting requirements, from:

C. Bustillo-Lecompte and M. Mehrvar (2016) Treatment of an actual slaughterhouse wastewater by integration of biological and advanced oxidation processes: modeling, optimization, and cost-effectiveness analysis. Journal of Environmental Management. (In Press).
} 


\subsection{Introduction}

Slaughterhouse wastewater (SWW) effluents are becoming one of the major agribusiness concerns because of the elevated amounts of water used during slaughtering, processing, and cleaning of the abattoir facilities. Although physical, chemical, and biological treatment can be used for SWW degradation, each treatment process has different benefits and drawbacks depending on the SWW characteristics, best available technology, jurisdictions, and regulations (Tabrizi and Mehrvar, 2004; Barrera et al., 2012; Franke-Whittle and Insam, 2013; Bustillo-Lecompte and Mehrvar, 2015; Valta et al., 2015; Bustillo-Lecompte et al., 2015, 2016a, 2016b). However, adopting combined processes for SWW treatment is considered operationally and economically advantageous because it incorporates and optimizes the advantages of different technologies to achieve high-quality effluents from industrial and high-strength wastewaters (Kurian et al., 2006; Mehrvar and Tabrizi, 2006; De Nardi et al., 2011; Bustillo-Lecompte et al., 2013, 2014; Bustillo-Lecompte and Mehrvar, 2015; Mowla et al., 2014).

Anaerobic treatment is the preferred biological treatment because of its effectiveness in treating high-strength wastewater such as SWW with less complex equipment requirements. Nevertheless, anaerobically treated effluents of SWW require post-treatment to comply with required discharge limits (Cao and Mehrvar, 2011; Bustillo-Lecompte et al., 2013, 2014). Therefore, aerobic treatment systems are more frequently used in wastewater treatment since they operate at higher rates than conventional anaerobic treatment methods in the case of lower strength wastewaters. Taking into account that oxygen requirements and treatment time are directly proportional to an increase in wastewater strength, the aerobic treatment are commonly used for further treatment and nutrient removal following physicochemical and anaerobic treatment methods (Bustillo-Lecompte and Mehrvar, 2015).

Furthermore, the SWW may contain toxic and non-biodegradable organic substances, making biological treatment alone insufficient. Thus, advanced oxidation processes (AOPs) are used to improve the biodegradability of wastewaters containing non-biodegradable organics and inactivate both pathogenic and non-pathogenic microorganisms without adding additional chemicals to the SWW, avoiding the formation of hazardous by-products. Consequently. AOPs are an attractive alternative to conventional treatment systems and a complementary treatment method to biological processes for the treatment of slaughterhouse effluents (Oller et al., 2011; Barrera et al., 2012; Bustillo-Lecompte and Mehrvar, 2015; Bustillo-Lecompte et al., 2016a, 2016b). 
As a result, considering the eventual reduction in operation and maintenance costs, high removal efficiency requirements, potential energy recovery from biogas production, and enhanced quality for water reuse purposes, combined biological processes and AOP systems are recommended for the SWW treatment if the system were optimized at an appropriate residence time in each reactor. (Tabrizi and Mehrvar, 2004; Oller et al., 2011; Bustillo-Lecompte and Mehrvar, 2015).

Combined processes for wastewater treatment are multifactor systems due to the interactions of different parameters on the overall process efficiency including the concentration of organic matter, the reaction time, the $\mathrm{pH}$, the light source intensity, the oxidant concentration, and the output power, among others, which have not been widely evaluated. Therefore, the optimization of such systems requires the consideration of both single-factor and cross-factor effects through a design of experiments (DOE) to identify the factors that influence the multivariable system while overcoming the limitations of traditional experimental methods in terms of the number of experimental trials, time, and materials. (Ghafoori et al., 2012, 2014a, 2015; Bustillo-Lecompte et al., 2016a, 2016b). On the other hand, the available information on the reaction mechanisms and detailed kinetic modeling of combined biological and AOP systems involving all free radicals and molecular species for the degradation of SWW is limited (Ghafoori et al., 2012; Bustillo-Lecompte and Mehrvar, 2015).

In this study, the effects of the influent concentration of TOC, the flow rate, the $\mathrm{pH}$, the inlet concentration of $\mathrm{H}_{2} \mathrm{O}_{2}$ to the photoreactor, and their interactions on the overall efficiency of the anaerobic-aerobic- $\mathrm{UV} / \mathrm{H}_{2} \mathrm{O}_{2}$ processes, the effluent $\mathrm{H}_{2} \mathrm{O}_{2}$ residual concentration at the photoreactor outlet, and the $\mathrm{CH}_{4}$ yield for the treatment of SWW were investigated. The DOE was used to optimize the SWW treatment using a combined system of an anaerobic baffled reactor (ABR), followed by an aerobic activated sludge (AS) reactor, and a $\mathrm{UV} / \mathrm{H}_{2} \mathrm{O}_{2}$ photoreactor with recycle in continuous mode at laboratory scale. The $\mathrm{CH}_{4}$ yield and the removal of the TOC and the TN were maximized while minimizing the $\mathrm{H}_{2} \mathrm{O}_{2}$ residual in the effluent of the photoreactor. The optimal parametric values from the DOE were obtained using a central composite design (CCD) with four factors at five levels combined with the response surface methodology (RSM). Statistical models were also developed to predict the percentual TOC and TN removals, the effluent concentration of $\mathrm{H}_{2} \mathrm{O}_{2}$, and $\mathrm{CH}_{4}$ yield as response variables by the combined anaerobic-aerobic- $\mathrm{UV} / \mathrm{H}_{2} \mathrm{O}_{2}$ processes. The statistical models were validated by an additional set of experiments at the optimum conditions in line with the DOE results. 
In the second part of this study, the reactors in the combined processes were analyzed to find the degradation models for the prediction of the percentual TOC removal as the output variable as a function of time. The degradation models were validated by another set of experimental data carried out under the optimized operating conditions based on the results of the experimental design. Finally, the optimized combined $\mathrm{ABR}-\mathrm{AS}-\mathrm{UV} / \mathrm{H}_{2} \mathrm{O}_{2}$ system with recycle was evaluated using a cost-effectiveness analysis (CEA), minimizing the incurred treatment costs, the electrical energy consumption, and the retention time required for the efficient treatment of slaughterhouse effluents. The results from this study contribute towards the cost-effective use of combined biological and advanced oxidation processes for the treatment of actual wastewater from the meat-processing sector.

\subsection{Materials and methods}

\subsubsection{Materials}

Actual SWW samples, with an average TOC concentration of $862 \mathrm{mg} / \mathrm{L}$, were taken from selected provincially licensed meat processing plants (Ontario, Canada) directly from their source (OMAFRA, 2016). The overall SWW characteristics from the selected meat processing plants are shown in Table 8.1 .

Table 8.1. Characteristics of the actual slaughterhouse wastewater from selected provincially licensed meat processing plants with study range values for the combined $A B R-A S-U V / H_{2} \mathrm{O}_{2}$ system.

J. Environ. Manage. (2016), In Press.

\begin{tabular}{ll}
\hline Parameter & Range \\
\hline BOD $(\mathrm{mg} / \mathrm{L})$ & $65.15-1,831$ \\
COD $(\mathrm{mg} / \mathrm{L})$ & $76.43-2,166$ \\
$\mathrm{TN}(\mathrm{mg} / \mathrm{L})$ & $101.1-366.1$ \\
$\mathrm{TOC}(\mathrm{mg} / \mathrm{L})$ & $48.91-1,691$ \\
TP $(\mathrm{mg} / \mathrm{L})$ & $0.1430-31.38$ \\
TSS (mg/L) & $0.2870-124.3$ \\
$\mathrm{pH}$ & $6.800-7.000$ \\
\hline
\end{tabular}

Five sample sites were used in this study due to the wide TOC range of the slaughterhouse effluents obtained from the meat processing plants. Anaerobic and aerobic sludge seeds in 
concentrations of 38,000 and 3,000 mg/L, respectively, were obtained from the Ashbridges Bay Wastewater Treatment Plant, a municipal wastewater treatment plant in Toronto, Canada. A hydrogen peroxide solution $(30 \% \mathrm{w} / \mathrm{w})$ was purchased from Sigma-Aldrich (Oakville, ON), whereas $\mathrm{NaOH}(50 \%$ w/w) and $\mathrm{H}_{2} \mathrm{SO}_{4}(98 \%$ w/w) were obtained from EMD Millipore (Etobicoke, ON) for pH adjustment. All purchased chemicals were used as received.

\subsubsection{Experimental setup}

Figure 8.1a illustrates the schematic diagram of the experimental setup for the combined ABR$\mathrm{AS}-\mathrm{UV} / \mathrm{H}_{2} \mathrm{O}_{2}$ processes. The combined system consisted of a 36-L ABR with five equal-volume chambers integrated with individual headspaces and biogas collection piping, a 12.65-L aerobic AS bioreactor with a monitored air flow rate to maintain dissolved oxygen (DO) concentrations over 2.0 $\mathrm{mg} / \mathrm{L}$, and a 1.35-L photoreactor with recycle and uniform light distribution. The stainless steel cylindrical photoreactor (Barrier SL-1S - Siemens Inc., Markham, ON) had an external diameter of 8 $\mathrm{cm}$, a length of $34 \mathrm{~cm}$, and a $2.5 \mathrm{~cm}$ diameter UV-C lamp inserted into the center of the photoreactor with an output power of $6 \mathrm{~W}$ and a $254 \mathrm{~nm}$ wavelength. A quartz sleeve covered the lamp to protect it from fouling and maintain a uniform UV-C radiation emission.

\subsubsection{Experimental procedure}

The anaerobic and aerobic sludge seeds were loaded into the anaerobic and aerobic bioreactors, respectively. The inoculum was acclimatized in sixty days by feeding the actual SWW continuously into the bioreactors at a constant flow rate $(75 \mathrm{~mL} / \mathrm{min})$ while gradually increasing its concentration on biweekly basis from 25,50 , and $75 \%$ up to $100 \%$ of the actual SWW. Biomass growth within the ABR and AS processes was monitored by collecting samples from each compartment of both ABR and AS bioreactors during the acclimatization period by measuring the concentrations of both total suspended solids (TSS) and volatile suspended solids (VSS). After the acclimatization period, the anaerobic and aerobic biomass concentrations, measured as VSS, were stabilized at 25,000 mg/L and 3,000 mg/L, respectively. The temperature of the processes remained under sub-mesophilic conditions with an average of $24.9 \pm 0.1^{\circ} \mathrm{C}$ in the combined $\mathrm{ABR}-\mathrm{AS}-\mathrm{UV} / \mathrm{H}_{2} \mathrm{O}_{2}$ system. 


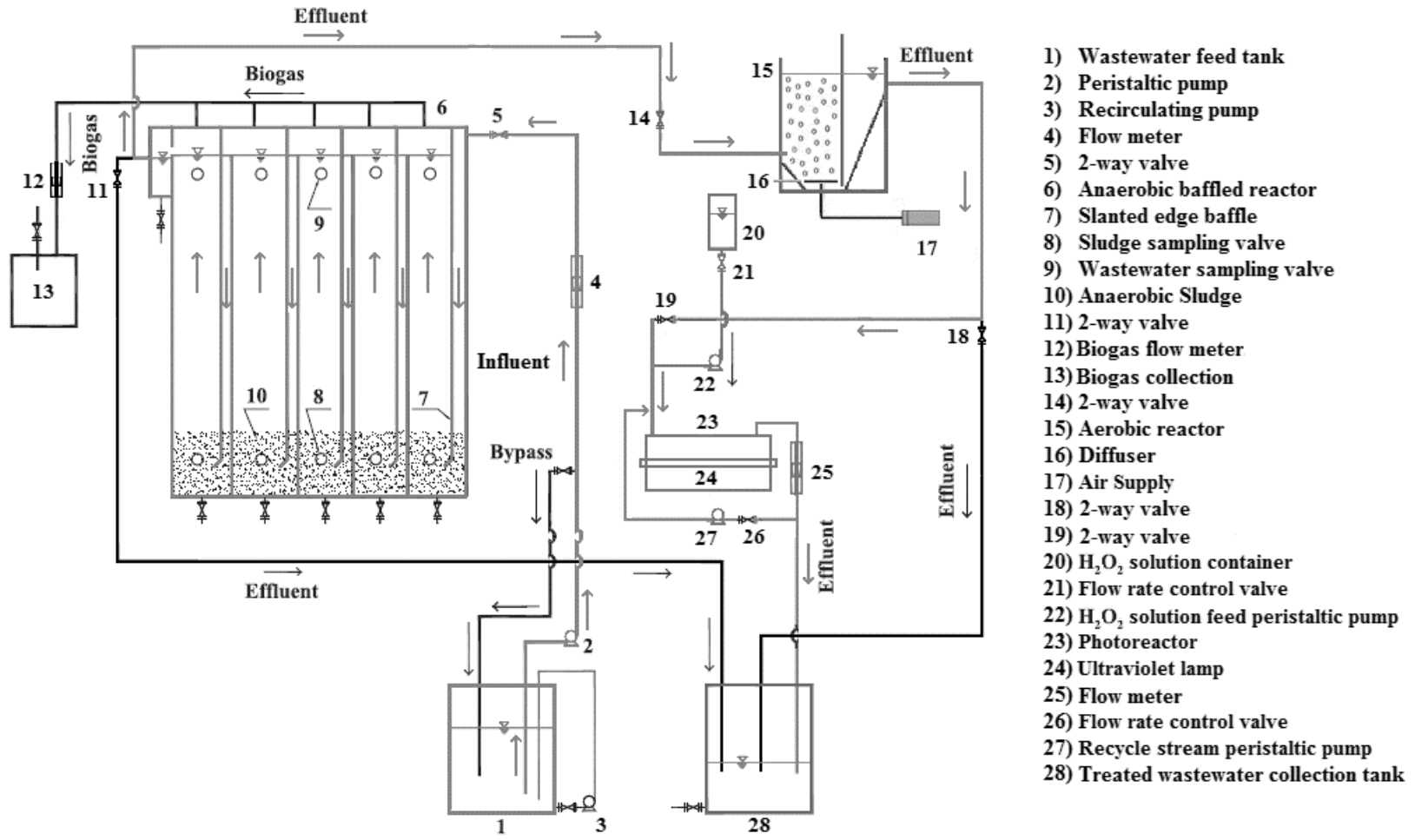

(a) Combined anaerobic-aerobic processes for the treatment of SWW
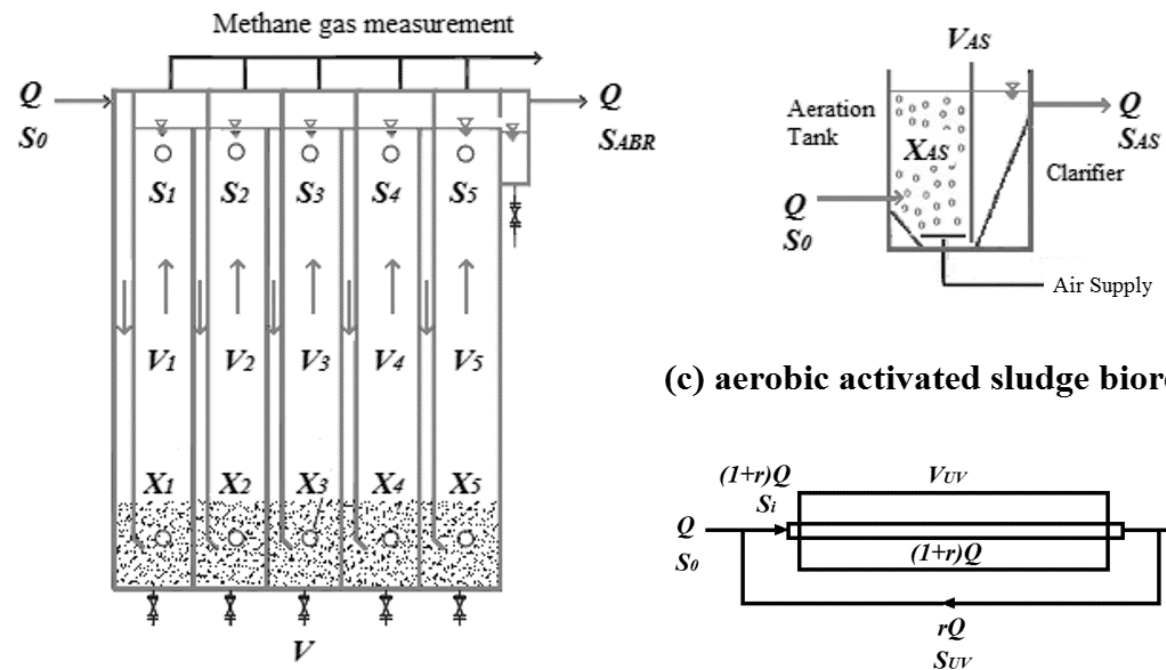

(c) aerobic activated sludge bioreator

(b) anaerobic baffled reactor

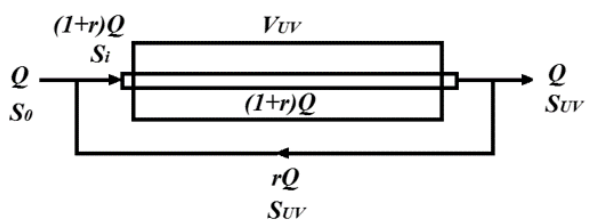

(d) $\mathrm{UV} / \mathrm{H}_{2} \mathrm{O} 2$ photoreactor with recycle

Figure 8.1. Schematic diagram of (a) the combined anaerobic-aerobic processes for the treatment of SWW and the individual processes (b) anaerobic baffled reactor, (c) aerobic activated sludge bioreactor, and (d) $\mathrm{UV} / \mathrm{H}_{2} \mathrm{O}_{2}$ photoreactor with recycle.

J. Environ. Manage. (2016), In Press. 
After the sixty-day acclimatization period, the following procedure was used during each experiment in the combined $\mathrm{ABR}-\mathrm{AS}-\mathrm{UV} / \mathrm{H}_{2} \mathrm{O}_{2}$ system for quality control:

1) SWW samples were filtered to separate the liquid from the solid portion of the SWW.

2) Filtered SWW samples were diluted to reach the desired TOC concentration of the feed in a 120-L solution.

3) Sulfuric acid $\left(\mathrm{H}_{2} \mathrm{SO}_{4}\right)$ and sodium hydroxide $(\mathrm{NaOH})$ solutions at $98 \%$ and $50 \%$ w/w, respectively, were used to adjust the $\mathrm{pH}$.

4) The SWW solution with the desired TOC concentration and $\mathrm{pH}$ was fed to the combined ABRAS-UV/ $\mathrm{H}_{2} \mathrm{O}_{2}$ system by a variable speed peristaltic pump, which was used to control and adjust the flow rate.

5) An adequate $\mathrm{H}_{2} \mathrm{O}_{2}$ concentration was calculated based on the material balance for each experiment, by which the $\mathrm{H}_{2} \mathrm{O}_{2}$ solution flow rate to the photoreactor was adjusted and fed by a secondary variable speed peristaltic pump.

6) In the photoreactor, there was a recycle stream, for which a third variable speed peristaltic pump was used to adjust the flow rate to the desired recycle ratio.

7) Effluent samples were taken at 3-h intervals until the system reached steady state conditions.

\subsubsection{Sample analysis}

An automated TOC/TN analyzer (Teledyne Tekmar Apollo 9000, Mason, OH) measured both TOC and TN concentrations for each sample. Temperature, $\mathrm{pH}$, and DO were measured daily using a $\mathrm{pH}$ meter with a temperature probe (Thermo Scientific Orion 230A+, Ottawa, ON), and a dissolved oxygen meter (YSI 58 Dissolved Oxygen Meter, Yellow Springs, OH), respectively. The concentrations of TSS and VSS were measured according to the standards methods (APHA, 2012). Biogas analysis was performed using a portable gas analyzer (Landtec Biogas 5000, Colton, CA) for $\mathrm{CH}_{4}, \mathrm{CO}_{2}, \mathrm{O}_{2}$, and $\mathrm{N}_{2}$-balance in a volume percentage measurement. The $\mathrm{H}_{2} \mathrm{O}_{2}$ residuals were measured with a UV-visible spectrophotometer (Ultrospec 1100 pro - Amersham Biosciences, Amersham, UK) at $454 \mathrm{~nm}$ using the copper (II) ion and 2,9-dimethyl-1,10-phenanthroline (neocuproine) method, also known as the copper-DMP method (Baga et al., 1988; Kosaka et al., 1998; Brandhuber and Korshin, 2009; Hamad et al., 2014, 2016; Bustillo-Lecompte et al., 2016a, 2016b). All experiments were repeated in triplicates, and the average values were reported. 


\subsubsection{Experimental design}

A four-factor with five levels CCD in combination with RSM was used to optimize the overall efficiency of the combined $\mathrm{ABR}-\mathrm{AS}-\mathrm{UV} / \mathrm{H}_{2} \mathrm{O}_{2}$ system, maximizing the percentual TOC and TN removals and the percentual methane gas yield, as the percent TOC converted to $\mathrm{CH}_{4}$, while minimizing the percentual $\mathrm{H}_{2} \mathrm{O}_{2}$ residuals in the effluent of the photoreactor. The influent concentration of TOC $\left(X_{1}\right)$, the flow rate $\left(X_{2}\right)$, the photoreactor inlet concentration of $\mathrm{H}_{2} \mathrm{O}_{2}\left(X_{3}\right)$, and the $\mathrm{pH}$ of the main feed $\left(X_{4}\right)$ were used as independent factors in the DOE. On the other hand, the percentual TOC removal $\left(Y_{1}\right)$, the TN removal $\left(Y_{2}\right)$, the $\mathrm{H}_{2} \mathrm{O}_{2}$ residuals in the photoreactor effluent $\left(Y_{3}\right)$, and the $\mathrm{CH}_{4}$ production in the anaerobic bioreactor $\left(\mathrm{Y}_{4}\right)$ were considered as process responses. Thus, each factor was coded at five levels, from -2 to +2 , as shown in Table 8.2. Experimental data from previous studies were used to determine and select the critical ranges of the factors (Bustillo-Lecompte and Mehrvar, 2015; BustilloLecompte et al., 2013, 2014, 2015, 2016a, 2016b).

Table 8.2. Independent variables with coded levels based on a four-factor, five level CCD for the combined ABR-AS-UV/ $/ \mathrm{H}_{2} \mathrm{O}_{2}$ system for $\mathrm{SWW}$ treatment.

J. Environ. Manage. (2016), In Press.

\begin{tabular}{lcccccc}
\hline & & \multicolumn{5}{c}{ Coded levels } \\
Independent variable & Symbol & $\mathbf{- 2}$ & $\mathbf{- 1}$ & $\mathbf{0}$ & $\mathbf{1}$ & $\mathbf{2}$ \\
\hline $\mathrm{TOC}_{\text {in }}(\mathrm{mg} / \mathrm{L})$ & $X_{1}$ & 50 & 450 & 850 & 1,250 & 1,650 \\
Flow rate $(\mathrm{mL} / \mathrm{min})$ & $X_{2}$ & 15 & 45 & 75 & 105 & 135 \\
$\mathrm{H}_{2} \mathrm{O}_{2}$ in $(\mathrm{mg} / \mathrm{L})$ & $X_{3}$ & 100 & 300 & 500 & 700 & 900 \\
$\mathrm{pH}$ & $X_{4}$ & 3 & 5 & 7 & 9 & 11 \\
\hline
\end{tabular}

A quadratic model was used to estimate the parametric coefficients by correlating dependent and independent variables using the least-squares regression as shown in Equation (8.1) (Ghafoori et al., 2012, 2014a, 2015; Bustillo-Lecompte et al., 2016a, 2016b):

$Y_{i}=\beta_{o}+\sum_{i=1}^{k} \beta_{i} X_{i}+\sum_{i=1}^{k} \beta_{i i} X_{i}^{2}+\sum_{i=1}^{k-1} \sum_{j=2}^{k} \beta_{i j} X_{i} X_{j}+c$ 
where $\beta_{o}, \beta_{i}, \beta_{i i}$, and $\beta_{i j}$ are the constant, linear, quadratic, and cross-factor interaction coefficients, respectively; $X_{i}$ and $X_{j}$ represent the independent variables; $Y_{i}$ is the predicted response; and $k$ and $c$ are the number of factors and the residual term, respectively.

The statistical software Design-Expert 10.0.0.3 was employed in the DOE to estimate the coefficients of the response functions. The significance of the model equations, individual parameters, and factor interactions were evaluated by analysis of variance (ANOVA) at the confidence intervals (CI) of 95\% $(\alpha=0.05)$. Two-dimensional (2D) contour plots and three-dimensional (3D) surface responses were obtained in the quadratic models. Additional experimental runs were carried out to validate the quadratic models for the maximum percentual $\mathrm{CH}_{4}$ production, the TOC and TN removals, and minimum $\mathrm{H}_{2} \mathrm{O}_{2}$ residuals in the effluent of the photoreactor at the optimal operating conditions, calculated by the software numerical optimization method.

\subsubsection{Optimization of the operating conditions}

To obtain a simultaneous objective function that represents the geometric mean of all transformed responses from the DOE, the desirability multiple response method was used to combine the desirable ranges for each response as shown in Equation (8.2) (Myers et al., 2004; Bustillo-Lecompte et al., 2016a, 2016b):

$D=\left(d_{1} \times d_{2} \times d_{3} \times d_{4} \ldots \times d_{n}\right)^{1 / n}=\left(\prod_{i=1}^{n} d_{i}\right)^{1 / n}$

where $D, d_{i}$, and $n$ are the desirability objective function, each response range, and the number of responses, respectively. For a simultaneous optimization, each response requires low and high values for the optimization. Otherwise, if any response is found outside its desirability range, the overall desirability becomes equal to zero. In this case, the percentual TOC removal $\left(d_{1}\right)$, TN removal $\left(d_{2}\right)$, $\mathrm{H}_{2} \mathrm{O}_{2}$ residual $\left(d_{3}\right)$, and $\mathrm{CH}_{4}$ production $\left(d_{4}\right)$ are optimized.

\subsubsection{Slaughterhouse wastewater degradation models}

In this study, the combined anaerobic-aerobic bioreactors and $\mathrm{UV} / \mathrm{H}_{2} \mathrm{O}_{2}$ with recycle were used in sequence to degrade an actual SWW in continuous mode at the laboratory scale. A simple model represents the biological treatment as a continuous anaerobic plug flow reactor (PFR) followed by a 
continuous aerated stirred tank reactor (CSTR), using first order kinetics and a biomass term to account for the rate of the limiting substrate consumption in the system. In the photochemical reactor, depending on the order of the reactions, the compound could be mineralized after treatment in the bioreactors.

\subsubsection{Slaughterhouse wastewater degradation in a continuous anaerobic baffled reactor}

The ABR can be considered as a continuous PFR, as illustrated in Figure 8.1b. The first order kinetic model shown below is used to describe the limiting substrate consumption:

$$
\frac{1}{X} \frac{d S}{d t}=-k S
$$

where $S$ is the limiting substrate concentration $(\mathrm{mg} / \mathrm{L}), X$ is the concentration of the active reactor biomass $(\mathrm{mg} / \mathrm{L})$, and $k$ is the first order rate constant $(\mathrm{L} / \mathrm{mg} . \mathrm{h})$, which could be calculated from the SWW treatment data knowing the substrate concentration and biomass in each of the ABR compartments. The substrate in an actual slaughterhouse wastewater is a multicomponent mixture; therefore, the TOC concentration was considered as a surrogate parameter for all organic substrates. This model assumes soluble components in the ABR and the system to be representative of an $n$-CSTRin-series, where $n$ represents the number of compartments of the ABR.

The model uses the material balance shown in Equation (8.4) for the first compartment, and assumes that $\mathrm{CH}_{4}$ production is the rate-limiting step since the total biomass concentration is used without recycle (Kennedy and Barriault, 2007).

$$
\frac{d S}{d t} V_{1}=Q S_{i n}-Q S_{1}-k_{1} S_{1} X_{1} V_{1}
$$

where $S_{\text {in }}$ is the influent limiting substrate concentration $(\mathrm{mg} / \mathrm{L}), k_{1}$ is the first order rate coefficient in the first compartment (L/mg.h), $V_{l}$ is the volume of the first compartment, $X_{l}$ is the concentration of biomass in the first compartment $(\mathrm{mg} / \mathrm{L})$, and $Q$ is the influent substrate flow rate $(\mathrm{L} / \mathrm{h})$. Thus, solving by integration, the effluent concentration for the first compartment at steady state without recycle is shown in Equation (8.5): 
$S_{1}=\frac{S_{i n}}{\left(1+k_{1} \mathrm{X}_{1} V_{1} / Q\right)}$

Consequently, the overall equation for the final effluent of an ABR with five compartments at steady state without recycle $\left(S_{A B R}\right)$ is as follows:

$S_{A B R}=\frac{S_{\text {in }}}{\left(1+k_{1} \mathrm{X}_{1} V_{1} / Q\right)\left(1+k_{2} \mathrm{X}_{2} V_{2} / Q\right)\left(1+k_{3} \mathrm{X}_{3} V_{3} / Q\right)\left(1+k_{4} \mathrm{X}_{4} V_{4} / Q\right)\left(1+k_{5} \mathrm{X}_{5} V_{5} / Q\right)}$

\subsubsection{Slaughterhouse wastewater degradation in a continuous completely-mixed activated sludge} bioreactor

The completely mixed AS bioreactor (Figure 8.1c) is a CSTR. The effluent concentration found by material balance and growth relationships between the limiting substrate and biological cell mass is as follows (Reynolds and Yang, 1966):

$S_{A S}=\frac{S_{i n}}{\left(1+k_{A S} X_{A S} V_{A S} / Q\right)}$

where $k_{\mathrm{AS}}$ is the first order reaction rate constant in the AS bioreactor (L/mg.h), $S_{\text {in }}$ is the concentration of substrate (TOC) in the influent of the AS bioreactor ( $\mathrm{mg} / \mathrm{L}$ ), $S_{A S}$ is the final effluent substrate (TOC) concentration in the AS bioreactor $(\mathrm{mg} / \mathrm{L}), X_{A S}$ is the biomass concentration in the AS bioreactor $(\mathrm{mg} / \mathrm{L}), V_{A S}$ is the volume of the AS bioreactor $(\mathrm{L})$, and $Q$ is the influent substrate flow rate $(\mathrm{L} / \mathrm{h})$.

\subsubsection{Slaughterhouse wastewater degradation in a continuous $\mathrm{UV} / \mathrm{H}_{2} \mathrm{O}_{2}$ photoreactor with recycle}

In the $\mathrm{UV} / \mathrm{H}_{2} \mathrm{O}_{2}$ photoreactor with recycle (Figure 1d), the recycled stream is drawn off from a point near the effluent and merged with the feed into the photoreactor. Then, the recycle ratio parameter, $r$, can be defined as the ratio of recycle flow rate to the main feed flow rate to the photoreactor. The only new step in calculating the conversion for a recycle reactor is a material balance at the stream intersections to properly express the species concentrations as a function of conversion. Thus, from the material balance at the photoreactor inlet, the following equation is written: 
$Q S_{i n}+r Q S_{U V}=(1+r) Q S_{r}$

where $S_{U V}$ is the concentration of the substrate (TOC) in the effluent of the $\mathrm{UV} / \mathrm{H}_{2} \mathrm{O}_{2}$ photoreactor $(\mathrm{mg} / \mathrm{L}), S_{\text {in }}$ is the influent substrate (TOC) concentration $(\mathrm{mg} / \mathrm{L}), S_{r}$ is the concentration of the substrate (TOC) in the stream fed to the photoreactor, $r$ is the recycle ratio, and $Q$ is the influent substrate flow rate (L/h). By solving for $S_{r}$ :

$S_{r}=\frac{S_{i n}+r S_{U V}}{1+r}$

Simultaneously, from the material balance in the photoreactor using time-based pseudo firstorder reaction, as demonstrated in previous studies (Edalatmanesh et al., 2008; Shu et al., 2013; Bustillo-Lecompte et al., 2014, 2016a), the following equations are obtained:

$$
\begin{aligned}
& \frac{d S}{d t} V_{U V}=(1+r) Q S_{r}-(1+r) Q\left(S_{r}-d S_{r}\right)+k^{\prime} S_{r} d V \\
& \frac{d S}{d t} V_{U V}=Q d S_{r}(1+r)+k^{\prime} S_{r} d V
\end{aligned}
$$

where $V_{U V}$ is the volume of the photoreactor and $k$ is the sum of the direct photolysis rate $\left(k_{U V}\right)$ and the hydroxyl radical $\left({ }^{\circ} \mathrm{OH}\right)$ oxidation rate or indirect photolysis rate $\left(k_{\bullet} \cdot \mathrm{OH}\right)$. Equation (11) at steady state is written as follows:

$$
S_{U V}=S_{r} \times \exp \left(\frac{-k^{\prime} V_{U V}}{(1+r) Q}\right)
$$

The direct photolysis rate $\left(k_{U V}\right)$ is described as follows:

$$
k_{U V}=K_{S} \times \phi_{S W W}
$$

where $\phi_{S W W}$ is the quantum yield for the SWW calculated by Equation (8.14) and $K_{s}$ is the specific rate of light absorption of the target compound calculated by Equation (8.15). 
$\phi_{S W W}=\frac{k_{U V} \times U}{\ln (10) \times \varepsilon_{S}}$

$K_{S}=\frac{E^{0} \times \varepsilon_{S} \times\left(1-10^{-\alpha \ell}\right)}{\alpha \ell}$

where $U$ is the molar photon energy $\left(4.72 \times 10^{5} \mathrm{~J} / \mathrm{E}\right.$ at $\left.254 \mathrm{~nm}\right), \varepsilon_{S}$ is the molar attenuation coefficient for the targeted substrate (1/M.cm), $E^{0}$ is the incident photon irradiance $\left(\mathrm{W} / \mathrm{cm}^{2}\right), \ell$ is the solution depth or path length $(\mathrm{cm})$, and $\alpha$ is the absorbance $(1 / \mathrm{cm})$ of the solution calculated by Equation (8.16). Considering the water background, $\mathrm{H}_{2} \mathrm{O}_{2}$ as the oxidant, and the SWW targeted substrate (Shu et al., 2013):

$\alpha=\alpha_{0}+\varepsilon_{H_{2} O_{2}} \times\left[H_{2} O_{2}\right]+\varepsilon_{S} \times\left[S_{r}\right]$

On the other hand, the oxidation rate $(k \cdot O H)$ is described as follows:

$k_{\bullet_{\mathrm{OH}}}=K_{\bullet_{\mathrm{OH} / \mathrm{SWW}}} \times\left[\bullet^{\mathrm{OH}}\right]_{S \mathrm{~S}}$

where $k_{\cdot} \mathrm{OH} / \mathrm{SWW}$ is the second-order rate constant describing the reaction between the ${ }^{\circ} \mathrm{OH}$ and a targeted substrate in SWW and [ $\left.{ }^{\circ} \mathrm{OH}\right]_{s s}$ is the steady state concentration of ${ }^{\circ} \mathrm{OH}$ formed via $\mathrm{H}_{2} \mathrm{O}_{2}$ photolysis calculated by Equation (8.18), considering the scavenging effect $\left(\Sigma K_{\cdot \mathrm{OH} / s v} \times[s v]\right)$ as follows (Baeza and Knappe, 2011):

$$
[\cdot \mathrm{OH}]_{S S}=\frac{K_{\mathrm{H}_{2} \mathrm{O}_{2}} \times \phi_{\mathrm{H}_{2} \mathrm{O}_{2}} \times\left[\mathrm{H}_{2} \mathrm{O}_{2}\right]}{\sum K_{{ }_{\mathrm{OH} / \mathrm{sv}}} \times[\mathrm{sv}]}
$$

\subsubsection{Economics study}

In order to gain the maximum benefit from the combined system, the residence time of the wastewater in each reactor should be optimized and the constraints should be considered in the model along with its limitations. Therefore, three objective functions were defined including the retention time 
minimization, the total power consumption minimization, and the overall treatment cost minimization using a cost-effectiveness analysis (CEA).

\subsection{Results and discussion}

\subsubsection{Experimental design and statistical analysis}

The influent TOC concentration was selected as the targeted substrate and one of the factors to be evaluated by DOE since TOC analysis provides a more efficient and accurate appraisal of the total organic compounds present in a wastewater sample in comparison to biological oxygen demand (BOD) or chemical oxygen demand (COD), due to the rapid sampling methodology using an automatized TOC analyzer without producing any toxic analytical waste (Dubber and Gray, 2010; Bustillo-Lecompte et al., 2014; Bustillo-Lecompte and Mehrvar, 2015). The flow rate and the $\mathrm{pH}$ were also selected due to their direct relationship to microorganism activity and growth (Chan et al., 2009; Cao and Mehrvar, 2011; Mees et al., 2014; Bustillo-Lecompte et al., 2013; Bustillo-Lecompte and Mehrvar, 2015). Whereas, the inlet concentration of $\mathrm{H}_{2} \mathrm{O}_{2}$ was selected since it is the oxidant used in the AOP for the post-treatment of the slaughterhouse wastewater (Bustillo-Lecompte and Mehrvar, 2015; BustilloLecompte et al., 2013, 2014, 2015, 2016a, 2016b).

Table 8.3 portrays the four-factor, five-level CCD with observed and predicted values for the percentual TOC removal $\left(Y_{1}\right)$, TN removal $\left(Y_{2}\right), \mathrm{H}_{2} \mathrm{O}_{2}$ residual $\left(Y_{3}\right)$, and $\mathrm{CH}_{4}$ production $\left(Y_{4}\right)$ by the developed quadratic models related to the combined $\mathrm{ABR}-\mathrm{AS}-\mathrm{UV} / \mathrm{H}_{2} \mathrm{O}_{2}$ system for $\mathrm{SWW}$ treatment. The response surface methodology (RSM) was used for parameter estimation, specifying the correlation between the input factors and the output responses, as previously shown in Equation (1). Consequently, in order to estimate the response functions for $Y_{1}, Y_{2}, Y_{3}$, and $Y_{4}$, second-order polynomial Equations were developed in terms of the coded factors, including the influent concentration of the TOC $\left(X_{1}\right)$, the flow rate $\left(X_{2}\right)$, the inlet concentration of $\mathrm{H}_{2} \mathrm{O}_{2}\left(X_{3}\right)$, and the $\mathrm{pH}\left(X_{4}\right)$. The coefficients for each model parameter are presented in Table 8.4.

Negative coefficients for the model components $X_{1}, X_{2}, X_{3}, X_{4}, X_{1} X_{2}, X_{1} X_{3}, X_{1} X_{4}, X_{3} X_{4}, X_{2}^{2}, X_{3}^{2}$, and $X_{4}^{2}$ in $Y_{1} ; X_{1}, X_{2}, X_{3}, X_{1} X_{4}, X_{3}^{2}$, and $X_{4}^{2}$ in $Y_{2} ; X_{1}, X_{1} X_{2}, X_{1} X_{3}, X_{2} X_{3}$, and $X_{2}^{2}$ in $Y_{3}$; and $X_{2}, X_{4}, X_{1} X_{2}$, $X_{1}^{2}, X_{2}{ }^{2}, X_{3}^{2}$, and $X_{4}^{2}$ in $Y_{3}$ indicate unfavorable effects on the percentual TOC removal, the TN removal, the $\mathrm{H}_{2} \mathrm{O}_{2}$ residuals in the effluent, and the $\mathrm{CH}_{4}$ production, respectively. 
Table 8.3. Four-factor, five-level CCD with observed and predicted percentual TOC removal, $\mathrm{TN}_{\mathrm{Nemoval}} \mathrm{H}_{2} \mathrm{O}_{2}$ residual, and $\mathrm{CH}_{4}$ production values.

J. Environ. Manage. (2016), In Press.

\begin{tabular}{|c|c|c|c|c|c|c|c|c|c|c|c|c|}
\hline \multirow[b]{2}{*}{ Run } & \multicolumn{4}{|c|}{ Independent coded variables } & \multicolumn{2}{|c|}{ TOC removal (\%) } & \multicolumn{2}{|c|}{ TN removal $(\%)$} & \multicolumn{2}{|c|}{$\mathrm{H}_{2} \mathrm{O}_{2}$ residual $(\%)$} & \multicolumn{2}{|c|}{$\mathrm{CH}_{4}$ production (\%) } \\
\hline & $X_{1}$ & $\boldsymbol{X}_{2}$ & $\boldsymbol{X}_{3}$ & $X_{4}$ & Observed & Predicted & Observed & Predicted & Observed & Predicted & Observed & Predicted \\
\hline 1 & -1 & -1 & -1 & -1 & 88.74 & 88.85 & 84.89 & 85.64 & 1.51 & 1.53 & 55.99 & 54.89 \\
\hline 2 & 1 & -1 & -1 & -1 & 83.11 & 83.01 & 77.77 & 77.87 & 1.78 & 1.78 & 62.58 & 62.69 \\
\hline 3 & -1 & 1 & -1 & -1 & 86.64 & 86.33 & 67.09 & 66.84 & 1.74 & 1.77 & 54.88 & 55.37 \\
\hline 4 & 1 & 1 & -1 & -1 & 78.42 & 78.60 & 61.62 & 61.42 & 1.92 & 1.94 & 49.08 & 49.64 \\
\hline 5 & -1 & -1 & 1 & -1 & 94.16 & 94.26 & 77.27 & 77.33 & 1.72 & 1.74 & 53.10 & 52.52 \\
\hline 6 & 1 & -1 & 1 & -1 & 83.29 & 83.37 & 79.27 & 79.99 & 1.84 & 1.87 & 62.72 & 63.83 \\
\hline 7 & -1 & 1 & 1 & -1 & 95.51 & 95.01 & 59.76 & 60.01 & 1.91 & 1.91 & 54.64 & 54.16 \\
\hline 8 & 1 & 1 & 1 & -1 & 82.58 & 82.24 & 65.04 & 65.03 & 1.93 & 1.95 & 52.35 & 51.95 \\
\hline 9 & -1 & -1 & -1 & 1 & 91.32 & 91.53 & 85.03 & 84.21 & 1.56 & 1.55 & 50.28 & 50.42 \\
\hline 10 & 1 & -1 & -1 & 1 & 84.25 & 84.46 & 69.60 & 70.29 & 1.42 & 1.46 & 59.13 & 59.59 \\
\hline 11 & -1 & 1 & -1 & 1 & 90.68 & 90.31 & 75.58 & 75.81 & 2.14 & 2.15 & 54.88 & 53.75 \\
\hline 12 & 1 & 1 & -1 & 1 & 81.58 & 81.35 & 65.15 & 64.25 & 1.98 & 1.97 & 49.08 & 49.40 \\
\hline 13 & -1 & -1 & 1 & 1 & 84.72 & 84.25 & 79.34 & 80.49 & 1.90 & 1.92 & 50.34 & 49.76 \\
\hline 14 & 1 & -1 & 1 & 1 & 71.97 & 72.14 & 77.60 & 77.01 & 1.71 & 1.69 & 63.21 & 62.45 \\
\hline 15 & -1 & 1 & 1 & 1 & 86.34 & 86.30 & 74.51 & 73.58 & 2.42 & 2.44 & 54.64 & 54.26 \\
\hline 16 & 1 & 1 & 1 & 1 & 72.71 & 72.31 & 72.26 & 72.45 & 2.11 & 2.13 & 52.35 & 53.43 \\
\hline 17 & -2 & 0 & 0 & 0 & 99.89 & 100.0 & 81.82 & 81.66 & 2.01 & 1.98 & 52.56 & 54.22 \\
\hline 18 & 2 & 0 & 0 & 0 & 80.48 & 80.48 & 72.70 & 72.76 & 1.95 & 1.93 & 62.56 & 61.18 \\
\hline 19 & 0 & -2 & 0 & 0 & 88.15 & 87.78 & 90.38 & 89.41 & 1.39 & 1.37 & 58.28 & 58.73 \\
\hline 20 & 0 & 2 & 0 & 0 & 84.63 & 85.42 & 65.18 & 66.05 & 2.08 & 2.05 & 50.35 & 50.18 \\
\hline 21 & 0 & 0 & -2 & 0 & 84.31 & 84.24 & 69.12 & 69.37 & 1.71 & 1.69 & 57.75 & 57.69 \\
\hline 22 & 0 & 0 & 2 & 0 & 80.11 & 80.60 & 69.62 & 69.26 & 2.09 & 2.06 & 58.99 & 59.34 \\
\hline 23 & 0 & 0 & 0 & -2 & 82.62 & 82.79 & 66.47 & 65.82 & 1.84 & 1.80 & 50.35 & 50.35 \\
\hline 24 & 0 & 0 & 0 & 2 & 75.28 & 75.53 & 71.26 & 71.81 & 2.01 & 2.00 & 47.07 & 47.35 \\
\hline 25 & 0 & 0 & 0 & 0 & 86.85 & 86.67 & 76.25 & 76.30 & 1.73 & 1.75 & 62.51 & 60.30 \\
\hline 26 & 0 & 0 & 0 & 0 & 85.95 & 86.67 & 75.75 & 76.30 & 1.73 & 1.75 & 59.89 & 60.30 \\
\hline 27 & 0 & 0 & 0 & 0 & 86.81 & 86.67 & 75.16 & 76.30 & 1.75 & 1.75 & 58.89 & 60.30 \\
\hline 28 & 0 & 0 & 0 & 0 & 86.30 & 86.67 & 76.86 & 76.30 & 1.76 & 1.75 & 59.37 & 60.30 \\
\hline 29 & 0 & 0 & 0 & 0 & 87.53 & 86.67 & 77.35 & 76.30 & 1.78 & 1.75 & 60.72 & 60.30 \\
\hline 30 & 0 & 0 & 0 & 0 & 86.60 & 86.67 & 76.40 & 76.30 & 1.75 & 1.75 & 60.44 & 60.30 \\
\hline
\end{tabular}


Table 8.4. Coefficients table for the percentual TOC removal, $\mathrm{TN}$ removal, $\mathrm{H}_{2} \mathrm{O}_{2}$ residual, and $\mathrm{CH}_{4}$ production quadratic models.

J. Environ. Manage. (2016), In Press.

\begin{tabular}{|c|c|c|c|c|c|c|c|c|c|c|c|c|c|c|c|}
\hline Response & Intercept & $X_{1}$ & $X_{2}$ & $X_{3}$ & $X_{4}$ & $X_{1} X_{2}$ & $X_{I} X_{3}$ & $X_{1} X_{4}$ & $X_{2} X_{3}$ & $\boldsymbol{X}_{2} \boldsymbol{X}_{4}$ & $X_{3} X_{4}$ & $X_{I}^{2}$ & $X_{2}^{2}$ & $X_{3}^{2}$ & $X_{4}^{2}$ \\
\hline$Y_{l}=\mathrm{TOC}_{\mathrm{removal}}$ & 86.71 & -4.96 & -0.59 & -0.91 & -1.82 & -0.47 & -1.26 & -0.31 & 0.82 & 0.33 & -3.17 & 0.93 & -0.02 & -1.06 & -1.88 \\
\hline$Y_{2}=\mathrm{TN}_{\text {removal }}$ & 76.30 & -2.23 & -5.84 & -0.03 & 1.50 & 0.59 & 2.61 & -1.53 & 0.37 & 2.60 & 1.15 & 0.23 & 0.36 & -1.75 & -1.87 \\
\hline$Y_{3}=\mathrm{H}_{2} \mathrm{O}_{2}$ residual & 1.73 & -0.01 & 0.17 & 0.09 & 0.05 & -0.02 & -0.03 & -0.09 & -0.02 & 0.09 & 0.04 & 0.05 & -0.01 & 0.03 & 0.04 \\
\hline$Y_{4}=\mathrm{CH}_{4}$ production & 60.30 & 1.74 & -2.14 & 0.41 & -0.75 & -3.38 & 0.88 & 0.34 & 0.29 & 0.71 & 0.43 & -0.65 & -1.46 & -0.45 & -2.86 \\
\hline
\end{tabular}


On the other hand, positive coefficients for $X_{2} X_{3}, X_{2} X_{4}$, and $X_{1}^{2}$ in $Y_{1} ; X_{4}, X_{1} X_{2}, X_{1} X_{3}, X_{2} X_{3}, X_{2} X_{4}$, $X_{3} X_{4}, X_{1}^{2}$, and $X_{2}^{2}$ in $Y_{2} ; X_{2}, X_{3}, X_{4}, X_{2} X_{4}, X_{3} X_{4}, X_{1}^{2}, X_{3}^{2}$, and $X_{4}^{2}$ in $Y_{3}$; and $X_{1}, X_{3}, X_{1} X_{3}, X_{1} X_{4}, X_{2} X_{3}$, $X_{2} X_{4}$, and $X_{3} X_{4}$ in $Y_{4}$ indicate favorable effects on the percentual TOC removal, the TN removal, the $\mathrm{H}_{2} \mathrm{O}_{2}$ residuals, and the $\mathrm{CH}_{4}$ production, respectively. Coefficients with values close to zero represent lower relative intensity; thus, $X_{2}^{2}$ do not intensely affect the percentual TOC removal, $X_{3}$ do not intensely affect the percentual TN removal, and $X_{1}, X_{1} X_{2}, X_{1} X_{3}, X_{2} X_{3}, X_{2}^{2}$, and $X_{3}^{2}$ do not intensely affect the percentual $\mathrm{H}_{2} \mathrm{O}_{2}$ residuals. However, the significance of the quadratic model must be evaluated to establish the actual effect of each model parameter as well as their interaction using statistical analysis. Consequently, ANOVA was employed with a 95\% CI to estimate the statistical significance of the four quadratic models for the percentual TOC removal $\left(Y_{1}\right)$, the TN removal $\left(Y_{2}\right)$, the $\mathrm{H}_{2} \mathrm{O}_{2}$ residual $\left(Y_{3}\right)$, and the $\mathrm{CH}_{4}$ production $\left(Y_{4}\right)$ as shown in Table 8.5.

Table 8.5. ANOVA of the prediction results for the percentual TOC removal, TN removal, $\mathrm{H}_{2} \mathrm{O}_{2}$ residual, and $\mathrm{CH}_{4}$ production by quadratic modeling.

J. Environ. Manage. (2016), In Press.

\begin{tabular}{|c|c|c|c|c|c|c|}
\hline Source & Sum of squares & $d f^{\mathrm{a}}$ & Mean square & $F$ value $^{\mathrm{b}}$ & $p$-value ${ }^{c}$ & Remark \\
\hline TOC $_{\text {removal }}$ model & 1065.3 & 14 & 76.094 & 288.16 & $<0.0001$ & Significant \\
\hline$X_{l}=\mathrm{TOC}_{\mathrm{in}}$ & 590.44 & 1 & 590.44 & 2235.9 & $<0.0001$ & Significant \\
\hline$X_{2}=$ Flow rate & 8.3308 & 1 & 8.3308 & 31.548 & $<0.0001$ & Significant \\
\hline$X_{3}=\mathrm{H}_{2} \mathrm{O}_{2}$ in & 19.947 & 1 & 19.947 & 75.538 & $<0.0001$ & Significant \\
\hline$X_{4}=\mathrm{pH}$ & 79.134 & 1 & 79.134 & 299.67 & $<0.0001$ & Significant \\
\hline$X_{1} X_{2}$ & 3.5721 & 1 & 3.5721 & 13.527 & 0.0022 & Significant \\
\hline$X_{1} X_{3}$ & 25.452 & 1 & 25.452 & 96.384 & $<0.0001$ & Significant \\
\hline$X_{1} X_{4}$ & 1.5129 & 1 & 1.5129 & 5.7292 & 0.0302 & Significant \\
\hline$X_{2} X_{3}$ & 10.726 & 1 & 10.726 & 40.617 & $<0.0001$ & Significant \\
\hline$X_{2} X_{4}$ & 1.6900 & 1 & 1.6900 & 6.3999 & 0.0231 & Significant \\
\hline$X_{3} X_{4}$ & 160.91 & 1 & 160.91 & 609.35 & $<0.0001$ & Significant \\
\hline$X_{1}^{2}$ & 23.755 & 1 & 23.755 & 89.957 & $<0.0001$ & Significant \\
\hline$X_{2}{ }^{2}$ & 0.0090 & 1 & 0.0090 & 0.0341 & 0.8559 & Not significant \\
\hline$X_{3}^{2}$ & 31.001 & 1 & 31.001 & 117.40 & $<0.0001$ & Significant \\
\hline$X_{4}^{2}$ & 96.750 & 1 & 96.750 & 366.38 & $<0.0001$ & Significant \\
\hline Residual & 3.9610 & 15 & 0.2641 & & & \\
\hline Lack of Fit & 2.5093 & 10 & 0.2509 & 0.8642 & 0.6067 & Not significant \\
\hline Pure error & 1.4517 & 5 & 0.2903 & & & \\
\hline Corrected total $S S^{\mathrm{d}}$ & 1069.3 & 29 & & & & \\
\hline$R^{2}$ & 0.9963 & & & & & \\
\hline Adjusted $R^{2}$ & 0.9928 & & & & & \\
\hline Adequate Precision & 77.555 & & & & & \\
\hline
\end{tabular}




\begin{tabular}{|c|c|c|c|c|c|c|}
\hline Source & Sum of squares & $d f^{a}$ & Mean square & $F$ value $^{b}$ & $p$-value ${ }^{c}$ & Remark \\
\hline $\mathrm{TN}_{\text {removal }}$ model & 1460.7 & 14 & 104.33 & 135.64 & $<0.0001$ & Significant \\
\hline$X_{I}=\mathrm{TOC}_{\mathrm{in}}$ & 118.82 & 1 & 118.82 & 154.46 & $<0.0001$ & Significant \\
\hline$X_{2}=$ Flow rate & 818.53 & 1 & 818.53 & 1064.1 & $<0.0001$ & Significant \\
\hline$X_{3}=\mathrm{H}_{2} \mathrm{O}_{2}$ in & 0.0193 & 1 & 0.0193 & 0.0250 & 0.8764 & Not significant \\
\hline$X_{4}=\mathrm{pH}$ & 53.820 & 1 & 53.820 & 69.968 & $<0.0001$ & Significant \\
\hline$X_{1} X_{2}$ & 5.5460 & 1 & 5.5460 & 7.2101 & 0.0170 & Significant \\
\hline$X_{1} X_{3}$ & 108.89 & 1 & 108.89 & 141.56 & $<0.0001$ & Significant \\
\hline$X_{1} X_{4}$ & 37.638 & 1 & 37.638 & 48.931 & $<0.0001$ & Significant \\
\hline$X_{2} X_{3}$ & 2.2052 & 1 & 2.2052 & 2.8669 & 0.1111 & Not significant \\
\hline$X_{2} X_{4}$ & 108.26 & 1 & 108.26 & 140.75 & $<0.0001$ & Significant \\
\hline$X_{3} X_{4}$ & 21.114 & 1 & 21.114 & 27.449 & 0.0001 & Significant \\
\hline$X_{1}^{2}$ & 1.4196 & 1 & 1.4196 & 1.8455 & 0.1944 & Not significant \\
\hline$X_{2}^{2}$ & 3.5055 & 1 & 3.5055 & 4.5573 & 0.0497 & Significant \\
\hline$X_{3}^{2}$ & 83.521 & 1 & 83.521 & 108.58 & $<0.0001$ & Significant \\
\hline$X_{4}^{2}$ & 96.043 & 1 & 96.043 & 124.86 & $<0.0001$ & Significant \\
\hline Residual & 11.538 & 15 & 0.7692 & & & \\
\hline Lack of Fit & 8.5076 & 10 & 0.8508 & 1.4036 & 0.3719 & Not significant \\
\hline Pure error & 3.0306 & 5 & 0.6061 & & & \\
\hline Corrected total $S S^{\mathrm{d}}$ & 1472.2 & 29 & & & & \\
\hline$R^{2}$ & 0.9922 & & & & & \\
\hline Adjusted $R^{2}$ & 0.9848 & & & & & \\
\hline Adequate Precision & 47.394 & & & & & \\
\hline $\mathrm{H}_{2} \mathrm{O}_{2}$ residual model & 1.3651 & 14 & 0.0975 & 115.39 & $<0.0001$ & Significant \\
\hline$X_{I}=\mathrm{TOC}_{\mathrm{in}}$ & 0.0043 & 1 & 0.0043 & 5.0493 & 0.0401 & Significant \\
\hline$X_{2}=$ Flow rate & 0.6801 & 1 & 0.6801 & 804.81 & $<0.0001$ & Significant \\
\hline$X_{3}=\mathrm{H}_{2} \mathrm{O}_{2}$ in & 0.2054 & 1 & 0.2054 & 243.02 & $<0.0001$ & Significant \\
\hline$X_{4}=\mathrm{pH}$ & 0.0600 & 1 & 0.0600 & 71.006 & $<0.0001$ & Significant \\
\hline$X_{1} X_{2}$ & 0.0064 & 1 & 0.0064 & 7.5740 & 0.0148 & Significant \\
\hline$X_{1} X_{3}$ & 0.0169 & 1 & 0.0169 & 20.000 & 0.0004 & Significant \\
\hline$X_{1} X_{4}$ & 0.1190 & 1 & 0.1190 & 140.86 & $<0.0001$ & Significant \\
\hline$X_{2} X_{3}$ & 0.0064 & 1 & 0.0064 & 7.5740 & 0.0148 & Significant \\
\hline$X_{2} X_{4}$ & 0.1190 & 1 & 0.1190 & 140.86 & $<0.0001$ & Significant \\
\hline$X_{3} X_{4}$ & 0.0210 & 1 & 0.0210 & 24.882 & 0.0002 & Significant \\
\hline$X_{1}^{2}$ & 0.0732 & 1 & 0.0732 & 86.650 & $<0.0001$ & Significant \\
\hline$X_{2}^{2}$ & 0.0032 & 1 & 0.0032 & 3.8095 & 0.0699 & \\
\hline$X_{3}^{2}$ & 0.0254 & 1 & 0.0254 & 30.031 & 0.0001 & Significant \\
\hline$X_{4}^{2}$ & 0.0394 & 1 & 0.0394 & 46.667 & $<0.0001$ & Significant \\
\hline Residual & 0.0127 & 15 & 0.0008 & & & \\
\hline Lack of Fit & 0.0109 & 10 & 0.0011 & 3.0208 & 0.1170 & Not significant \\
\hline Pure error & 0.0018 & 5 & 0.0004 & & & \\
\hline Corrected total $S S^{\mathrm{d}}$ & 1.3778 & 29 & & & & \\
\hline$R^{2}$ & 0.9908 & & & & & \\
\hline Adjusted $R^{2}$ & 0.9822 & & & & & \\
\hline Adequate Precision & 51.306 & & & & & \\
\hline
\end{tabular}




\begin{tabular}{|c|c|c|c|c|c|c|}
\hline Source & Sum of squares & $d f^{a}$ & Mean square & $F$ value $^{b}$ & $p$-value ${ }^{c}$ & Remark \\
\hline $\mathrm{CH}_{4 \text { production }}$ model & 666.11 & 14 & 47.579 & 34.394 & $<0.0001$ & Significant \\
\hline$X_{l}=\mathrm{TOC}_{\mathrm{in}}$ & 72.628 & 1 & 72.628 & 52.500 & $<0.0001$ & Significant \\
\hline$X_{2}=$ Flow rate & 109.70 & 1 & 109.70 & 79.296 & $<0.0001$ & Significant \\
\hline$X_{3}=\mathrm{H}_{2} \mathrm{O}_{2}$ in & 4.1085 & 1 & 4.1085 & 2.9699 & 0.1054 & Not significant \\
\hline$X_{4}=\mathrm{pH}$ & 13.485 & 1 & 13.485 & 9.7479 & 0.0070 & Significant \\
\hline$X_{1} X_{2}$ & 182.99 & 1 & 182.99 & 132.28 & $<0.0001$ & Significant \\
\hline$X_{1} X_{3}$ & 1.8980 & 1 & 1.8980 & 1.3716 & 0.2598 & Not significant \\
\hline$X_{1} X_{4}$ & 12.373 & 1 & 12.3728 & 8.9439 & 0.0091 & Significant \\
\hline$X_{2} X_{3}$ & 1.3631 & 1 & 1.3631 & 0.9853 & 0.3366 & Not significant \\
\hline$X_{2} X_{4}$ & 8.1653 & 1 & 8.1653 & 5.9024 & 0.0282 & Significant \\
\hline$X_{3} X_{4}$ & 2.9670 & 1 & 2.9670 & 2.1448 & 0.1637 & Not significant \\
\hline$X_{l}^{2}$ & 11.592 & 1 & 11.592 & 8.3797 & 0.0111 & Significant \\
\hline$X_{2}^{2}$ & 58.575 & 1 & 58.575 & 42.342 & $<0.0001$ & Significant \\
\hline$X_{3}^{2}$ & 5.4953 & 1 & 5.4953 & 3.9724 & 0.0648 & \\
\hline$X_{4}^{2}$ & 224.76 & 1 & 224.76 & 162.47 & $<0.0001$ & Significant \\
\hline Residual & 20.751 & 15 & 1.3834 & & & \\
\hline Lack of Fit & 12.650 & 10 & 1.2650 & 0.7807 & 0.6554 & Not significant \\
\hline Pure error & 8.1011 & 5 & 1.6202 & & & \\
\hline Corrected total $S S^{\mathrm{d}}$ & 686.86 & 29 & & & & \\
\hline$R^{2}$ & 0.9698 & & & & & \\
\hline Adjusted $R^{2}$ & 0.9416 & & & & & \\
\hline Adequate Precision & 19.812 & & & & & \\
\hline \multicolumn{7}{|c|}{ a. Degrees of freedom $(d f)$} \\
\hline b. Fisher's $(F)$ exact test & & & & & & \\
\hline
\end{tabular}

Consequently, each factor coefficient was evaluated in terms of statistical significance using the Fisher's $(F)$ exact test by comparing probability $(p)$ values greater than $F$. Thus, small probability values $(p<0.05)$ indicate the significance of the model parameters, whereas $p$-values $>0.10$ indicate the nonsignificance of the model factors, as indicated in the sixth column of Table 8.5. Probability values between 0.05 and 0.10 provide weak evidence against the null hypothesis and, by convention, are not considered low enough to justify rejecting it and requires further analysis. For instance, $X_{2}^{2}$ and $X_{3}^{2}$ had p-values between 0.05 and 0.10 for the $\mathrm{H}_{2} \mathrm{O}_{2}$ and the $\mathrm{CH}_{4}$ models, respectively. Thus, the nonsignificance of the quadratic effect is an appropriate designation since it indicates the optimal levels are located at the limits of the experimental region (Bustillo-Lecompte et al., 2016a). 
As shown in Table 8.5, the developed quadratic models for each response were found to be significant. $F$-values of $288.16,135.64,115.39$, and 34.39 were obtained for the percentual TOC removal $\left(Y_{1}\right)$, the $\mathrm{TN}$ removal $\left(Y_{2}\right)$, the $\mathrm{H}_{2} \mathrm{O}_{2}$ residuals $\left(Y_{3}\right)$, and the $\mathrm{CH}_{4}$ production $\left(Y_{4}\right)$, respectively. Furthermore, the accuracy of the developed models to predict the response functions was confirmed by small probability values $(p<0.05)$. However, some model terms were found to be not significant $(p>$ 0.10 ), including $X_{2}^{2}$ for the percentual TOC removal, $X_{3}, X_{2} X_{3}$, and $X_{1}^{2}$ for the percentual TN removal, and $X_{3}, X_{1} X_{3}, X_{2} X_{3}$, and $X_{3} X_{4}$, for the percentual methane production. These non-significant model terms could be expected to have this outcome due to their participation in each stage of the combined system. For instance, it is expected that the inlet $\mathrm{H}_{2} \mathrm{O}_{2}$ concentration and its combination with other model parameters do not have any significant effect on the percentual TN removal and methane production, since these two responses are more related to the biological treatment, not the AOP.

Besides, the adequate precision of the percentual TOC removal $\left(Y_{1}\right)$, the TN removal $\left(Y_{2}\right)$, the $\mathrm{H}_{2} \mathrm{O}_{2}$ residual $\left(Y_{3}\right)$, and the $\mathrm{CH}_{4}$ production $\left(Y_{4}\right)$ were $77.55,47.39$, 51.31, and 19.81, respectively. Because all adequate precision values were greater than 4.00, the developed models can be used to navigate the CCD space (Bustillo-Lecompte, et al., 2016a). Moreover, the $p$-values for the lack of fit in the models were calculated to be $0.6067,0.3719,0.1170$, and 0.6554 for the percentual TOC removal $\left(Y_{1}\right)$, the $\mathrm{TN}$ removal $\left(Y_{2}\right)$, the $\mathrm{H}_{2} \mathrm{O}_{2}$ residuals $\left(Y_{3}\right)$, and the $\mathrm{CH}_{4}$ production $\left(Y_{4}\right)$, respectively. Consequently, a non-significant lack of fit $(p>0.10)$ is desirable, indicating the model fits the data well. Additionally, the model goodness of fit was validated by the determination coefficient $\left(R^{2}\right)$ and the adjusted $R^{2}$, which ensures the adequate variation of the quadratic model in terms of the experimental values. $R^{2}$ and adjusted $R^{2}$ values for the percentual TOC removal $\left(Y_{1}\right)$, the TN removal $\left(Y_{2}\right)$, the $\mathrm{H}_{2} \mathrm{O}_{2}$ residuals $\left(Y_{3}\right)$, and the $\mathrm{CH}_{4}$ production $\left(Y_{4}\right)$ were 0.9963 and $0.9928,0.9922$ and 0.9848 , 0.9908 and 0.9822 , and 0.9698 and 0.9416 , respectively. Thus, the obtained $R^{2}$ and adjusted $R^{2}$ values for each model represent a high model significance.

On the other hand, the assumption of the constant variance was verified by plotting the internally studentized residual versus predicted values shown in the supplementary materials (Figure S.1). The studentized residuals were found by the ratio of the residuals to an estimate of their standard deviations showing a randomly scattered pattern within the outlier detection limits -3 and +3 . Moreover, the correlation between the observed and predicted values showed minor discrepancies represented by a straight-line trend, which indicates a good agreement between observed and predicted values. 
Therefore, model predictions for the percentual TOC removal, the TN removal, the $\mathrm{H}_{2} \mathrm{O}_{2}$ residuals, and the $\mathrm{CH}_{4}$ production, respectively, are satisfactory.

\subsubsection{Individual effect of model parameters}

The significance of each model parameter was also evaluated using the $F$ exact test and $p$-values for each factor including linear, quadratic, and cross-factor interaction. As shown in Table 8.5, $p$-values lower than 0.05 identify model coefficients as significant. Therefore, the influent TOC concentration $\left(X_{1}\right)$, the flow rate $\left(X_{2}\right)$, and the $\mathrm{pH}\left(X_{4}\right)$ showed significant effect on all responses while the inlet concentration of $\mathrm{H}_{2} \mathrm{O}_{2}\left(X_{3}\right)$ was found to be significant only on the percentual TOC removal $\left(Y_{1}\right)$ and the $\mathrm{H}_{2} \mathrm{O}_{2}$ residual $\left(Y_{3}\right)$ based on the $p$-value. As mentioned in the previous section, it is expected that the inlet concentration of $\mathrm{H}_{2} \mathrm{O}_{2}$ does not have a significant effect on the percentual TN removal and methane production, since these two responses are more related to the biological treatment stages of the combined system.

Figure 8.2 illustrates the effect of the influent TOC concentration, the flow rate, the inlet concentration of $\mathrm{H}_{2} \mathrm{O}_{2}$, and the $\mathrm{pH}$ on the TOC removal, TN removal, $\mathrm{H}_{2} \mathrm{O}_{2}$ residual, and $\mathrm{CH}_{4}$ yield, in the combined $\mathrm{ABR}-\mathrm{AS}-\mathrm{UV} / \mathrm{H}_{2} \mathrm{O}_{2}$ processes. All responses are shown in the $\mathrm{y}$-axis in percentage $(\%)$ units, excepting $\mathrm{H}_{2} \mathrm{O}_{2}$ residual, which is presented in per mil (\%o) for scaling purposes. The model predicted values along with the CI bands for the individual effect of model parameters on the TOC removal, TN removal, $\mathrm{H}_{2} \mathrm{O}_{2}$ residual, and $\mathrm{CH}_{4}$ yield are shown in the supplementary materials Figures S.2 to S.5, respectively.

It can be observed that the influent TOC concentration and the flow rate are inversely proportional to both the percentual TOC and TN removals, being slightly affected in the case of the flow rate influence on the TOC removal. This slight effect refers to the mass transfer as a non-limiting factor on the TOC degradation; thus, the TOC removal is due to reactions only. Moreover, there is an optimum inlet concentration of $\mathrm{H}_{2} \mathrm{O}_{2}$ required for maximum percentual TOC in the $\mathrm{UV} / \mathrm{H}_{2} \mathrm{O}_{2}$ process as well as no requirements to adjust $\mathrm{pH}$ for both maximum TOC and TN removal. On the other hand, results indicate that an optimum value for influent TOC concentration and no $\mathrm{pH}$ adjustment are required to achieve a minimum $\mathrm{H}_{2} \mathrm{O}_{2}$ residual in the effluent; whereas, both flow rate and the inlet $\mathrm{H}_{2} \mathrm{O}_{2}$ concentration are proportional to the $\mathrm{H}_{2} \mathrm{O}_{2}$ residual, the minimum residual is obtained at the low flow rate and low inlet concentration of $\mathrm{H}_{2} \mathrm{O}_{2}$. 

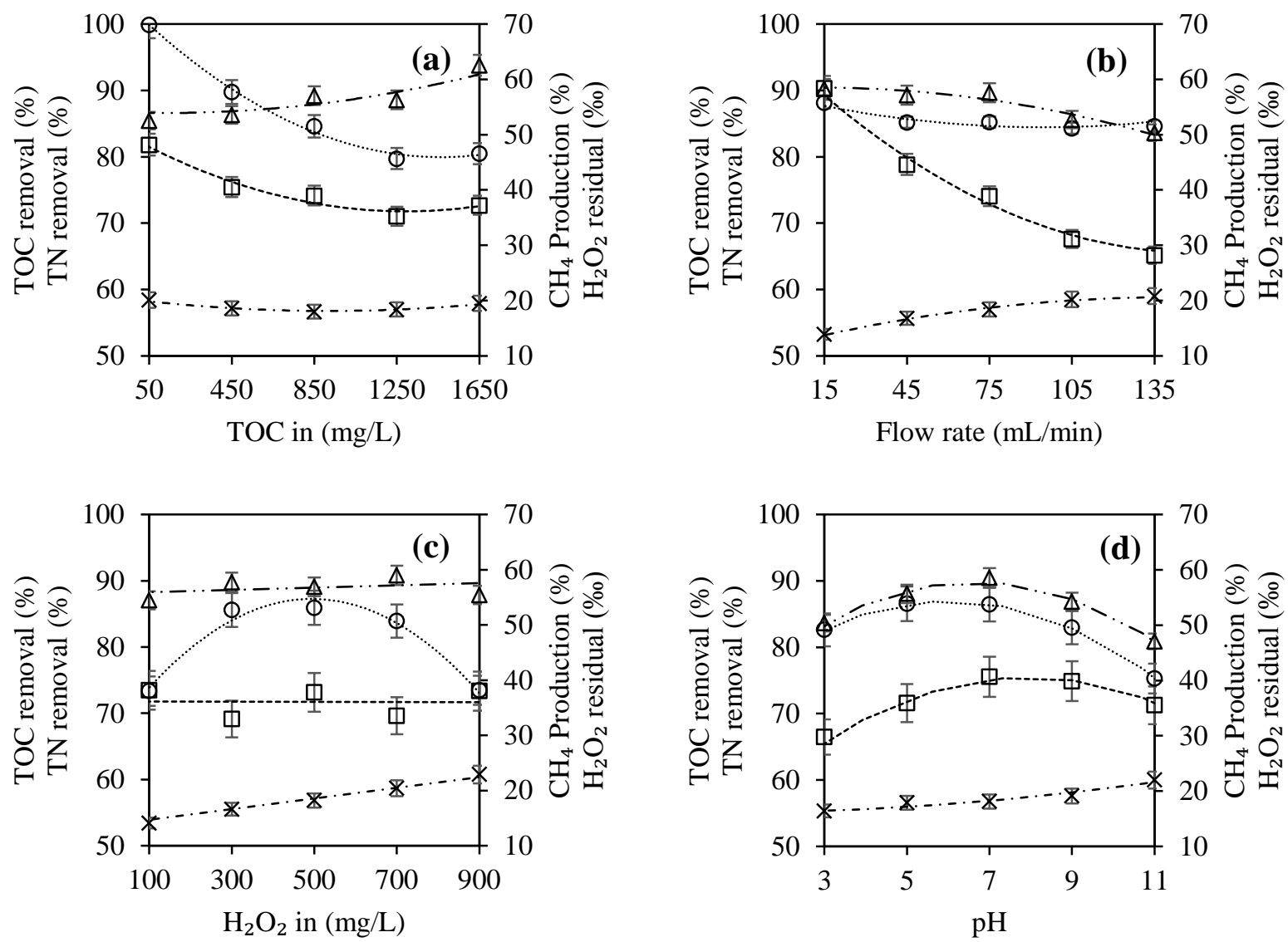

\begin{tabular}{ccccccc}
\hline TOC rem (\%) & $\square$ & $\mathrm{TN}$ rem $(\%)$ & $\times$ & $\mathrm{H}_{2} \mathrm{O}_{2}$ res $(\%)$ & $\Delta$ & $\mathrm{CH}_{4}$ prod (\%)
\end{tabular}

Figure 8.2. Individual effect of the (a) influent concentration of TOC; (b) flow rate; (c) inlet $\mathrm{H}_{2} \mathrm{O}_{2}$ concentration; and (d) $\mathrm{pH}$ on the percentual TOC removal, $\mathrm{TN}$ removal, $\mathrm{H}_{2} \mathrm{O}_{2}$ residual, and $\mathrm{CH}_{4}$ yield. The dashed lines represent model predicted values, whereas the marker points represent the experimental values. Error bars represent the standard deviation of the experimental data. J. Environ. Manage. (2016), In Press. 
Finally, the inlet concentration of $\mathrm{H}_{2} \mathrm{O}_{2}$ was not significant on both the $\mathrm{CH}_{4}$ production and TN removal since those responses are directly representative of the ABR stage of the combined process only. The predicted values demonstrate that to achieve a maximum methane yield, a high influent TOC concentration is needed while optimum flow rate and no $\mathrm{pH}$ adjustments are required.

\subsubsection{Interaction of model parameters, $2 D$ contour plots, and $3 D$ response surface}

The cross-factor interactions between independent variables were plotted into the $2 \mathrm{D}$ contour plots and 3D surfaces shown in Figure 8.3. The cross-factor interaction effect between the influent TOC concentration and the inlet concentration of $\mathrm{H}_{2} \mathrm{O}_{2}\left(X_{1} X_{3}\right)$ and between the inlet concentration of $\mathrm{H}_{2} \mathrm{O}_{2}$ and the $\mathrm{pH}$ on the percentual TOC removal, in the combined $\mathrm{ABR}-\mathrm{AS}-\mathrm{UV} / \mathrm{H}_{2} \mathrm{O}_{2}$ processes, are shown in Figures 8.3a and 8.3b, respectively. Thus, an optimum TOC removal was achieved when there was an optimum inlet concentration of $\mathrm{H}_{2} \mathrm{O}_{2}$, while the influent TOC concentration was minimum (Figure 8.3a). Similarly, the inlet concentration of $\mathrm{H}_{2} \mathrm{O}_{2}$ in the photoreactor of the combined $\mathrm{ABR}-\mathrm{AS}-$ $\mathrm{UV} / \mathrm{H}_{2} \mathrm{O}_{2}$ processes should be also optimum at low $\mathrm{pH}$ to achieve a maximum removal as shown in Figure $8.3 b$.

Figures $8.3 \mathrm{c}$ and $8.3 \mathrm{~d}$ depict the effect on the percentual TN removal by the interaction of the influent TOC concentration with the $\mathrm{pH}\left(X_{1} X_{4}\right)$ and the interaction of the flow rate with the $\mathrm{pH}\left(X_{2} X_{4}\right)$, respectively, in the anaerobic-aerobic stage of the combined $\mathrm{ABR}-\mathrm{AS}-\mathrm{UV} / \mathrm{H}_{2} \mathrm{O}_{2}$ processes. It can be inferred that at the low influent TOC concentrations with an optimum $\mathrm{pH}$, it is possible to achieve a maximum TN removal (Figure 8.3c). In contrast, the maximum TN removal was achieved with an optimum $\mathrm{pH}$ when the flow rate was minimum (i.e. at high residence time in the biological stages of the combined $\mathrm{ABR}-\mathrm{AS}-\mathrm{UV} / \mathrm{H}_{2} \mathrm{O}_{2}$ processes), as presented in Figure $8.3 \mathrm{~d}$.

Moreover, Figures 8.3e and 8.3f portray the effect of the influent TOC concentration with the inlet concentration of $\mathrm{H}_{2} \mathrm{O}_{2}$ in the photoreactor $\left(X_{1} X_{3}\right)$ and the effect of the flow rate with the $\mathrm{pH}\left(X_{2} X_{4}\right)$ on the percentual $\mathrm{H}_{2} \mathrm{O}_{2}$ residual, respectively, in the effluent of the combined $\mathrm{ABR}-\mathrm{AS}-\mathrm{UV} / \mathrm{H}_{2} \mathrm{O}_{2}$

processes. A minimum $\mathrm{H}_{2} \mathrm{O}_{2}$ concentration in the effluent was achieved at low inlet concentration of $\mathrm{H}_{2} \mathrm{O}_{2}$ with an optimum influent TOC concentration in the influent (Figure 8.3e) as well as the minimum flow rate with an optimum $\mathrm{pH}$ in the combined $\mathrm{ABR}-\mathrm{AS}-\mathrm{UV} / \mathrm{H}_{2} \mathrm{O}_{2}$ processes (Figure 8.3f). 

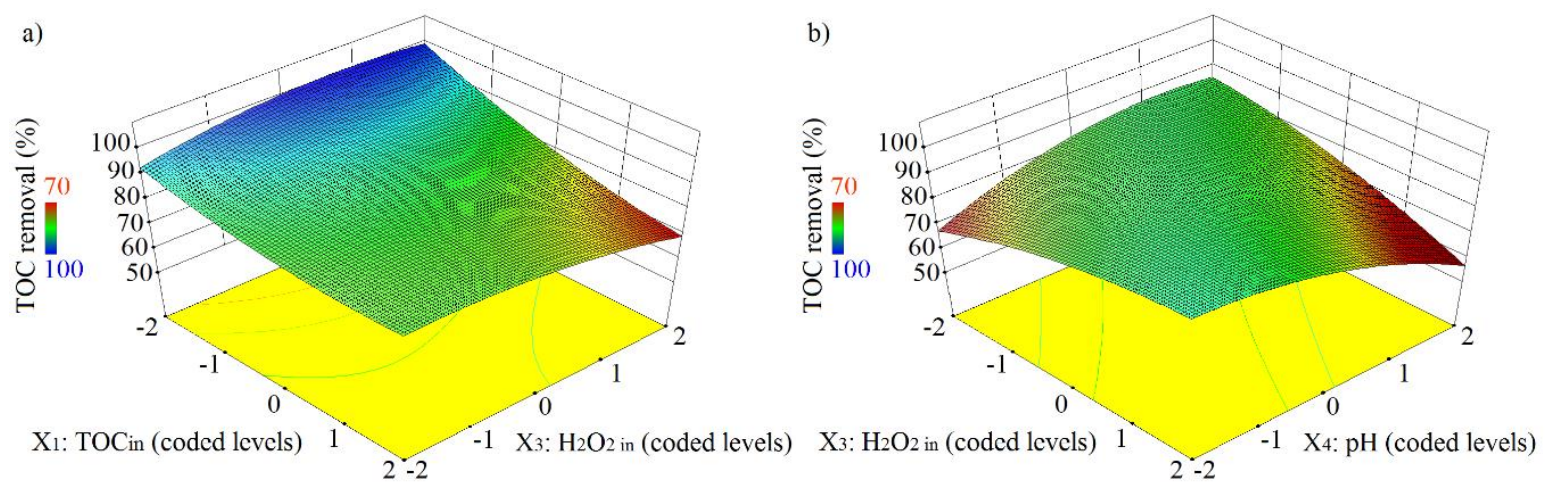

$\mathrm{X}_{1}$ : TOCin (coded levels) $1 \int_{2-2}-1 \quad \mathrm{X}_{3}: \mathrm{H}_{2} \mathrm{O}_{2}$ in (coded levels) $\mathrm{X}_{3}: \mathrm{H}_{2} \mathrm{O}_{2}$ in (coded levels) $1 \mathrm{X}_{-2}-1$ X: $\mathrm{pH}$ (coded levels)
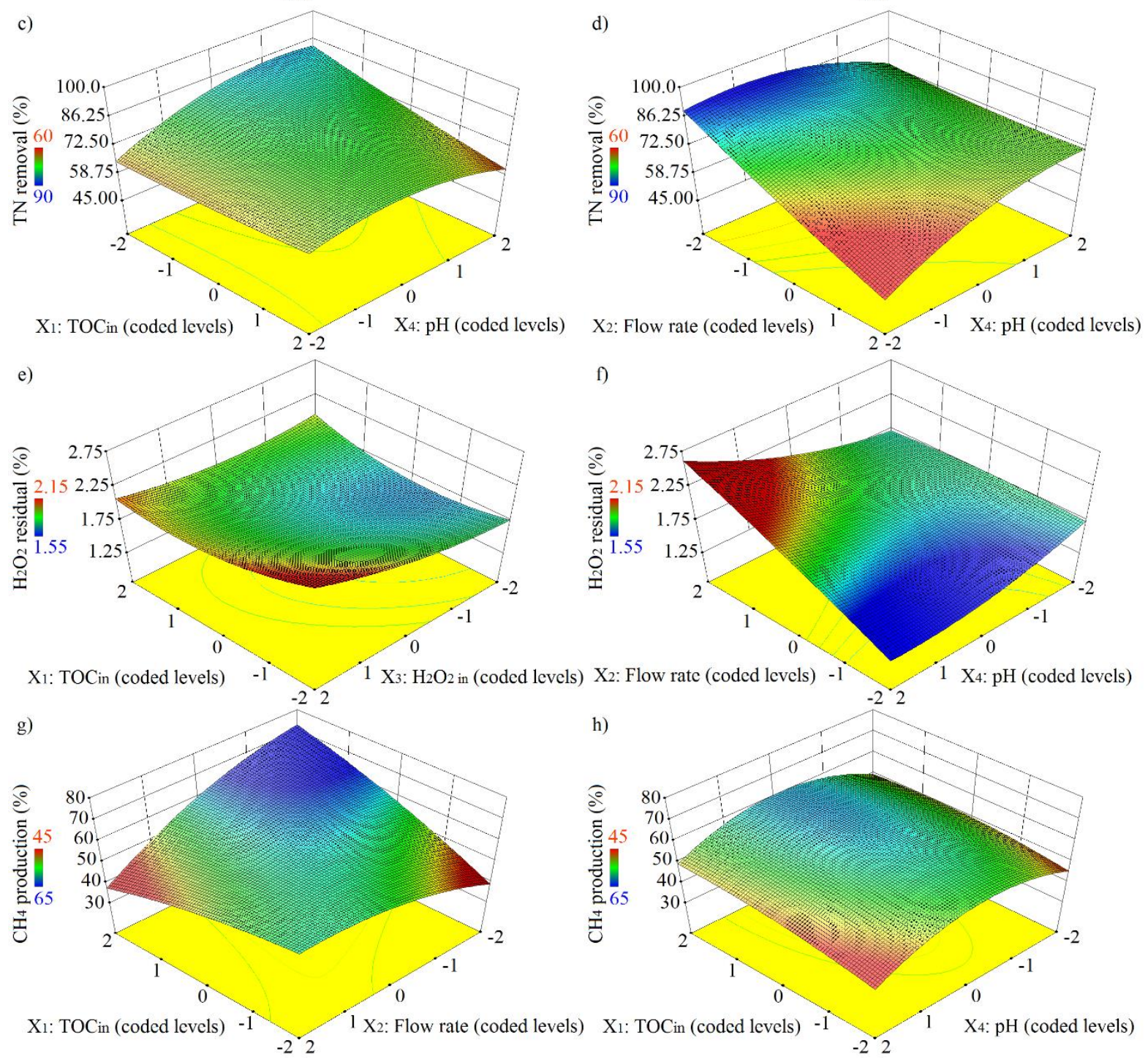

Figure 8.3. 3D surfaces and 2D plots of the interaction effects of (a) the influent TOC concentration with inlet $\mathrm{H}_{2} \mathrm{O}_{2}$ concentration $\left(X_{1} X_{3}\right)$ and (b) the inlet $\mathrm{H}_{2} \mathrm{O}_{2}$ concentration with $\mathrm{pH}\left(X_{3} X_{4}\right)$ on the percentual TOC removal; (c) the influent TOC concentration with $\mathrm{pH}\left(X_{1} X_{4}\right)$ and (d) the flow rate with $\mathrm{pH}\left(\mathrm{X}_{2} \mathrm{X}_{4}\right)$ on the percentual TN removal; (e) the influent TOC concentration with inlet $\mathrm{H}_{2} \mathrm{O}_{2}$ concentration $\left(X_{1} X_{3}\right)$ and (f) the flow rate with $\mathrm{pH}\left(X_{2} X_{4}\right)$ on the percentual $\mathrm{H}_{2} \mathrm{O}_{2}$ residual; and (g) the influent TOC concentration with flow rate $\left(X_{1} X_{2}\right)$ and $(h)$ the influent TOC concentration with $\mathrm{pH}$ $\left(X_{1} X_{4}\right)$ on the $\mathrm{CH}_{4}$ production in the combined $\mathrm{ABR}-\mathrm{AS}-\mathrm{UV} / \mathrm{H}_{2} \mathrm{O}_{2}$ processes.

J. Environ. Manage. (2016), In Press. 
Finally, Figures $8.3 \mathrm{~g}$ and $8.3 \mathrm{~h}$ represent the cross-factor interaction effect of the influent TOC concentration with the flow rate $\left(X_{1} X_{2}\right)$ and the effect of the influent TOC concentration with $\mathrm{pH}\left(X_{1} X_{4}\right)$ on the $\mathrm{CH}_{4}$ production, respectively, in the anaerobic stage of the combined $\mathrm{ABR}-\mathrm{AS}-\mathrm{UV} / \mathrm{H}_{2} \mathrm{O}_{2}$ processes. To achieve a maximum $\mathrm{CH}_{4}$ yield, it is necessary to have a high influent TOC concentration at a low flow rate (Figure 8.3g) and optimum $\mathrm{pH}$ (Figure 8.3h).

\subsubsection{Optimization of operating conditions and process parameters}

The RSM was used to determine the optimum experimental conditions of the four independent variables, including the influent concentration of TOC $\left(X_{1}\right)$, flow rate $\left(X_{2}\right)$, the inlet concentration of $\mathrm{H}_{2} \mathrm{O}_{2}\left(X_{3}\right)$, and the $\mathrm{pH}\left(X_{4}\right)$ to obtain maximum percentual TOC removal, the TN removal, and the $\mathrm{CH}_{4}$ production with minimum $\mathrm{H}_{2} \mathrm{O}_{2}$ residual. The optimization was accomplished at defined optimization conditions using the built-in numerical optimization method of the statistical software Design-Expert 10.0.0.3. The response equations shown in Table 8.4 were defined as objective functions and the independent factors in their critical range were used as constraints. The numerical optimization method explores the design space using the developed models to find the optimum factor conditions that meet the previously set goals of maximum percentual TOC removal, the TN removal, and the $\mathrm{CH}_{4}$ production with minimum $\mathrm{H}_{2} \mathrm{O}_{2}$ residual, simultaneously.

The multiple response approach shown in Equation (8.2) was used to obtain the desirability parameter interaction plots (Figure 8.4) at optimum factor settings by maximizing the percentual TOC removal $\left(d_{1}\right)$, the TN removal $\left(d_{2}\right)$, and the $\mathrm{CH}_{4}$ production $\left(d_{3}\right)$ while minimizing the $\mathrm{H}_{2} \mathrm{O}_{2}$ residual in the effluent $\left(d_{4}\right)$ by numerical optimization in the combined $\mathrm{ABR}-\mathrm{AS}-\mathrm{UV} / \mathrm{H}_{2} \mathrm{O}_{2}$ processes. Therefore, the desirability value of 0.75 was found for achieving the maximum removals of 90.10 and $84.70 \%$ for TOC and TN, respectively, the minimum $\mathrm{H}_{2} \mathrm{O}_{2}$ residual of $1.49 \mathrm{mg} / \mathrm{L}$, and the maximum $\mathrm{CH}_{4}$ yield of $58.22 \%$ at the optimum conditions for the influent TOC concentration of $626 \mathrm{mg} / \mathrm{L}$, the feed flow rate of $45 \mathrm{~mL} / \mathrm{min}$, the inlet concentration of $\mathrm{H}_{2} \mathrm{O}_{2}$ of $350 \mathrm{mg} / \mathrm{L}$, and the $\mathrm{pH}$ of 6.59 . As a final point, the obtained optimal operating conditions were used in another experimental run to validate the predicted values. Consequently, the TOC removal of $91.29 \%$, the TN removal of $86.05 \%$, the $\mathrm{H}_{2} \mathrm{O}_{2}$ residual of $1.45 \%$, and the maximum $\mathrm{CH}_{4}$ yield of $55.72 \%$ were obtained experimentally, confirming the reliability of the model since all model parameters were within the $95 \%$ CI of $88.89-91.31 \%$ for TOC removal, 82.64-86.77\% for TN removal, $1.42-1.56 \mathrm{mg} / \mathrm{L}$ for $\mathrm{H}_{2} \mathrm{O}_{2}$ residual, and 55.45-60.99\% for $\mathrm{CH}_{4}$ production. 

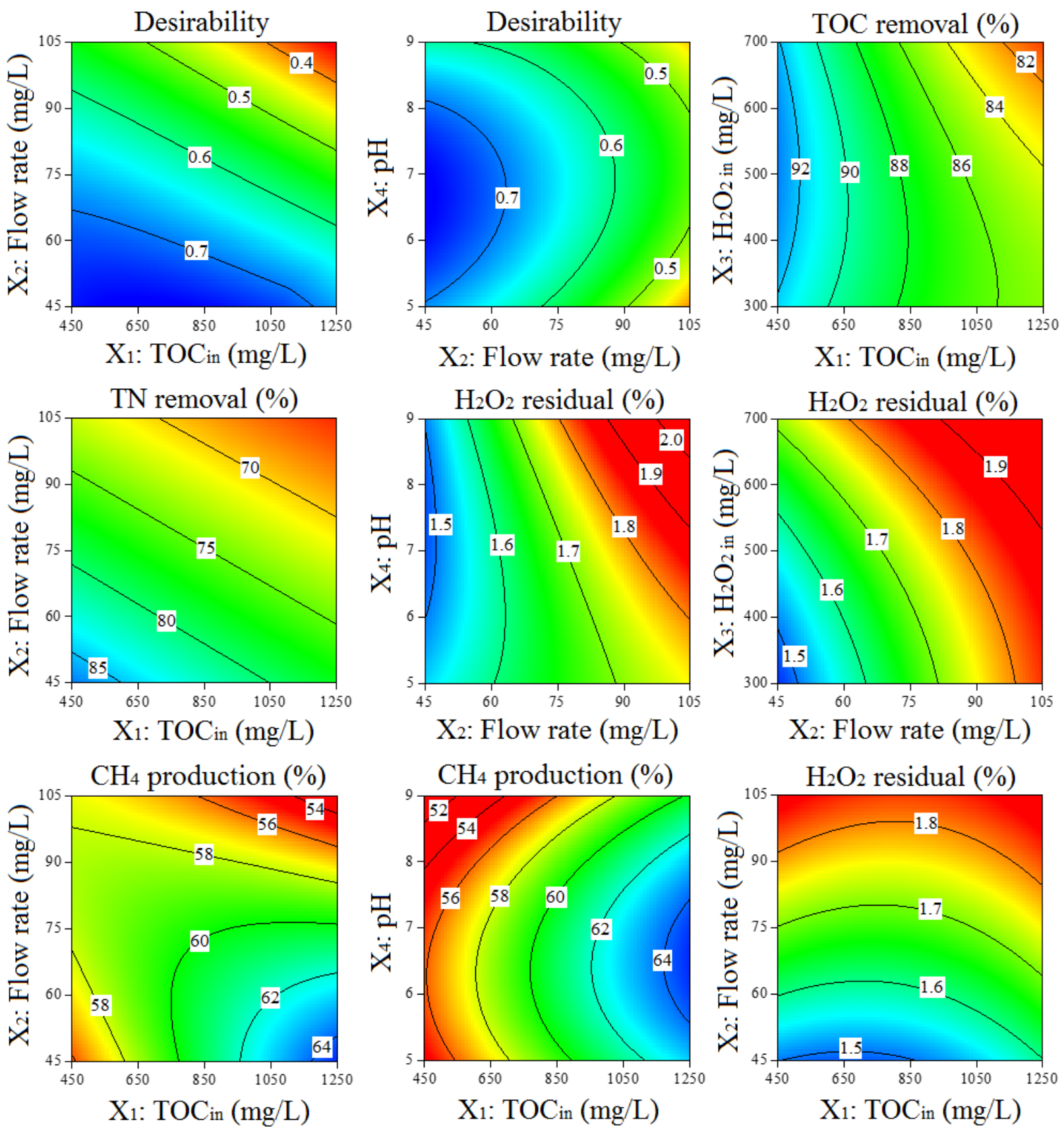

Figure 8.4. Desirability 2D plots maximizing the percentual TOC removal, TN removal, and $\mathrm{CH}_{4}$ production while minimizing the $\mathrm{H}_{2} \mathrm{O}_{2}$ residual at optimum factor settings of influent TOC concentration of $626 \mathrm{mg} / \mathrm{L}$, feed flow rate of $45 \mathrm{~mL} / \mathrm{min}$, inlet $\mathrm{H}_{2} \mathrm{O}_{2}$ concentration of $350 \mathrm{mg} / \mathrm{L}$, and $\mathrm{pH}$ of 6.59 in the combined $\mathrm{ABR}-\mathrm{AS}-\mathrm{UV} / \mathrm{H}_{2} \mathrm{O}_{2}$ processes.

J. Environ. Manage. (2016), In Press. 


\subsubsection{Analysis of reactors for the combined $\mathrm{ABR}-\mathrm{AS}-\mathrm{UV} / \mathrm{H}_{2} \mathrm{O}_{2}$ processes for the actual slaughterhouse wastewater treatment}

The core of this study was to analyze the integrated processes at the best operating conditions for maximum overall treatment. For designing purposes, the substrate concentrations emerging from the biological units are of a major importance. The substrate concentrations in the stream leaving the combined $\mathrm{ABR}-\mathrm{AS}-\mathrm{UV} / \mathrm{H}_{2} \mathrm{O}_{2}$ system depend on parameters such as the initial TOC concentration, retention times in each reactor, including anaerobic $\left(t_{A B R}\right)$, aerobic $\left(t_{A S}\right)$, and $\mathrm{UV} / \mathrm{H}_{2} \mathrm{O}_{2}\left(t_{U V}\right)$, and also the recycle ration in the photoreactor $(r)$. Upon determining these parameters, the combined ABR-AS$\mathrm{UV} / \mathrm{H}_{2} \mathrm{O}_{2}$ model should be able to predict substrate concentrations in the effluent stream.

The first order rate constant in each compartment in the ABR was calculated by Equation (8.5) with a net biomass concentration in each ABR compartment of 25,000 mgVSS/L. Consequently, the equation of an ABR with five compartments $\left(S_{A B R}\right)$ could be obtained by substitution on Equation (8.6). Thus, the overall equation for the final effluent of an ABR with five compartments at steady state without recycle $\left(S_{A B R}\right)$ can be expressed as a function of the flow rate $(Q)$ as shown in Equation (8.19) or as a function of the residence time in the $\mathrm{ABR}\left(t_{A B R}\right)$ as shown in Equation (8.20):

$$
\begin{aligned}
& S_{A B R}=\frac{S_{i n}}{(1+1.1589 / Q)(1+0.2128 / Q)(1+0.2232 / Q)(1+0.2433 / Q)(1+0.2486 / Q)} \\
& S_{A B R}=\frac{S_{i n}}{\left(1+0.0322 t_{A B R}\right)\left(1+0.0059 t_{A B R}\right)\left(1+0.0062 t_{A B R}\right)\left(1+0.0068 t_{A B R}\right)\left(1+0.0069 t_{A B R}\right)}
\end{aligned}
$$

Likewise, Equation (8.7) was used to calculate the first order rate constant in the AS reactor, considering a net biomass concentration in the AS bioreactor of 3,000 $\mathrm{mgVSS} / \mathrm{L}$. Therefore, Equation (8.7) is reduced to Equations (8.21) and (8.22) that were used to predict the effluent concentrations in the AS reactor as a function of the flow rate $(Q)$ or as a function of the residence time in the $\operatorname{AS}\left(t_{A S}\right)$, respectively:

$$
\begin{aligned}
& S_{A S}=\frac{S_{i n}}{(1+5.0318 / Q)} \\
& S_{A S}=\frac{S_{i n}}{\left(1+0.3978 t_{A S}\right)}
\end{aligned}
$$


Besides, uniform light distribution was assumed throughout the lab-scale $\mathrm{UV} / \mathrm{H}_{2} \mathrm{O}_{2}$ photoreactor due to the limited annular space. Thus, by employing the photon irradiation balance, the local volumetric rate of energy absorption (LVREA) could be written based on the Beer-Lambert law (Ghafoori et al., 2014a; Bustillo-Lecompte et al., 2016a), as shown below:

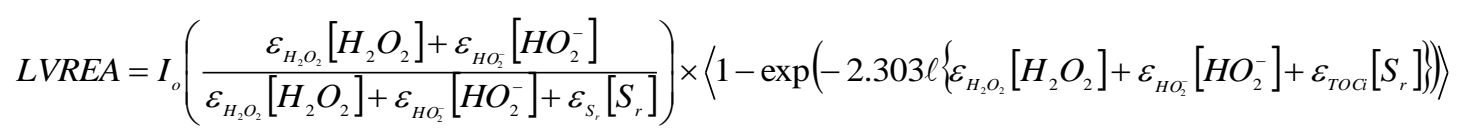

where the intensity of the incident light $\left(I_{o}\right)$ was calculated to be $2 \times 10^{-5}$ Einstein/L.s for the UV-C wavelength of $254 \mathrm{~nm}$. The photon irradiance was estimated from the $14 \mathrm{~W}$ power input of the low pressure lamp divided by the volume of the photoreactor with a $10 \%$ attenuation from the quartz sleeve, a 33\% efficiency of the low pressure lamp, and considering the portion of the UV radiation absorption by $\mathrm{H}_{2} \mathrm{O}_{2}$ (Bustillo-Lecompte et al., 2016a). Furthermore, the molar extinction coefficients of $\mathrm{H}_{2} \mathrm{O}_{2}$ $\left(\varepsilon_{\mathrm{H}_{2} \mathrm{O}_{2}}\right), \mathrm{HO}_{2}{ }^{-}\left(\varepsilon_{\mathrm{HO}_{2}}{ }^{-}\right)$, and $S_{r}\left(\varepsilon_{S r}\right)$ were calculated to be $18.71 / \mathrm{M} . \mathrm{cm}, 210.01 / \mathrm{M} . \mathrm{cm}$, and $132.71 / \mathrm{M} . \mathrm{cm}$ at $254 \mathrm{~nm}$, respectively, by measuring the absorbance by means of spectrophotometry at $254 \mathrm{~nm}$ (Bustillo-Lecompte et al., 2016a). Consequently, by substitution of Equation (8.9) into Equation (8.12) and assuming complete mineralization at steady-state conditions with a recycle ratio $(r)$ of 0.18 (Bustillo-Lecompte et al., 2016a), Equation (8.24) could be used to predict the effluent concentrations in the $\mathrm{UV} / \mathrm{H}_{2} \mathrm{O}_{2}$ photoreactor as a function of the flow rate $(Q)$ and Equation (8.25) as a function of the residence time in the $\mathrm{UV} / \mathrm{H}_{2} \mathrm{O}_{2}\left(t_{U V}\right)$, respectively.

$$
\begin{aligned}
& S_{U V}=\frac{S_{i n} \times \exp (-6.8655 / Q[1+r])}{(1+r)} \\
& S_{U V}=\frac{S_{i n} \times \exp \left(-4.3098 t_{U V} /[1+r]\right)}{(1+r)}
\end{aligned}
$$

Finally, for the continuous $\mathrm{ABR}-\mathrm{AS}-\mathrm{UV} / \mathrm{H}_{2} \mathrm{O}_{2}$ system with recycle, Equations (8.19), (8.21), and (8.24) were combined. As a result, Equation (8.26) was used to predict the effluent concentrations of TOC for the combined $\mathrm{ABR}-\mathrm{AS}-\mathrm{UV} / \mathrm{H}_{2} \mathrm{O}_{2}$ system with recycle.

$$
S_{f}=\frac{S_{i n} \times \exp (-6.8655 / Q[1+r])}{(1+r)(1+1.1589 / Q)(1+02128 / Q)(1+0.2232 / Q)(1+0.2433 / Q)(1+0.2486 / Q)(1+5.0318 / Q)}
$$


The TOC represented as all substrates for the model validation since the TOC analysis is more suitable for determining organic matter content by taking into account all oxidation states while providing an accurate appraisal of the organic compounds present in a wastewater sample including intermediates or by-products in comparison to BOD or COD and without generating toxic analytical waste. The TOC analysis excludes the inorganic carbon compounds by measuring the $\mathrm{CO}_{2}$ generated during the combustion when the organic compounds are oxidized in order to obtain more accurate results (Bustillo-Lecompte et al., 2014). The comparison between predicted and observed values for the influent concentrations of TOC, inlet $\mathrm{H}_{2} \mathrm{O}_{2}$ concentration, and $\mathrm{pH}$ is presented in Figures 5a to 5c, respectively. The non-linear least square function was used to determine the best-fit criterion showing an agreement between the predicted model and the experimental data. The results are also in line with

previous studies (Bustillo-Lecompte et al., 2014; Bustillo-Lecompte and Mehrvar, 2015). Therefore, Equation (8.26) could be used to predict the effluent TOC concentration at a specific retention times in the combined $\mathrm{ABR}-\mathrm{AS}-\mathrm{UV} / \mathrm{H}_{2} \mathrm{O}_{2}$ system with recycle.

\subsubsection{Cost-effectiveness analysis}

\subsubsection{Optimization of the total retention time}

For the combined $\mathrm{ABR}-\mathrm{AS}-\mathrm{UV} / \mathrm{H}_{2} \mathrm{O}_{2}$ processes, different sets of retention times to reduce the TOC concentration in the effluent were evaluated as shown in Figure 8.5d. For a TOC removal higher than $80 \%$, the smallest retention time in the combined system should be $7 \mathrm{~h}$; similar values have been reported in the previous study (Bustillo-Lecompte and Mehrvar, 2015). However, the system is expected to achieve high removal efficiencies of more than $90 \%$. Therefore, the overall retention time should be minimized to $10 \mathrm{~h}$ as shown in Figure 8.5d.

\subsubsection{Optimization of the electrical energy consumption}

The electrical energy consumption for each process was evaluated and its minimization was studied. In the case of the anaerobic process, the main energy consumption is coming from the pumping system as shown in Equation (8.27).

$$
E_{A B R}=\frac{Q \times \rho \times g \times h}{1000 \times \eta} t_{A B R}
$$



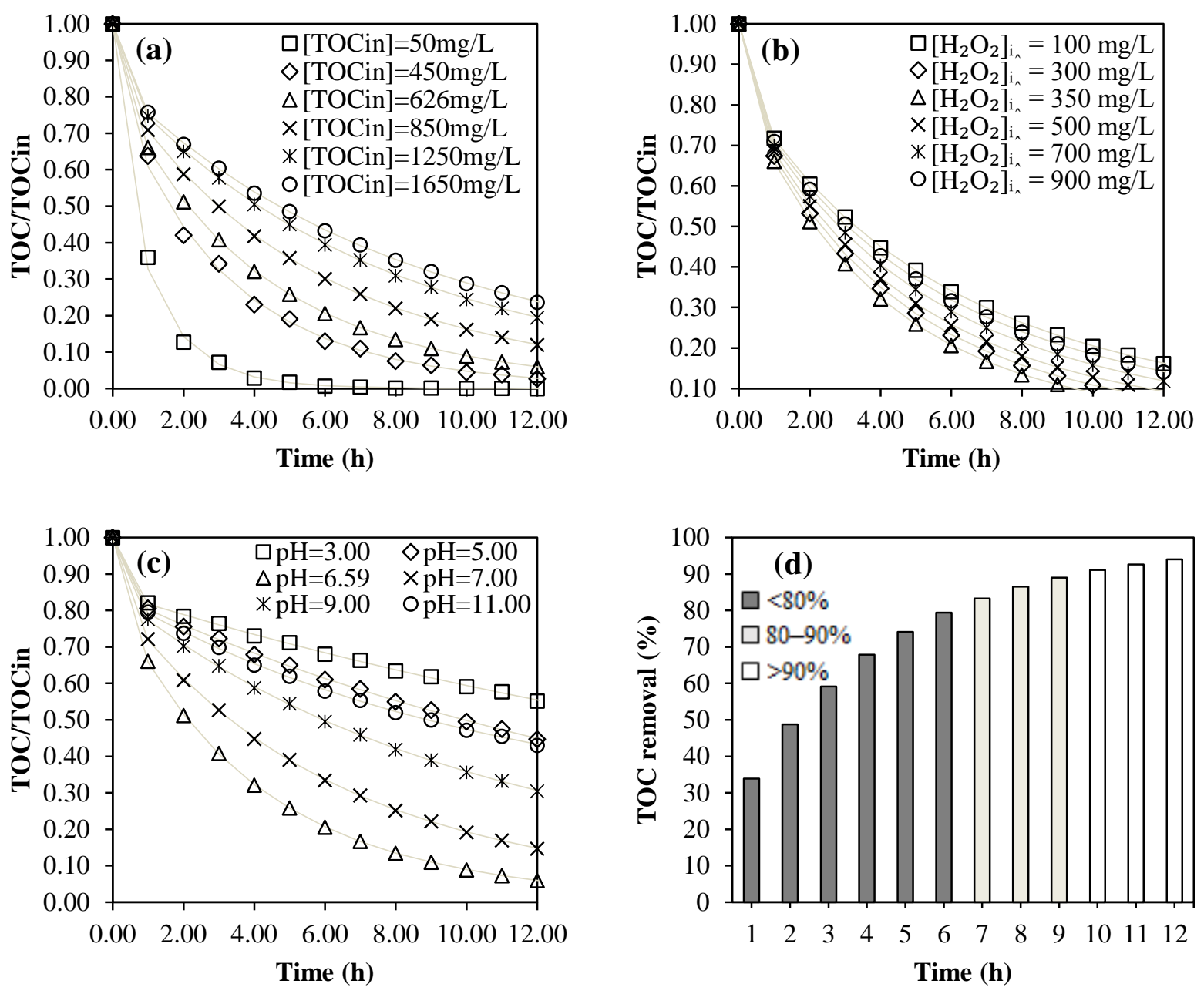

Figure 8.5. Comparison of model predictions and experimental data of TOC/TOCin as a function of retention time for different (a) influent concentrations of TOC; (b) inlet $\mathrm{H}_{2} \mathrm{O}_{2}$ concentration; (c) and pH in the combined $\mathrm{ABR}-\mathrm{AS}-\mathrm{UV} / \mathrm{H}_{2} \mathrm{O}_{2}$ processes; and (d) effect of retention time to reduce the TOC concentration in the actual slaughterhouse wastewater. The lines are the corresponding model predictions. Initial conditions: $T=22^{\circ} \mathrm{C}$, recycle rate $=0.18$, and optimum operating conditions of $[\mathrm{TOC}]_{\mathrm{in}}=626 \mathrm{mg} / \mathrm{L}$, inlet $\mathrm{H}_{2} \mathrm{O}_{2}$ concentration $=350 \mathrm{mg} / \mathrm{L}$, and $\mathrm{pH}=6.59$, excepting when analyzing each effect accordingly.

J. Environ. Manage. (2016), In Press. 
where $\rho, g, h$, and $\eta$ are the wastewater density $\left(1000 \mathrm{~kg} / \mathrm{m}^{3}\right)$, gravity $\left(9.81 \mathrm{~m} / \mathrm{s}^{2}\right)$, total head $(0.5 \mathrm{~m})$, and pump efficiency $(60 \%)$. Thus, the hourly energy consumption for the $\mathrm{ABR}\left(E_{A B R}\right)$ could be calculated by Equation (8.28) with the feed flow rate in L/s.

$$
E_{A B R}=0.0082 Q \times t_{A B R}
$$

In the case of the aerobic process, the aeration power requirements were estimated from the airflow rate, discharge and inlet pressures, and air temperature. By assuming adiabatic conditions, 1.2 $\mathrm{kg}$ air $/ \mathrm{m}^{3}$ required air mass flow rate, and inlet and outlet pressures of 0.95 and $1.56 \mathrm{~atm}$, respectively, the aeration electrical power $\left(P_{A S}\right)$ with an efficiency of $80 \%$ could be determined by Equation (8.29), where $R, T$, and $r_{\text {air }}$ are the gas constant $(8.314 \mathrm{~kJ} / \mathrm{kmole} \mathrm{K})$, the inlet temperature $(303 \mathrm{~K}$, in this case), and a constant for the air $(8.41 \mathrm{~kg} / \mathrm{kmole})$ calculated from the specific heat and the mean molecular weight of air, respectively. Thus, the hourly energy consumption for the AS bioreactor could be calculated by Equation (8.30) (Edalatmanesh et al., 2008).

$$
\begin{aligned}
& P_{A S}=\frac{q_{a i r} \times R \times T}{r_{\text {air }} \eta}\left[\left(\frac{p_{f}}{p_{\text {in }}}\right)^{0.283}-1\right] \\
& E_{A S}=0.0671 Q \times t_{A S}
\end{aligned}
$$

For the $\mathrm{UV} / \mathrm{H}_{2} \mathrm{O}_{2}$ process, the hourly energy consumption $\left(E_{U V}\right)$ was calculated based on the electric energy required to degrade the substrate by one order of magnitude in a unit of the actual SWW based on the rated power of the system (in this case, $0.0125 \mathrm{~kW}$ ), as shown in Equation (8.31) (Shu et al., 2013). Thus, the energy consumption for the photoreactor to degrade $90 \%$ of the substrate could be calculated by Equation (8.32).

$$
\begin{aligned}
& E_{U V}=\frac{P_{U V}}{\log \left(S_{i n} / S_{U V}\right)} t_{U V} \\
& E_{U V}=0.0125 t_{U V}
\end{aligned}
$$

Assuming loses to be negligible; Equation (8.33) is used to determine the residence time ratio between each unit operation. Therefore, Equations (8.28) and (8.30) were modified to be in terms of 
the photoreactor residence time $\left(t_{U V}\right)$ and overall residence time $\left(t_{\text {Toral }}\right)$ for the purpose of the minimization of the residence time in each unit operation as shown in Equations (8.34) and (8.35), respectively.

$$
\begin{aligned}
& Q=\frac{V_{\text {Total }}}{t_{\text {Total }}}=\frac{V_{A B R}}{t_{A B R}}=\frac{V_{A S}}{t_{A S}}=\frac{V_{U V}}{t_{U V}} \\
& E_{A B R}=0.0014 t_{A B R} / t_{U V} \\
& E_{A S}=0.0925 t_{A S} / t_{U V}
\end{aligned}
$$

Consequently, Figure 8.6a depicts the minimum total electrical energy consumption for the combined $\mathrm{ABR}-\mathrm{AS}-\mathrm{UV} / \mathrm{H}_{2} \mathrm{O}_{2}$ system by comparing each individual reactor consumption with the overall system consumption. It can be inferred that the minimum energy consumption of $0.0194 \mathrm{kWh}$ is achieved with a residence time in the photoreactor of $47 \mathrm{~min}$. Therefore, the residence times for the $\mathrm{ABR}$ and $\mathrm{AS}$ bioreactors are 6.82 and $2.40 \mathrm{~h}$, respectively, by using the minimized overall retention time of $10 \mathrm{~h}$ from Figure $8.5 \mathrm{~d}$.

\subsubsection{Optimization of the overall treatment cost}

The costs related to installation and commissioning were not considered in this analysis because the potential users in the meat processing industry have to evaluate these costs separately in a caseby-case basis. Therefore, the power consumption was used for each process multiplied by the electricity rate. Moreover, in the case of the ABR process, an optimum $\mathrm{CH}_{4}$ yield of $55.72 \%$ at a gas flow rate of $64 \mathrm{~mL} / \mathrm{min}$ was obtained by biogas analysis (Landtec Biogas 5000, Colton, CA). These values are in line with those found in the literature for lab-scale biogas reactors (Kaparaju et al., 2009; Cadena Pereda et al., 2010; León-Becerril et al., 2016). Therefore, the total methane production can be expressed in terms of TOC degraded:

$$
\frac{\mathrm{mLCH}_{4}}{\mathrm{mg} \mathrm{TOC} C_{\text {removed }}}=\frac{64 \mathrm{~mL} \mathrm{CH}_{4} / \mathrm{min}}{25.72 \mathrm{mg} \mathrm{TOC} / \mathrm{min}}=2.50 \mathrm{~mL} \mathrm{CH}_{4} / \mathrm{mg} \mathrm{TOC}
$$



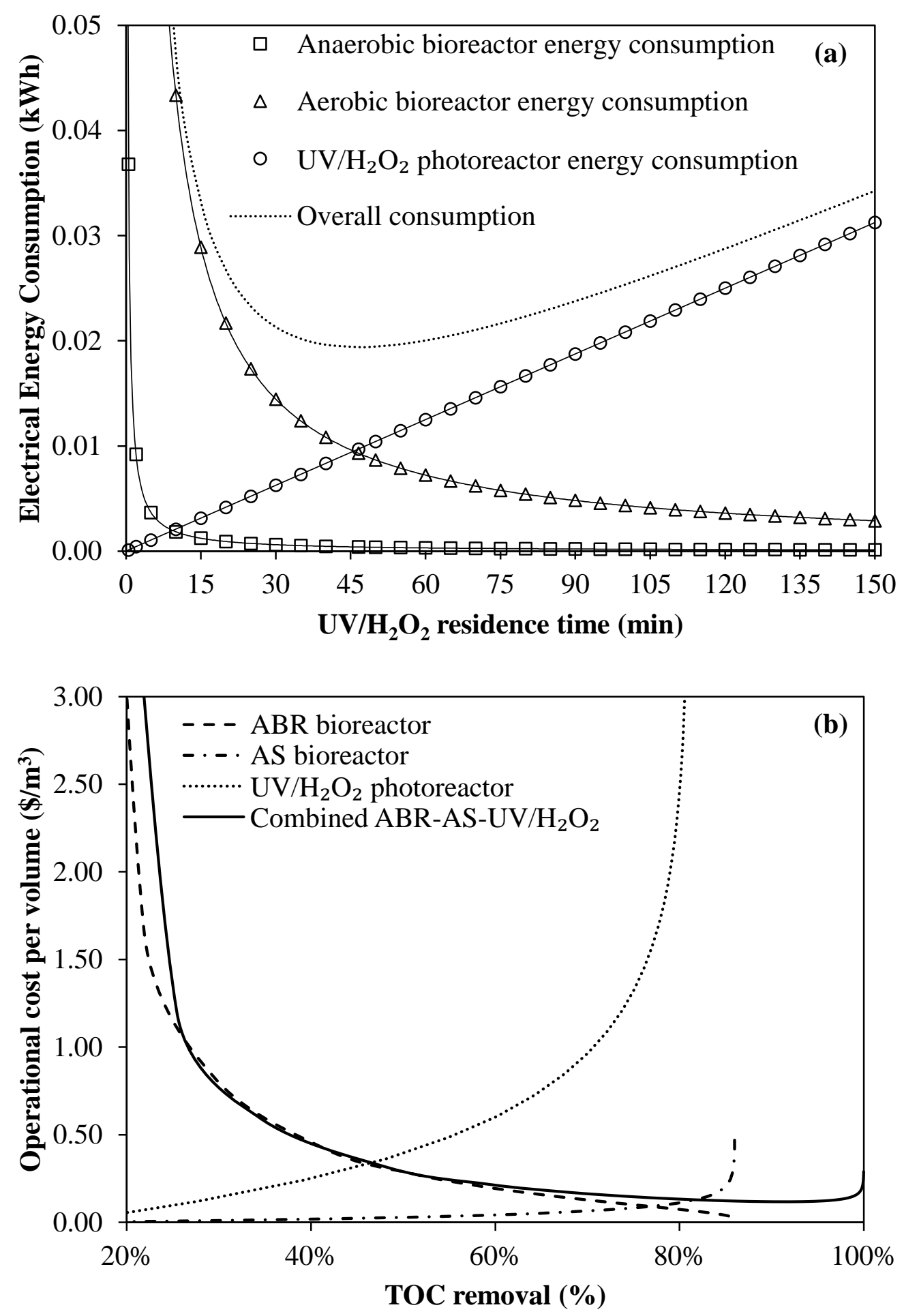

Figure 8.6. Comparison of individual $\mathrm{ABR}, \mathrm{AS}$, and $\mathrm{UV} / \mathrm{H}_{2} \mathrm{O}_{2}$ processes with the combined $\mathrm{ABR}-$ $\mathrm{AS}-\mathrm{UV} / \mathrm{H}_{2} \mathrm{O}_{2}$ system in continuous mode with recycle: (a) Electrical energy consumption based on the residence time in the photoreactor; and (b) Operational costs per cubic meter of treated actual slaughterhouse wastewater.

J. Environ. Manage. (2016), In Press. 
Consequently, by considering the lower heating value (LHV) of $\mathrm{CH}_{4}$ of $35.9 \mathrm{MJ} / \mathrm{m}^{3}$, a daily energy generation of $0.05 \mathrm{kWh}$ is obtained. According to de Mes et al. (2003), biological processes commonly require low power with energy requirements in the range $0.01-0.10 \mathrm{kWh} / \mathrm{m}^{3}$. In this case, $0.005 \mathrm{kWh}$ and $0.02 \mathrm{kWh}$ are required for the ABR process and combined $\mathrm{ABR}-\mathrm{AS}-\mathrm{UV} / \mathrm{H}_{2} \mathrm{O}_{2}$ system, respectively, representing about $39 \%$ of the generated power. This numbers will be representative as a base for future studies on process optimization, modeling, and scale-up.

As a result, Figure $8.6 \mathrm{~b}$ compares the operational costs for the individual $\mathrm{ABR}, \mathrm{AS}$, and $\mathrm{UV} / \mathrm{H}_{2} \mathrm{O}_{2}$ processes with that of the combined $\mathrm{ABR}-\mathrm{AS}-\mathrm{UV} / \mathrm{H}_{2} \mathrm{O}_{2}$ system in terms of cost per cubic meter of the treated actual SWW against the overall percentual TOC removal. A minimum overall treatment cost of $0.12 \$ / \mathrm{m}^{3}$ of actual SWW for a maximum TOC removal of $91.25 \%$ was achieved under the optimum conditions from the DOE.

It is confirmed that the overall operational costs increase with the TOC removal because of the electricity consumption, especially in the $\mathrm{UV} / \mathrm{H}_{2} \mathrm{O}_{2}$ process alone, reaching values of up to ten times higher than those of the biological processes. In contrast, although the maximum attainable removal in the ABR was $86 \%$, the costs have an inverse trend due to the potential energy recovery from $\mathrm{CH}_{4}$ production; whereas, in the AS bioreactor in order to achieve removals higher than $80 \%$, the aeration power consumption will increase the overall treatment costs. In the combined processes, the overall benefits of both biological treatment and AOPs are integrated. Thus, energy costs are offset by the onsite renewable energy from $\mathrm{CH}_{4}$ production.

\subsection{Conclusions}

The optimization of combined biological treatment with advanced oxidation processes allowed achieving a highly cost-effective degradation of actual SWW with percentual removals of 91 and $86 \%$ for TOC and TN, respectively, as well as obtaining a $\mathrm{CH}_{4}$ yield, as the percent TOC converted to $\mathrm{CH}_{4}$, of $55.72 \%$ while having a minimum $\mathrm{H}_{2} \mathrm{O}_{2}$ residual of $1.45 \%$ in the effluent. The combined processes were then simulated and promising results were obtained when compared to each individual process. The non-linear least square function was used to determine the best-fit criterion and the comparison between predicted and experimental values showed a good agreement between the predicted model values and the experimental data. 
A CEA was performed at the optimal conditions for the actual SWW treatment by optimizing the residence time, electrical energy consumption, and the overall treatment cost. The minimum total retention time was determined to be $10 \mathrm{~h}$ with individual residence times of $6.82 \mathrm{~h}, 2.40 \mathrm{~h}$, and $47 \mathrm{~min}$ in the $\mathrm{ABR}$, AS bioreactor, and $\mathrm{UV} / \mathrm{H}_{2} \mathrm{O}_{2}$ photoreactor, respectively, for the minimum electrical power consumption of $0.0194 \mathrm{kWh}$. A minimum overall treatment cost of $0.12 \$ / \mathrm{m}^{3}$ of actual SWW for a maximum TOC removal of $91.25 \%$ was achieved at the optimum conditions based on the experimental design and degradation mechanism results.

Therefore, the proposed models explaining the actual slaughterhouse wastewater treatment by combined anaerobic, aerobic, and $\mathrm{UV} / \mathrm{H}_{2} \mathrm{O}_{2}$ processes for organics removal and $\mathrm{CH}_{4}$ production could be used as a base for future studies for the reduction of operating costs while providing high-quality treated wastewater for water reuse in the meat processing industry becoming a cost-effective alternative to conventional methods and simultaneously beneficial to the environment.

\section{Acknowledgments}

The financial support of Natural Sciences and Engineering Research Council of Canada (NSERC), Ontario Trillium Scholarship (OTS) program, Colciencias (a funding agency in Colombia), and Ryerson University is greatly appreciated. 


\section{CHAPTER 9 \\ CONCLUSIONS AND RECOMMENDATIONS}

\subsection{Conclusions}

The purpose of this study was to determine the current wastewater treatment technologies used in the meat processing sector in Ontario, assess possible alternatives in order to minimize the impact of the discharge of these wastewaters to the environment, optimize reactors and systems for the treatment of actual slaughterhouse wastewater, maximize overall treatment efficiency, describe common degradation mechanisms, and perform a cost-effectiveness analysis, minimizing the incurred treatment costs, the electrical energy consumption, and the retention time required for the efficient treatment of slaughterhouse effluents and potential energy recovery from combined biological and advanced oxidation processes for the treatment of actual wastewater from the meat processing sector in Ontario. The following conclusions are drawn from this dissertation:

- A summary of the most commonly applied technologies and combined processes during the last decade with particular attention to treatment efficiencies in terms of organic and nutrient removal, highlighting commonly used parameters, such as COD, TOC, BOD, and TN was developed. The treatment efficiency of SWW was found to vary extensively and depends on several factors including, but not limited to, the characteristics of the SWW, the HRT, the type of treatment, and the pollutant concentration in the influent.

- SWWs are commonly pre-treated by screening, settling, blood collection, and fat separation, followed by physicochemical treatment, DAF, coagulation/flocculation, and/or secondary biological treatment prior to discharge on the sewage system. Although the organic matter and nutrient removal achieve high efficiencies, the treated SWW effluent need further treatment by membrane technologies, AOPs, or other appropriate treatment methods as combined processes to provide high-quality treated water allowing water recycle in the meat processing industry. 
- Combined processes have evolved into a reliable technology successfully used for many SWW effluents. However, the selection of a specific treatment mainly depends on the characteristics of the SWW being treated, the BAT, and the compliance with current regulations under different political jurisdictions.

- A CEA was used to determine the best alternative for SWW treatment from six different systems selected from the literature review, including individual $\mathrm{UV} / \mathrm{H}_{2} \mathrm{O}_{2}, \mathrm{AS}$, and $\mathrm{ABR}$ processes, and combined ABR-AS, AS-ABR, and ABR-AS-UV/ $/ \mathrm{H}_{2} \mathrm{O}_{2}$ processes. The combined ABR-AS$\mathrm{UV} / \mathrm{H}_{2} \mathrm{O}_{2}$ processes was more technically efficient than other individual and combined processes, removing $15 \%$ more TOC during the same amount of operating time.

- The $\mathrm{UV} / \mathrm{H}_{2} \mathrm{O}_{2}$ process alone was the least efficient technology with an optimum removal of $49.88 \%$ at a high cost of $67.06 \$ / \mathrm{kg}$ of TOC removed. However, it was also found that at low or intermediate TOC removal requirements, combined and individual processes are comparable in economic terms. In combined processes, the main costs are initially for pumps, reagents, and air injection. Only when the TOC removal is higher than $60 \%$, the electricity costs increase.

- It was determined that the optimum system for the TOC removal was ABR-AS-UV/ $/ \mathrm{H}_{2} \mathrm{O}_{2}$, with an optimal TOC removal of $92.46 \%$ at an HRT of $41 \mathrm{~h}$, at a cost of $1.25 \$ / \mathrm{kg}$ of TOC removed and $\$ 11.60 / \mathrm{m}^{3}$ of treated SWW. However, costs could be reduced by subtracting the electrical costs by considering potential energy recovery from anaerobic pre-treatment.

- During optimization of the combined ABR-AS system, results from the three-factor, three-level BBD to evaluate the treatment of SWW demonstrated the influent TOC concentration significant effects on all responses including percent TOC removal, TN removal, TSS residual, and biogas yield.

- The feed flow rate was also found to be significant on the percent TOC removal, TN removal, and TSS residual; whereas, the $\mathrm{pH}$ was found to be significant on percent TN removal and biogas yield. There was only one cross-factor interaction, between the feed flow rate and the $\mathrm{pH}$, which showed no significant effect on two responses, percent TN removal and TSS residual, despite being significant on TOC removal and biogas yield simultaneously. 
- On the other hand, a desirable interaction to reach maximum TOC and TN removal with minimum TSS residual was achieved when both the influent TOC concentration and the feed flow rate are minimum, for biogas yield it is necessary a high influent TOC concentration at an optimum value for the feed flow rate. Likewise, a desirable interaction to reach maximum TOC and for biogas yield was achieved when there is an optimum value for both the feed flow rate and $\mathrm{pH}$.

- Maximum removals of 85.03 and $72.10 \%$ for TOC and TN, respectively, minimum TSS residual of $19.54 \mathrm{mg} / \mathrm{L}$, and maximum biogas yield of $116.56 \mathrm{~mL} / \mathrm{min}$ were found at optimum conditions. The methane production was $3.76 \mathrm{~L} / \mathrm{kg}$ TOC removed, equivalent to a daily energy generation of $1.23 \mathrm{kWh}$. Consequently, the laboratory scale combined ABR-AS system could generate 0.12 \$/day. Thus, becoming a cost-effective alternative and simultaneously beneficial to the environment.

- The developed statistical models provided a detailed exploration of the simultaneous cross-factor interactive effects of the influent TOC concentration, the feed flow rate, and the $\mathrm{pH}$. Therefore, the proposed models explaining slaughterhouse wastewater treatment by combined anaerobicaerobic processes for biogas production and organics removal could be used as a base for future studies for the reduction of operating costs while providing high quality treated wastewater for water reuse in the meat processing industry.

- The individual $\mathrm{UV} / \mathrm{H}_{2} \mathrm{O}_{2}$ process in a continuous photoreactor with recycle was studied for optimization using a four-factor, five-level CCD. Results demonstrated that the influent concentrations of TOC and $\mathrm{H}_{2} \mathrm{O}_{2}$, the flow rate, and the recycle ratio presented considerable effect on the TOC and the $\mathrm{H}_{2} \mathrm{O}_{2}$ residual.

- The cross-factor interactions of the recycle ratio with other variables, including the influent concentration of TOC, the influent $\mathrm{H}_{2} \mathrm{O}_{2}$ concentration, and the flow rate were found to have a high significant effect on both the TOC removal and the $\mathrm{H}_{2} \mathrm{O}_{2}$ residual. Thus, an optimum recycle ratio was found to be highly significant to achieve a maximum TOC removal with a minimum $\mathrm{H}_{2} \mathrm{O}_{2}$ residual for the treatment of SWW. 
- A maximum TOC removal of $81 \%$ and minimum $\mathrm{H}_{2} \mathrm{O}_{2}$ residual of less than $2 \%$ were found at the optimum operating conditions of $24 \mathrm{mg} / \mathrm{L}$ influent concentration of total organic carbon, 860 $\mathrm{mg} / \mathrm{L}$ influent $\mathrm{H}_{2} \mathrm{O}_{2}$ concentration, $15 \mathrm{~mL} / \mathrm{min}$ flow rate, and recycle ratio of 0.18 based on the developed quadratic models and the desirability multiple response method.

- The developed mathematical models provided a detailed exploration of the simultaneous crossfactor interactive effects of the independent variables on the responses. A continuous $\mathrm{UV} / \mathrm{H}_{2} \mathrm{O}_{2}$ photoreactor with recycle could significantly increase the removal of TOC while reducing the percent $\mathrm{H}_{2} \mathrm{O}_{2}$ residual in the effluent as a post-treatment method. Therefore, the proposed models explaining the photochemical treatment of slaughterhouse wastewater by the continuous $\mathrm{UV} / \mathrm{H}_{2} \mathrm{O}_{2}$ photoreactor with recycle could be used as a base for future studies on process optimization, photoreactor design, modeling, and scale-up.

- The optimization of combined biological treatment with advanced oxidation processes allowed achieving a highly cost-effective degradation of actual SWW with percentual removals of 91 and $86 \%$ for TOC and TN, respectively, as well as obtaining a $\mathrm{CH}_{4}$ yield of $55.72 \%$ while having a minimum $\mathrm{H}_{2} \mathrm{O}_{2}$ residual of $1.45 \%$ in the effluent.

- A CEA was performed at the optimal conditions for the actual SWW treatment by optimizing the residence time, electrical energy consumption, and the overall treatment cost. The minimum total retention time was determined to be $10 \mathrm{~h}$ with individual residence times of $6.82 \mathrm{~h}, 2.40 \mathrm{~h}$, and 47 min in the $\mathrm{ABR}$, AS bioreactor, and $\mathrm{UV} / \mathrm{H}_{2} \mathrm{O}_{2}$ photoreactor, respectively, for the minimum electrical power consumption of $0.0194 \mathrm{kWh}$. A minimum overall treatment cost of $0.12 \$ / \mathrm{m}^{3}$ of actual SWW for a maximum TOC removal of $91.25 \%$ was achieved at the optimum conditions based on the experimental design and degradation mechanism results.

- The proposed models explaining the actual slaughterhouse wastewater treatment by combined anaerobic, aerobic, and $\mathrm{UV} / \mathrm{H}_{2} \mathrm{O}_{2}$ processes for organics removal and $\mathrm{CH}_{4}$ production could be used as a base for future studies for the reduction of operating costs while providing high-quality treated wastewater for water reuse in the meat processing industry becoming a cost-effective alternative to conventional methods and simultaneously beneficial to the environment. 


\subsection{Recommendations}

The following recommendations are suggested for further research on combined biological and AOPs processes for the treatment of actual SWW:

- Further studies should be focused on the characterization of the microorganisms present in the activated sludge to determine their nitrifying and denitrifying abilities.

- It is suggested to use different UV lamps with various intensities to compare the effect of the light intensity on actual SWW treatment since light intensity has significant effect on the photodegradation effectiveness.

- Further research should be also considered for the examination of emerging contaminants present in slaughterhouse wastewater, including pharmaceutical compounds used by veterinary physicians, anti-inflammatories, cleaning products, endocrine disruptors, and possible hazardous compounds.

- The literature review and actual SWW sampling revealed significant presence of heavy metals such as lead. Therefore, studies on the removal of heavy metals present in actual SWW should also be conducted.

- Further work should conduct the analysis of different intermediates that may be formed during the $\mathrm{UV} / \mathrm{H}_{2} \mathrm{O}_{2}$ treatment.

- The study of the health effects associated with wastewater treatment, disposal, and reuse in the meat processing industry should be considered due to the presence of pathogens in the SWW.

- Further studies should focus on the CFD modeling for a pilot-scale combined biological and advanced oxidation system, especially in the turbulent regime where literature is scarce.

- Finally, a life-cycle assessment integrating external costs in the meat processing industry could be a valuable contribution of future studies, evaluating, inputs and outputs, greenhouse gas emissions, and the benefits from the potential energy recovery as well as water recycle and reuse. 


\section{NOMENCLATURE}

\begin{tabular}{|c|c|}
\hline$c$ & residual term \\
\hline $\mathrm{C}_{\mathrm{H} 2 \mathrm{O} 2 \mathrm{in}}$ & hydrogen peroxide concentration in the influent \\
\hline $\mathrm{C}_{\mathrm{H}_{2} \mathrm{O} 2 \mathrm{M}}$ & hydrogen peroxide concentration entering the photoreactor \\
\hline $\mathrm{C}_{\mathrm{H} 2 \mathrm{O} 2 \mathrm{Out}}$ & hydrogen peroxide concentration in the effluent \\
\hline$C_{S W W i n}$ & slaughterhouse wastewater concentration in the influent \\
\hline$C_{S W W M}$ & slaughterhouse wastewater concentration entering the photoreactor \\
\hline$C_{S W W o u t}$ & slaughterhouse wastewater concentration in the effluent \\
\hline$D$ & desirability objective function \\
\hline$d_{i}$ & response range $i$ \\
\hline$d_{1}$ & total organic carbon removal response range \\
\hline$d_{2}$ & $\mathrm{H}_{2} \mathrm{O}_{2}$ residual response range \\
\hline$d f$ & Degrees of freedom \\
\hline$d f_{\text {Error }}$ & degree of freedom of the residuals \\
\hline$d f_{\text {Model }}$ & degrees of freedom for the model \\
\hline$E$ & Einstein unit \\
\hline$E^{0}$ & incident photon irradiance \\
\hline$E_{r}$ & energy rate $(\$ / \mathrm{kWh})$ \\
\hline$F$ & Fisher's exact test \\
\hline$F$-value & Fisher's exact test value \\
\hline$F / M$ & food to microorganism ratio \\
\hline$g$ & gravity $\left(9.81 \mathrm{~m} / \mathrm{s}^{2}\right)$ \\
\hline$h$ & total head $(\mathrm{m})$ \\
\hline$J$ & electricity cost $(\$ / \mathrm{kg})$ \\
\hline$K$ & first order rate coefficient of substrate \\
\hline$k$ & number of factors of the experimental design \\
\hline$k^{\prime}$ & the sum of the direct photolysis rate $\left(k_{U V}\right)$ and the indirect photolysis rate $(k \cdot O H)$ \\
\hline$k \cdot \mathrm{OH}$ & oxidation rate/indirect photolysis rate \\
\hline$k_{1}$ & first order rate coefficient of substrate in compartment 1 of the ABR \\
\hline
\end{tabular}




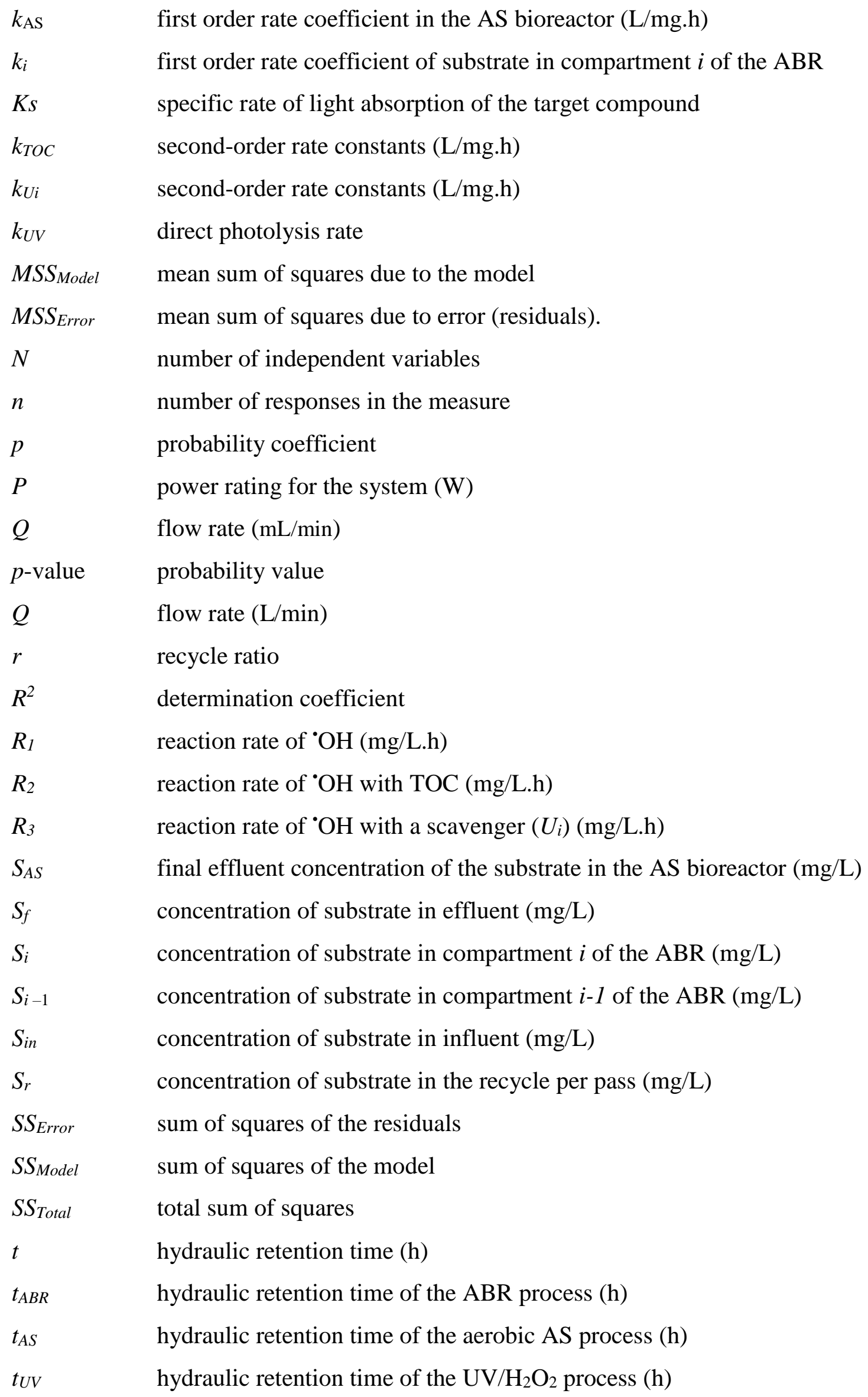




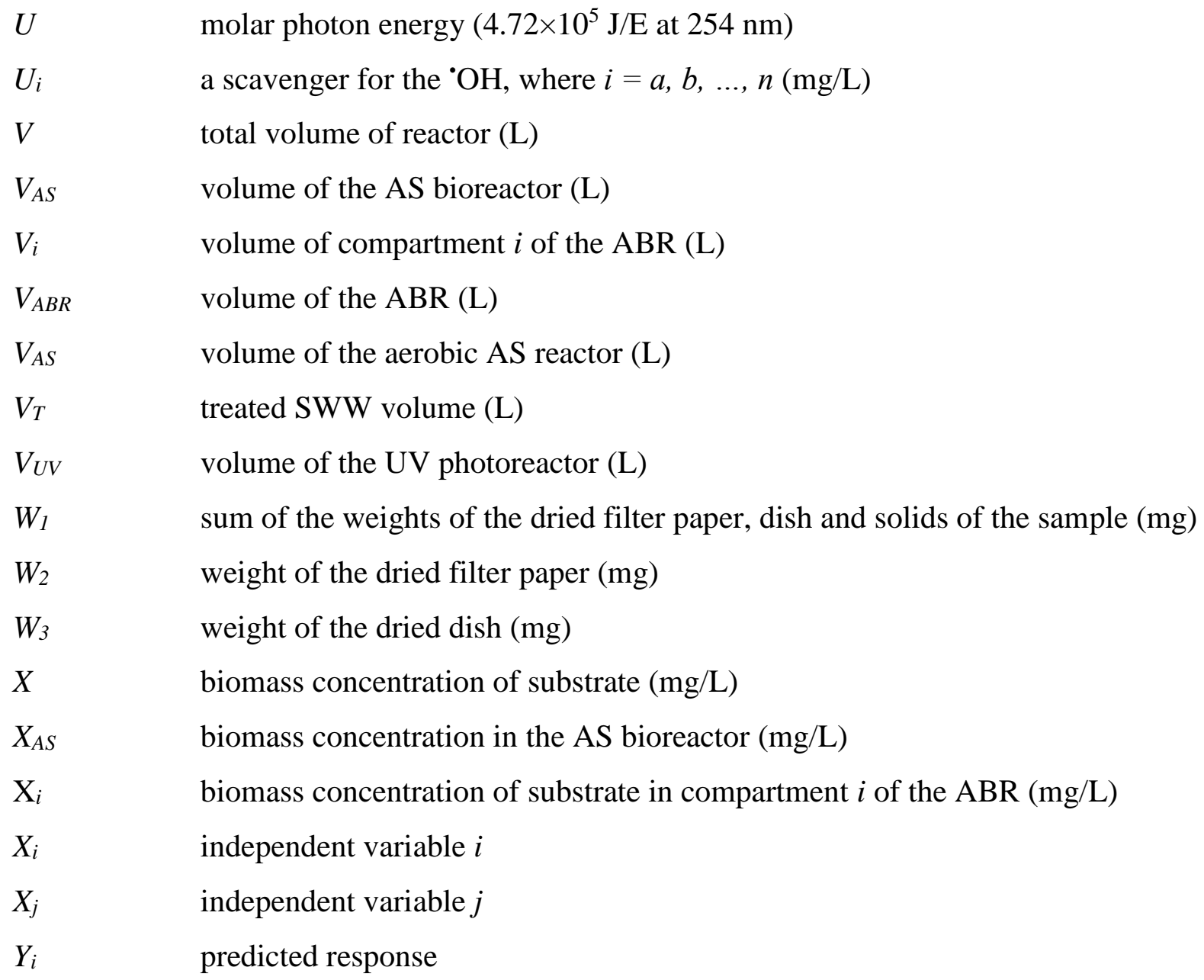

\section{Greek letters}

$\begin{array}{ll}\alpha & \text { significance level } \\ \alpha & \text { absorbance of the solution } \\ \beta_{o} & \text { constant coefficient of the statistical model } \\ \beta_{i} & \text { linear coefficients of the statistical model } \\ \beta_{i i} & \text { quadratic coefficients of the statistical model } \\ \beta_{i j} & \text { cross-factor interaction coefficients of the statistical model } \\ \xi & \text { constant that depends on type of AOP (mg/h.W) } \\ \varepsilon_{S} & \text { molar attenuation coefficient for the targeted substrate } \\ \ell & \text { solution depth or path length } \\ \rho & \left.\text { water density (1000 kg/m }{ }^{3}\right) \\ \phi_{S W W} & \text { quantum yield for the SWW } \\ \eta & \text { pump efficiency }\end{array}$




\section{Acronyms}

2D

two-dimensional

$3 \mathrm{D}$

three-dimensional

$\mathrm{ABR}$

anaerobic baffled reactor

$\mathrm{AC}$

activated carbon

AdP

adsorption process

AeP

aerobic process

$\mathrm{AF}$

anaerobic filter

AnaP

anaerobic process

ANOVA

analysis of variance

ANZECC

Australian and New Zealand Environment and Conservation Council

AOP advanced oxidation process

APHA

American Public Health Association

AS

activated sludge

BAT

best available technology

BBD Box-Behnken design

BOD biochemical oxygen demand

$\mathrm{BOD}_{\text {in }} \quad$ influent concentration of biochemical oxygen demand

$\mathrm{CC} \quad$ chemical coagulation

CCD central composite design

CEA cost-effectiveness analysis

CEC council of the European communities

CI confidence intervals

CM composite membrane

COD chemical oxygen demand

$\mathrm{COD}_{\text {in }} \quad$ influent concentration of chemical oxygen demand

CSTR continuous flow stirred-tank reactor

CW constructed wetland

DAF dissolved air flotation

DO dissolved oxygen

DOE design of experiments

DW distilled water

EC electrocoagulation 


\begin{tabular}{|c|c|}
\hline $\mathrm{ECO}$ & environmental commissioner of Ontario \\
\hline FAU & formazin attenuation units \\
\hline FTU & formazin turbidity units \\
\hline GR & gamma radiation \\
\hline HFCW & horizontal flow constructed wetland \\
\hline HRT & hydraulic retention time \\
\hline IR & internal recycle \\
\hline LVREA & local volumetric rate of energy absorption \\
\hline MBR & membrane bioreactor \\
\hline MF & microfiltration \\
\hline OEB & Ontario energy board \\
\hline OLR & organic loading rates \\
\hline OMAFRA & Ontario Ministry of Agricultural and Rural Affairs \\
\hline $\mathrm{PACl}$ & Polyaluminum chloride \\
\hline RO & reverse osmosis \\
\hline RSM & response surface methodology \\
\hline SBR & sequencing batch reactor \\
\hline SS & sum of squares \\
\hline SWW & slaughterhouse wastewater \\
\hline $\mathrm{TKN}$ & total Kjeldahl nitrogen \\
\hline $\mathrm{TN}$ & total nitrogen \\
\hline TNin & influent concentration of total nitrogen \\
\hline TOC & total organic carbon \\
\hline TOCin & influent concentration of total organic carbon \\
\hline TSS & total suspended solids \\
\hline UAF & up-flow anaerobic filter \\
\hline UAPF & up-flow anaerobic packed-bed filters \\
\hline UF & ultrafiltration \\
\hline $\mathrm{UV} / \mathrm{H}_{2} \mathrm{O}_{2}$ & ultraviolet light and hydrogen peroxide \\
\hline US EPA & United States Environmental Protection Agency \\
\hline VFCW & vertical flow constructed wetlands \\
\hline VSS & volatile suspended solids \\
\hline VUV & vacuum-ultraviolet light \\
\hline
\end{tabular}




\section{APPENDICES}

\section{Appendix A. Abstract reprint from Journal of Environmental Management 161 (2015) 287-302, with permission from Elsevier. License Number 3830960007849.}

Journal of Environmental Management 161 (2015) 287-302

\begin{tabular}{lcl}
\hline & Contents lists available at ScienceDirect & Journal of Environmental Management \\
ELSEVIER & journal homepage: www.elsevier.com/locate/jenvman \\
\hline
\end{tabular}

Review

Slaughterhouse wastewater characteristics, treatment, and management in the meat processing industry: A review on trends and advances

Ciro Fernando Bustillo-Lecompte ${ }^{\mathrm{a}}$, Mehrab Mehrvar ${ }^{\mathrm{b}, \text { " }}$

a Graduate Programs in Environmental Applied Science and Management, Ryerson University, 350 Victoria Street, Toronto, ON, M5B 2K3, Canada b Department of Chemical Engineering, Ryerson University, 350 Victoria Street, Toronto, ON, M5B 2K3, Canada

A R T I C L E I N F O

Article history:

Received 15 May 2015

Received in revised form

1 July 2015

Accepted 2 July 2015

Available online 17 July 2015

\section{Keywords:}

Slaughterhouse wastewater (SWW)

Wastewater treatmen

Combined process

Advanced oxid

\begin{abstract}
A B S T R A C T
A thorough review of advancement in slaughterhouse wastewater (SWW) characteristics, treatment, and management in the meat processing industry is presented. This study also provides a general review of the environmental impacts, health effects, and regulatory frameworks relevant to the SWW management. A significant progress in high-rate anaerobic treatment, nutrient removal, advanced oxidation processes (AOPs), and the combination of biological treatment and AOPs for SWW treatment is highlighted. The treatment processes are described and few examples of their applications are given Conversely, few advances are accounted in terms of waste minimization and water use reduction, reuse, and recycle in slaughterhouses, which may offer new alternatives for cost-effective waste management. An overview of the most frequently applied technologies and combined processes for organic and An oventric and nutrient ris processes have been used for the swW treatnent. Nevertheless, the selection of a particular technology depends on the characteristics of the wastewater, the available technology, and the compliance with regulations. This review facilitates a better understanding of current difficulties that can be found during production and management of the SWW, including treatment and characteristics of the final effluent. (1) 2015 Elsevier Ltd. All rights reserved.
\end{abstract}

\section{Introduction}

The increasing growth of world population has augmented the pollution of freshwater due to the inadequate discharge of wastewater, especially in developing countries (US EPA, 2004; Leitão et al., 2006; Gopala Krishna et al., 2009; Feng et al., 2009). For this reason, water and wastewater treatment has become crucial for the continuing development of the society. Moreover, the progressively stricter standards for effluent discharge worldwide have made the developing of advanced wastewater treatment technologies necessary (Environment Canada, 2000, 2012; US EPA, 2004 World Bank Group, 2007). Besides, the continuing decreasing availability of freshwater resources has rearranged the objectives in the wastewater treatment field from disposal to reuse and recycling. As a result, a high level of treatment efficiency has to be achieved. Given the differences in location, economic resources,

\footnotetext{
* Corresponding author.

E-mail address: mmehrvar@iverson.ca (M. Mehrvar).
}

living standards of different countries, and characteristics of water and its pollutants, many nations adopt diverse techniques for water and wastewater treatment (Daigger, 2009).

The meat processing sector produces large volumes of slaugh terhouse wastewater (SWW) due to the slaughtering of animals and cleaning of the slaughterhouse facilities and meat processing plants (MPPs). The meat processing industry uses $24 \%$ of the total freshwater consumed by the food and beverage industry (Table 1) and up to $29 \%$ of that consumed by the agricultural sector worldwide (Mekonnen and Hoekstra, 2012; Gerbens-Leenes et al., 2013). SWW composition varies significantly depending on the diverse industrial processes and specific water demand (Matsumura and Mierzwa, 2008; Debik and Coskun, 2009; Bustillo-Lecompte et al. 2013, 2014). Slaughterhouses are part of a large industry, which is common to numerous countries worldwide where meat is an important part of their diet. Therefore, SWWs require significant treatment for a safe and sustainable release to the environment (Johns, 1995). Nevertheless, review articles on SWW and the meat processing industry are not widely available (Bull et al., 1982; Trit and Schuchardt, 1992; Johns, 1995; Salminen and Rintala, 2002; 


\title{
Appendix B. Abstract reprint from Journal of Environmental Management 134 (2014) 145-152, with permission from Elsevier. License Number 3830951278377.
}

Journal of Environmental Management 134 (2014) 145-152

Contents lists available at ScienceDirect

Journal of Environmental Management

journal homepage: www.elsevier.com/locate/jenvman

\section{Cost-effectiveness analysis of TOC removal from slaughterhouse wastewater using combined anaerobic-aerobic and $\mathrm{UV} / \mathrm{H}_{2} \mathrm{O}_{2}$ processes}

\author{
Ciro Fernando Bustillo-Lecompte ${ }^{a}$, Mehrab Mehrvar ${ }^{b, *}$, Edgar Quiñones-Bolaños ${ }^{c}$ \\ ${ }^{a}$ Graduate Program in Environmental Applied Science and Management, Ryerson University, 350 Victoria Street, Toronto, ON M5B 2K3, Canada \\ ${ }^{\mathrm{b}}$ Department of Chemical Engineering, Ryerson University, 350 Victoria Street, Toronto, ON M5B 2K3, Canada
}

${ }^{c}$ Facultad de Ingeniería, Universidad de Cartagena, Centro - Cr6 No 36-100, Cartagena de Indias, Colombia

\section{A R T I C L E I N F O}

\section{Article history:}

Received 23 May 2013

Received in revised form

10 December 2013

Accepted 31 December 2013

Available online 30 January 2014

\section{Keywords:}

Cost-effectiveness analysis (CEA)

Slaughterhouse wastewater (SWW)

Activated sludge (AS)

Advanced oxidation processes (AOPs)

$\mathrm{UV} / \mathrm{H}_{2} \mathrm{O}_{2}$

TOC

\begin{abstract}
A B S T R A C T
The objective of this study is to evaluate the operating costs of treating slaughterhouse wastewater (SWW) using combined biological and advanced oxidation processes (AOPs). This study compares the performance and the treatment capability of an anaerobic baffled reactor (ABR), an aerated completely mixed activated sludge reactor (AS), and a UV/ $\mathrm{H}_{2} \mathrm{O}_{2}$ process, as well as their combination for the removal of the total organic carbon (TOC). Overall efficiencies are found to be up to 75.22, 89.47, 94.53, 96.10, 96.36, and $99.98 \%$ for the $\mathrm{UV} / \mathrm{H}_{2} \mathrm{O}_{2}, \mathrm{ABR}$, AS, combined $\mathrm{AS}-\mathrm{ABR}$, combined ABR-AS, and combined ABR $-\mathrm{AS}-\mathrm{UV} / \mathrm{H}_{2} \mathrm{O}_{2}$ processes, respectively. Due to the consumption of electrical energy and reagents, operating costs are calculated at optimal conditions of each process. A cost-effectiveness analysis (CEA) is performed at optimal conditions for the SWW treatment by optimizing the total electricity $\operatorname{cost}, \mathrm{H}_{2} \mathrm{O}_{2}$ consumption, and hydraulic retention time (HRT). The combined ABR-AS- $\mathrm{UV} / \mathrm{H}_{2} \mathrm{O}_{2}$ processes have an optimal TOC removal of $92.46 \%$ at an HRT of $41 \mathrm{~h}$, a cost of $\$ 1.25 / \mathrm{kg}$ of TOC removed, and $\$ 11.60 / \mathrm{m}^{3}$ of treated SWW. This process reaches a maximum TOC removal of $99 \%$ in $76.5 \mathrm{~h}$ with an estimated cost of $\$ 2.19 / \mathrm{kg}$ TOC removal and $\$ 21.65 / \mathrm{m}^{3}$ treated SWW, equivalent to $\$ 6.79 / \mathrm{m}^{3}$ day.

(c) 2014 Elsevier Ltd. All rights reserved.
\end{abstract}

\section{Introduction}

Slaughterhouse wastewater (SWW) is considered detrimental worldwide due to its composition, characterized mostly by a complex mixture of fats, proteins, and fibers (Johns, 1995; Muñoz, 2005). Wastewaters from slaughterhouses and meat processing plants (MPPs) have been considered as an industrial wastewater in the category of agricultural and food industries (Seif and Moursy, 2001). It has been classified as one of the most harmful wastewaters to the environment by the United States Environmental Protection Agency (US EPA, 2004). The effluent discharge from slaughterhouses causes deoxygenation of rivers (Quinn and McFarlane, 1989) and contamination of groundwater (Masse and Masse, 2000a).

The organic matter concentration in SWW is usually high and the residues are moderately solubilized, leading to a highly polluting effect (Ruiz et al., 1997). They usually contain high levels

\footnotetext{
* Corresponding author. Tel.: +1 416979 5000x6555; fax: +1 4169795083.

E-mail address: mmehrvar@ryerson.ca (M. Mehrvar).
}

of organics, pathogenic and non-pathogenic viruses and bacteria, and detergents and disinfectants used for cleaning activities (Debik and Coskun, 2009). High concentrations of biochemical oxygen demand (BOD), chemical oxygen demand (COD), total organic carbon (TOC), total nitrogen (TN), and total suspended solids (TSS) in SWW containing flesh and blood have been reported to be 4635 , $15,900,1200,841$, and $2800 \mathrm{mg} / \mathrm{L}$ or more, respectively (Tritt and Schuchardt, 1992; Masse and Masse, 2000b). Several studies have described the common characteristics of SWW (Gariepy et al., 1989; Seif and Moursy, 2001; Cao and Mehrvar, 2011; Wu and Mittal, 2011; Barrera et al., 2012; Bustillo-Lecompte et al., 2013). These characteristics are summarized in Table 1, in which their common ranges and averages of COD, TOC, BOD, TSS, TN, and pH for SWW are presented.

Commonly, research on wastewater treatment includes the study of different contaminants, the effects of operating variables, and the efficiency of the processes. Nevertheless, there are limited studies on the economic information and analysis, reaction mechanisms, and kinetic modeling that may help to estimate the costs of different technologies for scale-up and industrial applications (Durán et al., 2012; Benedetti et al., 2013; Ghafoori et al., 2012, 2013, 2014). 

Appendix C. Abstract reprint from Journal of Environmental Chemical Engineering 4 (2016)
719-732, with permission from Elsevier. License Number 3830960158225.

Journal of Environmental Chemical Engineering 4 (2016) 719-732

Contents lists available at ScienceDirect

Journal of Environmental Chemical Engineering

journal homepage: www.elsevier.com/locate/jece

\title{
Photochemical degradation of an actual slaughterhouse wastewater by continuous $\mathrm{UV} / \mathrm{H}_{2} \mathrm{O}_{2}$ photoreactor with recycle
}

\author{
Ciro Fernando Bustillo-Lecompte ${ }^{\mathrm{a}}$, Samira Ghafoori ${ }^{\mathrm{b}}$, Mehrab Mehrvar ${ }^{\mathrm{c}, *}$ \\ ${ }^{a}$ Graduate Programs in Environmental Applied Science and Management, Ryerson University, 350 Victoria Street, Toronto, ON M5B 2K3, Canada \\ ${ }^{\mathrm{b}}$ School of Engineering, Australian College of Kuwait, Mishrif, Kuwait City, Kuwait \\ ${ }^{\mathrm{C}}$ Department of Chemical Engineering, Ryerson University, 350 Victoria Street, Toronto, ON M5B 2K3, Canada
}

A R T I C LE IN F O

\section{Article history:}

Received 20 July 2015

Received in revised form 6 November 2015

Accepted 7 December 2015

Available online 10 December 2015

\section{Keywords:}

Slaughterhouse wastewater

Advanced oxidation processes

Recycle effect

$\mathrm{UV} / \mathrm{H}_{2} \mathrm{O}_{2}$

Central composite design

Experimental design

\begin{abstract}
A B S T R A C T
Slaughterhouse wastewater is treated using the $\mathrm{UV} / \mathrm{H}_{2} \mathrm{O}_{2}$ process in a continuous photoreactor with recycle, in which the effect of the recycle ratio (the ratio of recycle flow rate to the main feed flow rate) on the photoreactor efficiency is investigated. A four-factor, five-level central composite design along with response surface methodology is used to maximize the total organic carbon removal from an actual slaughterhouse wastewater and minimize the $\mathrm{H}_{2} \mathrm{O}_{2}$ residual in the effluent. The effects of the flow rate and the influent concentrations of total organic carbon and $\mathrm{H}_{2} \mathrm{O}_{2}$ on the photodegradation of the actual slaughterhouse wastewater are also investigated. Statistical models are developed to predict both the total organic carbon removal and the $\mathrm{H}_{2} \mathrm{O}_{2}$ residual as response variables. The recycle ratio is found to be significant in minimizing the $\mathrm{H}_{2} \mathrm{O}_{2}$ residual and the cross-factor interactions of recycle ratio with other variables demonstrate a significant effect on both total organic carbon removal and $\mathrm{H}_{2} \mathrm{O}_{2}$ residual. $A$ maximum total organic carbon removal of $81 \%$ and a minimum $\mathrm{H}_{2} \mathrm{O}_{2}$ residual of less than $2 \%$ are found at optimum operating conditions of $24 \mathrm{mg} / \mathrm{L}$ influent total organic carbon, $860 \mathrm{mg} / \mathrm{L}$ influent $\mathrm{H}_{2} \mathrm{O}_{2}$ concentration, $15 \mathrm{~mL} / \mathrm{min}$ flow rate, and 0.18 recycle ratio. The model is validated under optimal operating conditions based on the experimental design results. The good agreement between model predictions and experimental values indicates that the proposed model could successfully describe the photochemical treatment of actual slaughterhouse wastewater by the continuous $\mathrm{UV} / \mathrm{H}_{2} \mathrm{O}_{2}$ process with recycle and its applicability as a post-treatment method.
\end{abstract}

(c) 2015 Elsevier Ltd. All rights reserved.

\section{Introduction}

The global production of beef, pork, and poultry meat has been doubled in the past decade and is projected to steadily grow until 2050. Furthermore, the number of slaughterhouse facilities are increasing, which results in an expected higher volume of slaughterhouse wastewater (SWW) to be treated. The SWW is typically assessed in terms of bulk parameters because of the diverse pollutant loads in the SWW derived from the type and number of animals slaughtered that fluctuate amid the meat industry [1]. SWW usually contain high levels of organics and nutrients, expressed as bulk components such as biochemical oxygen demand (BOD), chemical oxygen demand (COD), and total organic carbon (TOC). Thus, SWW is considered detrimental worldwide, and on-site treatment would be the best option to treat

* Corresponding author. Fax: + 14169795083.

E-mail address: mmehrvar@ryerson.ca (M. Mehrvar). and disinfect the effluents to be discharged safely into receiving waters [1-5].

Advanced oxidation processes (AOPs) are becoming an attractive alternative over conventional treatment and a complimentary treatment option, as either pretreatment or post-treatment, to current biological processes for SWW treatment [3-9]. Furthermore, AOPs may inactivate microorganisms without adding additional chemicals to the SWW, avoiding the formation of hazardous by-products [6-10].

Several AOPs have been tested for SWW treatment including ozonation, gamma radiation, and $\mathrm{UV} / \mathrm{H}_{2} \mathrm{O}_{2}[5-12]$. However, the $\mathrm{UV} / \mathrm{H}_{2} \mathrm{O}_{2}$ process has been found to be more efficient for SWW treatment. The $\mathrm{UV} / \mathrm{H}_{2} \mathrm{O}_{2}$ process is five times faster in inactivation and inhibition of microorganisms as well as in degrading aromatic compounds than those of other technologies. Removal efficiencies of up to 97,95 , and $75 \%$ could be achieved by the $\mathrm{UV} / \mathrm{H}_{2} \mathrm{O}_{2}$ process for COD, BOD, and TOC, respectively [3-9]. Thus, AOPs might be considered to enhance the SWW quality for water reuse purposes.

On the other hand, AOPs are considered multifactor systems due to the interaction of several parameters including organics 


\title{
Slaughterhouse Wastewater Characterization and Treatment: An Economic and Public Health Necessity of the Meat Processing Industry in Ontario, Canada
}

\author{
Ciro Bustillo-Lecompte', Mehrab Mehrvar2*, Edgar Quiñones-Bolaños ${ }^{3}$ \\ ${ }^{1}$ Grad Programs in Environmental Applied Science and Management, Ryerson University, Toronto, Canada \\ ${ }^{2}$ Department of Chemical Engineering, Ryerson University, Toronto, Canada \\ ${ }^{3}$ Environmental Modeling Research Group, University of Cartagena, Cartagena de Indias, Colombia \\ Email:mmehrvar@ryerson.ca
}

Received 21 February 2016; accepted 26 April 2016; published 30 April 2016

\begin{abstract}
The characteristics of the slaughterhouse effluents and current wastewater treatment practices in the province of Ontario, Canada are analyzed. Meat processing plants are found to produce large amounts of wastewater due to the slaughtering process and cleaning of their facilities. Furthermore, the composition of the wastewater varies according to the type and number of animals slaughtered and the water requirements of the process. However, the slaughterhouse wastewater usually contains high levels of organics and nutrients. Several slaughterhouses in Ontario discharge their wastewater into the municipal sewer system after primary pretreatment at the meat processing plant. Therefore, due to the high-strength characteristics of the slaughterhouse effluents, an extensive treatment for a safe discharge into the environment is required. Thus, the combination of biological processes and advanced oxidation technologies for slaughterhouse wastewater treatment is evaluated in this study. Results show that the application of combined biological and advanced oxidation processes is recommended for on-site slaughterhouse wastewater treatment.
\end{abstract}

Keywords

Slaughterhouse Wastewater, Anaerobic Digestion, Activated Sludge, Advanced Oxidation Processes

\section{Introduction}

The treatment of water and wastewater has become crucial due to the continuous growth of world population "Corresponding author.

How to cite this paper: Bustillo-Lecompte, C., Mehrvar, M. and Quiñones-Bolaños, E. (2016) Slaughterhouse Wastewater Characterization and Treatment: An Economic and Public Health Necessity of the Meat Processing Industry in Ontario, Canada. Journal of Geoscience and Environment Protection, 4, 175-186. http://dx.doi.org/10.4236/gep.2016.44021 


\title{
Appendix E. Abstract reprint from J. Environ. Manage. (2016), In Press.
}

Research article

\section{Treatment of an actual slaughterhouse wastewater by integration of biological and advanced oxidation processes: Modeling, optimization, and cost-effectiveness analysis}

\author{
Ciro Fernando Bustillo-Lecompte a , Mehrab Mehrvar ${ }^{\text {b, * }}$ \\ ${ }^{a}$ Graduate Programs in Environmental Applied Science and Management, Ryerson University, 350 Victoria Street, Toronto, ON M5B 2K3, Canada \\ ${ }^{\mathrm{b}}$ Department of Chemical Engineering, Ryerson University, 350 Victoria Street, Toronto, ON M5B 2K3, Canada
}

\section{A R T I C L E I N F O}

Article history:

Received 3 June 2016

Received in revised form

13 July 2016

Accepted 14 July 2016

Available online $\mathrm{xxx}$

\section{Keywords:}

Slaughterhouse wastewater

Anaerobic digestion

Activated sludge

Advanced oxidation processes

Process optimization

Combined processes

\begin{abstract}
A B S T R A C T
Biological and advanced oxidation processes are combined to treat an actual slaughterhouse wastewater (SWW) by a sequence of an anaerobic baffled reactor, an aerobic activated sludge reactor, and a $\mathrm{UV} / \mathrm{H}_{2} \mathrm{O}_{2}$ photoreactor with recycle in continuous mode at laboratory scale. In the first part of this study, a quadratic modeling along with response surface methodology is used for the statistical analysis and optimization of the combined process. The effects of the influent total organic carbon (TOC) concentration, the flow rate, the $\mathrm{pH}$, the inlet $\mathrm{H}_{2} \mathrm{O}_{2}$ concentration, and their interaction on the overall treatment efficiency, $\mathrm{CH}_{4}$ yield, and $\mathrm{H}_{2} \mathrm{O}_{2}$ residual in the effluent of photoreactor are investigated. The models are validated at different operating conditions using experimental data. Maximum TOC and total nitrogen (TN) removals of 91.29 and $86.05 \%$, maximum $\mathrm{CH}_{4}$ yield of $55.72 \%$, and minimum $\mathrm{H}_{2} \mathrm{O}_{2}$ residual of $1.45 \%$ at the photoreactor effluent were found to be optimal conditions. In the second part of this study, continuous distribution kinetics is applied to establish a mathematical model for the degradation of SWW as a function of time. The agreement between model predictions and experimental values indicates that the proposed model could describe the performance of the combined anaerobic-aerobic $-\mathrm{UV} / \mathrm{H}_{2} \mathrm{O}_{2}$ processes for the SWW treatment. In the final part of the study, the optimized combined anaerobic-aerobic-UV/ $/ \mathrm{H}_{2} \mathrm{O}_{2}$ processes with recycle were evaluated using a cost-effectiveness analysis to minimize the retention time, the electrical energy consumption, and the overall incurred treatment costs required for the efficient treatment of slaughterhouse wastewater effluents.
\end{abstract}

(c) 2016 Elsevier Ltd. All rights reserved.

\section{Introduction}

Slaughterhouse wastewater (SWW) effluents are becoming one of the major agribusiness concerns because of the elevated amounts of water used during slaughtering, processing, and cleaning of the abattoir facilities. Although physical, chemical, and biological treatment can be used for SWW degradation, each treatment process has different benefits and drawbacks depending on the SWW characteristics, best available technology, jurisdictions, and regulations (Tabrizi and Mehrvar, 2004; Barrera et al. 2012; Franke-Whittle and Insam, 2013; Bustillo-Lecompte and Mehrvar, 2015; Valta et al., 2015; Bustillo-Lecompte et al., 2015 2016a, 2016b). However, adopting combined processes for SWW

\footnotetext{
* Corresponding author.

E-mail address: mmehrvar@ryerson.ca (M. Mehrvar).
}

treatment is considered operationally and economically advantageous because it incorporates and optimizes the advantages of different technologies to achieve high-quality effluents from industrial and high-strength wastewaters (Kurian et al., 2006; Mehrvar and Tabrizi, 2006; De Nardi et al., 2011; BustilloLecompte et al., 2013, 2014; Bustillo-Lecompte and Mehrvar, 2015; Mowla et al., 2014).

Anaerobic treatment is the preferred biological treatment because of its effectiveness in treating high-strength wastewater such as SWW with less complex equipment requirements. Nevertheless, anaerobically treated effluents of SWW require posttreatment to comply with required discharge limits (Cao and Mehrvar, 2011; Bustillo-Lecompte et al., 2013, 2014). Therefore, aerobic treatment systems are more frequently used in wastewater treatment since they operate at higher rates than conventional anaerobic treatment methods in the case of lower strength wastewaters. Taking into account that oxygen requirements and 


\section{Appendix F. Provincially licensed meat plants in Ontario.}

(Adopted from OMAFRA, 2016).

\begin{tabular}{|c|c|c|c|c|c|c|}
\hline $\begin{array}{l}\text { Plant Name } \\
\end{array}$ & Address & City & Postal Code & Website & E-mail & Fax \\
\hline A.S. Poultry & 7611 Kimbo Road & Smithville & LOR 2A0 & & & \\
\hline Abate Packers & 7597 Jones Baseline & Arthur & N0G 1A0 & http://www.abatepackers.com/ & info@abatepackers.com & $\begin{array}{l}519-848- \\
2793\end{array}$ \\
\hline Abattoir Brisson Ltd & 1100 St. André & Embrun & K0A 1W0 & & & \\
\hline Abattoir LeFaivre & 122 County Rd 15 & Lefaivre & K0B 1J0 & & & \\
\hline $\begin{array}{l}\text { Abattoir LeFaivre Meat } \\
\text { Abattoir LeFaivre Meat \& }\end{array}$ & 2100 Cholette St & Lefaivre & K0B 1J0 & & & $\begin{array}{l}613-524- \\
5371\end{array}$ \\
\hline Slaughterhouse & 2123 Joseph St, Lefaivre & Alfred & K0B 1A0 & & & \\
\hline Agram 2005 Meats Inc. & 10676 Trafalgar Road & Georgetown & L7G 4S5 & http://www.agrammeats.com/ & & $\begin{array}{l}905-877- \\
5120\end{array}$ \\
\hline Al Madina Halal Meat Packers & 3944 Carman Road & Brinston & $\mathrm{K} 0 \mathrm{E} 1 \mathrm{C} 0$ & & & \\
\hline Al Madina Halal Meat Packers & 2875 Lawrence Ave E & Toronto & M1P 2S8 & & babowath@hotmail.com & \\
\hline Al Madina Halal Meat Packers & $\begin{array}{l}799 \text { Brimley Rd } \\
286 \text { Main Street, PO Box }\end{array}$ & Toronto & M1J 1C9 & & & \\
\hline Aman's Abattoir & $\begin{array}{l}177 \\
556 \text { Birch Lake Road, RR }\end{array}$ & Wellington & $\mathrm{K} 0 \mathrm{~K} 3 \mathrm{~L} 0$ & http://www.amansabattoir.com/ & & \\
\hline Amos Weber & 3 & Massey & P0P 1P0 & & & \\
\hline Amos Weber & 405 Erb St W & Waterloo & N2L 1W7 & & & \\
\hline Athens Meat Packers & 63 Addison Road & Athens & K0E 1B0 & & & $\begin{array}{l}0958 \\
519-887-\end{array}$ \\
\hline Bachert Meats Inc. (2006) & $\begin{array}{l}43181 \text { Blyth Road, RR } 1 \\
7470 \text { Essex County Road }\end{array}$ & Walton & NOK $1 Z 0$ & & & $\begin{array}{l}9971 \\
519-726-\end{array}$ \\
\hline Barron Poultry Limited & 18 & Amherstburg & N9V 2 Y7 & & & 6839 \\
\hline Bearbrook Farm Abattoir & 5070 Herbert Drive & Navan & K4B 1J1 & & & \\
\hline Bearbrook Farm Abattoir & 8411 Russell Road, RR3 & Navan & K4B 1J1 & & & \\
\hline Bearbrook Games Meats Inc & 5396 Dunning Rd & Navan & K4B 1J1 & http://bearbrookgamemeats.com/ & info@bearbrookfarm.com & \\
\hline Beeton Meats & $\begin{array}{l}233 \text { Patterson Street North, } \\
\text { PO Box } 208\end{array}$ & Beeton & L0G $1 \mathrm{~A} 0$ & & & $\begin{array}{l}705-458- \\
4630 \\
705-563-\end{array}$ \\
\hline Belle Vallé Meats and Abattoir & 982125 Belle Valle Road & $\begin{array}{l}\text { Belle Valle } \\
\text { New }\end{array}$ & P0J 1M0 & & & 2403 \\
\hline Belle Vallé Meats and Abattoir & 6 Concession Casey TWSP & Liskeard & P0J 1P0 & & & \\
\hline Bennett Abattoir & 1984 Hwy, 572 & Ramore & P0K 1R0 & & & \\
\hline Bennett Abattoir & 2 Con Hislop & Ramore & P0K 1R0 & & & \\
\hline Bentinck Packers Limited & $\begin{array}{l}381488 \text { Concession } 4 \\
\text { NDR, RR } 3\end{array}$ & Hanover & N4N 3B9 & http://www.bentinckpackers.ca/ & * Use the website & $\begin{array}{l}519-364- \\
0898 \\
613-989-\end{array}$ \\
\hline Berube Poultry & 10135 McIntyre Road RR3 & $\begin{array}{l}\text { Mountain } \\
\text { Clarence }\end{array}$ & K0E 1S0 & & & 2020 \\
\hline Bilal Farms Inc. & 1924 Landry St & Creek & K0N 1NO & http://www.bilalfarms.com/ & wzazay@hotmail.com & \\
\hline Bilal Farms Inc. & 47 Farmfield Crescent & Kanata & K2M 2S8 & & & \\
\hline Bill's Turkey Farm Ltd. & 2978 Holborn Rd. & Queensville & L0G 1R0 & http://www.billsturkeyfarm.com/ & & \\
\hline Bismillah Halal Meats & 3176 Ridgeway Drive & Mississauga & L5L 5S6 & & & \\
\hline Bismillah Meats & 3900 Elginfield Road & Parkhill & NOM 2 K0 & & & \\
\hline Bismillah Meat Market & 1725 Kingston $\mathrm{Rd}$ & Pickering & L1V 4L9 & & & \\
\hline
\end{tabular}




\begin{tabular}{|c|c|c|c|c|c|c|}
\hline $\begin{array}{r}\text { Plant Name } \\
\end{array}$ & Address & City & Postal Code & Website & E-mail & Fax \\
\hline Blackwater Meats & 1255 Durham Road 13 & Sunderland & L0C 1H0 & & & 510864 \\
\hline Bluewater Beef & 1 & Mooretown & NON 1M0 & http://www.bluewaterbeef.com/ & info@bluewaterbeef.com & 4030 \\
\hline Bluewater Beef & 2873 Kimball Rd & Courtright & NON $1 M 0$ & ralphandbrenda@bluewaterbeef.com & murrayandsandi@bluewaterbeef.com & \\
\hline Brennan Poultry & 7109 Mosside Line & Alvinston & NON $1 A 0$ & http://brennanpoultry.com/ & brennanpoultry@msn.ca & \\
\hline $\begin{array}{l}\text { Brian Quinn's Meat Ltd. } \\
\text { Buchler Farms and Abattoir } \\
\text { Cargill Foods Toronto }\end{array}$ & $\begin{array}{l}3987 \text { County Rd. \#1, RR } 2 \\
186 \text { Horner Rd. } \\
71 \text { Rexdale Blvd }\end{array}$ & $\begin{array}{l}\text { Yarker } \\
\text { Magnetawan } \\
\text { Toronto }\end{array}$ & $\begin{array}{l}\text { K0K 3N0 } \\
\text { P0A 1P0 } \\
\text { M9W 1P1 }\end{array}$ & http://www.quinnsmeats.com/ & * Use the website & $\begin{array}{l}613-377- \\
1520\end{array}$ \\
\hline $\begin{array}{l}\text { Cargill Meat Solutions } \\
\text { Cargill Meat Solutions } \\
\text { Cedarview Farms }\end{array}$ & $\begin{array}{l}165 \text { Dunlop Drive } \\
180 \text { Watson Pkwy S } \\
3028 \text { Kimball Rd }\end{array}$ & $\begin{array}{l}\text { Guelph } \\
\text { Guelph } \\
\text { Courtright }\end{array}$ & $\begin{array}{l}\text { N1L 1P4 } \\
\text { N1L 1P4 } \\
\text { N0N 1H0 }\end{array}$ & $\frac{\text { http://www.cargill.ca/ }}{\text { http://www.cargill.ca/ }}$ & $\begin{array}{l}\text { rick_mcclure@ cargill.com } \\
\text { customer.care@betterbeef.ca } \\
\text { info@cedarviewfarms.org }\end{array}$ & $\begin{array}{l}519-823- \\
5451\end{array}$ \\
\hline Champagne Poultry Inc. & 18-30 Titan Rd & Toronto & M8Z 5 Y2 & $\underline{\text { http://goo.gl/7IM4Lz }}$ & http://goo.gl/iR5VrV & $\begin{array}{l}416-233- \\
3067 \\
519-747-\end{array}$ \\
\hline Charles Quality Meats & 1448 Wilby Road, RR 1 & Wilmot & NOB $2 \mathrm{LO}$ & & & 3663 \\
\hline Charles Quality Meats & 1476 Wilby Rd. & St. Agatha & NOB $2 \mathrm{LO}$ & & & \\
\hline Charlies Meats & 61 Skagway Ave & Toronto & M1M 3 T9 & http://www.charliesmeat.com/ & $\begin{array}{l}\text { info@charliesmeat.com } \\
\text { webmaster@charliesmeat.com }\end{array}$ & $\begin{array}{l}416-261- \\
2267\end{array}$ \\
\hline Clement Poultry \& Sons & $\begin{array}{l}85 \text { Lovekin Road, RR8 } \\
134 \text { Old Milford Rd, RR 9, }\end{array}$ & Newcastle & L1B 1L9 & & & \\
\hline Cole Bros. Meat Processing & PO Box 538 & Picton & K0K 2T0 & & & \\
\hline Cornell Meats & 7086 Pack Road & London & N6P 1M1 & & & \\
\hline $\begin{array}{l}\text { Corsetti Meat Packer Limited } \\
\text { Country Meadow Meats }\end{array}$ & $\begin{array}{l}2255 \text { St Clair Ave W } \\
122242 \text { Sideroad } 12 \text { RR } 3\end{array}$ & $\begin{array}{l}\text { Toronto } \\
\text { Owen Sound }\end{array}$ & $\begin{array}{l}\text { M6N 1K8 } \\
\text { N4K 5N5 }\end{array}$ & & & $\begin{array}{l}416-762- \\
4465\end{array}$ \\
\hline Country Meat Packing Ltd (CMP & 122242 Sideroad 12, RR 3 & Owen Sound & N4K 5N5 & http://www.countrymeadowmeats.com/ & pondwillow@bmts.com & $519-622-$ \\
\hline $\begin{array}{l}\text { Meats) } \\
\text { Country Meat Packing Ltd (CMP }\end{array}$ & 1188 Hwy 8 , RR 1 & Dundas & L9H 5E1 & http://www.countrymeatpacking.com/ & albert@countrymeatpacking.com & 5306 \\
\hline Meats) & 2255 St Clair Ave W & Toronto & M6N 1K8 & tony@countrymeatpacking.com & ron@ countrymeatpacking.com & \\
\hline Country Poultry Processing & 7707 Fourth Line, RR 2 & Wallenstein & NOB 2S0 & & & \\
\hline Country Poultry Processing & 7705 Fourth Line & Wallenstein & NOB $2 A 0$ & & & \\
\hline Creative Meats & 7437 Hwy 17 East, RR 1 & Warren & $\mathrm{POH} 2 \mathrm{NO}$ & & creative_meats@hotmail.com & $\begin{array}{l}705-967- \\
2643 \\
905-562-\end{array}$ \\
\hline CRO Quail Farms Inc. & 3625 Sixteen Road & St. Ann's & LOR $1 Y 0$ & http://www.croquail.com/contact.htm & croquail@gmail.com & 6999 \\
\hline Dean Butcher Shop & $\begin{array}{l}30 \text { Dean Park Rd } \\
1 \text { Queen Street, PO Box }\end{array}$ & Toronto & M1B 5S6 & & & \\
\hline Desormeaux Meats Incorporated & 112 & Crysler & K0A 1R0 & & jeanguydesormeaux@gmail.com & \\
\hline Dickenson Farms & $\begin{array}{l}3383 \text { Oil Springs Line } \\
7396 \text { W Garafraxa 3rd }\end{array}$ & Brigden & NON 1B0 & http://www.dickensonfarms.com/ & joe@dickensonfarms.com & $519-848-$ \\
\hline Domingos Meat Packers Ltd. & Line, RR 3 & Arthur & N0G 1A0 & $\frac{\text { http://www.domingosmeatpackers.com/ }}{\text { brian@domingosmeatpackers.com }}$ & $\frac{\text { company@domingosmeatpackers.com }}{\text { horacio@domingosmeatpackers.com }}$ & 5884 \\
\hline Doug's Meats & $\begin{array}{l}\text { Concession Road 10, RR } 3 \\
78 \text { Hwy, } 10210 \text { McCreary }\end{array}$ & Schomberg & L0G 1T0 & & & $519-683-$ \\
\hline Dresden Meat Packers Limited & Line, RR 2 & Dresden & NOP $1 \mathrm{M} 0$ & http://www.dresdenmeatpackers.com/ & * Use the website & 4558 \\
\hline Dresden Meat Packers Limited & $195 \mathrm{PK} \mathrm{St}$ & Dresden & NOP 1M0 & & & \\
\hline Dundalk Poultry Processing & 126815 Southgate Road 12 & Dundalk & NOC 1B0 & & & \\
\hline Dundalk Poultry Processing & 126715 Southgate Road 12 & Dundalk & NOC 1B0 & & & \\
\hline Dundalk Poultry Processing & 126715 Conc 8 & Dundalk & NOC 1B0 & & & \\
\hline
\end{tabular}




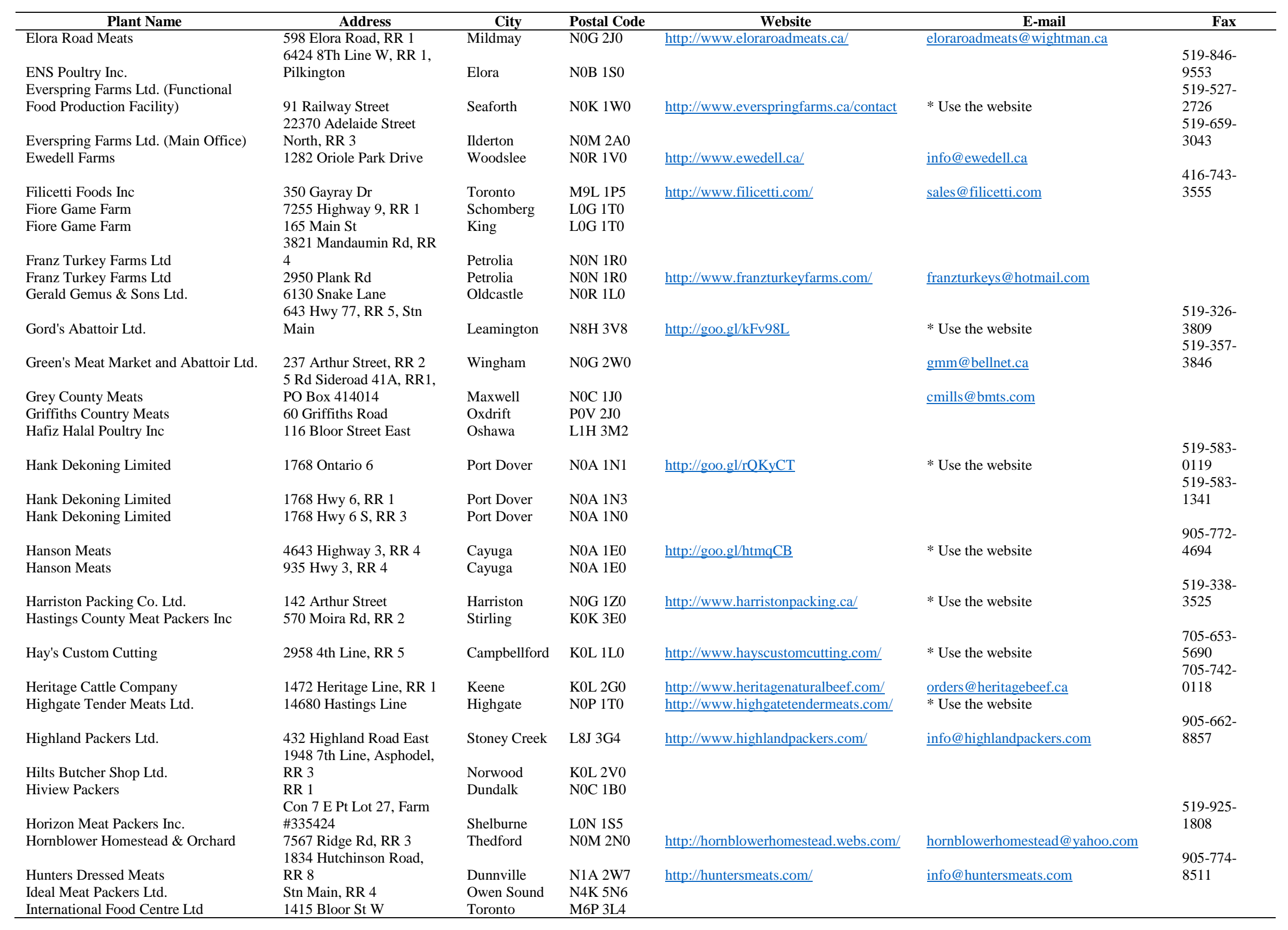




\begin{tabular}{|c|c|c|c|c|c|c|}
\hline $\begin{array}{c}\text { Plant Name } \\
\end{array}$ & Address & City & Postal Code & Website & E-mail & Fax \\
\hline International Food Centre Ltd & 1415 Bloor St W & Owen Sound & N4K 5N6 & & & \\
\hline International Food Centre Ltd & 3570 Wolfedale Rd & Mississauga & L5C 2 V6 & & & \\
\hline J Meat Distributing Inc. & $\begin{array}{l}14600 \text { Concession Rd } 10 \\
14600 \text { Concession Rd 10, }\end{array}$ & Nobleton & L0G 1N0 & http://goo.gl/j3bNQw & $*$ Use the website & $\begin{array}{l}416-425- \\
3792\end{array}$ \\
\hline J Meat Distributing Inc. & RR 3 & Schomberg & L0G $1 \mathrm{~T} 0$ & & & \\
\hline J.R. Meats & $\begin{array}{l}275 \text { Frankford Road, RR } 1 \\
\text { C.P. } 28 \text { - } 113 \text { Rue }\end{array}$ & Foxboro & K0K 2B0 & & & \\
\hline Joe Savage \& Fils Abattoir Inc. & Principale & St-Albert & $\mathrm{K} 0 \mathrm{~A} 3 \mathrm{C} 0$ & & & \\
\hline Joe Savage \& Fils Abattoir Inc. & 1461 Route 900 West & St-Albert & $\mathrm{K} 0 \mathrm{~A} 3 \mathrm{C} 0$ & & benoitsavage@hotmail.com & \\
\hline Johnson Meats & $\begin{array}{l}49801 \text { Glen Colin Line, } \\
\text { RR } 4\end{array}$ & Aylmer & N5H 2R3 & & & $\begin{array}{l}519-773- \\
9508 \\
905-957-\end{array}$ \\
\hline Julius Meat Packers Inc. & 2340 Patterson Road, RR 1 & St. Ann's & LOR $1 Y 0$ & & & 5986 \\
\hline Kam Li Food Co Ltd & 229 Broadview Ave & Toronto & M4M 2G7 & & & \\
\hline $\begin{array}{l}\text { KC Meat International Import Brokers } \\
\text { (1243275 Ontario Inc) }\end{array}$ & $\begin{array}{l}33 \text { Terry Dr } \\
18347 \text { Warden Avenue, }\end{array}$ & Toronto & M6N 3T4 & & & $\begin{array}{l}416-769- \\
7961\end{array}$ \\
\hline King Capon Ltd. & Box 353 & Sharon & L0G 1 V0 & http://www.kingcapon.com/ & * Use the website & \\
\hline King Cole Ducks Ltd. & 15336 Warden Avenue & Stouffville & L4G 3H3 & gwhite@kingcoleducks.com & mmoerat@kingcoleducks.com & \\
\hline King Cole Ducks Ltd. & 15351 Warden Avenue & Newmarket & L3Y4W1 & http://www.kingcoleducks.com/ & pthompson@kingcoleducks.com & $\begin{array}{l}905-836- \\
4440\end{array}$ \\
\hline King Cole Ducks Ltd. & $\begin{array}{l}15336 \text { Warden Avenue } \\
1150 \text { Regional Road 27, }\end{array}$ & Newmarket & L3Y4W1 & dconzelmann@kingcoleducks.com & rgrant@kingcoleducks.com & \\
\hline Kingma Meat Products Limited & RR 2 & St. Ann's & L0R 1Y0 & & & \\
\hline Kretschmar Inc & 71 Curlew Drive & Toronto & M3A2P8 & http://www.kretschmar.com/ & info@kretschmar.com & $\begin{array}{l}416-441- \\
3386 \\
613-675-\end{array}$ \\
\hline L'Orignal Packing Ltd & 2567 Route 17 & L'Orignal & K0B 1 K0 & $\begin{array}{l}\text { http://www.lorignalpacking.ca/ } \\
\text { christine@ lorignalpacking.ca }\end{array}$ & $\begin{array}{l}\text { general@ lorignalpacking.ca } \\
\text { order@1 lorignalpacking.ca }\end{array}$ & 2900 \\
\hline L \& M Meat Distributing & $\begin{array}{l}2487 \text { 14th Line } \\
5814 \text { Minielly Road, RR 2, }\end{array}$ & Gilford & LOL 1R0 & http://www.landmmeats.com/ & contact@landmmeats.com & \\
\hline Lambton Meat Products & PO Box 268 & Wyoming & N0N 1 T0 & & & \\
\hline $\begin{array}{l}\text { Laplante Poultry Farms Ltd } \\
\text { Laplante Poultry Farms Ltd/Ferme }\end{array}$ & 3105 Dunning Rd & Ottawa & K4B 1J1 & & & \\
\hline Avicole Laplante Ltée & 17141 Rombough Road & Monkland & K0C 1V0 & & & \\
\hline Len \& Patti Butcher Block & 2133 Little Britain Road & Lindsay & $\mathrm{K} 9 \mathrm{~V} 4 \mathrm{R} 2$ & & & 9100 \\
\hline Lena's Lamb & 2627 McCallum Line & Wilkesport & NOP 2R0 & http://www.lenaslamb.com/ & lenaslamb@gmail.com & \\
\hline Lindsay Zabiha Meat Packer & S 1255 Durham Road \#13 & Sunderland & LOC $1 \mathrm{H} 0$ & & & \\
\hline Lindsay Zabiha Meat Packer & 1094 Danforth Ave & Toronto & M4J 1M2 & & & \\
\hline Little Britain Meat Packers (2012) & 917 Little Britain Rd, RR 2 & Little Britain & $\mathrm{K} 0 \mathrm{M} 2 \mathrm{C} 0$ & http://littlebritainmeatpackers.com/ & $\begin{array}{l}\text { vgreco@littlebritainmeatpackers.com } \\
\text { inquiries@ littlebritainmeatpackers.com }\end{array}$ & $\begin{array}{l}705-786- \\
9972\end{array}$ \\
\hline Lloyd Miedema \& Sons & $\begin{array}{l}1812 \text { Thompson Road } \\
\text { East, RR } 5 \\
1142 \text { Reidsville Road, RR }\end{array}$ & Waterford & NOE 1 Y0 & & & $\begin{array}{l}519-443- \\
4170 \\
519-632-\end{array}$ \\
\hline Louro Bros. Meats Ltd. & $\begin{array}{l}1 \\
4510 \text { Hwy 6, RR 3, PO }\end{array}$ & Ayr & N0B 1E0 & & & $\begin{array}{l}8634 \\
905-768-\end{array}$ \\
\hline Lowbank Farms Ltd. & $\begin{array}{l}\text { Box } 786 \\
282 \text { Escott Rockport Rd, }\end{array}$ & Hagersville & N0A $1 \mathrm{H} 0$ & & & 0313 \\
\hline Lynch's Slaughterhouse & RR 2 & Mallorytown & K0E 1R0 & & & \\
\hline
\end{tabular}




\begin{tabular}{|c|c|c|c|c|c|c|}
\hline $\begin{array}{r}\text { Plant Name } \\
\end{array}$ & $\begin{array}{c}\text { Address } \\
\end{array}$ & City & Postal Code & Website & E-mail & Fax \\
\hline Lynch's Slaughterhouse & 34 Holland Road, RR 1 & Mallorytown & K0E 1R0 & & & \\
\hline Lynch's Slaughterhouse & 32 Holland Road, RR 1 & Lansdowne & K0E 1L0 & & & \\
\hline Macgregors Meat Seafood Ltd & 265 Garyray Dr & Toronto & M9L 1P2 & $\underline{\text { http://www.macgregors.com/ }}$ & $\frac{\text { angela@ macgregors.com }}{\text { john@macgregors.com }}$ & $\begin{array}{l}888-584- \\
3663\end{array}$ \\
\hline Manilla Halal Meats & 18619 Simcoe St, RR 2 & $\begin{array}{l}\text { Oakwood } \\
\text { Richmond }\end{array}$ & K0M 2M0 & & paul@macgregors.com & \\
\hline $\begin{array}{l}\text { Manilla Halal Meats } \\
\text { Manitoulin Island Community Abattoir }\end{array}$ & 9218 Yonge St & $\begin{array}{l}\text { Hill } \\
\text { Providence }\end{array}$ & L4C 7A2 & & & \\
\hline Inc. & 3120 Monument Road & Bay & P0P $1 \mathrm{~T} 0$ & & & \\
\hline $\begin{array}{l}\text { Maple Leaf Foods Cappola Cartwright } \\
\text { Maple Leaf Foods Cappola Lepage } \\
\text { Maple Leaf Foods Inc } \\
\text { Maple Leaf Foods Inc }\end{array}$ & $\begin{array}{l}92 \text { Cartwright Ave } \\
\text { 25 Lepage Ct } \\
\text { 100 Ethel Avenue } \\
\text { 550 Kipling Avenue } \\
\text { 30 St Clair Ave W, Suite }\end{array}$ & $\begin{array}{l}\text { Toronto } \\
\text { Toronto } \\
\text { Toronto } \\
\text { Toronto }\end{array}$ & $\begin{array}{l}\text { M6A 1V2 } \\
\text { M3J 3M3 } \\
\text { M6N 4Z7 } \\
\text { M8Z 5E9 }\end{array}$ & http://www.mapleleaffoods.com/ & $\begin{array}{l}\text { * Use the website } \\
\text { sales@cappolafood.com }\end{array}$ & $\begin{array}{l}416-787- \\
1535\end{array}$ \\
\hline $\begin{array}{l}\text { Maple Leaf Foods Inc } \\
\text { Mastro Foods Holdings Ltd }\end{array}$ & $\begin{array}{l}1500 \\
353 \text { Humberline Drive } \\
3515 \text { Albion Rd S, }\end{array}$ & $\begin{array}{l}\text { Toronto } \\
\text { Toronto }\end{array}$ & $\begin{array}{l}\text { M4V 3A1 } \\
\text { M9W 5X3 }\end{array}$ & & & \\
\hline $\begin{array}{l}\text { Matar Kabob House and Meat Shop } \\
\text { Matar Meat Shop } \\
\text { Matar Meat Shop } \\
\text { Matar Meats }\end{array}$ & $\begin{array}{l}\text { Gloucester } \\
1077 \text { Cyrville Road } \\
2527 \text { Bank St } \\
2690 \text { Stagecoach Rd, RR 1 }\end{array}$ & $\begin{array}{l}\text { Ottawa } \\
\text { Ottawa } \\
\text { Ottawa } \\
\text { Osgoode }\end{array}$ & $\begin{array}{l}\text { K1T 1P1 } \\
\text { K1J 7S6 } \\
\text { K1V 8R9 } \\
\text { K0A 2W0 }\end{array}$ & http://matarmeatshopkabobhouse.ca/ & & \\
\hline Mcgarroch of Micksburg Custom & & & & & & $613-732-$ \\
\hline Butchering & 2749 Micksburg Rd., RR 3 & Pembroke & K8A 6W4 & & & 7181 \\
\hline Meat Express & $\begin{array}{l}\text { 2-328 Passmore Ave } \\
\text { RR } 1,90936 / 7\end{array}$ & Toronto & M1V 3N8 & & & 705-466- \\
\hline Metheral Meats & Nottawasaga Side Rd. & Glen Huron & LOM 1L0 & & & 3135 \\
\hline Metheral Meats & 9093 Township Rd 6 \& 7 & Glen Huron & LOM 1L0 & & & \\
\hline Metheral Meats & Dunedin & Creemore & L0M 1G0 & & & \\
\hline Metheral Meats & $\begin{array}{l}34 \text { Caroline St W } \\
180 \text { Brock Avenue, Box }\end{array}$ & Creemore & L0M 1G0 & & & \\
\hline Metzger Meat Products & 514 & Hensall & NOM $1 X 0$ & http://www.metzgermeats.com/ & info@metzgermeats.com & \\
\hline Miedema's Country Meats & 41130 Thames Road East & Exeter & N0M 1S5 & & & \\
\hline Miedema's Meat Market Ltd & 129 Huron Street & Embro & NOJ $1 \mathrm{~J} 0$ & & & $\begin{array}{l}519-4 / 5- \\
4790 \\
705-362\end{array}$ \\
\hline Miky's Smoke House & 30 Hamann Road & Hearst & P0L 1N0 & http://www.mikyssmokehouse.ca/ & mikys@ntl.sympatico.ca & $\begin{array}{l}8433 \\
905-689\end{array}$ \\
\hline Millgrove Packers Limited & 549 Conc. 5 W., RR 2 & Waterdown & LOR $2 \mathrm{H} 2$ & & & 6272 \\
\hline Mogk's Butcher Shop & 516702 East Zorra, RR 2 & Tavistock & N0B 2R0 & & & \\
\hline $\begin{array}{l}\text { Morrison Custom Poultry Processing } \\
\text { Ltd. }\end{array}$ & $\begin{array}{l}3711 \text { Lindsay Highway, } \\
\text { RR } 3\end{array}$ & Omemee & K0L 2W0 & & & \\
\hline Mount Brydges Abattoir Ltd. & $\begin{array}{l}21618 \text { Adelaide Road, RR } \\
1 \\
223 \text { Mcwatty Road, Po }\end{array}$ & $\begin{array}{l}\text { Mount } \\
\text { Brydges }\end{array}$ & NOL 1 W0 & & & $\begin{array}{l}519-264- \\
2217\end{array}$ \\
\hline $\begin{array}{l}\text { Mr. Beef } \\
\text { N \& H Food Co Limited } \\
\text { Newmarket Meat Packers Ltd. }\end{array}$ & $\begin{array}{l}\text { Box } 51 \\
2-125 \text { Union St } \\
3491 \text { Highway } 89\end{array}$ & $\begin{array}{l}\text { Pakenham } \\
\text { Toronto } \\
\text { Cookstown }\end{array}$ & $\begin{array}{l}\text { K0A 2X0 } \\
\text { M6N 3N4 } \\
\text { L0L 1L0 }\end{array}$ & $\begin{array}{l}\text { http://www.mrbeefstore.com/ } \\
\text { http://www.nguyenhuong.ca/ }\end{array}$ & $\begin{array}{l}* \text { Use the website } \\
* \text { Use the website }\end{array}$ & \\
\hline Newmarket Meat Packers Ltd. & 15452 Warden Ave. & Newmarket & L3Y 9E5 & http://goo.gl//356OI & * Use the website & $\begin{array}{l}905-836- \\
9357\end{array}$ \\
\hline
\end{tabular}




\begin{tabular}{|c|c|c|c|c|c|c|}
\hline $\begin{array}{l}\text { Plant Name } \\
\end{array}$ & Address & City & Postal Code & Website & E-mail & Fax \\
\hline Niagara Sausage \& Meat Products & & & & & & 905-734- \\
\hline Limited & 40 Ridge Road, RR 4 & Welland & L3B 5N7 & http://niagarasausage.com/ & & 3948 \\
\hline Norfolk Packers & $\begin{array}{l}4051 \text { Lakeshore Road, RR } \\
2\end{array}$ & St. Williams & NOE $1 P 0$ & http://goo,gl/hZNsu8 & * Use the website & $\begin{array}{l}519-586- \\
7459\end{array}$ \\
\hline Northeast Meat Packers Ltd (Whitmore & & & & & & 705-325- \\
\hline Meat Packers Ltd) & 3765 Line 12 North, RR 2 & Coldwater & LOK 1E0 & & & 8511 \\
\hline Northern Meat Packers and Abattoir & 266 Mcfadden Line, PO & & & & & 705-723- \\
\hline Ltd. & Box 175 & Trout Creek & $\mathrm{POH} 2 \mathrm{LO}$ & & & $\begin{array}{l}5758 \\
705-782-\end{array}$ \\
\hline Northern Quality Meats Ltd. & 290 Deplonty Road & Bruce Mines & P0R 1C0 & & & $\begin{array}{l}0533 \\
519-468-\end{array}$ \\
\hline Norwich Packers Limited & 11 Robson Street & Norwich & NOJ $1 \mathrm{P} 0$ & http://www.norpacbeef.com/ & * Use the website & 2050 \\
\hline Oak Knoll Farms & 5754 3rd Line, RR 1 & Hillsburgh & NOB $1 Z 0$ & http://oakknollfarms.ca/ & * Use the website & \\
\hline Ontario Halal Meat Packers & 5593 Halton 25 & Milton & L9T 7E6 & & & \\
\hline Ontario Halal Meat Packers & 5593 Highway \#25 & Milton & L9T $2 X 5$ & & & $\begin{array}{l}905-875- \\
0370\end{array}$ \\
\hline $\begin{array}{l}\text { Ontario Lamb Company - A Division } \\
\text { of Newmarket Meat Packers }\end{array}$ & $\begin{array}{l}15452 \text { Warden Ave, RR } 3 \\
1120 \text { - } 100 \text { Conestoga }\end{array}$ & Newmarket & L3Y 4W1 & http://www.ontariolamb.ca/ & info@ontariolamb.ca & $\begin{array}{l}905-836- \\
9357 \\
519-748-\end{array}$ \\
\hline Ontario Turkey & $\begin{array}{l}\text { College Boulevard } \\
2043 \text { Drummond Line, RR }\end{array}$ & Kitchener & N2P $2 \mathrm{~N} 6$ & http://turkeyrecipes.ca/ & info@turkeyfarmers.on.ca & $\begin{array}{l}2742 \\
705-743-\end{array}$ \\
\hline Otonabee Meat Packers Ltd. & $\begin{array}{l}7 \\
2553 \text { River Street West, }\end{array}$ & Peterborough & K9J 6X8 & & & $\begin{array}{l}0998 \\
613-478-\end{array}$ \\
\hline Palmateer's Abattoir Ltd. & PO Box 484 & Tweed & K0K 3K0 & & & \\
\hline Peel Sausage Inc. & $\begin{array}{l}7860 \text { Sixth Line, RR } 2 \\
\text { Lot 6, Conc 5, Durham }\end{array}$ & Drayton & N0G 1P0 & & delmer@peelsausageinc.com & 3444 \\
\hline $\begin{array}{l}\text { Pine Ridge Packers (2003) } \\
\text { Pine Ridge Packers Inc \& Steak }\end{array}$ & Region & Scugog Twp & L0B $1 \mathrm{~B} 0$ & & & \\
\hline Heaven & 2910 7A Hwy & Blackstock & LOB 1B0 & & & \\
\hline Pine Ridge Packers (2003) & $\begin{array}{l}\text { Lot } 6 \text {, Conc } 5 \\
4311 \text { Mastwood Road, RR }\end{array}$ & Blackstock & LOB $1 \mathrm{~B} 0$ & & & 905-342- \\
\hline Prime Cut Meats & 3, Stn Main & Port Hope & L1A $3 \mathrm{~V} 7$ & & & $\begin{array}{l}1173 \\
905-871-\end{array}$ \\
\hline Prime Cut Specialty Meats & 310 Garrison Rd & Fort Erie & L2A $1 \mathrm{M} 7$ & http://www.primecutsdeliandmeats.com/ & & $\begin{array}{l}5477 \\
416-504-\end{array}$ \\
\hline Quality Meat Packers Limited & 1-2 Tecumseth St & Toronto & M5V 2R5 & http://www.legacypork.com/ & mmiller@qualitymeats.on.ca & $\begin{array}{l}3756 \\
613-377-\end{array}$ \\
\hline $\begin{array}{l}\text { Quinn's Brian Meats } \\
\text { Rainy River District Regional Abattoir }\end{array}$ & 3998 Country Road 1 E & Yarker & K0K 3N0 & http://www.quinnsmeats.com/ & * Use the website & 1520 \\
\hline Inc. & Box 299, 26 Byng Street & Emo & P0W 1E0 & & & \\
\hline Ralph Bos Meats Ltd. & 3742 Egremont Drive & Strathroy & N7G 3H6 & http://ralphbosmeats.ca/ & & \\
\hline Ranchland Meats Ltd. & 2021 Bruce Road \#3, RR 1 & Cargill & N0G 1J0 & & & \\
\hline Reiche Meat Products Ltd. & 38 B Line Rd & Pembroke & K8A 6W4 & & & \\
\hline $\begin{array}{l}\text { Reiche Meat Products Ltd. } \\
\text { Reist \& Weber Butchering Custom }\end{array}$ & 555 Reiche Rd., RR 3 & Pembroke & K8A 6W4 & & & \\
\hline Killing \& Whole Sales Pork & RR 1 & St. Jacobs & NOB 2 NO & & & \\
\hline Rideau Meats Ltd. & 12090 Hwy 15 N, RR 6 & Smith Falls & K7A 4S7 & & & \\
\hline Rua Meats Ltd. & 275 Frankford Road, RR 1 & Foxboro & K0K 2B0 & & & \\
\hline Russell Slaughter House & 424 Castor Street & Russell & K4R 1E5 & & & $\begin{array}{l}613-445- \\
2005\end{array}$ \\
\hline
\end{tabular}




\begin{tabular}{|c|c|c|c|c|c|c|}
\hline $\begin{array}{c}\text { Plant Name } \\
\end{array}$ & Address & City & Postal Code & Website & E-mail & Fax \\
\hline $\begin{array}{l}\text { Ryding-Regency Meat Packers Ltd } \\
\text { (Genesis Meat Packers Inc) }\end{array}$ & 70 Glen Scarlett Rd & Toronto & M6N 1P4 & http://www.rydingregency.com/ & info@rydingregency.com & $\begin{array}{l}416-767- \\
3249 \\
905-563-\end{array}$ \\
\hline Sanabil Halal Meat Farm & 5309 Spring Creek Road & Smithville & LOR 2A0 & http://goo.gl/ciLMVy & sanabill@live.com & 5401 \\
\hline Santa Maria Foods ULC & 10 Armthorpe Road & Brampton & L6T 5M4 & http://www.sharemastro.com/ & custsrv@smfulc.com & \\
\hline Santa Maria Foods ULC & 353 Humberline Drive & Toronto & M9W 5X3 & & & \\
\hline Sara's Natural Pork & 4922 LaSalle Line & Petrolia & N0N 1R0 & $\underline{\text { http://fieldfarms.ca/ }}$ & $\begin{array}{l}\text { info@fieldfarms.ca } \\
\text { info@ffmltd.ca }\end{array}$ & $\begin{array}{l}519-882- \\
3988\end{array}$ \\
\hline Sargent Farms Ltd. & 61 Garden Lane & Milton & L9T 2P7 & http://www.sargentfarms.ca/ & & $\begin{array}{l}905-878- \\
8998\end{array}$ \\
\hline Schefter Poultry Processing & $\begin{array}{l}44783 \text { Harriston Road } \\
193064 \text { Amaranth East, }\end{array}$ & Gorrie & N0G $1 X 0$ & & & \\
\hline Sheik Halal Farms Inc. & Luther Townline & Grand Valley & L9W 0M3 & & & \\
\hline Sheik Halal Farms Inc. & 12 Steinway Blvd Unit 18 & Toronto & M9W 6M5 & http://www.sheikhalal.com/ & sheik@sheikhalal.com & \\
\hline Smokey Joe's & 7949 Highway \#7 & Peterborough & K9J 6X3 & & & \\
\hline Springwater Packers & 9040 Springwater Rd, Rr 5 & Aylmer & N5H 2 R4 & & & \\
\hline Sprucedale Quality Meats Inc. & Rr 1, 438 Fourth Avenue & Sprucedale & P0A 1 Y0 & http://www.sprucedalemeats.com/ & $*$ Use the website & $\begin{array}{l}705-685- \\
7362\end{array}$ \\
\hline $\begin{array}{l}\text { St Ann's Foods Inc. } \\
\text { St. Helen's Meat Packers Limited }\end{array}$ & 145 Bethridge Rd & Toronto & M9W 1N4 & & & \\
\hline (Elbee Meat Packers Limited) & 706-208 Bloor St W & Toronto & M5S 3B4 & & & \\
\hline $\begin{array}{l}\text { St. Helen's Meat Packers Limited } \\
\text { (Elbee Meat Packers Limited) }\end{array}$ & 1-3 Glen Scarlett Rd & Toronto & M6N 1P5 & http://www.sthelensmeat.com/ & mail@sthelensmeat.com & $\begin{array}{l}416-769- \\
0649\end{array}$ \\
\hline Stayner Meat Packers Ltd. & $\begin{array}{l}352 \text { Warrington Road } \\
11544 \text { Northumberland }\end{array}$ & Stayner & L0M 1S0 & http://www.staynermeatpackers.com/ & staynermeatpackers@hotmail.ca & \\
\hline Taylor's Custom Meats & Rd. 29, $\operatorname{Rr} 4$ & Roseneath & $\mathrm{K} 0 \mathrm{~K} 2 \mathrm{X} 0$ & http://www.tcm.freewebspace.com/ & $\begin{array}{l}\text { taylorscustommeats@hotmail.com } \\
\text { haybon@eagle.ca }\end{array}$ & \\
\hline Tayyibat Meats Farm & $\begin{array}{l}8394 \text { Church Hill Road } \\
3099 \text { Broadway Street, PO }\end{array}$ & Alliston & L6R 1V1 & & & \\
\hline The Alvinston Butcher & Box 416 & Alvinston & N0N 1A0 & & & \\
\hline The Beef Way (1997) & 261 Dunharm St & Kincardine & $\mathrm{N} 2 \mathrm{Z} 2 \mathrm{X} 9$ & & & $\begin{array}{l}519-396- \\
5645\end{array}$ \\
\hline The Burt Farm & 1295 Tenth Line & Gore Bay & P0P 1H0 & http://goo.gl/J1iK9G & burtfarm@xplornet.com & \\
\hline The Chicken Coup & $\begin{array}{l}1302 \text { Garage Road } \\
500 \text { Exmouth Street, Unit }\end{array}$ & Burk's Falls & P0A1C0 & & & \\
\hline The Country Butcher/Lambton Meats & 13 & Sarnia & N7T 5P4 & & & \\
\hline Thunder Bay Meat Processing & & & & & & 807-935- \\
\hline Company (1986) Limited & 4754 Oliver Road, RR 1 & Murillo & P0T 2G0 & & & \\
\hline Tilbury Abattoir & 4049 Bonneau Line, RR 1 & Tilbury & NOP 2L0 & & & 2644 \\
\hline Tilbury Abattoir and Meats & $\begin{array}{l}17 \text { Superior St } \\
13200 \text { Mackenzie Rd., RR }\end{array}$ & Tilbury & NOP 2L0 & & & $613-448-$ \\
\hline Tom Henderson Custom Meat Cutting & 2 & Chesterville & K0C $1 \mathrm{H} 0$ & & & 3643 \\
\hline Town and Country Abattoir & 126 Steeles Ave W & Hornby & L0P 1E0 & & & \\
\hline Town and Country Farms & 13018 Steeles Avenue & Hornby & LOP 1E0 & & & \\
\hline Town and Country Meats and Abattoir & 19950 Hill Road & Ridgetown & NOP $2 \mathrm{CO}$ & & & \\
\hline Town and Country Meats and Abattoir & Hwy $21 \mathrm{~S}$ & Ridgetown & NOP $2 \mathrm{CO}$ & & & \\
\hline Townsend Butchers Inc. & 419 Conc. 14, RR 4 & Simcoe & N3Y 4K3 & http://goo.gl/Ofyicv & * Use the website & $\begin{array}{l}519-426- \\
9313 \\
519-542-\end{array}$ \\
\hline Uplands Pheasantry & 6282 Fleming Rd, RR 1 & Camlachie & NON 1E0 & http://uplands-pheasantry.ca/ & sales@uplands-pheasantry.ca & 2541 \\
\hline
\end{tabular}




\begin{tabular}{|c|c|c|c|c|c|c|}
\hline Plant Name & Address & City & Postal Code & Website & E-mail & Fax \\
\hline V. G. Packers Limited & $\begin{array}{l}966 \text { Woollen Mill Rd., RR } \\
5 \\
131 \text { Upper Centennial }\end{array}$ & Simcoe & N3Y 4K4 & http://www.vgmeats.ca/ & $*$ Use the website & $\begin{array}{l}519-426- \\
0063 \\
519-426-\end{array}$ \\
\hline V. G. Packers Limited & Parkway & $\begin{array}{l}\text { Stoney Creek } \\
\text { Blezard }\end{array}$ & L8J 0B2 & - & & 0063 \\
\hline Valley Poultry Packers & $\begin{array}{l}3134 \text { Main Street } \\
600 \text { Concession Rd 9, RR }\end{array}$ & Valley & P0M 1E0 & http://valleypoultry.org/ & webmaster@valleypoultry.org & 905-640- \\
\hline Valtoudis Meat Packers & 6 & Pickering & L1Y $1 \mathrm{~A} 3$ & & & 0389 \\
\hline Vanessa Meats \& Deli Inc. & $\begin{array}{l}1971 \text { Regional Road } 4 \\
963 \text { Old Durham Road, RR }\end{array}$ & Vanessa & NOE $1 \mathrm{~V} 0$ & http://www.vanessameatsinc.ca/ & john@vanessameatsinc.ca & \\
\hline Walkerton Meat Market & 2 & Walkerton & NOG 2 V0 & & & \\
\hline Walkerton Meat Market & 239 Durham St E & Walkerton & NOG 2 V0 & & & \\
\hline Wallace Beef Inc. & 3766 Hwy. 15 & Joyceville & K0H $1 \mathrm{Y} 0$ & & & $\begin{array}{l}613-536- \\
6499 \\
613-536-\end{array}$ \\
\hline Wallace Beef Inc. & 3505 Hwy 35, RR 3 & Odessa & $\mathrm{K} 0 \mathrm{H} 2 \mathrm{H} 0$ & & & $\begin{array}{l}6499 \\
807-937-\end{array}$ \\
\hline Wall's Pork Shop & 178 Wall St, PO Box 84 & Oxdrift & P0V 2J0 & & & 2457 \\
\hline Wayne's Meat Products Inc. & 8794 Indian Line, RR 1 & Hagersville & N0A $1 \mathrm{H} 0$ & & & \\
\hline Wayne's Meat Products Inc. & 8794 Haldimand Road 20 & Hagersville & NOA $1 \mathrm{H} 0$ & & & \\
\hline Wayne White & 1697 County Road \#22 & Belle River & NOR $1 A 0$ & http://www.whitesmeat.com/ & $\begin{array}{l}\underline{\text { wayne@whitesmeat.com }} \\
\underline{\text { wmeatman@aol.com }}\end{array}$ & \\
\hline Weiland Meats Ltd. & $\begin{array}{l}340 \text { Centre Street } \\
7514 \text { Wellington Road }\end{array}$ & Petrolia & N0N 1R0 & & weilandmeatsltd@on.aibn.com & $\begin{array}{l}519-882- \\
1215 \\
519-848-\end{array}$ \\
\hline Wellington Poultry Ltd. & 109, RR 4 & Arthur & N0G 1A0 & & & $\begin{array}{l}6818 \\
519-737-\end{array}$ \\
\hline Weston Abattoir Ltd. & 5409 North Talbot Road & $\begin{array}{l}\text { Maidstone } \\
\text { Lambton }\end{array}$ & N0R 1K0 & $\underline{\text { http://goo.gl/ZjX4sm }}$ & * Use the website & 1200 \\
\hline Williamson Farms & 7739 Lakeshore Rd & Shores & NON $1 J 3$ & http://williamsonfarms.ca/ & & \\
\hline Williamson Farms Country Store & $\begin{array}{l}14 \text { King St. W. } \\
2387 \text { 4Th Conc. West, RR }\end{array}$ & Forest & NON 1J0 & - & & \\
\hline Willie's Meats Ltd. & 1 & Troy & LOR 2B0 & & & \\
\hline $\begin{array}{l}\text { Windcrest Meat Packers } \\
\text { York Chicken Wholesale Ltd }\end{array}$ & $\begin{array}{l}1350 \text { Scugog - 3rd Line } \\
116 \text { Ryding Ave }\end{array}$ & Port Perry & L9L 1B3 & http://goo.gl/PwZvHd & * Use the website & $\begin{array}{l}905-985- \\
9393\end{array}$ \\
\hline York Chicken Wholesale Ltd & 116 Ryding Ave & Toronto & M6N 1H2 & - & & $416-855-$ \\
\hline York Chicken Wholesale Ltd & 188 New Toronto Street & $\begin{array}{l}\text { Toronto } \\
\text { New }\end{array}$ & M8V 2E8 & http://www.yorkchicken.com/ & abarrocas@yorkchicken.com & $\begin{array}{l}0091 \\
705-647-\end{array}$ \\
\hline Yves' Prime Cut Meats & 883306 Hwy 65 & Liskeard & P0J 1P0 & & ypcm@ntl.sympatico.ca & $\begin{array}{l}9845 \\
905-482-\end{array}$ \\
\hline Zamani \& Sons & 6120 Yonge St & Toronto & M2M 3W7 & http://www.zamanimeats.com/ & & $\begin{array}{l}8874 \\
519-565-\end{array}$ \\
\hline Zehr's Country Market & $\begin{array}{l}70963 \text { Bronson Line } \\
75073 \text { Bluewater Hwy RR }\end{array}$ & Dashwood & NOM 1N0 & & paulzehr@tcc.on.ca & $\begin{array}{l}2280 \\
519-565-\end{array}$ \\
\hline Zehr's Country Market & 1 & Bayfield & N0M 1G0 & & countrymarket@cyg.net & $\begin{array}{l}2280 \\
519-565-\end{array}$ \\
\hline Zehr's Country Market & 6979 Millbank Main St & Millbank & NOK 1L0 & & & 2280 \\
\hline
\end{tabular}




\section{Appendix G. Research ethics board approval and renewal.}

\section{RYERSONUNIVERSITY}

RESEARCH ETHICS BOARO

To: $\quad$ Ciro Fernando Bustillo Lecompte

Environmental Applied Science and Management

Re: $\quad$ REB 2013-190: Combination of Biological Processes and Advanced Oxidation Technologies for the Treatment of Actual Wastewater from the Meat Processing Sector in Ontario

Date: $\quad$ August 16, 2013

Dear Ciro Fernando Bustillo Lecompte,

The review of your protocol REB File REB 2013-190 is now complete. The project has been approved for a one-year period. Please note that before proceeding with your project, compliance with other required University approvals/certifications, institutional requirements, or governmental authorizations may be required.

This approval may be extended after one year upon request. Please be advised that if the project is not renewed, approval will expire and no more research involving humans may take place. If this is a funded project, access to research funds may also be affected.

Please note that REB approval policies require that you adhere strictly to the protocol as last reviewed by the REB and that any modifications must be approved by the Board before they can be implemented. Adverse or unexpected events must be reported to the REB as soon as possible with an indication from the Principal Investigator as to how, in the view of the Principal Investigator, these events affect the continuation of the protocol.

Finally, if research subjects are in the care of a health facility, at a school, or other institution or community organization, it is the responsibility of the Principal Investigator to ensure that the ethical guidelines and approvals of those facilities or institutions are obtained and filed with the REB prior to the initiation of any research.

Please quote your REB file number (REB 2013-190) on future correspondence.

Congratulations and best of luck in conducting your research.

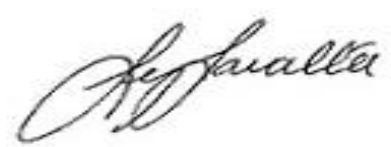

Lynn Lavallée, Ph.D.

Chair, Research Ethics Board 


\section{RYERSONUNIVERSITY}

RESEARCH ETHICS BOARD

To: $\quad$ Ciro Fernando Bustillo Lecompte

Environmental Applied Science and Management

Re: $\quad$ REB 2013-190: Combination of Biological Processes and Advanced Oxidation Technologies for the Treatment of Actual Wastewater from the Meat Processing Sector in Ontario Date: August 5, 2014

Dear Ciro Fernando Bustillo Lecompte,

The review of your protocol REB File REB 2013-190 is now complete. This is a renewal for REB File. The project has been approved for a one-year period. Please note that before proceeding with your project, compliance with other required University approvals/certifications, institutional requirements, or governmental authorizations may be required.

This approval may be extended after one year upon request. Please be advised that if the project is not renewed, approval will expire and no more research involving humans may take place. If this is a funded project, access to research funds may also be affected.

Please note that REB approval policies require that you adhere strictly to the protocol as last reviewed by the REB and that any modifications must be approved by the Board before they can be implemented. Adverse or unexpected events must be reported to the REB as soon as possible with an indication from the Principal Investigator as to how, in the view of the Principal Investigator, these events affect the continuation of the protocol.

Finally, if research subjects are in the care of a health facility, at a school, or other institution or community organization, it is the responsibility of the Principal Investigator to ensure that the ethical guidelines and approvals of those facilities or institutions are obtained and filed with the REB prior to the initiation of any research.

Please quote your REB file number (REB 2013-190) on future correspondence.

Congratulations and best of luck in conducting your research.

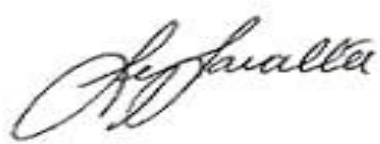

Lynn Lavallée, Ph.D.

Chair, Research Ethics Board 


\section{Appendix H. Questionnaire and consent agreement.}

\section{RYERSONUNIVERSITY}

Yeates School of Graduate Studies

Environmental Applied Science and Management Doctoral Program

\section{QUESTIONNAIRE}

\section{A Survey of Wastewater Treatment Practice and Experience in the Meat Processing Sector in Ontario}

Should you have any questions concerning the completion of the survey, please contact:

Ciro Fernando Bustillo Lecompte

PhD Student, Principal Investigator

Environmental Applied Science and Management

Ryerson University

350 Victoria Street, Toronto, ON M5B 2K3

E-mail: cbustill@ryerson.ca
Dr. Mehrab Mehrvar

Professor

Department of Chemical Engineering

Ryerson University

Phone: 416-979-5000 Ext. 6555

Fax: 416-979-5083

350 Victoria Street, Toronto, ON M5B 2K3

E-mail: mmehrvar@ryerson.ca

\section{Instructions for completing the questionnaire}

1. You must agree to the provisions of consent in order to complete the questionnaire.

2. The person(s) with the most knowledge of the plant's present wastewater system should complete this survey.

3. The survey has been prepared in an attempt to make it applicable to various meat processing operations; therefore, not all of the information requested will apply to each facility.

4. The questionnaire is designed for a completion time of up to 30 minutes.

5. If exact data is not available to answer a particular question, please provide your best engineering estimates.

6. To access the questionnaire, you may click here or on the link below. You may also fill this form along with the consent agreement and return them via e-mail or standard mail to the addresses shown above.

Link: http://goo.gl/mMiv22

7. Please complete the questionnaire and return it by e-mail or standard mail to the addresses shown above by Tuesday, December 31, 2013. Please make a copy of this questionnaire for your files, prior its return. 


\section{RYERSONUNIVERSITY}

Yeates School of Graduate Studies

Environmental Applied Science and Management Doctoral Program

\section{Survey Questions}

\section{General information}

1.1. Name of the Plant/Facility:

1.2. Location Address:

1.3. Number of years in Operation:

1.4. Operation days per year:

\section{Plant operations}

Slaughtering

2.1. Type of animal slaughtered (please choose all that apply)

$\square$ Beef $\quad \square$ Pork $\quad \square$ Poultry $\square$ Other:

2.2. Average number of animals slaughtered per day:

2.3. Maximum capacity of slaughtering per day: units

2.4. Average live weight per animal slaughtered (please choose one of the following units): $\mathrm{lb}$ other unit: 


\section{RYERSONUNIVERSITY}

Yeates School of Graduate Studies

Environmental Applied Science and Management Doctoral Program

Cutting, packing, debone, portion control, marination, Instant Quick Frozen, Cooking/Breading, Rendering

2.5. Production of plant operations other than slaughtering (please choose all that apply):

\begin{tabular}{|c|c|c|c|}
\hline Operation & Production per day & Units & Comment \\
\hline \multirow[t]{3}{*}{ Cutting } & & $\mathrm{kg}$ & \\
\hline & & $\mathrm{lb}$ & \\
\hline & & other: & \\
\hline \multirow[t]{3}{*}{ Packing } & & $\mathrm{kg}$ & \\
\hline & & $\mathrm{lb}$ & \\
\hline & & other: & \\
\hline \multirow[t]{3}{*}{ Debone } & & $\mathrm{kg}$ & \\
\hline & & $\mathrm{lb}$ & \\
\hline & & other: & \\
\hline \multirow[t]{3}{*}{ Portion control } & & $\mathrm{kg}$ & \\
\hline & & $\mathrm{lb}$ & \\
\hline & & other: & \\
\hline \multirow[t]{3}{*}{ Marination } & & $\mathrm{kg}$ & \\
\hline & & $\mathrm{lb}$ & \\
\hline & & other: & \\
\hline \multirow[t]{3}{*}{ Instant Quick Frozen } & & $\mathrm{kg}$ & \\
\hline & & $\mathrm{lb}$ & \\
\hline & & other: & \\
\hline \multirow[t]{3}{*}{ Cooking/Breading } & & $\mathrm{kg}$ & \\
\hline & & $\mathrm{lb}$ & \\
\hline & & other: & \\
\hline \multirow[t]{3}{*}{ Rendering } & & $\mathrm{kg}$ & \\
\hline & & $\mathrm{lb}$ & \\
\hline & & other: & \\
\hline
\end{tabular}




\section{RYERSONUNIVERSITY}

Yeates School of Graduate Studies

Environmental Applied Science and Management Doctoral Program

\section{Water usage}

3.1. Total plant water usage per day: $\square$ gallons/d $\square \mathrm{ft} 3 / \mathrm{d} \square \mathrm{m} 3 / \mathrm{d} \square \mathrm{L} / \mathrm{d} \square$ other:

3.2. Water usage during production shifts (if applicable): $1^{\text {st. }}$ $2^{\text {nd: }}$ $\mathrm{m}^{3}$

3.3. Water usage during sanitation shift: $\square$ gallons $/ \mathrm{d} \square \mathrm{ft}^{3} / \mathrm{d} \square \mathrm{m}^{3} / \mathrm{d} \square \mathrm{L} / \mathrm{d}$

3.4. Water cost: $\$$ per: $\square$ gallons $\square \mathrm{ft}^{3} \square \mathrm{m}^{3} \square$ litre $\square$ other:

\section{Wastewater treatment operations}

4.1. Wastewater treatment system (please choose all that apply):

$\square$ On-site treatment with direct disposal to surface water.

$\square$ On-site treatment with direct disposal to land application.

$\square$ On-site pre-treatment with indirect disposal to public sewer system.

$\square$ No on-site pre-treatment with indirect disposal to public sewer system.

Other:

4.2. Wastewater treatment objectives (please choose all that apply):

$\square$ Biological Oxygen Demand (BOD) reduction. $\square$ Odour control. $\square$ Mixing. $\square$ Post aeration $\square$ Nitrogen removal. $\square$ Phosphorous removal. $\square$ Solids removal. $\square$ Fat, oil, and grease removal. $\square$ Chemical Oxygen Demand (COD) reduction. $\square$ Total Organic Carbon (TOC) reduction. $\square$ pH. $\square$ Others:

4.3. Influent flow:

Design average: $\square$ gallons per day $\square \mathrm{ft}^{3} / \mathrm{d} \square \mathrm{m}^{3} / \mathrm{d} \square \mathrm{L} / \mathrm{d} \square$ other:

Actual average: $\square$ gallons per day $\square \mathrm{ft}^{3} / \mathrm{d} \square \mathrm{m}^{3} / \mathrm{d} \square \mathrm{L} / \mathrm{d} \square$ other: 


\section{RYERSONUNIVERSITY}

Yeates School of Graduate Studies

Environmental Applied Science and Management Doctoral Program

\section{Wastewater characteristics}

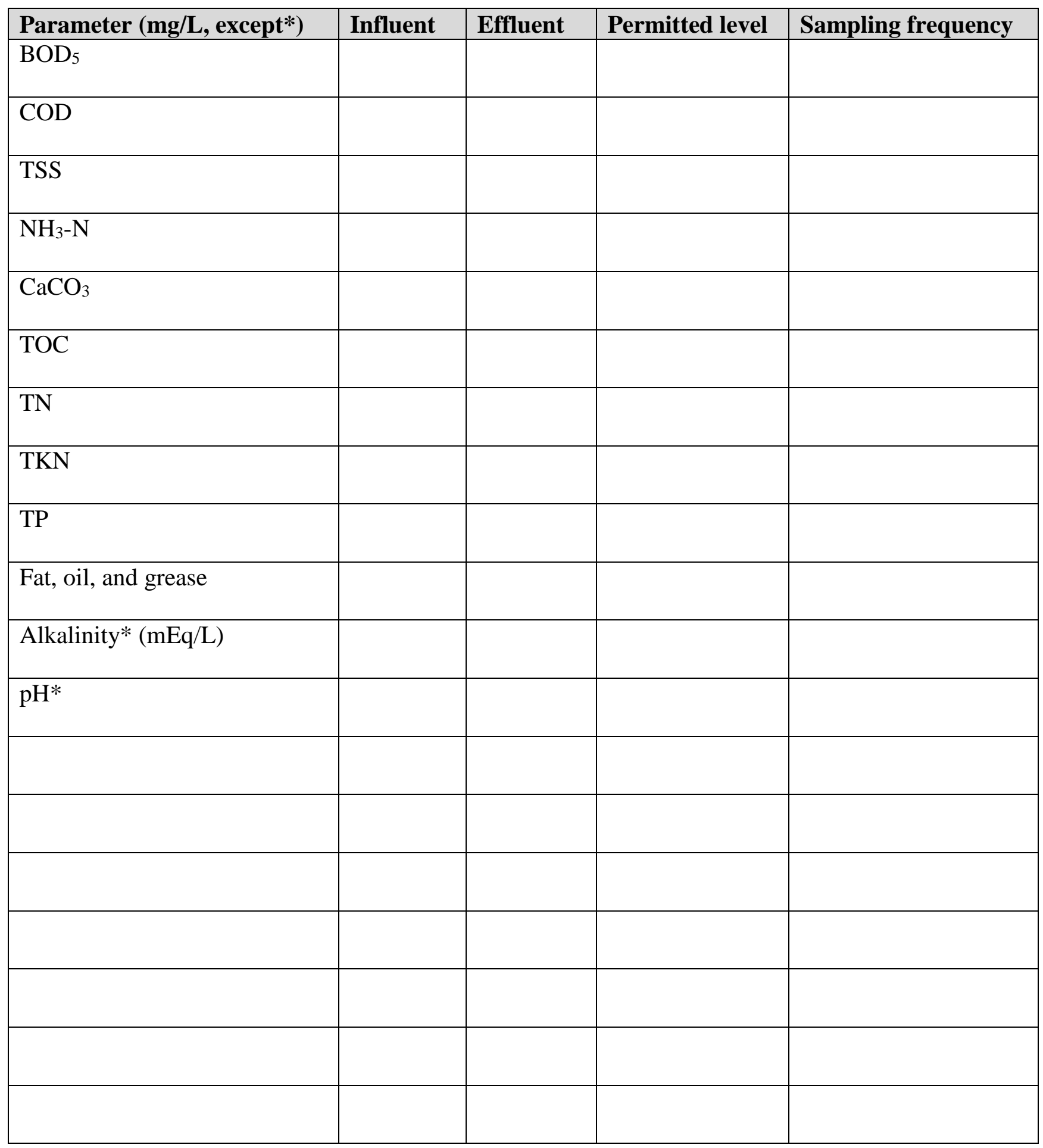

Page 5 of 7 
RYERSONUNIVERSITY

Yeates School of Graduate Studies

Environmental Applied Science and Management Doctoral Program

6. Wastewater treatment processes used in the plant/facility (please choose all that apply)

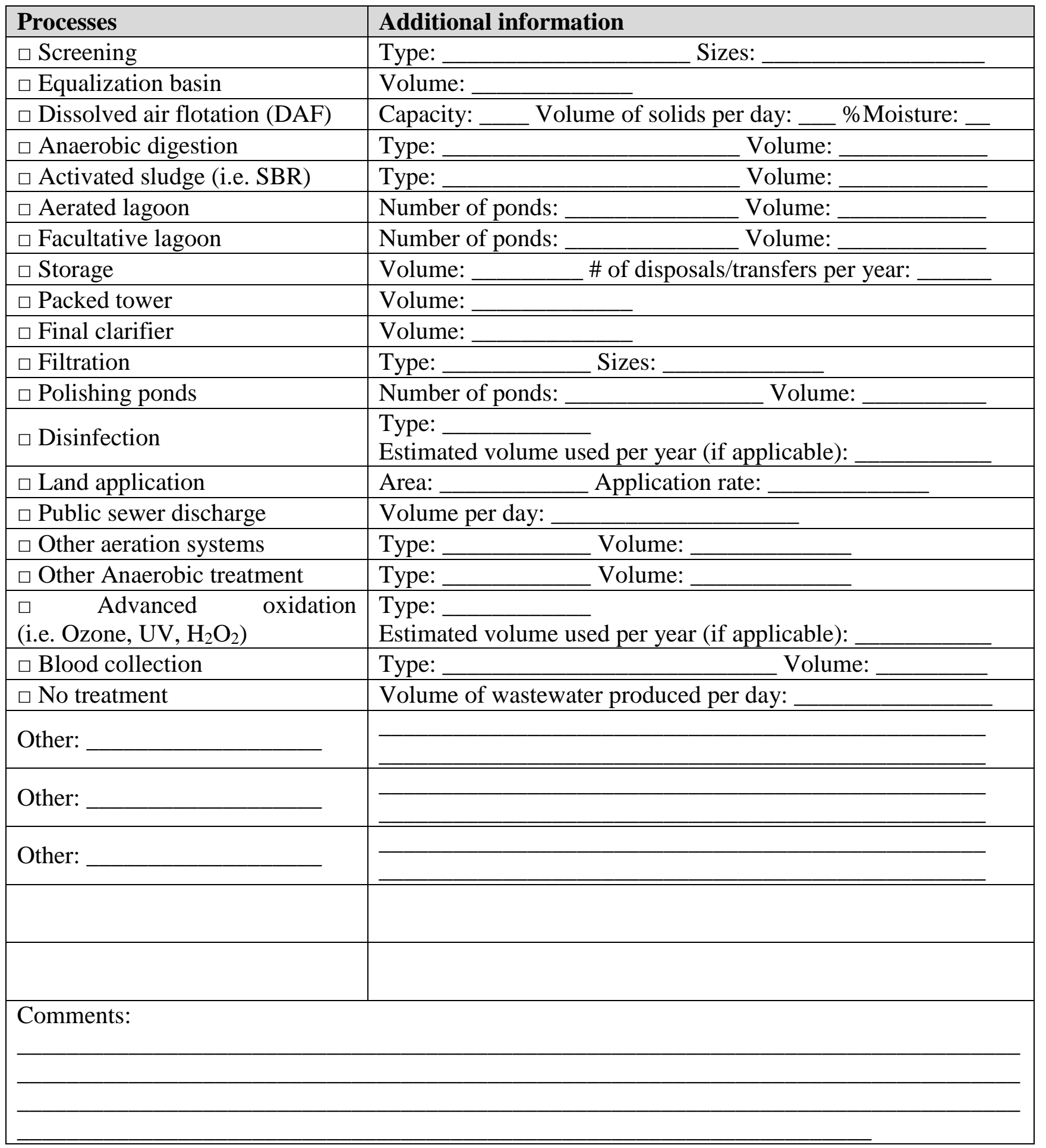




\section{RYERSONUNIVERSITY}

Yeates School of Graduate Studies

Environmental Applied Science and Management Doctoral Program

\section{Samples of the wastewater produced in the facility}

Would you like to help with the investigators by providing samples of the slaughterhouse wastewater produced in your facility for research purposes on optimizing treatment methods of this wastewater?

(Participation is voluntary. No individual name, plant, or company data will be released)

$\square$ Yes $\quad$ No

If yes, please complete the contact information in order to follow up:

Contact Name:

Job title:

E-mail address:

Telephone: 
Yeates School of Graduate Studies

Environmental Applied Science and Management Doctoral Program

\section{CONSENT AGREEMENT}

\section{A Survey of Wastewater Treatment Practice and Experience in the Meat Processing Sector in Ontario}

You are being invited to participate in a research study. Please read this Consent Agreement so that you understand what your participation will involve.

\section{Investigators}

Ciro Fernando Bustillo Lecompte (cbustill@ryerson.ca), Environmental Applied Science and Management Doctoral Program, Ryerson University.

Supervisor: Dr. Mehrab Mehrvar(mmehrvar@ryerson.ca), Department of Chemical Engineering, Ryerson University.

"Results will contribute to doctoral dissertation: "Combination of Biological Processes and Advanced Oxidation Technologies for the Treatment of Actual Wastewater from the Meat Processing Sector in Ontario". This study is sponsored by the Natural Sciences and Engineering Research Council of Canada (NSERC) and Ryerson University. In addition, the results will be published in refereed journals.

\section{Purpose of the study}

The purpose of the study is to determine what are the current wastewater treatment technologies used in the meat processing sector in Ontario; thus, assess possible alternatives in order to minimize the impact of the discharge of these wastewaters to the environment. This survey is conducted in an effort to establish baseline wastewater data.

\section{Description of the study and participation}

This study is aiming to collect information on current meat processing plants (MPPs) in Ontario, including characteristics of the actual wastewater, type of animals being processed, number of animals slaughtered per year, and type of treatment/storage/disposal used. The information collected by this survey will be used to determine the range and average production rates, water usage, wastewater generation, treatment, and disposal methods utilized by the poultry processing industry. Financial data collected will be used to characterize the economic impact of water use and wastewater generation on the industry. A copy of the final report will be provided to the companies that participate in the study. 
Yeates School of Graduate Studies

Environmental Applied Science and Management Doctoral Program

\section{Instructions for completing the questionnaire}

8. You must agree to the provisions of consent in order to complete the questionnaire.

9. The person(s) with the most knowledge of the plant's present wastewater system should complete this survey.

10. The survey has been prepared in an attempt to make it applicable to various meat processing operations; therefore, not all of the information requested will apply to each facility.

11. The questionnaire is designed for a completion time of up to 30 minutes.

12. If exact data is not available to answer a particular question, please provide your best engineering estimates.

13. To access the questionnaire, you may click here or on the link below. You may also fill this form along with the consent agreement and return them via e-mail or standard mail to the addresses shown above.

Link: http://goo.gl/mMiv22

14. Please complete the questionnaire and return it by e-mail or standard mail to the addresses shown in the Questions about the study section of this consent agreement by Tuesday, December 31, 2013. Please make a copy of this questionnaire for your files, prior its return.

\section{Risks or discomforts}

Potential risks/discomforts are very low. You may choose not to answer a particular question, or discontinue participating, if you wish, for any reason. Taking into account that information obtained through the questionnaire could reveal problems relating to the company's compliance with regulations and may also have an impact upon the relationship of the participants with their employers, no individuals' or company names will be used, this is one way to mitigate the risk.

\section{Benefits of the Study}

We hope that this study may be highly beneficial as a contribution to the advancement of knowledge due to the lack of information and enforcement on adequate treatment of Slaughterhouse Wastewaters (SWWs). The investigators cannot guarantee, however, that you will receive any benefits from participating in this study.

\section{Incentives to participate}

Participation in this study is voluntary; you will not be paid to participate in this study.

\section{Costs}

If you choose to complete and return the survey by standard mail, there will be a potential cost of mailing the questionnaire back. 


\section{Confidentiality}

The information provided in this questionnaire will be used to develop ranges and averages of wastewater systems at typical types of meat processing operations. Individual plants arid company data will be viewed and compiled internally by specified Ryerson University researchers only. Reports, publications, and other information generated as a result of this survey will contain only cumulative data presented by meat processing operation type and treatment in Ontario. No individual plant or company data will be released. Electronic data will be both password-protected and encrypted; hard copy data will be stored securely behind lock-and-key.

\section{Voluntary nature of participation and withdrawal}

Participation in this study is voluntary. You can choose whether to be in this study or not. If you volunteer to be in this study, you may withdraw your consent and stop your participation at any time without consequences of any kind. If you choose to withdraw from this study, you may also choose to withdraw your data from the study. At any particular point in the study, you may refuse to answer any particular question or stop participation altogether. You may also choose not to answer any question(s) and still remain in the study. Your choice of whether or not to participate will not influence your future relations with the investigator, departments, or Ryerson University.

\section{Questions about the Study}

If you have questions about the research, you may contact:

Ciro Fernando Bustillo Lecompte

PhD Student, Principal Investigator

Environmental Applied Science and Management

Ryerson University

350 Victoria Street, Toronto, ON M5B 2K3

E-mail: cbustill@ryerson.ca
Dr. Mehrab Mehrvar

Professor

Department of Chemical Engineering

Ryerson University

Phone: 416-979-5000 Ext. 6555

Fax: 416-979-5083

350 Victoria Street, Toronto, ON M5B 2K3

E-mail: mmehrvar@ryerson.ca

If you have questions regarding your rights as a human subject and participant in this study, you may contact the Ryerson University Research Ethics Board for information:

Research Ethics Board

c/o Office of the Vice President, Research and Innovation

Ryerson University

350 Victoria Street, Toronto, ON M5B 2K3

Phone: 416-979-5042 
Yeates School of Graduate Studies

Environmental Applied Science and Management Doctoral Program

\section{Agreement}

Your signature below indicates that you have read the information in this agreement and have had a chance to ask any questions you have about the study. Your signature also indicates that you agree to be in the study and have been told that you can change your mind and withdraw your consent to participate at any time. You have been given a copy of this agreement. You have been told that by signing this consent agreement you are not giving up any of your legal rights.

$\square$ I agree to the provisions of consent

Name of Participant (please print)

Date 
Appendix I. Respirometer raw data.

\begin{tabular}{|c|c|c|c|c|c|c|c|}
\hline $\begin{array}{l}\text { AS } \\
\text { time } \\
\text { (hrs) }\end{array}$ & $\begin{array}{l}\text { oxygen } \\
\text { (mg/L) }\end{array}$ & $\begin{array}{l}\text { SWW } \\
\text { time } \\
\text { (hrs) }\end{array}$ & $\begin{array}{l}\text { oxygen } \\
\text { (mg/L) }\end{array}$ & $\begin{array}{l}\text { ABR-AS } \\
\text { time } \\
\text { (hrs) }\end{array}$ & $\begin{array}{l}\text { oxygen } \\
(\mathrm{mg} / \mathrm{L})\end{array}$ & $\begin{array}{l}\text { ABR } \\
\text { time } \\
\text { (hrs) }\end{array}$ & $\begin{array}{l}\text { oxygen } \\
(\mathrm{mg} / \mathrm{L})\end{array}$ \\
\hline$=======$ & $===========$ & $=======$ & $==========$ & $=======$ & $==========$ & $=======$ & $==========$ \\
\hline 0.25 & 0.21 & 0.25 & 0.00 & 0.25 & 0.00 & 0.25 & 0.00 \\
\hline 0.50 & 0.21 & 0.50 & 0.21 & 0.50 & 0.21 & 0.50 & 0.17 \\
\hline 0.75 & 0.66 & 0.75 & 0.52 & 0.75 & 0.74 & 0.75 & 0.49 \\
\hline 1.00 & 0.94 & 1.00 & 0.91 & 1.00 & 0.96 & 1.00 & 0.63 \\
\hline 1.25 & 0.94 & 1.25 & 0.91 & 1.25 & 0.96 & 1.25 & 0.94 \\
\hline 1.50 & 1.16 & 1.50 & 1.57 & 1.50 & 0.96 & 1.50 & 1.50 \\
\hline 1.75 & 1.16 & 1.75 & 2.09 & 1.75 & 0.97 & 1.75 & 1.99 \\
\hline 2.00 & 1.37 & 2.00 & 2.58 & 2.00 & 0.98 & 2.00 & 2.54 \\
\hline 2.25 & 1.89 & 2.25 & 4.38 & 2.25 & 1.19 & 2.25 & 3.10 \\
\hline 2.50 & 2.10 & 2.50 & 4.83 & 2.50 & 1.79 & 2.50 & 4.66 \\
\hline 2.75 & 2.34 & 2.75 & 5.53 & 2.75 & 2.05 & 2.75 & 5.32 \\
\hline 3.00 & 2.56 & 3.00 & 6.02 & 3.00 & 2.29 & 3.00 & 5.95 \\
\hline 3.25 & 2.83 & 3.25 & 6.64 & 3.25 & 2.52 & 3.25 & 6.54 \\
\hline 3.50 & 2.83 & 3.50 & 7.41 & 3.50 & 2.76 & 3.50 & 7.17 \\
\hline 3.75 & 3.03 & 3.75 & 7.86 & 3.75 & 2.96 & 3.75 & 7.69 \\
\hline 4.00 & 3.25 & 4.00 & 8.28 & 4.00 & 3.15 & 4.00 & 8.18 \\
\hline 4.25 & 3.48 & 4.25 & 8.91 & 4.25 & 3.35 & 4.25 & 8.70 \\
\hline 4.50 & 3.70 & 4.50 & 9.29 & 4.50 & 3.51 & 4.50 & 9.12 \\
\hline 4.75 & 3.92 & 4.75 & 9.71 & 4.75 & 3.68 & 4.75 & 9.57 \\
\hline 5.00 & 4.17 & 5.00 & 10.20 & 5.00 & 3.84 & 5.00 & 9.99 \\
\hline 5.25 & 4.17 & 5.25 & 10.82 & 5.25 & 4.07 & 5.25 & 10.58 \\
\hline 5.50 & 4.40 & 5.50 & 11.17 & 5.50 & 4.23 & 5.50 & 11.00 \\
\hline 5.75 & 4.63 & 5.75 & 11.56 & 5.75 & 4.34 & 5.75 & 11.28 \\
\hline 6.00 & 4.63 & 6.00 & 11.90 & 6.00 & 4.48 & 6.00 & 11.66 \\
\hline 6.25 & 5.17 & 6.25 & 13.29 & 6.25 & 4.65 & 6.25 & 12.08 \\
\hline 6.50 & 5.42 & 6.50 & 13.67 & 6.50 & 5.15 & 6.50 & 13.39 \\
\hline 6.75 & 5.42 & 6.75 & 13.91 & 6.75 & 5.24 & 6.75 & 13.63 \\
\hline 7.00 & 5.68 & 7.00 & 14.26 & 7.00 & 5.39 & 7.00 & 14.02 \\
\hline 7.25 & 5.68 & 7.25 & 14.61 & 7.25 & 5.47 & 7.25 & 14.23 \\
\hline 7.50 & 5.87 & 7.50 & 14.92 & 7.50 & 5.60 & 7.50 & 14.57 \\
\hline 7.75 & 5.87 & 7.75 & 14.92 & 7.75 & 5.67 & 7.75 & 14.75 \\
\hline 8.00 & 6.34 & 8.00 & 16.31 & 8.00 & 5.79 & 8.00 & 15.06 \\
\hline 8.25 & 6.52 & 8.25 & 16.59 & 8.25 & 5.86 & 8.25 & 15.24 \\
\hline 8.50 & 6.75 & 8.50 & 17.04 & 8.50 & 6.05 & 8.50 & 15.72 \\
\hline 8.75 & 6.42 & 8.75 & 16.35 & 8.75 & 6.17 & 8.75 & 16.04 \\
\hline 9.00 & 6.92 & 9.00 & 17.35 & 9.00 & 6.59 & 9.00 & 17.14 \\
\hline 9.25 & 6.92 & 9.25 & 17.67 & 9.25 & 6.67 & 9.25 & 17.35 \\
\hline 9.50 & 7.14 & 9.50 & 17.67 & 9.50 & 6.74 & 9.50 & 17.52 \\
\hline 9.75 & 7.14 & 9.75 & 17.98 & 9.75 & 6.78 & 9.75 & 17.63 \\
\hline
\end{tabular}




\begin{tabular}{|c|c|c|c|c|c|c|c|}
\hline $\begin{array}{l}\text { AS } \\
\text { time } \\
\text { (hrs) }\end{array}$ & $\begin{array}{l}\text { oxygen } \\
\text { (mg/L) }\end{array}$ & $\begin{array}{l}\text { SWW } \\
\text { time } \\
\text { (hrs) }\end{array}$ & $\begin{array}{l}\text { oxygen } \\
\text { (mg/L) }\end{array}$ & $\begin{array}{l}\text { ABR-AS } \\
\text { time } \\
\text { (hrs) }\end{array}$ & $\begin{array}{l}\text { oxygen } \\
\text { (mg/L) }\end{array}$ & $\begin{array}{l}\text { ABR } \\
\text { time } \\
\text { (hrs) }\end{array}$ & $\begin{array}{l}\text { oxygen } \\
\text { (mg/L) }\end{array}$ \\
\hline$=======$ & $===========$ & $=======$ & $==========$ & $=======$ & $==========$ & $=======$ & $==========$ \\
\hline 10.00 & 7.35 & 10.00 & 18.22 & 10.00 & 6.86 & 10.00 & 17.84 \\
\hline 10.25 & 7.69 & 10.25 & 19.22 & 10.25 & 6.90 & 10.25 & 17.94 \\
\hline 10.50 & 7.53 & 10.50 & 18.47 & 10.50 & 7.02 & 10.50 & 18.26 \\
\hline 10.75 & 7.53 & 10.75 & 18.82 & 10.75 & 7.12 & 10.75 & 18.50 \\
\hline 11.00 & 7.69 & 11.00 & 19.41 & 11.00 & 7.26 & 11.00 & 18.88 \\
\hline 11.25 & 8.21 & 11.25 & 20.41 & 11.25 & 7.69 & 11.25 & 19.99 \\
\hline 11.50 & 8.21 & 11.50 & 20.69 & 11.50 & 7.75 & 11.50 & 20.16 \\
\hline 11.75 & 8.37 & 11.75 & 20.69 & 11.75 & 7.85 & 11.75 & 20.41 \\
\hline 12.00 & 8.37 & 12.00 & 21.00 & 12.00 & 7.90 & 12.00 & 20.54 \\
\hline 12.25 & 8.52 & 12.25 & 21.17 & 12.25 & 7.97 & 12.25 & 20.72 \\
\hline 12.50 & 8.72 & 12.50 & 21.42 & 12.50 & 8.05 & 12.50 & 20.93 \\
\hline 12.75 & 8.72 & 12.75 & 21.70 & 12.75 & 8.14 & 12.75 & 21.17 \\
\hline 13.00 & 9.23 & 13.00 & 23.01 & 13.00 & 8.60 & 13.00 & 22.35 \\
\hline 13.25 & 9.23 & 13.25 & 23.01 & 13.25 & 8.62 & 13.25 & 22.42 \\
\hline 13.50 & 9.39 & 13.50 & 23.32 & 13.50 & 8.70 & 13.50 & 22.62 \\
\hline 13.75 & 9.39 & 13.75 & 23.60 & 13.75 & 8.77 & 13.75 & 22.80 \\
\hline 14.00 & 9.53 & 14.00 & 23.60 & 14.00 & 8.82 & 14.00 & 22.94 \\
\hline 14.25 & 9.68 & 14.25 & 23.91 & 14.25 & 8.90 & 14.25 & 23.15 \\
\hline 14.50 & 10.01 & 14.50 & 25.23 & 14.50 & 8.96 & 14.50 & 23.29 \\
\hline 14.75 & 10.22 & 14.75 & 25.54 & 14.75 & 9.41 & 14.75 & 24.46 \\
\hline 15.00 & 10.22 & 15.00 & 25.54 & 15.00 & 9.47 & 15.00 & 24.63 \\
\hline 15.25 & 10.40 & 15.25 & 25.96 & 15.25 & 9.54 & 15.25 & 24.81 \\
\hline 15.50 & 10.55 & 15.50 & 25.96 & 15.50 & 9.62 & 15.50 & 25.02 \\
\hline 15.75 & 10.55 & 15.75 & 26.27 & 15.75 & 9.66 & 15.75 & 25.12 \\
\hline 16.00 & 10.69 & 16.00 & 26.48 & 16.00 & 9.72 & 16.00 & 25.26 \\
\hline 16.25 & 10.80 & 16.25 & 26.59 & 16.25 & 9.74 & 16.25 & 25.33 \\
\hline 16.50 & 10.80 & 16.50 & 26.59 & 16.50 & 9.79 & 16.50 & 25.44 \\
\hline 16.75 & 11.02 & 16.75 & 26.83 & 16.75 & 9.81 & 16.75 & 25.51 \\
\hline 17.00 & 11.02 & 17.00 & 26.83 & 17.00 & 9.85 & 17.00 & 25.61 \\
\hline 17.25 & 11.16 & 17.25 & 27.14 & 17.25 & 9.99 & 17.25 & 25.96 \\
\hline 17.50 & 11.16 & 17.50 & 27.42 & 17.50 & 10.02 & 17.50 & 26.06 \\
\hline 17.75 & 11.43 & 17.75 & 27.77 & 17.75 & 10.12 & 17.75 & 26.31 \\
\hline 18.00 & 11.43 & 18.00 & 28.12 & 18.00 & 10.17 & 18.00 & 26.45 \\
\hline 18.25 & 11.59 & 18.25 & 28.33 & 18.25 & 9.83 & 18.25 & 25.55 \\
\hline 18.50 & 11.26 & 18.50 & 27.43 & 18.50 & 9.88 & 18.50 & 25.69 \\
\hline 18.75 & 11.39 & 18.75 & 27.71 & 18.75 & 9.91 & 18.75 & 25.76 \\
\hline 19.00 & 11.51 & 19.00 & 27.96 & 19.00 & 9.95 & 19.00 & 25.86 \\
\hline 19.25 & 11.67 & 19.25 & 28.20 & 19.25 & 10.00 & 19.25 & 26.00 \\
\hline 19.50 & 11.67 & 19.50 & 28.20 & 19.50 & 10.05 & 19.50 & 26.14 \\
\hline 19.75 & 11.80 & 19.75 & 28.48 & 19.75 & 10.10 & 19.75 & 26.25 \\
\hline 20.00 & 11.99 & 20.00 & 28.76 & 20.00 & 10.15 & 20.00 & 26.39 \\
\hline
\end{tabular}




\begin{tabular}{|c|c|c|c|c|c|c|c|}
\hline $\begin{array}{l}\text { AS } \\
\text { time } \\
\text { (hrs) }\end{array}$ & $\begin{array}{l}\text { oxygen } \\
\text { (mg/L) }\end{array}$ & $\begin{array}{l}\text { SWW } \\
\text { time } \\
\text { (hrs) }\end{array}$ & $\begin{array}{l}\text { oxygen } \\
\text { (mg/L) }\end{array}$ & $\begin{array}{l}\text { ABR-AS } \\
\text { time } \\
\text { (hrs) }\end{array}$ & $\begin{array}{l}\text { oxygen } \\
\text { (mg/L) }\end{array}$ & $\begin{array}{l}\text { ABR } \\
\text { time } \\
\text { (hrs) }\end{array}$ & $\begin{array}{l}\text { oxygen } \\
\text { (mg/L) }\end{array}$ \\
\hline$=======$ & $===========$ & $=======$ & $==========$ & $=======$ & $==========$ & $=======$ & $==========$ \\
\hline 20.25 & 11.99 & 20.25 & 29.21 & 20.25 & 10.24 & 20.25 & 26.63 \\
\hline 20.50 & 12.15 & 20.50 & 29.70 & 20.50 & 9.94 & 20.50 & 25.84 \\
\hline 20.75 & 11.97 & 20.75 & 28.70 & 20.75 & 10.02 & 20.75 & 26.05 \\
\hline 21.00 & 12.04 & 21.00 & 29.15 & 21.00 & 10.10 & 21.00 & 26.26 \\
\hline 21.25 & 12.19 & 21.25 & 29.43 & 21.25 & 10.24 & 21.25 & 26.61 \\
\hline 21.50 & 12.34 & 21.50 & 30.09 & 21.50 & 10.31 & 21.50 & 26.81 \\
\hline 21.75 & 12.47 & 21.75 & 30.54 & 21.75 & 10.41 & 21.75 & 27.06 \\
\hline 22.00 & 12.80 & 22.00 & 30.82 & 22.00 & 10.53 & 22.00 & 27.37 \\
\hline 22.25 & 12.80 & 22.25 & 31.59 & 22.25 & 10.65 & 22.25 & 27.69 \\
\hline 22.50 & 12.91 & 22.50 & 31.94 & 22.50 & 10.75 & 22.50 & 27.96 \\
\hline 22.75 & 13.12 & 22.75 & 32.46 & 22.75 & 10.84 & 22.75 & 28.17 \\
\hline 23.00 & 13.26 & 23.00 & 32.77 & 23.00 & 10.94 & 23.00 & 28.45 \\
\hline 23.25 & 13.39 & 23.25 & 33.50 & 23.25 & 11.05 & 23.25 & 28.73 \\
\hline 23.50 & 13.84 & 23.50 & 33.85 & 23.50 & 11.16 & 23.50 & 29.01 \\
\hline 23.75 & 13.84 & 23.75 & 34.13 & 23.75 & 11.28 & 23.75 & 29.32 \\
\hline 24.00 & 14.08 & 24.00 & 34.55 & 24.00 & 11.40 & 24.00 & 29.64 \\
\hline 24.25 & 14.23 & 24.25 & 35.28 & 24.25 & 11.49 & 24.25 & 29.88 \\
\hline 24.50 & 14.36 & 24.50 & 35.66 & 24.50 & 11.64 & 24.50 & 30.26 \\
\hline 24.75 & 14.61 & 24.75 & 36.33 & 24.75 & 11.38 & 24.75 & 29.58 \\
\hline 25.00 & 14.76 & 25.00 & 36.99 & 25.00 & 11.50 & 25.00 & 29.89 \\
\hline 25.25 & 14.57 & 25.25 & 36.44 & 25.25 & 11.66 & 25.25 & 30.31 \\
\hline 25.50 & 14.74 & 25.50 & 37.10 & 25.50 & 11.79 & 25.50 & 30.66 \\
\hline 25.75 & 15.06 & 25.75 & 37.73 & 25.75 & 11.91 & 25.75 & 30.97 \\
\hline 26.00 & 15.38 & 26.00 & 38.32 & 26.00 & 12.02 & 26.00 & 31.25 \\
\hline 26.25 & 15.54 & 26.25 & 38.70 & 26.25 & 12.17 & 26.25 & 31.63 \\
\hline 26.50 & 15.69 & 26.50 & 39.26 & 26.50 & 12.29 & 26.50 & 31.94 \\
\hline 26.75 & 15.90 & 26.75 & 39.71 & 26.75 & 12.41 & 26.75 & 32.26 \\
\hline 27.00 & 16.08 & 27.00 & 40.38 & 27.00 & 12.49 & 27.00 & 32.47 \\
\hline 27.25 & 16.34 & 27.25 & 40.83 & 27.25 & 12.65 & 27.25 & 32.88 \\
\hline 27.50 & 16.49 & 27.50 & 41.63 & 27.50 & 12.78 & 27.50 & 33.23 \\
\hline 27.75 & 16.65 & 27.75 & 42.01 & 27.75 & 12.90 & 27.75 & 33.55 \\
\hline 28.00 & 16.94 & 28.00 & 42.85 & 28.00 & 13.04 & 28.00 & 33.89 \\
\hline 28.25 & 17.09 & 28.25 & 43.20 & 28.25 & 13.21 & 28.25 & 34.35 \\
\hline 28.50 & 17.25 & 28.50 & 43.93 & 28.50 & 13.33 & 28.50 & 34.66 \\
\hline 28.75 & 17.59 & 28.75 & 44.42 & 28.75 & 13.49 & 28.75 & 35.08 \\
\hline 29.00 & 17.74 & 29.00 & 45.22 & 29.00 & 13.74 & 29.00 & 35.71 \\
\hline 29.25 & 17.98 & 29.25 & 45.98 & 29.25 & 13.77 & 29.25 & 35.81 \\
\hline 29.50 & 18.13 & 29.50 & 46.40 & 29.50 & 13.84 & 29.50 & 35.98 \\
\hline 29.75 & 18.31 & 29.75 & 47.06 & 29.75 & 13.96 & 29.75 & 36.30 \\
\hline 30.00 & 18.50 & 30.00 & 47.48 & 30.00 & 14.08 & 30.00 & 36.61 \\
\hline 30.25 & 19.04 & 30.25 & 49.32 & 30.25 & 14.16 & 30.25 & 36.82 \\
\hline
\end{tabular}




\begin{tabular}{|c|c|c|c|c|c|c|c|}
\hline $\begin{array}{l}\text { AS } \\
\text { time } \\
\text { (hrs) }\end{array}$ & $\begin{array}{l}\text { oxygen } \\
\text { (mg/L) }\end{array}$ & $\begin{array}{l}\text { SWW } \\
\text { time } \\
\text { (hrs) }\end{array}$ & $\begin{array}{l}\text { oxygen } \\
\text { (mg/L) }\end{array}$ & $\begin{array}{l}\text { ABR-AS } \\
\text { time } \\
\text { (hrs) }\end{array}$ & $\begin{array}{l}\text { oxygen } \\
\text { (mg/L) }\end{array}$ & $\begin{array}{l}\text { ABR } \\
\text { time } \\
\text { (hrs) }\end{array}$ & $\begin{array}{l}\text { oxygen } \\
\text { (mg/L) }\end{array}$ \\
\hline$=======$ & $===========$ & $=======$ & $==========$ & $=======$ & $==========$ & $=======$ & $==========$ \\
\hline 30.50 & 18.89 & 30.50 & 48.67 & 30.50 & 13.78 & 30.50 & 35.82 \\
\hline 30.75 & 19.42 & 30.75 & 50.29 & 30.75 & 13.78 & 30.75 & 35.82 \\
\hline 31.00 & 19.09 & 31.00 & 49.92 & 31.00 & 14.16 & 31.00 & 36.82 \\
\hline 31.25 & 19.31 & 31.25 & 50.27 & 31.25 & 14.16 & 31.25 & 36.82 \\
\hline 31.50 & 19.85 & 31.50 & 52.07 & 31.50 & 14.20 & 31.50 & 36.93 \\
\hline 31.75 & 20.06 & 31.75 & 52.42 & 31.75 & 13.83 & 31.75 & 35.96 \\
\hline 32.00 & 19.94 & 32.00 & 52.11 & 32.00 & 14.27 & 32.00 & 37.10 \\
\hline 32.25 & 20.09 & 32.25 & 52.43 & 32.25 & 14.32 & 32.25 & 37.24 \\
\hline 32.50 & 20.14 & 32.50 & 53.02 & 32.50 & 14.40 & 32.50 & 37.45 \\
\hline 32.75 & 20.33 & 32.75 & 53.33 & 32.75 & 14.02 & 32.75 & 36.45 \\
\hline 33.00 & 20.51 & 33.00 & 53.96 & 33.00 & 14.02 & 33.00 & 36.45 \\
\hline 33.25 & 20.74 & 33.25 & 54.59 & 33.25 & 14.06 & 33.25 & 36.55 \\
\hline 33.50 & 20.97 & 33.50 & 54.83 & 33.50 & 14.07 & 33.50 & 36.59 \\
\hline 33.75 & 20.97 & 33.75 & 55.67 & 33.75 & 14.10 & 33.75 & 36.66 \\
\hline 34.00 & 21.22 & 34.00 & 56.26 & 34.00 & 14.21 & 34.00 & 36.94 \\
\hline 34.25 & 21.45 & 34.25 & 56.57 & 34.25 & 14.29 & 34.25 & 37.14 \\
\hline 34.50 & 21.45 & 34.50 & 56.96 & 34.50 & 14.35 & 34.50 & 37.32 \\
\hline 34.75 & 21.63 & 34.75 & 57.30 & 34.75 & 14.41 & 34.75 & 37.46 \\
\hline 35.00 & 21.82 & 35.00 & 57.93 & 35.00 & 14.53 & 35.00 & 37.77 \\
\hline 35.25 & 22.02 & 35.25 & 58.31 & 35.25 & 14.62 & 35.25 & 38.01 \\
\hline 35.50 & 22.02 & 35.50 & 58.70 & 35.50 & 14.91 & 35.50 & 38.76 \\
\hline 35.75 & 22.19 & 35.75 & 59.15 & 35.75 & 14.91 & 35.75 & 38.76 \\
\hline 36.00 & 22.38 & 36.00 & 59.57 & 36.00 & 15.22 & 36.00 & 39.56 \\
\hline 36.25 & 22.38 & 36.25 & 59.57 & 36.25 & 15.22 & 36.25 & 39.56 \\
\hline 36.50 & 22.55 & 36.50 & 60.23 & 36.50 & 15.44 & 36.50 & 40.15 \\
\hline 36.75 & 22.75 & 36.75 & 60.58 & 36.75 & 15.44 & 36.75 & 40.15 \\
\hline 37.00 & 22.95 & 37.00 & 60.79 & 37.00 & 15.71 & 37.00 & 40.85 \\
\hline 37.25 & 22.61 & 37.25 & 60.41 & 37.25 & 15.33 & 37.25 & 39.85 \\
\hline 37.50 & 23.15 & 37.50 & 61.83 & 37.50 & 15.51 & 37.50 & 40.33 \\
\hline 37.75 & 23.15 & 37.75 & 62.15 & 37.75 & 15.51 & 37.75 & 40.33 \\
\hline 38.00 & 23.31 & 38.00 & 62.46 & 38.00 & 15.51 & 38.00 & 40.33 \\
\hline 38.25 & 23.48 & 38.25 & 62.74 & 38.25 & 15.69 & 38.25 & 40.79 \\
\hline 38.50 & 23.68 & 38.50 & 63.22 & 38.50 & 15.84 & 38.50 & 41.17 \\
\hline 38.75 & 23.68 & 38.75 & 63.92 & 38.75 & 15.84 & 38.75 & 41.17 \\
\hline 39.00 & 23.86 & 39.00 & 64.27 & 39.00 & 16.05 & 39.00 & 41.73 \\
\hline 39.25 & 24.08 & 39.25 & 64.58 & 39.25 & 16.14 & 39.25 & 41.97 \\
\hline 39.50 & 24.08 & 39.50 & 64.90 & 39.50 & 16.22 & 39.50 & 42.18 \\
\hline 39.75 & 24.27 & 39.75 & 65.52 & 39.75 & 16.33 & 39.75 & 42.46 \\
\hline 40.00 & 24.32 & 40.00 & 65.87 & 40.00 & 16.36 & 40.00 & 42.53 \\
\hline 40.25 & 24.46 & 40.25 & 66.19 & 40.25 & 16.26 & 40.25 & 42.26 \\
\hline 40.50 & 24.64 & 40.50 & 66.50 & 40.50 & 16.30 & 40.50 & 42.37 \\
\hline
\end{tabular}




\begin{tabular}{|c|c|c|c|c|c|c|c|}
\hline $\begin{array}{l}\text { AS } \\
\text { time } \\
\text { (hrs) }\end{array}$ & $\begin{array}{l}\text { oxygen } \\
\text { (mg/L) }\end{array}$ & $\begin{array}{l}\text { SWW } \\
\text { time } \\
\text { (hrs) }\end{array}$ & $\begin{array}{l}\text { oxygen } \\
\text { (mg/L) }\end{array}$ & $\begin{array}{l}\text { ABR-AS } \\
\text { time } \\
\text { (hrs) }\end{array}$ & $\begin{array}{l}\text { oxygen } \\
\text { (mg/L) }\end{array}$ & $\begin{array}{l}\text { ABR } \\
\text { time } \\
\text { (hrs) }\end{array}$ & $\begin{array}{l}\text { oxygen } \\
\text { (mg/L) }\end{array}$ \\
\hline$=======$ & $===========$ & $=======$ & $==========$ & $=======$ & $==========$ & $=======$ & $==========$ \\
\hline 40.75 & 24.64 & 40.75 & 66.85 & 40.75 & 16.39 & 40.75 & 42.61 \\
\hline 41.00 & 24.82 & 41.00 & 67.13 & 41.00 & 16.48 & 41.00 & 42.85 \\
\hline 41.25 & 25.00 & 41.25 & 67.79 & 41.25 & 16.64 & 41.25 & 43.27 \\
\hline 41.50 & 25.00 & 41.50 & 68.21 & 41.50 & 16.71 & 41.50 & 43.45 \\
\hline 41.75 & 25.16 & 41.75 & 68.55 & 41.75 & 16.83 & 41.75 & 43.76 \\
\hline 42.00 & 25.36 & 42.00 & 68.87 & 42.00 & 16.95 & 42.00 & 44.07 \\
\hline 42.25 & 25.36 & 42.25 & 68.22 & 42.25 & 17.07 & 42.25 & 44.39 \\
\hline 42.50 & 25.57 & 42.50 & 69.53 & 42.50 & 17.14 & 42.50 & 44.56 \\
\hline 42.75 & 25.24 & 42.75 & 68.95 & 42.75 & 17.25 & 42.75 & 44.84 \\
\hline 43.00 & 25.45 & 43.00 & 69.68 & 43.00 & 17.39 & 43.00 & 45.22 \\
\hline 43.25 & 25.65 & 43.25 & 70.03 & 43.25 & 17.41 & 43.25 & 45.26 \\
\hline 43.50 & 25.65 & 43.50 & 70.31 & 43.50 & 17.53 & 43.50 & 45.57 \\
\hline 43.75 & 25.88 & 43.75 & 70.72 & 43.75 & 17.59 & 43.75 & 45.74 \\
\hline 44.00 & 25.88 & 44.00 & 71.00 & 44.00 & 17.70 & 44.00 & 46.02 \\
\hline 44.25 & 26.07 & 44.25 & 71.73 & 44.25 & 17.80 & 44.25 & 46.27 \\
\hline 44.50 & 26.29 & 44.50 & 72.19 & 44.50 & 17.96 & 44.50 & 46.68 \\
\hline 44.75 & 26.29 & 44.75 & 72.57 & 44.75 & 18.00 & 44.75 & 46.79 \\
\hline 45.00 & 26.48 & 45.00 & 72.99 & 45.00 & 17.69 & 45.00 & 46.00 \\
\hline 45.25 & 26.48 & 45.25 & 73.37 & 45.25 & 17.75 & 45.25 & 46.14 \\
\hline 45.50 & 26.69 & 45.50 & 73.72 & 45.50 & 17.88 & 45.50 & 46.49 \\
\hline 45.75 & 26.87 & 45.75 & 74.28 & 45.75 & 18.28 & 45.75 & 47.52 \\
\hline 46.00 & 26.54 & 46.00 & 73.59 & 46.00 & 18.00 & 46.00 & 46.80 \\
\hline 46.25 & 26.75 & 46.25 & 73.94 & 46.25 & 18.08 & 46.25 & 47.01 \\
\hline 46.50 & 26.75 & 46.50 & 74.36 & 46.50 & 18.17 & 46.50 & 47.25 \\
\hline 46.75 & 26.75 & 46.75 & 74.81 & 46.75 & 18.30 & 46.75 & 47.57 \\
\hline 47.00 & 26.95 & 47.00 & 75.26 & 47.00 & 18.35 & 47.00 & 47.70 \\
\hline 47.25 & 26.95 & 47.25 & 75.75 & 47.25 & 18.39 & 47.25 & 47.81 \\
\hline 47.50 & 27.14 & 47.50 & 76.38 & 47.50 & 18.51 & 47.50 & 48.12 \\
\hline 47.75 & 27.14 & 47.75 & 76.90 & 47.75 & 18.55 & 47.75 & 48.23 \\
\hline 48.00 & 27.02 & 48.00 & 76.11 & 48.00 & 18.64 & 48.00 & 48.47 \\
\hline 48.25 & 27.02 & 48.25 & 76.91 & 48.25 & 18.75 & 48.25 & 48.75 \\
\hline 48.50 & 27.23 & 48.50 & 77.19 & 48.50 & 18.81 & 48.50 & 48.89 \\
\hline 48.75 & 27.45 & 48.75 & 77.64 & 48.75 & 18.84 & 48.75 & 48.99 \\
\hline 49.00 & 27.45 & 49.00 & 78.06 & 49.00 & 18.95 & 49.00 & 49.27 \\
\hline 49.25 & 27.68 & 49.25 & 78.41 & 49.25 & 18.66 & 49.25 & 48.52 \\
\hline 49.50 & 27.68 & 49.50 & 78.82 & 49.50 & 18.73 & 49.50 & 48.69 \\
\hline 49.75 & 27.89 & 49.75 & 79.24 & 49.75 & 18.84 & 49.75 & 48.97 \\
\hline 50.00 & 28.12 & 50.00 & 79.94 & 50.00 & 18.90 & 50.00 & 49.14 \\
\hline 50.25 & 28.12 & 50.25 & 80.25 & 50.25 & 18.96 & 50.25 & 49.28 \\
\hline 50.50 & 28.32 & 50.50 & 80.64 & 50.50 & 19.04 & 50.50 & 49.49 \\
\hline 50.75 & 28.51 & 50.75 & 81.23 & 50.75 & 19.12 & 50.75 & 49.70 \\
\hline
\end{tabular}




\begin{tabular}{|c|c|c|c|c|c|c|c|}
\hline $\begin{array}{l}\text { AS } \\
\text { time } \\
\text { (hrs) }\end{array}$ & $\begin{array}{l}\text { oxygen } \\
\text { (mg/L) }\end{array}$ & $\begin{array}{l}\text { SWW } \\
\text { time } \\
\text { (hrs) }\end{array}$ & $\begin{array}{l}\text { oxygen } \\
\text { (mg/L) }\end{array}$ & $\begin{array}{l}\text { ABR-AS } \\
\text { time } \\
\text { (hrs) }\end{array}$ & $\begin{array}{l}\text { oxygen } \\
\text { (mg/L) }\end{array}$ & $\begin{array}{l}\text { ABR } \\
\text { time } \\
\text { (hrs) }\end{array}$ & $\begin{array}{l}\text { oxygen } \\
\text { (mg/L) }\end{array}$ \\
\hline$=======$ & $===========$ & $=======$ & $==========$ & $=======$ & $==========$ & $=======$ & $==========$ \\
\hline 51.00 & 28.38 & 51.00 & 80.54 & 51.00 & 19.18 & 51.00 & 49.87 \\
\hline 51.25 & 28.61 & 51.25 & 80.92 & 51.25 & 19.26 & 51.25 & 50.08 \\
\hline 51.50 & 28.61 & 51.50 & 81.52 & 51.50 & 19.34 & 51.50 & 50.29 \\
\hline 51.75 & 29.14 & 51.75 & 82.90 & 51.75 & 19.39 & 51.75 & 50.40 \\
\hline 52.00 & 29.05 & 52.00 & 82.18 & 52.00 & 19.42 & 52.00 & 50.50 \\
\hline 52.25 & 29.05 & 52.25 & 82.70 & 52.25 & 19.53 & 52.25 & 50.78 \\
\hline 52.50 & 29.25 & 52.50 & 83.12 & 52.50 & 19.59 & 52.50 & 50.92 \\
\hline 52.75 & 29.44 & 52.75 & 83.40 & 52.75 & 19.62 & 52.75 & 51.02 \\
\hline 53.00 & 29.44 & 53.00 & 83.75 & 53.00 & 19.72 & 53.00 & 51.27 \\
\hline 53.25 & 29.66 & 53.25 & 84.23 & 53.25 & 19.77 & 53.25 & 51.41 \\
\hline 53.50 & 29.88 & 53.50 & 84.69 & 53.50 & 19.83 & 53.50 & 51.55 \\
\hline 53.75 & 29.88 & 53.75 & 85.03 & 53.75 & 19.86 & 53.75 & 51.62 \\
\hline 54.00 & 30.08 & 54.00 & 85.59 & 54.00 & 19.92 & 54.00 & 51.79 \\
\hline 54.25 & 30.08 & 54.25 & 85.94 & 54.25 & 19.99 & 54.25 & 51.96 \\
\hline 54.50 & 30.31 & 54.50 & 86.29 & 54.50 & 20.06 & 54.50 & 52.14 \\
\hline 54.75 & 30.31 & 54.75 & 86.78 & 54.75 & 20.08 & 54.75 & 52.21 \\
\hline 55.00 & 30.49 & 55.00 & 86.78 & 55.00 & 20.15 & 55.00 & 52.38 \\
\hline 55.25 & 30.49 & 55.25 & 87.23 & 55.25 & 20.23 & 55.25 & 52.59 \\
\hline 55.50 & 30.69 & 55.50 & 87.61 & 55.50 & 20.29 & 55.50 & 52.76 \\
\hline 55.75 & 30.69 & 55.75 & 88.13 & 55.75 & 20.31 & 55.75 & 52.80 \\
\hline 56.00 & 30.90 & 56.00 & 88.41 & 56.00 & 20.34 & 56.00 & 52.87 \\
\hline 56.25 & 30.90 & 56.25 & 88.80 & 56.25 & 20.43 & 56.25 & 53.11 \\
\hline 56.50 & 31.11 & 56.50 & 89.11 & 56.50 & 20.48 & 56.50 & 53.25 \\
\hline 56.75 & 30.78 & 56.75 & 88.18 & 56.75 & 20.52 & 56.75 & 53.36 \\
\hline 57.00 & 30.99 & 57.00 & 88.53 & 57.00 & 20.61 & 57.00 & 53.57 \\
\hline 57.25 & 30.99 & 57.25 & 89.05 & 57.25 & 20.68 & 57.25 & 53.77 \\
\hline 57.50 & 31.18 & 57.50 & 89.29 & 57.50 & 20.76 & 57.50 & 53.98 \\
\hline 57.75 & 31.18 & 57.75 & 89.68 & 57.75 & 20.84 & 57.75 & 54.19 \\
\hline 58.00 & 31.40 & 58.00 & 90.09 & 58.00 & 20.91 & 58.00 & 54.37 \\
\hline 58.25 & 31.40 & 58.25 & 90.41 & 58.25 & 20.97 & 58.25 & 54.51 \\
\hline 58.50 & 31.40 & 58.50 & 90.72 & 58.50 & 21.02 & 58.50 & 54.65 \\
\hline 58.75 & 31.61 & 58.75 & 91.04 & 58.75 & 21.06 & 58.75 & 54.75 \\
\hline 59.00 & 31.61 & 59.00 & 91.35 & 59.00 & 21.06 & 59.00 & 54.75 \\
\hline 59.25 & 31.84 & 59.25 & 91.63 & 59.25 & 21.06 & 59.25 & 54.75 \\
\hline 59.50 & 31.84 & 59.50 & 92.15 & 59.50 & 21.06 & 59.50 & 54.75 \\
\hline 59.75 & 31.84 & 59.75 & 92.43 & 59.75 & 21.06 & 59.75 & 54.75 \\
\hline 60.00 & 31.74 & 60.00 & 91.71 & 60.00 & 21.06 & 60.00 & 54.75 \\
\hline 60.25 & 31.74 & 60.25 & 92.02 & 60.25 & 21.06 & 60.25 & 54.75 \\
\hline 60.50 & 31.96 & 60.50 & 92.40 & 60.50 & 21.06 & 60.50 & 54.75 \\
\hline 60.75 & 31.96 & 60.75 & 92.61 & 60.75 & 21.06 & 60.75 & 54.75 \\
\hline 61.00 & 31.96 & 61.00 & 92.96 & 61.00 & 21.09 & 61.00 & 54.82 \\
\hline
\end{tabular}




\begin{tabular}{|c|c|c|c|c|c|c|c|}
\hline $\begin{array}{l}\text { AS } \\
\text { time } \\
\text { (hrs) }\end{array}$ & $\begin{array}{l}\text { oxygen } \\
\text { (mg/L) }\end{array}$ & $\begin{array}{l}\text { SWW } \\
\text { time } \\
\text { (hrs) }\end{array}$ & $\begin{array}{l}\text { oxygen } \\
\text { (mg/L) }\end{array}$ & $\begin{array}{l}\text { ABR-AS } \\
\text { time } \\
\text { (hrs) }\end{array}$ & $\begin{array}{l}\text { oxygen } \\
\text { (mg/L) }\end{array}$ & $\begin{array}{l}\text { ABR } \\
\text { time } \\
\text { (hrs) }\end{array}$ & $\begin{array}{l}\text { oxygen } \\
\text { (mg/L) }\end{array}$ \\
\hline$=======$ & $===========$ & $=======$ & $==========$ & $=======$ & $==========$ & $=======$ & $==========$ \\
\hline 61.25 & 32.15 & 61.25 & 93.20 & 61.25 & 21.09 & 61.25 & 54.82 \\
\hline 61.50 & 32.15 & 61.50 & 93.55 & 61.50 & 21.10 & 61.50 & 54.86 \\
\hline 61.75 & 32.35 & 61.75 & 93.97 & 61.75 & 21.15 & 61.75 & 54.99 \\
\hline 62.00 & 32.35 & 62.00 & 94.25 & 62.00 & 21.18 & 62.00 & 55.06 \\
\hline 62.25 & 32.54 & 62.25 & 94.63 & 62.25 & 21.25 & 62.25 & 55.24 \\
\hline 62.50 & 32.54 & 62.50 & 94.91 & 62.50 & 21.31 & 62.50 & 55.41 \\
\hline 62.75 & 32.77 & 62.75 & 95.16 & 62.75 & 21.31 & 62.75 & 55.41 \\
\hline 63.00 & 32.77 & 63.00 & 95.54 & 63.00 & 21.36 & 63.00 & 55.52 \\
\hline 63.25 & 32.77 & 63.25 & 95.54 & 63.25 & 21.47 & 63.25 & 55.83 \\
\hline 63.50 & 32.94 & 63.50 & 95.85 & 63.50 & 21.50 & 63.50 & 55.90 \\
\hline 63.75 & 32.94 & 63.75 & 96.06 & 63.75 & 21.53 & 63.75 & 55.97 \\
\hline 64.00 & 32.94 & 64.00 & 96.48 & 64.00 & 21.66 & 64.00 & 56.32 \\
\hline 64.25 & 33.14 & 64.25 & 96.48 & 64.25 & 21.73 & 64.25 & 56.49 \\
\hline 64.50 & 33.14 & 64.50 & 96.79 & 64.50 & 21.76 & 64.50 & 56.57 \\
\hline 64.75 & 33.14 & 64.75 & 97.07 & 64.75 & 21.79 & 64.75 & 56.65 \\
\hline 65.00 & 33.33 & 65.00 & 97.49 & 65.00 & 21.82 & 65.00 & 56.72 \\
\hline 65.25 & 33.33 & 65.25 & 97.49 & 65.25 & 21.85 & 65.25 & 56.80 \\
\hline 65.50 & 33.33 & 65.50 & 97.94 & 65.50 & 21.88 & 65.50 & 56.88 \\
\hline 65.75 & 33.52 & 65.75 & 97.94 & 65.75 & 21.91 & 65.75 & 56.96 \\
\hline 66.00 & 33.52 & 66.00 & 98.22 & 66.00 & 21.94 & 66.00 & 57.03 \\
\hline 66.25 & 33.52 & 66.25 & 98.57 & 66.25 & 21.96 & 66.25 & 57.10 \\
\hline 66.50 & 33.72 & 66.50 & 98.57 & 66.50 & 21.99 & 66.50 & 57.18 \\
\hline 66.75 & 33.72 & 66.75 & 98.85 & 66.75 & 22.02 & 66.75 & 57.25 \\
\hline 67.00 & 33.72 & 67.00 & 99.16 & 67.00 & 22.05 & 67.00 & 57.32 \\
\hline 67.25 & 33.89 & 67.25 & 99.40 & 67.25 & 22.08 & 67.25 & 57.39 \\
\hline 67.50 & 33.89 & 67.50 & 99.72 & 67.50 & 22.10 & 67.50 & 57.46 \\
\hline 67.75 & 34.07 & 67.75 & 100.03 & 67.75 & 22.13 & 67.75 & 57.53 \\
\hline 68.00 & 34.07 & 68.00 & 100.35 & 68.00 & 22.16 & 68.00 & 57.60 \\
\hline 68.25 & 34.07 & 68.25 & 100.69 & 68.25 & 22.18 & 68.25 & 57.67 \\
\hline 68.50 & 34.26 & 68.50 & 100.69 & 68.50 & 22.21 & 68.50 & 57.73 \\
\hline 68.75 & 34.26 & 68.75 & 101.01 & 68.75 & 22.23 & 68.75 & 57.80 \\
\hline 69.00 & 34.46 & 69.00 & 101.36 & 69.00 & 22.26 & 69.00 & 57.86 \\
\hline 69.25 & 34.46 & 69.25 & 101.36 & 69.25 & 22.28 & 69.25 & 57.92 \\
\hline 69.50 & 34.46 & 69.50 & 101.36 & 69.50 & 22.30 & 69.50 & 57.99 \\
\hline 69.75 & 34.46 & 69.75 & 101.36 & 69.75 & 22.33 & 69.75 & 58.05 \\
\hline 70.00 & 34.46 & 70.00 & 101.36 & 70.00 & 22.35 & 70.00 & 58.11 \\
\hline 70.25 & 34.79 & 70.25 & 102.36 & 70.25 & 22.37 & 70.25 & 58.17 \\
\hline 70.50 & 34.46 & 70.50 & 101.36 & 70.50 & 22.40 & 70.50 & 58.23 \\
\hline 70.75 & 34.79 & 70.75 & 102.36 & 70.75 & 22.42 & 70.75 & 58.29 \\
\hline 71.00 & 34.46 & 71.00 & 101.36 & 71.00 & 22.44 & 71.00 & 58.34 \\
\hline 71.25 & 34.46 & 71.25 & 101.36 & 71.25 & 22.46 & 71.25 & 58.40 \\
\hline
\end{tabular}




\begin{tabular}{|c|c|c|c|c|c|c|c|}
\hline $\begin{array}{l}\text { AS } \\
\text { time } \\
\text { (hrs) }\end{array}$ & $\begin{array}{l}\text { oxygen } \\
\text { (mg/L) }\end{array}$ & $\begin{array}{l}\text { SWW } \\
\text { time } \\
\text { (hrs) }\end{array}$ & $\begin{array}{l}\text { oxygen } \\
\text { (mg/L) }\end{array}$ & $\begin{array}{l}\text { ABR-AS } \\
\text { time } \\
\text { (hrs) }\end{array}$ & $\begin{array}{l}\text { oxygen } \\
\text { (mg/L) }\end{array}$ & $\begin{array}{l}\text { ABR } \\
\text { time } \\
\text { (hrs) }\end{array}$ & $\begin{array}{l}\text { oxygen } \\
\text { (mg/L) }\end{array}$ \\
\hline$=======$ & $===========$ & $=======$ & $==========$ & $=======$ & $==========$ & $=======$ & $==========$ \\
\hline 71.50 & 34.46 & 71.50 & 101.36 & 71.50 & 22.48 & 71.50 & 58.46 \\
\hline 71.75 & 34.46 & 71.75 & 101.36 & 71.75 & 22.51 & 71.75 & 58.51 \\
\hline 72.00 & 34.46 & 72.00 & 101.36 & 72.00 & 22.53 & 72.00 & 58.56 \\
\hline 72.25 & 34.46 & 72.25 & 101.36 & 72.25 & 22.55 & 72.25 & 58.62 \\
\hline 72.50 & 34.46 & 72.50 & 101.36 & 72.50 & 22.57 & 72.50 & 58.67 \\
\hline 72.75 & 34.46 & 72.75 & 101.36 & 72.75 & 22.59 & 72.75 & 58.72 \\
\hline 73.00 & 34.46 & 73.00 & 101.36 & 73.00 & 22.61 & 73.00 & 58.77 \\
\hline 73.25 & 34.46 & 73.25 & 101.36 & 73.25 & 22.62 & 73.25 & 58.82 \\
\hline 73.50 & 34.59 & 73.50 & 101.36 & 73.50 & 22.64 & 73.50 & 58.87 \\
\hline 73.75 & 34.59 & 73.75 & 101.63 & 73.75 & 22.66 & 73.75 & 58.92 \\
\hline 74.00 & 34.76 & 74.00 & 101.95 & 74.00 & 22.68 & 74.00 & 58.96 \\
\hline 74.25 & 34.76 & 74.25 & 102.33 & 74.25 & 22.70 & 74.25 & 59.01 \\
\hline 74.50 & 34.76 & 74.50 & 102.33 & 74.50 & 22.71 & 74.50 & 59.05 \\
\hline 74.75 & 34.91 & 74.75 & 102.57 & 74.75 & 22.73 & 74.75 & 59.10 \\
\hline 75.00 & 34.91 & 75.00 & 102.89 & 75.00 & 22.75 & 75.00 & 59.14 \\
\hline 75.25 & 35.04 & 75.25 & 103.20 & 75.25 & 22.76 & 75.25 & 59.18 \\
\hline 75.50 & 35.04 & 75.50 & 103.51 & 75.50 & 22.78 & 75.50 & 59.22 \\
\hline 75.75 & 35.32 & 75.75 & 103.83 & 75.75 & 22.80 & 75.75 & 59.26 \\
\hline 76.00 & 35.32 & 76.00 & 104.32 & 76.00 & 22.81 & 76.00 & 59.30 \\
\hline 76.25 & 35.52 & 76.25 & 104.52 & 76.25 & 22.83 & 76.25 & 59.34 \\
\hline 76.50 & 35.52 & 76.50 & 104.80 & 76.50 & 22.84 & 76.50 & 59.38 \\
\hline 76.75 & 35.68 & 76.75 & 105.15 & 76.75 & 22.85 & 76.75 & 59.41 \\
\hline 77.00 & 35.68 & 77.00 & 105.40 & 77.00 & 22.87 & 77.00 & 59.45 \\
\hline 77.25 & 35.68 & 77.25 & 105.81 & 77.25 & 22.88 & 77.25 & 59.49 \\
\hline 77.50 & 35.90 & 77.50 & 105.81 & 77.50 & 22.89 & 77.50 & 59.52 \\
\hline 77.75 & 35.90 & 77.75 & 106.27 & 77.75 & 22.91 & 77.75 & 59.55 \\
\hline 78.00 & 36.05 & 78.00 & 106.51 & 78.00 & 22.92 & 78.00 & 59.59 \\
\hline 78.25 & 36.05 & 78.25 & 106.89 & 78.25 & 22.93 & 78.25 & 59.62 \\
\hline 78.50 & 36.25 & 78.50 & 107.24 & 78.50 & 22.94 & 78.50 & 59.65 \\
\hline 78.75 & 36.25 & 78.75 & 107.24 & 78.75 & 22.95 & 78.75 & 59.68 \\
\hline 79.00 & 36.25 & 79.00 & 107.83 & 79.00 & 22.97 & 79.00 & 59.71 \\
\hline 79.25 & 36.46 & 79.25 & 108.04 & 79.25 & 22.98 & 79.25 & 59.73 \\
\hline 79.50 & 36.46 & 79.50 & 108.04 & 79.50 & 22.99 & 79.50 & 59.76 \\
\hline 79.75 & 36.46 & 79.75 & 108.39 & 79.75 & 23.00 & 79.75 & 59.79 \\
\hline 80.00 & 36.67 & 80.00 & 108.67 & 80.00 & 23.01 & 80.00 & 59.81 \\
\hline 80.25 & 36.67 & 80.25 & 108.98 & 80.25 & 23.02 & 80.25 & 59.84 \\
\hline 80.50 & 36.88 & 80.50 & 109.33 & 80.50 & 23.02 & 80.50 & 59.86 \\
\hline 80.75 & 36.88 & 80.75 & 109.61 & 80.75 & 23.03 & 80.75 & 59.88 \\
\hline 81.00 & 36.88 & 81.00 & 109.89 & 81.00 & 23.04 & 81.00 & 59.90 \\
\hline 81.25 & 37.08 & 81.25 & 110.20 & 81.25 & 23.05 & 81.25 & 59.92 \\
\hline 81.50 & 37.08 & 81.50 & 110.48 & 81.50 & 23.06 & 81.50 & 59.94 \\
\hline
\end{tabular}




\begin{tabular}{|c|c|c|c|c|c|c|c|}
\hline $\begin{array}{l}\text { AS } \\
\text { time } \\
\text { (hrs) }\end{array}$ & $\begin{array}{l}\text { oxygen } \\
\text { (mg/L) }\end{array}$ & $\begin{array}{l}\text { SWW } \\
\text { time } \\
\text { (hrs) }\end{array}$ & $\begin{array}{l}\text { oxygen } \\
\text { (mg/L) }\end{array}$ & $\begin{array}{l}\text { ABR-AS } \\
\text { time } \\
\text { (hrs) }\end{array}$ & $\begin{array}{l}\text { oxygen } \\
\text { (mg/L) }\end{array}$ & $\begin{array}{l}\text { ABR } \\
\text { time } \\
\text { (hrs) }\end{array}$ & $\begin{array}{l}\text { oxygen } \\
\text { (mg/L) }\end{array}$ \\
\hline$=======$ & $===========$ & $=======$ & $==========$ & $=======$ & $==========$ & $=======$ & $==========$ \\
\hline 81.75 & 37.29 & 81.75 & 111.21 & 81.75 & 23.06 & 81.75 & 59.96 \\
\hline 82.00 & 37.29 & 82.00 & 111.21 & 82.00 & 23.07 & 82.00 & 59.98 \\
\hline 82.25 & 37.51 & 82.25 & 111.74 & 82.25 & 23.08 & 82.25 & 60.00 \\
\hline 82.50 & 37.51 & 82.50 & 112.26 & 82.50 & 23.08 & 82.50 & 60.01 \\
\hline 82.75 & 37.42 & 82.75 & 111.81 & 82.75 & 23.09 & 82.75 & 60.03 \\
\hline 83.00 & 37.95 & 83.00 & 113.30 & 83.00 & 23.10 & 83.00 & 60.04 \\
\hline 83.25 & 37.62 & 83.25 & 112.96 & 83.25 & 23.10 & 83.25 & 60.06 \\
\hline 83.50 & 37.82 & 83.50 & 113.70 & 83.50 & 23.11 & 83.50 & 60.07 \\
\hline 83.75 & 38.37 & 83.75 & 114.04 & 83.75 & 23.11 & 83.75 & 60.08 \\
\hline 84.00 & 38.04 & 84.00 & 114.67 & 84.00 & 23.11 & 84.00 & 60.09 \\
\hline 84.25 & 38.26 & 84.25 & 115.16 & 84.25 & 23.12 & 84.25 & 60.10 \\
\hline 84.50 & 38.81 & 84.50 & 116.54 & 84.50 & 23.12 & 84.50 & 60.11 \\
\hline 84.75 & 38.48 & 84.75 & 116.24 & 84.75 & 23.13 & 84.75 & 60.13 \\
\hline 85.00 & 39.05 & 85.00 & 117.80 & 85.00 & 23.13 & 85.00 & 60.14 \\
\hline 85.25 & 38.71 & 85.25 & 117.14 & 85.25 & 23.14 & 85.25 & 60.15 \\
\hline 85.50 & 38.96 & 85.50 & 117.49 & 85.50 & 23.14 & 85.50 & 60.16 \\
\hline 85.75 & 39.29 & 85.75 & 119.15 & 85.75 & 23.14 & 85.75 & 60.17 \\
\hline 86.00 & 39.22 & 86.00 & 118.33 & 86.00 & 23.15 & 86.00 & 60.18 \\
\hline 86.25 & 39.22 & 86.25 & 118.61 & 86.25 & 23.15 & 86.25 & 60.19 \\
\hline 86.50 & 39.43 & 86.50 & 118.85 & 86.50 & 23.16 & 86.50 & 60.20 \\
\hline 86.75 & 39.77 & 86.75 & 119.23 & 86.75 & 23.16 & 86.75 & 60.21 \\
\hline 87.00 & 39.77 & 87.00 & 120.23 & 87.00 & 23.16 & 87.00 & 60.22 \\
\hline 87.25 & 39.77 & 87.25 & 120.23 & 87.25 & 23.17 & 87.25 & 60.23 \\
\hline 87.50 & 39.43 & 87.50 & 119.23 & 87.50 & 23.17 & 87.50 & 60.24 \\
\hline 87.75 & 39.77 & 87.75 & 120.23 & 87.75 & 23.18 & 87.75 & 60.26 \\
\hline 88.00 & 39.77 & 88.00 & 120.23 & 88.00 & 23.18 & 88.00 & 60.27 \\
\hline 88.25 & 39.77 & 88.25 & 120.51 & 88.25 & 23.19 & 88.25 & 60.28 \\
\hline 88.50 & 39.77 & 88.50 & 120.51 & 88.50 & 23.19 & 88.50 & 60.29 \\
\hline 88.75 & 39.77 & 88.75 & 120.69 & 88.75 & 23.19 & 88.75 & 60.30 \\
\hline 89.00 & 39.77 & 89.00 & 120.69 & 89.00 & 23.20 & 89.00 & 60.31 \\
\hline 89.25 & 39.91 & 89.25 & 120.97 & 89.25 & 23.20 & 89.25 & 60.32 \\
\hline 89.50 & 39.91 & 89.50 & 120.97 & 89.50 & 23.21 & 89.50 & 60.33 \\
\hline 89.75 & 39.91 & 89.75 & 121.28 & 89.75 & 23.21 & 89.75 & 60.34 \\
\hline 90.00 & 39.91 & 90.00 & 121.28 & 90.00 & 23.21 & 90.00 & 60.35 \\
\hline 90.25 & 39.91 & 90.25 & 121.28 & 90.25 & 23.22 & 90.25 & 60.36 \\
\hline 90.50 & 39.91 & 90.50 & 121.52 & 90.50 & 23.22 & 90.50 & 60.38 \\
\hline 90.75 & 39.91 & 90.75 & 121.52 & 90.75 & 23.23 & 90.75 & 60.39 \\
\hline 91.00 & 39.91 & 91.00 & 121.52 & 91.00 & 23.23 & 91.00 & 60.40 \\
\hline 91.25 & 39.91 & 91.25 & 121.52 & 91.25 & 23.24 & 91.25 & 60.41 \\
\hline 91.50 & 39.91 & 91.50 & 121.52 & 91.50 & 23.24 & 91.50 & 60.42 \\
\hline 91.75 & 39.91 & 91.75 & 121.52 & 91.75 & 23.24 & 91.75 & 60.43 \\
\hline
\end{tabular}




\begin{tabular}{|c|c|c|c|c|c|c|c|}
\hline $\begin{array}{l}\text { AS } \\
\text { time } \\
\text { (hrs) }\end{array}$ & $\begin{array}{l}\text { oxygen } \\
\text { (mg/L) }\end{array}$ & $\begin{array}{l}\text { SWW } \\
\text { time } \\
\text { (hrs) }\end{array}$ & $\begin{array}{l}\text { oxygen } \\
\text { (mg/L) }\end{array}$ & $\begin{array}{l}\text { ABR-AS } \\
\text { time } \\
\text { (hrs) }\end{array}$ & $\begin{array}{l}\text { oxygen } \\
\text { (mg/L) }\end{array}$ & $\begin{array}{l}\text { ABR } \\
\text { time } \\
\text { (hrs) }\end{array}$ & $\begin{array}{l}\text { oxygen } \\
\text { (mg/L) }\end{array}$ \\
\hline$=======$ & $===========$ & $=======$ & $==========$ & $=======$ & $==========$ & $=======$ & $==========$ \\
\hline 92.00 & 39.91 & 92.00 & 121.52 & 92.00 & 23.25 & 92.00 & 60.44 \\
\hline 92.25 & 39.91 & 92.25 & 121.52 & 92.25 & 23.25 & 92.25 & 60.45 \\
\hline 92.50 & 39.91 & 92.50 & 121.52 & 92.50 & 23.26 & 92.50 & 60.46 \\
\hline 92.75 & 40.24 & 92.75 & 121.52 & 92.75 & 23.26 & 92.75 & 60.47 \\
\hline 93.00 & 39.91 & 93.00 & 121.52 & 93.00 & 23.27 & 93.00 & 60.48 \\
\hline 93.25 & 39.91 & 93.25 & 121.52 & 93.25 & 23.27 & 93.25 & 60.50 \\
\hline 93.50 & 40.24 & 93.50 & 122.52 & 93.50 & 23.27 & 93.50 & 60.51 \\
\hline 93.75 & 39.91 & 93.75 & 121.52 & 93.75 & 23.28 & 93.75 & 60.52 \\
\hline 94.00 & 40.24 & 94.00 & 122.52 & 94.00 & 23.28 & 94.00 & 60.53 \\
\hline 94.25 & 40.24 & 94.25 & 122.52 & 94.25 & 23.29 & 94.25 & 60.54 \\
\hline 94.50 & 40.24 & 94.50 & 122.52 & 94.50 & 23.29 & 94.50 & 60.55 \\
\hline 94.75 & 40.24 & 94.75 & 122.52 & 94.75 & 23.29 & 94.75 & 60.56 \\
\hline 95.00 & 39.91 & 95.00 & 121.52 & 95.00 & 23.30 & 95.00 & 60.57 \\
\hline 95.25 & 40.24 & 95.25 & 122.52 & 95.25 & 23.30 & 95.25 & 60.58 \\
\hline 95.50 & 40.24 & 95.50 & 122.52 & 95.50 & 23.31 & 95.50 & 60.59 \\
\hline 95.75 & 40.24 & 95.75 & 122.52 & 95.75 & 23.31 & 95.75 & 60.60 \\
\hline 96.00 & 40.24 & 96.00 & 122.52 & 96.00 & 23.32 & 96.00 & 60.62 \\
\hline 96.25 & 40.24 & 96.25 & 122.52 & 96.25 & 23.32 & 96.25 & 60.63 \\
\hline 96.50 & 40.24 & 96.50 & 122.52 & 96.50 & 23.32 & 96.50 & 60.64 \\
\hline 96.75 & 40.24 & 96.75 & 122.52 & 96.75 & 23.33 & 96.75 & 60.65 \\
\hline 97.00 & 40.24 & 97.00 & 122.52 & 97.00 & 23.33 & 97.00 & 60.66 \\
\hline 97.25 & 40.24 & 97.25 & 122.52 & 97.25 & 23.34 & 97.25 & 60.67 \\
\hline 97.50 & 40.24 & 97.50 & 122.52 & 97.50 & 23.34 & 97.50 & 60.68 \\
\hline 97.75 & 40.24 & 97.75 & 122.52 & 97.75 & 23.34 & 97.75 & 60.69 \\
\hline 98.00 & 40.24 & 98.00 & 122.52 & 98.00 & 23.35 & 98.00 & 60.70 \\
\hline 98.25 & 40.24 & 98.25 & 122.52 & 98.25 & 23.35 & 98.25 & 60.71 \\
\hline 98.50 & 40.24 & 98.50 & 122.52 & 98.50 & 23.36 & 98.50 & 60.72 \\
\hline 98.75 & 40.24 & 98.75 & 122.52 & 98.75 & 23.36 & 98.75 & 60.73 \\
\hline 99.00 & 40.24 & 99.00 & 122.52 & 99.00 & 23.37 & 99.00 & 60.75 \\
\hline 99.25 & 40.24 & 99.25 & 122.52 & 99.25 & 23.37 & 99.25 & 60.76 \\
\hline 99.50 & 40.24 & 99.50 & 122.52 & 99.50 & 23.37 & 99.50 & 60.77 \\
\hline 99.75 & 40.24 & 99.75 & 122.52 & 99.75 & 23.38 & 99.75 & 60.78 \\
\hline 100.00 & 40.24 & 100.00 & 122.52 & 100.00 & 23.38 & 100.00 & 60.79 \\
\hline 100.25 & 40.24 & 100.25 & 122.52 & 100.25 & 23.39 & 100.25 & 60.80 \\
\hline 100.50 & 40.24 & 100.50 & 122.52 & 100.50 & 23.39 & 100.50 & 60.81 \\
\hline 100.75 & 40.24 & 100.75 & 122.52 & 100.75 & 23.39 & 100.75 & 60.82 \\
\hline 101.00 & 40.24 & 101.00 & 122.52 & 101.00 & 23.40 & 101.00 & 60.83 \\
\hline 101.25 & 40.24 & 101.25 & 122.52 & 101.25 & 23.40 & 101.25 & 60.84 \\
\hline 101.50 & 40.24 & 101.50 & 122.52 & 101.50 & 23.41 & 101.50 & 60.85 \\
\hline 101.75 & 40.24 & 101.75 & 122.52 & 101.75 & 23.41 & 101.75 & 60.87 \\
\hline 102.00 & 40.24 & 102.00 & 122.52 & 102.00 & 23.42 & 102.00 & 60.88 \\
\hline
\end{tabular}


AS

time
(hrs)

==ニ===-

102.25

102.50

102.75

103.00

103.25

103.50

103.75

104.00

104.25

104.50

104.75

105.00

105.25

105.50

105.75

106.00

106.25

106.50

106.75

107.00

107.25

107.50

107.75

108.00

108.25

108.50

108.75

109.00

109.25

109.50

109.75

110.00

110.25

110.50

110.75

111.00

111.25

111.50

111.75

112.00

112.25 oxygen

(mg/L)

==-=========

40.24

40.24

40.24

40.24

40.24

40.24

40.24

40.24

40.24

40.24

40.57

40.57

40.24

40.24

40.24

40.24

40.24

40.24

40.24

40.24

40.24

40.32

40.32

40.39

40.46

40.60

40.60

40.60

40.74

40.74

40.74

40.74

40.87

40.99

41.55

41.27

41.76

42.09

42.43

42.65

42.65
sWW

time

(hrs)
==ニ==ニ=

102.25

102.50

102.75

103.00

103.25

103.50

103.75

104.00

104.25

104.50

104.75

105.00

105.25

105.50

105.75

106.00

106.25

106.50

106.75

107.00

107.25

107.50

107.75

108.00

108.25

108.50

108.75

109.00

109.25

109.50

109.75

110.00

110.25

110.50

110.75

111.00

111.25

111.50

111.75

112.00

112.25
ABR-AS

oxygen

(mg/L)

time (hrs) (mg/L)

=======

122.52

122.52

122.52

122.52

122.52

122.52

122.52

122.87

122.87

123.12

124.12

124.39

123.74

124.02

124.61

124.96

125.24

125.59

125.83

126.35

126.60

126.88

127.12

127.43

127.68

128.03

128.44

128.44

128.69

128.69

128.90

129.11

129.31

129.63

131.26

131.27

131.96

133.48

134.15

134.70

135.26
102.25

102.50

102.75

103.00

103.25

103.50

103.75

104.00

104.25

104.50

104.75

105.00

105.25

105.50

105.75

106.00

106.25

106.50

106.75

107.00

107.25

107.50

107.75

108.00

108.25

108.50

108.75

109.00

109.25

109.50

109.75

110.00

110.25

110.50

110.75

111.00

111.25

111.50

111.75

112.00

112.25
$==========$

23.42

23.42

23.43

23.43

23.44

23.44

23.45

23.45

23.45

23.46

23.46

23.47

23.47

23.47

23.48

23.48

23.49

23.49

23.50

23.50

23.50

23.51

23.51

23.52

23.52

23.52

23.53

23.53

23.54

23.54

23.55

23.55

23.55

23.56

23.56

23.57

23.57

23.58

23.58

23.58

23.59

ABR

time oxygen

(hrs) (mg/L)

=ニニニニニ=

102.25

102.50

102.75

103.00

103.25

103.50

103.75

104.00

104.25

104.50

104.75

105.00

105.25

105.50

105.75 
AS

time

$=====$

112.75

113.00

113.25

113.50

113.75

114.00

114.25

114.50

114.75

115.00

115.25

115.50

115.75

116.00

116.25

116.50

116.75

117.00

117.25

117.50

117.75

118.00

118.25

118.50

118.75

119.00

119.25

119.50

119.75

120.00

120.25

120.50

120.75

121.00

121.25

121.50

121.75

122.00

122.25

122.50

\begin{tabular}{|c|c|c|c|}
\hline $\begin{array}{l}\text { oxygen } \\
(\mathrm{mg} / \mathrm{L})\end{array}$ & $\begin{array}{l}\text { SWW } \\
\text { time } \\
\text { (hrs) }\end{array}$ & $\begin{array}{l}\text { oxygen } \\
\text { (mg/L) }\end{array}$ & $\begin{array}{l}\text { ABR-AS } \\
\text { time } \\
\text { (hrs) }\end{array}$ \\
\hline$===========$ & $=======$ & $==========$ & $=======$ \\
\hline 42.80 & 112.50 & 135.50 & 112.50 \\
\hline 43.02 & 112.75 & 136.13 & 112.75 \\
\hline 43.02 & 113.00 & 136.45 & 113.00 \\
\hline 43.03 & 113.25 & 137.18 & 113.25 \\
\hline 43.36 & 113.50 & 137.49 & 113.50 \\
\hline 43.36 & 113.75 & 137.66 & 113.75 \\
\hline 43.53 & 114.00 & 138.12 & 114.00 \\
\hline 43.53 & 114.25 & 138.50 & 114.25 \\
\hline 43.70 & 114.50 & 138.88 & 114.50 \\
\hline 43.70 & 114.75 & 139.13 & 114.75 \\
\hline 43.83 & 115.00 & 139.34 & 115.00 \\
\hline 44.17 & 115.25 & 140.79 & 115.25 \\
\hline 44.01 & 115.50 & 140.10 & 115.50 \\
\hline 44.34 & 115.75 & 141.38 & 115.75 \\
\hline 44.11 & 116.00 & 140.38 & 116.00 \\
\hline 44.57 & 116.25 & 141.76 & 116.25 \\
\hline 44.57 & 116.50 & 142.22 & 116.50 \\
\hline 44.69 & 116.75 & 142.36 & 116.75 \\
\hline 44.69 & 117.00 & 142.67 & 117.00 \\
\hline 44.86 & 117.25 & 142.88 & 117.25 \\
\hline 45.03 & 117.50 & 143.51 & 117.50 \\
\hline 45.18 & 117.75 & 143.89 & 117.75 \\
\hline 45.29 & 118.00 & 144.69 & 118.00 \\
\hline 45.45 & 118.25 & 145.18 & 118.25 \\
\hline 45.54 & 118.50 & 145.53 & 118.50 \\
\hline 45.69 & 118.75 & 145.84 & 118.75 \\
\hline 45.84 & 119.00 & 146.68 & 119.00 \\
\hline 46.06 & 119.25 & 147.13 & 119.25 \\
\hline 46.14 & 119.50 & 147.48 & 119.50 \\
\hline 46.30 & 119.75 & 147.72 & 119.75 \\
\hline 46.30 & 120.00 & 147.96 & 120.00 \\
\hline 46.57 & 120.25 & 148.59 & 120.25 \\
\hline 46.57 & 120.50 & 149.11 & 120.50 \\
\hline 46.73 & 120.75 & 149.74 & 120.75 \\
\hline 46.88 & 121.00 & 149.92 & 121.00 \\
\hline 46.98 & 121.25 & 150.26 & 121.25 \\
\hline 47.13 & 121.50 & 150.96 & 121.50 \\
\hline 47.30 & 121.75 & 151.34 & 121.75 \\
\hline 47.43 & 122.00 & 152.11 & 122.00 \\
\hline 47.58 & 122.25 & 152.39 & 122.25 \\
\hline 47.87 & 122.50 & 153.08 & 122.50 \\
\hline
\end{tabular}

$\begin{array}{lll} & A B R & \\ \text { oxygen } & \text { time } & \\ (m g / L) & \text { oxygen }\end{array}$

$(\mathrm{mg} / \mathrm{L}) \quad(\mathrm{hrs}) \quad(\mathrm{mg} / \mathrm{L})$

$==========$

23.59

$======$

23.60

112.50

$==========$

23.60

112.75

61.33

61.34

23.60

113.00

61.36

61.37

23.61

113.25

61.38

23.61

113.50

61.39

23.62

113.75

61.40

23.62

114.25

61.41

$23.63 \quad 114.50$

61.42

23.63

114.75

61.43

23.63

115.00

61.44

23.64

115.25

61.45

23.64

115.50

61.46

23.65

115.75

61.48

23.65

116.00

61.49

23.65

116.25

61.50

23.66

116.50

61.51

23.66

116.75

61.52

23.67

117.00

61.53

23.67

117.25

61.54

23.68

117.50

61.55

23.68

117.75

61.56

23.68

118.00

61.57

23.69

118.25

61.58

23.69

118.50

61.60

23.70

118.75

61.61

$23.70 \quad 119.00$

61.62

23.70

119.25

61.63

$23.71 \quad 119.50$

61.64

$23.71 \quad 119.75$

61.65

23.72

120.00

120.25

61.66

61.67

120.50

61.68

120.75

61.69

121.00

61.70

121.25

61.71

121.50

61.73

121.75

61.74

122.00

61.75

122.25

61.76

122.50

61.77 
AS

time

122.75

123.00

123.25

123.50

123.75

124.00

124.25

124.50

124.75

125.00

125.25

125.50

125.75

126.00

126.25

126.50

126.75

127.00

127.25

127.50

127.75

128.00

128.25

128.50

128.75

129.00

129.25

129.50

129.75

130.00

130.25

130.50

130.75

131.00

131.25

131.50

131.75

132.00

132.25

132.50

132.75
SWW

oxygen

(mg/L)

$===========$

47.87

48.05

48.17

48.38

48.56

48.72

48.81

49.03

49.03

49.22

49.22

49.39

49.39

49.56

49.56

49.71

50.21

49.88

50.04

50.04

50.21

50.21

50.31

50.50

50.50

50.50

50.93

51.08

51.08

51.27

51.27

51.2

51.39

51.72

51.87

52.06

52.06

52.06

52.55

52.22

52.22 time

(hrs)

=ニニ=ニニ=

122.75

123.00

123.25

123.50

123.75

124.00

124.25

124.50

124.75

125.00

125.25

125.50

125.75

126.00

126.25

126.50

126.75

127.00

127.25

127.50

127.75

128.00

128.25

128.50

128.75

129.00

129.25

129.50

129.75

130.00

130.25

130.50

130.75

131.00

131.25

131.50

131.75

132.00

132.25

132.50

132.75

\section{oxygen}

(mg/L)
ABR-AS

time

(hrs) (mg/L)

122.75

123.00

153.85

154.09

154.90

155.35

155.80

156.08

156.46

156.99

157.23

157.47

157.93

158.38

158.73

158.97

159.28

160.49

159.77

159.77

160.26

160.68

160.99

161.27

161.44

161.58

161.76

163.00

163.35

163.77

163.77

164.05

164.33

164.67

166.06

166.06

166.30

166.65

166.65

167.93

166.93

167.31
123.25

123.50

123.75

124.00

124.50

124.75

125.00

125.25

125.50

125.75

126.00

126.25

126.50

126.75

127.00

127.25

127.50

127.75

128.00

128.25

128.50

128.75

129.00

129.25

129.50

129.75

130.00

130.25

130.50

130.75

131.00

131.25

131.50

131.75

132.00

132.25

132.50

132.75
124.25 $\begin{array}{lll} & A B R & \\ \text { oxygen } & \text { time } & \text { oxygen }\end{array}$

(hrs) (mg/L)

$\begin{array}{cr}====== & ========= \\ 122.75 & 61.78 \\ 123.00 & 61.79 \\ 123.25 & 61.80 \\ 123.50 & 61.81 \\ 123.75 & 61.82 \\ 124.00 & 61.83\end{array}$

$124.25 \quad 61.85$

$124.50 \quad 61.86$

$124.75 \quad 61.87$

$125.00 \quad 61.88$

$125.25 \quad 61.89$

$125.50 \quad 61.90$

$125.75 \quad 61.91$

$126.00 \quad 61.92$

$126.25 \quad 61.93$

$126.50 \quad 61.94$

$126.75 \quad 61.95$

$127.00 \quad 61.97$

$127.25 \quad 61.98$

$127.50 \quad 61.99$

$127.75 \quad 62.00$

$128.00 \quad 62.01$

$128.25 \quad 62.02$

$128.50 \quad 62.03$

$128.75 \quad 62.04$

$129.00 \quad 62.05$

$129.25 \quad 62.06$

$129.50 \quad 62.07$

$129.75 \quad 62.09$

$130.00 \quad 62.10$

$130.25 \quad 62.11$

$130.50 \quad 62.12$

$130.75 \quad 62.13$

$131.00 \quad 62.14$

$131.25 \quad 62.15$

$131.50 \quad 62.16$

$131.75 \quad 62.17$

$132.00 \quad 62.18$

$132.25 \quad 62.19$

$132.50 \quad 62.20$

132.75

62.22 
AS

time

==ニ=ニ==

133.00

133.25

133.50

133.75

134.00

134.25

134.50

134.75

135.00

135.25

135.50

135.75

136.00

136.25

136.50

136.75

137.00

137.25

137.50

137.75

138.00

138.25

138.50

138.75

139.00

139.25

139.50

139.75

140.00

140.25

140.50

140.75

141.00

141.25

141.50

141.75

142.00

142.25

142.50

142.75

143.00

\begin{tabular}{|c|c|c|c|}
\hline $\begin{array}{l}\text { oxygen } \\
\text { (mg/L) }\end{array}$ & $\begin{array}{l}\text { SWW } \\
\text { time } \\
\text { (hrs) }\end{array}$ & $\begin{array}{l}\text { oxygen } \\
(\mathrm{mg} / \mathrm{L})\end{array}$ & $\begin{array}{l}\text { ABR-AS } \\
\text { time } \\
\text { (hrs) }\end{array}$ \\
\hline$=========-=$ & $=======$ & $==========$ & $======$ \\
\hline 51.89 & 133.00 & 166.31 & 133.00 \\
\hline 52.02 & 133.25 & 166.66 & 133.25 \\
\hline 52.02 & 133.50 & 166.66 & 133.50 \\
\hline 52.02 & 133.75 & 166.66 & 133.75 \\
\hline 52.15 & 134.00 & 166.97 & 134.00 \\
\hline 52.15 & 134.25 & 166.97 & 134.25 \\
\hline 52.15 & 134.50 & 167.15 & 134.50 \\
\hline 51.98 & 134.75 & 166.39 & 134.75 \\
\hline 51.98 & 135.00 & 166.39 & 135.00 \\
\hline 52.31 & 135.25 & 167.67 & 135.25 \\
\hline 52.79 & 135.50 & 169.05 & 135.50 \\
\hline 52.79 & 135.75 & 169.47 & 135.75 \\
\hline 52.64 & 136.00 & 168.78 & 136.00 \\
\hline 52.64 & 136.25 & 168.78 & 136.25 \\
\hline 52.64 & 136.50 & 169.03 & 136.50 \\
\hline 52.77 & 136.75 & 169.03 & 136.75 \\
\hline 52.77 & 137.00 & 169.27 & 137.00 \\
\hline 52.90 & 137.25 & 169.58 & 137.25 \\
\hline 53.05 & 137.50 & 170.01 & 137.50 \\
\hline 53.05 & 137.75 & 170.08 & 137.75 \\
\hline 53.05 & 138.00 & 171.22 & 138.00 \\
\hline 53.15 & 138.25 & 170.63 & 138.25 \\
\hline 53.15 & 138.50 & 170.63 & 138.50 \\
\hline 53.31 & 138.75 & 170.88 & 138.75 \\
\hline 53.31 & 139.00 & 171.16 & 139.00 \\
\hline 53.42 & 139.25 & 171.40 & 139.25 \\
\hline 53.42 & 139.50 & 171.40 & 139.50 \\
\hline 53.42 & 139.75 & 171.40 & 139.75 \\
\hline 53.55 & 140.00 & 171.71 & 140.00 \\
\hline 53.55 & 140.25 & 171.71 & 140.25 \\
\hline 53.55 & 140.50 & 171.71 & 140.50 \\
\hline 53.55 & 140.75 & 172.10 & 140.75 \\
\hline 53.65 & 141.00 & 172.10 & 141.00 \\
\hline 53.65 & 141.25 & 172.48 & 141.25 \\
\hline 53.77 & 141.50 & 172.48 & 141.50 \\
\hline 53.77 & 141.75 & 172.48 & 141.75 \\
\hline 53.77 & 142.00 & 172.72 & 142.00 \\
\hline 53.85 & 142.25 & 172.72 & 142.25 \\
\hline 53.85 & 142.50 & 173.00 & 142.50 \\
\hline 53.85 & 142.75 & 173.00 & 142.75 \\
\hline 54.29 & 143.00 & 174.32 & 143.00 \\
\hline
\end{tabular}

oxygen time oxygen

$(\mathrm{mg} / \mathrm{L}) \quad(\mathrm{hrs}) \quad(\mathrm{mg} / \mathrm{L})$

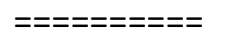

=ニ=ニ=ニ

133.00

133.25

133.50

133.75

134.00

134.25

134.50

134.75

135.00

135.25

135.50

135.75

136.00

136.25

136.50

136.75

137.00

137.25

137.50

137.75

138.00

138.25

138.50

138.75

139.00

139.25

139.50

139.75

140.00

140.25

140.50

140.75

141.00

141.25

141.50

141.75

142.00

142.25

142.50

142.75

143.00

$=======$
62.23
62.24
62.25
62.26
62.27
62.28
62.29
62.30
62.31
62.32
62.34
62.35
62.36
62.37
62.38
62.39
62.40
62.41
62.42
62.43
62.44
62.46
62.47
62.48
62.49
62.50
62.51
62.52
62.53
62.54
62.55
62.56
62.58
62.59
62.60
62.61
62.62
62.63
62.64
62.65
62.66


AS

time

143.25

143.50

143.75

144.00

144.25

144.50

144.75

145.00

145.25

145.50

145.75

146.00

146.25

146.50

146.75

147.00

147.25

147.50

147.75

148.00

148.25

148.50

148.75

149.00

149.25

149.50

149.75

150.00

150.25

150.50

150.75

151.00

151.25

151.50

151.75

152.00

152.25

152.50

152.75

153.00

153.25
SWW

oxygen

(mg/L)

===========

53.95

54.04

54.04

54.16

54.16

54.27

54.27

54.27

54.37

54.54

54.54

54.54

54.37

54.56

54.89

54.89

54.89

54.89

55.23

55.23

55.23

55.23

55.30

55.30

55.36

55.36

55.36

55.36

55.41

55.41

55.47

55.52

55.52

55.60

55.60

55.68

55.75

55.75

55.75

55.82

55.89 time

(hrs)

=ニニ=ニ==

143.25

143.50

143.75

144.00

144.25

144.50

144.75

145.00

145.25

145.50

145.75

146.00

146.25

146.50

146.75

147.00

147.25

147.50

147.75

148.00

148.25

148.50

148.75

149.00

149.25

149.50

149.75

150.00

150.25

150.50

150.75

151.00

151.25

151.50

151.75

152.00

152.25

152.50

152.75

153.00

153.25

\begin{tabular}{|c|c|c|}
\hline $\begin{array}{l}\text { oxygen } \\
\text { (mg/L) }\end{array}$ & $\begin{array}{l}\text { ABR-AS } \\
\text { time } \\
\text { (hrs) }\end{array}$ & $\begin{array}{l}\text { oxygen } \\
\text { (mg/L) }\end{array}$ \\
\hline$==========$ & $=======$ & $==========$ \\
\hline 173.32 & 143.25 & \\
\hline 173.32 & 143.50 & \\
\hline 173.59 & 143.75 & \\
\hline
\end{tabular}

$173.87 \quad 144.00$

$173.87 \quad 144.25$

$174.19 \quad 144.50$

$174.57 \quad 144.75$

$174.57 \quad 145.00$

$174.85 \quad 145.25$

$174.85 \quad 145.50$

$175.13 \quad 145.75$

$175.13 \quad 146.00$

$174.75 \quad 146.25$

$175.00 \quad 146.50$

$176.00 \quad 146.75$

$176.00 \quad 147.00$

$176.00 \quad 147.25$

$176.28 \quad 147.50$

$177.28 \quad 147.75$

$177.28 \quad 148.00$

$177.28 \quad 148.25$

$177.28 \quad 148.50$

$177.62 \quad 148.75$

$177.62 \quad 149.00$

$178.04 \quad 149.25$

$178.04 \quad 149.50$

$178.04 \quad 149.75$

$178.04 \quad 150.00$

$178.04 \quad 150.25$

$178.29 \quad 150.50$

$178.29 \quad 150.75$

$178.53 \quad 151.00$

$178.53 \quad 151.25$

$178.70 \quad 151.50$

$178.70 \quad 151.75$

$179.09 \quad 152.00$

$179.09 \quad 152.25$

$179.40 \quad 152.50$

$179.40 \quad 152.75$

$179.64 \quad 153.00$

$179.64 \quad 153.25$
ABR

time oxygen

(hrs) (mg/L)

$\begin{array}{cr}====== & ========= \\ 143.25 & 62.67 \\ 143.50 & 62.68 \\ 143.75 & 62.69 \\ 144.00 & 62.71\end{array}$

144.25

144.50

144.75

145.00

145.25

145.50

145.75

146.00

146.25

146.50

146.75

147.00

147.25

147.50

147.75

148.00

148.25

148.50

148.75

149.00

149.25

149.50

149.75

150.00

150.25

150.50

150.75

151.00

151.25

151.50

151.75

152.00

152.25

152.50

152.75

153.00

153.25 
AS

time

==ニ==ニ

153.50

153.75

154.00

154.25

154.50

154.75

155.00

155.25

155.50

155.75

156.00

156.25

156.50

156.75

157.00

157.25

157.50

157.75

158.00

158.25

158.50

158.75

159.00

159.25

159.50

159.75

160.00

160.25

160.50

160.75

161.00

161.25

161.50

161.75

162.00

162.25

162.50

162.75

163.00

163.25

163.50
sWW

time

(hrs)

(mg/L)

===========

55.96

55.96

$====$

153.50

153.75

56.05

56.05

154.00

154.25

56.13

154.50

56.13

154.75

56.21

155.00

56.21

155.25

56.38

155.50

56.38

155.75

56.38

156.00

56.44

156.25

56.55

156.50

56.55

156.75

56.55

157.00

56.64

157.25

56.64

157.50

56.64

157.75

56.64

158.00

$56.64 \quad 158.25$

56.64

56.71

158.50

158.75

56.71

159.00

$56.71 \quad 159.25$

$56.71 \quad 159.50$

$56.71 \quad 159.75$

$56.71 \quad 160.00$

$56.71 \quad 160.25$

$56.71 \quad 160.50$

$56.71 \quad 160.75$

$57.05 \quad 161.00$

$56.78 \quad 161.25$

$57.11 \quad 161.50$

$57.11 \quad 161.75$

$57.11 \quad 162.00$

$57.17 \quad 162.25$

$57.17 \quad 162.50$

$56.91 \quad 162.75$

$57.00 \quad 163.00$

$57.34 \quad 163.25$

$57.41 \quad 163.50$

oxygen

(mg/L)

==-=======

179.89

179.89

180.20

180.20

180.41

180.69

181.00

181.00

181.28

181.28

181.63

181.63

181.84

181.84

182.05

182.05

182.29

182.29

182.57

182.57

182.57

182.57

182.57

182.57

182.74

182.74

182.74

182.74

182.74

182.74

183.92

183.23

184.23

184.23

184.23

184.55

184.55

183.79

184.07

184.07

185.42
ABR-AS

time oxygen

(hrs) $\quad(\mathrm{mg} / \mathrm{L})$

ニニニニニニニ =ニニニニニニニニニ

153.50

153.75

154.00

154.25

154.50

154.75

155.00

155.25

155.50

155.75

156.00

156.25

156.50

156.75

157.00

157.25

157.50

157.75

158.00

158.25

158.50

158.75

159.00

159.25

159.50

159.75

160.00

160.25

160.50

160.75

161.00

161.25

161.50

161.75

162.00

162.25

162.50

162.75

163.00

163.25

163.50
ABR

time oxygen

(hrs) (mg/L)

$==$
153.50

153.75

154.00

154.25

154.50

154.75

155.00

155.25

155.50

155.75

156.00

156.25

156.50

156.75

157.00

157.25

157.50

157.75

158.00

158.25

158.50

158.75

159.00

159.25

159.50

159.75

160.00

160.25

160.50

160.75

161.00

161.25

161.50

161.75

162.00

162.25

162.50

162.75

163.00

163.25

163.50 
AS

time
(hrs)
$====$

163.75

164.00

164.25

164.50

164.75

165.00

165.25

165.50

165.75

166.00

166.25

166.50

166.75

167.00

167.25

167.50

167.75

168.00

168.25

168.50

168.75

169.00

169.25

169.50

169.75

170.00

170.25

170.50

170.75

171.00

171.25

171.50

171.75

172.00

172.25

172.50

172.75

173.00

173.25

173.50

173.75 oxygen

(mg/L)

===========

57.41

57.41

57.50

57.50

57.50

57.58

57.58

57.72

57.87

57.87

57.87

57.87

57.97

57.97

58.02

58.12

58.12

58.12

58.12

58.12

58.12

58.18

58.29

58.62

58.73

58.83

58.50

58.61

58.61

58.73

58.73

58.87

58.96

58.98

59.11

59.11

59.25

59.25

59.25

59.25

59.25
SWW

time

(hrs)

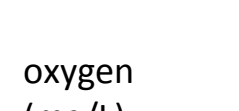

(mg/L)

========== 185.42

185.42

185.42

185.70

185.70

186.01

186.01

186.25

186.60

186.60

186.60

186.88

187.30

187.30

187.30

187.75

187.75

187.75

187.75

187.75

188.03

188.03

188.27

189.62

189.97

189.97

189.21

189.42

189.70

190.05

190.12

190.33

190.68

190.68

190.95

190.95

191.27

191.27

191.27

191.62

191.62
ABR-AS

time oxygen

(hrs) (mg/L)

163.75

164.00

164.25

164.50

164.75

165.00

165.25

165.50

165.75

166.00

166.25

166.50

166.75

167.00

167.25

167.50

167.75

168.00

168.25

168.50

168.75

169.00

169.25

169.50

169.75

170.00

170.25

170.50

170.75

171.00

171.25

171.50

171.75

172.00

172.25

172.50

172.75

173.00

173.25

173.50

173.75
ABR

time oxygen

(hrs) (mg/L)

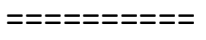

163.7

164.00

164.25

164.50

164.75

165.00

165.25

165.50

165.75

166.00

166.25

166.50

166.75

167.00

167.25

167.50

167.75

168.00

168.25

168.50

168.75

169.00

169.25

169.50

169.75

170.00

170.25

170.50

170.75

171.00

171.25

171.50

171.75

172.00

172.25

172.50

172.75

173.00

173.25

173.50

173.75 
AS

time

$======$

174.25

174.50

174.75

175.00

175.25

175.50

175.75

176.00

176.25

176.50

176.75

177.00

177.25

177.50

177.75

178.00

178.25

178.50

178.75

179.00

179.25

179.50

179.75

180.00

180.25

180.50

180.75

181.00

181.25

181.50

181.75

182.00

182.25

182.50

182.75

183.00

183.25

183.50

183.75

184.00
sWW

time

(hrs) oxygen

(mg/L)

59.36

59.36

59.51

59.51

59.51

59.70

59.70

59.70

59.70

59.70

59.70

59.70

59.70

59.70

59.76

59.76

59.84

59.84

59.92

60.04

60.04

60.04

60.12

60.27

60.6

60.27

60.2

60.37

60.37

60.45

60.45

60.61

60.61

60.61

60.61

60.61

60.61

60.61

60.61

60.61

60.61
=======

174.00

174.25

174.50

174.75

175.00

175.25

175.50

175.75

176.00

176.25

176.50

176.75

177.00

177.25

177.50

177.75

178.00

178.25

178.50

178.75

179.00

179.25

179.50

179.75

180.00

180.25

180.50

180.75

181.00

181.25

181.50

181.75

182.00

182.25

182.50

182.75

183.00

183.25

183.50

183.75

184.00
ABR-AS

oxygen time oxygen

(hrs) (mg/L)

$==========\quad=======$

$$
191.62
$$

191.62

191.89

192.28

192.28

192.28

192.56

192.56

192.56

192.84

192.84

193.22

193.22

193.53

193.53

193.74

194.02

194.33

194.68

194.68

195.03

195.03

195.31

195.55

196.55

195.83

196.00

196.35

196.35

196.35

196.81

196.81

196.81

197.15

197.15

197.15

197.40

197.40

197.40

197.40

197.40
174.00

174.25

174.50

174.75

175.00

175.25

175.50

175.75

176.00

176.25

176.50

176.75

177.00

177.25

177.50

177.75

178.00

178.25

178.50

178.75

179.00

179.25

179.50

179.75

180.00

180.25

180.50

180.75

181.00

181.25

181.50

181.75

182.00

182.25

182.50

182.75

183.00

183.25

183.50

183.75

184.00
ABR

time oxygen

(hrs) (mg/L)

ニニニニニニニニニニ

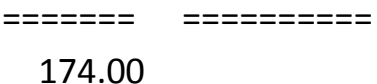

174.25

174.50

174.75

175.00

175.25

175.50

175.75

176.00

176.25

176.50

176.75

177.00

177.25

177.50

177.75

178.00

178.25

178.50

178.75

179.00

179.25

179.50

179.75

180.00

180.25

180.50

180.75

181.00

181.25

181.50

181.75

182.00

182.25

182.50

182.75

183.00

183.25

183.50

183.75

184.00 
AS

time
(hrs)

184.25

184.50

184.75

185.00

185.25

185.50

185.75

186.00

186.25

186.50

186.75

187.00

187.25

187.50

187.75

188.00

188.25

188.50

188.75

189.00

189.25

189.50

189.75

190.00

190.25

190.50

190.75

191.00

191.25

191.50

191.75

192.00

192.25

192.50

192.75

193.00

193.25

193.50

193.75

194.00

194.25
sWW

oxygen

(mg/L)

=========== 60.61

60.61

60.61

60.70

60.70

60.70

60.70

61.04

61.04

61.04

61.04

61.04

61.04

61.04

61.37

61.04

61.37

61.37

61.37

61.37

61.37

61.37

61.43

61.43

61.43

61.43

61.43

61.52

61.52

61.52

61.52

61.71

61.71

61.71

61.71

61.71

61.71

61.71

61.71

61.71

61.47 time

(hrs)

=ニ=ニ=ニ=

184.25

184.50

184.75

185.00

185.25

185.50

185.75

186.00

186.25

186.50

186.75

187.00

187.25

187.50

187.75

188.00

188.25

188.50

188.75

189.00

189.25

189.50

189.75

190.00

190.25

190.50

190.75

191.00

191.25

191.50

191.75

192.00

192.25

192.50

192.75

193.00

193.25

193.50

193.75

194.00

194.25
ABR-AS

oxygen

(mg/L)

==========

$$
197.40
$$

197.68

197.68

197.68

197.68

197.68

197.68

198.68

198.68

198.68

199.03

199.03

199.03

199.03

200.03

199.03

200.03

200.03

200.03

200.03

200.03

200.03

200.27

200.27

200.27

200.27

200.27

200.27

200.27

200.27

200.27

200.27

200.27

200.27

200.27

200.41

200.41

200.41

200.72

200.72

200.21 time

(hrs) (mg/L)

=======

184.25

184.50

184.75

185.00

185.25

185.50

185.75

186.00

186.25

186.50

186.75

187.00

187.25

187.50

187.75

188.00

188.25

188.50

188.75

189.00

189.25

189.50

189.75

190.00

190.25

190.50

190.75

191.00

191.25

191.50

191.75

192.00

192.25

192.50

192.75

193.00

193.25

193.50

193.75

194.00

194.25
ABR

time oxygen

(hrs) (mg/L)

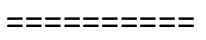

184.25
184.50
184.75

185.25

185.50

185.75

186.00

186.25

186.50

186.75

187.00

187.25

187.50

187.75

188.00

188.25

188.50

188.75

189.00

189.25

189.50

189.75

190.00

190.25

190.50

190.75

191.00

191.25

191.50

191.75

192.00

192.25

192.50

192.75

193.00

193.25

193.50

193.75

194.00

194.25 


\begin{tabular}{|c|c|c|c|c|c|c|c|}
\hline $\begin{array}{l}\text { AS } \\
\text { time } \\
\text { (hrs) }\end{array}$ & $\begin{array}{l}\text { oxygen } \\
\text { (mg/L) }\end{array}$ & $\begin{array}{l}\text { SWW } \\
\text { time } \\
\text { (hrs) }\end{array}$ & $\begin{array}{l}\text { oxygen } \\
\text { (mg/L) }\end{array}$ & $\begin{array}{l}\text { ABR-AS } \\
\text { time } \\
\text { (hrs) }\end{array}$ & $\begin{array}{l}\text { oxygen } \\
(\mathrm{mg} / \mathrm{L})\end{array}$ & $\begin{array}{l}\text { ABR } \\
\text { time } \\
\text { (hrs) }\end{array}$ & $\begin{array}{l}\text { oxygen } \\
\text { (mg/L) }\end{array}$ \\
\hline$=======$ & =======-=== & $=======$ & $==========$ & $=======$ & $======ニ===$ & $=======$ & $==========$ \\
\hline 194.50 & 61.94 & 194.50 & 201.21 & 194.50 & & 194.50 & \\
\hline 194.75 & 61.94 & 194.75 & 201.59 & 194.75 & & 194.75 & \\
\hline 195.00 & 62.07 & 195.00 & 201.59 & 195.00 & & 195.00 & \\
\hline 195.25 & 62.07 & 195.25 & 201.59 & 195.25 & & 195.25 & \\
\hline 195.50 & 62.07 & 195.50 & 202.01 & 195.50 & & 195.50 & \\
\hline 195.75 & 62.16 & 195.75 & 202.01 & 195.75 & & 195.75 & \\
\hline 196.00 & 62.16 & 196.00 & 202.29 & 196.00 & & 196.00 & \\
\hline 196.25 & 62.37 & 196.25 & 202.29 & 196.25 & & 196.25 & \\
\hline 196.50 & 62.37 & 196.50 & 202.67 & 196.50 & & 196.50 & \\
\hline 196.75 & 62.03 & 196.75 & 201.67 & 196.75 & & 196.75 & \\
\hline 197.00 & 62.03 & 197.00 & 201.67 & 197.00 & & 197.00 & \\
\hline 197.25 & 62.37 & 197.25 & 202.02 & 197.25 & & 197.25 & \\
\hline 197.50 & 62.37 & 197.50 & 203.02 & 197.50 & & 197.50 & \\
\hline 197.75 & 62.37 & 197.75 & 203.02 & 197.75 & & 197.75 & \\
\hline 198.00 & 62.12 & 198.00 & 202.33 & 198.00 & & 198.00 & \\
\hline 198.25 & 62.45 & 198.25 & 203.33 & 198.25 & & 198.25 & \\
\hline 198.50 & 62.45 & 198.50 & 203.65 & 198.50 & & 198.50 & \\
\hline 198.75 & 62.54 & 198.75 & 203.65 & 198.75 & & 198.75 & \\
\hline 199.00 & 62.54 & 199.00 & 203.65 & 199.00 & & 199.00 & \\
\hline 199.25 & 62.54 & 199.25 & 203.96 & 199.25 & & 199.25 & \\
\hline 199.50 & 62.66 & 199.50 & 204.03 & 199.50 & & 199.50 & \\
\hline 199.75 & 62.66 & 199.75 & 204.03 & 199.75 & & 199.75 & \\
\hline 200.00 & 62.66 & 200.00 & 204.34 & 200.00 & & 200.00 & \\
\hline 200.25 & 62.79 & 200.25 & 204.34 & 200.25 & & 200.25 & \\
\hline 200.50 & 62.79 & 200.50 & 204.34 & 200.50 & & 200.50 & \\
\hline 200.75 & 62.79 & 200.75 & 204.34 & 200.75 & & 200.75 & \\
\hline 201.00 & 62.79 & 201.00 & 204.76 & 201.00 & & 201.00 & \\
\hline 201.25 & 62.79 & 201.25 & 204.76 & 201.25 & & 201.25 & \\
\hline 201.50 & 62.92 & 201.50 & 204.76 & 201.50 & & 201.50 & \\
\hline 201.75 & 62.92 & 201.75 & 204.76 & 201.75 & & 201.75 & \\
\hline 202.00 & 62.92 & 202.00 & 205.11 & 202.00 & & 202.00 & \\
\hline 202.25 & 62.92 & 202.25 & 205.11 & 202.25 & & 202.25 & \\
\hline 202.50 & 62.92 & 202.50 & 205.11 & 202.50 & & 202.50 & \\
\hline 202.75 & 62.92 & 202.75 & 205.39 & 202.75 & & 202.75 & \\
\hline 203.00 & 62.92 & 203.00 & 205.39 & 203.00 & & 203.00 & \\
\hline 203.25 & 63.01 & 203.25 & 205.39 & 203.25 & & 203.25 & \\
\hline 203.50 & 63.01 & 203.50 & 205.39 & 203.50 & & 203.50 & \\
\hline 203.75 & 63.01 & 203.75 & 205.74 & 203.75 & & 203.75 & \\
\hline 204.00 & 63.10 & 204.00 & 205.74 & 204.00 & & 204.00 & \\
\hline
\end{tabular}


Appendix J. Photoreactor experimental design raw data of the effect of $\mathrm{TOC}_{\mathrm{in}}$.

\begin{tabular}{|l|c|c|}
\hline \multicolumn{1}{|c|}{ HRT } & \multicolumn{2}{c|}{$\mathbf{~ h}$} \\
\hline Parameter & Value & Unit \\
\hline $\begin{array}{l}\text { Reactor } \\
\text { Volume }\end{array}$ & 1.5 & $\mathrm{~L}$ \\
\hline TOCin & 10 & $\begin{array}{c}\mathrm{mg} / \\
\mathrm{L}\end{array}$ \\
\hline H2O2 & 900 & $\mathrm{mg} /$ \\
\hline pH & 7 & \\
\hline Recycle ratio & 0 & \\
\hline Flow rate & 24 & $\mathrm{ccm}$ \\
\hline & 1.44 & $\mathrm{~L} / \mathrm{h}$ \\
\hline & 36 & $\%$ \\
\hline HRT & 1.04 & $\mathrm{~h}$ \\
\hline & 1.8052 & $\mathrm{~L} /$ \\
\hline TOCeff & 81.95 & $\%$ \\
\hline TOCrem & 20.257 & $\mathrm{mg} /$ \\
& 3 & $\mathrm{~L}$ \\
\hline H2O2eff & 2.2508 & $\%$ \\
\hline H2O2res & & \\
\hline
\end{tabular}

\begin{tabular}{|l|c|c|}
\hline \multicolumn{1}{|c|}{ HRT } & \multicolumn{2}{c|}{$\mathbf{1 ~ h}$} \\
\hline Parameter & Value & Unit \\
\hline $\begin{array}{l}\text { Reactor } \\
\text { Volume }\end{array}$ & 1.5 & $\mathrm{~L}$ \\
\hline TOCin & 30 & $\begin{array}{c}\mathrm{mg} / \\
\mathrm{L}\end{array}$ \\
\hline $\mathrm{H} 2 \mathrm{O} 2$ & 900 & $\begin{array}{c}\mathrm{mg} / \\
\mathrm{L}\end{array}$ \\
\hline $\mathrm{pH}$ & 7 & \\
\hline Recycle ratio & 0 & \\
\hline Flow rate & 24 & $\mathrm{ccm}$ \\
\hline & 1.44 & $\mathrm{~L} / \mathrm{h}$ \\
\hline & 36 & $\%$ \\
\hline HRT & 1.04 & $\mathrm{~h}$ \\
\hline TOCeff & 8.5594 & $\mathrm{~L} /$ \\
\hline TOCrem & 71.47 & $\%$ \\
\hline H2O2eff & 16.919 & $\mathrm{mg} /$ \\
\hline H2O2res & 4 & $\mathrm{~L}$ \\
\hline
\end{tabular}

\begin{tabular}{|l|c|c|}
\hline \multicolumn{1}{|c|}{ HRT } & \multicolumn{2}{c|}{$\mathbf{1 ~ h}$} \\
\hline Parameter & Value & Unit \\
\hline $\begin{array}{l}\text { Reactor } \\
\text { Volume }\end{array}$ & 1.5 & $\mathrm{~L}$ \\
\hline TOCin & 50 & $\begin{array}{c}\mathrm{mg} / \\
\mathrm{L}\end{array}$ \\
\hline H2O2 & 900 & $\mathrm{mg} /$ \\
\hline $\mathrm{pH}$ & 7 & \\
\hline Recycle ratio & 0 & \\
\hline Flow rate & 24 & $\mathrm{ccm}$ \\
\hline & 1.44 & $\mathrm{~L} / \mathrm{h}$ \\
\hline & 36 & $\%$ \\
\hline HRT & 1.04 & $\mathrm{~h}$ \\
\hline & 16.977 & $\mathrm{mg} /$ \\
TOCeff & 1 & $\mathrm{~L}$ \\
\hline TOCrem & 66.05 & $\%$ \\
\hline H2O2eff & 17.843 & $\mathrm{mg} /$ \\
\hline H2O2res & 3 & $\mathrm{~L}$ \\
\hline
\end{tabular}

\begin{tabular}{|l|c|c|}
\hline \multicolumn{1}{|c|}{ HRT } & \multicolumn{2}{c|}{$\mathbf{1 ~ h}$} \\
\hline Parameter & Value & Unit \\
\hline Reactor Volume & 1.5 & $\mathrm{~L}$ \\
\hline TOCin & 70 & $\mathrm{mg} / \mathrm{L}$ \\
\hline H2O2 & 900 & $\mathrm{mg} / \mathrm{L}$ \\
\hline $\mathrm{pH}$ & 7 & \\
\hline Recycle ratio & 0 & \\
\hline Flow rate & 24 & $\mathrm{ccm}$ \\
\hline & 1.44 & $\mathrm{~L} / \mathrm{h}$ \\
\hline & 36 & $\%$ \\
\hline HRT & 1.04 & $\mathrm{~h}$ \\
\hline TOCeff & 25.0202 & $\mathrm{mg} / \mathrm{L}$ \\
\hline TOCrem & 64.26 & $\%$ \\
\hline H2O2eff & 21.1490 & $\mathrm{mg} / \mathrm{L}$ \\
\hline H2O2res & 2.3499 & $\%$ \\
\hline
\end{tabular}

\begin{tabular}{|l|c|c|}
\hline \multicolumn{1}{|c|}{ HRT } & \multicolumn{2}{c|}{ 1 h } \\
\hline Parameter & Value & Unit \\
\hline Reactor Volume & 1.5 & $\mathrm{~L}$ \\
\hline TOCin & 90 & $\mathrm{mg} / \mathrm{L}$ \\
\hline $\mathrm{H} 2 \mathrm{O} 2$ & 900 & $\mathrm{mg} / \mathrm{L}$ \\
\hline $\mathrm{pH}$ & 7 & \\
\hline Recycle ratio & 0 & \\
\hline Flow rate & 24 & $\mathrm{ccm}$ \\
\hline & 1.44 & $\mathrm{~L} / \mathrm{h}$ \\
\hline & 36 & $\%$ \\
\hline HRT & 1.04 & $\mathrm{~h}$ \\
\hline TOCeff & 32.8541 & $\mathrm{mg} / \mathrm{L}$ \\
\hline TOCrem & 63.50 & $\%$ \\
\hline H2O2eff & 25.7839 & $\mathrm{mg} / \mathrm{L}$ \\
\hline H2O2res & 2.8649 & $\%$ \\
\hline
\end{tabular}


Appendix K. Photoreactor experimental design raw data of the effect of $\mathrm{H}_{2} \mathrm{O}_{2}$ in.

\begin{tabular}{|l|c|c|}
\hline \multicolumn{1}{|c|}{ HRT } & \multicolumn{2}{c|}{$\mathbf{~ h}$} \\
\hline Parameter & Value & Unit \\
\hline $\begin{array}{l}\text { Reactor } \\
\text { Volume }\end{array}$ & 1.5 & $\mathrm{~L}$ \\
\hline TOCin & 50 & $\begin{array}{c}\mathrm{mg} / \\
\mathrm{L}\end{array}$ \\
\hline H2O2 & 300 & $\begin{array}{c}\mathrm{mg} / \\
\mathrm{L}\end{array}$ \\
\hline $\mathrm{pH}$ & 7 & \\
\hline Recycle ratio & 0 & 0 \\
\hline Flow rate & 24 & $\mathrm{ccm}$ \\
\hline & 1.44 & $\mathrm{~L} / \mathrm{h}$ \\
\hline & 36 & $\%$ \\
\hline HRT & 1.04 & $\mathrm{~h}$ \\
\hline & 19.514 & $\mathrm{mg} /$ \\
TOCeff & 1 & $\mathrm{~L}$ \\
\hline TOCrem & 60.97 & $\%$ \\
\hline & & $\mathrm{mg} /$ \\
H2O2eff & 4.6800 & $\mathrm{~L}$ \\
\hline H2O2res & 1.5600 & $\%$ \\
\hline
\end{tabular}

\begin{tabular}{|l|c|c|}
\hline \multicolumn{1}{|c|}{ HRT } & \multicolumn{2}{c|}{$\mathbf{1 ~ h}$} \\
\hline Parameter & Value & Unit \\
\hline $\begin{array}{l}\text { Reactor } \\
\text { Volume }\end{array}$ & 1.5 & $\mathrm{~L}$ \\
\hline TOCin & 50 & $\begin{array}{c}\mathrm{mg} / \\
\mathrm{L}\end{array}$ \\
\hline $\mathrm{H} 2 \mathrm{O} 2$ & 600 & $\begin{array}{c}\mathrm{mg} / \\
\mathrm{L}\end{array}$ \\
\hline $\mathrm{pH}$ & 7 & \\
\hline Recycle ratio & 0 & 0 \\
\hline Flow rate & 24 & $\mathrm{ccm}$ \\
\hline & 1.44 & $\mathrm{~L} / \mathrm{h}$ \\
\hline & 36 & $\%$ \\
\hline HRT & 1.04 & $\mathrm{~h}$ \\
\hline & 16.790 & $\mathrm{mg} /$ \\
TOCeff & 1 & $\mathrm{~L}$ \\
\hline TOCrem & 66.42 & $\%$ \\
\hline & 11.050 & $\mathrm{mg} /$ \\
H2O2eff & 2 & $\mathrm{~L}$ \\
\hline H2O2res & 1.8417 & $\%$ \\
\hline
\end{tabular}

\begin{tabular}{|l|c|c|}
\hline \multicolumn{1}{|c|}{ HRT } & \multicolumn{2}{c|}{$\mathbf{1 ~ h}$} \\
\hline Parameter & Value & Unit \\
\hline $\begin{array}{l}\text { Reactor } \\
\text { Volume }\end{array}$ & 1.5 & $\mathrm{~L}$ \\
\hline TOCin & 50 & $\begin{array}{c}\mathrm{mg} / \\
\mathrm{L}\end{array}$ \\
\hline H2O2 & 900 & $\mathrm{mg} /$ \\
\hline $\mathrm{pH}$ & 7 & \\
\hline Recycle ratio & 0 & 0 \\
\hline Flow rate & 24 & $\mathrm{ccm}$ \\
\hline & 1.44 & $\mathrm{~L} / \mathrm{h}$ \\
\hline & 36 & $\%$ \\
\hline HRT & 1.04 & $\mathrm{~h}$ \\
\hline & 14.942 & $\mathrm{mg} /$ \\
TOCeff & 7 & $\mathrm{~L}$ \\
\hline TOCrem & 70.11 & $\%$ \\
\hline & 17.741 & $\mathrm{mg} /$ \\
H2O2eff & 0 & $\mathrm{~L}$ \\
\hline H2O2res & 1.9712 & $\%$ \\
\hline
\end{tabular}

\begin{tabular}{|l|c|c|}
\hline \multicolumn{1}{|c|}{ HRT } & \multicolumn{2}{c|}{$1 \mathbf{h}$} \\
\hline Parameter & Value & Unit \\
\hline Reactor Volume & 1.5 & $\mathrm{~L}$ \\
\hline TOCin & 50 & $\mathrm{mg} / \mathrm{L}$ \\
\hline H2O2 & 1200 & $\mathrm{mg} / \mathrm{L}$ \\
\hline $\mathrm{pH}$ & 7 & \\
\hline Recycle ratio & 0 & 0 \\
\hline Flow rate & 24 & $\mathrm{ccm}$ \\
\hline & 1.44 & $\mathrm{~L} / \mathrm{h}$ \\
\hline & 36 & $\%$ \\
\hline HRT & 1.04 & $\mathrm{~h}$ \\
\hline TOCeff & 15.4123 & $\mathrm{mg} / \mathrm{L}$ \\
\hline TOCrem & 69.18 & $\%$ \\
\hline H2O2eff & 24.9570 & $\mathrm{mg} / \mathrm{L}$ \\
\hline H2O2res & 2.0798 & $\%$ \\
\hline
\end{tabular}

\begin{tabular}{|l|c|c|}
\hline \multicolumn{1}{|c|}{ HRT } & \multicolumn{2}{c|}{$\mathbf{1 ~ h}$} \\
\hline Parameter & Value & Unit \\
\hline Reactor Volume & 1.5 & $\mathrm{~L}$ \\
\hline TOCin & 50 & $\mathrm{mg} / \mathrm{L}$ \\
\hline $\mathrm{H} 2 \mathrm{O} 2$ & 1500 & $\mathrm{mg} / \mathrm{L}$ \\
\hline $\mathrm{pH}$ & 7 & \\
\hline Recycle ratio & 0 & 0 \\
\hline Flow rate & 24 & $\mathrm{ccm}$ \\
\hline & 1.44 & $\mathrm{~L} / \mathrm{h}$ \\
\hline & 36 & $\%$ \\
\hline HRT & 1.04 & $\mathrm{~h}$ \\
\hline TOCeff & 17.8235 & $\mathrm{mg} / \mathrm{L}$ \\
\hline TOCrem & 64.35 & $\%$ \\
\hline H2O2eff & 31.2043 & $\mathrm{mg} / \mathrm{L}$ \\
\hline H2O2res & 2.0803 & $\%$ \\
\hline
\end{tabular}


Appendix L. Photoreactor experimental design raw data of the effect of flow rate.

\begin{tabular}{|l|c|c|}
\hline \multicolumn{1}{|c|}{ HRT } & \multicolumn{2}{c|}{$\mathbf{2 . 5} \mathbf{~ h}$} \\
\hline Parameter & Value & Unit \\
\hline $\begin{array}{l}\text { Reactor } \\
\text { Volume }\end{array}$ & 1.5 & $\mathrm{~L}$ \\
\hline TOCin & 50 & $\mathrm{mg} / \mathrm{L}$ \\
\hline $\mathrm{H} 2 \mathrm{O} 2$ & 900 & $\mathrm{mg} / \mathrm{L}$ \\
\hline $\mathrm{pH}$ & 7 & \\
\hline Recycle ratio & 0 & \\
\hline & & $\mathrm{mL} / \mathrm{mi}$ \\
Flow rate & 15 & $\mathrm{n}$ \\
\hline & 0.9 & $\mathrm{~L} / \mathrm{h}$ \\
\hline & 22.5 & $\%$ \\
\hline HRT & 1.67 & $\mathrm{~h}$ \\
\hline & 13.607 & \\
TOCeff & 1 & $\mathrm{mg} / \mathrm{L}$ \\
\hline TOCrem & 72.79 & $\%$ \\
\hline & 14.901 & \\
H2O2eff & 0 & $\mathrm{mg} / \mathrm{L}$ \\
\hline H2O2res & 1.6557 & $\%$ \\
\hline
\end{tabular}

\begin{tabular}{|l|c|c|}
\hline \multicolumn{1}{|c|}{ HRT } & \multicolumn{2}{c|}{$1.25 \mathrm{~h}$} \\
\hline Parameter & Value & Unit \\
\hline Reactor & & \\
Volume & 1.5 & $\mathrm{~L}$ \\
\hline TOCin & 50 & $\mathrm{mg} / \mathrm{L}$ \\
\hline $\mathrm{H} 2 \mathrm{O} 2$ & 900 & $\mathrm{mg} / \mathrm{L}$ \\
\hline $\mathrm{pH}$ & 7 & \\
\hline Recycle ratio & 0 & \\
\hline & & $\mathrm{mL} / \mathrm{mi}$ \\
Flow rate & 45 & $\mathrm{n}$ \\
\hline & 2.7 & $\mathrm{~L} / \mathrm{h}$ \\
\hline & 67.5 & $\%$ \\
\hline HRT & 0.56 & $\mathrm{~h}$ \\
\hline & 14.716 & \\
TOCeff & 6 & $\mathrm{mg} / \mathrm{L}$ \\
\hline TOCrem & 70.57 & $\%$ \\
\hline & 16.544 & \\
H2O2eff & 5 & $\mathrm{mg} / \mathrm{L}$ \\
\hline H2O2res & 1.8383 & $\%$ \\
\hline
\end{tabular}

\begin{tabular}{|l|c|c|}
\hline \multicolumn{1}{|c|}{ HRT } & \multicolumn{2}{c|}{$\mathbf{1 . 0} \mathbf{~}$} \\
\hline Parameter & Value & Unit \\
\hline Reactor & & \\
Volume & 1.5 & $\mathrm{~L}$ \\
\hline TOCin & 50 & $\mathrm{mg} / \mathrm{L}$ \\
\hline $\mathrm{H} 2 \mathrm{O} 2$ & 900 & $\mathrm{mg} / \mathrm{L}$ \\
\hline $\mathrm{pH}$ & 7 & \\
\hline Recycle ratio & 0 & \\
\hline & & $\mathrm{mL} / \mathrm{mi}$ \\
Flow rate & 75 & $\mathrm{n}$ \\
\hline & 4.5 & $\mathrm{~L} / \mathrm{h}$ \\
\hline & 112.5 & $\%$ \\
\hline HRT & 0.33 & $\mathrm{~h}$ \\
\hline & 15.453 & \\
TOCeff & 8 & $\mathrm{mg} / \mathrm{L}$ \\
\hline TOCrem & 69.09 & $\%$ \\
\hline & 17.356 & \\
H2O2eff & 7 & $\mathrm{mg} / \mathrm{L}$ \\
\hline H2O2res & 1.9285 & $\%$ \\
\hline
\end{tabular}

\begin{tabular}{|l|c|c|}
\hline \multicolumn{1}{|c|}{ HRT } & \multicolumn{2}{c|}{$\mathbf{5 0} \mathbf{~ m i n}$} \\
\hline Parameter & Value & Unit \\
\hline $\begin{array}{l}\text { Reactor } \\
\text { Volume }\end{array}$ & 1.5 & $\mathrm{~L}$ \\
\hline TOCin & 50 & $\mathrm{mg} / \mathrm{L}$ \\
\hline $\mathrm{H} 2 \mathrm{O} 2$ & 900 & $\mathrm{mg} / \mathrm{L}$ \\
\hline $\mathrm{pH}$ & 7 & \\
\hline Recycle ratio & 0 & \\
\hline & 105 & $\mathrm{~mL} / \mathrm{mi}$ \\
\hline Flow rate & 6.3 & $\mathrm{~L} / \mathrm{h}$ \\
\hline & 157.5 & $\%$ \\
\hline & 0.24 & $\mathrm{~h}$ \\
\hline HRT & 16.656 & \\
\hline & 7 & $\mathrm{mg} / \mathrm{L}$ \\
\hline TOCeff & 66.69 & $\%$ \\
\hline TOCrem & 18.158 & \\
\hline & 9 & $\mathrm{mg} / \mathrm{L}$ \\
\hline H2O2eff & 2.0177 & $\%$ \\
\hline H2O2res & &
\end{tabular}

\begin{tabular}{|l|c|c|}
\hline \multicolumn{1}{|c|}{ HRT } & \multicolumn{2}{c|}{$\mathbf{3 7 . 5}$ min } \\
\hline Parameter & Value & Unit \\
\hline $\begin{array}{l}\text { Reactor } \\
\text { Volume }\end{array}$ & 1.5 & $\mathrm{~L}$ \\
\hline TOCin & 50 & $\mathrm{mg} / \mathrm{L}$ \\
\hline $\mathrm{H} 2 \mathrm{O} 2$ & 900 & $\mathrm{mg} / \mathrm{L}$ \\
\hline $\mathrm{pH}$ & 7 & \\
\hline Recycle ratio & 0 & \\
\hline & & $\mathrm{mL} / \mathrm{mi}$ \\
Flow rate & 135 & $\mathrm{n}$ \\
\hline & 8.1 & $\mathrm{~L} / \mathrm{h}$ \\
\hline & 202.5 & $\%$ \\
\hline HRT & 0.19 & $\mathrm{~h}$ \\
\hline & 17.647 & \\
TOCeff & 0 & $\mathrm{mg} / \mathrm{L}$ \\
\hline TOCrem & 64.71 & $\%$ \\
\hline & 18.823 & \\
H2O2eff & 4 & $\mathrm{mg} / \mathrm{L}$ \\
\hline H2O2res & 2.0915 & $\%$ \\
\hline
\end{tabular}

\begin{tabular}{|l|c|c|}
\hline \multicolumn{1}{|c|}{ HRT } & \multicolumn{2}{c|}{$30 \mathrm{~min}$} \\
\hline Parameter & Value & Unit \\
\hline $\begin{array}{l}\text { Reactor } \\
\text { Volume }\end{array}$ & 1.5 & $\mathrm{~L}$ \\
\hline TOCin & 50 & $\mathrm{mg} / \mathrm{L}$ \\
\hline $\mathrm{H} 2 \mathrm{O} 2$ & 900 & $\mathrm{mg} / \mathrm{L}$ \\
\hline $\mathrm{pH}$ & 7 & \\
\hline Recycle ratio & 0 & \\
\hline & 165 & $\mathrm{~mL}$ \\
\hline Flow rate & 9.9 & $\mathrm{~L} / \mathrm{h}$ \\
\hline & 247.5 & $\%$ \\
\hline & 0.15 & $\mathrm{~h}$ \\
\hline HRT & 18.838 & \\
\hline & 1 & $\mathrm{mg} / \mathrm{L}$ \\
\hline TOCeff & 62.32 & $\%$ \\
\hline TOCrem & 19.180 & \\
\hline & 0 & $\mathrm{mg} / \mathrm{L}$ \\
\hline H2O2eff & 2.1311 & $\%$ \\
\hline H2O2res & &
\end{tabular}


Appendix M. Photoreactor experimental design raw data of the effect of recycle ratio.

\begin{tabular}{|l|c|c|}
\hline \multicolumn{1}{|c|}{ HRT } & \multicolumn{2}{c|}{$\mathbf{~ h}$} \\
\hline Parameter & Value & Unit \\
\hline $\begin{array}{l}\text { Reactor } \\
\text { Volume }\end{array}$ & 1.5 & $\mathrm{~L}$ \\
\hline TOCin & 50 & $\begin{array}{c}\mathrm{mg} / \\
\mathrm{L}\end{array}$ \\
\hline H2O2 & 900 & $\begin{array}{c}\mathrm{mg} / \\
\mathrm{L}\end{array}$ \\
\hline $\mathrm{pH}$ & 7 & \\
\hline Recycle ratio & 0 & 0 \\
\hline Flow rate & 24 & $\mathrm{ccm}$ \\
\hline & 1.44 & $\mathrm{~L} / \mathrm{h}$ \\
\hline & 36 & $\%$ \\
\hline HRT & 1.04 & $\mathrm{~h}$ \\
\hline & 17.440 & $\mathrm{mg} /$ \\
TOCeff & 1 & $\mathrm{~L}$ \\
\hline TOCrem & 65.12 & $\%$ \\
\hline & 17.999 & $\mathrm{mg} /$ \\
H2O2eff & 0 & $\mathrm{~L}$ \\
\hline H2O2res & 2.00 & $\%$ \\
\hline
\end{tabular}

\begin{tabular}{|l|c|c|}
\hline \multicolumn{1}{|c|}{ HRT } & \multicolumn{2}{c|}{$\mathbf{1 ~ h}$} \\
\hline Parameter & Value & Unit \\
\hline $\begin{array}{l}\text { Reactor } \\
\text { Volume }\end{array}$ & 1.5 & $\mathrm{~L}$ \\
\hline TOCin & 50 & $\begin{array}{c}\mathrm{mg} / \\
\mathrm{L}\end{array}$ \\
\hline H2O2 & 900 & $\begin{array}{c}\mathrm{mg} / \\
\mathrm{L}\end{array}$ \\
\hline $\mathrm{pH}$ & 7 & \\
\hline Recycle ratio & 0.2 & 7 \\
\hline Flow rate & 24 & $\mathrm{ccm}$ \\
\hline & 1.44 & $\mathrm{~L} / \mathrm{h}$ \\
\hline & 36 & $\%$ \\
\hline HRT & 1.04 & $\mathrm{~h}$ \\
\hline & 15.093 & $\mathrm{mg} /$ \\
TOCeff & 9 & $\mathrm{~L}$ \\
\hline TOCrem & 69.81 & $\%$ \\
\hline & 16.737 & $\mathrm{mg} /$ \\
H2O2eff & 2 & $\mathrm{~L}$ \\
\hline H2O2res & 1.86 & $\%$ \\
\hline
\end{tabular}

\begin{tabular}{|l|c|c|}
\hline \multicolumn{1}{|c|}{ HRT } & \multicolumn{2}{c|}{$\mathbf{1 ~ h}$} \\
\hline Parameter & Value & Unit \\
\hline $\begin{array}{l}\text { Reactor } \\
\text { Volume }\end{array}$ & 1.5 & $\mathrm{~L}$ \\
\hline TOCin & 50 & $\begin{array}{c}\mathrm{mg} / \\
\mathrm{L}\end{array}$ \\
\hline H2O2 & 900 & $\mathrm{mg} /$ \\
\hline $\mathrm{pH}$ & 7 & \\
\hline Recycle ratio & 0.4 & 14 \\
\hline Flow rate & 24 & $\mathrm{ccm}$ \\
\hline & 1.44 & $\mathrm{~L} / \mathrm{h}$ \\
\hline & 36 & $\%$ \\
\hline HRT & 1.04 & $\mathrm{~h}$ \\
\hline & 14.857 & $\mathrm{mg} /$ \\
TOCeff & 9 & $\mathrm{~L}$ \\
\hline TOCrem & 70.28 & $\%$ \\
\hline H2O2eff & 17.138 & $\mathrm{mg} /$ \\
2 & $\mathrm{~L}$ \\
\hline H2O2res & 1.90 & $\%$ \\
\hline
\end{tabular}

\begin{tabular}{|l|c|c|}
\hline \multicolumn{1}{|c|}{ HRT } & \multicolumn{2}{c|}{ 1 h } \\
\hline Parameter & Value & Unit \\
\hline Reactor Volume & 1.5 & $\mathrm{~L}$ \\
\hline TOCin & 50 & $\mathrm{mg} / \mathrm{L}$ \\
\hline $\mathrm{H} 2 \mathrm{O} 2$ & 900 & $\mathrm{mg} / \mathrm{L}$ \\
\hline $\mathrm{pH}$ & 7 & \\
\hline Recycle ratio & 0.6 & 22 \\
\hline Flow rate & 24 & $\mathrm{ccm}$ \\
\hline & 1.44 & $\mathrm{~L} / \mathrm{h}$ \\
\hline & 36 & $\%$ \\
\hline HRT & 1.04 & $\mathrm{~h}$ \\
\hline TOCeff & 16.3607 & $\mathrm{mg} / \mathrm{L}$ \\
\hline TOCrem & 67.28 & $\%$ \\
\hline H2O2eff & 18.2455 & $\mathrm{mg} / \mathrm{L}$ \\
\hline H2O2res & 2.03 & $\%$ \\
\hline
\end{tabular}

\begin{tabular}{|l|c|c|}
\hline \multicolumn{1}{|c|}{ HRT } & \multicolumn{2}{c|}{$\mathbf{1 ~ h}$} \\
\hline Parameter & Value & Unit \\
\hline Reactor Volume & 1.5 & $\mathrm{~L}$ \\
\hline TOCin & 50 & $\mathrm{mg} / \mathrm{L}$ \\
\hline $\mathrm{H} 2 \mathrm{O} 2$ & 900 & $\mathrm{mg} / \mathrm{L}$ \\
\hline $\mathrm{pH}$ & 7 & \\
\hline Recycle ratio & 0.8 & 29 \\
\hline Flow rate & 24 & $\mathrm{ccm}$ \\
\hline & 1.44 & $\mathrm{~L} / \mathrm{h}$ \\
\hline & 36 & $\%$ \\
\hline HRT & 1.04 & $\mathrm{~h}$ \\
\hline TOCeff & 18.6200 & $\mathrm{mg} / \mathrm{L}$ \\
\hline TOCrem & 62.76 & $\%$ \\
\hline H2O2eff & 20.9680 & $\mathrm{mg} / \mathrm{L}$ \\
\hline H2O2res & 2.33 & $\%$ \\
\hline
\end{tabular}


Appendix N. Analysis of residuals in the photoreactor models.

\begin{tabular}{|c|c|c|c|c|c|c|c|c|c|}
\hline Run & TOCin & Predicted TOCrem & Residuals & Block & Run & $\mathrm{H} 2 \mathrm{O} 2$ & Predicted TOCrem & Residuals & Block \\
\hline 2 & 10 & 80.43 & 0.00 & 80.43 & 12 & 300 & 60.15 & 0.00 & 60.15 \\
\hline 3 & 25 & 69.21 & -2.13 & \multirow{8}{*}{71.34} & 3 & 600 & 69.21 & 2.38 & \multirow{8}{*}{66.83} \\
\hline 6 & 25 & 77.45 & 6.11 & & 14 & 600 & 71.23 & 4.40 & \\
\hline 8 & 25 & 71.94 & 0.60 & & 18 & 600 & 67.09 & 0.26 & \\
\hline 11 & 25 & 76.17 & 4.83 & & 23 & 600 & 74.31 & 7.48 & \\
\hline 14 & 25 & 71.23 & -0.11 & & 5 & 600 & 60.55 & -6.28 & \\
\hline 18 & 25 & 67.09 & -4.25 & & 16 & 600 & 66.79 & -0.04 & \\
\hline 23 & 25 & 74.31 & 2.97 & & 20 & 600 & 68.77 & 1.94 & \\
\hline 24 & 25 & 63.31 & -8.03 & & 22 & 600 & 56.72 & -10.11 & \\
\hline 4 & 40 & 71.90 & 3.44 & \multirow{12}{*}{68.46} & 2 & 900 & 80.43 & 10.28 & \multirow{12}{*}{70.15} \\
\hline 7 & 40 & 71.96 & 3.50 & & 4 & 900 & 71.90 & 1.75 & \\
\hline 9 & 40 & 72.08 & 3.62 & & 7 & 900 & 71.96 & 1.81 & \\
\hline 12 & 40 & 60.15 & -8.31 & & 9 & 900 & 72.08 & 1.93 & \\
\hline 15 & 40 & 64.70 & -3.76 & & 15 & 900 & 64.70 & -5.45 & \\
\hline 19 & 40 & 63.41 & -5.05 & & 19 & 900 & 63.41 & -6.74 & \\
\hline 21 & 40 & 72.31 & 3.85 & & 21 & 900 & 72.31 & 2.16 & \\
\hline 26 & 40 & 70.72 & 2.26 & & 26 & 900 & 70.72 & 0.57 & \\
\hline 27 & 40 & 66.89 & -1.57 & & 27 & 900 & 66.89 & -3.26 & \\
\hline 28 & 40 & 64.43 & -4.03 & & 29 & 900 & 72.81 & 2.66 & \\
\hline 29 & 40 & 72.81 & 4.35 & & 30 & 900 & 70.19 & 0.04 & \\
\hline 30 & 40 & 70.19 & 1.73 & & 10 & 900 & 64.39 & -5.76 & \\
\hline 1 & 55 & 66.12 & 0.80 & \multirow{8}{*}{65.32} & 6 & 1200 & 77.45 & 7.63 & \multirow{8}{*}{69.82} \\
\hline 5 & 55 & 60.55 & -4.77 & & 8 & 1200 & 71.94 & 2.12 & \\
\hline 13 & 55 & 66.83 & 1.51 & & 11 & 1200 & 76.17 & 6.35 & \\
\hline 16 & 55 & 66.79 & 1.47 & & 24 & 1200 & 63.31 & -6.51 & \\
\hline 17 & 55 & 64.31 & -1.01 & & 1 & 1200 & 66.12 & -3.70 & \\
\hline 20 & 55 & 68.77 & 3.45 & & 13 & 1200 & 66.83 & -2.99 & \\
\hline 22 & 55 & 56.72 & -8.60 & & 17 & 1200 & 64.31 & -5.51 & \\
\hline 25 & 55 & 72.44 & 7.12 & & 25 & 1200 & 72.44 & 2.62 & \\
\hline 10 & 70 & 64.39 & 0.00 & 64.39 & 28 & 1500 & 64.43 & 0.00 & 64.43 \\
\hline
\end{tabular}




\begin{tabular}{|c|c|c|c|c|c|c|c|c|c|}
\hline Run & Flow rate & Predicted TOCrem & Residuals & Block & Run & Recycle ratio & Predicted TOCrem & Residuals & Block \\
\hline 29 & 15 & 72.81 & 0.00 & 72.81 & 27 & 0 & 66.89 & 0.00 & 66.89 \\
\hline 18 & 45 & 67.09 & -2.88 & \multirow{8}{*}{69.97} & 23 & 0.2 & 74.31 & 4.74 & \multirow{8}{*}{69.57} \\
\hline 23 & 45 & 74.31 & 4.34 & & 20 & 0.2 & 68.77 & -0.80 & \\
\hline 20 & 45 & 68.77 & -1.20 & & 6 & 0.2 & 77.45 & 7.88 & \\
\hline 22 & 45 & 56.72 & -13.25 & & 25 & 0.2 & 72.44 & 2.87 & \\
\hline 6 & 45 & 77.45 & 7.48 & & 3 & 0.2 & 69.21 & -0.36 & \\
\hline 11 & 45 & 76.17 & 6.20 & & 16 & 0.2 & 66.79 & -2.78 & \\
\hline 13 & 45 & 66.83 & -3.14 & & 24 & 0.2 & 63.31 & -6.26 & \\
\hline 25 & 45 & 72.44 & 2.47 & & 17 & 0.2 & 64.31 & -5.26 & \\
\hline 12 & 75 & 60.15 & -8.92 & \multirow{12}{*}{69.07} & 29 & 0.4 & 72.81 & 3.14 & \multirow{12}{*}{69.67} \\
\hline 2 & 75 & 80.43 & 11.36 & & 12 & 0.4 & 60.15 & -9.52 & \\
\hline 4 & 75 & 71.90 & 2.83 & & 2 & 0.4 & 80.43 & 10.76 & \\
\hline 7 & 75 & 71.96 & 2.89 & & 4 & 0.4 & 71.90 & 2.23 & \\
\hline 9 & 75 & 72.08 & 3.01 & & 7 & 0.4 & 71.96 & 2.29 & \\
\hline 19 & 75 & 63.41 & -5.66 & & 9 & 0.4 & 72.08 & 2.41 & \\
\hline 21 & 75 & 72.31 & 3.24 & & 21 & 0.4 & 72.31 & 2.64 & \\
\hline 26 & 75 & 70.72 & 1.65 & & 26 & 0.4 & 70.72 & 1.05 & \\
\hline 27 & 75 & 66.89 & -2.18 & & 30 & 0.4 & 70.19 & 0.52 & \\
\hline 30 & 75 & 70.19 & 1.12 & & 10 & 0.4 & 64.39 & -5.28 & \\
\hline 10 & 75 & 64.39 & -4.68 & & 28 & 0.4 & 64.43 & -5.24 & \\
\hline 28 & 75 & 64.43 & -4.64 & & 15 & 0.4 & 64.70 & -4.97 & \\
\hline 3 & 105 & 69.21 & 2.53 & \multirow{8}{*}{66.68} & 18 & 0.6 & 67.09 & 0.01 & \multirow{8}{*}{67.08} \\
\hline 14 & 105 & 71.23 & 4.55 & & 22 & 0.6 & 56.72 & -10.36 & \\
\hline 5 & 105 & 60.55 & -6.13 & & 11 & 0.6 & 76.17 & 9.09 & \\
\hline 16 & 105 & 66.79 & 0.11 & & 13 & 0.6 & 66.83 & -0.25 & \\
\hline 8 & 105 & 71.94 & 5.26 & & 14 & 0.6 & 71.23 & 4.15 & \\
\hline 24 & 105 & 63.31 & -3.37 & & 5 & 0.6 & 60.55 & -6.53 & \\
\hline 1 & 105 & 66.12 & -0.56 & & 8 & 0.6 & 71.94 & 4.86 & \\
\hline 17 & 105 & 64.31 & -2.37 & & 1 & 0.6 & 66.12 & -0.96 & \\
\hline 15 & 135 & 64.70 & 0.00 & 64.70 & 19 & 0.8 & 63.41 & 0.00 & 63.41 \\
\hline
\end{tabular}




\begin{tabular}{|c|c|c|c|c|c|c|c|c|c|}
\hline Run & & D2res & iduals & ock & Run & & Predicted $\mathrm{H} 2 \mathrm{O} 2$ res & iduals & lock \\
\hline 2 & 10 & 2.25 & 0.00 & 2.25 & 12 & 300 & 1.55 & 0.00 & 1.55 \\
\hline 3 & 25 & 1.63 & -0.32 & \multirow{8}{*}{1.95} & 3 & 600 & 1.63 & -0.22 & \multirow{8}{*}{1.85} \\
\hline 6 & 25 & 1.78 & -0.17 & & 5 & 600 & 1.96 & 0.11 & \\
\hline 8 & 25 & 2.35 & 0.40 & & 14 & 600 & 2.10 & 0.25 & \\
\hline 11 & 25 & 1.87 & -0.08 & & 16 & 600 & 1.78 & -0.07 & \\
\hline 14 & 25 & 2.10 & 0.15 & & 18 & 600 & 2.03 & 0.18 & \\
\hline 18 & 25 & 2.03 & 0.08 & & 20 & 600 & 1.71 & -0.14 & \\
\hline 23 & 25 & 1.36 & -0.59 & & 22 & 600 & 2.21 & 0.36 & \\
\hline 24 & 25 & 2.48 & 0.53 & & 23 & 600 & 1.36 & -0.49 & \\
\hline 4 & 40 & 1.82 & -0.03 & \multirow{12}{*}{1.85} & 2 & 900 & 2.25 & 0.31 & \multirow{12}{*}{1.94} \\
\hline 7 & 40 & 1.75 & -0.10 & & 4 & 900 & 1.82 & -0.12 & \\
\hline 9 & 40 & 1.75 & -0.10 & & 7 & 900 & 1.75 & -0.19 & \\
\hline 12 & 40 & 1.55 & -0.30 & & 9 & 900 & 1.75 & -0.19 & \\
\hline 15 & 40 & 2.11 & 0.26 & & 10 & 900 & 2.35 & 0.41 & \\
\hline 19 & 40 & 2.30 & 0.45 & & 15 & 900 & 2.11 & 0.17 & \\
\hline 21 & 40 & 1.77 & -0.08 & & 19 & 900 & 2.30 & 0.36 & \\
\hline 26 & 40 & 1.77 & -0.08 & & 21 & 900 & 1.77 & -0.17 & \\
\hline 27 & 40 & 1.99 & 0.14 & & 26 & 900 & 1.77 & -0.17 & \\
\hline 28 & 40 & 2.01 & 0.16 & & 27 & 900 & 1.99 & 0.05 & \\
\hline 29 & 40 & 1.61 & -0.24 & & 29 & 900 & 1.61 & -0.33 & \\
\hline 30 & 40 & 1.77 & -0.08 & & 30 & 900 & 1.77 & -0.17 & \\
\hline 1 & 55 & 2.03 & 0.05 & \multirow{8}{*}{1.98} & 1 & 1200 & 2.03 & -0.05 & \multirow{8}{*}{2.08} \\
\hline 5 & 55 & 1.96 & -0.02 & & 6 & 1200 & 1.78 & -0.30 & \\
\hline 13 & 55 & 1.79 & -0.19 & & 8 & 1200 & 2.35 & 0.27 & \\
\hline 16 & 55 & 1.78 & -0.20 & & 11 & 1200 & 1.87 & -0.21 & \\
\hline 17 & 55 & 2.42 & 0.44 & & 13 & 1200 & 1.79 & -0.29 & \\
\hline 20 & 55 & 1.71 & -0.27 & & 17 & 1200 & 2.42 & 0.34 & \\
\hline 22 & 55 & 2.21 & 0.23 & & 24 & 1200 & 2.48 & 0.40 & \\
\hline 25 & 55 & 1.94 & -0.04 & & 25 & 1200 & 1.94 & -0.14 & \\
\hline 10 & 70 & 2.35 & 0.00 & 2.35 & 28 & 1500 & 2.01 & 0.00 & 2.01 \\
\hline
\end{tabular}


Run Flow rate Predicted H2O2res Residuals Block Run Recycle ratio Predicted H2O2res Residuals Block

\begin{tabular}{|c|c|c|c|c|c|c|c|c|c|}
\hline 29 & 15 & 1.61 & 0.00 & 1.61 & 27 & 0 & 1.99 & 0.00 & 1.99 \\
\hline 6 & 45 & 1.78 & -0.06 & \multirow{8}{*}{1.84} & 3 & 0.2 & 1.63 & -0.26 & \multirow{8}{*}{1.89} \\
\hline 11 & 45 & 1.87 & 0.03 & & 6 & 0.2 & 1.78 & -0.11 & \\
\hline 13 & 45 & 1.79 & -0.05 & & 16 & 0.2 & 1.78 & -0.11 & \\
\hline 18 & 45 & 2.03 & 0.19 & & 17 & 0.2 & 2.42 & 0.53 & \\
\hline 20 & 45 & 1.71 & -0.13 & & 20 & 0.2 & 1.71 & -0.18 & \\
\hline 22 & 45 & 2.21 & 0.37 & & 23 & 0.2 & 1.36 & -0.53 & \\
\hline 23 & 45 & 1.36 & -0.48 & & 24 & 0.2 & 2.48 & 0.59 & \\
\hline 25 & 45 & 1.94 & 0.10 & & 25 & 0.2 & 1.94 & 0.05 & \\
\hline 2 & 75 & 2.25 & 0.33 & \multirow{12}{*}{1.92} & 2 & 0.4 & 2.25 & 0.37 & \multirow{12}{*}{1.88} \\
\hline 4 & 75 & 1.82 & -0.10 & & 4 & 0.4 & 1.82 & -0.06 & \\
\hline 7 & 75 & 1.75 & -0.17 & & 7 & 0.4 & 1.75 & -0.13 & \\
\hline 9 & 75 & 1.75 & -0.17 & & 9 & 0.4 & 1.75 & -0.13 & \\
\hline 10 & 75 & 2.35 & 0.43 & & 10 & 0.4 & 2.35 & 0.47 & \\
\hline 12 & 75 & 1.55 & -0.37 & & 12 & 0.4 & 1.55 & -0.33 & \\
\hline 19 & 75 & 2.30 & 0.38 & & 15 & 0.4 & 2.11 & 0.23 & \\
\hline 21 & 75 & 1.77 & -0.15 & & 21 & 0.4 & 1.77 & -0.11 & \\
\hline 26 & 75 & 1.77 & -0.15 & & 26 & 0.4 & 1.77 & -0.11 & \\
\hline 27 & 75 & 1.99 & 0.07 & & 28 & 0.4 & 2.01 & 0.13 & \\
\hline 28 & 75 & 2.01 & 0.09 & & 29 & 0.4 & 1.61 & -0.27 & \\
\hline 30 & 75 & 1.77 & -0.15 & & 30 & 0.4 & 1.77 & -0.11 & \\
\hline 1 & 105 & 2.03 & -0.06 & \multirow{8}{*}{2.09} & 1 & 0.6 & 2.03 & -0.01 & \multirow{8}{*}{2.04} \\
\hline 3 & 105 & 1.63 & -0.46 & & 5 & 0.6 & 1.96 & -0.08 & \\
\hline 5 & 105 & 1.96 & -0.13 & & 8 & 0.6 & 2.35 & 0.31 & \\
\hline 8 & 105 & 2.35 & 0.26 & & 11 & 0.6 & 1.87 & -0.17 & \\
\hline 14 & 105 & 2.10 & 0.01 & & 13 & 0.6 & 1.79 & -0.25 & \\
\hline 16 & 105 & 1.78 & -0.31 & & 14 & 0.6 & 2.10 & 0.06 & \\
\hline 17 & 105 & 2.42 & 0.33 & & 18 & 0.6 & 2.03 & -0.01 & \\
\hline 24 & 105 & 2.48 & 0.39 & & 22 & 0.6 & 2.21 & 0.17 & \\
\hline 15 & 135 & 2.11 & 0.00 & 2.11 & 19 & 0.8 & 2.30 & 0.00 & 2.30 \\
\hline
\end{tabular}


Appendix O. Analysis of residuals in the biological processes models.

\begin{tabular}{|c|c|c|c|c|c|c|c|c|c|}
\hline Run & TOCin & Predicted TOCrem & Residuals & Block & Run & Flow rate & Predicted TOCrem & Residuals & Block \\
\hline 1 & 100 & 88.87 & 6.82 & \multirow{4}{*}{82.05} & 1 & 45 & 88.87 & 10.18 & \multirow{4}{*}{78.69} \\
\hline 3 & 100 & 76.81 & -5.24 & & 2 & 45 & 70.80 & -7.89 & \\
\hline 5 & 100 & 79.03 & -3.02 & & 9 & 45 & 80.01 & 1.32 & \\
\hline 7 & 100 & 83.49 & 1.44 & & 11 & 45 & 75.09 & -3.60 & \\
\hline 9 & 550 & 80.01 & 1.78 & \multirow{9}{*}{78.23} & 5 & 75 & 79.03 & 0.63 & \multirow{9}{*}{78.40} \\
\hline 10 & 550 & 70.49 & -7.74 & & 6 & 75 & 70.84 & -7.56 & \\
\hline 11 & 550 & 75.09 & -3.14 & & 7 & 75 & 83.49 & 5.09 & \\
\hline 12 & 550 & 76.34 & -1.89 & & 8 & 75 & 70.15 & -8.25 & \\
\hline 13 & 550 & 80.83 & 2.60 & & 13 & 75 & 80.83 & 2.43 & \\
\hline 14 & 550 & 79.94 & 1.71 & & 14 & 75 & 79.94 & 1.54 & \\
\hline 15 & 550 & 80.45 & 2.22 & & 15 & 75 & 80.45 & 2.05 & \\
\hline 16 & 550 & 81.05 & 2.82 & & 16 & 75 & 81.05 & 2.65 & \\
\hline 17 & 550 & 79.83 & 1.60 & & 17 & 75 & 79.83 & 1.43 & \\
\hline 2 & 1000 & 70.80 & 0.04 & \multirow{4}{*}{70.76} & 3 & 105 & 76.81 & 3.09 & \multirow{4}{*}{73.72} \\
\hline 4 & 1000 & 71.25 & 0.49 & & 4 & 105 & 71.25 & -2.47 & \\
\hline 6 & 1000 & 70.84 & 0.08 & & 10 & 105 & 70.49 & -3.23 & \\
\hline 8 & 1000 & 70.15 & -0.61 & & 12 & 105 & 76.34 & 2.62 & \\
\hline
\end{tabular}

\begin{tabular}{|rrrrr|r|}
\multicolumn{1}{r|}{ Run } & $\mathrm{pH}$ & Predicted TOCrem & Residuals & Block \\
\hline 5 & 5.0 & 79.03 & 3.94 & \\
6 & 5.0 & 70.84 & -4.25 & 75.09 \\
9 & 5.0 & 80.01 & 4.92 & \\
10 & 5.0 & 70.49 & -4.60 & \\
\hline 1 & 7.0 & 88.87 & 10.00 & \\
2 & 7.0 & 70.80 & -8.07 & \\
3 & 7.0 & 76.81 & -2.06 & \\
4 & 7.0 & 71.25 & -7.62 & \\
13 & 7.0 & 80.83 & 1.96 & 78.87 \\
14 & 7.0 & 79.94 & 1.07 & \\
15 & 7.0 & 80.45 & 1.58 & \\
16 & 7.0 & 81.05 & 2.18 & \\
17 & 7.0 & 79.83 & 0.96 & \\
\hline 7 & 9.0 & 83.49 & 7.22 & \\
8 & 9.0 & 70.15 & -6.12 & 76.27 \\
11 & 9.0 & 75.09 & -1.18 & \\
12 & 9.0 & 76.34 & 0.07 & \\
\hline
\end{tabular}




\begin{tabular}{|c|c|c|c|c|}
\hline Run & TOCin & Predicted TNCrem & Residuals & Block \\
\hline 1 & 100 & 79.53 & 23.88 & \multirow{4}{*}{55.65} \\
\hline 3 & 100 & 46.17 & -9.48 & \\
\hline 5 & 100 & 56.92 & 1.27 & \\
\hline 7 & 100 & 39.98 & -15.67 & \\
\hline 9 & 550 & 51.04 & -2.09 & \multirow{9}{*}{53.13} \\
\hline 10 & 550 & 31.67 & -21.46 & \\
\hline 11 & 550 & 49.60 & -3.53 & \\
\hline 12 & 550 & 31.64 & -21.49 & \\
\hline 13 & 550 & 61.67 & 8.54 & \\
\hline 14 & 550 & 62.27 & 9.14 & \\
\hline 15 & 550 & 62.81 & 9.68 & \\
\hline 16 & 550 & 63.45 & 10.32 & \\
\hline 17 & 550 & 64.05 & 10.92 & \\
\hline 2 & 1000 & 48.89 & 10.43 & \multirow{4}{*}{38.46} \\
\hline 4 & 1000 & 45.25 & 6.79 & \\
\hline 6 & 1000 & 25.36 & -13.10 & \\
\hline 8 & 1000 & 34.35 & -4.11 & \\
\hline
\end{tabular}

\begin{tabular}{|c|c|c|c|c|}
\hline Run & Flow rate & Predicted TNCrem & Residuals & Block \\
\hline 1 & 45 & 79.53 & 22.27 & \multirow{4}{*}{57.27} \\
\hline 2 & 45 & 48.89 & -8.38 & \\
\hline 9 & 45 & 51.04 & -6.23 & \\
\hline 11 & 45 & 49.60 & -7.67 & \\
\hline 5 & 75 & 56.92 & 4.60 & \multirow{9}{*}{52.32} \\
\hline 6 & 75 & 25.36 & -26.96 & \\
\hline 7 & 75 & 39.98 & -12.34 & \\
\hline 8 & 75 & 34.35 & -17.97 & \\
\hline 13 & 75 & 61.67 & 9.35 & \\
\hline 14 & 75 & 62.27 & 9.95 & \\
\hline 15 & 75 & 62.81 & 10.49 & \\
\hline 16 & 75 & 63.45 & 11.13 & \\
\hline 17 & 75 & 64.05 & 11.73 & \\
\hline 3 & 105 & 46.17 & 7.49 & \multirow{4}{*}{38.68} \\
\hline 4 & 105 & 45.25 & 6.57 & \\
\hline 10 & 105 & 31.67 & -7.01 & \\
\hline 12 & 105 & 31.64 & -7.04 & \\
\hline
\end{tabular}

\begin{tabular}{|rrrrrl|}
\multicolumn{1}{r|r}{ Run } & $\mathrm{pH}$ & Predicted TNCrem & Residuals & \multicolumn{1}{l|}{ Block } \\
\hline 5 & 5.0 & 56.92 & 15.67 & \\
6 & 5.0 & 25.36 & -15.89 & \\
9 & 5.0 & 51.04 & 9.79 & 41.25 \\
10 & 5.0 & 31.67 & -9.58 & \\
\hline 1 & 7.0 & 79.53 & 20.19 & \\
2 & 7.0 & 48.89 & -10.45 & \\
3 & 7.0 & 46.17 & -13.17 & \\
4 & 7.0 & 45.25 & -14.09 & \\
13 & 7.0 & 61.67 & 2.33 & 59.34 \\
14 & 7.0 & 62.27 & 2.93 & \\
15 & 7.0 & 62.81 & 3.47 & \\
16 & 7.0 & 63.45 & 4.11 & \\
17 & 7.0 & 64.05 & 4.71 & \\
\hline 7 & 9.0 & 39.98 & 1.09 & \\
8 & 9.0 & 34.35 & -4.54 & \multirow{2}{*}{38.89} \\
11 & 9.0 & 49.60 & 10.71 & \\
12 & 9.0 & 31.64 & -7.25 & \\
\hline
\end{tabular}




\begin{tabular}{|c|c|c|c|c|}
\hline Run & TOCin & Predicted Biogas & Residuals & Block \\
\hline 1 & 100 & 94.02 & -8.53 & \multirow{4}{*}{102.55} \\
\hline 3 & 100 & 106.70 & 4.15 & \\
\hline 5 & 100 & 103.24 & 0.69 & \\
\hline 7 & 100 & 106.22 & 3.67 & \\
\hline 9 & 550 & 104.28 & -8.67 & \multirow{9}{*}{112.95} \\
\hline 10 & 550 & 97.89 & -15.06 & \\
\hline 11 & 550 & 87.30 & -25.65 & \\
\hline 12 & 550 & 91.18 & -21.77 & \\
\hline 13 & 550 & 127.25 & 14.30 & \\
\hline 14 & 550 & 125.13 & 12.18 & \\
\hline 15 & 550 & 126.13 & 13.18 & \\
\hline 16 & 550 & 129.01 & 16.06 & \\
\hline 17 & 550 & 128.41 & 15.46 & \\
\hline 2 & 1000 & 125.62 & 6.51 & \multirow{4}{*}{119.11} \\
\hline 4 & 1000 & 104.28 & -14.83 & \\
\hline 6 & 1000 & 135.32 & 16.21 & \\
\hline 8 & 1000 & 111.22 & -7.89 & \\
\hline
\end{tabular}

\begin{tabular}{|c|c|c|c|c|}
\hline Run & Flow rate & Predicted Biogas & Residuals & Block \\
\hline 1 & 45 & 94.02 & -8.79 & \multirow{4}{*}{102.81} \\
\hline 2 & 45 & 125.62 & 22.82 & \\
\hline 9 & 45 & 104.28 & 1.47 & \\
\hline 11 & 45 & 87.30 & -15.51 & \\
\hline 5 & 75 & 103.24 & -18.09 & \multirow{9}{*}{121.33} \\
\hline 6 & 75 & 135.32 & 13.99 & \\
\hline 7 & 75 & 106.22 & -15.11 & \\
\hline 8 & 75 & 111.22 & -10.11 & \\
\hline 13 & 75 & 127.25 & 5.92 & \\
\hline 14 & 75 & 125.13 & 3.80 & \\
\hline 15 & 75 & 126.13 & 4.80 & \\
\hline 16 & 75 & 129.01 & 7.68 & \\
\hline 17 & 75 & 128.41 & 7.08 & \\
\hline 3 & 105 & 106.70 & 6.69 & \multirow{4}{*}{100.01} \\
\hline 4 & 105 & 104.28 & 4.27 & \\
\hline 10 & 105 & 97.89 & -2.12 & \\
\hline 12 & 105 & 91.18 & -8.83 & \\
\hline
\end{tabular}

\begin{tabular}{|rrrrrl|}
\hline Run & $\mathrm{pH}$ & Predicted Biogas & Residuals & Block \\
\hline 5 & 5.0 & 103.24 & -6.94 & \\
6 & 5.0 & 135.32 & 25.14 & \multirow{2}{*}{110.18} \\
9 & 5.0 & 104.28 & -5.90 & \\
10 & 5.0 & 97.89 & -12.29 & \\
\hline 1 & 7.0 & 94.02 & -24.49 & \\
2 & 7.0 & 125.62 & 7.11 & \\
3 & 7.0 & 106.70 & -11.81 & \\
4 & 7.0 & 104.28 & -14.23 & \\
13 & 7.0 & 127.25 & 8.74 & 118.51 \\
14 & 7.0 & 125.13 & 6.62 & \\
15 & 7.0 & 126.13 & 7.62 & \\
16 & 7.0 & 129.01 & 10.50 & \\
17 & 7.0 & 128.41 & 9.90 & \\
\hline 7 & 9.0 & 106.22 & 7.24 & \\
8 & 9.0 & 111.22 & 12.24 & \multirow{2}{*}{98.98} \\
11 & 9.0 & 87.30 & -11.68 & \\
12 & 9.0 & 91.18 & -7.80 & \\
\hline
\end{tabular}




\begin{tabular}{|rr|r|r|r|}
\multicolumn{1}{r|}{ Run } & TOCin & Predicted TSSres & Residuals & \multicolumn{1}{l|}{ Block } \\
\hline 1 & 100 & 18.62 & -5.07 & \\
3 & 100 & 22.83 & -0.86 & \multirow{2}{*}{23.69} \\
5 & 100 & 26.14 & 2.46 & \\
7 & 100 & 27.15 & 3.47 & \\
\hline 9 & 550 & 20.90 & -4.18 & \\
10 & 550 & 30.31 & 5.23 & \\
11 & 550 & 24.98 & -0.10 & \\
12 & 550 & 36.95 & 11.87 & \\
13 & 550 & 22.52 & -2.56 & 25.08 \\
\hline 14 & 550 & 21.71 & -3.37 & \\
15 & 550 & 22.10 & -2.98 & \\
16 & 550 & 22.92 & -2.16 & \\
17 & 550 & 23.35 & -1.73 & \\
\hline 2 & 1000 & 18.95 & -11.33 & \\
\hline 4 & 1000 & 33.56 & 3.29 & \multirow{2}{*}{30.28} \\
\hline 6 & 1000 & 30.76 & 0.48 & \\
\hline 8 & 1000 & 37.83 & 7.56 & \\
\hline
\end{tabular}

\begin{tabular}{|rr|rrr|}
\multicolumn{1}{r|}{ Run } & Flow rate & Predicted TSSres & Residuals & Block \\
\hline 1 & 45 & 18.62 & -2.24 & \\
2 & 45 & 18.95 & -1.91 & \multirow{2}{*}{20.86} \\
9 & 45 & 20.90 & 0.04 & \\
11 & 45 & 24.98 & 4.12 & \\
\hline 5 & 75 & 26.14 & 0.09 & \\
6 & 75 & 30.76 & 4.71 & \\
7 & 75 & 27.15 & 1.10 & \\
8 & 75 & 37.83 & 11.78 & \\
13 & 75 & 22.52 & -3.53 & 26.05 \\
14 & 75 & 21.71 & -4.34 & \\
15 & 75 & 22.10 & -3.95 & \\
16 & 75 & 22.92 & -3.13 & \\
17 & 75 & 23.35 & -2.70 & \\
\hline 3 & 105 & 22.83 & -8.08 & \\
4 & 105 & 33.56 & 2.65 & \multirow{2}{*}{30.91} \\
10 & 105 & 30.31 & -0.60 & \\
\hline 12 & 105 & 36.95 & 6.04 & \\
\hline
\end{tabular}

\begin{tabular}{|rr|r|r|r|}
\multicolumn{1}{r|}{ Run } & pH & Predicted TSSres & Residuals & \multicolumn{1}{l|}{ Block } \\
\hline 5 & 5.0 & 26.14 & -0.89 & \\
6 & 5.0 & 30.76 & 3.73 & 27.03 \\
9 & 5.0 & 20.90 & -6.13 & \\
10 & 5.0 & 30.31 & 3.28 & \\
\hline 1 & 7.0 & 18.62 & -4.33 & \\
2 & 7.0 & 18.95 & -4.00 & \\
3 & 7.0 & 22.83 & -0.12 & \\
4 & 7.0 & 33.56 & 10.61 & \\
13 & 7.0 & 22.52 & -0.43 & 22.95 \\
14 & 7.0 & 21.71 & -1.24 & \\
15 & 7.0 & 22.10 & -0.85 & \\
16 & 7.0 & 22.92 & -0.03 & \\
17 & 7.0 & 23.35 & 0.40 & \\
\hline 7 & 9.0 & 27.15 & -4.58 & \\
8 & 9.0 & 37.83 & 6.10 & 31.73 \\
11 & 9.0 & 24.98 & -6.75 & \\
12 & 9.0 & 36.95 & 5.22 & \\
\hline
\end{tabular}




\section{Appendix P. Combined anaerobic-aerobic $\mathrm{UV} / \mathrm{H}_{2} \mathrm{O}_{2}$ processes reactor-modeling example.}

Combined Anaerobic-Aerobic $\mathrm{UV} / \mathrm{H}_{2} \mathrm{O}_{2}$ Processes

\begin{tabular}{|c|c|c|c|c|c|c|}
\hline HRT (h) & $\mathrm{S}_{0}(\mathrm{mg} / \mathrm{L})$ & $\mathrm{S}_{\mathrm{f}}$ Experiments (mg/L) & $\mathrm{S}_{\mathrm{f}} \operatorname{Model}(\mathrm{mg} / \mathrm{L})$ & ABR-AS-UV/H2O2 & ABR-AS-UV/H2O2 Model & Error \\
\hline 0.00 & & & & 1.00 & 1.00 & \\
\hline 1.00 & 50.00 & 17.9986 & 16.3624 & 0.36 & 0.33 & $0.11 \%$ \\
\hline 2.00 & 50.00 & 6.3843 & 7.0936 & 0.13 & 0.14 & $0.02 \%$ \\
\hline 3.00 & 50.00 & 3.6105 & 3.2823 & 0.07 & 0.07 & $0.00 \%$ \\
\hline 4.00 & 50.00 & 1.4258 & 1.5842 & 0.03 & 0.03 & $0.00 \%$ \\
\hline 5.00 & 50.00 & 0.8665 & 0.7878 & 0.02 & 0.02 & $0.00 \%$ \\
\hline 6.00 & 50.00 & 0.3605 & 0.4006 & 0.01 & 0.01 & $0.00 \%$ \\
\hline 7.00 & 50.00 & 0.2280 & 0.2073 & 0.00 & 0.00 & $0.00 \%$ \\
\hline 8.00 & 50.00 & 0.0979 & 0.1088 & 0.00 & 0.00 & $0.00 \%$ \\
\hline 9.00 & 50.00 & 0.0636 & 0.0578 & 0.00 & 0.00 & $0.00 \%$ \\
\hline 10.00 & 50.00 & 0.0279 & 0.0310 & 0.00 & 0.00 & $0.00 \%$ \\
\hline 11.00 & 50.00 & 0.0184 & 0.0168 & 0.00 & 0.00 & $0.00 \%$ \\
\hline 12.00 & 50.00 & 0.0082 & 0.0091 & 0.00 & 0.00 & $0.00 \%$ \\
\hline 13.00 & 50.00 & 0.0055 & 0.0050 & 0.00 & 0.00 & $0.00 \%$ \\
\hline 14.00 & 50.00 & 0.0025 & 0.0028 & 0.00 & 0.00 & $0.00 \%$ \\
\hline 15.00 & 50.00 & 0.0017 & 0.0015 & 0.00 & 0.00 & $0.00 \%$ \\
\hline 16.00 & 50.00 & 0.0008 & 0.0009 & 0.00 & 0.00 & $0.00 \%$ \\
\hline 17.00 & 50.00 & 0.0005 & 0.0005 & 0.00 & 0.00 & $0.00 \%$ \\
\hline 18.00 & 50.00 & 0.0002 & 0.0003 & 0.00 & 0.00 & $0.00 \%$ \\
\hline 19.00 & 50.00 & 0.0002 & 0.0002 & 0.00 & 0.00 & $0.00 \%$ \\
\hline 20.00 & 50.00 & 0.0001 & 0.0001 & 0.00 & 0.00 & $0.00 \%$ \\
\hline 21.00 & 50.00 & 0.0001 & 0.0000 & 0.00 & 0.00 & $0.00 \%$ \\
\hline 22.00 & 50.00 & 0.0000 & 0.0000 & 0.00 & 0.00 & $0.00 \%$ \\
\hline 23.00 & 50.00 & 0.0000 & 0.0000 & 0.00 & 0.00 & $0.00 \%$ \\
\hline 24.00 & 50.00 & 0.0000 & 0.0000 & 0.00 & 0.00 & $0.00 \%$ \\
\hline
\end{tabular}




\section{Appendix Q. Combined anaerobic-aerobic $\mathrm{UV} / \mathrm{H}_{2} \mathrm{O}_{2}$ processes energy estimation.}

\begin{tabular}{|c|c|c|}
\hline $\mathrm{t}(\mathrm{min})$ & $A B R$ & AS \\
\hline 0.5 & 0.0368 & 0.8671 \\
\hline 2 & 0.0092 & 0.2168 \\
\hline 5 & 0.0037 & 0.0867 \\
\hline 10 & 0.0018 & 0.0434 \\
\hline 15 & 0.0012 & 0.0289 \\
\hline 20 & 0.0009 & 0.0217 \\
\hline 25 & 0.0007 & 0.0173 \\
\hline 30 & 0.0006 & 0.0145 \\
\hline 35 & 0.0005 & 0.0124 \\
\hline 40 & 0.0005 & 0.0108 \\
\hline 47 & 0.0004 & 0.0093 \\
\hline 50 & 0.0004 & 0.0087 \\
\hline 55 & 0.0003 & 0.0079 \\
\hline 60 & 0.0003 & 0.0072 \\
\hline 65 & 0.0003 & 0.0067 \\
\hline 70 & 0.0003 & 0.0062 \\
\hline 75 & 0.0002 & 0.0058 \\
\hline 80 & 0.0002 & 0.0054 \\
\hline 85 & 0.0002 & 0.0051 \\
\hline 90 & 0.0002 & 0.0048 \\
\hline 95 & 0.0002 & 0.0046 \\
\hline 100 & 0.0002 & 0.0043 \\
\hline 105 & 0.0002 & 0.0041 \\
\hline 110 & 0.0002 & 0.0039 \\
\hline 115 & 0.0002 & 0.0038 \\
\hline 120 & 0.0002 & 0.0036 \\
\hline 125 & 0.0001 & 0.0035 \\
\hline 130 & 0.0001 & 0.0033 \\
\hline 135 & 0.0001 & 0.0032 \\
\hline 140 & 0.0001 & 0.0031 \\
\hline 145 & 0.0001 & 0.0030 \\
\hline 150 & 0.0001 & 0.0029 \\
\hline
\end{tabular}

$\begin{array}{ccc}\mathrm{UV} / \mathrm{H}_{2} \mathrm{O}_{2} & \text { Overall consumption } \\ 0.0001 & 0.9040 & 0.0014 \\ 0.0004 & 0.2264 & 0.0003 \\ 0.0010 & 0.0914 & 0.0001 \\ 0.0021 & 0.0473 & 0.0001 \\ 0.0031 & 0.0333 & 0.0000 \\ 0.0042 & 0.0268 & 0.0000 \\ 0.0052 & 0.0233 & 0.0000 \\ 0.0063 & 0.0213 & 0.0000 \\ 0.0073 & 0.0202 & 0.0000 \\ 0.0083 & 0.0196 & 0.0000 \\ 0.0097 & 0.0194 & 0.0000 \\ 0.0104 & 0.0195 & 0.0000 \\ 0.0115 & 0.0197 & 0.0000 \\ 0.0125 & 0.0200 & 0.0000 \\ 0.0135 & 0.0205 & 0.0000 \\ 0.0146 & 0.0210 & 0.0000 \\ 0.0156 & 0.0217 & 0.0000 \\ 0.0167 & 0.0223 & 0.0000 \\ 0.0177 & 0.0230 & 0.0000 \\ 0.0188 & 0.0238 & 0.0000 \\ 0.0198 & 0.0245 & 0.0000 \\ 0.0208 & 0.0254 & 0.0000 \\ 0.0219 & 0.0262 & 0.0000 \\ 0.0229 & 0.0270 & 0.0000 \\ 0.0240 & 0.0279 & 0.0000 \\ 0.0250 & 0.0288 & 0.0000 \\ 0.0260 & 0.0297 & 0.0000 \\ 0.0271 & 0.0306 & 0.0000 \\ 0.0281 & 0.0315 & 0.0000 \\ 0.0292 & 0.0324 & 0.0000 \\ 0.0302 & 0.0333 & 0.0000 \\ 0.0313 & 0.0343 & 0.0000\end{array}$




\section{Appendix R.Combined anaerobic-aerobic $\mathrm{UV} / \mathrm{H}_{2} \mathrm{O}_{2}$ processes overall treatment costs estimation.}

\begin{tabular}{|c|c|c|c|c|c|c|c|c|c|c|c|c|c|}
\hline $\begin{array}{l}\text { TOC removal } \\
\text { ABR-AS-UV }\end{array}$ & $t(\min )$ & $\begin{array}{l}\text { Anaerobic bioreactor } \\
\text { energy consumption }\end{array}$ & $\begin{array}{l}\text { Overall } \\
\text { Cost }\end{array}$ & $\begin{array}{l}\mathrm{ABR} \\
\text { bioreactor }\end{array}$ & $\begin{array}{l}\text { Aerobic b } \\
\text { energy } c 0\end{array}$ & $\begin{array}{l}\text { eactor } \\
\text { umption }\end{array}$ & $\begin{array}{l}\text { AS } \\
\text { bioreactor }\end{array}$ & $\begin{array}{l}\mathrm{UV} / \mathrm{H}_{2} \mathrm{O}_{2} \\
\text { energy cc }\end{array}$ & $\begin{array}{l}\text { toreactor } \\
\text { umption }\end{array}$ & $\begin{array}{l}\mathrm{UV} / \mathrm{H}_{2} \mathrm{O}_{2} \\
\text { photoreactor }\end{array}$ & $\begin{array}{l}\text { Overall } \\
\text { consumption }\end{array}$ & $\begin{array}{l}\text { Overall } \\
\text { Cost }\end{array}$ & $\begin{array}{l}\text { Combined } \\
\text { ABR-AS- } \\
\text { UV/ } / \mathrm{H}_{2} \mathrm{O}_{2}\end{array}$ \\
\hline $17.41 \%$ & 0.1 & 2.5751 & 0.2987 & 8.2976 & 0.0001 & 0.0000 & 0.0010 & 0.0001 & 0.0000 & 0.0121 & 2.5754 & 0.2987 & 5.9749 \\
\hline $25.44 \%$ & 0.5 & 0.5150 & 0.0597 & 1.6595 & 0.0005 & 0.0001 & 0.0050 & 0.0007 & 0.0001 & 0.0604 & 0.5163 & 0.0599 & 1.1977 \\
\hline $34.24 \%$ & 1 & 0.2575 & 0.0299 & 0.8298 & 0.0011 & 0.0001 & 0.0100 & 0.0014 & 0.0002 & 0.1208 & 0.2600 & 0.0302 & 0.6032 \\
\hline $48.52 \%$ & 2 & 0.1288 & 0.0149 & 0.4149 & 0.0022 & 0.0003 & 0.0199 & 0.0028 & 0.0003 & 0.2417 & 0.1337 & 0.0155 & 0.3103 \\
\hline $59.38 \%$ & 3 & 0.0858 & 0.0100 & 0.2766 & 0.0033 & 0.0004 & 0.0299 & 0.0042 & 0.0005 & 0.3625 & 0.0933 & 0.0108 & 0.2165 \\
\hline $67.74 \%$ & 4 & 0.0644 & 0.0075 & 0.2074 & 0.0043 & 0.0005 & 0.0398 & 0.0056 & 0.0007 & 0.4833 & 0.0743 & 0.0086 & 0.1725 \\
\hline $74.24 \%$ & 5 & 0.0515 & 0.0060 & 0.1660 & 0.0054 & 0.0006 & 0.0498 & 0.0070 & 0.0008 & 0.6042 & 0.0640 & 0.0074 & 0.1484 \\
\hline $79.32 \%$ & 6 & 0.0429 & 0.0050 & 0.1383 & 0.0065 & 0.0008 & 0.0598 & 0.0084 & 0.0010 & 0.7250 & 0.0579 & 0.0067 & 0.1343 \\
\hline $83.33 \%$ & 7 & 0.0368 & 0.0043 & 0.1185 & 0.0076 & 0.0009 & 0.0697 & 0.0098 & 0.0011 & 0.8458 & 0.0542 & 0.0063 & 0.1258 \\
\hline $86.51 \%$ & 8 & 0.0322 & 0.0037 & 0.1037 & 0.0087 & 0.0010 & 0.0797 & 0.0113 & 0.0013 & 0.9667 & 0.0521 & 0.0060 & 0.1209 \\
\hline $89.04 \%$ & 9 & 0.0286 & 0.0033 & 0.0922 & 0.0098 & 0.0011 & 0.0897 & 0.0127 & 0.0015 & 1.0875 & 0.0510 & 0.0059 & 0.1184 \\
\hline $91.07 \%$ & 10 & 0.0258 & 0.0030 & 0.0830 & 0.0109 & 0.0013 & 0.0996 & 0.0141 & 0.0016 & 1.2083 & 0.0507 & 0.0059 & 0.1176 \\
\hline $92.70 \%$ & 11 & 0.0234 & 0.0027 & 0.0754 & 0.0120 & 0.0014 & 0.1096 & 0.0155 & 0.0018 & 1.3292 & 0.0508 & 0.0059 & 0.1179 \\
\hline $94.02 \%$ & 12 & 0.0215 & 0.0025 & 0.0691 & 0.0130 & 0.0015 & 0.1195 & 0.0169 & 0.0020 & 1.4500 & 0.0514 & 0.0060 & 0.1192 \\
\hline $95.08 \%$ & 13 & 0.0198 & 0.0023 & 0.0638 & 0.0141 & 0.0016 & 0.1295 & 0.0183 & 0.0021 & 1.5708 & 0.0522 & 0.0061 & 0.1211 \\
\hline $95.95 \%$ & 14 & 0.0184 & 0.0021 & 0.0593 & 0.0152 & 0.0018 & 0.1395 & 0.0197 & 0.0023 & 1.6917 & 0.0533 & 0.0062 & 0.1236 \\
\hline $96.66 \%$ & 15 & 0.0172 & 0.0020 & 0.0553 & 0.0163 & 0.0019 & 0.1494 & 0.0211 & 0.0024 & 1.8125 & 0.0546 & 0.0063 & 0.1266 \\
\hline $97.24 \%$ & 16 & 0.0161 & 0.0019 & 0.0519 & 0.0174 & 0.0020 & 0.1594 & 0.0225 & 0.0026 & 1.9333 & 0.0560 & 0.0065 & 0.1299 \\
\hline $97.71 \%$ & 17 & 0.0151 & 0.0018 & 0.0488 & 0.0185 & 0.0021 & 0.1694 & 0.0239 & 0.0028 & 2.0542 & 0.0575 & 0.0067 & 0.1335 \\
\hline $98.10 \%$ & 18 & 0.0143 & 0.0017 & 0.0461 & 0.0196 & 0.0023 & 0.1793 & 0.0253 & 0.0029 & 2.1750 & 0.0592 & 0.0069 & 0.1373 \\
\hline $98.42 \%$ & 19 & 0.0136 & 0.0016 & 0.0437 & 0.0206 & 0.0024 & 0.1893 & 0.0267 & 0.0031 & 2.2958 & 0.0609 & 0.0071 & 0.1413 \\
\hline $98.69 \%$ & 20 & 0.0129 & 0.0015 & 0.0415 & 0.0217 & 0.0025 & 0.1992 & 0.0281 & 0.0033 & 2.4167 & 0.0627 & 0.0073 & 0.1455 \\
\hline $98.90 \%$ & 21 & 0.0123 & 0.0014 & 0.0395 & 0.0228 & 0.0026 & 0.2092 & 0.0295 & 0.0034 & 2.5375 & 0.0646 & 0.0075 & 0.1499 \\
\hline $99.08 \%$ & 22 & 0.0117 & 0.0014 & 0.0377 & 0.0239 & 0.0028 & 0.2192 & 0.0309 & 0.0036 & 2.6583 & 0.0665 & 0.0077 & 0.1544 \\
\hline $99.23 \%$ & 23 & 0.0112 & 0.0013 & 0.0361 & 0.0250 & 0.0029 & 0.2291 & 0.0323 & 0.0038 & 2.7792 & 0.0685 & 0.0079 & 0.1590 \\
\hline $99.36 \%$ & 24 & 0.0107 & 0.0012 & 0.0346 & 0.0261 & 0.0030 & 0.2391 & 0.0338 & 0.0039 & 2.9000 & 0.0706 & 0.0082 & 0.1637 \\
\hline $99.46 \%$ & 25 & 0.0103 & 0.0012 & 0.0332 & 0.0272 & 0.0032 & 0.2490 & 0.0352 & 0.0041 & 3.0208 & 0.0726 & 0.0084 & 0.1685 \\
\hline 99.55\% & 26 & 0.0099 & 0.0011 & 0.0319 & 0.0282 & 0.0033 & 0.2590 & 0.0366 & 0.0042 & 3.1417 & 0.0747 & 0.0087 & 0.1733 \\
\hline
\end{tabular}




\begin{tabular}{|c|c|c|c|c|c|c|c|c|c|c|c|c|c|}
\hline \multirow{2}{*}{$\begin{array}{l}\text { TOC removal } \\
\text { ABR-AS-UV } \\
99.62 \%\end{array}$} & \multirow{2}{*}{$\begin{array}{r}t(\min ) \\
27\end{array}$} & \multirow{2}{*}{$\begin{array}{c}\text { Anaerobic bioreactor } \\
\text { energy consumption } \\
0.0095\end{array}$} & \multirow{2}{*}{$\begin{array}{l}\text { Overall } \\
\text { Cost } \\
0.0011\end{array}$} & \multirow{2}{*}{$\begin{array}{l}\text { ABR } \\
\text { bioreactor } \\
0.0307\end{array}$} & \multicolumn{2}{|c|}{$\begin{array}{l}\text { Aerobic bioreactor } \\
\text { energy consumption }\end{array}$} & \multirow{2}{*}{$\begin{array}{l}\text { AS } \\
\text { bioreactor } \\
\quad 0.2690\end{array}$} & \multicolumn{2}{|c|}{$\begin{array}{l}\mathrm{UV} / \mathrm{H}_{2} \mathrm{O}_{2} \text { photoreactor } \\
\text { energy consumption }\end{array}$} & \multirow{2}{*}{$\begin{array}{c}\mathrm{UV} / \mathrm{H}_{2} \mathrm{O}_{2} \\
\text { photoreactor } \\
3.2625\end{array}$} & \multirow{2}{*}{$\begin{array}{l}\begin{array}{l}\text { Overall } \\
\text { consumption }\end{array} \\
\quad 0.0768\end{array}$} & \multirow{2}{*}{$\begin{array}{l}\text { Overall } \\
\text { Cost } \\
0.0089\end{array}$} & \multirow{2}{*}{$\begin{array}{r}\text { Combinec } \\
\text { ABR-AS- } \\
\text { UV/ } \mathrm{H}_{2} \mathrm{O}_{2} \\
0.1783\end{array}$} \\
\hline & & & & & 0.0293 & 0.0034 & & 0.0380 & 0.0044 & & & & \\
\hline $99.68 \%$ & 28 & 0.0092 & 0.0011 & 0.0296 & 0.0304 & 0.0035 & 0.2789 & 0.0394 & 0.0046 & 3.3833 & 0.0790 & 0.0092 & 0.1833 \\
\hline $99.73 \%$ & 29 & 0.0089 & 0.0010 & 0.0286 & 0.0315 & 0.0037 & 0.2889 & 0.0408 & 0.0047 & 3.5042 & 0.0812 & 0.0094 & 0.1883 \\
\hline $99.77 \%$ & 30 & 0.0086 & 0.0010 & 0.0277 & 0.0326 & 0.0038 & 0.2989 & 0.0422 & 0.0049 & 3.6250 & 0.0834 & 0.0097 & 0.1934 \\
\hline $99.81 \%$ & 31 & 0.0083 & 0.0010 & 0.0268 & 0.0337 & 0.0039 & 0.3088 & 0.0436 & 0.0051 & 3.7458 & 0.0856 & 0.0099 & 0.1985 \\
\hline $99.84 \%$ & 32 & 0.0080 & 0.0009 & 0.0259 & 0.0348 & 0.0040 & 0.3188 & 0.0450 & 0.0052 & 3.8667 & 0.0878 & 0.0102 & 0.2037 \\
\hline $99.86 \%$ & 33 & 0.0078 & 0.0009 & 0.0251 & 0.0359 & 0.0042 & 0.3287 & 0.0464 & 0.0054 & 3.9875 & 0.0901 & 0.0104 & 0.2089 \\
\hline $99.89 \%$ & 34 & 0.0076 & 0.0009 & 0.0244 & 0.0369 & 0.0043 & 0.3387 & 0.0478 & 0.0055 & 4.1083 & 0.0923 & 0.0107 & 0.2142 \\
\hline $99.90 \%$ & 35 & 0.0074 & 0.0009 & 0.0237 & 0.0380 & 0.0044 & 0.3487 & 0.0492 & 0.0057 & 4.2292 & 0.0946 & 0.0110 & 0.2195 \\
\hline $99.92 \%$ & 36 & 0.0072 & 0.0008 & 0.0230 & 0.0391 & 0.0045 & 0.3586 & 0.0506 & 0.0059 & 4.3500 & 0.0969 & 0.0112 & 0.2248 \\
\hline $99.93 \%$ & 37 & 0.0070 & 0.0008 & 0.0224 & 0.0402 & 0.0047 & 0.3686 & 0.0520 & 0.0060 & 4.4708 & 0.0992 & 0.0115 & 0.2301 \\
\hline $99.94 \%$ & 38 & 0.0068 & 0.0008 & 0.0218 & 0.0413 & 0.0048 & 0.3786 & 0.0534 & 0.0062 & 4.5917 & 0.1015 & 0.0118 & 0.2355 \\
\hline $99.95 \%$ & 39 & 0.0066 & 0.0008 & 0.0213 & 0.0424 & 0.0049 & 0.3885 & 0.0548 & 0.0064 & 4.7125 & 0.1038 & 0.0120 & 0.2409 \\
\hline $99.96 \%$ & 40 & 0.0064 & 0.0007 & 0.0207 & 0.0435 & 0.0050 & 0.3985 & 0.0563 & 0.0065 & 4.8333 & 0.1061 & 0.0123 & 0.2463 \\
\hline $99.96 \%$ & 41 & 0.0063 & 0.0007 & 0.0202 & 0.0445 & 0.0052 & 0.4084 & 0.0577 & 0.0067 & 4.9542 & 0.1085 & 0.0126 & 0.2517 \\
\hline $99.97 \%$ & 42 & 0.0061 & 0.0007 & 0.0198 & 0.0456 & 0.0053 & 0.4184 & 0.0591 & 0.0069 & 5.0750 & 0.1108 & 0.0129 & 0.2571 \\
\hline $99.97 \%$ & 43 & 0.0060 & 0.0007 & 0.0193 & 0.0467 & 0.0054 & 0.4284 & 0.0605 & 0.0070 & 5.1958 & 0.1132 & 0.0131 & 0.2626 \\
\hline $99.98 \%$ & 44 & 0.0059 & 0.0007 & 0.0189 & 0.0478 & 0.0055 & 0.4383 & 0.0619 & 0.0072 & 5.3167 & 0.1155 & 0.0134 & 0.2680 \\
\hline $99.98 \%$ & 45 & 0.0057 & 0.0007 & 0.0184 & 0.0489 & 0.0057 & 0.4483 & 0.0633 & 0.0073 & 5.4375 & 0.1179 & 0.0137 & 0.2735 \\
\hline $99.98 \%$ & 46 & 0.0056 & 0.0006 & 0.0180 & 0.0500 & 0.0058 & 0.4583 & 0.0647 & 0.0075 & 5.5583 & 0.1203 & 0.0139 & 0.2790 \\
\hline $99.99 \%$ & 47 & 0.0055 & 0.0006 & 0.0177 & 0.0511 & 0.0059 & 0.4682 & 0.0661 & 0.0077 & 5.6792 & 0.1226 & 0.0142 & 0.2845 \\
\hline 99.99\% & 48 & 0.0054 & 0.0006 & 0.0173 & 0.0521 & 0.0060 & 0.4782 & 0.0675 & 0.0078 & 5.8000 & 0.1250 & 0.0145 & 0.2900 \\
\hline
\end{tabular}


Appendix S. Supplementary Materials.
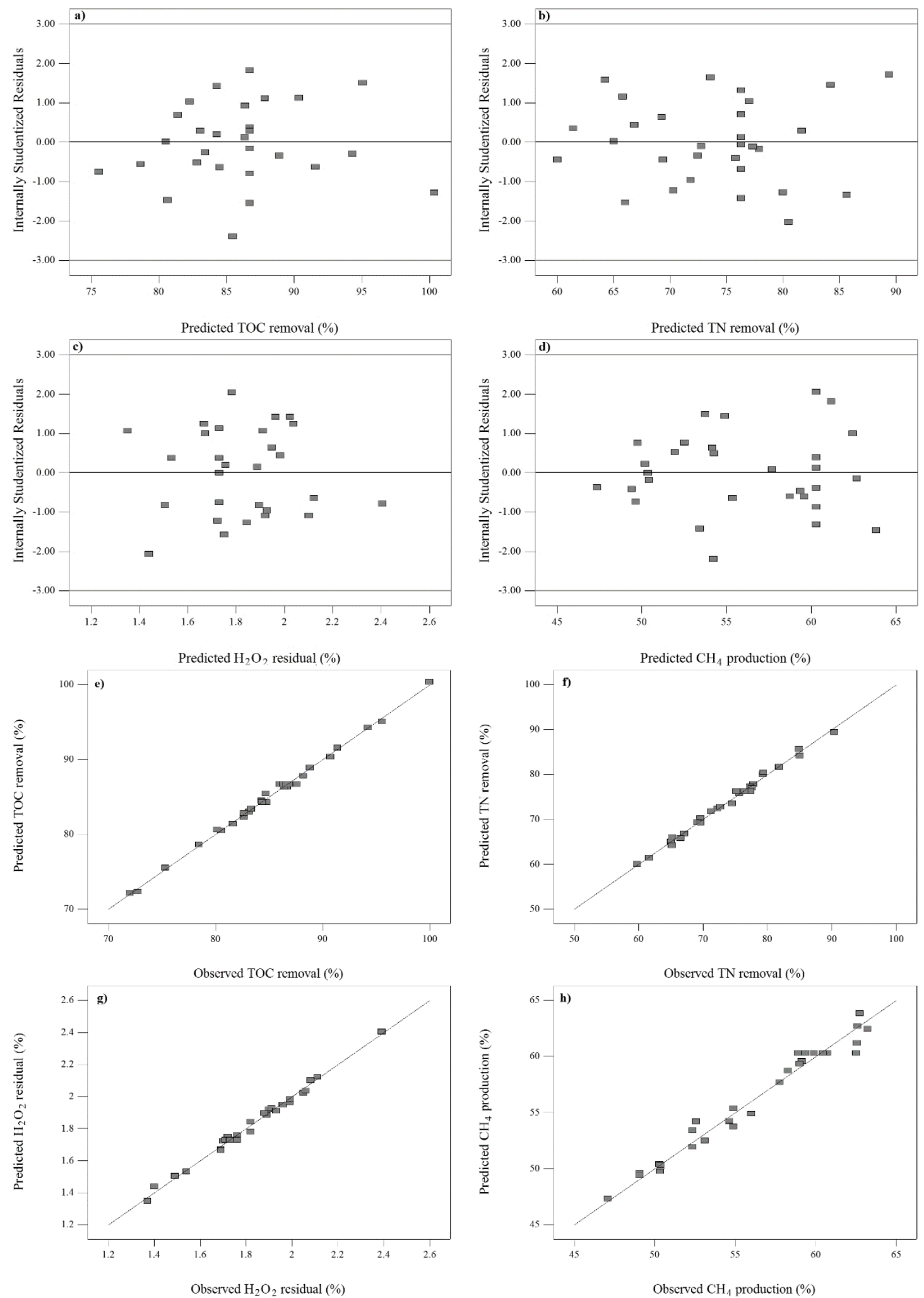

Figure S.1. Internally studentized residuals versus predicted values for the percentual TOC removal, TN removal, $\mathrm{H}_{2} \mathrm{O}_{2}$ residual, and $\mathrm{CH}_{4}$ production (a, b, c, and d, respectively); and model validation using experimental data for the percentual TOC removal, percentual TN removal, $\mathrm{H}_{2} \mathrm{O}_{2}$ residual, and $\mathrm{CH}_{4}$ production (e, $\mathrm{f}, \mathrm{g}$, and $\mathrm{h}$, respectively) in the combined $\mathrm{ABR}-\mathrm{AS}-\mathrm{UV} / \mathrm{H}_{2} \mathrm{O}_{2}$ processes.

J. Environ. Manage. (2016), In Press. 

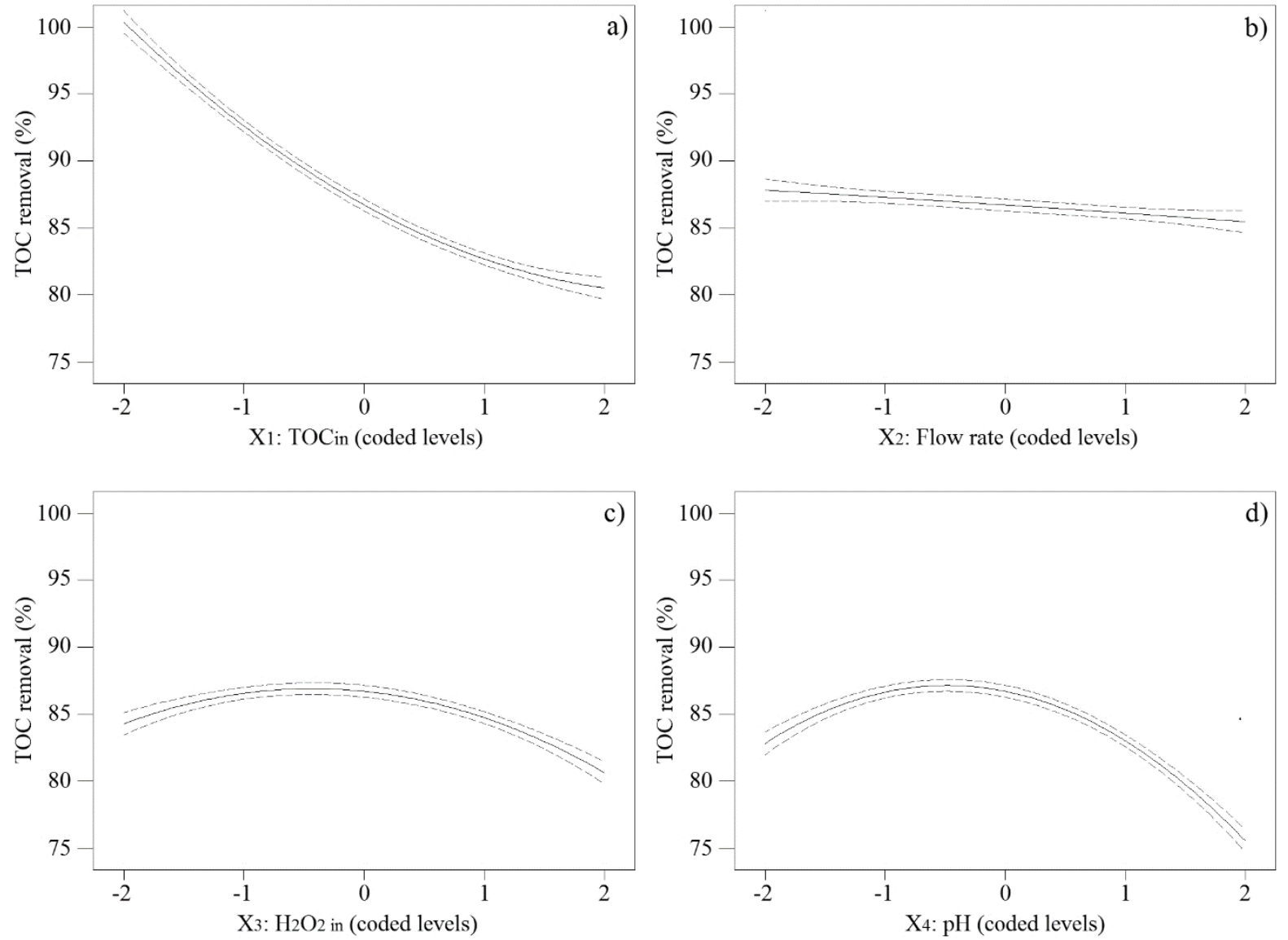

Figure S.2. The individual effect of model parameters on the percentual TOC removal: (a) influent concentration of TOC; (b) flow rate; (c) inlet $\mathrm{H}_{2} \mathrm{O}_{2}$ concentration; and (d) pH in the combined $\mathrm{ABR}-\mathrm{AS}-\mathrm{UV} / \mathrm{H}_{2} \mathrm{O}_{2}$ processes. The continuous lines represent model predicted values; whereas the dashed lines represent the $95 \%$ confidence interval bands. 

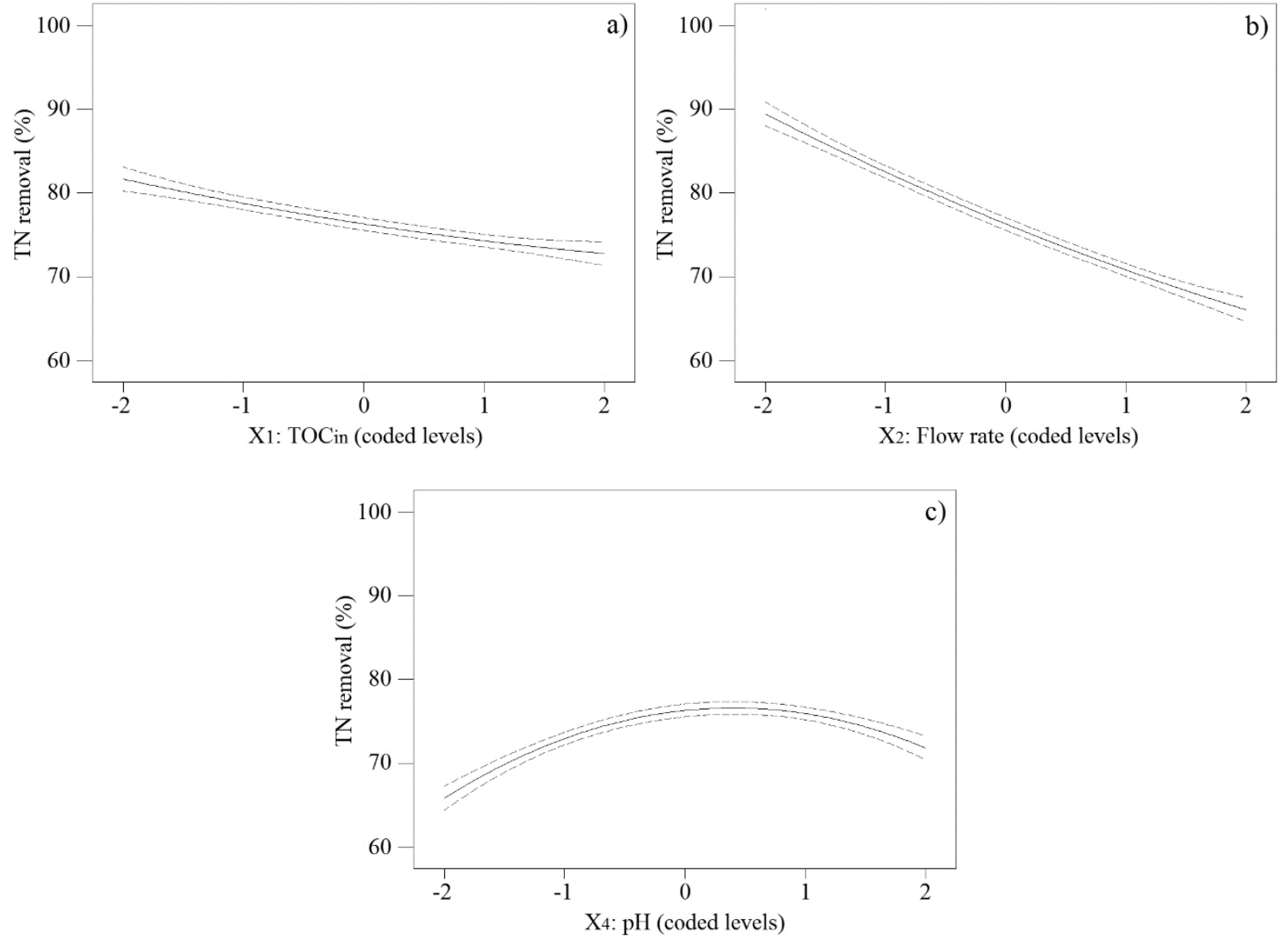

Figure S.3. The individual effect of model parameters on the percentual TN removal: (a) influent concentration of TOC; (b) flow rate; and (c) $\mathrm{pH}$ in the combined $\mathrm{ABR}-\mathrm{AS}-\mathrm{UV} / \mathrm{H}_{2} \mathrm{O}_{2}$ processes. The continuous lines represent model predicted values; whereas the dashed lines represent the 95\% confidence interval bands. 

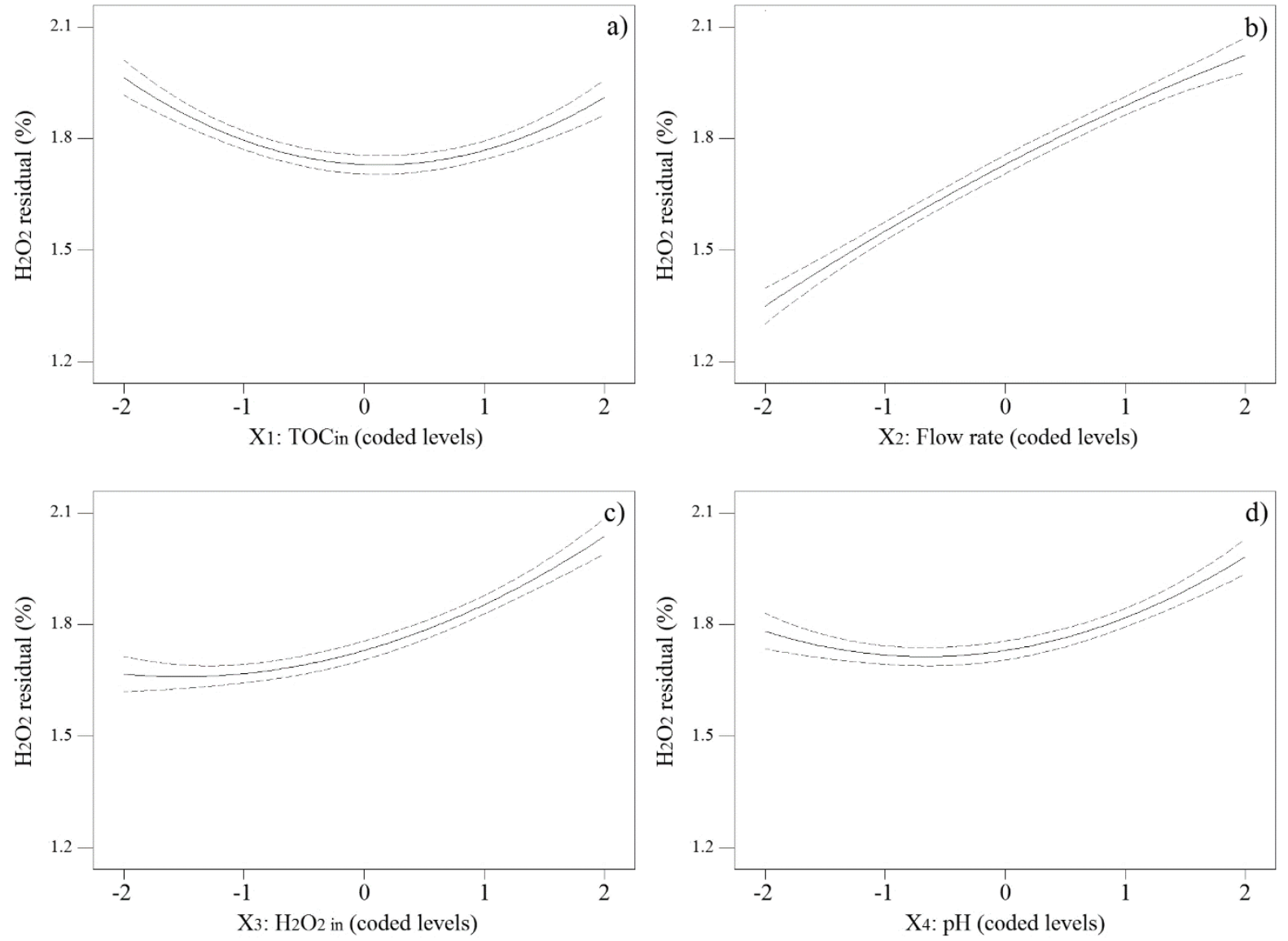

Figure S.4. The individual effect of model parameters on the percentual $\mathrm{H}_{2} \mathrm{O}_{2}$ residual: (a) influent concentration of TOC; (b) flow rate; (c) inlet $\mathrm{H}_{2} \mathrm{O}_{2}$ concentration; and (d) $\mathrm{pH}$ in the combined $\mathrm{ABR}-\mathrm{AS}-\mathrm{UV} / \mathrm{H}_{2} \mathrm{O}_{2}$ processes. The continuous lines represent model predicted values; whereas the dashed lines represent the $95 \%$ confidence interval bands. 

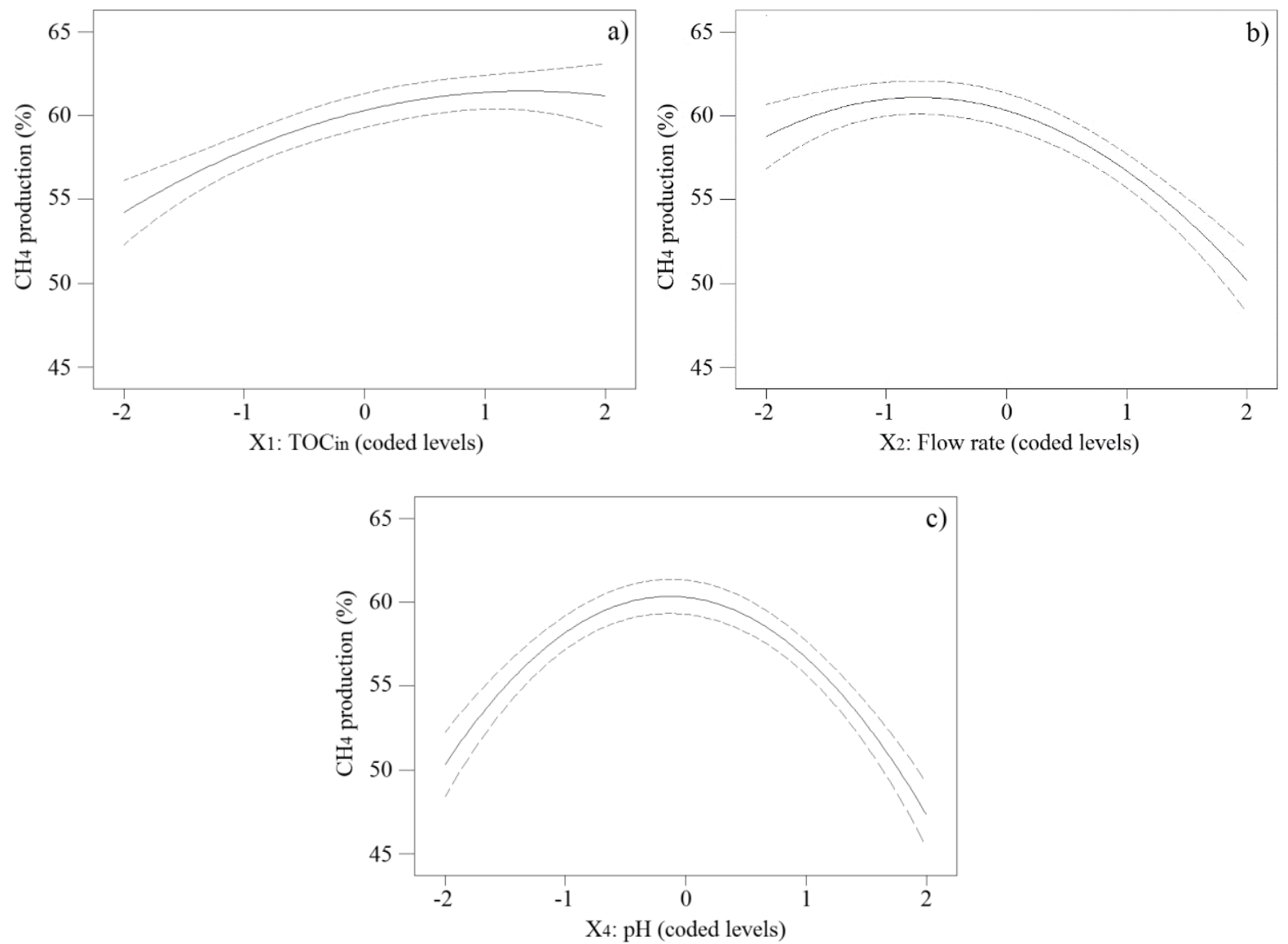

Figure S.5. The individual effect of model parameters on the $\mathrm{CH}_{4}$ yield: (a) influent concentration of TOC; (b) flow rate; and (c) $\mathrm{pH}$ in the combined $\mathrm{ABR}-\mathrm{AS}-\mathrm{UV} / \mathrm{H}_{2} \mathrm{O}_{2}$ processes. The continuous lines represent model predicted values; whereas the dashed lines represent the $95 \%$ confidence interval bands. 

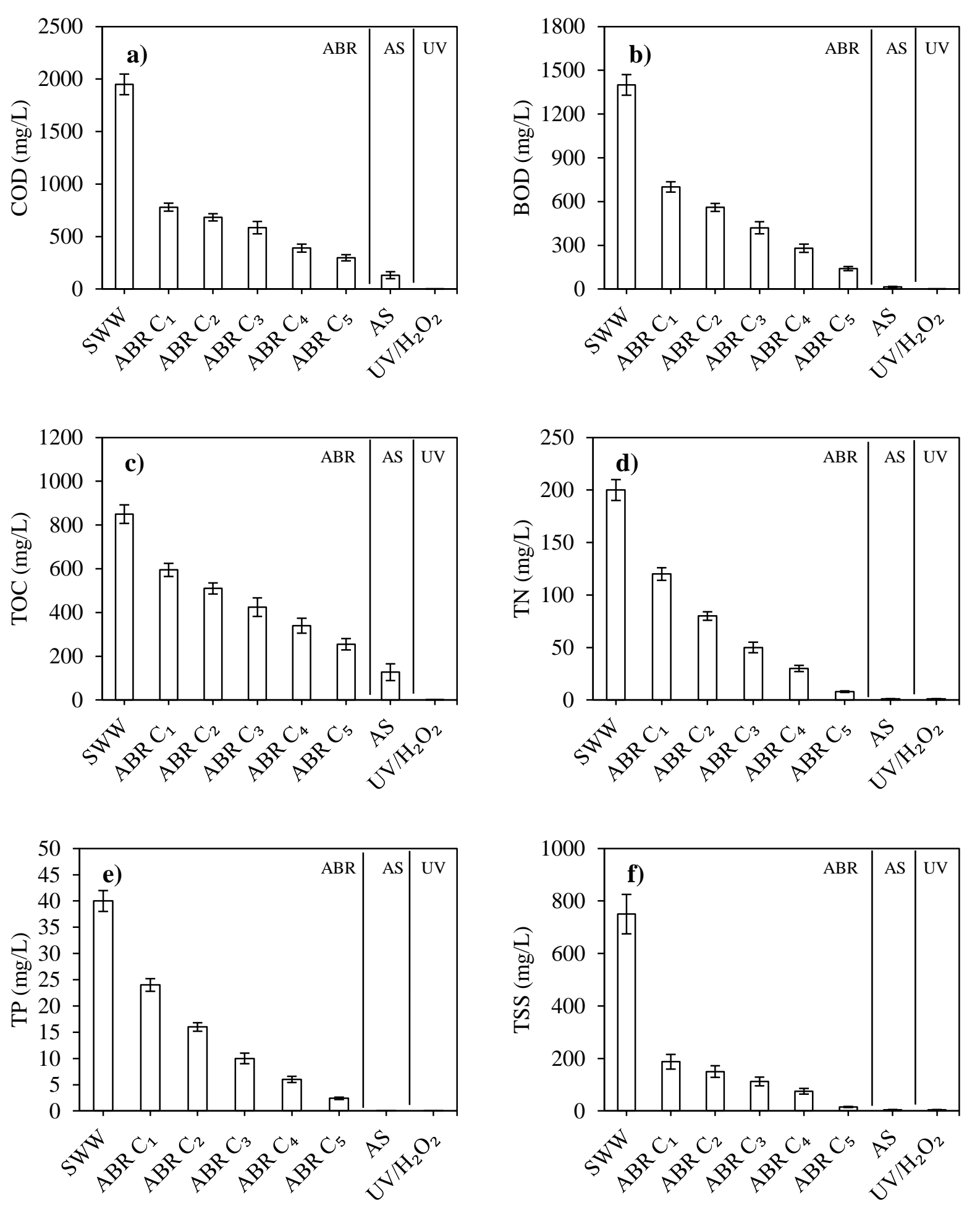

Figure S.6. Maximum remaining values of (a) COD, (b) BOD, (c) TOC, (d) TN, (e) TP, and (f) TSS from an actual slaughterhouse wastewater SWW using combined ABR-AS-UV/ $/ \mathrm{H}_{2} \mathrm{O}_{2}$. Error bars represent the standard deviation of the experimental data. 
Table S.1. Comparison of different technologies maximum efficiencies for slaughterhouse wastewater treatment from 2014 to 2016.

\begin{tabular}{|c|c|c|c|c|c|c|c|c|c|c|}
\hline Method & $\begin{array}{l}\text { HRT } \\
\text { (h) }\end{array}$ & $\begin{array}{l}\text { BOD }_{\text {in }} \\
(\mathrm{mg} / \mathrm{L})\end{array}$ & $\begin{array}{l}\mathrm{COD}_{\text {in }} \\
(\mathrm{mg} / \mathrm{L})\end{array}$ & $\begin{array}{l}\text { TOC }_{\text {in }} \\
(\mathrm{mg} / \mathrm{L})\end{array}$ & $\begin{array}{l}\mathrm{TN}_{\mathrm{in}} \\
(\mathrm{mg} / \mathrm{L})\end{array}$ & $\begin{array}{l}\text { BOD rem } \\
(\%)\end{array}$ & $\begin{array}{l}\text { COD }_{\text {rem }} \\
(\%)\end{array}$ & $\begin{array}{l}\text { TOC }_{\text {rem }} \\
(\%)\end{array}$ & $\begin{array}{l}\mathrm{TN}_{\text {rem }} \\
(\%)\end{array}$ & References \\
\hline UST-AF-UF & 144 & - & 3000 & - & - & - & 96 & - & - & Abdurahman et al. (2015) \\
\hline UST-AF-UF & 144 & - & 3000 & - & - & - & 96 & - & - & Abdurahman et al. (2015) \\
\hline $\mathrm{CW}$ & 28 & - & 468 & - & 61 & - & 60 & - & 46 & Odong et al. (2015) \\
\hline SBR & 12 & 4240 & 6057 & 1436 & 576 & - & 93 & - & 93 & Pan et al. (2015) \\
\hline $\mathrm{AOP}$ & 1 & - & 406 & - & - & - & 84 & - & - & Paramo-Vargas et al. (2015) \\
\hline SBR & 3 & - & 8604 & - & 1493 & - & 80 & - & 88 & Wosiack et al. (2015) \\
\hline UST-AF-UF & 343 & - & 5200 & - & 74 & - & 96 & - & - & Abdurahman et al. (2016) \\
\hline UF-RO & 160 & - & 7970 & - & - & - & 80 & - & - & Coskun et al. (2016) \\
\hline $\mathrm{AOP}$ & 2 & 340 & - & 94 & 55 & - & - & 81 & - & $\begin{array}{l}\text { Bustillo-Lecompte et al. } \\
\text { (2016a) }\end{array}$ \\
\hline ABR-AS & 18 & 1339 & 1998 & 1694 & 255 & 84 & 89 & 89 & 79 & $\begin{array}{l}\text { Bustillo-Lecompte and } \\
\text { Mehrvar (2016a) }\end{array}$ \\
\hline ABR-AS-AOP & 55 & 1635 & 2000 & 1200 & 841 & 100 & 99 & 100 & 85 & $\begin{array}{l}\text { Bustillo-Lecompte et al. } \\
\text { (2016b) }\end{array}$ \\
\hline ABR-AS-AOP & 10 & 1831 & 2043 & 1691 & 866 & 100 & 99 & 100 & 90 & $\begin{array}{l}\text { Bustillo-Lecompte and } \\
\text { Mehrvar (2016b) }\end{array}$ \\
\hline
\end{tabular}




\section{REFERENCES}

Abdurahman, N.H., Rosli, Y.M., Azhari, N.H., Bari, H.A., 2015. The potential of ultrasonic membrane anaerobic systems in treating slaughterhouse wastewater. J. Water Reuse Desal. 5 (3), 293-300. http://dx.doi.org/10.2166/wrd.2015.107

Abdurahman, N.H., Rosli, Y.M., Azhari, N.H., 2016. The potential of ultrasonic membrane anaerobic system (UMAS) in treating slaughterhouse wastewater. ARPN J. Eng. Appl. Sci. 11 (4), 2653-2659.

Affes, R., Palatsi, J., Flotats, X., Carrère, H., Steyer, J.P., Battimelli, A., 2013. Saponification pretreatment and solids recirculation as a new anaerobic process for the treatment of slaughterhouse waste. Bioresour. Technol. 131, 460-467. http://dx.doi.org/10.1016/j.biortech.2012.12.187

Aguilar, M.I., Saez, J., Llorens, M., Soler, A., Ortuno, J.F., 2002. Nutrient removal and sludge production in the coagulation-flocculation process. Water Res. 36 (11), 2910-2919. http://dx.doi.org/10.1016/S0043-1354(01)00508-5

Ahmadian, M., Yousefi, N., Van Ginkel, S.W., Zare, M.R., Rahimi, S., Fatehizadeh, A., 2012. Kinetic study of slaughterhouse wastewater treatment by electrocoagulation using Fe electrodes. Water Sci. Technol. 66 (4), 754-760. http://dx.doi.org/10.2166/wst.2012.232

Ahn, Y.T., Kang, S.T., Chae, S.R., Lee, C.Y., Bae, B.U., Shin, H.S., 2007. Simultaneous high-strength organic and nitrogen removal with combined anaerobic upflow bed filter and aerobic membrane bioreactor. Desalination 202 (1-3), 114-121. http://dx.doi.org/10.1016/j.desal.2005.12.046

Akbaripoor, S., Moazed, H., Pendashteh, A. 2014. Investigation of Aerobic-Anaerobic Integrated Bioreactor System for Treatment of Slaughterhouse Wastewater. Int. J. Nat. Eng. Sci. 8 (3), 12-17. http://www.nobel.gen.tr/MakaleSayac.aspx?ID=3551

Al-Ahmady, K.K., 2005. Effect of organic loading on rotating biological contactor efficiency. Int. J. Env. Res. Pub. He. 2 (3-4), 469-477. http://dx.doi.org/10.3390/ijerph2005030012

Al-Mutairi, N.Z., 2008. Aerobic selectors in slaughterhouse activated sludge systems: A preliminary investigation. Bioresour. Technol. 100 (1), 50-58. http://dx.doi.org/10.1016/j.biortech.2007.12.030

Al-Mutairi, N. Z., Al-Sharifi, F. A., Al-Shammari, S. B., 2008. Evaluation study of a slaughterhouse wastewater treatment plant including contact-assisted activated sludge and DAF. Desalination 225 (1), 167-175. http://dx.doi.org/10.1016/j.desal.2007.04.094 
Al-Mutairi, N.Z., 2010. Reusing date seed residues as a low cost adsorbent for slaughterhouse wastewater purification. Int. J. Environ. Waste Manage. 6 (3-4), 393-409. http://dx.doi.org/10.1504/IJEWM.2010.035071

Almandoz, M.C., Pagliero, C.L., Ochoa, N.A., Marchese, J., 2015. Composite ceramic membranes from natural aluminosilicates for microfiltration applications. Ceram. Int. 41 (4), 5621-5633. http://dx.doi.org/10.1016/j.ceramint.2014.12.144

Amorim, A. K. B., De Nardi, I. R., Del Nery, V., 2007. Water conservation and effluent minimization: Case study of a poultry slaughterhouse. Resour. Conserv. Recycl. 51 (1), 93-100. http://dx.doi.org/10.1016/j.resconrec.2006.08.005

Amuda, O.S., Alade, A., 2006. Coagulation/flocculation process in the treatment of abattoir wastewater. Desalination 196 (1-3), http://dx.doi.org/22-31. 10.1016/j.desal.2005.10.039

ANZECC, 2000. Australian and New Zealand guidelines for fresh and marine water quality: Volume 1 - The guidelines. Australian and New Zealand Environment and Conservation Council (ANZECC, 2000). Artarmon, NSW. Accessed April 23, 2015. Available online: http://www.environment.gov.au/system/files/resources/53cda9ea-7ec2-49d4-af29d1dde09e96ef/files/nwqms-guidelines-4-vol1.pdf

APHA, 1998. Standards methods for the examination of water and wastewater, 20th Ed. American Public Health Association: Washington, DC.

APHA, 2012. Standard methods for the examination of water and wastewater, $22^{\text {nd }}$ edition, American Public Health Association (APHA), Washington, DC, USA.

Arvanitoyannis, I.S., Ladas, D., 2008. Meat waste treatment methods and potential uses. Int. J. Food Sci. Technol. 43 (3), 543-559. http://dx.doi.org/10.1111/j.1365-2621.2006.01492.x

Asselin, M., Drogui, P., Benmoussa, H., Blais, J.-F., 2008. Effectiveness of electrocoagulation process in removing organic compounds from slaughterhouse wastewater using monopolar and bipolar $\begin{array}{lllll}\text { electrolytic } & \text { cells. } & \text { Chemosphere } & 72 & \text { (11), }\end{array}$ http://dx.doi.org/10.1016/j.chemosphere.2008.04.067

Avery, L.M., Killham, K., Jones, D.L., 2005. Survival of E. coli O157:H7 in organic wastes destined for land application. J. Appl. Microbiol. 98 (4), 814-822. http://dx.doi.org/10.1111/j.1365$\underline{2672.2004 .02524 . x}$

Awang, Z.B., Bashir, M.J.K., Kutty, S.R.M., Isa, M.H., 2011. Post-treatment of slaughterhouse wastewater using electrochemical oxidation. Res. J. Chem. Environ 15 (2), 229-237. http://www.researchgate.net/publication/236177043 
Baga, A.N., Johnson, G.R.A., Nazhat, N.B., Saadalla-Nazhat, R.A., 1988. A simple spectrophotometric determination of hydrogen peroxide at low concentrations in aqueous solution. Anal. Chim. Acta 204 (C), 349-353. http://dx.doi.org/10.1016/S0003-2670(00)86374-6

Baeza, C., Knappe, D.R.U., 2011. Transformation kinetics of biochemically active compounds in lowpressure UV Photolysis and $\mathrm{UV} / \mathrm{H}_{2} \mathrm{O}_{2}$ advanced oxidation processes. Water Res. 45 (15), 45314543. http://dx.doi.org/10.1016/j.watres.2011.05.039

Bali, U., Çatalkaya, E., Şengül, F., 2004. Photodegradation of reactive black 5, direct red 28 and direct yellow 12 using $\mathrm{UV}, \mathrm{UV} / \mathrm{H}_{2} \mathrm{O}_{2}$ and $\mathrm{UV} / \mathrm{H}_{2} \mathrm{O}_{2} / \mathrm{Fe}_{2}{ }^{+}$: A comparative study. J. Hazard. Mater. 114 (13), 159-166. http://dx.doi.org/10.1016/j.jhazmat.2004.08.013

Barana, A.C., Lopes, D.D., Martins, T.H., Pozzi, E., Damianovic, M.H.R.Z., Del Nery, V., Foresti, E., 2013. Nitrogen and organic matter removal in an intermittently aerated fixed-bed reactor for posttreatment of anaerobic effluent from a slaughterhouse wastewater treatment plant. J. Environ. Chem. Eng. 1 (3), 453-459. http://dx.doi.org/10.1016/j.jece.2013.06.015

Barber, W.P., Stuckey, D.C., 1999. The use of the anaerobic baffled reactor (ABR) for wastewater treatment: A review. Water Res. 33 (7), 1559-1578. http://dx.doi.org/10.1016/S0043$\underline{1354(98) 00371-6}$

Barrera, M., Mehrvar, M., Gilbride, K., McCarthy, L., Laursen, A., Bostan, V., Pushchak, R., 2012. Photolytic treatment of organic constituents and bacterial pathogens in secondary effluent of synthetic slaughterhouse wastewater. Chem. Eng. Res. Des. 90 (9), 1335-1350. http://dx.doi.org/10.1016/j.cherd.2011.11.018

Bayar, S., Yildiz, Y.S., Yilmaz, A.E., Irdemez, S., 2011. The effect of stirring speed and current density on removal efficiency of poultry slaughterhouse wastewater by electrocoagulation method. Desalination 280 (1-3), 103-107. http://dx.doi.org/10.1016/j.desal.2011.06.061

Bayar, S., Yildiz, Y.S., Yilmaz, A.E., Koparal, A.S., 2014. The effect of initial pH on treatment of poultry slaughterhouse wastewater by electrocoagulation method. Desalin. Water Treat. 52 (16-18), 3047-3053. http://dx.doi.org/10.1080/19443994.2013.800268

Bayramoglu, M., Kobya, M., Eyvaz, M., Senturk, E., 2006. Technical and economic analysis of electrocoagulation for the treatment of poultry slaughterhouse wastewater. Sep. Purif. Technol. 51 (3), 404-408. http://dx.doi.org/10.1016/j.seppur.2006.03.003

Bazrafshan, E., Kord Mostafapour, F., Farzadkia, M., Ownagh, K.A., Mahvi, A.H., 2012. Slaughterhouse wastewater treatment by combined chemical coagulation and electrocoagulation process. PLoS One 7 (6), art. no. e40108. http://dx.doi.org/10.1371/journal.pone.0040108 
Beard, T.W., Temple, M.A., Roberts, M.L., 2007. An experimental design approach for optimizing SMSE waveforms to minimize coexistent interference. IEEE International Conference on Communications, art. no. 4289596, 5581-5585. http://dx.doi.org/10.1109/ICC.2007.925

Benedetti, L., Langeveld, J., Nieuwenhuijzen, A.F.V., Jonge, J.D., Klein, J.D., Flameling, T., Nopens, I., Zanten, O.V., Weijers, S., 2013. Cost-effective solutions for water quality improvement in the Dommel River supported by sewer-WWTP-river integrated modelling. Water Sci. Technol. 68 (5), 965-973. http://dx.doi.org/10.2166/wst.2013.312

Bielski, B.H.J., Cabelli, D.E., Arudi, R.L., Ross, A.B., 1985. Reactivity of $\mathrm{HO}_{2} / \mathrm{O}_{2}{ }^{-}$Radicals in Aqueous Solution. J. Phys. Chem. Ref. Data 14 (4), 1041-1100. http://dx.doi.org/10.1063/1.555739

Bohdziewicz, J., Sroka, E., 2005. Integrated system of activated sludge-reverse osmosis in the treatment of the wastewater from the meat industry. Process Biochem. 40 (5), 1517-1523. http://dx.doi.org/10.1016/j.procbio.2003.11.047

Bolton, J., Bircher, K., Tumas, W., and Tolman, C., 2001. Figures-of-merit for the technical development and application of advanced oxidation technologies for both electric- and solar-driven systems. Pure Appl. Chem. 73 (4), 627-637. http://dx.doi.org/10.1351/pac200173040627

Botha, G.E., Oliveira, J.C., Ahrné, L., 2012. Quality optimisation of combined osmotic dehydration and microwave assisted air drying of pineapple using constant power emission. Food Bioprod. Process. 90 (2), 171-179. http://dx.doi.org/10.1016/j.fbp.2011.02.006

Bouwman, L., Goldewijk, K.K., Van Der Hoek, K.W., Beusen, A.H.W., Van Vuuren, D.P., Willems, J., Rufino, M.C., Stehfest, E., 2013. Exploring global changes in nitrogen and phosphorus cycles in agriculture induced by livestock production over the 1900-2050 period. Proc. Natl. Acad. Sci. U. S. A. 110 (52), 20882-20887. http://dx.doi.org/10.1073/pnas.1012878108

Box, G.E.P., Behnken, D.W., 1960. Some New Three Level Designs for the Study of Quantitative Variables. Technometrics, 2 (4), 455-475. http://dx.doi.org/10.1080/00401706.1960.10489912

Brandhuber, P.J., Korshin, G., 2009. Methods for the detection of residual concentrations of hydrogen peroxide in advanced oxidation processes. Project: 04-19. Water Reuse Foundation, Alexandria, VA, ISBN: 978-1-934183-15-1.

Bugallo, P. M., Andrade, L. C., de la Torre, M. A., and López, R. T., 2014. Analysis of the slaughterhouses in Galicia (NW Spain). Sci. Total Environ. 481, 656-661. http://dx.doi.org/10.1016/j.scitotenv.2013.11.079 
Bull, M.A., Sterritt, R.M., Lester, J.N., 1982. The treatment of wastewaters from the meat industry: A review. Environ. Technol. Lett. 3 (3), 117-126. http://dx.doi.org/10.1080/09593338209384107

Bustillo-Lecompte, C.F., Mehrvar, M., Quiñones-Bolaños, E., 2013. Combined anaerobic-aerobic and $\mathrm{UV} / \mathrm{H}_{2} \mathrm{O}_{2}$ processes for the treatment of synthetic slaughterhouse wastewater. J. Environ. Sci. Heal. A 48 (9), 1122-1135. http://dx.doi.org/10.1080/10934529.2013.774662

Bustillo-Lecompte, C.F., Mehrvar, M., Quiñones-Bolaños, E., 2014. Cost-effectiveness analysis of TOC removal from slaughterhouse wastewater using combined anaerobic-aerobic and $\mathrm{UV} / \mathrm{H}_{2} \mathrm{O}_{2}$ processes. J. Environ. Manage. 134, 145-152. http://dx.doi.org/10.1016/j.jenvman.2013.12.035

Bustillo-Lecompte, C. F., Knight, M., Mehrvar, M., 2015. Assessing the performance of $\mathrm{UV} / \mathrm{H}_{2} \mathrm{O}_{2}$ as a pre-treatment process in TOC removal of an actual petroleum refinery wastewater and its inhibitory effects on activated sludge. Can. J. Chem. Eng. 93 (5), 798-807. http://dx.doi.org/10.1002/cjce.22180

Bustillo-Lecompte, C.F., Mehrvar, M., 2015. Slaughterhouse wastewater characteristics, treatment, and management in the meat processing industry: a review on trends and advances. J. Environ. Manage. 1611, 287-302. http://dx.doi.org/10.1016/j.jenvman.2015.07.008

Bustillo-Lecompte, C.F., Mehrvar, M., 2016a. Treatment of actual slaughterhouse wastewater by combined anaerobic-aerobic processes for biogas generation and removal of organics and nutrients: an optimization study towards a cleaner production in the meat processing industry. J. Clean. Prod. (Submitted).

Bustillo-Lecompte, C.F., Mehrvar, M., 2016b. Treatment of an actual slaughterhouse wastewater by integration of biological and advanced oxidation processes: modeling, optimization, and costeffectiveness analysis. J. Environ. Manage. (In Press). http://dx.doi.org/10.1016/j.jenvman.2016.07.044

Bustillo-Lecompte, C.F., Ghafoori, S., Mehrvar, M., 2016a. Photochemical degradation of an actual slaughterhouse wastewater by continuous $\mathrm{UV} / \mathrm{H}_{2} \mathrm{O}_{2}$ photoreactor with recycle. J. Environ. Chem. Eng. 4 (1), 719-732. http://dx.doi.org/10.1016/j.jece.2015.12.009

Bustillo-Lecompte, C.F., Mehrvar, M., Quiñones-Bolaños, E., 2016b. Slaughterhouse wastewater characterization and treatment: an economic and public health necessity of the meat processing industry in Ontario, Canada. J. Geosci. Environ. Protection 4, 175-186. http://dx.doi.org/10.4236/gep.2016.44021

Buxton, G.V., Greenstock, C.L., Helman, W.P., Ross, A.B., 1988. Critical Review of rate constants for reactions of hydrated electrons, hydrogen atoms and hydroxyl radicals $\left(\cdot \mathrm{OH} / \mathrm{O}^{-}\right.$in Aqueous Solution. J. Phys. Chem. Ref. Data 17 (2), 513-886. http://dx.doi.org/10.1063/1.555805 
Cadena Pereda, R.O., Rivera Muñoz, E.M., Herrera Ruiz, G., 2010. Automatic volumetric gas flow meter for monitoring biogas production from laboratory-scale anaerobic digester. Sensor. Actuat. BChem. 147 (1), 10-14. http://dx.doi.org/10.1016/j.snb.2010.03.053

Caldera, Y., Madueño, P., Griborio, A., Fernández, N., Gutiérrez, E., 2005. Effect of the organic load in the performance the UASB reactor treating slaughterhouse effluent. Rev. Tec. Fac. Ing. Univ. Zulia 28 (2), 119-127. http://www.scielo.org.ve/scielo.php?script=sci_arttext\&pid=S0254$\underline{07702005000200003}$

Cao, W., Mehrvar, M., 2011. Slaughterhouse wastewater treatment by combined anaerobic baffled reactor and $\mathrm{UV} / \mathrm{H}_{2} \mathrm{O}_{2}$ processes. Chem. Eng. Res. Des. 89 (7), http://dx.doi.org/10.1016/j.cherd.2010.12.001

Carreau, R., Van Acker, S., Van Der Zaag, A.C., Madani, A., Drizo, A., Jamieson, R., Gordon, R.J., 2012. Evaluation of a surface flow constructed wetland treating abattoir wastewater. Appl. Eng. Agric. 28 (5), 757-766. http://agris.fao.org/agris-search/search.do?recordID=US201400097811

Carvalho, P.N., Pirra, A., Basto, M.C.P., Almeida, C.M.R., 2013. Activated sludge systems removal efficiency of veterinary pharmaceuticals from slaughterhouse wastewater. Environ. Sci. Pollut. Res. 20 (12), 8790-8800. http://dx.doi.org/10.1007/s11356-013-1867-7

Casani, S., Rouhany, M., Knøchel, S., 2005. A discussion paper on challenges and limitations to water reuse and hygiene in the food industry. Water Res. 39 (6), 1134-1146. http://dx.doi.org/10.1016/j.watres.2004.12.015

CEC, 1991. Urban Wastewater Treatment Directive 91/271/EEC, Council of the European Communities (CEC). Off. J. Eur. Comm. L (135), 40-52. http://eur-lex.europa.eu/legalcontent/EN/TXT/PDF/?uri=CELEX:31991L0271\&from=EN

Chan, Y. J., Chong, M. F., Law, C. L., Hassell, D., 2009. A review on anaerobic-aerobic treatment of industrial and municipal wastewater. Chem. Eng. J. 155 (1-2), 1-18. http://dx.doi.org/10.1016/j.cej.2009.06.041

Chávez, P., C., Castillo L., R., Dendooven, L., Escamilla-Silva, E.M., 2005. Poultry slaughter wastewater treatment with an up-flow anaerobic sludge blanket (UASB) reactor. Bioresour. Technol. 96 (15), 1730-1736. http://dx.doi.org/10.1016/j.biortech.2004.08.017

Chernicharo, C., 2006. Post-treatment options for the anaerobic treatment of domestic wastewater. Rev. Environ. Sci. Biotechnol. 5 (1), 73-92. http://dx.doi.org/10.1007/s11157-005-5683-5

Christensen, H., Sehested, K., Corfitzen, H., 1982. Reactions of hydroxyl radicals with hydrogen peroxide at ambient and elevated temperatures. J. Phys. Chem. 86 (9), 1588-1590. http://dx.doi.org/10.1021/j100206a023 
Crittenden, J.C., Hu, S., Hand, D.W., Green, S.A., 1999. A kinetic model for $\mathrm{H}_{2} \mathrm{O}_{2} / \mathrm{UV}$ process in a completely mixed batch reactor. Water Res. 33 (10), 2315-2328. http://dx.doi.org/10.1016/S0043$\underline{1354(98) 00448-5}$

Coskun, T., Debik, E., Kabuk, H.A., Manav Demir, N., Basturk, I., Yildirim, B., Temizel, D., Kucuk, S., 2016. Treatment of poultry slaughterhouse wastewater using a membrane process, water reuse, and economic analysis. Desalin. Water Treat. 57 (11), 4944-4951. http://dx.doi.org/10.1080/19443994.2014.999715

Daigger, G.T., 2009. Evolving urban water and residuals management paradigms: Water reclamation and reuse, decentralization, and resource recovery. Water Environ. Res. 81 (8), 809-823. http://dx.doi.org/10.2175/106143009X425898

Dallago, R.C., Gomes, S.D., Mees, J.B.R., de Assis, T.M., Hasan, S.D.M., Kunz, A., 2012. Nitrification and denitrification of a poultry slaughterhouse wastewater according to cycle time and ammoniacal nitrogen concentration using surface response methodology. J. Food Agric. Environ. 10 (2), 856860. http://world-food.net/download/journals/2012-issue_2/157.pdf

de Mes, T.Z.D., A.J.M. Stams, J.H. Reith, G. Zeeman., 2003. Methane production by anaerobic digestion of wastewater and solid wastes, in: Reith, J.H., Wijffels, R.H., Harten, H., Bio-methane \& Bio-hydrogen: Status and perspectives of biological methane and hydrogen production. Dutch Biological Hydrogen Foundation, Petten, N8-102. http://www.biohydrogen.nl/downloadattachment/20804/12843/bio_methane_and_bio_hydrogen_2 003.pdf

De Nardi, I.R., Fuzi, T.P., Del Nery, V., 2008. Performance evaluation and operating strategies of dissolved-air flotation system treating poultry slaughterhouse wastewater. Resour. Conserv. Recycl. 52 (3), 533-544. http://dx.doi.org/10.1016/j.resconrec.2007.06.005

De Nardi, I. R., Del Nery, V., Amorim, A. K. B., dos Santos, N. G., Chimenes, F., 2011. Performances of SBR, chemical-DAF and UV disinfection for poultry slaughterhouse wastewater reclamation. Desalination 269 (1), 184-189. http://dx.doi.org/10.1016/j.desal.2010.10.060

De Sena, R.F., Moreira, R.F.P.M., José, H.J., 2008. Comparison of coagulants and coagulation aids for treatment of meat processing wastewater by column flotation. Bioresour. Technol. 99 (17), 82218225. http://dx.doi.org/10.1016/j.biortech.2008.03.014

De Sena, R.F., Tambosi, J.L., Genena, A.K., Moreira, R.d.F.P.M., Schröder, H.Fr., José, H.J., 2009. Treatment of meat industry wastewater using dissolved air flotation and advanced oxidation processes monitored by GC-MS and LC-MS. Chem. Eng. J. 152 (1), 151-157. http://dx.doi.org/10.1016/j.cej.2009.04.021 
Debik, E., Coskun, T., 2009. Use of the Static Granular Bed Reactor (SGBR) with anaerobic sludge to treat poultry slaughterhouse wastewater and kinetic modeling. Bioresour. Technol. 100 (11), 27772782. http://dx.doi.org/10.1016/j.biortech.2008.12.058

Del Nery, V., de Nardi, I.R., Damianovic, M.H.R.Z., Pozzi, E., Amorim, A.K.B., Zaiat, M., 2007. Longterm operating performance of a poultry slaughterhouse wastewater treatment plant. Resour. Conserv. Recycl. 50 (1), 102-114. http://dx.doi.org/10.1016/j.resconrec.2006.06.001

Del Nery, V., Pozzi, E., Damianovic, M.H.R.Z., Domingues, M.R., Zaiat, M., 2008. Granules characteristics in the vertical profile of a full-scale upflow anaerobic sludge blanket reactor treating poultry slaughterhouse wastewater. Bioresour. Technol. 99 (6), 2018-2024. http://dx.doi.org/10.1016/j.biortech.2007.03.019

Del Pozo, R., Diez, V., 2005. Integrated anaerobic-aerobic fixed-film reactor for slaughterhouse wastewater treatment. Water Res. 39 (6), 1114-1122. http://dx.doi.org/10.1016/j.watres.2005.01.013

Dubber, D. and Gray, N.F., 2010. Replacement of chemical oxygen demand (COD) with total organic carbon (TOC) for monitoring wastewater treatment performance to minimize disposal of toxic analytical waste. J. Environ. Sci. Health A 45 (12), 1595-1600. http://dx.doi.org/10.1080/10934529.2010.506116

Durán, A., Monteagudo, J., and San Martín, I., 2012. Photocatalytic treatment of an industrial effluent using artificial and solar UV radiation: An operational cost study on a pilot plant scale. J. Environ. Manage. 98 (1), 1-4. http://dx.doi.org/10.1016/j.jenvman.2011.12.007

Edalatmanesh, M., Mehrvar, M., Dhib, R., 2008. Optimization of phenol degradation in a combined photochemical-biological wastewater treatment system. Chem. Eng. Res. Des. 86 (11), 1243-1252. http://dx.doi.org/10.1016/j.cherd.2008.06.001

Emamjomeh, M., Sivakumar, M., 2009. Review of pollutants removed by electrocoagulation and electrocoagulation/flotation processes. J. Environ. Manage. 90 (5), 1663-1679. http://dx.doi.org/10.1016/j.jenvman.2008.12.011

Environment Canada, 2000. Framework and recommendations concerning effluent quality of wastewater disposed by federal institutions, Final Report, Federal Committee on Environmental Management Systems (FCEMS)/Wastewater Working Group. Accessed March 10, 2015. Available online: http://www.csc-scc.gc.ca/text/plcy/doc/318-6-gl_e.pdf

Environment Canada, 2012. Wastewater Systems Effluent Regulations. Fisheries Act. SOR/2012-139. Accessed March 10, 2015. Available online: http://laws-lois.justice.gc.ca/PDF/SOR-2012-139.pdf 
Eryuruk, K., Tezcanun, U., Bakir Ogutveren, U., 2014. Electrocoagulation in a plugflow reactor: The treatment of cattle abattoir wastewater by iron rod anodes. Int. J. Env. Res. Pub. He. 8 (2), 461-468. http://www.ijer.ir/article_738_36.html

FAO, 2013. Food Outlook: Biannual report on global food markets. Meat and meat products. Rome, Italy: Food and Agriculture Organization (FAO) of the United Nations (UN). Accessed March 10, 2015. Available online: http://www.fao.org/docrep/019/i3473e/i3473e.pdf

Feng, H., Hu, L., Mahmood, Q., Fang, C., Qiu, C., Shen, D., 2009. Effects of temperature and feed strength on a carrier anaerobic baffled reactor treating dilute wastewater. Desalination 238 (1-3), 111-121. http://dx.doi.org/10.1016/j.desal.2008.03.011

Filali-Meknassi, Y., Auriol, M., Tyagi, R.D., Comeau, Y., Surampalli, R.Y., 2005a. Design strategy for a simultaneous nitrification/denitrification of a slaughterhouse wastewater in a sequencing batch reactor: ASM2d modeling and verification. Environ. Technol. 26 (10), 1081-1100. http://dx.doi.org/10.1080/09593332608618478

Filali-Meknassi, Y., Auriol, M., Tyagi, R.D., Comeau, Y., Surampalli, R.Y., 2005b. Phosphorus coprecipitation in the biological treatment of slaughterhouse wastewater in a sequencing batch reactor. Pract. Period. Hazard. Toxic Radioact. Waste Manage. 9 (3), 179-192. http://dx.doi.org/10.1061/(ASCE)1090-025X(2005)9:3(179)

Fongsatitkul, P., Wareham, D.G., Elefsiniotis, P., Charoensuk, P., 2011. Treatment of a slaughterhouse wastewater: Effect of internal recycle rate on chemical oxygen demand, total Kjeldahl nitrogen and total phosphorus removal. Environ. Technol. 32 (15), 1755-1759. http://dx.doi.org/10.1080/09593330.2011.555421

Franke-Whittle, I.H., Insam, H., 2013. Treatment alternatives of slaughterhouse wastes, and their effect on the inactivation of different pathogens: A review. Crit. Rev. Microbiol. 39 (2), 139-151. http://dx.doi.org/10.3109/1040841X.2012.694410

Gannoun, H., Bouallagui, H., Okbi, A., Sayadi, S., Hamdi, M., 2009. Mesophilic and thermophilic anaerobic digestion of biologically pretreated abattoir wastewaters in an upflow anaerobic filter. J. Hazard. Mater. 170 (1), 263-271. http://dx.doi.org/10.1016/j.jhazmat.2009.04.111

Gannoun, H., Khelifi, E., Omri, I., Jabari, L., Fardeau, M.-L., Bouallagui, H., Godon, J.-J., Hamdi, M., 2013. Microbial monitoring by molecular tools of an upflow anaerobic filter treating abattoir wastewaters. Bioresour. Technol. 142, 269-277. http://dx.doi.org/10.1016/j.biortech.2013.05.036

Gariepy, S., Tyagi, R. D., Couillard, D., and Tran, F., 1989. Thermophilic process for protein recovery as an alternative to slaughterhouse wastewater treatment. Biological Wastes 29, 93-105. http://dx.doi.org/10.1016/0269-7483(89)90090-6 
Gerbens-Leenes, P.W., Mekonnen, M.M., Hoekstra, A.Y., 2013. The water footprint of poultry, pork and beef: A comparative study in different countries and production systems. Water Resour. Ind. 12, 25-36. http://dx.doi.org/10.1016/j.wri.2013.03.001

Ghafoori, S., Mehrvar, M., and Chan, P.K., 2012. Free-radical-induced degradation of aqueous polyethylene oxide by $\mathrm{UV} / \mathrm{H}_{2} \mathrm{O}_{2}$ : Experimental design, reaction mechanisms, and kinetic modeling. Ind. Eng. Chem. Res., 51 (46), 14980-14993. http://dx.doi.org/10.1021/ie3005995

Ghafoori, S., 2013. Modeling, simulation, and optimization of advanced oxidation processes for treatment of polymeric wastewater. Doctoral dissertation: Ryerson University.

Ghafoori, S., Mehrvar, M., and Chan, P.K., 2013. Photoassisted Fenton-like degradation of aqueous poly(acrylic acid): From mechanistic kinetic model to CFD modeling. Chem. Eng. Res. Des., 91 (12), 2617-2629. http://dx.doi.org/10.1016/j.cherd.2013.05.019

Ghafoori, S., Mehrvar, M., and Chan, P., 2014a. Optimisation of photo-Fenton-like degradation of aqueous polyacrylic acid using Box-Behnken experimental design. Can. J. Chem. Eng., 92 (1), 97108. http://dx.doi.org/10.1002/cjce.21849

Ghafoori, S., Mehrvar, M., Chan, P.K., 2014b. Photoreactor scale-up for degradation of aqueous poly(vinyl alcohol) using $\mathrm{UV} / \mathrm{H}_{2} \mathrm{O}_{2}$ process. Chem. Eng. J. 245, 133-142. http://dx.doi.org/10.1016/j.cej.2014.01.055

Ghafoori, S., Mowla, A., Jahani, R., Mehrvar, M., Chan, P.K., 2015. Sonophotolytic degradation of synthetic pharmaceutical wastewater: Statistical experimental design and modeling. J. Environ. Manage. 150, 128-137. http://dx.doi.org/10.1016/j.jenvman.2014.11.011

Gomec, C.Y., 2010. High-rate anaerobic treatment of domestic wastewater at ambient operating temperatures: A review on benefits and drawbacks. J. Environ. Sci. Heal. A 45 (10), 1169-1184. http://dx.doi.org/10.1080/10934529.2010.493774

González-González, A., Collares-Pereira, M., Cuadros, F., Fartaria, T., 2013. Energy self-sufficiency through hybridization of biogas and photovoltaic solar energy: an application for an Iberian pig slaughterhouse. J. Clean. Prod. 65, 318-323. http://dx.doi.org/10.1016/j.jclepro.2013.08.021

Gopala Krishna, G.V.T., Kumar, P., Kumar, P., 2009. Treatment of low-strength soluble wastewater using an anaerobic baffled reactor (ABR). J. Environ. Manage. 90 (1), 166-176. http://dx.doi.org/10.1016/j.jenvman.2007.08.017

Gürel, L., Büyükgüngör, H., 2011. Treatment of slaughterhouse plant wastewater by using a membrane bioreactor. Water Sci. Technol. 64 (1), 214-219. http://dx.doi.org/10.2166/wst.2011.677 
Gutiérrez-Sarabia, A., Fernández-Villagómez, G., Martínez-Pereda, P., Rinderknecht-Seijas, N., PoggiVaraldo, H.M., 2004. Slaughterhouse wastewater treatment in a full-scale system with constructed wetlands. Water Environ. Res. 76 (4), 334-343. http://dx.doi.org/10.2175/106143004X141924

Hamad, D., Mehrvar, M., Dhib, R., 2014. Experimental study of polyvinyl alcohol degradation in aqueous solution by $\mathrm{UV} / \mathrm{H}_{2} \mathrm{O}_{2}$ process. Polym. Degrad. Stabil. 103 (1), 75-82. http://dx.doi.org/10.1016/j.polymdegradstab.2014.02.018

Hamad, D., Dhib, R., Mehrvar, M., 2016. Photochemical degradation of aqueous polyvinyl alcohol in a continuous $\mathrm{UV} / \mathrm{H}_{2} \mathrm{O}_{2}$ process: experimental and statistical analysis. J. Polym. Environ. 24 (1), $72-$ 83. http://dx.doi.org/10.1007/s10924-016-0750-2

He, Y., Xu, P., Li, C., Zhang, B., 2005. High-concentration food wastewater treatment by an anaerobic membrane bioreactor. Water $\quad$ Res. $39 \quad$ (17), http://dx.doi.org/10.1016/j.watres.2005.07.030

Hernández-Ramírez, D.A., Herrera-López, E.J., Rivera, A.L., Del Real-Olvera, J., 2014. Artificial neural network modeling of slaughterhouse wastewater removal of COD and TSS by electrocoagulation. Studies in Fuzziness and Soft Computing 312, 273-280. http://dx.doi.org/10.1007/978-3-319-03674-8_26

Hossaini, H., Fatehizadeh, A., Yousefi, N., Reshadat, S., Rajabi Gilan, N., Ghasemi, S.R., Ahmadian, M., 2013. Application of enhanced softening process in slaughterhouse wastewater treatment. Indian J. Chem. Technol. 20 (3), 217-221. http://nopr.niscair.res.in/handle/123456789/18367

Hsiao, T.-H., Huang, J.-S., Huang, Y.-I., 2012. Process kinetics of an activated-sludge reactor system treating poultry slaughterhouse wastewater. Environ. Technol. 33 (7), 829-835. http://dx.doi.org/10.1080/09593330.2011.597782

Jensen, P.D., Yap, S.D., Boyle-Gotla, A., Janoschka, J., Carney, C., Pidou, M., Batstone, D.J., 2015. Anaerobic membrane bioreactors enable high rate treatment of slaughterhouse wastewater. Biochem. Eng. J. 97, 132-141. http://dx.doi.org/10.1016/j.bej.2015.02.009

Johns, M., 1995. Developments in wastewater treatment in the meat processing industry: A review. Bioresour. Technol. 54, 203-216. http://dx.doi.org/10.1016/0960-8524(95)00140-9

Kabdaş1, I., Tunay, O., Özcan, P., 2009. Application of struvite precipitation coupled with biological treatment to slaughterhouse wastewaters. Environ. Technol. 30 (10), 1095-1101. http://dx.doi.org/10.1080/09593330903136856

Kaparaju, P., Ellegaard, L., Angelidaki, I., 2009. Optimisation of biogas production from manure through serial digestion: Lab-scale and pilot-scale studies. Bioresource Technol. 100 (2), 701-709. http://dx.doi.org/10.1016/j.biortech.2008.07.023 
Kennedy, K., Barriault, M., 2007. Treatment kinetics of aircraft deicing fluid in an anaerobic baffled reactor. J. Environ. Eng. Sci. 6 (1), 11-17. http://dx.doi.org/10.1139/s06-024

Keskes, S., Hmaied, F., Gannoun, H., Bouallagui, H., Godon, J.J., Hamdi, M., 2012. Performance of a submerged membrane bioreactor for the aerobic treatment of abattoir wastewater. Bioresour. Technol. 103 (1), 28-34. http://dx.doi.org/10.1016/j.biortech.2011.09.063

Keskes, S., Bouallagui, H., Godon, J.J., Abid, S., Hamdi, M., 2013. Biological sludge reduction during abattoir wastewater treatment process using a sequencing batch aerobic system. Environ. Technol. 34 (3), 333-341. http://dx.doi.org/10.1080/09593330.2012.696713

Khennoussi, A., Chaouch, M., Chahlaouider, A., 2013. Treatment of the effluent from a red meat slaughterhouse by electrocoagulation flotation with iron electrodes. Rev. Sci. Eau 26 (2), 135-150. http://dx.doi.org/10.7202/1016064ar

Kiepper, B., 2001. A survey of wastewater treatment practices in the broiler industry. Proceedings of $\begin{array}{llllll}\text { the } & \text { Water } & \text { Environment } & \text { Federation } & 2001 & \text { (12), }\end{array}$ http://dx.doi.org/10.2175/193864701790864854

Kist, L. T., Moutaqi, S. E., Machado, Ê. L., 2009. Cleaner production in the management of water use at a poultry slaughterhouse of Vale do Taquari, Brazil: a case study. J. Clean Prod. 17 (13), 12001205. http://dx.doi.org/10.1016/j.jclepro.2009.04.006

Kobya, M., Senturk, E., Bayramoglu, M., 2006. Treatment of poultry slaughterhouse wastewaters by $\begin{array}{llllll}\text { electrocoagulation. } & \text { J. } & \text { Hazard. } & \text { Mater. } & 133 & \text { (1-3), }\end{array}$ http://dx.doi.org/10.1016/j.jhazmat.2005.10.007

Koppenol, W.H., Butler, J., Leeuwen, J.W.v., 1978. The Haber-Weiss cycle. Photochem. Photobiol. 28, 655-658. http://dx.doi.org/10.1111/j.1751-1097.1978.tb06989.x

Kosaka, K., Yamada, H., Matsui, S., Echigo, S., Shishida, K., 1998. Comparison among the methods for hydrogen peroxide measurements to evaluate advanced oxidation processes: Application of a spectrophotometric method using copper(II) ion and 2,9-dimethyl-1,10-phenanthroline. Environ. Sci. Technol. 32 (23), 3821-3824. http://dx.doi.org/10.1021/es9800784

Kralik, P., Kusic, H., Koprivanac, N., Loncaric Bozic, A., 2010. Degradation of chlorinated hydrocarbons by $\mathrm{UV} / \mathrm{H}_{2} \mathrm{O}_{2}$ : The application of experimental design and kinetic modeling approach. Chem. Eng. J. 158 (2), 154-166. http://dx.doi.org/10.1016/j.cej.2009.12.023

Kundu, P., Debsarkar, A., Mukherjee, S., 2013. Treatment of slaughter house wastewater in a sequencing batch reactor: Performance evaluation and biodegradation kinetics. Biomed Res. Int. 2013, art. no. 134872. http://dx.doi.org/10.1155/2013/134872 
Kundu, P., Debsarkar, A., Mukherjee, S., 2014. Kinetic modeling for simultaneous organic carbon oxidation, nitrification, and denitrification of abattoir wastewater in sequencing batch reactor. Bioremediat. J. 18 (4), 267-286. http://dx.doi.org/10.1080/10889868.2014.939134

Kurian, R., Nakhla, G., Bassi, A., 2006. Biodegradation kinetics of high strength oily pet food wastewater in a membrane-coupled bioreactor (MBR). Chemosphere 65 (7), 1204-1211. http://dx.doi.org/10.1016/j.chemosphere.2006.03.050

Kuşçu, Ö.S., Sponza, D.T., 2005. Performance of anaerobic baffled reactor (ABR) treating synthetic wastewater containing p-nitrophenol. Enzyme Microb. Technol. 36 (7), 888-895. http://dx.doi.org/10.1016/j.enzmictec.2005.01.001

Kuşçu, O.S., Sponza, D.T., 2006. Treatment efficiencies of a sequential anaerobic baffled reactor $(\mathrm{ABR}) /$ completely stirred tank reactor (CSTR) system at increasing p-nitrophenol and COD loading rates. Process Biochem. 41 (7), 1484-1492. http://dx.doi.org/10.1016/j.procbio.2006.02.004

Leitão, R.C., Van Haandel, A.C., Zeeman, G., Lettinga, G., 2006. The effects of operational and environmental variations on anaerobic wastewater treatment systems: A review. Bioresour. Technol. 97 (9), 1105-1118. http://dx.doi.org/10.1016/j.biortech.2004.12.007

Lemaire, R., Marcelino, M., Yuan, Z., 2008. Achieving the nitrite pathway using aeration phase length control and step-feed in an SBR removing nutrients from abattoir wastewater. Biotechnol. Bioeng. 100 (6), 1228-1236. http://dx.doi.org/10.1002/bit.21844

Lemaire, R., Yuan, Z., Bernet, N., Marcos, M., Yilmaz, G., Keller, J., 2009. A sequencing batch reactor system for high-level biological nitrogen and phosphorus removal from abattoir wastewater. Biodegradation 20 (3), 339-350. http://dx.doi.org/10.1007/s10532-008-9225-Z

León-Becerril, E., García-Camacho, J.E., Del Real-Olvera, J., López-López, A., 2016. Performance of an upflow anaerobic filter in the treatment of cold meat industry wastewater. Process Saf. Environ. Protect. 102, 385-391. http://dx.doi.org/10.1016/j.psep.2016.04.016

Li, J., Healy, M.G., Zhan, X., Norton, D., Rodgers, M., 2008. Effect of aeration rate on nutrient removal from slaughterhouse wastewater in intermittently aerated sequencing batch reactors. Water Air Soil Pollut. 192 (1-4), 251-261. http://dx.doi.org/10.1007/s11270-008-9652-9

Li, A., Zhang, Y., Guo, H., Pan, T., 2014. Slaughterhouse wastewater treatment by hydrolysis and Bardenpho process. Advanced Engineering and Technology - Proceedings of the 2014 Annual Congress on Advanced Engineering and Technology CAET 2014, 559-566. http://dx.doi.org/10.1201/b16699-88 
Liu, J., Olsson, G., Mattiasson, B., 2004. A volumetric meter for monitoring of low gas flow rate from laboratory-scale biogas reactors. Sensor. Actuat. B-Chem. 97 (2-3), 369-372. http://dx.doi.org/10.1016/j.snb.2003.09.014

López-López, A., Vallejo-Rodriguez, R., Méndez-Romero, D.C., 2010. Evaluation of a combined anaerobic and aerobic system for the treatment of slaughterhouse wastewater. Environ. Technol. 31 (3), 319-326. http://dx.doi.org/10.1080/09593330903470693

Louvet, J.N., Homeky, B., Casellas, M., Pons, M.N., Dagot, C., 2013. Monitoring of slaughterhouse wastewater biodegradation in a SBR using fluorescence and UV-Visible absorbance. Chemosphere 91 (5), 648-655. http://dx.doi.org/10.1016/j.chemosphere.2013.01.011

Luiz, D.B., Genena, A.K., José, H.J., Moreira, R.F.P.M., Schröder, H.Fr., 2009. Tertiary treatment of slaughterhouse effluent: Degradation kinetics applying UV radiation or $\mathrm{H}_{2} \mathrm{O}_{2} / \mathrm{UV}$. Water Sci. Technol. 60 (7), 1869-1874. http://dx.doi.org/10.2166/wst.2009.583

Luiz, D.B., Silva, G.S., Vaz, E.A.C., José, H.J., Moreira, R.F.P.M., 2011. Evaluation of hybrid treatments to produce high quality reuse water. Water Sci. Technol. 63 (9), 2046-2051. http://dx.doi.org/10.2166/wst.2011.468

Mahtab, A., Tariq, M., Shafiq, T., Nasir, A., 2009. Coagulation/adsorption combined treatment of slaughterhouse wastewater. Desalin. Water Treat. 12 (1-3), 270-275. http://dx.doi.org/10.5004/dwt.2009.952

Manh, L.H., Dung, N.N.X., Van Am, L., Le Minh, B.T., 2014. Treatment of wastewater from slaughterhouse by biodigester and Vetiveria zizanioides L. Livestock Research for Rural Development 26 (4), art. no. 68. http://www.lrrd.org//rrd26/4/manh26068.htm

Marcos, A., Al-Kassir, A., Mohamad, A.A., Cuadros, F., López-Rodríguez, F., 2010. Combustible gas production (methane) and biodegradation of solid and liquid mixtures of meat industry wastes. Appl. Energ. 87 (5), 1729-1735. http://dx.doi.org/10.1016/j.apenergy.2009.09.037

Martínez, J., Borzacconi, L., Mallo, M., Galisteo, M., Viñas, M., 1995. Treatment of slaughterhouse wastewater. Water Sci. Technol. 32 (12), 99-104. http://dx.doi.org/10.1016/0273-1223(96)00143-6 Martinez, S.L., Torretta, V., Minguela, J.V., Siñeriz, F., Raboni, M., Copelli, S., Rada, E.C., Ragazzi, M., 2014. Treatment of slaughterhouse wastewaters using anaerobic filters. Environ. Technol. 35 (3), 322-332. http://dx.doi.org/10.1080/09593330.2013.827729

Massé, D.I., Masse, L., 2000a. Characterization of wastewater from hog slaughterhouses in Eastern Canada and evaluation of their in-plant wastewater treatment systems. Can. Agric. Eng. 42 (3), 139146. https://www.researchgate.net/publication/238703180 
Massé, D., Masse, L., 2000b. Treatment of slaughterhouse wastewater in anaerobic sequencing batch reactors. Can. Agr. Eng. 42, 131-137. https://www.researchgate.net/publication/265225618

Masse, L., Massé, D.I., 2005. Effect of soluble organic, particulate organic, and hydraulic shock loads on anaerobic sequencing batch reactors treating slaughterhouse wastewater at $20^{\circ} \mathrm{C}$. Process Biochem. 40 (3-4), 1225-1232. http://dx.doi.org/10.1016/j.procbio.2004.04.012

Matsumura, E.M., Mierzwa, J.C., 2008. Water conservation and reuse in poultry processing plant-A $\begin{array}{llllll}\text { case } & \text { study. } & \text { Resour. } & \text { Conserv. } & \text { Recycl. } & 52\end{array}$ http://dx.doi.org/10.1016/j.resconrec.2007.10.002

McCabe, B.K., Hamawand, I., Baillie, C., 2013. Investigating wastewater modelling as a tool to predict anaerobic decomposition and biogas yield of abattoir effluent. J. Environ. Chem. Eng. 1 (4), 13751379. http://dx.doi.org/10.1016/j.jece.2013.07.015

McCabe, B.K., Hamawand, I., Harris, P., Baillie, C., Yusaf, T., 2014. A case study for biogas generation from covered anaerobic ponds treating abattoir wastewater: Investigation of pond performance and potential biogas production. Appl. Energ. 198-808. http://dx.doi.org/10.1016/j.apenergy.2013.10.020

Mees, J.B.R., Gomes, S.D., Vilas Boas, M.A., Gomes, B.M., Passig, F.H., 2011. Kinetic behavior of nitrification in the post-treatment of poultry wastewater in a sequential batch reactor. Eng. Agric. 31 (5), 954-964. http://dx.doi.org/10.1590/S0100-69162011000500013

Mees, J.B.R., Gomes, S.D., Hasan, S.D.M., Gomes, B.M., Vilas Boas, M.A., 2014. Nitrogen removal in a SBR operated with and without pre-denitrification: Effect of the carbon:nitrogen ratio and the cycle time. Environ. Technol. 35 (1), 115-123. http://dx.doi.org/10.1080/09593330.2013.816373

Mehrvar, M., Anderson, W.A., Moo-Young, M., Reilly, P.M., 2000. Non-linear parameter estimation for a dynamic model in photocatalytic reaction engineering. Chem. Eng. Sci. 55 (21), 4885-4891. http://dx.doi.org/10.1016/S0009-2509(00)00114-7

Mehrvar, M., Anderson, W.A., Moo-Young, M., 2001. Photocatalytic degradation of aqueous organic solvents in the presence of hydroxyl radical scavengers. Int. J. Photoenergy 3 (4), 187-191. http://dx.doi.org/10.1155/S1110662X01000241

Mehrvar, M., Tabrizi, G.B., 2006. Combined photochemical and biological processes for the treatment of linear alkylbenzene sulfonate in water. J. Environ. Sci. Heal. A 41 (4), 581-597. http://dx.doi.org/10.1080/10934520600572975

Mekonnen, M.M., Hoekstra, A.Y., 2012. A Global Assessment of the Water Footprint of Farm Animal Products. Ecosystems 15 (3), 401-415. http://dx.doi.org/10.1007/s10021-011-9517-8 
Melo, R., Cabo Verde, S., Branco, J., Botelho, M.L., 2008. Gamma radiation induced effects on slaughterhouse wastewater treatment. Radiat. Phys. Chem. 77 (1), 98-100. http://dx.doi.org/10.1016/j.radphyschem.2007.03.006

Méndez-Romero, D.C., López-López, A., Vallejo-Rodríguez, R., León-Becerril, E., 2011. Hydrodynamic and kinetic assessment of an anaerobic fixed-bed reactor for slaughterhouse $\begin{array}{lllllll}\text { wastewater treatment. } & \text { Chem. } & \text { Eng. } & \text { Process. } & 50 & \text { (3), } 280 .\end{array}$ http://dx.doi.org/10.1016/j.cep.2011.02.002

Mijalova Nacheva, P., Reyes Pantoja, M., Lomelí Serrano, E.A., 2011. Treatment of slaughterhouse wastewater in upflow anaerobic sludge blanket reactor. Water Sci. Technol. 63 (5), 877-884. http://dx.doi.org/10.2166/wst.2011.265

Millamena, O.M., 1992. Ozone treatment of slaughterhouse and laboratory wastewaters. Aquac. Eng. 11 (1), 23-31. http://dx.doi.org/10.1016/0144-8609(92)90018-S

Miranda, L.A.S., Henriques, J.A.P., Monteggia, L.O., 2005. A full-scale UASB reactor for treatment of pig and cattle slaughterhouse wastewater with a high oil and grease content. Braz. J. Chem. Eng. 22 (4), 601-610. http://dx.doi.org/10.1590/S0104-66322005000400013

Mittal, G. S., 2004. Characterization of the effluent wastewater from abattoirs for land application. Food Rev. Int. 20 (3), 229-256. http://dx.doi.org/10.1081/LFRI-200029422

Mittal, G.S., 2006. Treatment of wastewater from abattoirs before land application - A review. Bioresour. Technol. 97 (9), 1119-1135. http://dx.doi.org/10.1016/j.biortech.2004.11.021

Mohajerani, M., Mehrvar, M., Ein-Mozaffari, F., 2012. Photoreactor design and CFD modelling of a $\mathrm{UV} / \mathrm{H}_{2} \mathrm{O}_{2}$ process for distillery wastewater treatment. Can. J. Chem. Eng. 90 (3), 719-729. http://dx.doi.org/10.1002/cjce.20569

Mowla, A., Mehrvar, M., Dhib, R., 2014. Combination of sonophotolysis and aerobic activated sludge processes for treatment of synthetic pharmaceutical wastewater. Chem. Eng. J. 255, 411-423. http://dx.doi.org/10.1016/j.cej.2014.06.064

Muñoz, D., 2005. System of residual water treatment of slaughter house: for a smaller population 2000 $\begin{array}{llllll}\text { inhabitants. } & \text { Fac. } & \text { Ciencias } & \text { Agropecu. } & 3 & \text { (1), }\end{array}$ http://uniciencia.ambientalex.info/infoCT/Tratamientoaguas2000h.pdf

Myers, R.H., Montgomery, D.C., Vining, G.G., Borror, C.M., Kowalski, S.M., 2004. Response Surface Methodology: A Retrospective and Literature Survey. J. Qual. Technol. 36 (1), 53-77.

Nery, V.D., Damianovic, M.H.Z., Pozzi, E., De Nardi, I.R., Caldas, V.E.A., Pires, E.C., 2013. Longterm performance and operational strategies of a poultry slaughterhouse waste stabilization pond 
system in a tropical climate. Resour. Conserv. Recycl. 71, 7-14. http://dx.doi.org/10.1016/j.resconrec.2012.11.006

Núñez, L.A., Fuente, E., Martínez, B., García, P.A., 1999. Slaughterhouse wastewater treatment using ferric and aluminium salts and organic polyelectrolites. J. Environ. Sci. Heal. A 34 (3), 721-736. http://dx.doi.org/10.1080/10934529909376861

Odong, R., Kansiime, F., Omara, J., Kyambadde, J., 2013. The potential of four tropical wetland plants for the treatment of abattoir effluent. Int. J. Environ. Technol. Manage. 16 (3), 203-222. http://dx.doi.org/10.1504/IJETM.2013.053640

Odong, R., Kansiime, F., Omara, J., Kyambadde, J., 2015. Tertiary treatment of abattoir wastewater in a horizontal subsurface flow-constructed wetland under tropical conditions. Int. J. Environ. Waste Manage. 15 (3), 257-270. http://dx.doi.org/10.1504/IJEWM.2015.069160

Oliveira, S.C., Von Sperling, M., 2009. Performance evaluation of UASB reactor systems with and $\begin{array}{lllllll}\text { without } & \text { post-treatment. } & \text { Water } & \text { Sci. } & \text { Technol. } & 59 & \text { (7), }\end{array}$ http://dx.doi.org/10.2166/wst.2009.138

Oller, I., Malato, S., Sanchez-Perez, J., 2011. Combination of Advanced Oxidation Processes and biological treatments for wastewater decontamination - A review. Sci. Total Environ. 409 (20), 4141-4166. http://dx.doi.org/10.1016/j.scitotenv.2010.08.061

OEB, 2013. Ontario Energy Board Electricity Prices. Retrieved October 1, 2013, from: http://www.ontarioenergyboard.ca/oeb/Consumers/Electricity/Electricity\%20Prices

OEB, 2016. Ontario Energy Board Electricity Prices. Retrieved August 2, 2016, from: http://www.ontarioenergyboard.ca/oeb/Consumers/Electricity/Electricity\%20Prices

OMAFRA, 2014. Provincially Licensed Meat Plants in Ontario. Ontario Ministry of Agricultural and Rural Affairs (OMAFRA). March 17, 2014. Accessed July 10, 2014. Available online: http://www.omafra.gov.on.ca/english/food/inspection/maps/TblAllAbattoirs.htm

OMAFRA, 2015a. Provincially Licensed Meat Plants in Ontario. Ontario Ministry of Agricultural and Rural Affairs (OMAFRA). February 19, 2015. Accessed March 23, 2015. Available online: http://www.omafra.gov.on.ca/english/food/inspection/maps/TblAllAbattoirs.htm

OMAFRA, 2015b. Provincially Licensed Meat Plants in Ontario. Ontario Ministry of Agricultural and Rural Affairs (OMAFRA). November 9, 2015. Accessed December 4, 2015. Available online: http://www.omafra.gov.on.ca/english/food/inspection/maps/TblAllAbattoirs.htm

OMAFRA, 2016. Provincially Licensed Meat Plants in Ontario. Ontario Ministry of Agricultural and Rural Affairs (OMAFRA). March 10, 2016. Accessed April 30, 2016. Available online: http://www.omafra.gov.on.ca/english/food/inspection/maps/TblAllAbattoirs.htm 
Ozyonar, F., Karagozoglu, B., 2014. Investigation of technical and economic analysis of electrocoagulation process for the treatment of great and small cattle slaughterhouse wastewater. Desalin. Water Treat. 52 (1-3), 74-87. http://dx.doi.org/10.1080/19443994.2013.787373

Pabón, S.L., Gélvez, J.H.S., 2009. Starting-up and operating a full-scale activated sludge system for $\begin{array}{llllll}\text { slaughterhouse } & \text { wastewater. } & \text { Ing. } & \text { Invest. } & 29 & \text { 53-58, }\end{array}$ http://www.scielo.org.co/pdf/iei/v29n2/v29n2a08.pdf

Pan, M., Henry, L.G., Liu, R., Huang, X., Zhan, X., 2014. Nitrogen removal from slaughterhouse wastewater through partial nitrification followed by denitrification in intermittently aerated sequencing batch reactors at $11^{\circ} \mathrm{C}$. Environ. Technol. 35 (4), 470-477. http://dx.doi.org/10.1080/09593330.2013.832336

Pan, M., Hu, Z., Liu, R., Zhan, X., 2015. Effects of loading rate and aeration on nitrogen removal and $\mathrm{N}_{2} \mathrm{O}$ emissions in intermittently aerated sequencing batch reactors treating slaughterhouse wastewater at $11^{\circ} \mathrm{C}$. Bioproc. Biosyst. Eng. 38 (4), 681-689. http://dx.doi.org/10.1007/s00449-014$\underline{1307-1}$

Paramo-Vargas, J., Camargo, A.M.E., Gutierrez-Granados, S., Godinez, L.A., Peralta-Hernandez, J.M., 2015. Applying electro-Fenton process as an alternative to a slaughterhouse effluent treatment. J. Electroanal. Chem. 754, art. no. 2169, 80-86. http://dx.doi.org/10.1016/j.jelechem.2015.07.002

Park, J., Oh, J.H., Ellis, T.G., 2012. Evaluation of an on-site pilot static granular bed reactor (SGBR) for the treatment of slaughterhouse wastewater. Bioproc. Biosyst. Eng. 35 (3), 459-468. http://dx.doi.org/10.1007/s00449-011-0585-0

Pierson, J. A., Pavlostathis, S. G., 2000. Real-time monitoring and control of sequencing batch reactors for secondary treatment of a poultry processing wastewater. Water Environ. Res. 72 (5), 585-592. http://dx.doi.org/10.2175/106143000X138166

Pingali, P., 2007. Westernization of Asian diets and the transformation of food systems: Implications for research and policy. Food Policy 32 (3), 281-298. http://dx.doi.org/10.1016/j.foodpol.2006.08.001

Qin, X., Yang, B., Gao, F., Chen, G., 2013. Treatment of restaurant wastewater by pilot-scale electrocoagulation- electroflotation: Optimization of operating conditions. J. Environ. Eng. 139 (7), 1004-1016. http://dx.doi.org/10.1061/(ASCE)EE.1943-7870.0000687

Quinn, J., McFarlane, P., 1989. Effects of slaughterhouse and dairy factory wastewaters on epilithon: a comparison in laboratory streams. Water Res. 23, 1267-1273. http://dx.doi.org/10.1016/00431354(89)90188-7 
Rajakumar, R., Meenambal, T., 2008. Comparative study on start-up performance of HUASB and AF reactors treating poultry slaughterhouse wastewater. Int. J. Env. Res. Pub. He. 2 (4), 401-410. http://ijer.ut.ac.ir/article_221_4.html

Rajakumar, R., T. Meenambal, J. Rajesh Banu, I.T. Yeom., 2011. Treatment of poultry slaughterhouse wastewater in upflow anaerobic filter under low upflow velocity. Int. J. Environ. Sci. Te. 8 (1), 149158. http://dx.doi.org/10.1007/BF03326204

Rajakumar, R., Meenambal, T., Saravanan, P.M., Ananthanarayanan, P., 2012. Treatment of poultry slaughterhouse wastewater in hybrid upflow anaerobic sludge blanket reactor packed with pleated poly vinyl chloride rings. Bioresour. Technol. 103 (1), 116-122. http://dx.doi.org/10.1016/j.biortech.2011.10.030

Reynolds, T., Yang, J., 1966. Model of the completely-mixed activated sludge process. In: Proc. 21st Ind. Waste Conf., Purdue Univ. Part 2, pp. 696-713.

Ruiz, I., Veiga, M.C., De Santiago, P., Blázquez, R., 1997. Treatment of slaughterhouse wastewater in a UASB reactor and an anaerobic filter. Bioresour. Technol. 60 (3), 251-258. http://dx.doi.org/10.1016/S0960-8524(97)00020-5

Saddoud, A., Sayadi, S., 2007. Application of acidogenic fixed-bed reactor prior to anaerobic membrane bioreactor for sustainable slaughterhouse wastewater treatment. J. Hazard. Mater. 149 (3), 700-706. http://dx.doi.org/10.1016/j.jhazmat.2007.04.031

Salminen, E., Rintala, J., 2002. Anaerobic digestion of organic solid poultry slaughterhouse waste - A review. Bioresour. Technol. 83 (1), 13-26. http://dx.doi.org/10.1016/S0960-8524(01)00199-7

San José, T., 2004. Bird slaughterhouse: generation and purification of their water. Tecnologia del Agua 24 (251), 48-51. http://dialnet.unirioja.es/servlet/articulo?codigo=969301

Satyanarayan, S., Ramakant, Vanerkar, A.P., 2005. Conventional approach for abattoir wastewater treatment. Environ. Technol. 26 (4), 441-447. http://dx.doi.org/10.1080/09593332608618554

Sehested, K., Rasmussen, O.L., Fricke, H., 1968. Rate constants of $\mathrm{OH}$ with $\mathrm{HO}_{2}, \mathrm{O}_{2}{ }^{-}$, and $\mathrm{H}_{2} \mathrm{O}_{2}{ }^{+}$from hydrogen peroxide formation in pulse-irradiated oxygenated water. J. Phys. Chem. 72 (2), 626-631. http://dx.doi.org/10.1021/j100848a040

Seif, H., Moursy, A., 2001. Treatment of slaughterhouse wastes. In: Sixth International Water Technology Conference. IWTC, Alexandria, Egypt, pp. 269-275. http://www.iwtc.info/2001_pdf/04-3.pdf

Selmane, D., Christophe, V., Gholamreza, D., 2008. Extraction of proteins from slaughterhouse byproducts: Influence of operating conditions on functional properties. Meat Sci. 79 (4), 640-647. http://dx.doi.org/10.1016/j.meatsci.2007.10.029 
Šereš, Z., Maravić, N., Takači, A., Nikolić, I., Šoronja-Simović, D., Jokić, A., Hodur, C., 2016. Treatment of vegetable oil refinery wastewater using alumina ceramic membrane: optimization using response surface methodology. J. Clean. Prod. 112, 3132-3137. http://dx.doi.org/10.1016/j.jclepro.2015.10.070

Shu, Z., Bolton, J.R., Belosevic, M., Gamal El Din, M., 2013. Photodegradation of emerging micropollutants using the medium-pressure UV/H2O2 Advanced Oxidation Process. Water Res. 47 (8), 2881-2889. http://dx.doi.org/10.1016/j.watres.2013.02.045

Siqueira, L.M., Damiano, E.S.G., Silva, E.L., 2013. Influence of organic loading rate on the anaerobic treatment of sugarcane vinasse and biogas production in fluidized bed reactor. J. Environ. Sci. Heal. A 48 (13), 1707-1716. http://dx.doi.org/10.1080/10934529.2013.815535

Sneeringer, S.E., 2009. Effects of environmental regulation on economic activity and pollution in commercial agriculture. B.E. Journal of Economic Analysis and Policy 9 (1), art. no. 31. http://dx.doi.org/10.2202/1935-1682.2248

Soroko, M., 2007. Treatment of wastewater from small slaughterhouse in hybrid constructed wetlands systems. Ecohydrol. Hydrobiol. 7 (3-4), 339-343. http://dx.doi.org/10.1016/S1642-3593(07)70117$\underline{9}$

Staehelin, J., Bühler, R.E., Hoigné, J., 1984. Ozone decomposition in water studied by pulse radiolysis. 2. $\mathrm{OH}$ and $\mathrm{HO} 4$ as chain intermediates. J. Phys. Chem. 88 (24), 5999-6004. http://dx.doi.org/10.1021/j150668a051

Stets, M.I., Etto, R.M., Galvão, C.W., Ayub, R.A., Cruz, L.M., Steffens, M.B.R., Barana, A.C., 2014. Microbial community and performance of slaughterhouse wastewater treatment filters. Genet. Mol. Res. 13 (2), 4444-4455. http://dx.doi.org/10.4238/2014.June.16.3

Tabrizi, G.B., Mehrvar, M., 2004. Integration of advanced oxidation technologies and biological processes: Recent developments, trends, and advances. J. Environ. Sci. Heal. A 39 (11-12), 30293081. http://dx.doi.org/10.1081/LESA-200034939

Tariq, M., Ahmad, M., Siddique, S., Waheed, A., Shafiq, T., Khan, M.H., 2012. Optimization of coagulation process for the treatment of the characterized slaughterhouse wastewater. Pak. J. Sci. Ind. Res. 55 (1), 43-48.

Torkian, A., Alinejad, K., Hashemian, S.J., 2003. Posttreatment of upflow anaerobic sludge blankettreated industrial wastewater by a rotating biological contactor. Water Environment Research 75 (3), 232-237. http://dx.doi.org/10.2175/106143003X141015 
Tritt, W.P., Schuchardt, F., 1992. Materials flow and possibilities of treating liquid and solid wastes from slaughterhouses in Germany. A review. Bioresour. Technol. 41 (3), 235-245. http://dx.doi.org/10.1016/0960-8524(92)90008-L

US EPA, 2004. Effluent limitations guidelines and new source performance standards for the meat and poultry products point source category, vol. 69 (173). United States Environmental Protection $\begin{array}{lllll}\text { Agency } & \text { EPA): } & \text { Fegister. }\end{array}$ http://nepis.epa.gov/Exe/ZyPDF.cgi/20002F0Q.PDF?Dockey=20002F0Q.PDF

Valta, K., Kosanovic, T., Malamis, D., Moustakas, K., Loizidou, M., 2015. Overview of water usage and wastewater management in the food and beverage industry. Desalin. Water Treat. 53 (12), 3335 3347. http://dx.doi.org/10.1080/19443994.2014.934100

Vymazal, J., 2014. Constructed wetlands for treatment of industrial wastewaters: A review. Ecol. Eng. 73, 724-751. http://dx.doi.org/10.1016/j.ecoleng.2014.09.034

Wang, X.-W., Fei, Q.-Z., Xu, Z., Guo, H.-Y., Zhang, S.-T., 2009. Study on treatment of slaughterhouse wastewater with co-coagulation flotation and SBR process. 3rd International Conference on Bioinformatics and Biomedical Engineering iCBBE 2009, art. no. 5163535. http://dx.doi.org/10.1109/ICBBE.2009.5163535

Weinstein, J., Bielski, B.H.J., 1979. Kinetics of the interaction of $\mathrm{HO}_{2}$ and $\mathrm{O}_{2}{ }^{-}$radicals with hydrogen peroxide. The Haber-Weiss reaction. J. Am. Chem. Soc. 101 (1), 58-62. http://dx.doi.org/10.1021/ja00495a010

World Bank Group, 2007. Environmental, Health and Safety (EHS) Guidelines for Meat Processing. General EHS Guidelines: Environmental Wastewater and Ambient Water Quality. Accessed March 10, 2015. Available online: http://www.ifc.org/ehsguidelines

Wosiack, P.A., Lopes, D.D., Rissato Zamariolli Damianovic, M.H., Foresti, E., Granato, D., Barana, A.C., 2015. Removal of COD and nitrogen from animal food plant wastewater in an intermittentlyaerated structured-bed reactor. J. Environ. Manage. 154, 145-150. http://dx.doi.org/10.1016/j.jenvman.2015.02.026

Wu, J., Doan, H., 2005. Disinfection of recycled red-meat processing wastewater by ozone. J. Chem. Technol. Biotechnol. 80 (7), 828-833. http://dx.doi.org/10.1002/jctb.1324

Wu, P., Mittal, G., 2011. Characterization of provincially inspected slaughterhouse wastewater in Ontario, Canada. Can. Biosyst. Eng. 53, 6.9-6.18. http://www.csbescgab.ca/docs/journal/54/C12062.pdf 
Yoon, Y.-M., Kim, S.-H., Oh, S.-Y., Kim, C.-H., 2014. Potential of anaerobic digestion for material recovery and energy production in waste biomass from a poultry slaughterhouse. Waste Manage. 34 (1), 204-209. http://dx.doi.org/10.1016/j.wasman.2013.09.020

Yordanov, D., 2010. Preliminary study of the efficiency of ultrafiltration treatment of poultry slaughterhouse wastewater. Bulgarian Journal of Agricultural Science 16 (6), 700-704. http://www.agrojournal.org/16/06-06-10.pdf

Zhan, X., Healy, M.G., Li, J., 2009. Nitrogen removal from slaughterhouse wastewater in a sequencing batch reactor under controlled low DO conditions. Bioproc. Biosyst. Eng. 32 (5), 607-614. http://dx.doi.org/10.1007/s00449-008-0283-8 